LILIAN MARQUES SILVA

CONJUNTO DE ESTRUTURAS MINIATURIZADAS PARA MANIPULAÇÃO DE MISTURAS

SÃO PAULO

2010 
CONJUNTO DE ESTRUTURAS MINIATURIZADAS PARA MANIPULAÇÃO DE MISTURAS

Tese apresentada à Escola Politécnica da Universidade de São Paulo para obtenção do Título de Doutor(a) em Engenharia Elétrica

SÃO PAULO 


\section{CONJUNTO DE ESTRUTURAS MINIATURIZADAS PARA MANIPULAÇÃO DE MISTURAS}

Tese apresentada à Escola Politécnica da Universidade de São Paulo para obtenção do Título de Doutor(a) em Engenharia Elétrica

Área de Concentração: Microeletrônica

Orientação: Prof. ${ }^{a}$ Dr. ${ }^{a}$ Maria Lúcia Pereira da Silva

SÃO PAULO 
FICHA CATALOGRAFICA

Silva, Lílian Marques

Conjuntos de estruturas miniaturizadas usadas para manipulação de misturas / L.M. Silva. - São Paulo, 2010.

$184 p$.

Tese (Doutorado) - Escola Politécnica da Universidade de São Paulo. Departamento de Engenharia de Sistemas Eletrônicos.

1. Microeletrônica I. Universidade de São Paulo. Escola Politécnica. Departamento de Engenharia de Sistemas Eletrônicos II.t. 


\section{AGRADECIMENTOS}

A Prof ${ }^{a}$. Dr ${ }^{a}$. Maria Lúcia Pereira da Silva pela orientação, pela amizade, compreensão, incentivo, confiança, paciência e principalmente por ter me dado a oportunidade de realizar este trabalho.

Aos meus familiares, principalmente, à minha mãe, à minha filha e ao meu companheiro.

Aos meus amigos Dr. Roberto da Rocha Lima, Dr. Alexsander Tressino de Carvalho, MSc. Leonardo Frois Hernandez pela ajuda e apoio.

Ao Prof. Dr. Eliphas Wagner Simões pela parceria nas simulações.

Aos alunos de Iniciação Científica da Fatec-SP, Eduardo e Michele.

Ao CNPq pela concessão da bolsa de doutorado e pelo apoio financeiro para realização desta pesquisa.

À FAPESP pelo apoio financeiro para participação em congresso internacional. 


\section{Simplicidade}

É curioso observar como a vida nos oferece resposta aos mais variados questionamentos do cotidiano.

Vejamos:

A mais longa caminhada só é possível passo a passo. O mais belo livro do mundo foi escrito letra por letra. "No princípio, Deus criou o céu e a terra." Os milênios se sucedem, segundo a segundo. As mais violentas cachoeiras se formam de pequenas fontes. A imponência do pinheiro e a beleza do ipê começaram, ambas, na simplicidade das sementes.

Se não fosse a gota, não haveria chuvas. O mais singelo ninho se fez de pequenos gravetos. A mais bela construção não se teria efetuado senão a partir do primeiro tijolo. As imensas dunas se compõem de minúsculos grãos de areia. Como já refere o adágio popular, nos menores frascos se guardam as melhores fragrâncias.

É quase incrível imaginar que apenas sete notas musicais tenham dado vida à "Ave Maria" de Bach, e à "Aleluia" de Handel: dó, ré, mi, fá, sol, la, si. O brilhantismo de Einstein e a ternura de Tereza de Calcutá tiveram que estagiar no período fetal, e nem mesmo Jesus, expressão maior de Amor, dispensou a fragilidade do berço. Assim também o mundo de paz, de harmonia e de amor com que tanto sonhamos, só será construído a partir de pequenos gestos de compreensão, de solidariedade, respeito, ternura, fraternidade, benevolência, indulgência e perdão, no dia-a-dia. Ninguém pode mudar o mundo.

Mas podemos mudar uma pequena parcela dele: esta parcela que chamamos de "Eu". Não é fácil, nem rápido. Mas vale a pena tentar.

(Alexandre Garcia) 


\section{RESUMO}

Atualmente a Engenharia supera novas fronteiras, principalmente devido à redução das dimensões dos equipamentos, e um exemplo desses impactos é o atual estágio de desenvolvimento da nanotecnologia. Ademais, não só as questões ambientais inerentes à contaminação do meio físico como também seu monitoramento devem ser continuamente abordadas para garantir que o profissional possa atuar nessa nova condição. O objetivo deste trabalho foi determinar como um grupo de estruturas miniaturizadas pode ser usado na remoção de partículas de um meio líquido ou gasoso e a separação de componentes de uma mistura. Também objetivou-se desenvolver uma metodologia simples de testes voltada para o estudo do comportamento dos fluidos no interior de estruturas onde material particulado e pequenas dimensões dificultam a passagem deste fluido. A utilização de canais preenchidos com material particulado ocorre tanto na Engenharia Química, para produção de compostos, como na Química, para a análise de substâncias. Os testes utilizaram equipamentos comuns em laboratório de química, uma estrutura para produção de spray, duas estruturas impactadoras distintas - para remoção de partículas, e duas estruturas, denominadas como canais tridimensionais e de separação preliminar, para separação de compostos orgânicos voláteis. As substâncias puras permitem avaliar o tempo de residência e compará-lo com as misturas. As estruturas apresentaram comportamento muito semelhante quando comparadas as filmagens com o auxílio de traçadores e as simulações usando FEMLAB ${ }^{\circledR}$. O conjunto proposto de estruturas permite produzir spray com gotas de até $10 \mu \mathrm{m}$ e obter uma impressão digital de compostos orgânicos em uma mistura, pois os resultados permitem montar tabelas qualitativas e semi-quantitativas que descrevem vários fenômenos, tais como, difusão, separação de compostos, perda de carga, etc. Estas estruturas apresentaram uma série de vantagens, tais como, mesodimensionamento, que facilita sua produção e manuseio, e possibilidade de uso em demonstrações de como ocorrem os fenômenos internos à estrutura.

Palavras-chave: Estruturas miniaturizadas, impactador, destilação, separação de misturas, filmes adsorventes. 


\begin{abstract}
Nowadays, mainly due to products miniaturization, engineering faces new horizons, which can be easily exemplified by the enhancement on nanotechnology development. Furthermore, not only environmental contamination but also environmental monitoring must be addressed in order to produce a systemic knowledge. Therefore, the aim of this work was to determine how a group of miniaturized structures could be used on particle removal and component separation on a mixture. Also a secondary target was to develop a simple methodology in order to determine the fluid behavior inside the structures where particle material and small dimensions hinder flow passage. The use of packed channels is common not only in Chemical Engineering, on synthesis production, but also in Chemistry, for chemical analysis. Tests were carried out using equipment normally present in Chemistry to evaluate a set of structures composed by: one spray, two different impactors and other two different structures (one of them with five different outlets) for separation of volatile organic compounds. Tests were performed in liquid and gaseous phases and used several reactants (kerosene, gasoline, acetone, 2-propanol and ethanol) and their mixtures; pure reactants allow evaluation of the resident time and comparison with mixtures behavior. Simulations were also performed and the structure behavior evaluated by tracers shows good agreement with simulations data. The whole group of structures allows the production of spray with up to $10 \mu \mathrm{m}$ droplet dimension and the footprint of components in a mixture, i.e., the obtained data can be disposed as qualitative and quantitative tables, which describe several phenomena, such as diffusion, separation of compounds, load loss, etc. These structures present several advantages since dimensions on mesorange not only facilitate their production and manipulation bur also allow to unravel phenomena occurring inside the structures.
\end{abstract}

Key-word: miniaturized structures, impactors, distillation, separation of mixtures, adsorbents thin films. 


\section{LISTA DE FIGURAS}

Figura 2.1 - Processo de destilação (A) simples (B) fracionada [39]......................

Figura 2.2 - Esquema de uma coluna de destilação [41]....................................... 11

Figura 2.3 - Princípios para a escolha de uma coluna de destilação com catalisador [42]

Figura 2.4 - (A) Atomizadores de pressão; (B) atomizador giratório; e (C) atomizador para dois fluidos [72][73]........................................

Figura 2.5 - Sistema miniaturizado para geração de gotas por força de cisalhamento (Mechano Hydrodynamic Droplet Generator, MHDG): junção (A) dos microcanais formadores de gotas; (B) em T; e em (C) linha reta. Múltiplas junções em T, (D) para formar gotas com diâmetro comparável ao canal e (E) sistema eletrostático [74].....

Figura 2.6 - Esquema do sistema F.I.A. [86]...

Figura 2.7 - (A) Esquema e (B) fotografia da estrutura, tubos em acrílico, junção entre barra roscada e tubos de aço inoxidável [103]

Figura 2.8 - (A) Esquema e (B) fotografia da estrutura, substrato em acrílico e tubos de aço inoxidável [54].

Figura 2.9 - (A) Esquema e (B) fotografia da estrutura, substrato em acrílico e tubos de silicone [70].

Figura $2.1 \quad$ - (A) Esquema e (B) fotografia da estrutura, substrato em acrílico e

$0 \quad$ tubos de aço inoxidável [99].

Figura $3.1 \quad$ - Software de Freqüencímetro utilizado para realizar medidas.

Figura 3.2 - Tela interativa visualizada durante os testes usando o simulador de osciloscópio para computador.

Figura 3.3 - (A) Esquema e (B) fotografia do aparato utilizado durante os testes no modo de admissão pulsada com aquecimento externo a estrutura

Figura $3.4 \quad$ - (A) Esquema e (B) fotografia do aparato utilizado durante os testes no modo de admissão contínua..

Figura 3.5 - (A) Esquema e (B) detalhe da parte referente a forma de aquecimento externo a estrutura do aparato utilizado durante os testes no modo de admissão contínua com aquecimento

Figura 3.6 - (A) Esquema e (B) fotografia do aparato utilizado durante os testes no modo de admissão pulsada com aquecimento do reagente

Figura 3.7 - Fotografia do aparato usado como medidor de vazão: "bolhometro".....................................................................................

Figura 3.8 - (A) Esquema e (B) fotografia do aparato utilizado durante as filmagens.

Desenho (em mm) (A) estrutura proposta por Beraldo [99]; estrutura otimizadas por simulação (B) impactadora angular; (C) impactador semi-circular; a largura das estruturas podem variar de dimensões em: $5 \mathrm{~mm} ; 10 \mathrm{~mm} ; 20 \mathrm{~mm}$ e $50 \mathrm{~mm}$ 
Figura 3.10 - Desenho da (A) chicana original [70]; (B) novo desenho proposto; (C) detalhe da última cela; além de fotos da estrutura (D) sem ou (E) com recheio.

Figura 3.11 - Microcanais: (A) tridimensionais para colunas cromatográficas [103], (B) planares para pré-concentração [55] e (C) tridimensionais modificados para catálise [100]

Figura 3.12 - (A) Aparato usado para obtenção de spray usando a estrutura planar e (B) esquema do aparato usado....

Figura 3.13 - (A) Aparto usado para obtenção de spray usando a estrutura tridimensional e (B) esquema do aparato...

Figura 3.14 - (A) Diagramas esquemáticos do arranjo experimental e (B) fotografia do equipamento usado para medidas elétricas.............. 60

Figura 3.15 - Diagrama esquemático da câmara de plasma [121].........................

Figura 4.1 - Análise SEM: em silício, deposição de filme fluorado na superfície (A) polida ou (B) rugosa............................................... 73

Figura 4.2 - Detalhe do microcanal com $100 \mu \mathrm{m}$ usinado na estrutura tridimensional...................................................................... 78

Figura 4.3 - Detalhe $(\mathrm{mm})$ do microcanal usinado na estrutura (microcanal pode varia em $100 \mu \mathrm{m}$, ou $200 \mu \mathrm{m}$ ou $500 \mu \mathrm{m})$ [55]....................

Figura 4.4 - Comportamento do fluido: esquema de como ocorre o escoamento dentro de um tubo (A) regime de escoamento laminar e (B) regime de escoamento turbulento

Figura 4.5 - Seqüência de fotografias para a injeção do traçador sob escoamento aquoso: azul de metileno (A) água e (B) comparação com a simulação referente a velocidade $(\mathrm{cm} / \mathrm{s})$ usando água...

Figura 4.6 - Seqüência de fotografias para a injeção do traçador sob escoamento aquoso: azul de metileno (A) solução de glicerol e (B) comparação com a simulação referente a velocidade $(\mathrm{cm} / \mathrm{s})$ usando glicerol.

Figura 4.7 - Seqüência de injeção do traçador sob escoamento aquoso usando solução de glicerol.

Figura 4.8 - (A) Seqüência de fotografias da solução de glicerol injetada nos microcanais tridimensionais e (B) detalhes dos microcanais fotografados usando um microscópio óptico (1- sem traçador; 2traçador; 3- traçador parcialmente resolvido; 4- sem

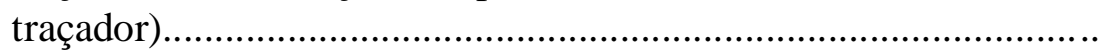

Figura 4.9 - Microscopia Eletrônica de Varredura (MEV) dos microcanais tridimensionais: (A) microcanal e rugosidade; (B) microcanal planar com rugosidade e efeito de planarização devido à deposição do filme a base de HMDS.

Figura 4.10 - Produção de spray com os microcanais: (A) planares e (B) tridimensionais e (C) detalhe de como é formado o spray nas estruturas planares. 
Figura 4.11 - Esquema do aparato montado para a formação do spray usando

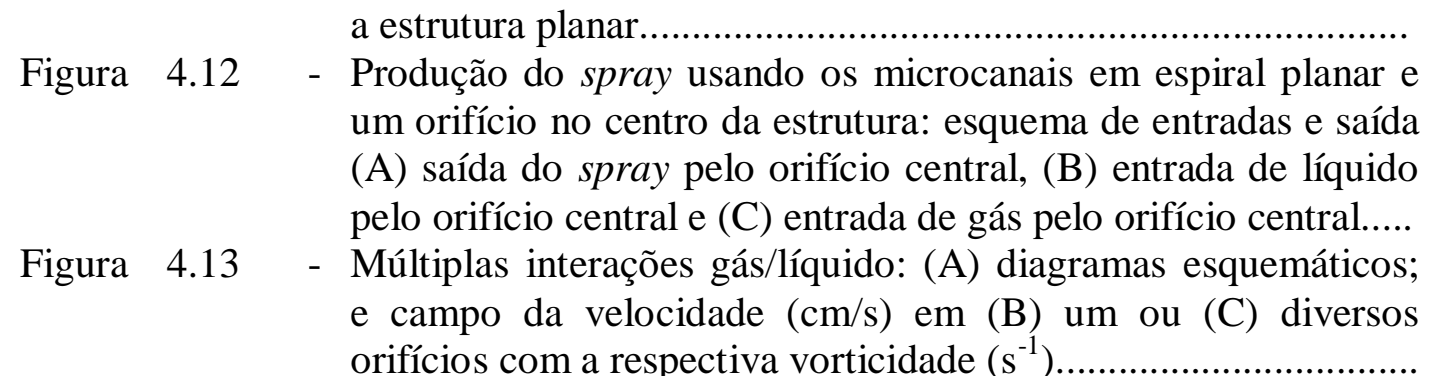

Figura $4.14 \quad$ - (A) Esquema para geração do spray; (B) saída do spray pela região central da estrutura; (C) saída do spray pela lateral com inserção de líquido pela região central; e (D) saída do spray pela lateral com inserção de ar atmosférico pela região central da estrutura. Os detalhes representam a formação correspondente das gotas usando a solução aquosa e anilina inserida na estrutura planar.

Figura 4.15 - Dispersão de partículas usando spray: (A) formação da "primeira gota em forma de bolha" e (B) seqüência de formação de gotas menores.

Figura 4.16 - Dispersão de partículas usando spray: (A) partículas de $13 \mu \mathrm{m}$ e $50 \mu \mathrm{m}$ obtidas na primeira gota, depositadas sobre o anteparo; (B) spray com partículas de $13 \mu \mathrm{m}$ e (C) $50 \mu \mathrm{m}$ sobre anteparo.

Figura 4.17 - A melhor configuração para a formação do spray; mistura e gotas obtidas com suspensões de $13 \mu \mathrm{m}$ e/ou de $50 \mu \mathrm{m}$.

Figura 4.18 - Fotografia do microreator (formato cavidade selada) quando (A) um ou (B) dois fluidos são admitidos com o uso da estrutura espiral planar.

Figura 4.19 - (A) Esquema da estrutura usada para formação do spray; (B) detalhe da formação do spray, escoamento aquoso; jato do spray com suspensão de partículas de (C) $13 \mu \mathrm{m}$ e (D) $50 \mu \mathrm{m}$....

Figura 4.20 - Filmagens realizadas com a inserção de solução (A) aquosa; (B) silicone em azul de metileno na estrutura proposta por Beraldo [53][16][99]; novos desenhos utilizados para os impactadores (C) angular e (D) semi-circular.....

Figura 4.21

- Partículas de $13 \mu \mathrm{m}$ e $50 \mu \mathrm{m}$ em 50 mL de água.

Figura 4.22 - Estrutura impactadora angular com a inserção de grãos de café torrados e moídos sob escoamento aquoso

Figura 4.23 - Retenção de partículas de $13 \mu \mathrm{m}$, condição posterior a inserção.

Figura 4.24 - Retenção de partículas de $50 \mu \mathrm{m}$, esquema dos locais mais prováveis de ocorrer a retenção após a inserção.

Figura 4.25 - Imagens do impactador angular com (A) solução $10 \%$ azul de metileno em água destilada e (B) solução $10 \%$ azul de metileno em glicerol; (C) Retenção na placa coletora do impactador semi-circular e (D) detalhe das partículas, usando pequena admissão, $5 \mu \mathrm{L}$, de amostra. 
Figura 4.26 - (A) Aparato para injeção do spray no impactador e (B) seqüência de fotografias que indicam a remoção da partícula no impactador angular e uso de spray.

Figura 4.27 - (A) Esquema da microestrutura em perspectiva; (B) detalhe de como são os microcanais modificados com 4 cortes ortogonais e a adição de uma segunda entrada, denominada amostra, utilizada neste trabalho; (C) detalhe do tubo externo e (D) tubo interno, com dimensões do microcanal [100]....

Figura 4.28 - Perfil da velocidade nos microcanais (N2, velocidade linear na entrada de $2 \mathrm{~cm} / \mathrm{s}$, canais de $500 \mu \mathrm{m}$ ) (A) canais não empacotados e (B) canais empacotados, perfil de velocidade (eixo vertical, $\mathrm{mm} / \mathrm{s}$ ) e de temperatura (variação de cor, ${ }^{\circ} \mathrm{C}$ ) para admissão de amostra em estrutura aquecida a $300^{\circ} \mathrm{C}[100] .$.

Figura 4.29 - Simulação com injeção de dois diferentes gases (N2 e O2) no canal indicando o gradiente de concentração (eixo vertical, em porcentagem) e a temperatura (cores, ${ }^{\circ} \mathrm{C}$ ) [100].

Figura 4.30 - Esquema do aparato utilizado para testes usando a estrutura tridimensional modificada com 4 canais verticais ortogonais......

Figura 4.31 - Simulação das linhas de velocidade (linha azuis) e perfil de velocidade na saída (cor, cm.s-1) para estrutura tridimensional modificada como apresentado no detalhe da Figura 4.30 e supondo vapor de água admitida em uma das entradas: (A) gasolina e (B) isopropanol.

Figura 4.32 - (A) Fotografia da estrutura não empacotada e (B) estrutura com anéis de Raschig (empacotada)

Figura 4.33 - Retenção de partículas de (A) $13 \mu \mathrm{m}$ e (B) $50 \mu \mathrm{m}$ : condição depois da inserção.

Figura 4.34 - Comportamento do fluido: (A) resultados típicos para a vazão em estruturas empacotadas em função da câmara avaliada. (B) sequiência de fotos na estrutura não preenchida após a adição do traçador: (1) entrada do fluido; (2) saída do fluido; (3) caminho preferencial; (4) difusão; (5) espaço morto. (C) visualização da região da chicana onde observa-se a mistura de reagentes, no caso, corantes vermelho e azul..

Figura 4.35 - Imagens da chicana com (A) solução $10 \%$ de azul de metileno em água destilada e (B) solução $10 \%$ de azul de metileno em glicerol.

Figura 4.36 - Seqüência de fotografias exemplificando fenômenos possíveis de se observar na estrutura preenchida com anéis: (A) início do encontro de dois escoamentos de traçadores; (B) caminho de dois traçadores; (C) passagem do traçador internamente ao anel.

Figura 4.37

Figura 4.38

Figura 4.39
- Esquema do aparato utilizado durante os testes.

- Estrutura empacotada e sistema de aquecimento....

- (A) Fotografia da placa de aquisição, (B) detalhe da conexão com o sensor e (C) respectivo diagrama elétrico [154].... 
Figura 4.40 - Fotografia do (A) conjunto de estruturas; (B) sistema de detecção, 1, 2, 3 e 4 indicam os microcontroladores; e (C) tela interativa do programa de análise de dados.

Figura A.1 - Perfis da (A) pressão absoluta (Pa) e da (B) velocidade resultante $(\mathrm{cm} / \mathrm{s})$ em estrutura espiral planar usando ar atmosférico, glicerol e água como fluidos, usando o programa de simulação das linhas de fluxo COSMOS Flow 5.0..

Figura A.2 - Imagens das simulações da estrutura espiral planar: (A) simulação com nitrogênio; (B) concentração de n-hexano (1\% em vol.) em Nitrogênio; (C) concentração de n-hexano obtido a partir de solução aquosa saturada usando o simulador FEMLAB3.2®. Cor - velocidade $(\mathrm{cm} / \mathrm{s})$. Altura do sinal, concentração relativa do n-hexano..

Figura A.3 - Perfil da (A) pressão absoluta (Pa) e da (B) velocidade resultante $(\mathrm{cm} / \mathrm{s})$ em uma espiral planar com ar atmosférico, glicerol e água como fluidos usando COSMOS Flow 5.0............

Figura A.4 - Variação de (A) pressão $(\mathrm{Pa})$ e de $(\mathrm{B})$ velocidade $(\mathrm{cm} / \mathrm{s})$ do fluido $-\mathrm{v}_{\mathrm{y}} \mathrm{e}(\mathrm{C})$ lateral $-\mathrm{v}_{\mathrm{z}}$ para canais tridimensionais, usando como gás de arraste $\mathrm{N}_{2}$

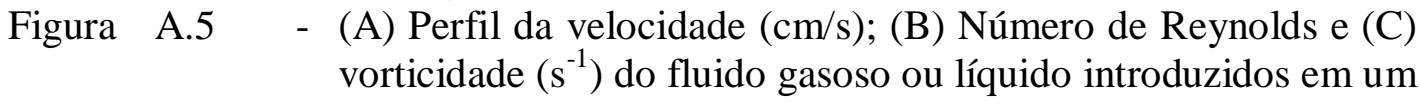

$\begin{aligned} \text { Figura } & \text { A.5 } \quad \text { (A) Perfil da velocidade }(\mathrm{cm} / \mathrm{s}) \text {; (B) Número de Reynolds e (C) } \\ & \text { vorticidade }\left(\mathrm{s}^{-1}\right) \text { do fluido gasoso ou líquido introduzidos em um }\end{aligned}$ canal planar.

Figura A.6 - Produção do spray usando os microcanais em espiral planar e um orifício no centro da estrutura: (A) esquema de entradas e saída, (B) perfil da velocidade $(\mathrm{cm} / \mathrm{s})$ e $(\mathrm{C})$ vorticidade $(\mathrm{s}-$ 1).

Figura A.7 - Múltiplas interações gás/líquido: (A) diagramas esquemáticos; e campo da velocidade $(\mathrm{cm} / \mathrm{s})$ em (B) um, (C) diversos orifícios e (D) orifícios intercalados com a respectiva vorticidade (s-1).......

Figura A.8 - (A) Perfil da velocidade (cm/s); (B), Número de Reynolds; (C) vorticidade (s-1) do fluido gasoso ou líquido introduzidos em um microcanal tridimensional

Figura A.9 - Interação na primeira volta de dois canais: perfil de velocidade para gás e líquido $(\mathrm{cm} / \mathrm{s})$ quando (A) um dos canais tem passo da rosca 4 vezes maior ( $40 \mu \mathrm{m}$ para o menor passo de rosca); ou (B) está em ângulo de $90^{\circ}$, além de respectiva vorticidade (cm1) e Número de Reynolds; e (C) interação entre três voltas consecutivas da estrutura com o canal secundário em ângulo de $90^{\circ}$ e passo.

Figura A.10 - Simulações do desenho do impactador com velocidade da água $(\mathrm{cm} / \mathrm{s})$ no interior da estrutura e vazão de $0,1 \mathrm{~mL} / \mathrm{min}$..

Figura A.11 - (A) Simulação da concentração relativa de partículas de $10 \mu \mathrm{m}$ (identificadas pela coloração) e respectiva velocidade $(\mathrm{cm} / \mathrm{s})$ do fluido (representada pela altura); (B) simulação das linhas de velocidade na presença de partículas.

Figura A.12 - Simulação da velocidade $(\mathrm{cm} / \mathrm{s})$ para o fluxo da água.................. XV

Figura A.13 - Simulação da concentração de partículas.................................... XV 
Figura A.14 - (A) Simulação da concentração relativa de partículas; (B) simulação da concentração relativa de partículas de $10 \mu \mathrm{m}$ (representada pelas cores) e respectiva velocidade de fluido $(\mathrm{cm} / \mathrm{s}$, representada pela altura)

Figura A.15 - Simulação das linhas de velocidade na presença de partículas.

Figura A.16 - Simulação das estruturas usando como gás de arraste $\mathrm{N}_{2}$ (10 $\mathrm{mL} / \mathrm{min}$ padrão): linhas de velocidade (A) sem ou (B) com recheio e respectivas pressões (atm); para duas configurações de estrutura (C) sem constrições e (D) com constrições.

Figura A.17 - (A) Perfil de velocidade $(\mathrm{cm} / \mathrm{s})$ na chicana para vazão de 10 $\mathrm{mL} / \mathrm{min}$ (padrão) e usando como gás de arraste $\mathrm{N}_{2}$ ou (B) usando querosene.

Figura A.18 - Simulação de dois fluxos (vapores de água e querosene), interagindo na estrutura a temperatura ambiente; (A) linhas de velocidade, e detalhe, obtidas com adição de querosene na primeira cela e água em todas as celas restantes; (B) perfil da velocidade $(\mathrm{cm} / \mathrm{s})$ pela adição de querosene na primeira cela e água na última; (C) perfil da velocidade $(\mathrm{cm} / \mathrm{s})$ na adição de querosene aquecido a $100^{\circ} \mathrm{C}$ na primeira cela e água na última em uma estrutura empacotada

Figura A.19 - (A) Perfil da velocidade $(\mathrm{cm} / \mathrm{s}$ - representada pela altura) e a concentração relativa de partículas de $10 \mu \mathrm{m}$ (representada pela cor) em cada cela da estrutura; (B) perfil de velocidade $(\mathrm{cm} / \mathrm{s}$ representada pela cor) e a concentração relativa de partículas de $50 \mu \mathrm{m}$ (representada pela altura) em cada cela da estrutura.........

Figura A.20 - Simulação da chicana empacotada e admissão de $10 \mathrm{~mL} / \mathrm{min}$ padrão de querosene e temperatura ambiente, parede neutral: perfil da (A) velocidade $(\mathrm{cm} / \mathrm{s})$ e (B) da pressão $(\mathrm{atm})$. 


\section{LISTA DE GRÁFICOS}

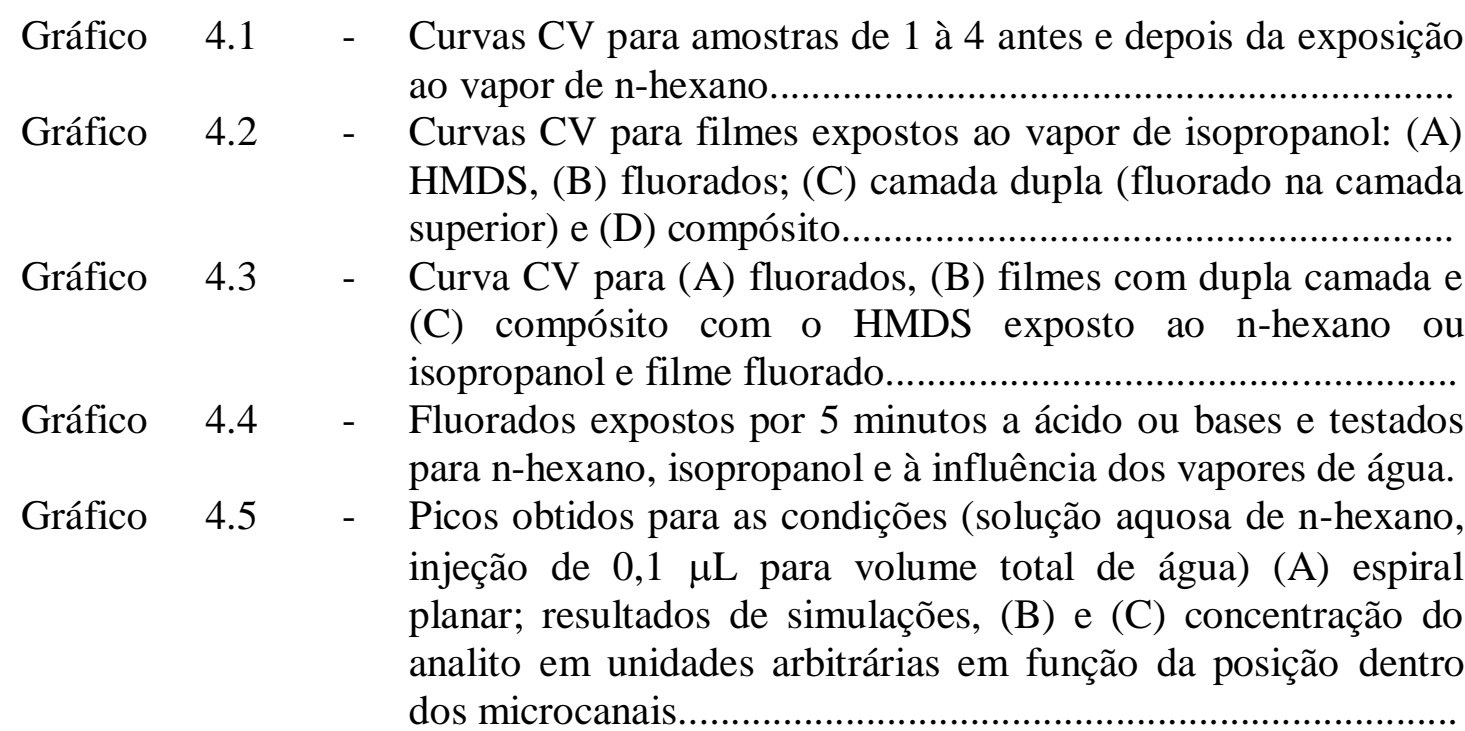

Gráfico 4.6 - Picos obtidos sob as "piores" condições (solução aquosa de nhexano, injeção de $0,1 \mu \mathrm{L}$ para volume total de água) espiral (A) tridimensional; (B) helicoidal com difusão isotrópica $\left(10^{-8}\right.$ $\mathrm{m}^{2} / \mathrm{s}$ ); (C) aumento na difusão lateral (de 2 vezes) ou (D) aumento na taxa da difusão $\left(10^{-4} \mathrm{~m}^{2} / \mathrm{s}\right)$....

Gráfico 4.7 - Microcanal tridimensional, $10 \mathrm{sccm}$ de $\mathrm{N}_{2}$, injeção seqüencial de 0,3 mg de isopropanol, usado como traçador, e, detecção em função do tempo: na microestrutura (A) não empacotada e (B) na microestrutura empacotada. As flechas indicam o momento da injeção do reagente.

Gráfico $4.8 \quad-\quad$ Sequiência de injeções de isopropanol $(50 \mu \mathrm{g})$ nos microcanais (A) não empacotados e (B) microcanais empacotados.

Gráfico 4.9 - Injeção seqüencial na estrutura não empacotada de 30, 20, 10 e $1 \mu \mathrm{g}$ de isopropanol.

Gráfico 4.10 - Traçadores: injeções seqüenciais de n-dodecano e isopropanol em microestruturas (A) não empacotadas e (B) empacotadas (razão entre as amostras de $2: 1 ; 1: 1,5 ; 1: 2,5 ; 1: 4,5 \mathrm{em}$ volume).

Gráfico 4.11 - Intensidade relativa (Amps definido como Ampères pelo equipamento) obtida no espectrômetro de massa em função da água (18 u.m.a.), nitrogênio (28 u.m.a.), oxigênio (32 u.m.a.), n-hexano (41, 43 u.m.a.) e $\mathrm{CO} 2$ (44 u.m.a.) para cada varredura (Scan no equipamento) de 5 segundos. (A) Adição de isopropanol na estrutura sem cobre na superfície, a temperatura ambiente; (B) Adição de isopropanol na estrutura com cobre na superfície, a $300^{\circ} \mathrm{C}$; (C) Adição de n-hexano na estrutura com cobre na superfície a $300^{\circ} \mathrm{C}$; e (D) Adição de nhexano: 2-propanol, 1:1 em vol., na estrutura com cobre na superfície a $300^{\circ} \mathrm{C}$. 
Gráfico 4.12 - Inserção de isopropanol na estrutura modificada: (A) primeiro pico presente no gráfico e (B) pico obtido experimentalmente com a estrutura utilizada com fluxo cruzado de ar atmosférico.

Gráfico 4.13 - Inserção de isopropanol na estrutura modificada: (A)

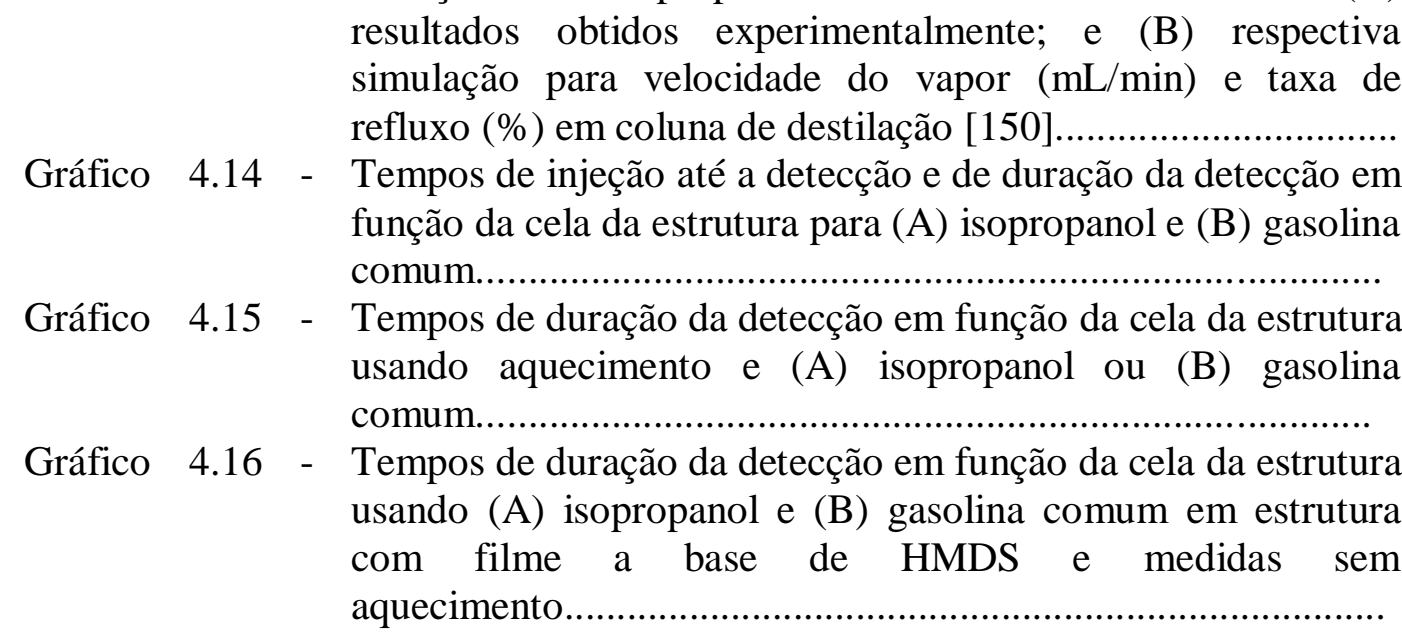

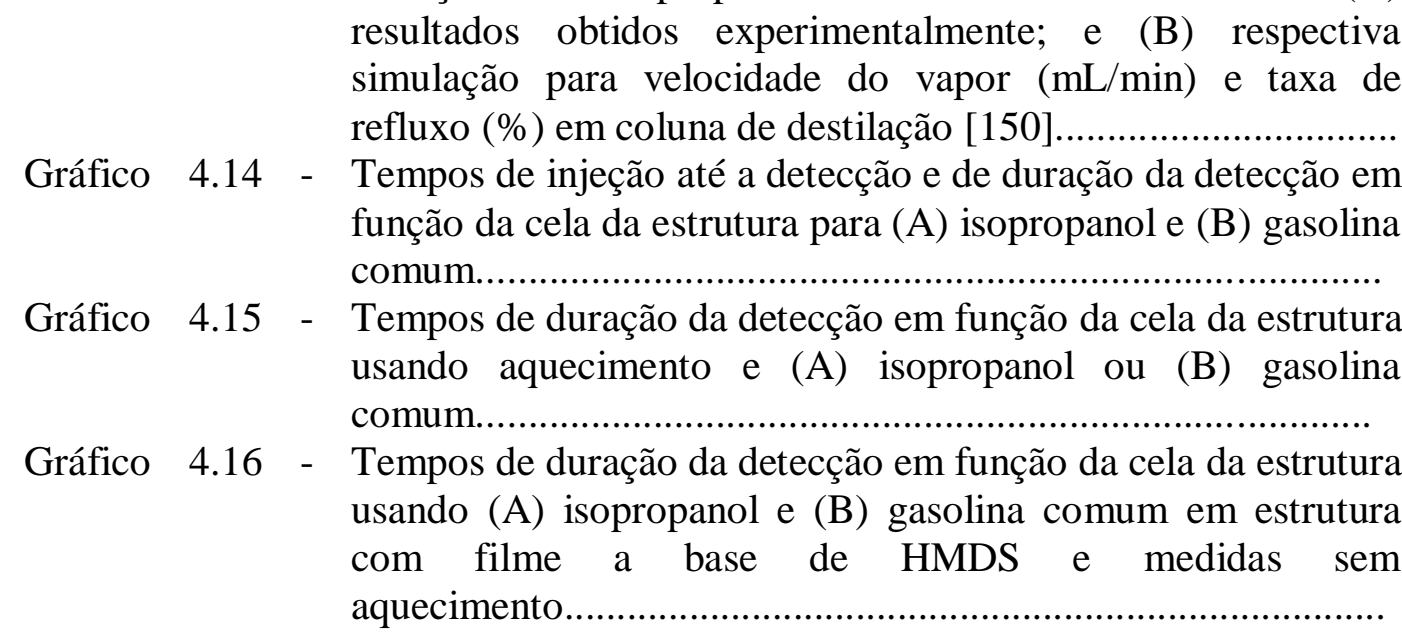

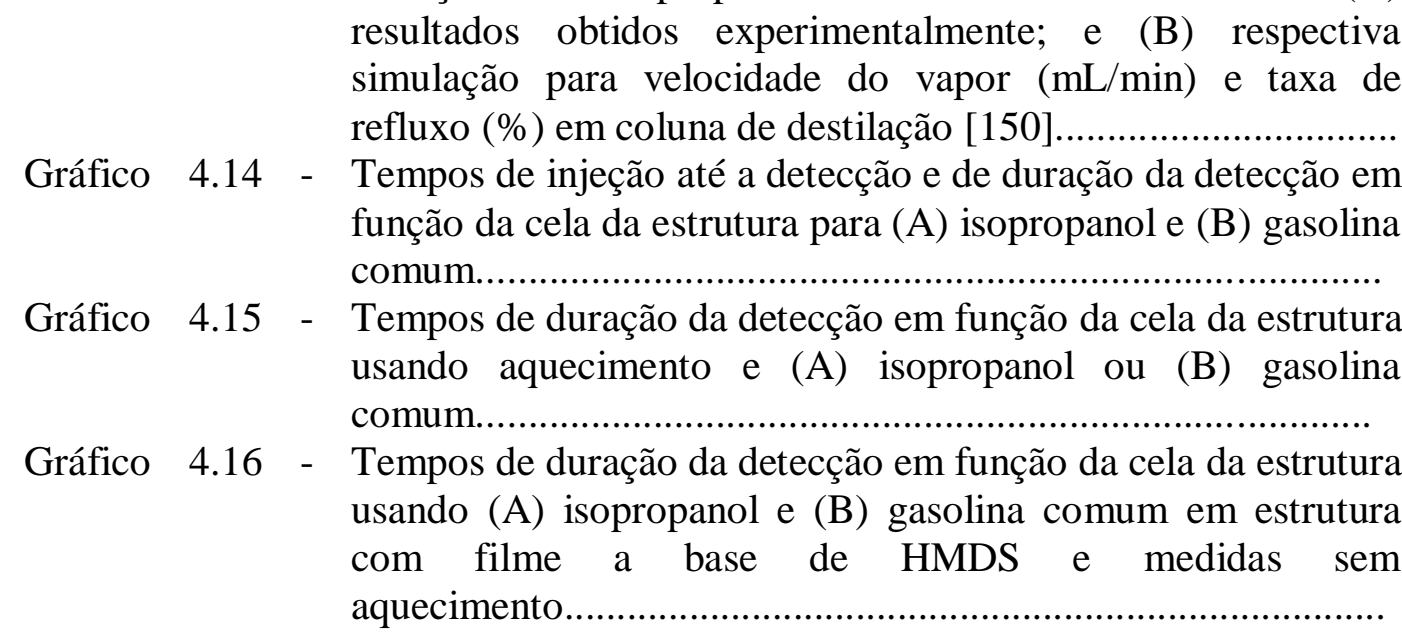

Gráfico B.1 - (A) Teste e (B) Transformada de Fourier usando apenas o capilar com o minicompressor de ar desconectado, usando como reagente isopropanol....

Gráfico B.2 - (A) Teste e (B) Transformada de Fourier usando apenas o capilar com o minicompressor de ar ligado, usando como reagente isopropanol.

Gráfico B.3 - (A) Teste e (B) Transformada de Fourier usando a estrutura tridimensional modificada não empacotada, usando como reagente isopropanol.

Gráfico B.4 - (A) Teste e (B) Transformada de Fourier usando a estrutura tridimensional modificada não empacotada, usando como reagente n-hexano.

XXVI

Gráfico B.5 - (A) Teste e (B) Transformada de Fourier usando a estrutura tridimensional modificada não empacotada, usando como reagente acetona.

Gráfico B.6 - (A) Teste e (B) Transformada de Fourier usando a estrutura tridimensional modificada não empacotada, usando como reagente gasolina comum.

Gráfico B.7 - (A) Teste e (B) Transformada de Fourier usando a estrutura tridimensional modificada não empacotada, usando como reagente mistura (etanol+isopropanol+água, $33 \%$ em vol.)......

Gráfico B.8 - (A) Teste e (B) Transformada de Fourier usando a estrutura tridimensional modificada empacotada, usando como reagente isopropanol.

XXIX

XXXI

Gráfico B.9 - (A) Teste e (B) Transformada de Fourier usando a estrutura tridimensional modificada empacotada, usando como reagente n-hexano 
Gráfico B.10 - (A) Teste e (B) Transformada de Fourier usando a estrutura tridimensional modificada empacotada, usando como reagente acetona.

XXXIII

Gráfico B.11 - (A) Teste e (B) Transformada de Fourier usando a estrutura tridimensional modificada empacotada, usando como reagente gasolina comum

Gráfico B.12 - (A) Teste e (B) Transformada de Fourier usando a estrutura tridimensional modificada empacotada, usando como reagente mistura (etanol+isopropanol+água, $33 \% \mathrm{em}$ vol.).

Gráfico B.13 - (A) Teste e (B) Transformada de Fourier usando a estrutura tridimensional modificada não empacotada, usando como reagente gasolina comum (posto 1).

Gráfico B.14 - (A) Teste e (B) Transformada de Fourier usando a estrutura tridimensional modificada não empacotada, usando como reagente gasolina comum (posto 2).

Gráfico B.15 - (A) Teste e (B) Transformada de Fourier usando a estrutura tridimensional modificada não empacotada, usando como reagente gasolina comum (posto 3 )

XXXIX

Gráfico B.16 - (A) Teste e (B) Transformada de Fourier usando a estrutura tridimensional modificada não empacotada, usando como reagente gasolina com isopropanol (posto 1)

XL

Gráfico B.17 - (A) Teste e (B) Transformada de Fourier usando a estrutura tridimensional modificada empacotada, usando como reagente gasolina comum (posto 1)

Gráfico B.18 - (A) Teste e (B) Transformada de Fourier usando a estrutura tridimensional modificada empacotada, usando como reagente gasolina comum (posto 2 )

Gráfico B.19 - (A) Teste e (B) Transformada de Fourier usando a estrutura tridimensional modificada empacotada, usando como reagente gasolina comum (posto 3).

Gráfico B.20 - (A) Teste e (B) Transformada de Fourier usando a estrutura tridimensional modificada não empacotada, usando como reagente gasolina com isopropanol (posto 1). 


\section{LISTA DE ESQUEMAS}

Esquema 1.1 - Proposta de protótipo para formação do conjunto de

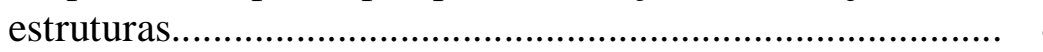

pg 4

\section{LISTA DE FLUXOGRAMAS}

Fluxograma $3.1 \quad$ - $\quad$ Seqüência de etapas para desenvolvimento do trabalho.. 37 Fluxograma 3.2 - Esquema das etapas seguidas para o desenvolvimento deste trabalho.................................................................. 38

\section{LISTA DE EQUAÇÕES}

\begin{tabular}{|c|c|c|}
\hline Equação & $1 \mathrm{a}$ & Equação para o cálculo do número de pratos teóricos............. \\
\hline Equação & $1 b$ & 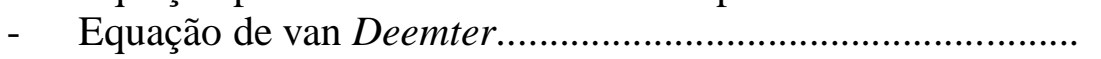 \\
\hline Equação & $1 \mathrm{c}$ & Equação para o cálculo do fator de separação............................. \\
\hline Equação & $1 d$ & Equação para o cálculo do fator de capacidade... \\
\hline Equação & 2 & 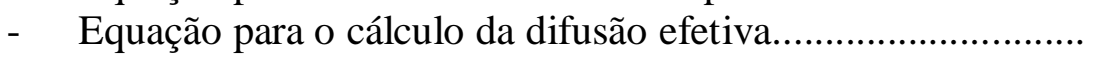 \\
\hline Equação & 3 & Equação para o cálculo do número de Dean............................. \\
\hline Equação & 4 & - Equação para o cálculo do número de Reynolds...................... \\
\hline Equação & 5 & 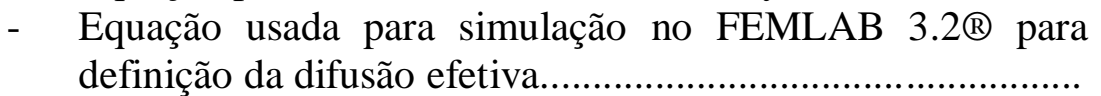 \\
\hline
\end{tabular}




\section{LISTA DE TABELAS}

Tabela $2.1 \quad$ - $\quad$ Processos de separação e propriedades básicas [35]

Tabela 3.1 - Dados de variação de temperaturas de cada cela de saída obtidos durante cinco testes consecutivos para a estrutura da Figura 3.4.

Tabela 3.2 - Testes realizados para obtenção de vazão obtidos na estrutura da Figura 3.3.

Tabela 4.1 - Condições de deposição dos filmes a base de $\operatorname{Vertrel}^{(\mathrm{R})} \mathrm{e}$ HMDS na câmara de plasma.

Tabela $4.2 \quad$ - Intensidades relativas obtidas por FTIR para filmes a base de HMDS e fluorados (Vertrel®).

Tabela $\quad 4.3 \quad$ - $\quad$ Resultados típicos para análise SEM dos filmes finos a base de HMDS e de fluorado (Vertrel®).

Tabela

Condições de deposição na câmara de plasma.

Tabela

4.4

$-$

Medidas referentes ao índice de refração e ao ângulo de contato com a água para filmes da Tabela 4.4.

Tabela

Velocidades máximas nos microcanais em espiral planar usando a água, o glicerol e ar atmosférico como fluidos. Simulação tridimensional com pressão de saída igual a 1 atm.....

Tabela 4.7 - Picos de máximo das velocidades nos microcanais tridimensionais usando a água, glicerol e ar atmosférico como fluidos. Simulações tridimensionais com pressão de saída igual a 1 atm e $300 \mathrm{~K}$.

Tabela

4.8 - O número calculado de pratos teóricos e o tempo de retenção medido para a espiral planar $(10 \mathrm{sccm}$ de ar atmosférico).

Tabela 4.9 - Cálculo do número de pratos teóricos e tempo de retenção medido para a espiral tridimensional $(10 \mathrm{sccm}$ de ar atmosférico).

Tabela 4.10 - Valores médios de 5 testes consecutivos usando estrutura espiral: tridimensional ou planar, modo de admissão pulsada.

Tabela 4.11 - Parâmetros testados na estrutura para a determinação da separação de compostos.

Tabela 4.12 - Parâmetros mais importantes a serem avaliados na estrutura.

Tabela

4.13 - Estruturas miniaturizadas e respectiva função.

Tabela

C.1 - Dados obtidos para estrutura não empacotada, sem aquecimento e isopropanol.

Tabela C.2 - Dados obtidos para estrutura não empacotada, sem

Tabela C.3 - Dados obtidos para estrutura não empacotada, sem aquecimento e acetona........................................................

Tabela C.4 - Dados obtidos para estrutura não empacotada, sem aquecimento e Varsol® 
Tabela C.5 - Dados obtidos para estrutura não empacotada, sem

Tabela C.6 - aquecimento e mistura......................................................

Tabela C.6 Dados obtidos para estrutura não empacotada, com

Tabela C.7 - Dados obtidos para estrutura não empacotada, com aquecimento e gasolina comum...........................................

Tabela C.8 - Dados obtidos para estrutura não empacotada, com aquecimento e acetona...................................................... L

Tabela C.9 - Dados obtidos para estrutura não empacotada, com aquecimento e Varsol®.

Tabela C.10 - Dados obtidos para estrutura não empacotada, com aquecimento e mistura $(1 \mathrm{~mL}$ de mistura 1:1:1 de acetona + isopropanol + álcool etílico).

XLIX

XLIX

\section{$\mathrm{L}$}

$\mathrm{L}$

Tabela C.11 - Dados obtidos para estrutura não empacotada, sem

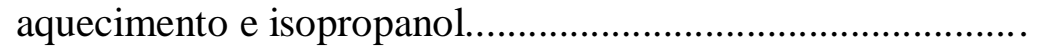

Tabela C.12 - Dados obtidos para estrutura não empacotada, sem aquecimento e gasolina comum...........................................

Tabela C.13 - Dados obtidos para estrutura não empacotada, sem

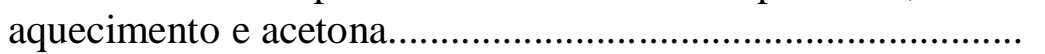

Tabela C.14 - Dados obtidos para estrutura não empacotada, sem aquecimento e Varsol $\AA$....................................................

Tabela C.15 - Dados obtidos para estrutura não empacotada, sem aquecimento e mistura $(1 \mathrm{~mL}$ de mistura 1:1:1 de acetona + isopropanol + álcool etílico).

Tabela C.16 - Dados obtidos para estrutura não empacotada, com aquecimento e isopropanol.

Tabela C.17 - Dados obtidos para estrutura não empacotada, com aquecimento e gasolina comum........................................... LIII

Tabela C.18 - Dados obtidos para estrutura não empacotada, com aquecimento e acetona....................................................... LIII

Tabela C.19 - Dados obtidos para estrutura não empacotada, com aquecimento e Varsol ${ }^{\circledR}$.........................................................

Tabela C.20 - Dados obtidos para estrutura não empacotada, com aquecimento e mistura $(1 \mathrm{~mL}$ de mistura 1:1:1 de acetona + isopropanol + álcool etílico).....

Tabela C.21 - Dados obtidos para estrutura empacotada, sem aquecimento e isopropanol.......................................................................

Tabela C.22 - Dados obtidos para empacotada, sem aquecimento e gasolina comum.

Tabela C.23 - Dados obtidos para estrutura empacotada, sem aquecimento e acetona......

Tabela C.24 - Dados obtidos para estrutura empacotada, sem aquecimento e Varsol@.

Tabela C.25 - Dados obtidos para estrutura empacotada, sem aquecimento e mistura (1 mL de mistura 1:1:1 de acetona + isopropanol + álcool etílico). 


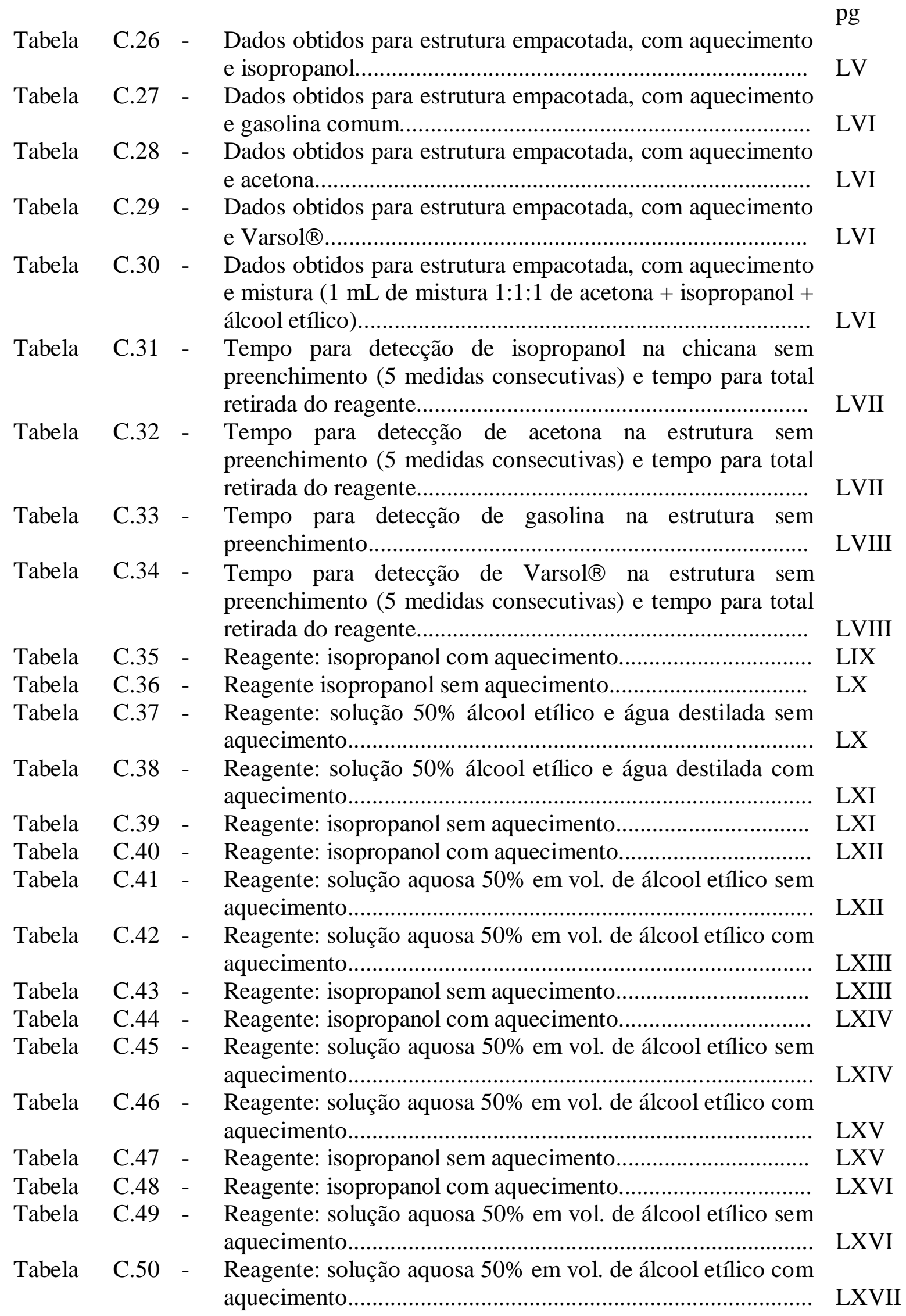




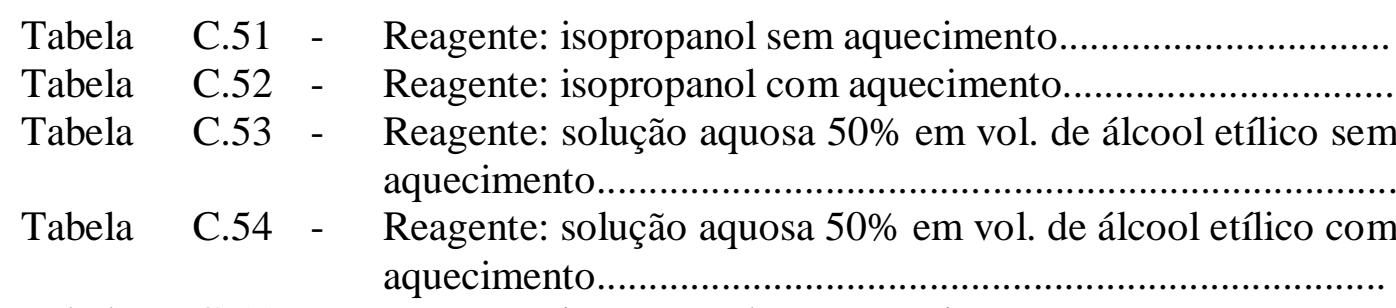

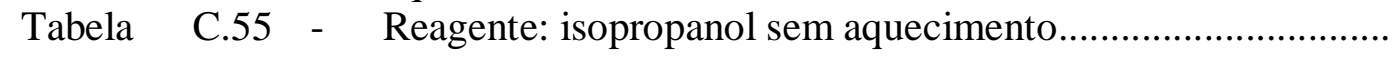

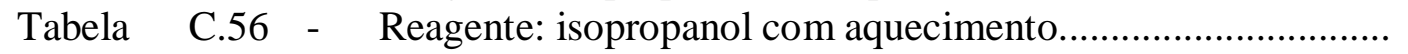

Tabela C.57 - Reagente: solução aquosa 50\% em vol. de álcool etílico sem aquecimento......

Tabela C.58 - Reagente: solução aquosa 50\% em vol. de álcool etílico com aquecimento.....

pg

LXVIII

LXVIII

LXIX

LXIX

LXX

LXX

LXXI

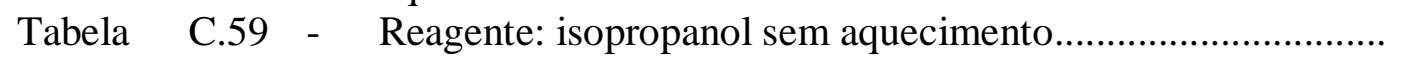

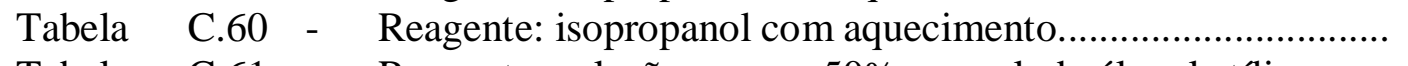

Tabela C.61 - Reagente: solução aquosa 50\% em vol. de álcool etílico sem aquecimento.

Tabela C.62 - Reagente: solução aquosa 50\% em vol. de álcool etílico com aquecimento

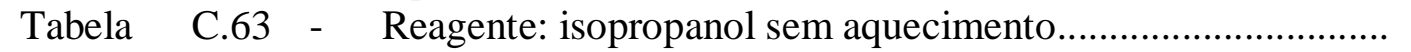

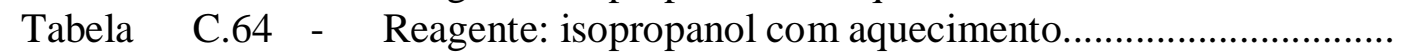

Tabela C.65 - Reagente: solução aquosa 50\% em vol. de álcool etílico sem aquecimento.

LXXI

LXXII

LXXII

LXXIII

LXXIII

LXXIV

LXXIV

LXXV

Tabela C.66 - Reagente: solução aquosa 50\% em vol. de álcool etílico com aquecimento......

Tabela C.67 - Dados obtidos em medidas usando modo de admissão contínua de álcool na chicana empacotada sem o uso de aquecimento

Tabela C.68 - Dados obtidos em medidas usando modo de admissão contínua de $\operatorname{Varsol}{ }^{\circledR}$ na chicana empacotada sem o uso de aquecimento.

LXXV

LXXVII

LXXVIII

Tabela C.69 - Dados obtidos em medidas usando modo de admissão contínua de álcool na chicana empacotada com o uso de aquecimento......

Tabela C.70 - Dados obtidos em medidas usando modo de admissão contínua de Varsol® na chicana empacotada com o uso de aquecimento.

Tabela C.71 - Dados obtidos para teste de escoamento inverso em função do tempo (segundos) na estrutura chicana não empacotada para diferentes reagentes (isopropanol, n-hexano, gasolina) e para diferentes temperaturas (sem e com aquecimento gradativo $-85^{\circ}, 65^{\circ}, 45^{\circ}, 20^{\circ} \mathrm{C}$ ).

LXXXI

Tabela C.72 - Dados obtidos para teste de escoamento inverso em função do tempo (segundos) na estrutura chicana empacotada para diferentes reagentes (isopropanol, n-hexano, gasolina) e para diferentes temperaturas (sem e com aquecimento gradativo $\left.85^{\circ}, 65^{\circ}, 45^{\circ}, 20^{\circ} \mathrm{C}\right)$. 


\section{SUMÁRIO}

CAPÍTULO 1 - INTRODUÇÃO...............................................................

CAPÍTULO 2 - ASPECTOS TEÓRICOS …………………………………..... 5

2.1 TENDÊNCIAS.

2.2 OPERAÇÕES UNITÁRIAS NA INDÚSTRIA QUÍMICA............................... 6

2.3 PROCESSOS DE SEPARAÇÃO................................................................. 7

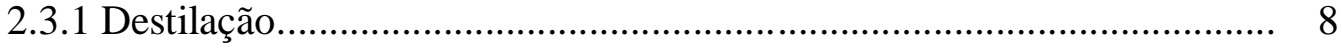

2.3.2 Pré-tratamento............................................................................... 14

2.3.2.1 Fase gasosa......................................................................... 14

2.3.2.2 Fase líquida............................................................................ 15

2.3.3 Manipulação da amostra................................................................... 16

2.4 ANÁLISES QUÍMICAS........................................................................ 18

2.4.1 Cromatografia................................................................................... 18

2.4.1.1 Definições cromatográficas........................................................ 20

2.4.1.2 Comparação entre cromatografia e colunas de destilação............. 23

2.5 MANIPULAÇÃO DE AMOSTRA............................................................ 24

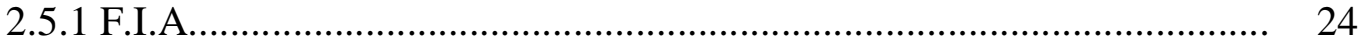

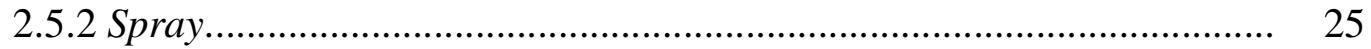

2.6 MINIATURIZAÇÃO e $\mu$ TAS................................................................... 25

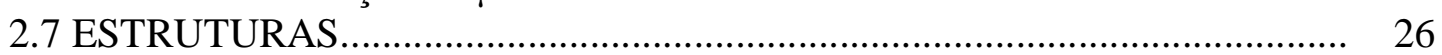

2.7.1 Estruturas Helicoidais................................................................... 27

2.7.2 Estrutura Espiral Planar...................................................................... 28

2.7.3 Estrutura Chicana.............................................................................. 29

2.7.4 Estrutura Impactadora...................................................................... $\quad 30$

2.8 SUPERFÍCIE ADSORVENTE................................................................... 31

2.8.1 Filmes depositados por plasma e respectiva caracterização.................... 31

2.8.2 Compostos Orgânicos Voláteis.............................................................. 34

2.9 OUTROS ASPECTOS …………………………………………. 35

CAPÍTULO 3 - MATERIAIS E MÉTODOS ………………………………….... 36

3.1 ETAPAS DO TRABALHO................................................................... 36

3.2 SIMULAÇÃO E CONSTRUÇÃO DAS ESTRUTURAS................................... 38

3.3 CARACTERIZAÇÃO E DETECÇÃO NAS ESTRUTURAS............................ 39

3.3.1 Admissão de amostra....................................................................... $\quad 39$

3.3.2 Sistemas de deteç̧ão....................................................................... 40

3.3.3 Modos de admissão............................................................................. 42

3.3.3.1 Modo de admissão pulsada....................................................... 42

3.3.3.2 Modo de admissão contínua........................................................... 43

3.3.4 Medidas com aquecimento................................................................... 44

3.4 COMPORTAMENTO DO FLUIDO........................................................ 47

3.4.1 Retenção de partículas....................................................................... 47

3.4.2 Medidas de vazão....................................................................... 48

3.4.3 Filmagens................................................................................ 50 
3.5 MATERIAIS

3.5.1 Confecção das estruturas miniaturizadas............................................. 51

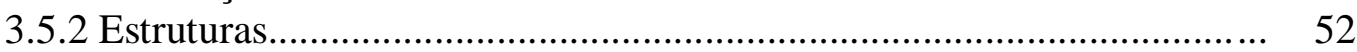

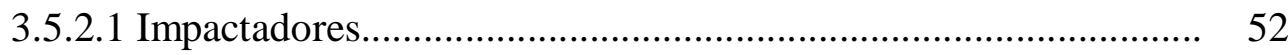

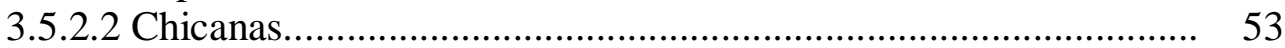

3.5.2.3 Microcanais tridimensionais................................................. 55

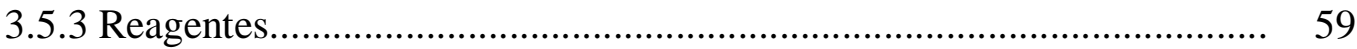

3.5.4 - Caracterização dos filmes poliméricos............................................. 59

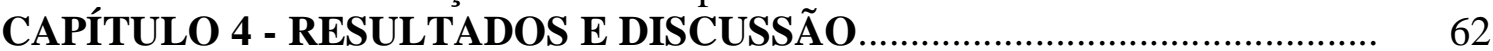

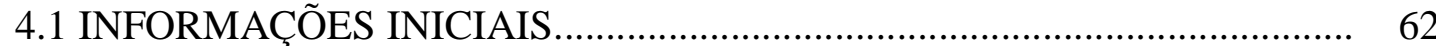

4.1.1 Tratamento de superfície................................................................. 64

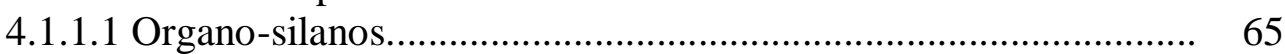

4.1.1.1.1 Caracterização: reagente apolar................................ 68

4.1.1.1.2 Caracterização: reagente polar.................................. 69

4.1.1.2 Compostos orgânicos fluorados................................................... 71

4.1.1.3 Conclusão parcial.................................................................. 77

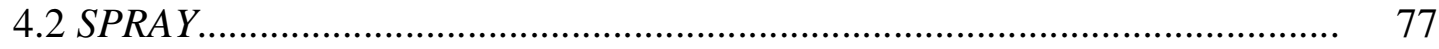

4.2.1 Simulações dos canais planares e tridimensionais................................ 79

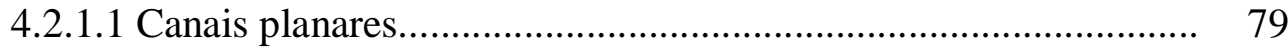

4.2.1.2 Canais tridimensionais......................................................... 82

4.2.2 Testes experimentais usando traçadores em canais planares e

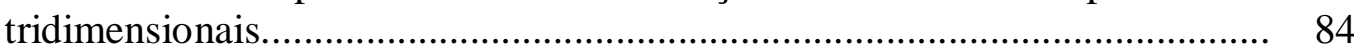

4.2.2.1 Canais planares................................................................. 84

4.2.2.2 Canais tridimensionais ........................................................... 89

4.2.2.3 Condições experimentais....................................................... 90

4.2.2.3.1 Microcanais.................................................................... 90

4.2.2.3.2 Número de pratos teóricos: outras observações................ 92

4.2.3 Modelo qualitativo......................................................................... 95

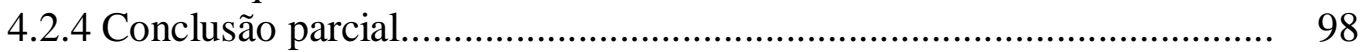

4.2.5 Configurações do spray................................................................... 99

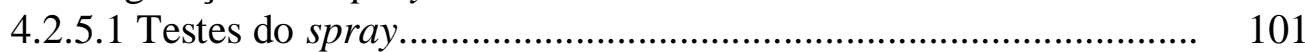

4.2.5.1.1 Spray: microcanais planares........................................... 101

4.2.5.1.2 Spray: microcanais tridimensionais................................ 109

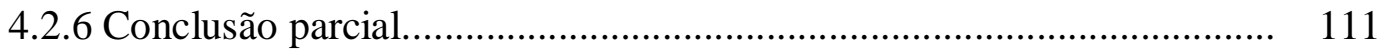

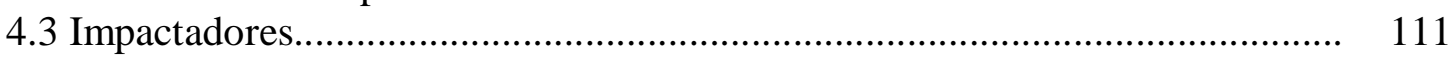

4.3.1 Simulações..................................................................................... 113

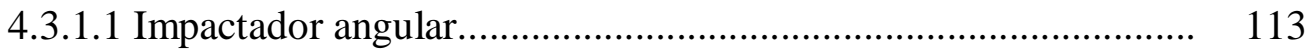

4.3.1.2 Impactador semi-circular........................................................ 114

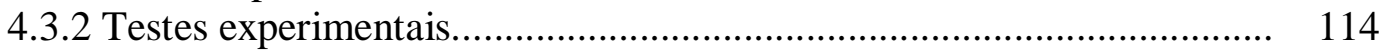

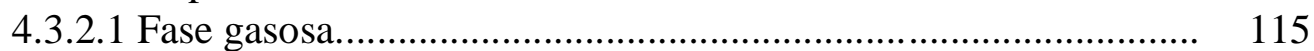

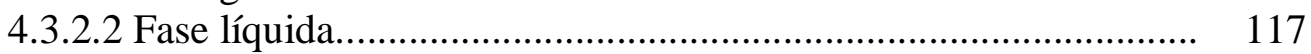

4.3.2.3 Sistema de spray................................................................ 118

4.3.3 Conclusão parcial............................................................................ 119

4.4 CANAIS TRIDIMENSIONAIS MODIFICADOS ...................................... 119

4.4.1 Construção dos canais................................................................... 122

4.4.2 Testes dos microcanais.................................................................... 123 
4.4.3.1 Testes com a estrutura não empacotada................................... 135

4.4.3.2 Testes com a estrutura empacotada........................................ 140

4.4.4 Conclusão parcial............................................................................ 141

4.5 ESTRUTURA PARA SEPARAÇÃO PRELIMINAR DE COMPOSTOS..... 141

4.5.1 Simulação da estrutura....................................................................... 143

4.5.2 Retenção de partículas e comportamento do fluido............................... 144

4.5.2.1 Retenção de partículas............................................................ 145

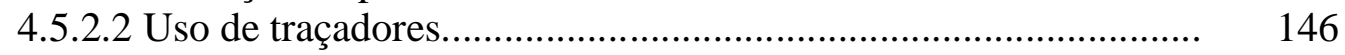

4.5.3 Conclusão parcial.............................................................................. 151

4.5.4 Teste da estrutura................................................................ 151

4.5.4.1 Estrutura não empacotada.................................................... 153

4.5.4.1.1 Sem aquecimento..................................................... 153

4.5.4.1.2 Com aquecimento..................................................... 154

4.5.4.1.3 Recobrimento com filme adsorvente a base de HMDS..... 155

4.5.4.1.3.1 Sem aquecimento............................................... 155

4.5.4.1.3.2 Com aquecimento.............................................. 156

4.5.4.2 Estrutura empacotada............................................................. 157

4.5.4.2.1 Recobrimento com filme adsorvente a base de HMDS.... 157

4.5.4.2.1.1 Sem aquecimento.................................................. 158

4.5.4.2.1.2 Com aquecimento............................................. 158

4.5.4.3 Conclusão parcial................................................................ 158

4.6 PROPOSTA DE PROTÓTIPO............................................................... 159

4.6.1 Engenharia Química e Análises......................................................... 159

4.6.2 Aspecto educacional..................................................................... 163

4.6.3 Conclusão parcial.......................................................................... 163

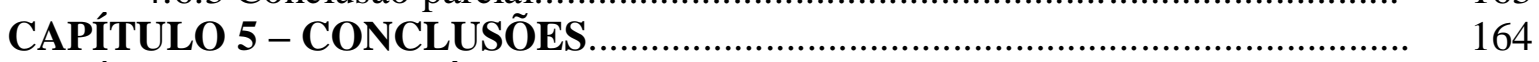

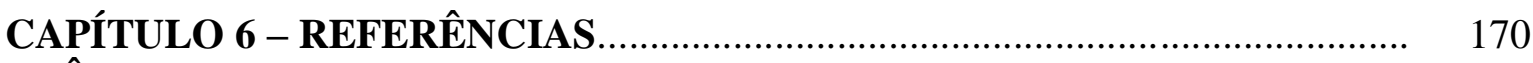

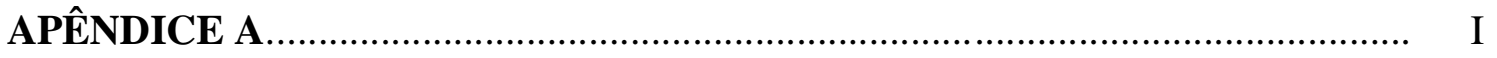

A.1 Simulações dos canais planares e tridimensionais....................................... I

A.1.1 Canais planares.......................................................................... I

A.1.2 Canais tridimensionais.................................................................. IV

A.1.3 Spray: microcanais planares........................................................... VI

A.1.4 Spray: microcanais tridimensionais.................................................. $\mathrm{X}$

A.2 Simulações dos impactadores................................................................... XIII

A.2.1 Impactador angular...................................................................... XIII

A.2.2 Impactador semi-circular............................................................... XIV

A.3 Simulações do separador.......................................................................... XVI

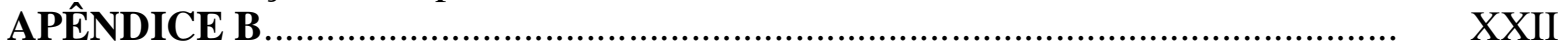

B.1 Canais tridimensionais modificados......................................................... XXII

B.1.1 Testes experimentais......................................................................... XXII

B.1.1.1 Testes a temperatura ambiente................................................. XXII

B.1.1.1.1 Estrutura não empacotada............................................. XXII

B.1.1.1.2 Estrutura empacotada................................................. XXX

B.1.1.2 Testes com aquecimento...................................................... XXXVI

B.1.1.2.1 Gasolinas de postos diferentes: não empacotada.............. XXXVI 
B.1.1.2.2 Gasolinas de postos diferentes: empacotada.

C.1 Estrutura chicana - variação dos parâmetros de teste..

C.1.1 Modo de admissão pulsada.

C.1.1.1 Condição 1

C.1.1.2 Condição 2

C.1.1.3 Condição 3

XLIX

C.1.1.4 Condição 4

$\mathrm{L}$

C.1.1.5 Condição 5

LII

C.1.1.6 Condição 6

LIV

C.1.1.7 Condição 7

LV

C.1.1.8 Condição 8

LVI

C.1.1.8.1 Estrutura não empacotada

C.1.1.8.2 Estrutura não empacotada e com filme a base de HMDS.

C.1.1.8.3 Chicana empacotada

LXI

C.1.1.8.4 Chicana empacotada e com filme a base de HMDS depositado.

LXIII

C.1.1.8.5 Chicana não empacotada......

LXV

C.1.1.8.6 Chicana não empacotada e com filme a base de HMDS...

LXVIII

C.1.1.8.7 Chicana empacotada

LXX

C.1.1.8.8 Chicana empacotada e com filme a base de HMDS depositado.

LXXII

C.1.2 Modo de admissão contínua.

LXXIV

C.1.2.1 Medidas sem aquecimento

LXXVI

C.1.2.2 Medidas com aquecimento

LXXVI

C.1.2.3 Aquecimento do reagente.

LXXVIII

C.1.2.4 Adição de água 


\section{CAPÍTULO 1 - INTRODUÇÃO}

A evolução tecnológica na área de MEMS[1][2] (Microelectromechanical Systems) levou à criação de equipamentos cada vez mais complexos e, para a área de análises, à tentativa de não apenas processar amostras cada vez mais complexas e de menor volume, mas fazê-lo rapidamente, de modo contínuo e com pouco uso de recursos. É neste contexto que o TAS (micro Total Analysis System) se insere e provoca a mudança em uma série de procedimentos de análise [3][4][5][6][7]. De fato, o uso de sistemas miniaturizados de modo geral, e de $\mu$ TAS em particular, tornou-se tão abrangente que hoje influencia inclusive os modos/métodos de ensino [8].

Dentre as diversas propostas de construção de $\mu$ TAS duas são bem distintas. A construção de sistemas miniaturizados altamente complexos e com precisão/exatidão nas medidas, é uma alternativa comum para a área de análises químicas de modo geral. Neste caso, quanto mais complexas são as amostras, mais complexos serão os equipamentos e as operações envolvidas. Por outro lado, é comum o uso de sensores mais baratos - na forma de arranjo de sensores - para a análise de amostras complexas, como as de produtos naturais, nesse caso para obter informações mais genéricas sobre o conteúdo da amostra; essa é a abordagem, por exemplo, utilizada na construção de nariz [9] e língua eletrônicos [10]. Esses sistemas costumam ser portáteis e apresentam respostas rápidas, pois não costumam exigir o pré-tratamento da amostra para remoção de interferentes, como é comumente feito em análises químicas [11]. Porém, apresentam uma resposta, em geral, semi-quantitativa. Este trabalho apresenta abordagem intermediária propondo a separação de interferentes da matriz com a possibilidade de pré-tratamento qualitativo de amostras, mas análise objetivando a impressão digital da amostra, não sua identificação.

Atualmente, a miniaturização de dispositivos por processos MEMS não ocorre de modo semelhante ao observado em outras áreas produtivas, como é o caso da Engenharia Química, onde reatores menores apresentam inúmeras vantagens, entre elas a maior relação área/volume, que favorece, por exemplo, as reações de catalise [12].

\footnotetext{
${ }^{a}$ Matriz é aqui definida como a parte restante da amostra depois da remoção do analito, isto é, após remoção da parte que se quer analisar.
} 
Apesar da miniaturização, na maioria das vezes os dispositivos produzidos em Engenharia Química são bem maiores do que aqueles produzidos por processos MEMS.

A vantagem de dispositivos maiores é que alguns fenômenos, por exemplo, capilaridade têm menor influência, ou seja, ainda podem ser considerados secundários, como ocorre em dispositivos macroscópicos [13]. Assim, pesquisadores da área de Engenharia Química já alertaram para a existência de barreiras (gap) entre o nano, o micro e o macro nesta área tecnológica e para a necessidade de diminuí-las.

Além disso, há uma correlação entre os processos ocorrendo em um $\mu$ TAS e as

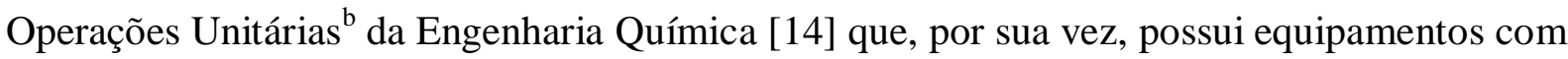
funções muito semelhantes às desenvolvidas no pré-tratamento de amostras para $\mu$ TAS. De fato, no grupo da EPUSP onde este trabalho foi desenvolvido, sete estruturas miniaturizadas com funções bem distintas foram desenvolvidas pelo escalamento linear de estruturas macroscópicas da Engenharia Química. Estas estruturas foram testadas para diversas funções, inclusive educacional [15]. Portanto, há inegáveis vantagens em atuar no desenvolvimento de dispositivos com tamanhos intermediários entre os comuns em Engenharia Química e processos MEMS.

Dentre as amostras complexas que necessitam de detecção e eventual análise, misturas de $\operatorname{VOCs}^{c}$ (compostos orgânicos voláteis - COVs) são bem importantes. VOCs podem ser contaminantes do ciclo hidrológico e da atmosfera já que de modo geral, estes compostos são solventes, combustíveis, etc., ou seja, estão bastantes presentes na sociedade moderna. Muitas destas análises, contudo, só necessitam de informações simples, tais como, existência ou não de contaminação, adulteração, etc.

Portanto, é objetivo geral deste trabalho a simulação, construção e caracterização de estruturas úteis na fabricação de $\mu \mathrm{TAS}$, preservando, porém, a concepção comum ao nariz/língua eletrônico, com construção mais simples que estes dispositivos e obtenção de informação semi-quantitativa. O termo $\mu$ TAS é aqui utilizado de modo amplo, já que, em geral, este termo compreende desde sensores one way de fácil fabricação até sistemas bastante complexos. Assim, definir-se-á como escopo deste trabalho o desenvolvimento de partes e peças que possam ser úteis na manipulação e análise de matrizes complexas, isto é, matrizes

\footnotetext{
b Operação Unitária, em Engenharia Química, corresponde à etapa básica de um processo. Portanto, cada operação unitária segue as mesmas leis físicas e são semelhantes em todas as Indústrias Químicas. Essas operações tratam principalmente de escoamento de fluidos, transferência de massa e calor, mistura, separação e reações químicas.

${ }^{\mathrm{c}}$ VOCs - Volatile Organic Compounds.
} 
da área ambiental, e eventualmente de análises clínicas ${ }^{\mathrm{d}}$ [16]. Além disso, as estruturas a serem construídas são de baixo custo e obtidas por escalamento de sistemas macroscópicos.

Para a análise de VOCs, o pré-tratamento exige principalmente estruturas capazes de separação e/ou retenção de partículas e/ou classes de compostos.

Quanto à seleção e/ou retenção de partículas em fase gasosa, especialmente em amostras ambientais e amostras atmosféricas, devido às fontes naturais e aos seres humanos, há a formação desde grandes partículas até a emissão de aerossóis e smog [17][18][19], havendo compostos tóxicos na composição de alguns deles [20]. Ademais, as indústrias estão constantemente emitindo particulados para a atmosfera que são responsáveis, entre outras coisas, pela formação destes aerossóis e smog. As dimensões dos particulados podem variar de centenas de Angstroms a algumas micras de diâmetro e podem causar sérios problemas ambientais. Por esta razão, a poluição do ar é um dos maiores problemas da vida moderna e, sendo assim, as análises de amostras de ar se tornam de suma importância, especialmente no que se refere às partículas pequenas, por exemplo, aerossóis, que podem permanecer suspensas na atmosfera por longos períodos [21][22][23].

Em amostras aquosas, isto é, dentro do ciclo hidrológico, as partículas têm dimensões variadas e podem se tornar um grande problema. Segundo Lawler [24] muitos dos contaminantes presentes em águas, comuns e/ou residuárias, se transformarão em partículas instantânea ou posteriormente à coleta de amostras, portanto, muitas destas partículas influenciarão o comportamento destas amostras [25][26]. Santos [27] afirma que tanto em água comum como na residuária o tamanho das partículas pode variar de dimensões mínimas (poucos Angstroms) até acima de $10^{2} \mu \mathrm{m}$.

Várias operações unitárias são utilizadas para a remoção de partículas e/ou aerossóis em fase gasosa e partículas ou emulsões/dispersões em fase líquida. No ar, partículas com diâmetros iguais a $100 \mu \mathrm{m}$ são tipicamente removidas por efeitos gravitacionais, de $10 \mu \mathrm{m}$ por efeitos de centrifugação, de $1 \mu \mathrm{m}$ por filtros e $0,1 \mu \mathrm{m}$ com filtros eletrostáticos. No líquido, a remoção de moléculas com alto peso molecular faz uso da adsorção e osmose reversa, as nanopartículas podem ser eliminadas por ultrafiltração e as partículas grandes com filtração ou sedimentação.

A separação de compostos, em $\mu \mathrm{TAS}$, de um meio seja este líquido ou gasoso, de modo geral, depende da adsorção, caso se deseje uma situação reversível, ou seja, que a

\footnotetext{
d Tanto análises ambientais quanto clínicas, neste caso, são compreendidas como análises químicas cuja matriz para avaliação foi obtida de sistemas ambientais ou clínicos, respectivamente.
} 
remoção deste composto do local onde foi aprisionado não seja dificultada posteriormente. Este é o caso dos pré-concentradores, e alguns destes já foram miniaturizados [28]. Quando a separação não visa o pré-tratamento de amostras, esta pode ocorrer por aquecimento, como é o caso em sistemas da destilação. A retenção de compostos, por outro lado, de modo geral, corresponde ao pré-tratamento de amostra com o objetivo de tornar a matriz sob análise mais simples e, neste caso, a reação com a superfície é desejável. Isto é possível através da catálise, e estrutura miniaturizada para este fim já foi apresentada tendo-se como exemplo o uso de cobre em microcanais para promover catálise [29]. A retenção pode ocorrer sem que haja reação; por exemplo, tem-se a retenção de VOCs em microcanais com constrições [30]. Assim, duas Operações Unitárias são relevantes neste trabalho e correspondem à remoção de partículas e a separação de compostos, tanto da fase líquida como da gasosa. Portanto, o objetivo geral deste trabalho será implementado através da proposta de protótipo que poderá ser utilizado para pré-tratamento de amostra tanto para meio aquoso quanto para meio gasoso. A proposta é apresentada no Esquema 1.1; neste são apresentadas às estruturas para a formação de gotículas (spray), retenção de particulados (impactador) e separação de compostos orgânicos (separador), associadas a um sistema de detecção.

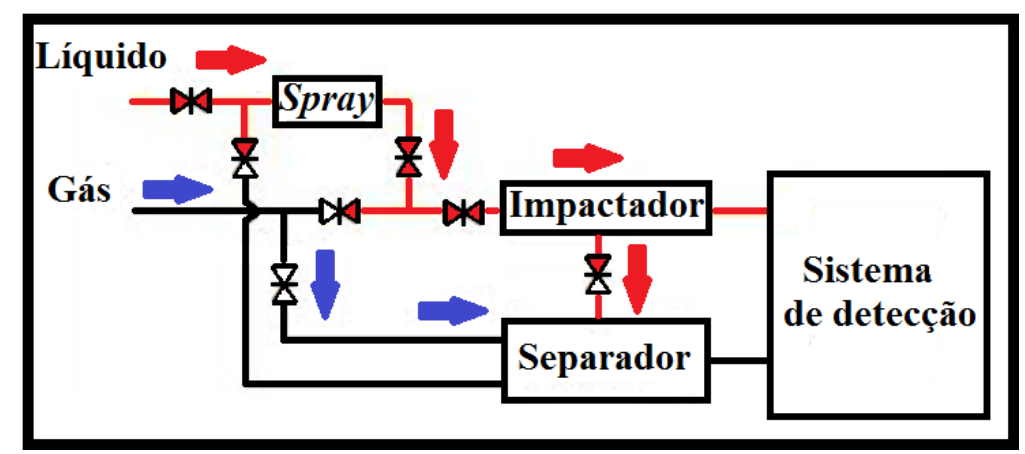

Esquema 1.1 - Proposta de protótipo para formação do conjunto de estruturas.

Este trabalho é dividido nos seguintes capítulos: o capítulo 1 faz uma breve introdução aos assuntos que serão abordados; o capítulo 2 descreve os embasamentos teóricos; o capítulo 3 descreve a metodologia e os materiais empregados; o capítulo 4 apresenta os resultados e discussões sobre os dados obtidos; o capítulo 5 contém as conclusões e o capítulo 6 as referências. 


\section{CAPÍTULO 2 - ASPECTOS TEÓRICOS}

Neste capítulo descrever-se-á conceitos importantes para a compreensão do desenvolvimento proposto neste trabalho, assim, este embasamento teórico aborda principalmente miniaturização e $\mu$ TAS, pré-tratamento de amostras e processos de análise dos resultados.

\subsection{TENDÊNCIAS}

Na década passada, novas tecnologias geraram profundas mudanças no escopo da Engenharia, principalmente para as Engenharias Química e Eletrônica, onde mais ocorreram tais variações. Nessas áreas, novas tecnologias, tais como a miniaturização, apareceram e, em muitos casos, ainda necessitam de melhor conceituação. Esse é o caso anteriormente abordado do conceito de Operação Unitária para a área de Engenharia Química, pois o conceito pode se tornar mais multidisciplinar, em especial para as áreas tecnológicas que utilizem sequiências de processos químicos, como é o caso da Microeletrônica [16]. De fato, Koretsky [31] descreveu as etapas de processo de Microeletrônica seguindo conceitos fundamentais, tais como, "mecânica dos fluidos, termodinâmica, aquecimento e transferência de massa, engenharia eletroquímica, processos de controle, cinética e engenharia de reações", ou seja, de acordo com o conceito de Operação Unitária [31].

Outra similaridade entre as áreas de Engenharia Química e Microeletrônica é a questão educacional. O alto investimento para ensinar, especialmente, na Engenharia, fez com que o uso de ferramentas educacionais de baixo custo se tornasse cada vez mais necessárias. Além disso, atualmente dá-se ênfase em estudos que visem o desenvolvimento sustentável, principalmente no que diz respeito à preservação dos recursos naturais aliado ao melhor aproveitamento de energia e matéria-prima. Assim, a simulação tornou-se um caminho para diminuir custos e Dahm [32] afirma que as simulações são normalmente sub-utilizadas e sugere que "processos de simulação de projetos podem fazer parte do ensino, em especial, da Engenharia Química devido à incorporação de novas e inovadoras Operações Unitárias além de melhorar a termodinâmica dos modelos". E, segundo Williams [33] é possível ter inúmeras vantagens das simulações, especialmente para Operações Unitárias em laboratórios: "aproximação da realidade, segurança, e custo efetivo [...] a simulação beneficia o controle de gastos desnecessários associados à compra e manutenção de equipamentos dos laboratórios". 
Segundo Silva [16] o uso da simulação e de miniaturização não apenas minimiza o uso de insumos, ou seja, colabora com o Desenvolvimento Sustentável, mas é de grande valia para desenvolver programas de redução de resíduos se aliado ao ensino com base em estudo de $\operatorname{caso}^{\mathrm{e}}(\mathrm{PBL})$, pois possibilita a resolução de problemas enquanto desenvolve outras habilidades.

\subsection{OPERAÇÕES UNITÁRIAS NA INDÚSTRIA QUÍMICA}

Na Engenharia Química, cada etapa de processo é denominada Operação Unitária. Em 1923, W. H. Walker et. al., no livro The Principles of Chemical Engineering, demonstrou que muitos processos aparentemente distintos seguiam as mesmas leis físicas e poderiam ser agrupados como Operações Unitárias. Estas operações são principalmente agrupadas como transporte de fluidos, transferência de calor e/ou massa, processos termodinâmicos e mecânicos [15]. Ao longo do tempo, muita literatura foi dedicada à descrição matemática dos princípios físico-químicos envolvidos nas Operações Unitárias e, mais recentemente, a simulação se tornou uma das ferramentas mais importantes para a compreensão das Operações Unitárias [34].

Freund, Hannsjorg e Sundmacher [34] consideram que o conceito de Operação Unitária ajudou a justificar a necessidade da Engenharia Química como uma disciplina separada e independente, pois relacionava classes de operações específicas e reações químicas. Além disso, o conceito de Operações Unitárias é usado como a metodologia para o projeto e a otimização de processo. Porém, uma questão emerge: ao pensar em termos de Operações Unitárias, associa-se a instrumentos que executam estas operações, tais como misturador, reator, torre de destilação e assim por diante. É importante observar que uma Operação Unitária compreende uma ou várias fases termodinâmicas. Portanto, neste artigo, Freund, Hannsjorg e Sundmacher [34] sugerem uma nova aproximação que não seja baseada no conceito clássico de Operação Unitária, mas sim, com base na análise dos princípios funcionais básicos que são encontrados na maioria dos processos químicos. A vantagem desta abordagem é que foca as bases da física fundamental, da química de processos e escoamentos. Os módulos funcionais próprios podem ser decompostos e representados por uma combinação linear de funções elementares do processo. Estes vetores são baseados em processos termodinâmicos. Dentro desta estrutura teórica, pode-se individualmente examinar possíveis

\footnotetext{
${ }^{\mathrm{e}} \mathrm{PBL}$ - comumente definido em Engenharia, Project Based Learning.
} 
linhas de escoamento e identificar a resistência em etapas separadas do processo. Isto permite analisar e propor opções possíveis para o processo químico a ser considerado.

Outra questão importante é a freqüência com que o processo é associado a termos como mais barato, redução de dimensões, utilização de pouco reagente, instrumentos multifuncionais, etc., enquanto todas essas variáveis deveriam ser vistas como otimização do processo.

Os autores também separam as melhorias quantitativas de um lado e melhorias em conseqüência de dados qualitativos em outro. A tecnologia da micro-reação, os reatores monolíticos e as separações reativas são exemplos da primeira categoria (quantitativa), já que permite uma melhor transferência de massa e calor quando comparado aos mesmos mecanismos físico-químicos aplicados aos instrumentos convencionais.

A segunda categoria (qualitativa) compreende, por exemplo, formas alternativas de energia para reações químicas, como microondas e ultra-som, o uso de meios novos para reação, como micro-emulsão e fluídos supercríticos, ou o uso de agentes auxiliares (catalisadores).

A miniaturização do equipamento se enquadra na segunda categoria (qualitativa) com várias opções, tais como, microreator, micro-aquecedor, micro-misturadores, colunas de destilação, micro-separadores ou o uso de mini-emulsão. Além da miniaturização, atualmente tem-se também a escolha da geometria espacial das estruturas para os reatores, arranjos de partículas em canais e as nanofibras como a sustentação do catalisador.

Os métodos de separação podem ser divididos em processos de destilação extrativa, adsorção em membrana, destilação em membrana, cristalização-destilação e destilação adsorptiva. A aplicação de estruturas seladas e preenchidas com partículas do catalisador faz parte do processo de destilação reativa industrial.

\subsection{PROCESSOS DE SEPARAÇÃO}

Os processos de separação podem ser principalmente, encontrados em Indústrias Químicas e Petroquímicas. Na literatura encontram-se muitos trabalhos focados em aperfeiçoar processos de separação ora através de novos solventes, ora através de novas configurações, podendo ainda, ser alterados em outros aspectos.

Em se tratando de separação, não existe uma regra que determine qual processo é o mais indicado; o fator determinante é a disponibilidade financeira e quais os dados que se deseja obter do produto final com tal processo. Para tanto, tem-se a necessidade de 
caracterizar o sistema, isto vai ser útil para a identificação de quais processos de separação poderão ser usados e com quais reagentes/solventes deve-se trabalhar. Na Tabela 2.1, listamse alguns processos de separação e respectivas propriedades básicas relacionadas à separação de forma bastante simples [35]. Nestes processos, os que dependem de difusividade e tamanho molecular (osmose reversa, membranas, ultrafiltração, diálise) no geral também apresentam alta perda de carga, mas é bastante adequado para separação de partículas; por outro lado, a eletroforese é bastante adequada para separação de espécies carregadas, mas em geral requer aplicação de grandes diferenças de potencial e a cristalização demanda tempos longos. A extração é um processo similar ao que ocorre na cromatografia e a destilação depende de aquecimento. Neste trabalho dar-se-á ênfase no processo de destilação simples e fracionada.

Tabela 2.1 - Processos de separação e propriedades básicas [35].

\begin{tabular}{||l|l||}
\hline \multicolumn{1}{|c|}{ Processo } & \multicolumn{1}{c|}{ Propriedade Básica } \\
\hline \hline Extração & Coeficiente de adsorção e Seletividade \\
\hline \hline Osmose Reversa & Difusividade e Solubilidade \\
\hline Membranas & Difusividade e Solubilidade \\
\hline \hline Cristalização & Temperatura de fusão e solubilidade \\
\hline Ultrafiltração & Tamanho molecular \\
\hline Eletroforese & Carga elétrica e mobilidade iônica \\
\hline Diálise & Difusividade \\
\hline Destilação & Volatilidade Relativa, Pressão de Vapor \\
\hline \hline
\end{tabular}

\subsubsection{Destilação}

A destilação tem por finalidade a purificação/separação de produtos e baseia-se na diferença de volatilidade dos diversos componentes, ou do ponto de ebulição, de uma mistura [36]. A destilação costuma ser utilizada desde pequena escala, escala laboratorial, até grandes volumes, ou seja, industrialmente.

O uso laboratorial [37][38] é comum principalmente na purificação/separação de compostos orgânicos. Para a destilação ocorrer, normalmente o componente muda de estado físico tornando-se gasoso e condensando posteriormente, devido ao aquecimento da mistura, embora também seja utilizada a variação de pressão, especialmente para compostos que podem sofrer decomposição por aquecimento. A destilação de dois líquidos miscíveis segue a Lei de Raoult onde a pressão parcial de um componente, numa solução, a uma dada 
temperatura, é igual à pressão de vapor desta substância, multiplicada por sua fração molar na solução.

Vários são os tipos de destilação. A destilação simples, consiste na vaporização de um líquido por aquecimento seguida da condensação do vapor e recolhimento do condensado num frasco apropriado e mostra-se útil para separar um líquido de impurezas não voláteis ou líquidos cujo ponto de ebulição são bem distintos. A aparelhagem utilizada é simples e consiste essencialmente de balão de destilação, condensador e termômetro.

Para substâncias que não podem ser destiladas em pressão ambiente devido ao alto ponto de ebulição ou por ocorrer reação, é comum reduzir a pressão do sistema. O método de redução de pressão é conhecido por destilação sob pressão reduzida.

A destilação fracionada destina-se à separação de líquidos miscíveis entre si e/ou com pontos de ebulição próximos e corresponde a repetidas destilações ocorrendo em um único arranjo a um só tempo. Esta depende de uma coluna de destilação, que apresenta uma grande superfície para a troca de calor, nas condições de equilíbrio, entre vapor e condensado. Portanto, existe tanto fluxo como contrafluxo nesse sistema além de repetidas evaporações e condensações parciais ao longo da coluna. A modificação no arranjo físico em relação à destilação simples é a inserção da coluna entre condensador e o balão de destilação. Nesta coluna, enquanto vapores do líquido mais volátil atingem a saída, no contrafluxo, regressa ao balão a mistura de vapores dos outros componentes.

A destilação por arraste a vapor é utilizada se as substâncias que se decompõem próximo ao seu ponto de ebulição, são insolúveis em água ou em outros vapores que possam ser utilizados para o arraste dos componentes da mistura [39]. A Figura 2.1 mostra esquemas gerais de como ocorrem os sistemas de destilação. 


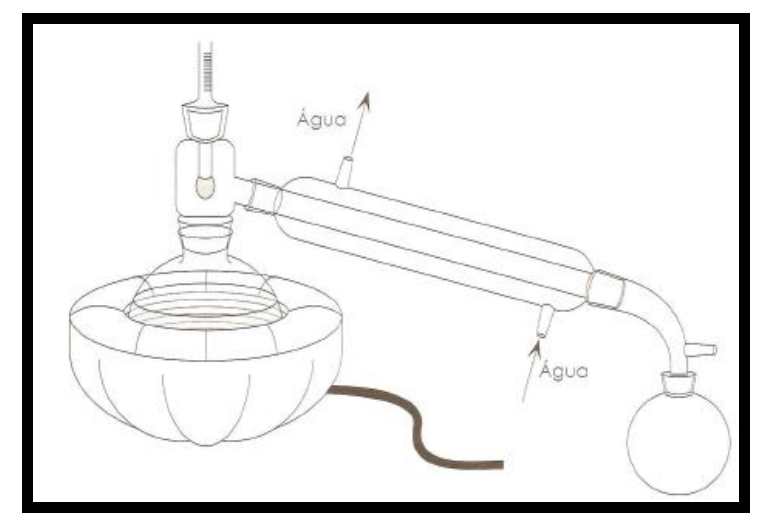

(A)

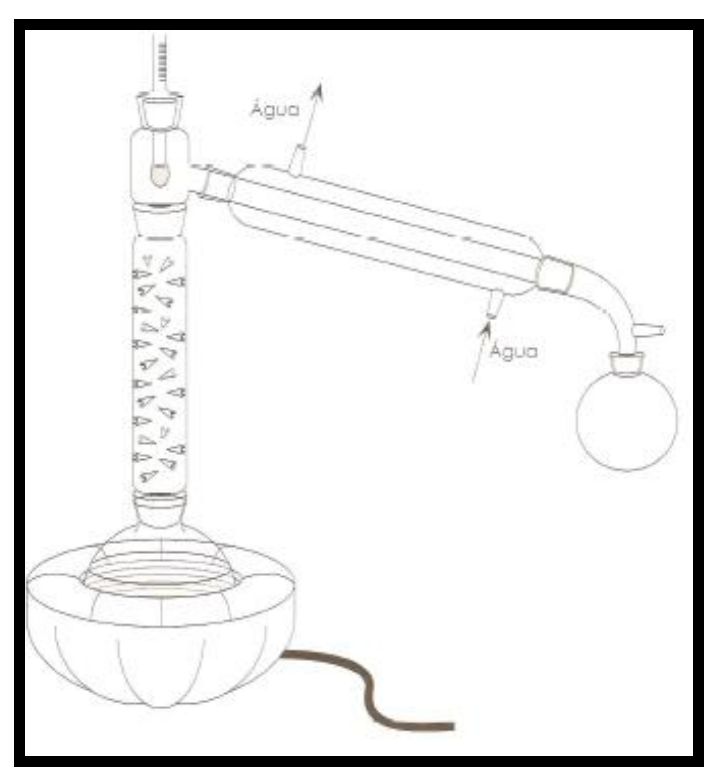

(B)

Figura 2.1 - Processo de destilação (A) simples (B) fracionada [39].

Industrialmente, a destilação é considerada a Operação Unitária mais utilizada globalmente. Quando a separação é dificultada pela pequena diferença de pontos de ebulição entre os componentes da mistura, e/ou a mistura é muito complexa, é comum utilizar-se a destilação fracionada [40].

Um conceito importante para construção/operação de uma coluna de destilação é o de número de pratos teóricos. Esse número é definido como a seção da coluna de destilação onde vapor e líquido estejam em equilíbrio, ou seja, a composição é a mesma. Assim, o cálculo do número de estágios ${ }^{\mathrm{f}}$ necessários a uma coluna de destilação exige que a composição do líquido e do vapor seja estimada em cada estágio, o que por sua vez, depende da volatilidade dos componentes da mistura e da cinética de equilíbrio. Devido à dificuldade de obter tais parâmetros, por exemplo, devendo ser considerada a transferência térmica entre várias frações dentro de um sistema complexo, é comum a simplificação ou o acerto experimental de tais condições. Para o acerto desses parâmetros vários modelos já foram propostos, mas tendem a atender um conjunto de condições já pré-estabelecidas [41].

A destilação pode ocorrer tanto em sistemas contínuos como em batelada e quando a diferença de pontos de ebulição dos componentes é pequena, geralmente, usam-se pequenas peças, chamadas de recheio, para dificultar o caminho do fluido e facilitar o encontro da fase

\footnotetext{
${ }^{\mathrm{f}}$ Estágios são partes onde o equilíbrio entre a fase líquida e o vapor se estabelece.
} 
líquida com a gasosa. Um desenho genérico de uma coluna de destilação é apresentado na Figura 2.2.

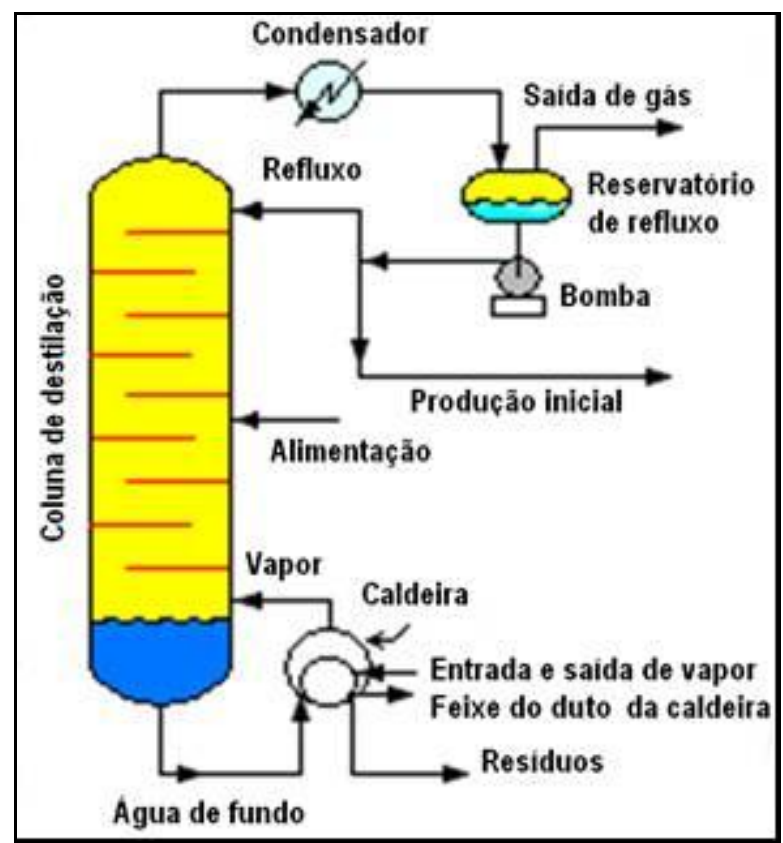

Figura 2.2 - Esquema de uma coluna de destilação [41].

Atualmente as colunas de destilação com catalisadores são uma boa opção porque se tem duas operações ocorrendo simultaneamente. Neste caso são processados de 100-3000 kt/ano em cerca de 150 empreendimentos [42]. Por reduzir o número de equipamentos e aumentar a desempenho do empreendimento, tais dispositivos são considerados ambientalmente corretos. Por fim, são consideradas como úteis para melhorar a sustentabilidade do ambiente pela menor perda de calor que ocorre para o entorno, ou seja, são socialmente mais aceitáveis. Estas colunas normalmente são empacotadas e o catalisador para a reação é depositado sobre o recheio. O uso ou não destas colunas depende da velocidade de reação desejada e da volatilidade dos componentes, como pode ser visto na Figura 2.3. Os parâmetros importantes para a definição da coluna são principalmente a cinética de reação além da transferência de massa e calor, e sua obtenção em geral é feita por simulação. Apesar de suas grandes vantagens, tal arranjo é bem mais complexo de definir e operar do que as duas operações separadamente. 


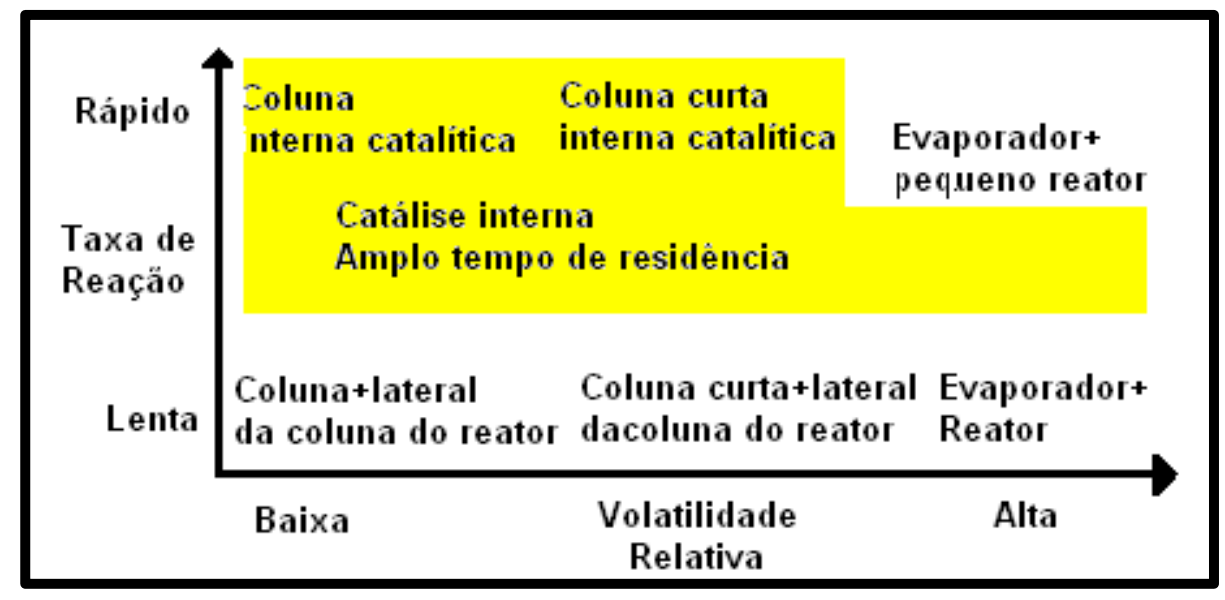

Figura 2.3 - Princípios para a escolha de uma coluna de destilação com catalisador [42].

Charpentier [43], em sua revisão, apresenta uma avaliação interessante sobre colunas de destilação com catalisadores, cromatografia e miniaturização. Charpentier [43] considera que o principal motivo para o mau funcionamento dessas colunas é a má distribuição do líquido ao redor do recheio e sugere que a pequena escala é um modo eficiente para melhorar o desempenho. Portanto, o autor chega à conclusão que uma alternativa interessante à coluna é a cromatografia, já que esta utiliza a adsorção, não a volatilidade, na separação dos componentes, ou seja, é útil para compostos que não podem ser muito aquecidos ou quando a diferença de volatilidade na mistura é pequena. $\mathrm{O}$ autor também aborda a miniaturização, informando que a produção de "microreatores, micromisturadores, microseparadores, microtrocadores de calor a microanalisadores permite o controle preciso das condições das reações quanto à mistura e ao perfil de temperatura"; o autor, contudo, não elabora qualquer comentário sobre a possibilidade de miniaturizar a destilação de modo semelhante aos outros processos. Para Charpentier [43][44][45] o mais importante é o uso da simulação e o ensino, com especial ênfase na multidisciplinariedade, das mudanças que estão e que irão ocorrer de modo geral na área da Engenharia Química e Engenharia de Processo.

Outra correlação estabelecida entre destilação e miniaturização foi feita por Su [46], que argumenta que os processos de produção de semicondutores apresentam similaridades com processos de Engenharia Química no que concerne ao controle de qualidade e exemplifica com uma coluna de destilação. O equilíbrio termodinâmico relaciona a composição do produto numa coluna de destilação com a temperatura da bandeja (estágio onde ocorre o aquecimento), mas, enquanto é possível observar uma correlação forte entre 
temperatura e composição na coluna de destilação o mesmo não é tão simples de se observar nos processos de produção de semicondutores, ou seja, temperatura e resistência de folha.

Uma microestrutura desenvolvida por Wootton e Mello [47] é denominada destilador em microescala. A estrutura foi projetada para purificar continuamente líquidos voláteis.

Segundo Wootton e Mello [47], a destilação refere-se à extração líquido/líquido, um dos poucos métodos em escoamento contínuo de purificação. É um método bastante aplicado em escala industrial, diversificando a produção de produtos ligados à química fina para a produção de bebidas destiladas, como whiskies. A maioria das técnicas envolvendo destilação gera vapor de um líquido em ebulição e a recuperação deste vapor ocorre em um sistema de refrigeração onde este sofre condensação. Sendo assim, o papel do vapor é induzir, pelo seu próprio transporte, a geração de mais vapor. Isto é possível através da ebulição controlada de um líquido em um reservatório (que ocorre devido aos efeitos gravitacionais na movimentação do líquido). Em ambientes microfluídicos, o controle da ebulição deste tipo não é possível porque as forças gravitacionais são menos significativas e outros efeitos como, a tensão superficial e a viscosidade são predominantes.

A extensão dos efeitos gravitacionais pode ser avaliada com o uso do número Bond (BO). O número Bond é a medida dos efeitos relativos às forças gravitacionais e à tensão de superfície. As forças gravitacionais são significativas quando BO for muito maior que 1. Para a água em um canal de aproximadamente 100 micra o número Bond é, geralmente, inferior a 0,01, indicando o desequilíbrio da tensão superficial com relação à gravidade.

A ebulição nesta escala é, conseqüentemente, incontrolável devido à atenuação significativa no movimento do líquido, proporcionada pela significativa afinidade superficial do líquido com as paredes do canal.

Wootton e Mello [47], contudo, criaram um arranjo de canais que permite que uma mistura de compostos voláteis seja separada de acordo com as variações das pressões de vapor, de maneira similar à destilação padrão. Para tanto, existe o contrafluxo nestes canais e a amostra é carregada por Hélio. Os canais onde ocorre a condensação têm uma largura média de 150 micra, número de Reynolds de 1,4 e a relação entre a área superficial e o volume de $1300 \mathrm{~m}^{2} / \mathrm{L}$. O projeto permite que o regime de escoamento seja laminar de forma que a contaminação durante o processo de destilação seja mínima. 


\subsubsection{Pré-tratamento}

Muitas vezes, antes da destilação, ou de qualquer outra operação, é necessário tratar a matéria-prima, para garantir a bom desempenho do equipamento. Do mesmo modo, após a produção, é preciso controlar as emissões. Esse é o caso, muitas vezes, da remoção de partículas, como descrito a seguir.

\subsubsection{Fase gasosa}

Atualmente, na área Engenharia Química observa-se notável evolução na área de pré-tratamento de amostra devido à miniaturização de estruturas capazes de melhorar o aproveitamento não só da preparação de amostra, mas também, da obtenção ou manipulação de pequenos volumes de amostras, tais como impactadores.

Fox [20] estudou uma gama de partículas e aerossóis apontando a importância de se determinar o tamanho, forma e composição das partículas. Por esta razão, depois de capturar as partículas, também faz as análises químicas e as estuda, porém, com pouca probabilidade de $100 \%$ de eficiência, devido à dificuldade de capturar eficientemente todas estas partículas. Devido à perda em uma operação, é dada uma atenção especial para compostos orgânicos, voláteis e semi-voláteis, emitidos para o meio ambiente no que se refere às partículas presentes na poluição do ar. Metais pesados e outros materiais altamente tóxicos devem ser analisados e para isso geralmente são coletados em impactadores. A maioria das análises ambientais, para os metais presentes em partículas, leva em consideração a pré-concentração, eventualmente por retenção, devido à pequena concentração na amostra [48].

Os dispositivos capazes de capturar partículas, segundo Marple [49], são os impactadores, cuja definição por ele proposta é de "dispositivos simples que promovem retenção baseada na relação peso da partícula e a dimensão característica do coletor”. "Um dos impactadores mais comuns são os impactadores de jato cuja entrada dirige o escoamento para o coletor e o uso de constrições ajuda a captura de maior quantidade de partículas. A eficiência de tais equipamentos é ampliada de acordo com a quantidade de anteparos que são dispostos dentro da estrutura, ou ainda, colocando-se armadilhas e/ou gerando seletividade de partículas de acordo com o tamanho [...]. Estes equipamentos possuem regime laminar que possibilita o aprisionamento das partículas no prato coletor" [49].

Para estes dispositivos têm-se como parâmetro importante a velocidade do fluido, tanto no que diz respeito a regime laminar quanto no que se refere a regime turbulento, 
especialmente em regiões com "espaços mortos" que também podem gerar acúmulo de partículas. Além de partículas de modo geral pode-se também utilizá-los para captura de microorganismos [50][51].

Até o presente momento são raras as tentativas de miniaturização de impactadores. Beraldo [52], miniaturizou um impactador em cascata que oferece grande vazão e boa eficiência de retenção de partículas numa larga faixa de tamanho, características comuns aos impactadores macroscópicos [53]. Nascimento [54] usou impactadores miniaturizados para pré-concentração de VOCs, tanto em meio gasoso quanto em meio aquoso. Para tanto, adicionou filmes adsorventes às estruturas miniaturizadas, inclusive o impactador estudado por Beraldo [52].

\subsubsection{Fase líquida}

Das várias formas de coleta e separação de partículas, a mais comum é a sedimentação. A sedimentação depende dos efeitos gravitacionais e, geralmente, necessita de muito tempo para ocorrer completamente. Assim, em sistemas macroscópicos, para a diminuição da velocidade e conseqüente aumento do tempo de residência e da área de contato, constrições - normalmente denominadas chicanas - são adicionadas aos sistemas de sedimentação [55]. Nestes sistemas, em conjunto com a velocidade do fluido, outros parâmetros críticos precisam ser considerados, tais como, o gradiente da velocidade, tempo de retenção e os desenhos, da câmara e das constrições [56][57][58][59].

Estas constrições também permitem a remoção de nutrientes das águas residuárias devido à adesão dos microorganismos nas paredes e ao alto tempo de retenção dos fluidos [60][61][62]. Ademais, com o desenho correto, as constrições também promovem a mistura de dois ou mais reagentes adicionados ao fluido [63][64]. Apesar de alguns modelamentos terem surgido a partir destes dispositivos, os sistemas são desenhados com base em informações obtidas experimentalmente em laboratório e posterior escalamento das dimensões.

Sistemas semelhantes às chicanas já foram miniaturizados, muito embora não pareça ter ocorrido devido ao escalamento dos dispositivos macroscópicos. Esses dispositivos são os misturadores, bastante utilizados em estruturas MEMS. São montados usando dispositivos com dimensões na faixa de 1 a 100 micra e que possuem, geralmente, tamanhos total na faixa de 20 micra a alguns milímetros. Muitos dos micromisturadores revisados por Nguyen [65] e 
nanocatálise em microreatores estudada por Kuila [66] podem ser dados como bons exemplos de dispositivos que usam chicanas.

Misturadores de onda quadrática (Square Wave Mixer), por exemplo, são comuns em dispositivos MEMS e apresentam extraordinárias semelhanças com o desenho de chicanas comumente usadas para tratamento de água residuária em sistemas grandes, assim como, os de tratamento de água para os municípios. Os misturadores de onda quadrática foram desenhados e simulados para que as partículas caminhem facilmente pelos microcanais [67] e o dispositivo, de modo geral, mostrou boas características de performance tais como, dimensão reduzida, baixa perda de carga, alta superfície interna e volumes pequenos, o que os torna com boa relação custo/benefício para produção em massa. Os sistemas mostram bons resultados experimentais utilizando traçadores, mesmo com baixo número de Reynolds [68]. Mengeaud [69] simulou e testou microcanais em zigue-zague e apontou a importância da velocidade de escoamento e da geometria do canal (assim como tamanho do canal e a formação de cantos) na hidrodinâmica e a eficiência da mistura em micro-misturadores passivos. Na maioria das vezes, o número de Reynolds crítico é de 80; neste caso, a mistura decorre da difusão molecular e não de eddy diffusion. Os misturadores em 3D também permitem a presença de outros efeitos como à formação de zonas de advecção (devido à presença de constrições). Para altos números de Reynolds, as simulações revelam as contribuições das recirculações no regime laminar para a ocorrência de mistura. Para todos os misturadores aqui citados, a profundidade dos microcanais varia de $50 \mu \mathrm{m}$ a $250 \mu \mathrm{m}$.

Assim, é importante enfatizar que sistemas macroscópicos e microscópicos, mas com desenho semelhante, podem apresentar funções diferentes: no presente caso, a separação de partículas e misturas de fluidos. Santos [70], contudo, demonstrou que é possível miniaturizar um sistema de chicanas e ainda ter a função de retenção de partículas preservada.

\subsubsection{Manipulação da amostra}

A manipulação da matéria-prima, ou da amostra, no caso da análise, depende de equipamentos diversos, mas essencialmente irá ocorrer em fluxo contínuo ou em batelada. Para líquidos, a manipulação em fluxo contínuo é comum e, devido à ampla variedade de procedimentos/equipamentos existentes, foge ao escopo deste trabalho abordá-los, contudo, é interessante observar que os líquidos podem ser manipulados na forma de spray, já que o 
spray apresenta a vantagem de uma maior superfície de contato com o ambiente, o que melhora a transferência de massa e energia.

Bayvel [71] e Lefebvre [72][73] sugerem como modos de se formar um spray dispensando um líquido através de orifícios por ação da gravidade; a interação de uma coluna de líquido com um jato de gás e a desintegração, por formação de ondas, de uma camada muito fina de líquido. Para os atomizadores (produtores do spray), Lefebvre [72][73] classifica os tipos mais comuns em três categorias: os orifícios de pressão, os pneumáticos ou com dois fluidos e os dispositivos rotatórios, que são apresentados na Figura 2.4. Contudo, também avalia que mais recentemente outros dispositivos apareceram baseados em campo elétrico, ultra-som, jatos, etc.

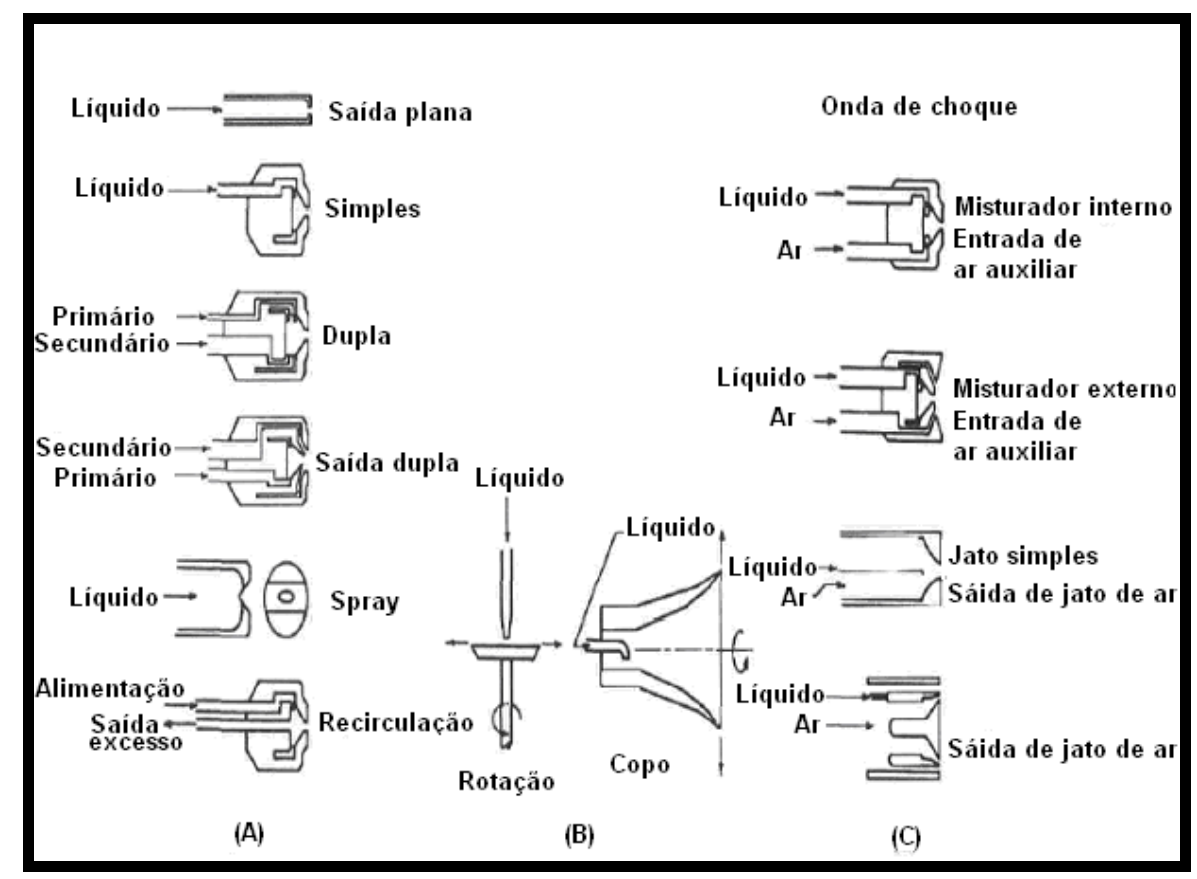

Figura 2.4 - (A) Atomizadores de pressão; (B) atomizador giratório; e (C) atomizador para dois fluidos [72][73].

A secagem por spray é considerada uma Operação Unitária [74] muito útil para a fabricação de pós. Atualmente os sprays utilizados para secagem foram melhorados pelo uso de uma tecnologia híbrida, em conjunto com a tecnologia ink-jet, que produz partículas com características uniformes. Neste caso, as gotas geradas são atomizadas no spray para secagem. $\mathrm{Wu}$ [74] revisou alguns dos modelos que podem ser usados, que são apresentados na Figura 2.5. Wu [74] também sugere que a miniaturização, nesse caso, pode gerar micro ou 
nanopartículas. Uma possibilidade de formação de gotas é o uso de eletrospray. Assim, um jato é formado (ink-jet) e as gotas são imediatamente aceleradas (Figura 2.5).

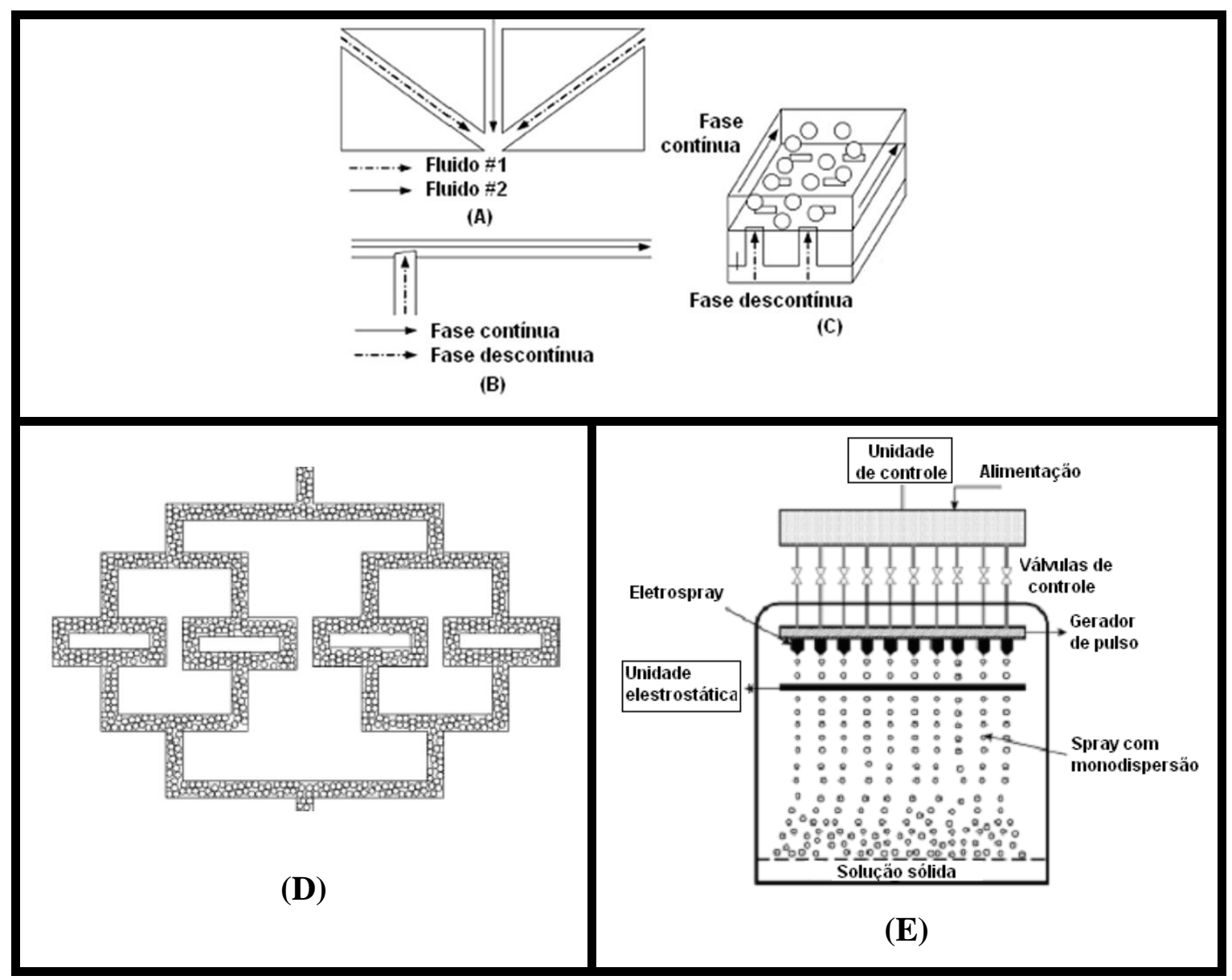

Figura 2.5 - Sistema miniaturizado para geração de gotas por força de cisalhamento (Mechano Hydrodynamic Droplet Generator, MHDG): junção (A) dos microcanais formadores de gotas; (B) em T; e em (C) linha reta. Múltiplas junções em T (D) para formar gotas com diâmetro comparável ao canal e (E) sistema eletrostático [74].

\subsection{ANÁLISES QUÍMICAS}

\subsubsection{Cromatografia}

Cromatografia é definida como uma técnica de análise, qualitativa e quantitativa, que tem como fundamento teórico a separação de misturas complexas de acordo com a afinidade dos componentes da mistura com duas fases distintas, uma que carrega a amostra e outra fixa, denominadas fases móvel e estacionária, respectivamente. Assim, a cromatografia tem, para a área de análises, uma função similar à destilação para a área de preparação. 
Várias são as técnicas cromatográficas e são normalmente divididas de acordo com a técnica empregada, as diferentes fases usadas, o procedimento de introdução da amostra, o desenvolvimento da amostra e o mecanismo de separação envolvido. A técnica empregada pode ser definida pela forma física do sistema utilizado pela cromatografia: fase estacionária colocada em tubo cilíndrico ou disposta em superfície plana. Com base nisto, subdivide-se a cromatografia em cromatografia em coluna e cromatografia planar. Levando em conta o estado físico da fase móvel, a cromatografia pode ser dividida em cromatografia gasosa, quando a fase móvel é um gás, cromatografia líquida, quando a fase móvel é um líquido, e cromatografia super crítica, quando a fase móvel é um vapor pressurizado em temperatura acima de sua temperatura crítica. As técnicas cromatográficas mais comuns são as conhecidas como cromatografia gasosa e cromatografia líquida [75].

A cromatografia gasosa possui como fluxo contínuo da fase móvel, até que todos os componentes tenham saído da coluna e as suas respectivas presenças sejam detectadas pelo detector e indicadas graficamente. Têm-se, ainda, duas situações que podem ser consideradas, o estado físico da fase estacionária que pode estar no estado líquido ou sólido. O líquido pode estar apenas espalhado sobre o suporte sólido ou imobilizado sobre o mesmo e, neste caso, é referido como fase ligada por envolver ligações químicas entre o líquido e o suporte e/ou entre as cadeias do próprio líquido.

Como a maioria das técnicas de análise, os cromatógrafos vêm sendo miniaturizados nas últimas décadas. A vantagem da miniaturização de cromatógrafos [76] é sua portabilidade, ou seja, conseguir que uma gama ampla de análises, tanto de amostras líquidas como gasosas, sejam feitas in situ ${ }^{g}$. Isto é de grande importância para análises ambientais, controle de processos, diagnósticos clínicos, aplicações aeroespaciais, sistemas implantados de medidas biomédicas etc. Podem ainda apresentar uma melhoria na eficiência de separação e na velocidade de resposta. A preocupação com a miniaturização, contudo, também estendese à questão de custo e confiabilidade. Os cromatógrafos a gás que são alvos de miniaturização desde as décadas de 60 e 70 possuem várias revisões na literatura [77][78], mas a revisão de Yashiin [79] tem a vantagem de classificar os cromatógrafos a gás já existentes de acordo com seu local de uso em: “(1) compactos, que se destinam a laboratórios móveis, (2) de campo, também portáteis, para análise gasosa on-site ${ }^{h}$; (3) microcromatógrafos para utilização espacial" e de acordo com sua principal utilidade que é reportada como

\footnotetext{
${ }^{\mathrm{g}}$ in situ - análises que ocorrem dentro do processo ou próximas ao ponto de coleta da amostra.

${ }^{\mathrm{h}}$ on site - refere-se ao ambiente onde será realizado o teste.
} 
"solução de problemas ambientais, tais como, pesticidas, policlorobifenilas (PCBs), freons e compostos orgânicos voláteis."

Assim como em sistemas convencionais, a cromatografia gasosa com sistemas miniaturizados possui os mesmos princípios de funcionamento, o que significa que a teoria desenvolvida para os cromatógrafos convencionais aplica-se aos menores. Além disso, tanto os cromatógrafos convencionais como os miniaturizados possuem quatro componentes básicos:

1) fonte de gás de arraste;

2) sistema de injeção da amostra;

3) coluna cromatográfica e;

4) sistema de detector e de análise de dados.

\subsubsection{Definições cromatográficas}

Para compreender o modelo proposto, algumas definições cromatográficas serão utilizadas e, portanto, são abordadas a seguir.

Um dos conceitos mais importantes é o de número de pratos teóricos. Para ocorrer à separação entre dois ou mais componentes da mistura é necessário que ocorram sucessivas interações, ou seja, estabelecer-se-ão sucessivos estágios de equilíbrio entre analito, fase estacionária e fase móvel. Cada estágio de equilíbrio é denominado de prato teórico e quanto maior o número de pratos teóricos melhor a separação do componente nessa coluna. $\mathrm{O}$ número de pratos teóricos para um componente percorrendo a coluna é calculado através da relação expressa na Equação 1a:

$$
\mathrm{N}=16 \cdot\left(\frac{\mathrm{t}_{\mathrm{R}}}{\mathrm{W}_{\mathrm{b}}}\right)^{2}
$$

\section{Equação 1a}

onde $\mathrm{n}$ representa o número de pratos teóricos; tr significa o tempo de retenção (tempo exigido para o analito ser removido da coluna); wb é a largura do pico.

Eventualmente não se calcula o número de pratos teóricos, mas sim a altura equivalente para pratos teóricos; para tanto se divide o comprimento da coluna pelo número de pratos teóricos desta. 
Embora o desempenho de uma coluna cromatográfica dependa de diversos parâmetros físicos, informação significativa pode ser obtida analisando-se a forma do pico no cromatograma, ou seja, analisando-se o tempo de retenção e o perfil da concentração de tal analito observado na saída da coluna. O tempo de retenção é correlacionado, principalmente, à adsorção na fase estacionária e à velocidade da fase móvel. O perfil da concentração é devido a muitos parâmetros e é descrito pela Equação de van Deemter (Equação 1b), que relaciona a altura equivalente a um prato teórico com os fenômenos ocorrendo na coluna.

Cada parâmetro da Equação 1b explica alguns fatores que influenciam o tempo para obter o valor de máximo do pico e a forma do pico. Essa equação também assume que cada uma das constantes (A, B, C) depende de diferentes processos e que estes são independentes uns dos outros e cada um deles gera uma função de distribuição de probabilidade Gaussiana:

$$
H=A+\frac{B}{u}+C u
$$

\section{Equação 1b}

onde $\mathrm{H}$ é a altura equivalente de um prato teórico; u é a velocidade linear da fase móvel; A/B/C são constantes, que se relacionam com parâmetros da coluna como segue: A - a geometria da coluna; B - difusão longitudinal na fase móvel e C - resistência processos de transferência de massa.

Dois parâmetros importantes para uma coluna cromatográfica são: fator de capacidade e o fator de separação. O primeiro avalia se dois componentes foram separados devidamente na coluna, o segundo se houve retenção do componente quando comparado ao solvente, que não deve ter interação com a coluna. $O$ fator de capacidade e de separação são definidos como:

$$
\alpha=\frac{t_{r_{1}}}{t_{r_{2}}}
$$

\section{Equação 1c}

onde $\alpha$ é o fator de separação e tr é o tempo de retenção, 1 do componente corrigido para eliminar o tempo de retenção 2 do solvente: 


$$
\mathrm{k}=\frac{\mathrm{t}_{\mathrm{r}_{1}}}{\mathrm{t}_{\mathrm{m}}}
$$

\section{Equação 1d}

onde k é o fator de capacidade; $\operatorname{tr}_{\mathrm{i}}$ é o tempo de retenção do componente 1 corrigido para eliminar o tempo de retenção do solvente; tm é o tempo de retenção do solvente.

A constante A explica os efeitos de eddy diffusion e de outros fatores da coluna. A difusão longitudinal [B] é proporcional ao tempo de residência do analito na fase móvel. A constante $\mathrm{C}$ deriva do fato de que a transferência de massa entre regiões distintas do fluido não pode ser instantânea, e três coeficientes de transferência de massa devem ser considerados: na fase móvel, na fase estacionária e na interface, devido ao processo de partição.

Além disso, o perfil da velocidade em uma coluna é normalmente parabólico e o regime de escoamento é laminar; se não, "A" tende a aumentar, isto é, ocorre uma diminuição no desempenho total. Durante a fabricação e o uso das colunas cromatográficas, "A" é minimizado, geralmente pela escolha correta das partes e peças que irão compor o sistema e pela otimização dos parâmetros; além disso, nas colunas capilares é comum assumir-se "A" como zero.

$\mathrm{Na}$ última década, esta equação foi usada diversas vezes em simulações computacionais da dinâmica de fluidos da cromatografia líquida ou gasosa [80]. Na maioria das simulações, tais como, as obtidas com COMSOL (FEMLAB 3.2®), assume-se que o equilíbrio do analito entre a fase móvel e a fase estacionária é atingido imediatamente. Conseqüentemente, o alargamento da gaussiana gerada normalmente é correlacionado com processos de difusão e expressado em função de uma constante de difusão "efetiva" e da velocidade do analito através da coluna (Equação 2):

$$
\mathrm{D}_{\mathrm{eff}}=\frac{\mathrm{Hv}_{\mathrm{z} i}}{2}
$$

\section{Equação 2}

Tem-se como constante de difusão efetiva a representação $D_{\text {eff }}$; $v_{z i}$ é a velocidade de migração do analito ao longo da coluna; e H refere-se a altura equivalente ao número de pratos teóricos. 


\subsubsection{Comparação entre cromatografia e colunas de destilação}

Pelo exposto acima, podem-se resumir as tendências na área de separação de compostos orgânicos como segue. Amostras complexas, tais como, as derivadas do petróleo, são analisadas geralmente em equipamentos específicos para determinar exatamente sua composição [81], outra possibilidade são sistemas miniaturizados, baseados normalmente em narizes eletrônicos [82].

As análises usando cromatografia são custosas, requerem muito tempo e necessitam de quantidades significativas de amostras, porém, resultam em dados mais precisos. Em sistemas miniaturizados, baseado nos narizes eletrônicos é possível fazer análises qualitativas e quantitativas simultaneamente, contudo, alguns inconvenientes, tais como interferência e não-reprodutibilidade podem surgir durante os testes. Em ambas as situações, o sistema de detecção não é específico, isto é, responde para mais do que uma única classe de compostos. Os instrumentos analíticos normalmente usam a adsorção e aquecimento, em canais ou microcanais, a fim separar compostos análogos.

De modo similar, em equipamentos de destilação, o aquecimento é um dos parâmetros principais, mas, geralmente, não se tem um controle exato e a maior importância está no contato entre fase gasosa e líquida, para permitir a obtenção de um equilíbrio físicoquímico, responsável pela separação dos componentes. Embora os dois apresentem conceitos análogos, tais como pratos teóricos, o comportamento do escoamento é normalmente diferente, uma vez que, em instrumentos analíticos, o regime turbulento é evitado. Porém, não ocorre o mesmo no processo de destilação [83]. Assim, o método de destilação é um processo mais simples para conseguir a separação que, todavia, apresenta uma separação mais "grosseira" da matriz, isto é, não separa com a mesma eficiência que a cromatografia.

Na cromatografia a interação envolve um sólido (fase estacionária, que pode ou não ter um líquido sobre sua superfície) e um componente que pode estar na fase líquida ou na fase gasosa. Nesse contexto, o fluxo deve ter regime laminar, pois qualquer turbulência pode favorecer a dispersão da amostra. Por outro lado, na destilação a interação ocorre entre líquidos, que estão continuamente vaporizando/condensando; assim, o regime de fluxo não necessita ser laminar, o refluxo, que seria o equivalente à dispersão na cromatografia, pode ser útil para aumentar a separação. Dentro deste contexto, percebem-se as dificuldades para compatibilizar os sistemas, como propõe Charpentier [43]. 


\subsection{MANIPULAÇÃO DE AMOSTRA}

\subsubsection{F.I.A. ${ }^{\text {i }}$}

Espera-se que os equipamentos de análise, miniaturizados ou não, apresentem regime laminar ${ }^{j}$, como se observa nos sistemas F.I.A. (Análise por Injeção em Fluxo) típicos [84], onde o intuito é, entre outros, facilitar a detecção. No F.I.A. é comum a análise em fluxo contínuo com procedimento de injeção baseado na introdução de volume altamente definido da amostra em fluido denominado como de arraste e onde a vazão é constante. O F.I.A. caracteriza-se por elevadas frequiências analíticas (60 a 300 determinações/hora), baixo consumo de reagentes e amostras, excelentes exatidão e precisão, o necessário para alcançar bom êxito nas análises. A amostra, ao ser introduzida forma uma zona bem definida que é transportada até o detector (região de fácil monitoração do sinal gerado de forma contínua). Durante o transporte, a região em que a amostra recebe reagente sofre reações químicas, passa por etapas de separação, etapas de pré-concentração ou diluição, etc. [85]. A Figura 2.6 mostra um esquema de um Sistema F.I.A. típico.

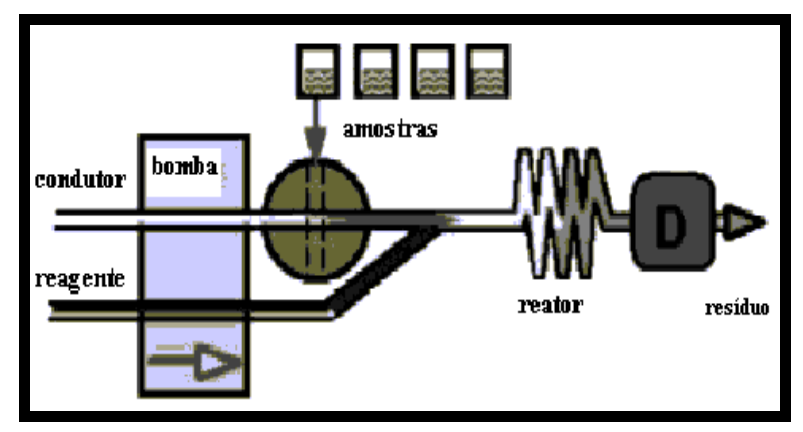

Figura 2.6 - Esquema do sistema F.I.A. [86].

Entretanto, a simplicidade operacional e a versatilidade, tanto na concepção dos diagramas quanto na facilidade de acoplamento em diferentes sistemas de detecção, foram às características que mais contribuíram para a sua aceitação e uso.

\footnotetext{
${ }^{\mathrm{i}}$ F.I.A. - Flow Injection Analysis

${ }^{\mathrm{j}}$ Regime turbulento é o escoamento de um fluido em que as partículas se misturam de forma não linear, isto é, de forma caótica com turbulência e/ou movimentação Randômica, em oposição ao regime laminar.
} 


\subsubsection{Spray}

O uso de spray na área analítica também é comum [87] e a ionização por eletrospray é a esperança para interfaciar a cromatografia líquida e a eletroforese capilar com a espectrometria de massas. A eficiência da ionização pode ser aumentada pelo uso de ultrasom no lugar de campo elétrico para a produção das gotas e sistemas similares já foram miniaturizados. Microestrutura para produção de jatos, obtidos por efeito Venturi ${ }^{\mathrm{k}}$ e eletrospray [88], foi útil para a análise de peptídeos por espectrometria de massas.

\subsection{MINIATURIZAÇÃO e $\mu$ TAS}

Como abordado anteriormente, a miniaturização influiu em muitas áreas, entre elas a Engenharia Química - já brevemente avaliada - e a área Química, especialmente no que concerne à análise química. Para esta área, a produção de equipamentos de análise e especialmente o $\mu$ TAS vem recebendo grande atenção [1][89][90], pois uma das grandes vantagens da miniaturização é a manipulação de amostras de pequeno volume [91]. Assim, os sistemas de análise total ( $\mu \mathrm{TAS}$ ) serão alvo de pesquisa ainda nas próximas décadas [92] e, em especial, algumas das etapas de preparação de amostras [12].

Portanto, dentre as várias estruturas para a fabricação de $\mu \mathrm{TAS}$, dá-se significativo valor àquelas capazes de certas Operações Unitárias, como é o caso das estruturas capazes de separação ou retenção de partículas e classes de compostos químicos, pois um dos grandes problemas que enfrentamos atualmente é a poluição do ar, águas e solos. Estes poluentes podem ter as mais diversas dimensões, porém, um dos maiores problemas a serem estudados é o dos poluentes particulados que podem variar de centenas de Angstroms a micrômetros de diâmetro e podem causar sérios problemas ambientais [18][19][23][24]. A remoção de partículas tanto de meio líquido quanto de meio gasoso é de interesse para aplicações que envolvam pré-tratamentos de amostras para a análise química, especialmente com matrizes complexas, tais como, as medidas de amostras ambientais [93].

Várias são as Operações Unitárias utilizadas para a remoção de partículas e aerossóis em fase gasosa e as partículas ou emulsões/dispersões em fase líquida. No ar, partículas com diâmetro igual a $100 \mu \mathrm{m}$ são tipicamente removidas por efeitos gravitacionais, de $10 \mu \mathrm{m}$ por efeitos de centrifugação, de $1 \mu \mathrm{m}$ por filtros e de $0,1 \mu \mathrm{m}$ com filtros eletrostáticos. No líquido,

\footnotetext{
${ }^{\mathrm{k}}$ Esse efeito corresponde à redução da pressão do fluido quando o fluido atravessa uma constrição.
} 
para a remoção de moléculas com alto peso molecular, faz-se uso da adsorção e osmose reversa; para as nanopartículas, pode-se eliminá-las por ultrafiltração e as partículas grandes, com filtração ou sedimentação. Porém, para se chegar a estes dispositivos, uma série de etapas deverá ser executada. Entre as várias etapas envolvendo o pré-tratamento de amostras, a préconcentração, isto é, a diminuição do limite de detecção, é um dos passos mais relevantes.

Para ocorrer a pré-concentração em fase líquida, geralmente, utiliza-se o método eletro-cinético e soluções aquosas pela facilidade de movimentação de íons em capilares. Contudo, a utilização de processos de adsorção também faz-se possível na extração em fase sólida. Usa-se também a voltametria, processo que exige adsorção para iniciar-se, para analisar o comportamento dos íons em soluções aquosas [94]. A adsorção em um filme polimérico foi utilizada para pré-concentração e separação de proteínas em um dispositivo fluídico [95]. Assim, a separação de compostos de um meio, seja este líquido ou gasoso, de modo geral, depende de adsorção, no que se refere ao caso de uma situação reversível, ou seja, onde a remoção deste composto não seja dificultada posteriormente. Este é o caso dos pré-concentradores e alguns destes já foram miniaturizados [96]. A retenção de compostos de modo geral, atende ao pré-tratamento de amostra com o objetivo de tornar a matriz sob análise mais simples e, neste caso, a reação com a superfície é desejável. A retenção pode ocorrer sem que haja reação. Por exemplo, tem-se a retenção de compostos orgânicos voláteis (VOCs) em microcanais com constrições.

Silva e Gameiro [97] recentemente revisaram o uso de pré-concentradores miniaturizados, especialmente para uso no estado gasoso, e observaram a importância de novos desenhos de estruturas, de baixo custo, e de superfícies adsorventes. Além disso, Silva, Furlan e Ramos [16] chamaram a atenção para a possibilidade do uso dessas estruturas para ensino de Engenharia.

Como muitas das estruturas utilizadas neste trabalho baseiam-se em desenhos e filmes adsorventes desenvolvidos por este grupo da EPUSP, a seguir faz-se uma breve revisão.

\subsection{ESTRUTURAS}

O item a seguir baseia-se nos estudos desenvolvidos por Silva [98], Santos [70], Beraldo [99], Carvalho [100], Nascimento [54] e Lima [101] que, em geral, objetivava a simulação e a criação de novas estruturas impactadoras e pré-concentradoras além de microreatores. 


\subsubsection{Estruturas Helicoidais}

Em sistema para retenção e pré-concentração, as características principais são: a área superficial, pois, quanto maior a área, maior será a probabilidade de adsorção [102] e a dinâmica do fluido, cujo comportamento tem suma relevância para definir uma série de fenômenos secundários indesejáveis, tais como efeito de capilaridade, formação de vórtices, etc.

Deste modo, Lima [103] propôs novas estruturas usando filmes finos adsorventes para aumentar a capacidade de retenção e pré-concentração de amostras ou reagentes. Lima [103] desenvolveu estruturas em substrato orgânico, acrílico ${ }^{\circledR}$, usinadas em torno convencional, onde provavelmente a retenção de produtos depende exclusivamente de interações químicas (adsorção e dessorção). A Figura 2.7 apresenta o esquema da estrutura usinada.

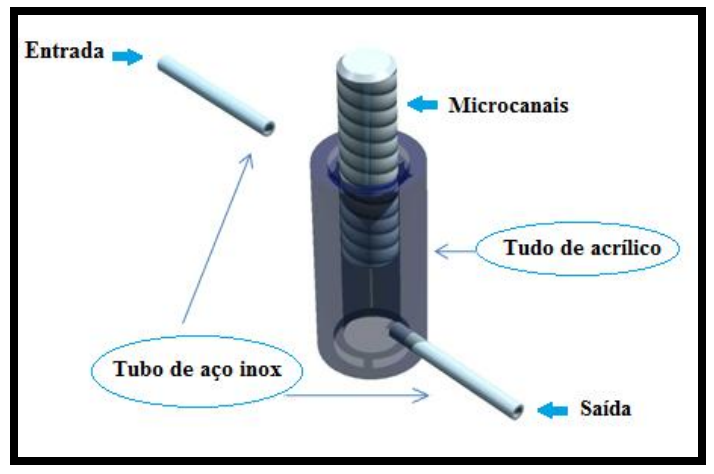

(A)

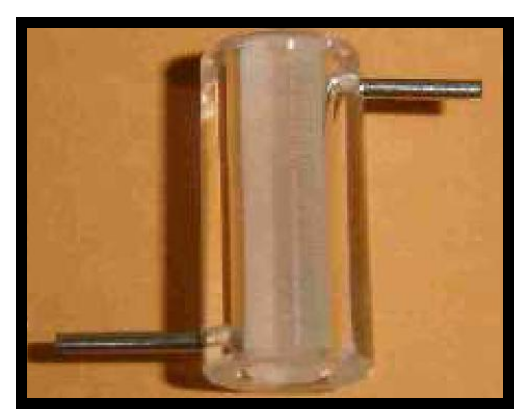

(B)

\section{Figura 2.7 - (A) Esquema e (B) fotografia da estrutura, tubos em acrílico, junção entre barra roscada e tubos de aço inoxidável [103].}

Para a selagem dos microcanais utilizou-se cola de silicone e as entradas e saídas correspondem a tubos de aço inoxidável, que foram fixados na estrutura com uso de clorofórmio.

Para verificar como a química da superfície ou área superficial influenciam na retenção dos compostos, filmes adsorventes foram depositados na superfície ou o canal foi recoberto por partículas finas. Esta estrutura comporta-se como uma coluna cromatográfica, podendo ser uma pré-coluna para retenção em fase gasosa, se fosse recoberta por partículas [104]. 
Estudos posteriores foram feitos, com base em simulações usando o FEMLAB 3.2®, para adaptar tal estrutura como um microreator. Nestes foram alterados o passo da rosca para verificação de alterações na velocidade do fluido perpendicular ao escoamento, concluindo-se que o aumento do passo tornava o regime turbulento [105]. Essas estruturas, posteriormente, foram modificadas pela inserção de quatro riscos verticais ao canal principal, para a produção de microreatores, sendo proposto que tais estruturas, quando empacotadas com partículas, serviriam como misturadores. Por fim, as estruturas foram usadas para catálises e, por isso, foram usinadas em aço inoxidável.

\subsubsection{Estrutura Espiral Planar}

Estruturas chamadas de espiral planar, construídas em substrato acrílico ${ }^{\circledR}$ e formadas por microcanais em forma espiral planar, foram usinadas com torno CNC e seladas com clorofórmio entre o substrato com microcanais e flange cega foram desenvolvidas por Nascimento [54]. Foram testados vários tamanhos de microcanais, em especial, neste trabalho, foca-se o estudo nas estruturas com dimensões iguais a 500 micrômetros de largura, 200 micrômetros de profundidade e $40 \mathrm{~cm}$ de comprimento. Para a conexão da entrada e saída foram utilizados tubos de aço inoxidável (diâmetro interno de 1/16") fixados com cola de silicone. $\mathrm{O}$ esquema e a foto da estrutura em questão encontra-se na Figura 2.8. Para alterações das condições da superfície foram depositados filmes polimerizados por plasma de HMDS (hexametildissilazana) dentro de um reator alimentado por uma fonte de $40 \mathrm{kHz}$.

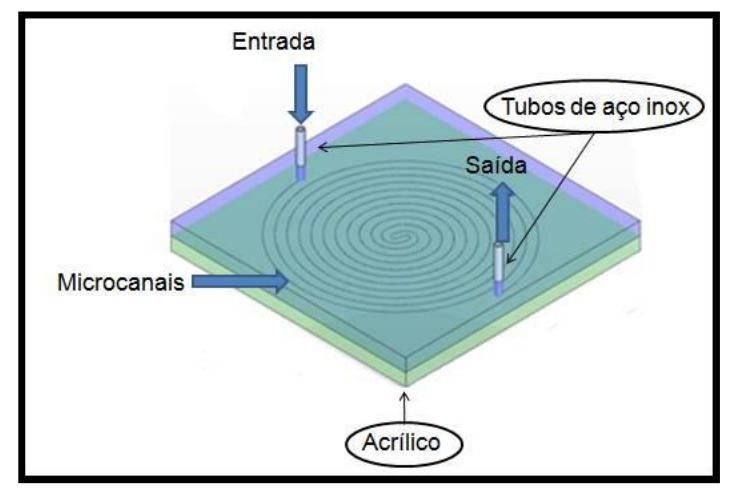

(A)

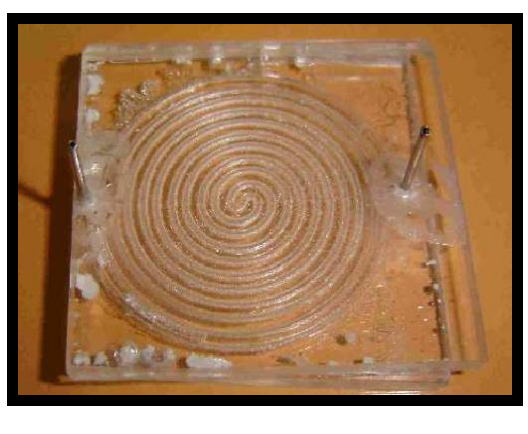

(B)

Figura 2.8 - (A) Esquema e (B) fotografia da estrutura, substrato em acrílico e tubos de aço inoxidável [54]. 
Nascimento [54] demonstrou que tais estruturas eram mais adequadas para préconcentração que as estruturas tridimensionais helicoidais devido ao comportamento do escoamento, pois a velocidade lateral é alta.

\subsubsection{Estrutura Chicana}

Encontram-se na literatura estudos relacionados a estruturas com comportamento de chicanas desenvolvidos por Nascimento [54] e Santos [70]. Nascimento [54] propõe estruturas com microcanais de $0,5 \mathrm{~mm}$ de profundidade e $1 \mathrm{~mm}$ de largura que apresentaram boas características de adsorção quando depositados filmes adsorventes na superfície destes microcanais. Dentre outros fenômenos estudados por Nascimento [54] observa-se o efeito de capilaridade. Por este motivo, tais dimensões são consideradas eventualmente como mínimas para estes tipos de estruturas.

A possibilidade de retenção foi utilizada por Santos [70]. Devido ao ângulo de $90^{\circ}$ nas regiões de borda tem-se a diminuição de velocidade, com o respectivo aumento da retenção de partículas. Os resultados obtidos a partir da caracterização e simulação mostraram que estas estruturas podem servir em preparações de amostras para análises químicas, bem como manipulação de microorganismos [70]. Na Figura 2.9, pode-se observar o esquema e a foto das chicanas estudadas por este autor.

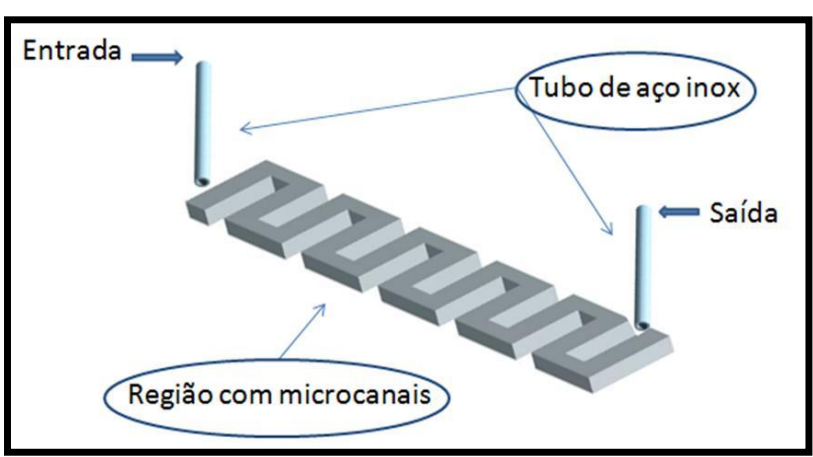

(A)

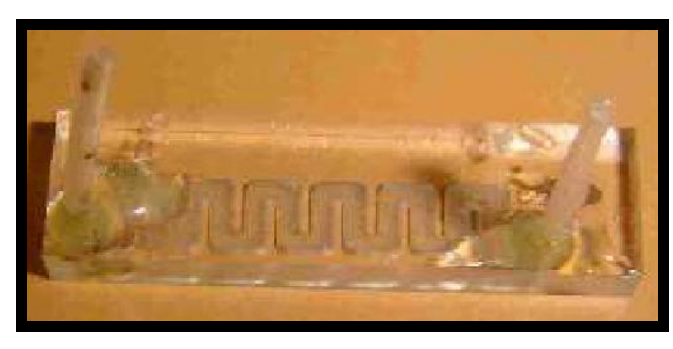

(B)

Figura 2.9 - (A) Esquema e (B) fotografia da estrutura, substrato em acrílico e tubos de silicone [70]. 


\subsubsection{Estrutura Impactadora}

Beraldo [99] desenhou um impactador em forma de cascata que é capaz de reter e selecionar, de acordo com as dimensões, partículas; contudo a estrutura proposta apenas pode ser usada para análises de amostras em fase gasosa. Deste modo, esta estrutura vem para completar a proposta por Santos [70]. Assim como as estruturas anteriores, estas também apresentam baixo custo de fabricação, pois, são fabricadas em substratos à base de acrílico ${ }^{\circledR}$, usinados com técnicas mecânicas convencionais. As estruturas são seladas, ou poderiam ser, com fita adesiva dupla face de 5 micrômetros de espessura (3M, YR-9767), item este que determina a possibilidade de abrir as estruturas e estudar a superfície/amostra com o auxílio de microscopia ótica, após os testes realizados.

A idéia da estrutura impactadora é a de um feixe atingindo um prato coletor que pode ser facilmente reproduzido em pequenas dimensões. Como Nascimento [54] estudou arranjo similar, para adsorção de compostos orgânicos voláteis (VOCs) [54], duas Operações Unitárias inicialmente abordadas neste trabalho - remoção/separação de partículas e préconcentração de compostos - foram acopladas numa única estrutura. $\mathrm{O}$ fato de o acrílico ser um material transparente possibilita a filmagem de tais estruturas e a Figura 2.10 apresenta a foto e o esquema dos impactadores.

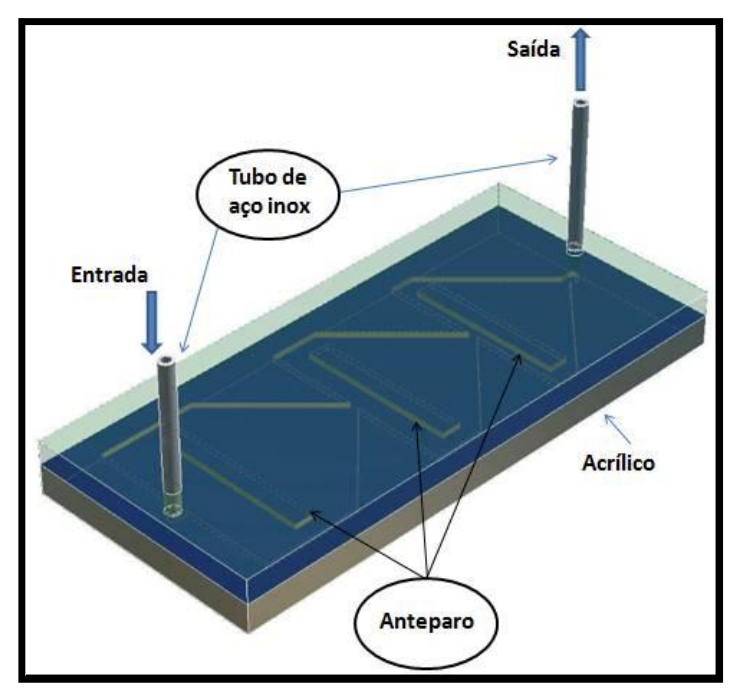

(A)

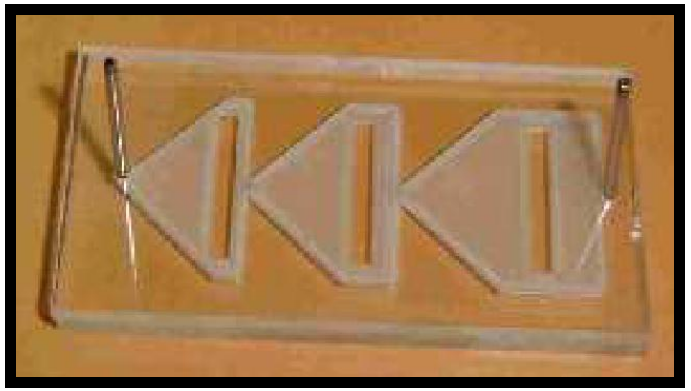

(B)

Figura 2.10 - (A) Esquema e (B) fotografia da estrutura, substrato em acrílico e tubos de aço inoxidável [99]. 
Estas estruturas foram simuladas, inclusive para determinar as dimensões críticas, utilizando FEMLAB3.2B ${ }^{\circledR}$. Tanto testes quanto simulações utilizaram escoamento de 10 $\mathrm{mL} / \mathrm{min}$ para amostras gasosas e $1 \mathrm{~mL} / \mathrm{min}$ para amostras líquidas e mostraram boa coerência nos resultados.

\subsection{SUPERFÍCIE ADSORVENTE}

Filmes adsorventes são muito usados em cromatografia há várias décadas. $\mathrm{Na}$ cromatografia, especialmente a cromatografia gasosa, há uma série de filmes adsorventes, desenvolvidos para muitas separações distintas, entre elas, compostos orgânicos em ampla faixa de polaridade, macromoléculas, etc [106][107]. Por outro lado, filmes adsorventes depositados por polimerização por plasma não são comuns. Contudo, tais filmes finos podem ser usados para uma série de aplicações, tais como a compatibilização das interfaces e a proteção de superfície, ou mesmo para a produção de dispositivos miniaturizados de análise [108] e existiram estudos de produção por plasma de filme fino de ftalocianina de cobre para adsorção de compostos [109][110].

A polimerização por plasma também apresenta uma série de vantagens, entre elas, a produção de filmes que não poderiam ser obtidos por outro método de produção. Outras vantagens são o baixo consumo de reagentes e de formação de resíduos, pois trata-se de uma tecnologia mais limpa. Uma propriedade muito importante da polimerização por plasma é a possibilidade da mudança das características do filme pelas mudanças nas condições do plasma, como potência e pressão [111][112].

\subsubsection{Filmes depositados por plasma e respectivas caracterizações}

Dentre os diversos processos de obtenção de filmes finos, a deposição feita em fase gasosa e ativada por descarga luminescente, $\operatorname{PECVD}^{\mathrm{m}}$ - deposição química a vapor por plasma - destaca-se devido a algumas de suas particularidades. O processo é de fácil execução, limpo, seco, rápido e resulta em materiais uniformes, homogêneos, livres de defeitos e com propriedades bastante dependentes dos parâmetros de deposição. O plasma é gerado pela à aplicação de campos elétricos contínuos normalmente com gás a baixa pressão $\left(10^{-1}\right.$ a $\left.10^{3} \mathrm{~Pa}\right)$. De modo geral, espécies orgânicas ativadas pela descarga são muito reativas e

\footnotetext{
${ }^{\mathrm{m}}$ PECVD - Plasma Enhanced Chemical Vapor Deposition
} 
tendem a interagir com as superfícies, muitas vezes formando um filme por polimerização. A técnica de PECVD permite a obtenção de filmes com uma ampla gama de propriedades através do controle dos parâmetros do processo. Uma outra vantagem deste processo é que a estrutura é totalmente embebida pelo plasma. Assim, toda a estrutura, mesmo que com formatos complexos e mesmo perfurações recebem uma camada de filme com alto grau de uniformidade.

HMDS: A deposição por plasma de organo-silanos é normalmente baseada em reações íon/molécula [113][114][115]. Dentre os organo-silanos, Hexametildissilazana (HMDS), que depende destas reações íon/molécula [116], pode formar filmes adsorventes. Entre os organo-silanos mais conhecidos, o HMDS apresenta a vantagem de radicais $\mathrm{CH}_{3}$ (metil), que podem tornar as superfícies hidrofóbicas e/ou organofílicas e que apresentam características interessantes na adsorção de compostos orgânicos, polar ou apolar, na fase gasosa ou líquida.

Além disso, há um grande interesse no desenvolvimento de detectores de baixo custo e, para tanto, pode-se utilizar a deposição de filmes adsorventes para aumentar a eficácia desses detectores. Por fim, o uso em microcanais permite e obtenção de estruturas com propriedades bem distintas, de pré-coluna cromatográfica a sistema de detecção em fluxo contínuo.

HFE $^{\text {n: }}$ para se produzir filmes finos em ampla faixa de polaridade ou mesmo repelentes a óleo usam-se compostos orgânicos, por sua variabilidade. Assim, a possibilidade de uso de compostos orgânicos oxigenados, reagentes que têm cadeia carbônica e o heteroátomo oxigênio, um átomo bastante eletronegativo, permite formar um filme fino orgânico e de alta polaridade. Reagentes como: éter etílico, acetato de etila e acetato de metila foram polimerizados e a partir disto obteve-se filmes finos hidrofílicos com boas propriedades de adsorção de VOCs, porém com pouca resistência à variação de pH [101]. Por outro lado, o uso de compostos orgânicos fluorados [117] pode gerar polímeros hidro-oleofóbicos e resistentes à corrosão e temperatura, mas não bons adsorventes. Sendo assim, em si tratando de compostos fluorados a melhor aplicabilidade é a proteção de superfície [118].

MEV ou SEM': para caracterização da superfície dos filmes é comum o microscópio eletrônico de varredura (MEV), que é um tipo de microscópio eletrônico que fornece a imagem da superfície da amostra através da "varredura" feita com um feixe de elétrons de alta energia. Os elétrons interagem com os átomos fazendo com que seja

\footnotetext{
${ }^{\mathrm{n}}$ HFE - metil- nonafluoro(iso)butil eter.

${ }^{\circ} \mathrm{MEV}$ - Microscópio Eletrônico de Varredura ou SEM - Scanning Electron Microscope
} 
produzido um sinal que contem informações sobre a topografia da superfície da amostra, assim como sua composição e outras propriedades como a condutividade elétrica. Os detectores de elétrons secundários estão, geralmente, presentes em todos os MEV, mas são raros os MEV que possuem um detector para todos sinais possíveis. Estes sinais são resultantes das interações do feixe de elétrons com os átomos da superfície ou próximos a ela. Esta técnica produz imagens de alta resolução da superfície da amostra, revelando detalhes de amostras que tenham dimensões variando de $1 \mathrm{~nm}$ a $5 \mathrm{~nm}$.

MS $^{\mathrm{p}}$ : para verificar a influência da exposição da superfície a vários ciclos de contaminantes polares e apolares, testou-se as estruturas em um espectrômetro de massa (MS) [102]. A MS é uma técnica analítica por meio da qual as substâncias químicas são identificadas através da formação e separação dos íons por campos elétricos e/ou magnéticos, que os classificam de acordo com sua relação massa-carga. Os espectrômetros de massas constam de quatro partes básicas: um sistema manipulação para introduzir a amostra desconhecida no equipamento; uma fonte de íons, na qual é produzido um feixe de partículas provenientes da amostra; um analisador que separa partículas de acordo com a massa e um detector, no qual os íons separados são recolhidos e caracterizados. MS oferece informações qualitativas e quantitativas sobre a composição atômica e molecular de materiais inorgânicos e orgânicos.

QCM ${ }^{\text {: }}$ a análise de adsorção e/ou permeação dos filmes depositados e de adsorção/dessorção de microestruturas, tanto em fase gasosa quanto líquida, pode utilizar a técnica de microbalança de quartzo (QCM) [102]. O sistema usa cela de detecção com um cristal piezoelétrico de quartzo ${ }^{\mathrm{r}}$ (PQC) modificado pela deposição de um filme adsorvente. Com a adição de massa à superfície do cristal (deposição do filme e/ou adsorção), faz-se uma mudança na freqüência de ressonância. Desta forma, pelas medidas das freqüências anteriormente e após a exposição a um composto qualquer, podem-se determinar as propriedades de adsorção deste filme, através da diferença entre as freqüências de oscilação do cristal. Esta variação é detectada por uma interface com um computador que amplifica o sinal e o converte em forma de gráfico da freqüência em função do tempo.

FTIR $^{\text {s: }}$ A interação da onda eletromagnética com comprimento de onda no infravermelho com a matéria pode definir a espectroscopia de infravermelho. A radiação infravermelha pode ser absorvida gerando vibração nas ligações químicas do material, quando

\footnotetext{
${ }^{\mathrm{p}}$ MS - Espectrometria de Massa ou Mass Spectroscopy

${ }^{\mathrm{q}}$ QCM - Microbalança de Quartzo ou Quartz Crystal Measurements.

${ }^{r}$ PQC - Cristal de Quartzo Piezelétrico ou Piezoelectric Quartz Crystal.

${ }^{\mathrm{s}}$ FTIR - Espectroscopia de Infravermelho ou Infrared Spectroscopy.
} 
interage com a matéria. O grupo funcional da molécula que absorve a radiação pode ser correlacionado com o comprimento de onda. Assim, por esta correlação identifica-se as moléculas desconhecidas através da análise do espectro de infravermelho. Esse espectro é um gráfico de medida de intensidade de radiação de infravermelho em função do comprimento de onda. Existem vários modos de se obter espectro de infravermelho; para análise de bandas fracas - ou de amostras em pequenas quantidades como é o caso de filmes finos - o uso de FTIRs (Fourier Transform Infrared Spectroscopy) é comum, pois nessa configuração a análise é rápida e o sinal pode ser acumulado, permitindo melhor limite de detecção. Nos instrumentos de FTIR a luz é modulada por um interferômetro de Michelson, onde um dos espelhos é móvel e a amostra é inserida entre os feixes.

\subsubsection{Compostos Orgânicos Voláteis}

Têm-se, nos dias de hoje, como fontes de poluição, além das naturais, as originárias das indústrias e de automóveis, que emitem constantemente poluentes gasosos e líquidos e geram sérios problemas ambientais. As principais emissões correspondem aos compostos conhecidos como orgânicos voláteis (VOCs), que podem ser emitidos em grande quantidade em reações de combustão ocorridas em automóveis e até mesmo em chaminés ou queimas de lixo, são também solventes e podem contaminar tanto rios como solos. Assim, torna-se cada vez mais importante estudar e desenvolver métodos capazes de analisar cada tipo de contaminante despejado no meio ambiente.

Há uma infinidade de equipamentos capazes de realizar análises referentes à poluição, porém, requerem grandes quantidades de amostra. Sendo assim, os equipamentos ficam cada vez mais limitados. Daí a necessidade de pré-concentradores já que pequena quantidade de amostra, independentemente do tipo de amostra, pode ser analisada em frações de segundos.

A separação de compostos é comumente conseguida, especialmente para amostras complexas, pelo uso de cromatografia. VOCs são normalmente analisados por cromatografia gasosa, mas também pode ocorrer o uso de cromatografia líquida, e pode-se fazer uso de préconcentradores para melhorar a análise quanto ao limite de detecção. No caso de contaminantes particulados metálicos podem-se utilizar, no lugar de pré-concentradores, os impactadores, comuns apenas na fase gasosa. A coleta e separação de partículas na fase líquida é um pouco mais complexa [117][118][119][120][121]. 


\subsection{OUTROS ASPECTOS}

O alto investimento para ensinar, especialmente, na Engenharia, fez com que os usos de ferramentas educacionais de baixo custo tornassem cada vez mais necessários. Ademais, atualmente dá-se ênfase em estudos que visem o desenvolvimento sustentável, principalmente no que diz respeito à preservação do meio ambiente pelo melhor aproveitamento de energia e matéria-prima. Um modo eficiente de proteger o ambiente é pela miniaturização. Assim, dispositivos produzidos MEMS e/ou sua simulação podem ser úteis no ensino. Contudo, a produção destes dispositivos, em geral, exige equipamentos muito sofisticados e não é comum utilizá-los em projetos educacionais.

É relevante lembrar que o desenvolvimento de estruturas miniaturizadas pode ajudar a desenvolver multidisciplinaridade no ensino. Também é interessante a possibilidade de integrar todos os conceitos interdisciplinares para melhor aplicá-los na resolução de problemas. Muitos destes conceitos poderiam ser facilmente ensinados usando-se ferramentas de simulação. Entre as principais miniaturizações estão microestruturas sensoras. Partindo deste preceito, um avanço tecnológico de grande valia seria garantir o baixo custo de tais estruturas. Neste contexto, polímeros orgânicos tornam-se atraentes. Portanto, o próximo passo no desenvolvimento de tecnologias na área de microeletrônica será, além do uso de polímeros orgânicos, a tecnologia conhecida como roll to roll $^{t}[122]$.

Assim, torna-se importante desenhar, construir, caracterizar e simular, estruturas pouco maiores, da ordem de centenas de micrômetros, para estudar os possíveis efeitos comportamentais gerados pela adsorção, retenção, permeação e dessorção, e suas respectivas alterações na mecânica dos fluidos [16].

\footnotetext{
${ }^{\mathrm{t}}$ roll to roll-processo contínuo.
} 


\section{CAPÍTULO 3 - MATERIAIS E MÉTODOS}

Neste capítulo serão descritas as etapas propostas para esse trabalho: metodologias e materiais utilizados. Tais metodologias são propostas para determinar, semi-quantitativamente e/ou comparativamente, a capacidade de retenção, adsorção, permeação e dessorção em diferentes estruturas. Para isto, estudos prévios em estruturas já existentes foram usados como base para o desenvolvimento de novas estruturas, como mencionado no capítulo referente aos aspectos teóricos.

\subsection{ETAPAS DO TRABALHO}

Para a concretização deste trabalho segue-se as etapas:

1. Escolha de estruturas capazes de pré-concentrar/ separar/ reter compostos químicos tanto em estado líquido quanto em estado gasoso;

2. Simulação do comportamento destas estruturas;

3. Construção de protótipo inicial e caracterização do mesmo;

4. Otimização do protótipo testado através de simulações e novos testes;

5. Seleção da(s) estrutura(s) promissora(s) e testes finais em condições mais próximas às "condições de uso em situações reais".

É relevante observar que os protótipos iniciais, principalmente considerando-se custo e necessidade de compreensão dos mecanismos do fluído, necessariamente não possuem dimensões pequenas, já que dimensões maiores facilitam a observação visual.

Para garantir o melhor aproveitamento do tempo todas as etapas de desenvolvimento deste trabalho foram feitas com base em engenharia simultânea, ou seja, não necessariamente as etapas foram cumpridas seqüencialmente, mas em paralelo. O Fluxograma 3.1 apresenta as etapas a serem seguidas para o desenvolvimento deste trabalho. 


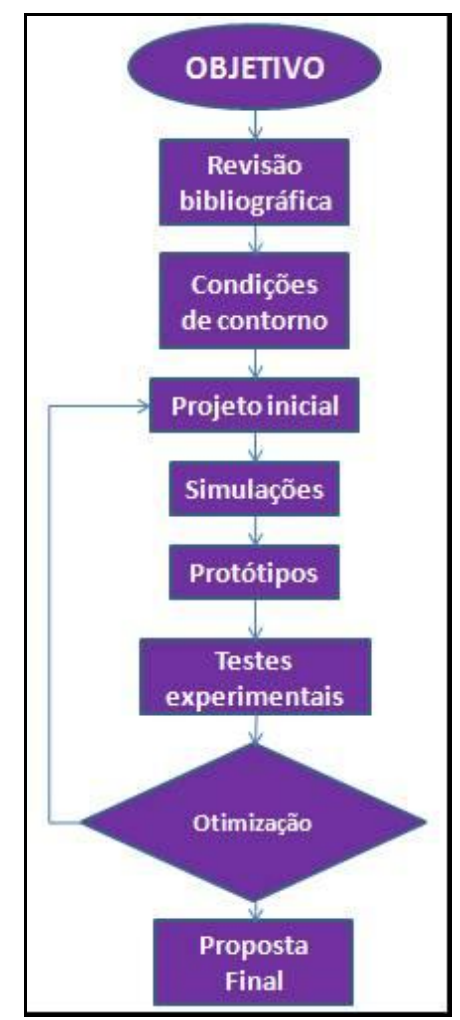

\section{Fluxograma 3.1 - Seqüência de etapas para desenvolvimento do trabalho.}

Como condições de contorno têm-se que:

- A concepção das estruturas tomou como base o escalamento de estruturas macroscópicas;

- A possibilidade de manipulação de amostras líquidas e gasosas nas mesmas estruturas;

- A função das estruturas é a remoção de particulados ou a análise grosseira de compostos orgânicos voláteis em misturas complexas, tais como combustíveis;

- A construção deve apresentar simplicidade, portanto, com concepção mais próxima do nariz e língua eletrônicos e não de equipamentos de análise mais complexos;

- O baixo custo - devido às dimensões das estruturas que permite usinagem com equipamentos convencionais - e possibilidade de desmontagem das estruturas.

Para possibilitar o uso de uma mesma estrutura com amostras na fase líquida ou gasosa, optou-se por transformar amostras líquidas em spray, o que também facilita outras etapas do procedimento, como aquecimento, por facilitar a troca de calor.

No conjunto, portanto, as estruturas constituem um protótipo de equipamento de análise que apresenta nova concepção, dimensões pequenas e baixo custo, muito embora tenha como função análise grosseira, ou seja, semi-quantitativa. Esse tipo de abordagem é útil para análises ambientais, mas não recebe atenção na área de pesquisa em $\mu$ TAS. 
Genericamente, o esquema de uso das estruturas em um protótipo é como apresentado na introdução deste trabalho e melhor descrito no Fluxograma 3.2-que determina as principais condições de contorno a serem seguidas. A partir do fluxograma definiu-se a metodologia, descrita a seguir.
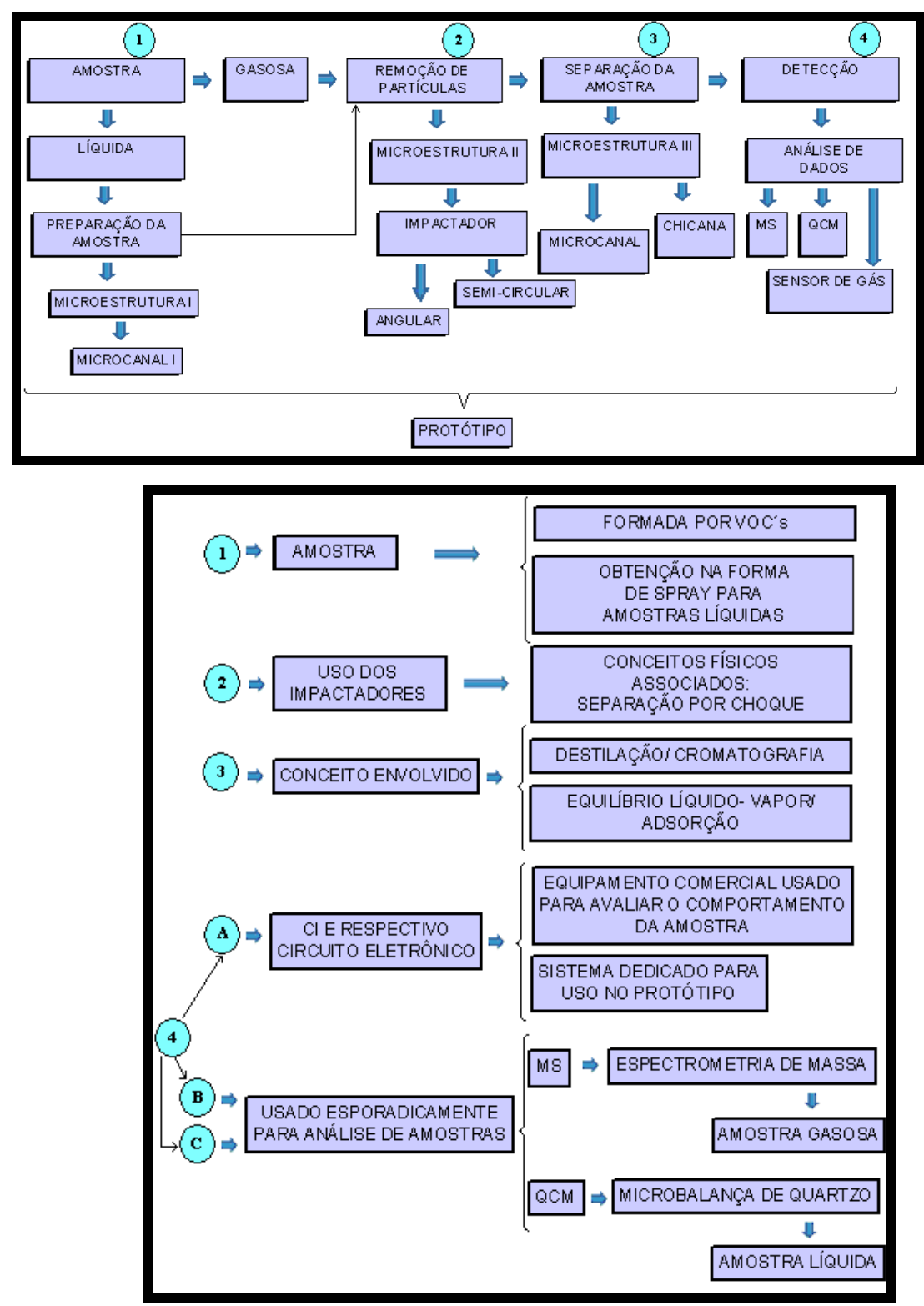

Fluxograma 3.2 - Esquema das etapas seguidas para o desenvolvimento deste trabalho.

\subsection{SIMULAÇÃO E CONSTRUÇÃO DAS ESTRUTURAS}

Quanto à simulação dos desenhos propostos para estruturas, utilizou-se o programa FEMLAB3.2®, que corresponde a uma ferramenta bastante adequada para a simulação de 
fenômenos físico-químicos ocorrendo no interior de fluidos líquidos ou gasosos ${ }^{\mathrm{u}}$. As simulações são realizadas em um microcomputador Pentium IV com plataforma de $2.4 \mathrm{GHz}, 2$ GB de RAM.

Neste trabalho o simulador foi usado apenas como ferramenta de apoio para definições de dimensões e formatos das estruturas. Portanto, a maioria dos resultados obtidos são apresentados em Apêndice A.

O trabalho considerou para modelamento as equações de Navier-Stokes, velocidade de escoamento da fonte até o descarte é aproximada em $10 \mathrm{~cm} / \mathrm{s}$ e $1 \mathrm{~cm} / \mathrm{s}$, para fluidos gasosos e líquidos, respectivamente. A malha é normalmente definida manualmente.

\subsection{CARACTERIZAÇÃO E DETECÇÃO NAS ESTRUTURAS}

\subsubsection{Admissão de amostra}

Para a caracterização destas estruturas é necessária a construção de um arranjo experimental $\left(\operatorname{setup}^{v}\right)$ para inserção controlada de amostras e no presente caso o arranjo deve atender não só testes com fluidos gasosos como também líquidos. Já existe na literatura autores que desenvolveram um setup para análise de estruturas miniaturizadas [70], contudo, este não é adequado ao uso com traçadores coloridos. Ademais, para o uso de traçadores líquidos é útil a existência de arranjo pequeno, facilmente desmontável e transportável para, por exemplo, uso em conjunto com microscopia óptica, o que permite a visualização do comportamento interno a estrutura e comparação com as observações nas simulações. Desta forma, fica mais fácil entender o funcionamento e o desempenho da estrutura. Portanto, um sistema de admissão, tanto de liquido como de gás, que permite a observação e filmagem de estruturas foi construído. Devido à sua simplicidade tal sistema pode ser desmontado e remontado em outra ordem, para facilitar o acesso às medidas e será mais bem descrito no decorrer de seu uso. Contudo, pode ser resumido como segue: são utilizados principalmente uma bomba de ar (Inalar Compact motor 1/40HP, potência $200 \mathrm{VA}$, freqüência $60 \mathrm{~Hz}$, Voltagem $127 \mathrm{~V}$, Sistema a Pistão, vazão de $10 \mathrm{~mL} / \mathrm{min}$ ), um cronômetro (Taksun®, $\mathrm{TS}^{*} 613^{\mathrm{A}}$ ), seringas (BD Tuberculina $0,05 \mathrm{~mL}$ ou $1,0 \mathrm{~mL}$ ), Capilares (poliflow $\left.{ }^{\circledR}\right), 5$

\footnotetext{
" Esta etapa do trabalho foi desenvolvida com o auxílio do Prof. Dr. E. W. Simões, especialista na área de simulações usando este programa.

${ }^{v}$ Setup - sistema, configuração.
} 
eppendorf $^{w}$, reagentes puros, e suas soluções, em larga escala de polaridade (tais como isopropanol - puro, solução 50\% álcool etílico e 50\% água destilada) e misturas comerciais (Varsol®, gasolina etc.), termômetro (L-056/07 Toptherm), garra e suporte universal.

\subsubsection{Sistemas de detecção}

Os sistemas de detecção para caracterizar microestruturas são, principalmente, a microbalança de quartzo ${ }^{\mathrm{x}}(\mathrm{QCM})$ e a espectrometria de massas ${ }^{\mathrm{y}}$ (MS). Enquanto o primeiro é pequeno, permite analisar tanto fluido líquido quanto gasoso, além de trabalhar à pressão atmosférica (PA), o segundo necessita de sistemas de alto vácuo e é mais adequado a sistemas gasosos. Porém, apresenta a vantagem de permitir a determinação da fórmula estrutural do composto sob análise. Tanto a técnica de QCM, através de medidas indiretas de variação de massa do reagente, quanto a MS, através da intensidade relativa dos picos, permite verificar se há adsorção e/ou dessorção além de retenção nos sistemas miniaturizados.

Por fim, geralmente, os sistemas de detecção usados em cromatógrafos podem também ser acoplados a arranjo experimental para caracterização de estruturas, mas não foram aqui considerados por apresentar maiores dificuldades de acoplamento além de alto custo. A vantagem mais evidente de tal sistema de detecção é o uso em pressão atmosférica.

No presente caso, foi utilizada a espectrometria de massas para avaliar a reação de catálise em uma das estruturas. O setup foi construído utilizando câmara de vácuo, onde foi inserido um espectrômetro de massas (Transpector 2, Inficon Gas Analysis Systems, USA), bombeada por bomba turbo e com uma válvula de precisão (agulha) para injeção da amostra, que sai da estrutura em pressão atmosférica. A pressão na câmara de vácuo é controlada durante a admissão para atingir $5.10^{-6}$ Torr, ou seja, cinco vezes a pressão base.

O arranjo utilizado [70] para medidas com microbalança de quartzo é bastante similar ao de inserção de amostras, já descrito, e possui limite de detecção da ordem de ppm.

Quanto aos sistemas de detecção para o arranjo experimental, a definição de um protótipo mais adequado para ser usado em condições próximas às condições de uso, ou seja, em campo, pressupõe-se o uso de sistema de detecção mais comercial. Assim, para amostras

\footnotetext{
${ }^{\text {w }}$ Eppendorfs - é um tipo de tubo de ensaio; no presente caso com volume total de aproximadamente 1,5 mL (4 $\mathrm{cm}$ de altura), no entanto existem tubos de até $200 \mu \mathrm{L}(2 \mathrm{~cm})$; são feitos de plásticos que suportam muitos solventes orgânicos e as pressões a que são submetidos em centrífugas; possuem tampas anexadas, facilitando o armazenamento sem perda de amostras; a vantagem destes é o formato afunilado ao final, servindo para coletar quantidades mínimas de líquidos.

x QCM - Quartz Crystal Microbalance ou Microbalança de Quartzo.

y MS - Mass Spectrometry ou Espectrometria de Massa.
} 
gasosas, um equipamento comercial e de baixo custo (Instrutherm, Modelo DFG-4000, sensibilidade de $50 \mathrm{ppm}$, sensor tipo semicondutor de baixo consumo, tempo de resposta inferior a 2 segundos, alimentação de 3 pilhas de 1,5 V “tipo C", indicação audiovisual) baseado em sensores de gases para compostos orgânicos voláteis e com limite de detecção de até ppb - foi selecionado. Esse detector comercial foi acoplado ao sistema de inserção de amostras e ao computador usando um cabo P2 estereofônico. Após os testes com tal equipamento, um sistema semelhante, mas de uso dedicado, foi construído.

No caso do uso de um único detector, este foi acoplado ao computador através de seu sistema de som, gerando gráficos de intensidade em função do tempo de detecção (ms). Para realizar as medidas de frequiência utilizou-se um programa obtido na internet no site www.atma-software.com usando a versão Frequency Counter 1.01. As medições de tempo são feitas usando um cronômetro. A Figura 3.1 apresenta a tela do freqüencímetro como aparece na tela do computador durante as medições. Esse arranjo tem inúmeras vantagens para uso em sistemas educacionais.

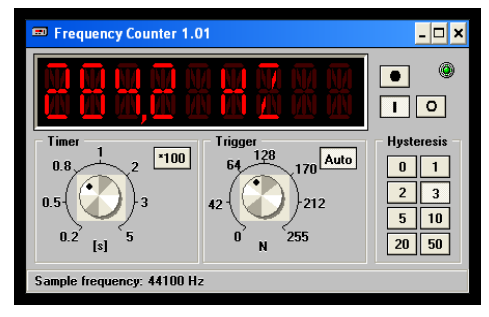

Figura 3.1 - Software $^{z}$ de Freqüencímetro utilizado para realizar medidas.

O simulador Frequency Counter 1.01 não gera tabelas com dados obtidos durante os testes. Por isso, fez-se necessária a aquisição de um programa de baixo custo que simula a freqüência e que também gera tabelas de dados. Este foi adquirido em sites de vendas existentes na internet. O programa adquirido é o Osciloscópio para PC 3 em 1 (Microhard囚). Este osciloscópio funciona como um osciloscópio analógico, quando usado com ponta de prova capacitiva, ou seja, visualiza e mede sinais AC e DC oscilante, sendo que em caso de DC, mede e visualiza o ripple. A entrada LINE IN sempre é estéreo podendo visualizar dois sinais com formas de onda diferentes em cada canal. A entrada MIC geralmente é mono, ou seja, vai aparecer a mesma forma de onda nos dois canais, podendo assim trabalhar com um canal de cada vez. Mede tensão até $600 \mathrm{~V}$ (pico de onda). Também pode ser usado em

\footnotetext{
${ }^{\mathrm{z}}$ Por ex. Frequency Counter 1.01, home.nexgo.de. Acesso 07/11/2008.
} 
Notebooks. Para conexão do sinal analisado, usou-se garras jacaré, tornando mais prático o manuseio. Segue a Figura 3.2 com a tela usada para as medidas com este programa.

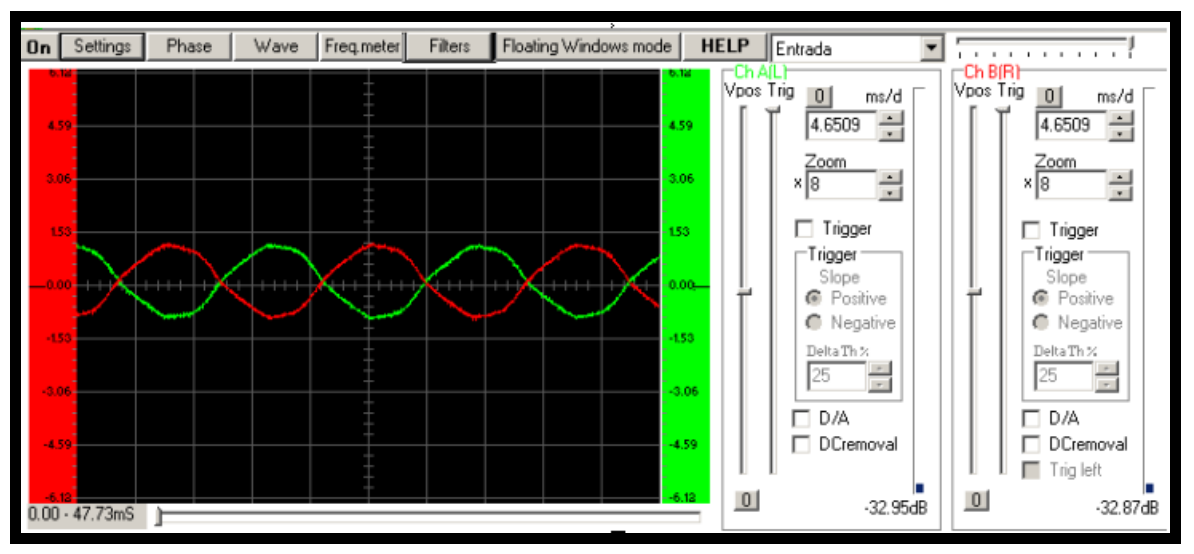

\section{Figura 3.2 - Tela interativa visualizada durante os testes usando o simulador de osciloscópio para computador.}

\subsubsection{Modos de admissão}

Para analisar com o máximo de eficiência qualquer dos dados fornecidos pelas duas técnicas - freqüência versus tempo para QCM, relação massa/carga em função do tempo para espectrômetros de massa - ou os cromatogramas, alguns tópicos têm de ser levados em consideração e estudos anteriores [98] indicaram procedimentos adequados, como descritos a seguir.

A adição de uma substância/partícula em um escoamento pode funcionar tanto como traçador, para compreender os processos físico-químicos, ou como amostra, para testar a funcionalidade da estrutura. A adição pode ocorrer continuamente e por tempo longo, da ordem de segundo ou maior, denominada modo de admissão contínua, ou em uma única injeção, em pequena quantidade e tempo curto, muito menor que segundo, denominada modo de admissão pulsado. O primeiro método permite compreender os fenômenos e o segundo averiguar funcionalidade.

\subsubsection{Modo de admissão pulsada}

O modo pulsado corresponde à admissão de uma quantidade pequena e bem definida, da ordem de mg ou menor, do reagente e em menor tempo possível, da ordem de décimo de 
segundo ou menor. A quantidade mínima de reagente a ser inserida em uma única vez na estrutura é denominada "pulso" e determinada experimentalmente; deve ser a quantidade mínima que o detector é capaz de detectar. A inserção é manual, na maioria das vezes, manual e efetuadas com o uso de seringas.

Para o método pulsado é possível que ocorra a retenção do primeiro pulso do reagente utilizado; assim, torna-se necessária a admissão de vários pulsos do mesmo reagente, para determinar o mínimo exigido para a "saturação" da superfície. O procedimento é: No primeiro pulso é verificado se acontece alguma variação no sinal do detector na saída da estrutura. Caso não ocorra alteração, é feita nova inserção e assim é sucessivamente até que ocorra uma mudança no sinal.

A Figura 3.3 apresenta arranjo típico para medidas em modo de admissão pulsado composto por mini compressor de ar, para criar o escoamento gasoso (usando ar atmosférico como fluido) que carrega o reagente para a estrutura, conexões foram realizadas com o auxílio de tubulação de polipropileno de 1/4" (poliflow ${ }^{\circledR}$ ), detector de fuga de gás combustível (Instrutherm, Modelo DFG-4000). Há uma região específica para a inserção de reagentes através de seringas de 1,00 mL, localizada bem próxima entrada da estrutura. A análise dos fenômenos envolvidos se dá com o auxílio de um detector de gás.

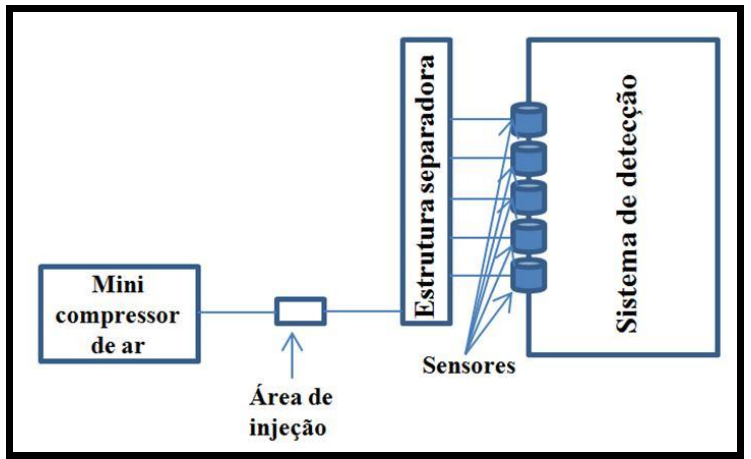

(A)

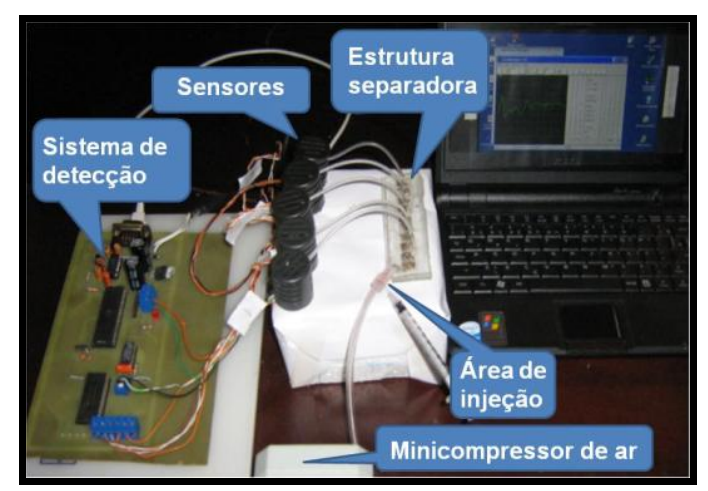

(B)

Figura 3.3 - (A) Esquema e (B) fotografia do aparato utilizado durante os testes no modo de admissão pulsada com aquecimento externo a estrutura.

\subsubsection{Modo de admissão contínua}

Pelo método contínuo é possível, por exemplo, medir a capacidade de uma estrutura em promover a retenção do reagente, pois a admissão de forma contínua determina o tempo para a "saturação" da superfície. Além disso, é possível observar o comportamento de saída 
de uma amostra de grande volume até atingir o equilíbrio, avaliando-se a taxa de mudança em função do tempo.

O arranjo experimental da Figura 3.4 é um exemplo para medidas em modo de admissão contínua e é composto dos mesmos itens citados no modo de admissão pulsado substitui a região específica para a inserção de reagentes por um frasco (dedo frio) para a inserção de vapor de reagente nele inserido. Neste arranjo usam-se de tubulações (poliflow ${ }^{\circledR}$ ) coladas na tampa do frasco e seladas com silicone para que não ocorra vazamento de reagente. $\mathrm{O}$ ar advindo do compressor funciona como gás de arraste do reagente em fluido gasoso e a quantidade inserida é determinada pela sua pressão de vapor. A detecção é feita de modo similar ao modo pulsado.

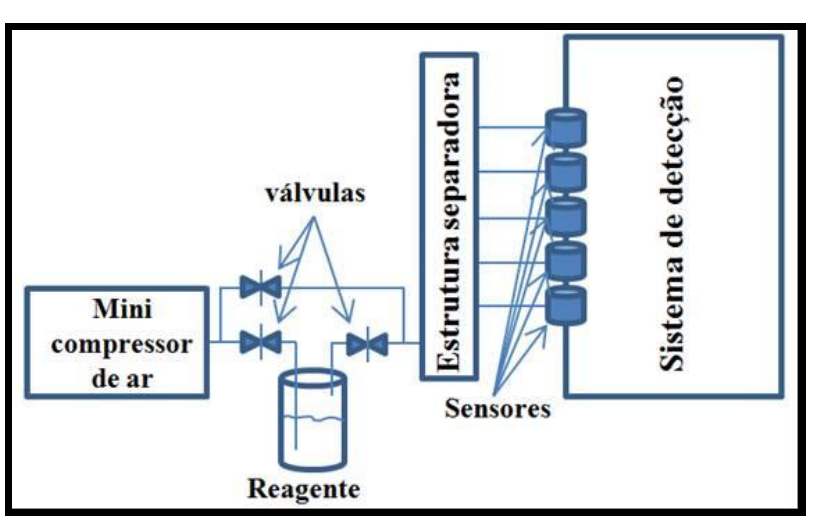

(A)

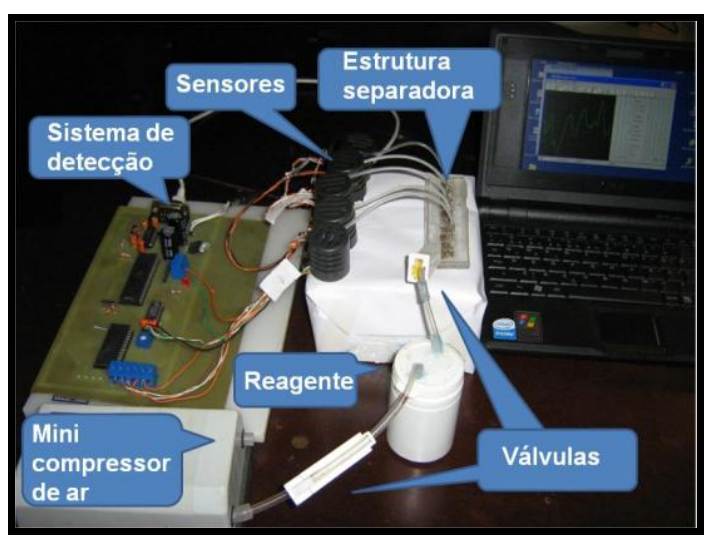

(B)

Figura 3.4 - (A) Esquema e (B) fotografia do aparato utilizado durante os testes no modo de admissão contínua.

\subsubsection{Medidas com aquecimento}

Para avaliar se ocorre alguma alteração significativa no comportamento dos reagentes dentro da estrutura por variação de temperatura, fez-se o aquecimento do reagente de forma externa ou interna. $\mathrm{O}$ aquecimento externo corresponde ao aquecimento da estrutura enquanto o aquecimento interno ao do reagente a ser inserido. Os controles das temperaturas foram feitos com o auxílio de um termômetro analógico (Toptherm, L-056/07) alocado diretamente na estrutura. Para garantir que a temperatura não variará por longo tempo após atingir-se o equilíbrio térmico, as medidas utilizaram estrutura usinada em vidro, não em acrílico. 
Para o aquecimento externo, a Tabela 3.1 apresenta, para a estrutura apresentada na Figura 3.4, as faixas de aquecimento utilizadas.

Tabela 3.1 - Dados de variação de temperaturas de cada cela de saída obtidos durante cinco testes consecutivos para a estrutura da Figura 3.4.

\begin{tabular}{|c|c|c|c|c|c|}
\hline & \multicolumn{5}{|c|}{ Testes } \\
\hline Celas $\downarrow$ & $\mathbf{1}$ & $\mathbf{2}$ & $\mathbf{3}$ & $\mathbf{4}$ & $\mathbf{5}$ \\
\hline $\mathbf{1}$ & $87-92$ & $88-90$ & $82-95$ & $87-93$ & $88-91$ \\
\hline $\mathbf{2}$ & $73-65$ & $72-66$ & $78-59$ & $74-61$ & $72-62$ \\
\hline $\mathbf{3}$ & $56-45$ & $52-43$ & $55-42$ & $59-45$ & $58-43$ \\
\hline $\mathbf{4}$ & $39-41$ & $38-42$ & $37-41$ & $35-39$ & $31-39$ \\
\hline $\mathbf{5}$ & $22-25$ & $21-26$ & $22-29$ & $21-23$ & $20-27$ \\
\hline \multicolumn{6}{|c|}{ Temperaturas $\left({ }^{\circ} \mathbf{C}\right) \uparrow$} \\
\hline
\end{tabular}

$\mathrm{O}$ aquecimento utiliza um processo de banho-maria. Assim, usado-se uma estrutura com o mesmo comprimento e largura da estrutura sob teste - que no presente caso é uma estrutura separadora, porém, com profundidade de $20 \mathrm{~mm}$ e com divisões formando regiões capazes de conter água e propiciar aquecimento em temperatura distinta. Para aquecer a água usa-se um bico de Bunsen aquecendo um béquer com água e com o auxílio de um conta-gotas faz-se a alteração da temperatura da água nas regiões descritas anteriormente. Esse recipiente é isolado do ambiente por isopor, o que garante que a temperatura não varia significativamente durante os testes. Para cada cela da estrutura a temperatura é controlada para uma faixa de aquecimento como indicado na tabela anterior. Estas temperaturas são controladas a cada medida, que ocorre em tempo máximo de 5 minutos, e o controle é feito com o uso de um termômetro em cada cela. $\mathrm{O}$ aquecimento ocorreu em cinco zonas, a partir da entrada: $90^{\circ} \mathrm{C}, 70^{\circ} \mathrm{C}, 50^{\circ} \mathrm{C}, 30^{\circ} \mathrm{C}$ e temperatura ambiente $20^{\circ} \mathrm{C}$, porque estas são faixas comuns para vaporização de VOCs. Observe-se que nas medidas, devido ao pequeno tempo de trânsito do fluido na estrutura, as regiões não precisam necessariamente entrar em equilíbrio termodinâmico com o reagente. $\mathrm{O}$ objetivo do aquecimento, portanto, é gerar alterações no comportamento do reagente dentro da estrutura.

No aquecimento interno, insere-se o reagente aquecido (aproximadamente $80^{\circ} \mathrm{C}$ ) dentro da estrutura. Isso é conseguido aquecendo-se a tubulação de admissão do reagente, que deve ser metálica, previamente à inserção de reagente, e mantendo a amostra dentro dessa estrutura por longo tempo, da ordem de minutos. A faixa de temperatura escolhida para os testes levou em consideração a temperatura de ebulição dos compostos orgânicos voláteis 
mais comuns. O aquecimento é feito com o auxílio de um bico de Bunsen sob a tubulação que será aquecida, o controle da temperatura é feito por um termômetro colocado na extremidade da tubulação que será aquecida.

Para o protótipo, a estrutura é usinada em aço inoxidável, utilizou-se resistência elétrica de $75 \mathrm{~W}$ que gera um gradiente de aquecimento ao longo da estrutura similar ao conseguido durante os testes usando a água como aquecedor, e a temperatura neste caso é controlada com o uso de controlador Contemp (CTW 45, Brasil) colocado nas extremidades da estrutura. Este modo de aquecimento é o mais eficaz para controle do aquecimento quando o modo de operação já está determinado.

No modo de admissão contínua com aquecimento, o procedimento é semelhante aos testes anteriores, sendo necessária apenas a adição do recipiente que comporta o "banho Maria" de aquecimento. Para testes em tempos longos, o aquecimento por bico de Bunsen deve ser utilizado. A Figura 3.5 (A) apresenta o esquema do aparato usado e (B) a fotografia onde se observa o isopor contendo a estrutura onde é colocada a água aquecida sob a estrutura em teste.

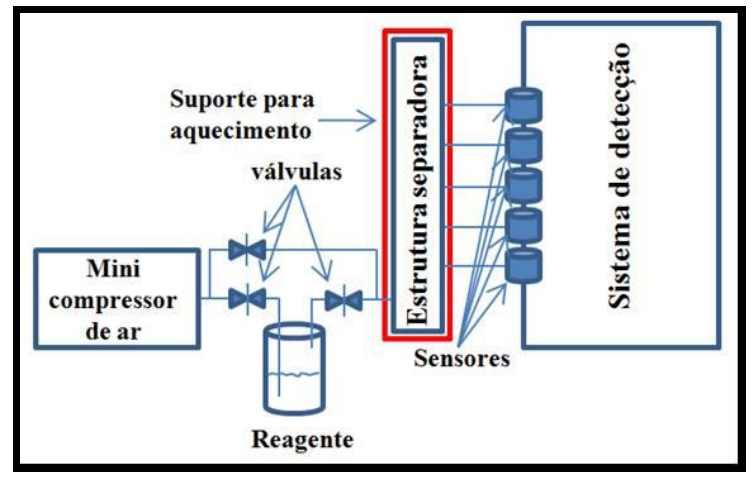

(A)

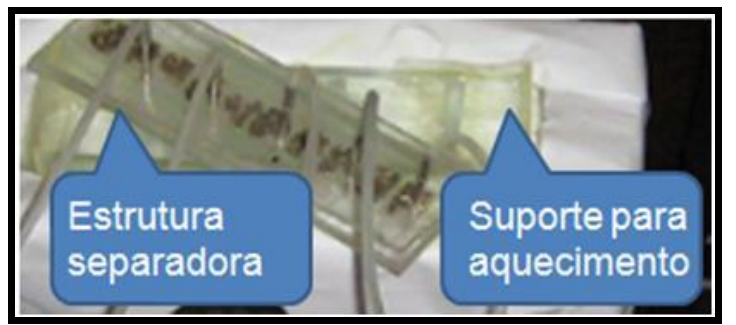

(B)

\section{Figura 3.5 - (A) Esquema e (B) detalhe da parte referente a forma de aquecimento externo a estrutura do aparato utilizado durante os testes no modo de admissão contínua com aquecimento.}

Para o modo do admissão pulsada com aquecimento também se pode usar o "banhomaria”, de modo semelhante ao proposto para aquecimento contínuo. Contudo, utilizou-se principalmente o aquecimento apenas do reagente antes de inseri-lo na estrutura, pois o tempo de residência do reagente nesta é baixo, A Figura 3.5 (A) apresenta o esquema do aparato usado e (B) a respectiva fotografia. 


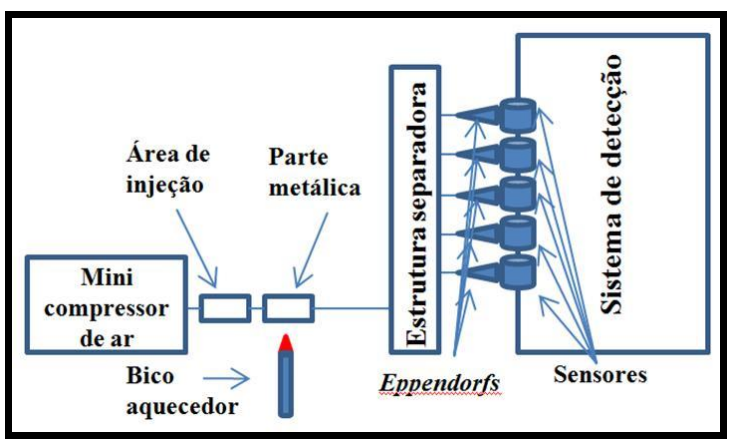

(A)

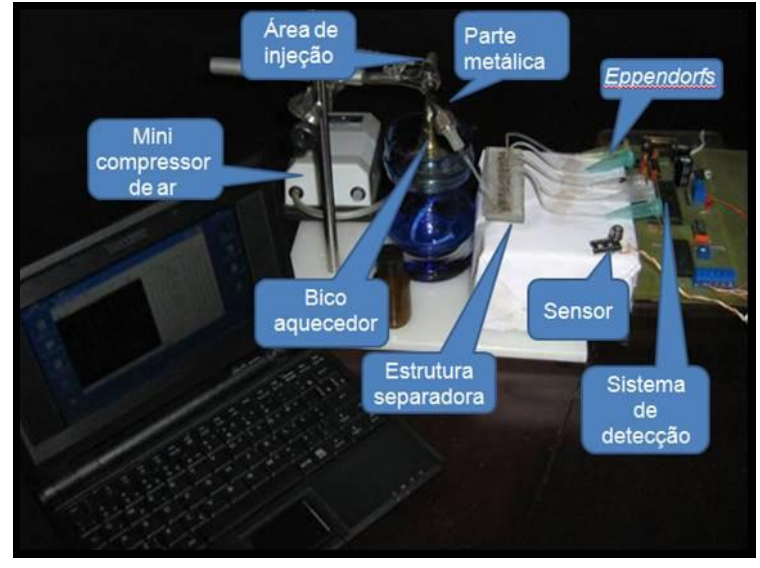

(B)

Figura 3.6 - (A) Esquema e (B) fotografia do aparato utilizado durante os testes no modo de admissão pulsada com aquecimento do reagente.

\subsection{COMPORTAMENTO DO FLUIDO}

O procedimento de teste para entender o comportamento dos fluidos dentro da estrutura foi otimizado a partir de estudos de Santos [70] e Beraldo [99] e é descrito brevemente a seguir:

\subsubsection{Retenção de partículas}

Para caracterização destas estruturas utilizou-se como fluido ar (fase gasosa) ou água (fase líquida). Para interagir com o fluido de arraste utilizaram-se partículas com dimensões da ordem de $50 \mu \mathrm{m}$ (cerâmica SG-85, da Fillite Co. Fornecida no Brasil pela Adexim S/C) e $13 \mu \mathrm{m}$ (carbeto de silício, abrasivo comum, granulometria 1000 na série Tyler, Casa Florêncio). Os testes foram feitos com a seguinte metodologia de inserção das partículas nos microcanais:

- a estrutura é inicialmente pesada;

- para inserir as partículas nas estruturas: a) para gás, coloca-se uma pequena quantidade na região próxima da entrada da estrutura, e com o auxílio da bomba dá-se um pulso de ar e observa-se onde na parte interna da estrutura ficam retidas as partículas; b) para líquido, dispersa-se as partículas e as inserem com seringa diretamente no fluido.

- $\quad$ a estrutura é então desmontada e pesada novamente. 
Também pode-se fazer a inserção de partículas abrindo-se a estrutura e as colocando aleatoriamente e utilizando um fluido como reagente para verificar como as partículas irão se dispersar.

Para realização das medidas, foi montado arranjo experimental tanto para inserção por gás quanto para inserção por líquido, esquematizado na Figura 3.6, composto de um mini compressor de ar atmosférico, fluido, estrutura, filmagem e recipiente para recolhimento do fluido líquido. O mini o compressor de ar tem duas saídas: em uma delas passa apenas ar atmosférico e na outra o líquido, que irá passar pelo porta amostra que contém partículas, localizado próximo a estrutura; e para controle do escoamento de ar são usadas válvulas on/off. Portanto, quando liga-se o mini compressor a inserção de líquido/partículas e gás é feita simultaneamente.

\subsubsection{Medidas de vazão}

Para determinar a vazão do fluido gasoso faz-se uso de um "bolhometro", como é comum em testes de vazão para estruturas pequenas além de ser considerado um procedimento padrão para medida de vazão em cromatografia [88]. O teste utiliza-se de uma bureta, que contém uma com solução diluída com detergente, ligada à saída do compressor de ar atmosférico ou da estrutura. Durante o teste usa-se um cronômetro para medir o tempo necessário para a passagem de uma bolha de ar na bureta (vide Figura 3.7). Este sistema é o mais antigo método de medida desenvolvido para a cromatografia e até o momento apresenta valores de medida bastante precisos e é reconhecido em metrologia como método de calibração [93].

As medidas de vazão são feitas tanto sem e com as estruturas. A vantagem do uso deste sistema é a possibilidade de medição da vazão na saída da estrutura, considerando, portanto, sua perda de carga. 


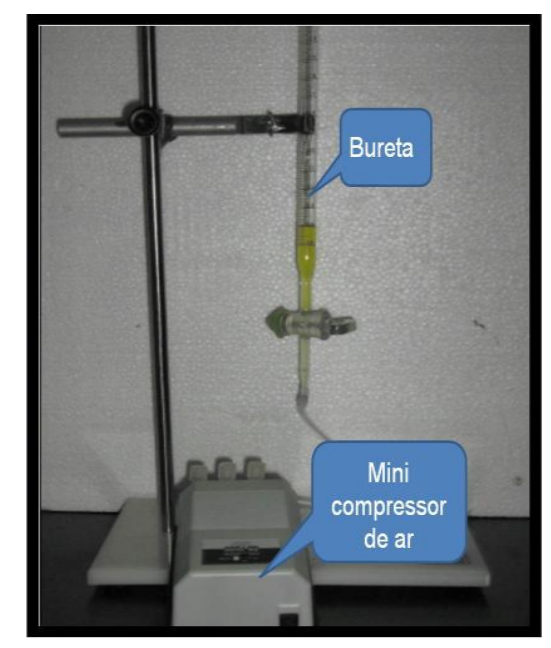

Figura 3.7 - Fotografia do aparato usado como medidor de vazão: "bolhometro".

Utilizando este aparato determinou-se que o compressor de ar (Precision air pump, SR-7500, Aqua One, air output 7500 C.C/min, 210L/h, outlets twin, 240V) usado trabalha com um escoamento da ordem de $0,01 \mathrm{~mL} / \mathrm{min}$, para água e $0,10 \mathrm{~mL} / \mathrm{min}$, para ar atmosférico, na maioria das estruturas. Nas estruturas que foram empacotadas, isto é, colocados os anéis de Raschig $^{a a}$, se fez necessário o uso de um compressor de ar mais potente (Inalar Compact, potência $200 \mathrm{VA}, 127 \mathrm{~V}$ ) com vazão de $10 \mathrm{~L} / \mathrm{min}$ para o ar e $5 \mathrm{~L} / \mathrm{min}$ para água, devido à perda de carga. A Tabela 3.2 sumaria os dados de vazão obtidos na estrutura da Figura 3.3.

Tabela 3.2 - Testes realizados para obtenção de vazão obtidos na estrutura da Figura 3.3.

\begin{tabular}{|c|c|c|c|c|}
\hline \multirow{2}{*}{ Testes } & \multicolumn{4}{|c|}{ Vazão } \\
\cline { 2 - 5 } & Estruturas não empacotadas & \multicolumn{2}{c|}{ Estruturas empacotadas } \\
\cline { 2 - 5 } & Ar atmosférico & Água & Ar atmosférico & Água \\
\hline 1 & 0,10 & 0,01 & 10 & 5 \\
\hline 2 & 0,09 & 0,01 & 9 & 5 \\
\hline 3 & 0,09 & 0,02 & 10 & 4,5 \\
\hline 4 & 0,10 & 0,01 & 10 & 5 \\
\hline 5 & 0,10 & 0,02 & 9 & 4,5 \\
\hline
\end{tabular}

\footnotetext{
aa Anéis de Raschig correspondem a anéis com diâmetro igual ao comprimento ( $1 \mathrm{~mm}$ de comprimento e $1 \mathrm{~mm}$ diâmetro no presente caso).
} 
Para estruturas com múltiplas saídas, como as da Figura 3.3, realizaram-se medidas de vazão em diferentes situações: saídas desobstruídas, válvulas on/off na saída variando a vazão (estrangulamento - aumento ou redução de vazão), como segue.

Para avaliar a perda de carga sem obstrução nas saídas fizeram-se medidas sem que houvesse válvulas obstruindo as saídas, utilizou-se o mini compressor de ar (vazão de 0,10 $\mathrm{mL} / \mathrm{min}$ para gás). O impacto do uso de válvulas também foi avaliado. Na primeira medida apenas a primeira válvula estava aberta. Para a segunda medida, as duas primeiras válvulas estavam abertas. E assim sucessivamente até que todas as saídas fossem desobstruídas. As válvulas nas saídas reduzem em $50 \%$ da vazão total.

Caso uma ou mais das válvulas estejam fechadas há um aumento da vazão nas outras saídas, mas não se observou uma correlação simples entre a vazão total e o fechamento parcial de cada válvula.

\subsubsection{Filmagens}

Neste trabalho, usaram-se filmagens e traçadores. A utilização do traçador corresponde à injeção de substâncias - cujo comportamento, pelo aspecto hidrodinâmico, assemelha-se ao do fluido sob estudo - ao escoamento [119]. Assim, pode-se avaliar qualitativamente o regime em que o fluido se encontra, a formação de vórtices, retenção de produtos, etc. O comportamento dos traçadores foi avaliado com o auxílio de uma câmera digital Cânon Power A430, com 4 Mega Pixels, sensor de imagem CCD de 1/3 de polegada, lente objetiva com grade angular de 5.4, e telefoto $21.6 \mathrm{~mm}$, zoom digital de 7.9 aproximações quando associado com zoom óptico, visor óptico LCD a cores. Para situações onde a observação de pequenas áreas é vantajosa usou-se microscópio óptico (Quimis, Q719TK-PL). As filmagens apresentam como vantagem a possibilidade de visualização, em tempo real, do comportamento do escoamento do fluido em toda a estrutura e a microscopia analisa uma região específica. Para a fase líquida, a importância da variação de viscosidade do fluido e o comportamento de misturas de reagentes líquidos (amostras) também foi estimada com este método.

O aparato construído para as filmagens usando fluido aquoso é indicado na Figura 3.8. 


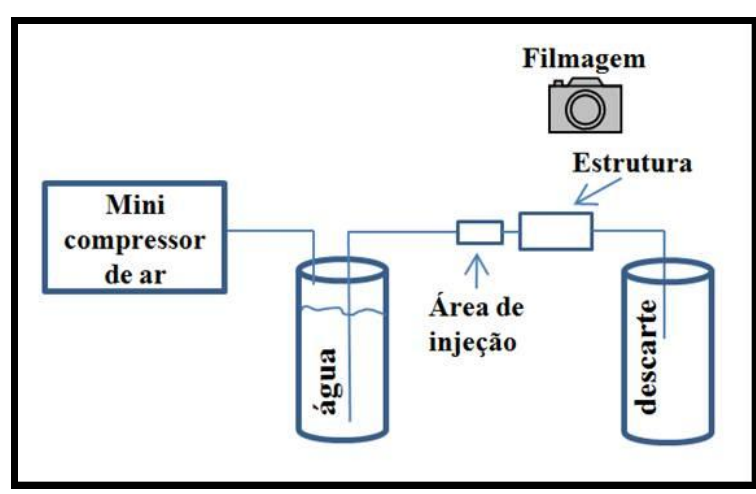

(A)

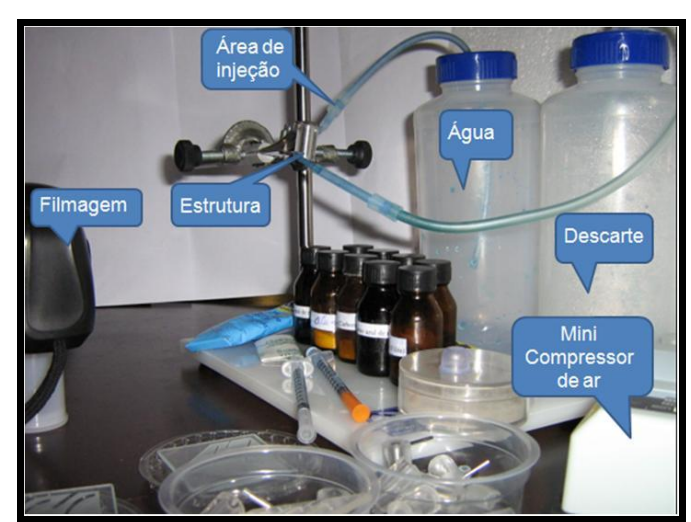

(B)

Figura 3.8 - (A) Esquema e (B) fotografia do aparato utilizado durante as filmagens.

Os procedimentos usados baseiam-se nos já descrito por Beraldo [99] e Santos [70] anteriormente. A inserção de traçador ocorre simplesmente pelo uso de seringas de $1,0 \mathrm{~mL}$ de volume total e inserção bem próxima à entrada da estrutura. A inserção, apesar de manual, pode ser pulsada ou contínua. Admissão pulsada corresponde a uma massa pequena e bem definida do traçador, da ordem de mg ou menor, admitida no menor tempo possível. Admissão contínua ocorre por tempo indeterminado, mas a vazão do traçador deve ser bem menor que a do fluido.

Para inserir as partículas nas estruturas sob escoamento gasoso, coloca-se uma pequena quantidade na região de entrada da estrutura e inicia-se a admissão do ar. Para o fluido líquido produz-se uma dispersão e adiciona-se, on line, com seringa de 5,0 mL.

Além de permitir avaliar o comportamento do fluido nas estruturas, estas medidas, quando comparadas à simulação, que pode ser feita dinamicamente, isto é, em função do tempo, indicam quais os principais fenômenos que estão ocorrendo devido à viscosidade, solubilidade, dimensões, etc.

\subsection{MATERIAIS}

\subsubsection{Confecção das estruturas miniaturizadas}

Para a construção de protótipos foram investigados outros substratos além de acrílico, usado anteriormente por outros autores, como abordado em aspectos teóricos deste trabalho. No presente caso, utilizou-se também estruturas metálicas e em vidro, esta última, com usinagem por jato de areia enquanto acrílico e aço inoxidável são usinados em torno 
CNC. Aço e vidro são mais adequados para o aquecimento rápido ou o isolamento térmico, respectivamente. Deste modo, consegue-se garantir não só o baixo custo, mas também a rapidez de fabricação. Além disso, vidro e acrílico têm como vantagem a transparência, o que facilita a visualização dos fenômenos internos às estruturas.

As estruturas planares foram seladas usando uma placa de PVC (cloreto de polivinila) com 1,5 mm de espessura, com o auxílio de uma fita dupla face (3M, YR-9767) com $5 \mu \mathrm{m}$ de espessura, a fita apenas é colocada na parte externa da estrutura, preservando a região onde ocorrerá a passagem do fluido. As estruturas tridimensionais foram seladas com cola de silicone, sem que haja interferência da selagem nos microcanais. Para entradas e saídas usou-se tubo de aço inoxidável com 1,2 $\mathrm{mm}$ de diâmetro interno e fixados a uma profundidade de $500 \mu \mathrm{m}$ com o auxílio de clorofórmio. Com estes procedimentos fica fácil abrir a estrutura e verificar o que ficou retido e em qual região usando a microscopia óptica.

\subsubsection{Estruturas}

As estruturas desenhadas, simuladas, construídas e caracterizadas são indicadas a seguir.

\subsubsection{Impactadores}

Impactadores são usados para retenção e seleção de partículas e funcionam pela interrupção do escoamento gasoso por uma placa coletora. Devido à inércia das partículas estas tendem a se alocar na placa, contudo, para fluidos líquidos, devido à pequena distância entre as moléculas, a transferência de momento é grande e as partículas podem ser facilmente arrastadas da placa. Beraldo [99] miniaturizou um impactador, mas este só permitiu a retenção de partículas em meio gasoso. Assim, para suplantar essas dificuldades, várias modificações foram adicionadas ao desenho e a Figura 3.9 apresenta o (A) impactador original, (B) e (C) os novos desenhos propostos dos impactadores. 


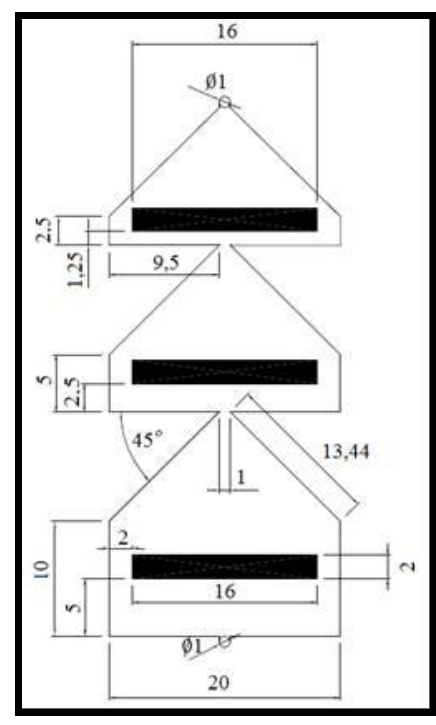

(A)

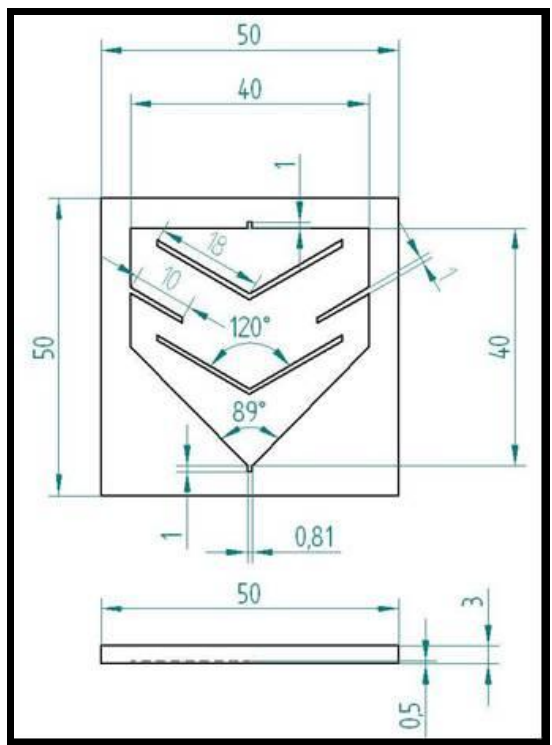

(B)

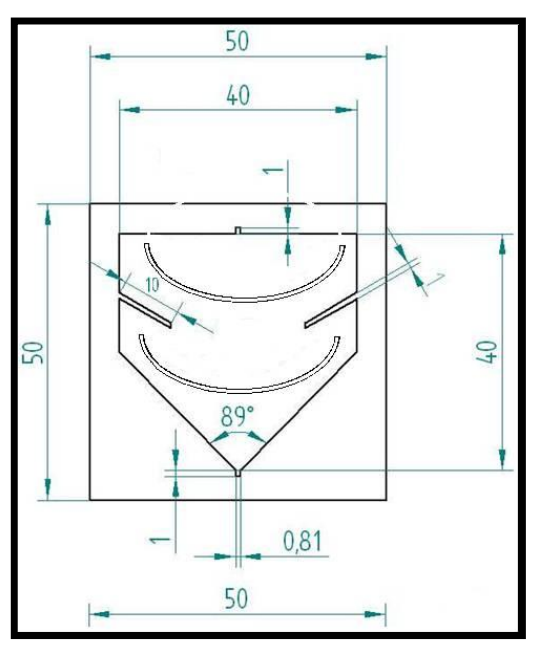

(C)

Figura 3.9 - Desenho (em mm) (A) estrutura proposta por Beraldo [99]; estrutura otimizada por simulação (B) impactadora angular e (C) impactador semi-circular; a largura das estruturas podem variar de dimensões em: 5 mm; 10 mm; 20 mm e 50 mm.

No novo desenho, as placas coletoras do impactador foram modificadas, adicionando-se um ângulo agudo em seu centro, o que permite que a partícula se mova nessa região com baixa velocidade, especialmente se o fluido é água. O impactador original era em cascata, ou seja, reuniformiza-se o escoamento após a placa coletora e adiciona-se nova cela para separação de partículas. Porém, para fase líquida, a adição de constrições severas podem criar vórtice, portanto, como na estrutura original proposta por Beraldo [99], fez-se o uso de anteparos internos a estrutura e em forma de cascata na mesma área de análise. O primeiro anteparo tem o intuito de concentrar, na região central, os reagentes/ partículas inseridos na estrutura; o segundo serve para recolher possíveis sobras de reagentes/ partículas que não ficaram aprisionadas no primeiro. Os dispositivos foram fabricados em diferentes tamanhos, 5 mm; $10 \mathrm{~mm} ; 20 \mathrm{~mm}$ e $50 \mathrm{~mm}$ e foram usinados em acrílico com espessura de $250 \mu \mathrm{m}$.

\subsubsection{Chicanas}

Chicanas, como definidas por Santos [70], funcionam pela variação abrupta da velocidade do escoamento, o que facilita a separação de partículas e, pelo aumento do tempo 
de residência das substâncias dentro do canal, a remoção por reação. Contudo, as dimensões são bastantes críticas para definir que tamanho de partícula será removida. Além disso, a variação de viscosidade de dois fluidos permite velocidades muito distintas, o que pode levar à retenção de um deles. Estas estruturas não foram testadas quanto a seu comportamento por aquecimento. Dessa forma, a idéia da chicana - mudança brusca de velocidade - separando líquidos, foi adaptada em conjunto com a idéia de destilação descrita nos aspectos teóricos, para a montagem de uma nova estrutura.

A estrutura é formada por várias regiões distintas, denominadas de celas, correspondendo a um braço de uma chicana ou a um prato teórico de uma coluna de destilação. Em cada uma dessas regiões, é possível que o regime de escoamento se uniformize antes de deixar a estrutura. Após a primeira saída há duas outras possibilidades de remoção do fluído: para a próxima cela ou para fora da estrutura. Como a saída da estrutura apresenta uma região isolada, onde a velocidade do fluido pode diminuir consideravelmente, é possível que ocorra retenção e/ou seleção de partículas.

Para aumentar a interação dos fluidos entre si e o tempo de residência em cada cela, fez-se a inserção de minitubos metálicos simulando anéis de Raschig. A partir desta etapa, esta estrutura é considerada como empacotada. Para aumentar a interação com a superfície da cela utilizou-se a deposição por plasma de filme adsorvente a base de HMDS [120]. Tais filmes permitem a adsorção de compostos orgânicos polares e apolares e também apresenta boa aderência e boa cobertura de degrau nos substratos de silício, óxido de silício e acrílico, sem apresentar descolamento por longo tempo ou sob uso com VOCs. Este filme foi depositado tanto na estrutura como nos anéis. Assim, tem-se para a realização dos testes: (a) estrutura considerada como limpa, ou seja, não há nenhum tipo de interferente na superfície, serve para obter dados de base (background); (b) estrutura com anéis (c) apenas com filme depositado sobre a superfície e (d) estrutura e anéis com filme depositado na superfície. Assim, utilizam-se tais estruturas para a separação grosseira, de acordo com a volatilidade dos reagentes inseridos de misturas. A adsorção e existência de recheio fazem com que a estrutura também se assemelhe a uma coluna empacotada. Contudo, o desenho planar, é mais similar à cromatografia por camada delgada.

A Figura 3.10 apresenta a (A) chicana descrita anteriormente, (B) o desenho da nova estrutura, (C) apresenta o detalhe da última cela de saída da estrutura, (D) estrutura não empacotada e (E) estrutura empacotada. Estas estruturas são formadas por seis celas, 1 entrada e 5 saídas para o fluído, são usinadas em vidro, com $80 \mathrm{~mm}$ de comprimento e $10 \mathrm{~mm}$ de espessura, com jato de areia controlado para profundidade de aproximadamente $500 \mu \mathrm{m}$. 
Foram inseridos anéis de Raschig com dimensões de $1 \mathrm{~mm}$ de comprimento e $1 \mathrm{~mm}$ de diâmetro e espessura desprezível.

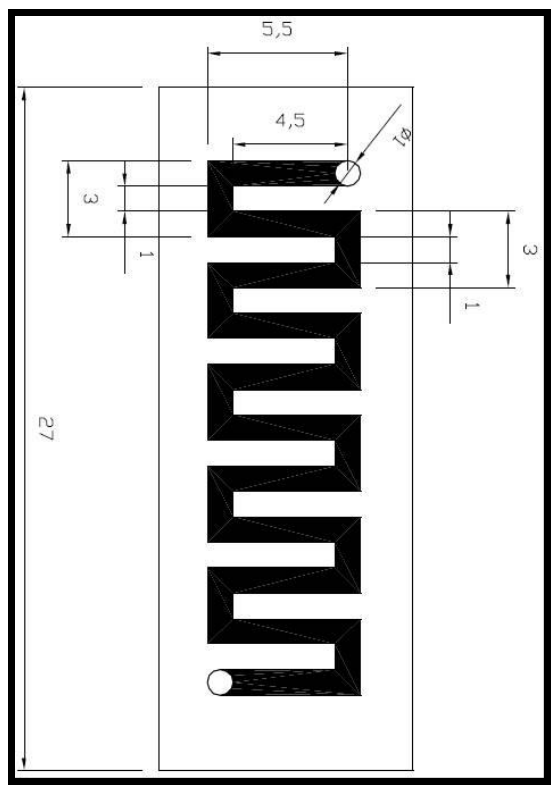

(A)

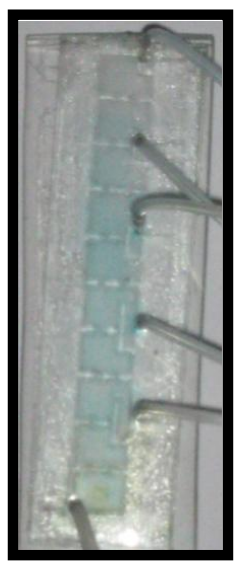

(D)

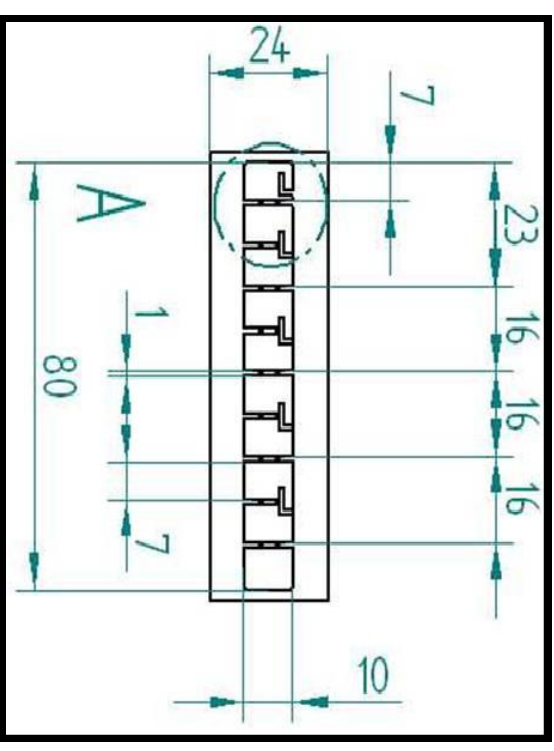

(B)

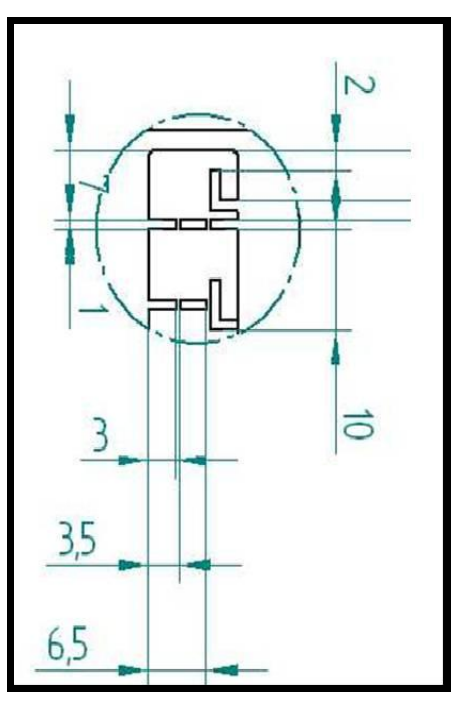

(C)

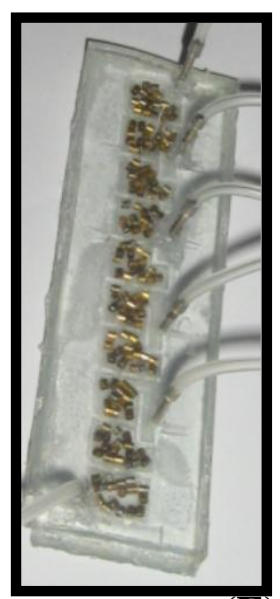

$(\mathbf{E})$

Figura 3.10 - Desenho da (A) chicana original [70]; (B) novo desenho proposto; (C) detalhe da última cela; além de fotos da estrutura (D) sem ou (E) com recheio.

\subsubsection{Microcanais tridimensionais}

É possível a obtenção de spray pelo uso de dois ou mais microcanais em escoamento cruzado. Microcanais tridimensionais foram usados como colunas cromatográficas (Figura 3.11A) e microcanais planares para pré-concentração (Figura 3.11B), respectivamente [55][103]. Assim, esses canais foram modificados para a produção do spray. 
Carvalho [100] modificou os microcanais tridimensionais para uso como microreatores para catálise (Figura 3.11C). Pela modificação inserida o microcanal apresenta várias regiões paralelas e contíguas, assim, o conceito é similar ao da chicana descrita anteriormente e tais canais foram igualmente testados para avaliar possível separação de compostos. 

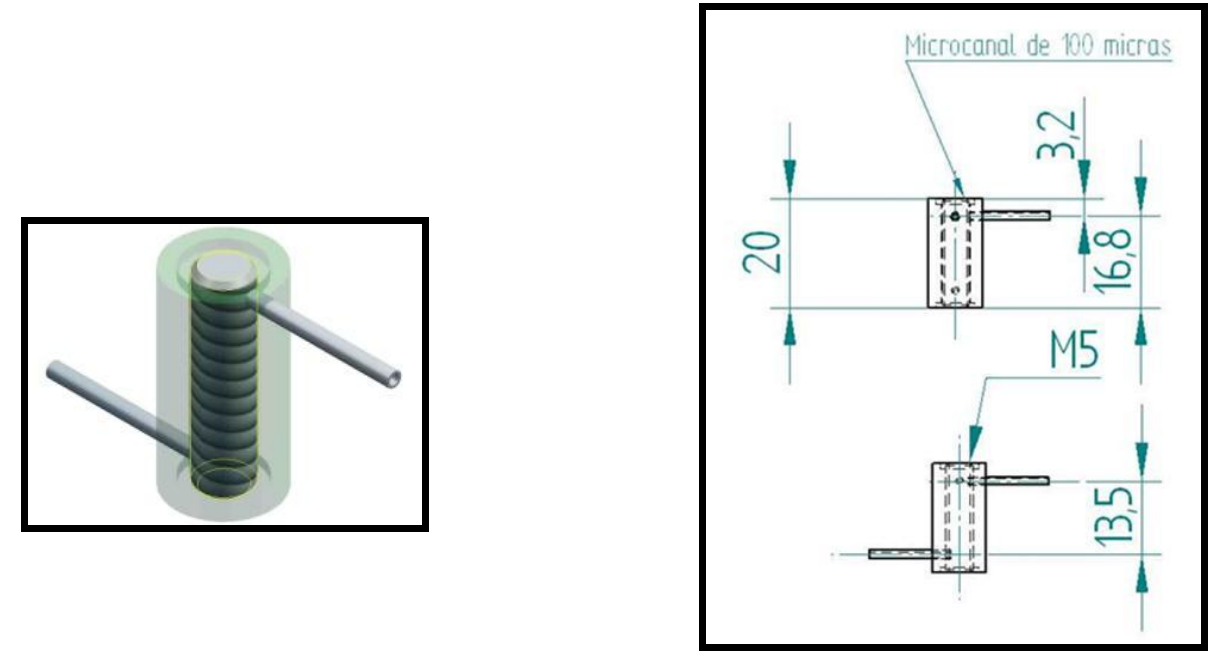

(A)
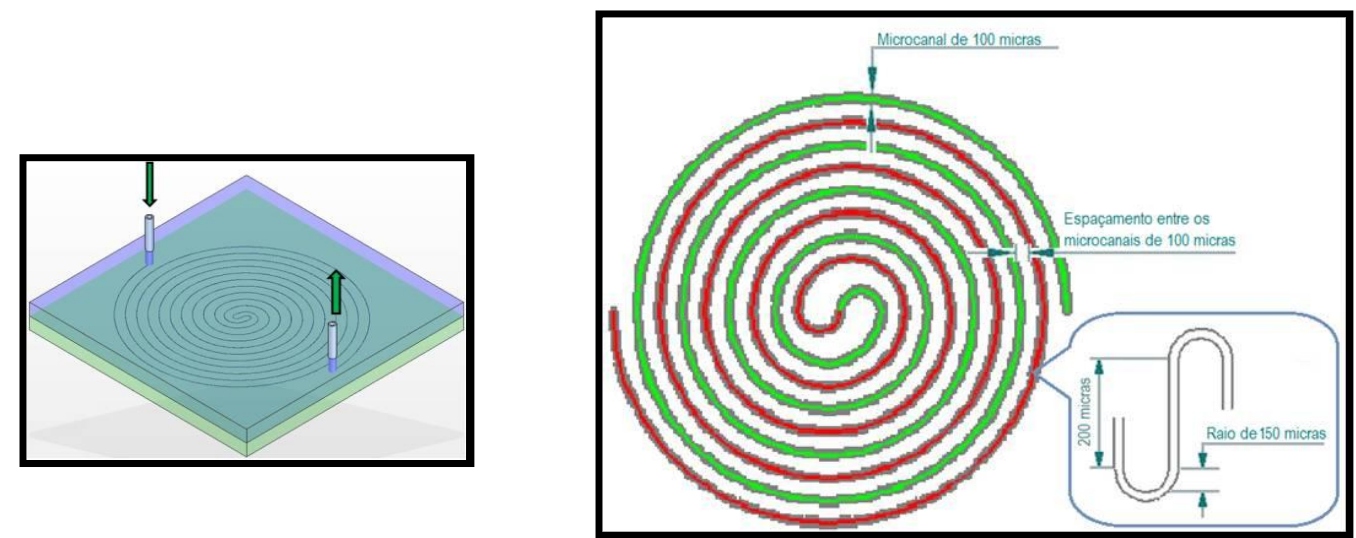

(B)
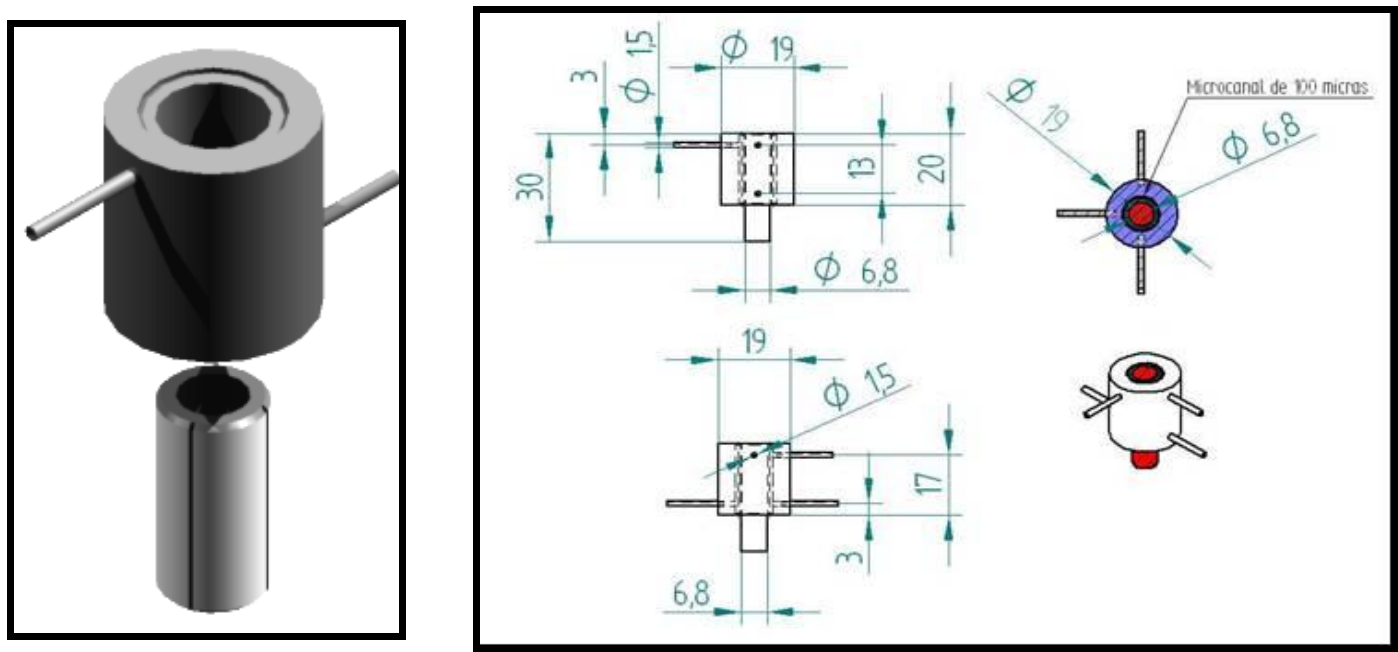

(C)

Figura 3.11 - Microcanais: (A) tridimensionais para colunas cromatográficas [103], (B) planares para pré-concentração [55] e (C) tridimensionais modificados para catálise [100]. 
Testou-se a obtenção de spray tanto em estrutura planar quanto em estrutura tridimensional e usando um aparato apresentado nas Figuras 3.12 e 3.13. O spray faz-se necessário para a inserção de amostra (reagente) nas estruturas impactadoras. Quanto menor a quantidade de amostra/reagente utilizado nestas estruturas, melhor seu comportamento. $\mathrm{O}$ volume inserido depende do capilar utilizado e no presente caso corresponde a no máximo 2 $\mathrm{mL}$. Durante os procedimentos de teste, o volume de amostra foi variado para avaliar se a quantidade de amostra/ reagente no capilar gera uma alteração significativa no spray.

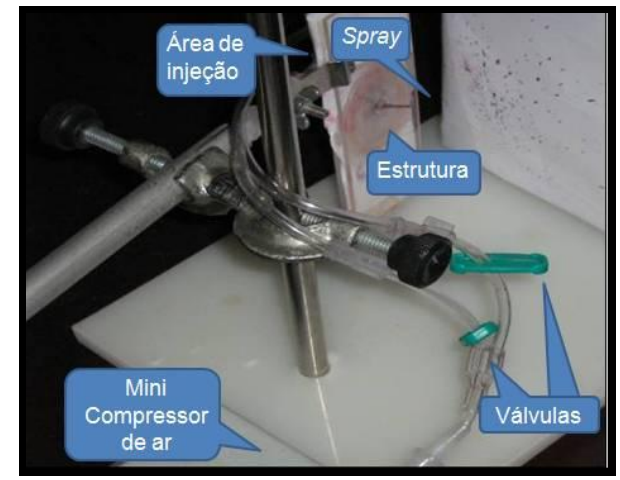

(A)

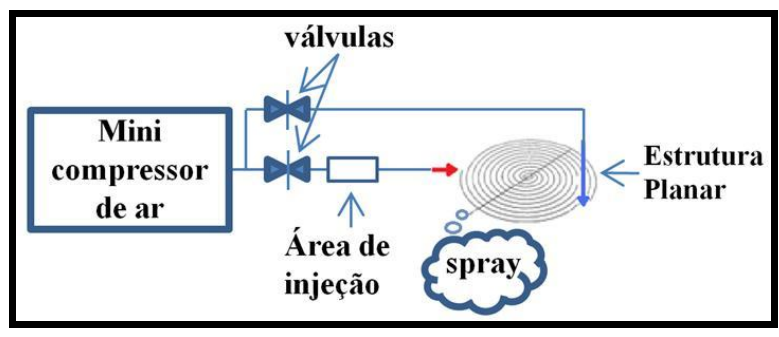

(B)

Figura 3.12 - (A) Aparato usado para obtenção de spray usando a estrutura planar e (B) esquema do aparato usado.

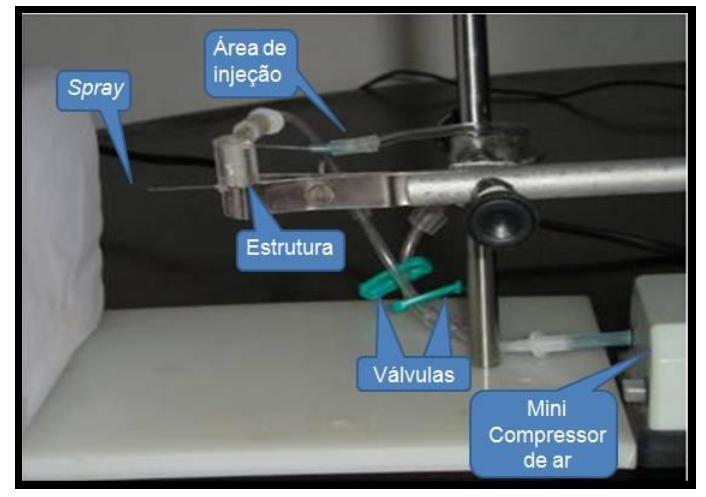

(A)

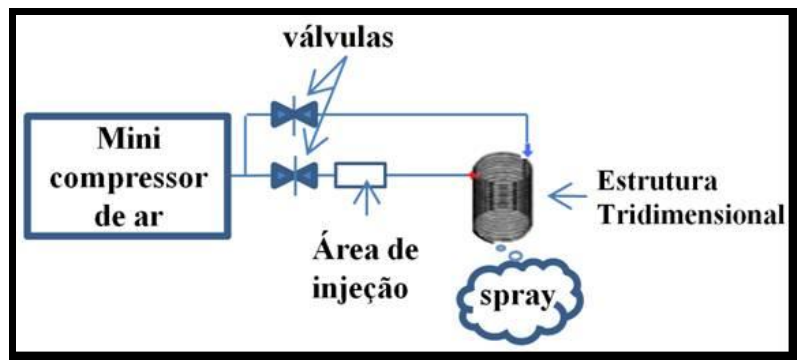

(B)

Figura 3.13 - (A) Aparto usado para obtenção de spray usando a estrutura tridimensional e (B) esquema do aparato. 


\subsubsection{Reagentes}

Todos os traçadores e reagentes utilizados são P.A. (para análise) - para análise - e obtidos na Casa Americana S.A. Água destilada foi utilizada para a montagem das soluções. Neste trabalho, usaram-se como traçadores para a fase líquida solução $10 \%$ em massa de azul de metileno em água destilada ou glicerol (como solvente), o que permite avaliar a importância da variação de viscosidade do fluido. Utilizou-se gravimetria, com balança analítica para a montagem das soluções onde o soluto é sólido; para solutos líquidos, utilizouse a medida de volume.

\subsection{4 - Caracterização dos filmes poliméricos}

A caracterização teve como objetivo a escolha de um filme adsorvente que pudesse sofrer vários ciclos de aquecimento, além de exposição a ácidos e bases. O procedimento é semelhante ao utilizado para caracterizar substratos vítreos (Laboratório de Vidros e Datação, Fatec/SP). Nessas medidas, os dados obtidos devem ser avaliados apenas qualitativamente e foram usados apenas para acompanhar a variação do comportamento do filme em cada ciclo. A espessura do filme é de aproximadamente 100 nanômetros para todas as amostras, depositadas em amostras quadradas de silício com $2 \mathrm{~cm}^{2}$. Nestes testes o silício foi usado como substrato, devido à sua planicidade, o filme fino atua como material dielétrico e os elétrodos (diâmetro mínimo de $20 \mathrm{~mm}$, ou seja, atinge uma ampla área do filme) são colocados nas camadas externas durante a medição (Figura 3.14). A caracterização se dá através da medição da capacitância em função da tensão em alta freqüência (1 MHz) e a DC BIAS ajustável, e os valores variaram, geralmente, de 0 à $30 \mathrm{~V}$. Para realização das medidas usou-se um analisador da impedância (Agilent 4294, EUA) e os resultados usados neste trabalho, são a média de três medidas consecutivas. Avaliou-se a mudança de comportamento pela exposição a compostos orgânicos de filmes recém depositados ou submetidos a ácidos, bases ou aquecimento. Assim, as medidas usaram 2-propanol e n-hexano como os reagentes e o procedimento constitui na exposição do filme ao fluido de ar atmosférico saturado com o reagente $(5 \mathrm{sccm})$ e a temperatura ambiente, durante $10 \mathrm{~s}$. A remoção do reagente ocorreu devido à exposição ao ar atmosférico nas mesmas condições usadas anteriormente. Tempos de exposição foram longos, de aproximadamente 1 minuto, foram usados com o intuito de avaliar a saturação da superfície. 


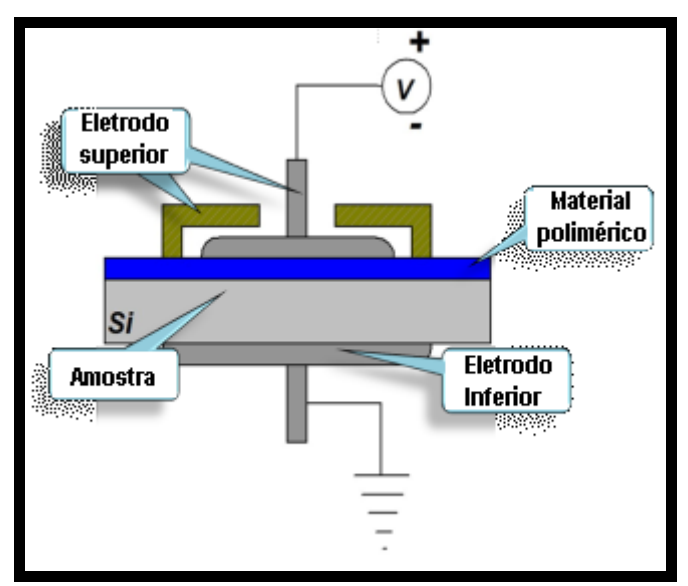

(A)

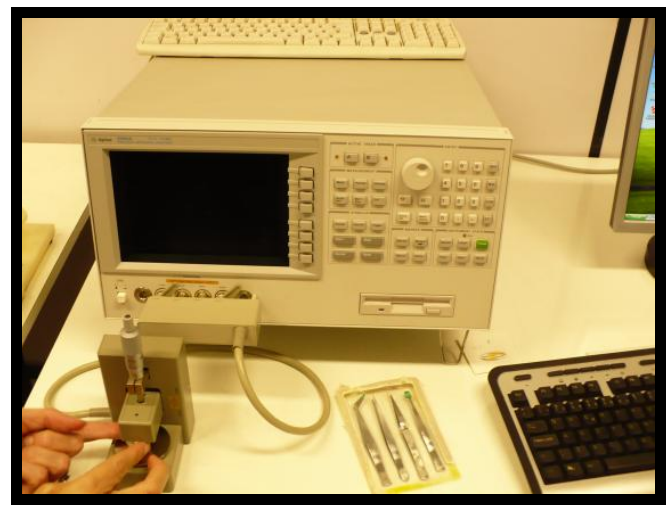

(B)

Figura 3.14 - (A) Diagramas esquemáticos do arranjo experimental e (B) fotografia do equipamento usado para medidas elétricas.

Os filmes foram depositados em substratos de silício, tipo $\mathrm{p}$, com orientação cristalográfica 100, $10^{-20} \Omega . c m$, (Silicon Sence, Inc., EUA) usando HMDS (Fluka Chemie GmbH, Switzerland) e 2, 3-dihidrodecafluoropentano (Vertrel®, Clarus Technology do Brazil, Ltda) ou metil- nonafluoro(iso)butil eter (HFE®, 3M, EUA), todos em grau industrial.

O plasma produzido é em corrente contínua (DC) e foi obtido em equipamento desenvolvido para a produção de filmes adsorventes [121]. A Figura 3.15 mostra o diagrama esquemático da câmara de plasma, que possui dois sistemas de injeção e três eletrodos (detalhe, Figura 3.15). Os dois sistemas de injeção são completamente independentes e podem ser alimentados; assim o sistema de injeção principal é o anodo e o sistema de injeção auxiliar o eletrodo auxiliar. Este eletrodo auxiliar é usado para inserir não apenas reagentes, mas também partículas dentro da região de plasma. Embora o eletrodo auxiliar pudesse ser alimentado, foi mantido em potencial flutuante durante as deposições, pois esta é a condição de melhor deposição dos filmes [121] e a amostra foi mantida no catodo. A integridade do plasma próxima ao substrato é conseguida usando dois ímãs permanentes com $300 \mathrm{G}$ na região de plasma. 


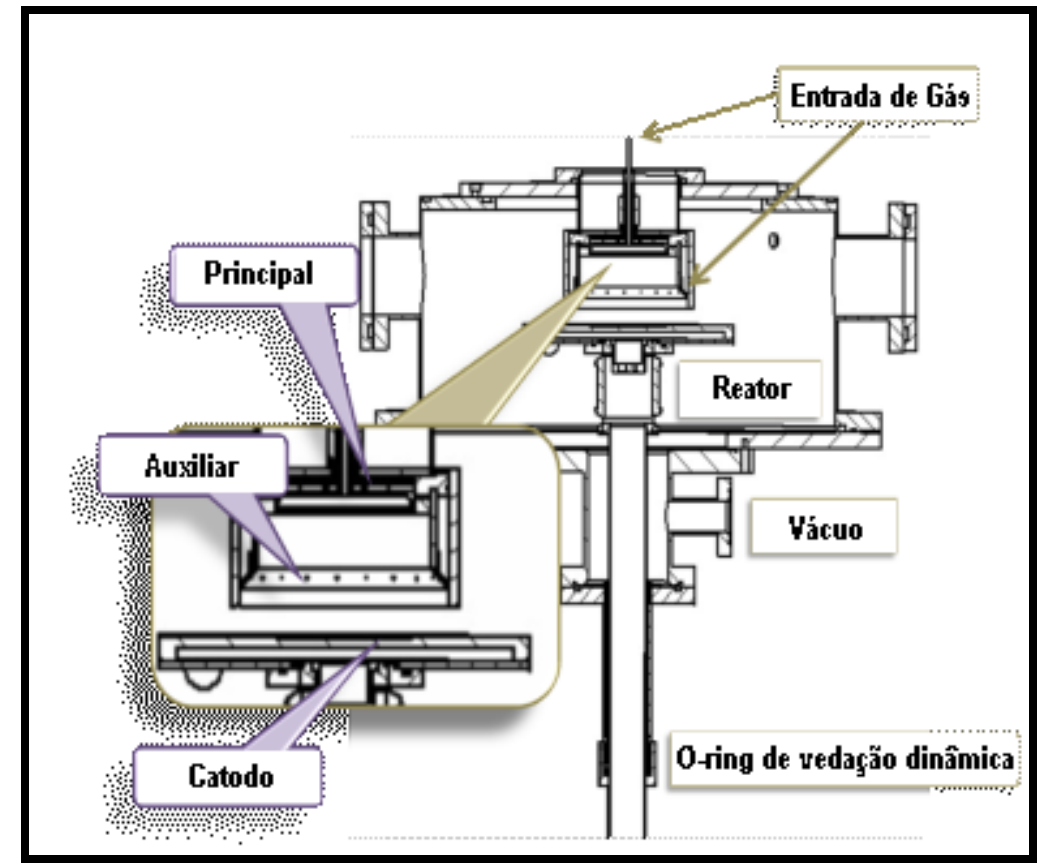

Figura 3.15 - Diagrama esquemático da câmara de plasma [121].

Neste trabalho, foram produzidos e testados filmes em dupla camada e compósitos. O filme de compósito corresponde a uma mistura de dois ou mais filmes descontínuos, em que a dimensão do grânulo pôde variar em uma escala nanométrica à milimétrica, Os filmes depositados por plasma foram caracterizados usando espectroscopia por infravermelho (FTIR, BioRad, EUA) e microscopia eletrônica de varredura (MEV, NovaNanoSEM 400, FEI, EUA) para determinar a estrutura química e as não uniformidades, respectivamente. 


\section{CAPÍTULO 4 - RESULTADOS E DISCUSSÃO}

Esse trabalho, tem como objetivo geral a utilização de um conjunto de estruturas para a separação preliminar (grosseira) de amostras complexas. Assim, neste capítulo descrevemse os testes efetuados para escolha/otimização de estruturas que cumprissem pelo menos uma de cada etapa descrita no capítulo 3 (materiais e métodos).

De modo geral, os resultados obtidos são divididos pelo fluido utilizado, meio gasoso ou aquoso, pelo modo de admissão, contínua ou pulsada, pelo tipo de reagente, polar ou apolar, pelo aquecimento ou não, da estrutura ou do reagente, pelo tempo de resposta da detecção. Todos os testes foram repetidos pelo menos 5 vezes para avaliar se o comportamento é reprodutivo, e cada conjunto de 5 medidas comparados com pelo menos outros dois obtidos em dias diferentes. Observe-se que para cada modo de admissão, comparam-se todas as estruturas utilizadas, o que permite sugerir um modo de utilização em conjunto de todas as estruturas. Algumas estruturas foram preparadas com filme fino apolar a base de HMDS e/ou foram modificadas pelo uso de anéis de Raschig. Todos os testes executados utilizaram sensores de baixo custo; inicialmente utilizou-se o equipamento da Instrutherm Ltda., anteriormente descrito, e respectivo acoplamento ao computador através de placas de som (no máximo cinco equipamentos acoplados simultaneamente), mas os testes finais ocorreram com o protótipo de placa desenvolvida especificamente para esse fim.

\subsection{INFORMAÇÕES INICIAIS}

Devido à perda de carga que ocorre nas estruturas, torna-se necessário determinar qual é a vazão ao final destas, uma vez que tais estruturas são usadas em diferentes situações, tais como, com o uso de constrições e válvulas. Dois compressores de ar atmosférico foram usados nestas estruturas, de alta e baixa vazão (vazão volumétrica de $10 \mathrm{~mL} / \mathrm{min}$ ou 1 $\mathrm{mL} / \mathrm{min}$, respectivamente), são discriminados ao longo do trabalho. De modo geral, para cada estrutura tem-se a seguinte vazão quando o fluido é ar atmosférico: 
*spray: o longo canal das espirais, tanto a planar quanto a tridimensional, torna a vazão baixa, cerca de $10 \%$ do valor obtido com os compressores quando não há perda de carga. Deste modo, as vazões são da ordem de $0,1 \mathrm{~mL} / \mathrm{min}$ e $1 \mathrm{~mL} / \mathrm{min}$, respectivamente.

*impactadores: para os impactadores a vazão está na mesma ordem de grandeza do compressor utilizado. Tem-se para as dimensões de $50 \mathrm{~mm}$ x $50 \mathrm{~mm}$ a vazão de saída é igual a $0,8 \mathrm{~mL} / \mathrm{min}$ e $9,4 \mathrm{~mL} / \mathrm{min}$ usando os compressores de ar atmosférico de $1 \mathrm{~mL} / \mathrm{min}$ ou de 10 $\mathrm{mL} / \mathrm{min}$, respectivamente. Caso válvulas sejam inseridas na saída dessa estrutura, as vazões de saída tornam-se $0,6 \mathrm{~mL} / \mathrm{min}$ e $8,9 \mathrm{~mL} / \mathrm{min}$.

*chicanas: foram utilizadas de várias formas, o que leva a variação significativa de vazão dependendo do modo de uso. De modo geral, para as chicanas que não receberam recheio, tem-se:

Vazão com saídas desobstruídas: Neste caso, as medidas foram realizadas sem válvulas obstruindo as saídas da estrutura e/ou dos compressores de ar atmosférico. As medidas resultaram em vazão de $0,55 \mathrm{~mL} / \mathrm{min}$ para as duas primeiras celas de saídas e nula para as outras três saídas. Para que o escoamento chegue até a última cela de saída, fez-se necessários vários testes experimentais, realizados com o intuito de igualar a vazão em todas as celas, para isso, alterou-se a usinagem dos diâmetros da saída das celas; os valores determinados foram: $0,5 \mathrm{~mm}$ para a primeira cela, $1 \mathrm{~mm}$ para a segunda cela, $2 \mathrm{~mm}$ para a terceira cela, $4 \mathrm{~mm}$ para a quarta cela e $5 \mathrm{~mm}$ para a quinta cela; assim, todas as celas de saída possuem vazão de $0,55 \mathrm{~mL} / \mathrm{min}$. Quando a chicana teve o controle da vazão alterado pela mudança do diâmetro das saídas, com o auxílio de válvulas, em todas as saídas a vazão foi da ordem de $0,50 \mathrm{~mL} / \mathrm{min}$.

Vazão com válvulas on/off na saída: Se todas as saídas da estrutura apresentam válvulas, tem-se a vazão de aproximadamente $3,3 \mathrm{~mL} / \mathrm{min}$ para as três primeiras saídas e 2,9 para as outras duas saídas, se estas válvulas são abertas seqüencialmente, ou seja, no primeiro teste apenas a primeira válvula estava aberta. Para o segundo teste, as duas primeiras válvulas estavam abertas, e assim sucessivamente, até que todas as saídas fossem desobstruídas. Quando apenas a válvula correspondente à da cela a ser medida é aberta, tem-se a vazão crescente a partir da primeira cela de saída com valores de $3,0 \mathrm{~mL} / \mathrm{min}, 2,5 \mathrm{~mL} / \mathrm{min}, 1,2$ $\mathrm{mL} / \mathrm{min}$, respectivamente para a primeira, segunda e terceira cela e as duas últimas com aproximadamente $0,5 \mathrm{~mL} / \mathrm{min}$.

A adição de anéis de Raschig não diminui significativamente os valores obtidos. Assim, tais valores indicam que não há perda de carga significativa nessa estrutura. 
Para fluidos líquidos, como água, os valores podem variar muito, como informado no decorrer do texto.

\subsubsection{Tratamento de superfície}

O uso de filmes finos adsorventes, facilita a separação dos compostos orgânicos ou mesmo favorece sua retenção [79], portanto, a modificação da superfície da estrutura ou de seu recheio, pode ser útil para facilitar uma separação de compostos.

Filmes a base de organo-silanos e compostos orgânicos fluorados foram testados para modificação superficial da estrutura. Os motivos da escolha são como segue:

*organo-silanos: filmes a base de HMDS, são adsorventes para compostos orgânicos, polares ou apolares. Contudo, a superfície pode inchar pela exposição a tais produtos. Portanto, não há como de antemão, garantir que não haverá modificações no comportamento da estrutura ao longo do tempo devido à deposição do filme [121];

*fluorados: filmes fluorados geralmente são hidrofóbicos e oleofóbicos, possíveis contaminantes a serem encontrados nas amostras a serem avaliadas na estrutura. Filme a base de $\mathrm{HFE}^{\circledR}$, mostrou-se útil tanto na adsorção quanto na proteção de superfícies, mas trata-se de um filme que permite a permeação de compostos, o que pode dificultar o uso em estruturas [121].

Portanto, para a escolha do filme a ser utilizado, tanto filmes a base de HMDS como a base de HFE, testou-se também os compósitos obtidos com a mistura dos dois. Como abordado em Materiais e Métodos, estes filmes tiveram as curvas Capacitância em função da Tensão (CV) avaliadas, porque é um modo rápido e bastante sensível de verificar se o filme sofre modificação pela exposição a reagentes ou por envelhecimento. O filme é exposto momentaneamente (por 1 segundo) ao ar saturado pelo composto orgânico e imediatamente é feita a medição. A medida é repetida a fim avaliar a saturação; caso necessário, o material adsorvido era removido com a passagem de ar durante 1 minuto. A faixa de tensão foi escolhida para que fosse atingida a variação máxima. As curvas correspondem a uma média de três medidas consecutivas.

Os filmes foram caracterizados sobre silício, contudo, tais filmes apresentam boa deposição e aderência também sobre aço inoxidável, vidro e acrílico [101]. 


\subsubsection{Organo-silanos}

Foram depositados filmes a base de HMDS e apenas para comparação, filmes fluorados obtidos a partir de Vertrel®. O fluorado forma um filme muito fino, o que permite a permeação de compostos orgânicos. Assim, a deposição de dupla camada com filme a base de HMDS permite que o reagente inserido na estrutura, rapidamente atinja a interface entre os filmes, mas, devido à adsorção nesta interface, sua saída é dificultada [121].

As condições de deposição dos filmes a base de HMDS e Vertrel® analisados, são apresentadas na Tabela 4.1. Como pode ser visto nesta tabela, devido à facilidade da polimerização por plasma da molécula de HMDS, a deposição deste, exige pouca energia (baixa tensão de deposição) e apresenta uma taxa de deposição elevada quando comparada ao filme fluorado. Por outro lado, compostos fluorados requerem alta energia para a formação dos precursores responsáveis pela produção do filme, o que exige maior tensão na deposição do filme ou de seus compósitos ou dupla camada. A espessura das amostras depositadas é sempre próxima a $100 \mathrm{~nm}$.

Tabela 4.1 - Condições de deposição dos filmes a base de Vertrel® e HMDS na câmara de plasma.

\begin{tabular}{|c|c|c|c|c|c|}
\hline \multirow{2}{*}{ Filmes } & \multicolumn{2}{|c|}{$\begin{array}{c}\text { Sistema de injeção do } \\
\text { reagente }\end{array}$} & \multirow{2}{*}{$\begin{array}{c}\text { Faixa da pressão } \\
\text { de deposição } \\
\text { (mTorr) }\end{array}$} & \multirow{2}{*}{$\begin{array}{c}\text { Faixa de } \\
\text { tensão durante } \\
\text { a deposição } \\
\text { (V) }\end{array}$} & \multirow{2}{*}{$\begin{array}{c}\text { Taxa de } \\
\text { deposição } \\
\text { (Å/min) }\end{array}$} \\
\hline & Auxiliar & Principal & & & \\
\hline HMDS & HMDS & HMDS & $10-200$ & $300-450$ & $30-100$ \\
\hline Fluorado & Fluorado & Fluorado & $10-200$ & $350-600$ & Muito baixa \\
\hline Dupla Camada & Fluorado & HMDS & $10-200$ & $350-600$ & nd \\
\hline Compósito & Fluorado & HMDS & $10-200$ & $350-600$ & nd \\
\hline
\end{tabular}

nd - não determinado porque existe mais de uma camada ou um compósito envolvido.

A análise por FTIR das amostras, indicou a existência de espécies advindas do HMDS e/ou do fluorado junto com as espécies oxigenadas, como relatado previamente [121], e a Tabela 4.2 apresenta as intensidades relativas das bandas obtidas por FTIR. Os filmes finos de HMDS apresentam bandas em $2950 \mathrm{~cm}^{-1}$ (CH estiramento), $1730 \mathrm{~cm}^{-1}$ (espécie oxigenada), $1450 \mathrm{~cm}^{-1}\left(\mathrm{CH}_{2}\right), 1370 \mathrm{~cm}^{-1}\left(\mathrm{CH}_{3}\right), 1260 \mathrm{~cm}^{-1}\left(\mathrm{Si}\left(\mathrm{CH}_{3}\right)_{3}\right), 1180 \mathrm{~cm}^{-1}(\mathrm{Si}-\mathrm{N}), 1070 \mathrm{~cm}^{-1}$ (Si-

O) [121]. As bandas dos filmes fluorados são encontradas em $3300 \mathrm{~cm}^{-1}$ (CF próximo a oxigênio), $2950 \mathrm{~cm}^{-1}$ (C-H estiramento), $1300 \mathrm{~cm}^{-1}-1000 \mathrm{~cm}^{-1}$ (CF estiramento) [121][122][ $123][124][125]$. 
Tabela 4.2 - Intensidades relativas obtidas por FTIR para filmes a base de HMDS e fluorados (Vertrel $\left.{ }^{\circledR}\right)$.

\begin{tabular}{|c|c|c|c|c|c|c|}
\hline \multicolumn{7}{|c|}{ Filme a base de HMDS (\%) } \\
\hline \multirow{2}{*}{$\begin{array}{c}\text { Normalizado } \\
\text { para } \\
1260 \mathrm{~cm}^{-1}\end{array}$} & $2950 \mathrm{~cm}^{-1}$ & $1730 \mathrm{~cm}^{-1}$ & $1450 \mathrm{~cm}^{-1}$ & $1370 \mathrm{~cm}^{-1}$ & $1180 \mathrm{~cm}^{-1}$ & $1070 \mathrm{~cm}^{-1}$ \\
\hline & 0,09 & 90,7 & 36,7 & 21,2 & 60,5 & 48,8 \\
\hline \multicolumn{7}{|c|}{ Filme Fluorados (\%) } \\
\hline \multirow{2}{*}{$\begin{array}{c}\text { Normalizado } \\
\text { para } \\
1068 \mathrm{~cm}^{-1}\end{array}$} & $3300 \mathrm{~cm}^{-1}$ & \multicolumn{2}{|c|}{$2950 \mathrm{~cm}^{-1}$} & $1300 \mathrm{~cm}^{-1}$ & \multicolumn{2}{|c|}{$1260 \mathrm{~cm}^{-1}$} \\
\hline & 87,5 & \multicolumn{2}{|c|}{21,1} & 25,1 & \multicolumn{2}{|c|}{35,5} \\
\hline
\end{tabular}

A deposição de HMDS normalmente é baseada em reação íon/molécula, que requer o bombardeamento para atingir alta taxa de deposição. Conseqüentemente, a variação em parâmetros de deposição conduz principalmente às diferenças na topografia [126]. Por outro lado, os filmes fluorados são obtidos com radicais livres [127], isso significa que a adsorção na superfície do silício é um parâmetro importante na deposição e leva a obtenção de um filme com superfície lisa. Na Tabela 4.3, a principal diferença entre a amostra 1 e as amostras 2, 3 e 4 é a posição destas, onde a amostra 1 foi coloca verticalmente na câmara, ou seja, de modo a não sofrer bombardeamento. Além disso, devido à diferença de tensão, as amostras número 2, 3 e 4 são bombardeadas com intensidades diferentes. Assim, estas amostras foram analisadas por SEM e os resultados típicos são apresentados na Tabela 4.3. 
Tabela 4.3 - Resultados típicos para análise SEM dos filmes finos a base de HMDS e de fluorado (Vertrel®).

\begin{tabular}{|c|c|c|c|c|}
\hline \multicolumn{4}{|c|}{$\begin{array}{ll}\text { Condições das deposições de amostras } \\
\end{array}$} & \multirow{3}{*}{$\begin{array}{l}\text { Resultado das análises SEM/ } \\
\text { Número das amostras }\end{array}$} \\
\hline \multicolumn{2}{|c|}{$\begin{array}{c}\begin{array}{c}\text { Sistema de injeção de } \\
\text { reagente }\end{array} \\
\text {. }\end{array}$} & \multirow{2}{*}{$\begin{array}{c}\text { Pressão de } \\
\text { deposição } \\
\text { (mTorr) }\end{array}$} & \multirow{2}{*}{$\begin{array}{c}\text { Tensão de } \\
\text { deposição } \\
\text { (V) }\end{array}$} & \\
\hline Auxiliar & Principal & & & \\
\hline HMDS & HMDS & 100 & 400 & \\
\hline HMDS & HMDS & 100 & 400 & \\
\hline HMDS & HMDS & 100 & 410 & \\
\hline HMDS & HMDS & 100 & 420 & \\
\hline Fluorado & HMDS & 100 & $\begin{array}{l}\text { 455(HMDS) } \\
\text { 470(Fluorado) }\end{array}$ & \\
\hline HMDS & Fluorado & 100 & 470 & \\
\hline Fluorado & Fluorado & 100 & 440 & \\
\hline & & & & 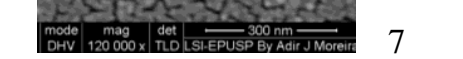 \\
\hline
\end{tabular}

A amostra 1 é lisa e sua aparência é similar à camada fina do ouro depositada sobre ela, ou seja, a deposição dependeu principalmente da adsorção do reagente sobre a superfície. Os aglomerados vistos nas amostras 2, 3 e 4, são característicos da deposição com HMDS e são resultantes da adsorção do reagente simultaneamente ao bombardeio por espécies ativas, o que induz as reações de superfície. Nestas amostras, a variação da tensão influenciou a 
dimensão do aglomerado. Essa variação é reprodutível, já que resultados semelhantes são obtidos com as amostras 3 e 4 .

O filme fluorado (amostra número 7, Tabela 4.3), devido ao mecanismo do depósito baseado principalmente em radicais livres, tem superfície similar à da amostra 1. A dupla camada (amostra número 5) apresenta aglomerados grandes devido à adsorção de espécies ativas, provavelmente radicais livres, à superfície do filme fino a base de HMDS previamente depositado. Todavia, como a amostra não é tão rugosa, como a amostra 2, efeitos de planarização devem ter ocorrido. A amostra do compósito (amostra número 6) apresenta grande desuniformidade em cada um dos aglomerados, que provavelmente são formados ou por filme a base de HMDS ou por filme fluorado. Assim, a comparação entre características das amostras 5 e 6 fornece informações sobre a vantagem de cobrir parcial ou totalmente a superfície do filme a base de HMDS com filme fluorado.

\subsection{Caracterização: reagente apolar}

Os reagentes apolares, como o n-hexano, são facilmente adsorvidos na superfície de filmes a base de HMDS, mas também causam o inchamento deste. Gráfico 4.1 apresenta medidas CV das amostras 1 a 4, como depositadas, expostas ao ar saturado com vapores de nhexano e, em uma tentativa da remoção do reagente, exposição ao ar durante 1 minuto. A escala da tensão mostrada nos gráficos foi escolhida para apresentar o intervalo com variação máxima, e as curvas correspondem à média de três medidas consecutivas; além disso, nenhuma destas amostras mostraram a histerese antes da exposição ao n-hexano.

Todas as amostras antes da exposição ao reagente, apresentaram curvas similares, ou seja, a espessura, não a topografia, é o parâmetro principal a influir na medida. Depois da exposição aos vapores do n-hexano, a curva desloca-se para tensões maiores, provavelmente devido ao comportamento viscoelástico destes filmes, que muda a distância entre os dipólos permanentes, que funcionam como uma carga dentro do filme. Estes dipolos, por exemplo, devido à ligação Si-O, possivelmente são também responsáveis pelas mudanças nas outras duas condições.

Muito embora seja difícil estabelecer uma correlação clara entre variação de dipolos e a formação da camada da adsorção, a impossibilidade das amostras para retornar o sinal aos valores anteriores, mesmo após uma exposição de um minuto ao ar limpo, é um bom indicativo de que houve uma variação irreversível, provavelmente o inchaço do filme em tal caso. Por fim, filmes fluorados não são sensíveis à exposição ao n-hexano. 


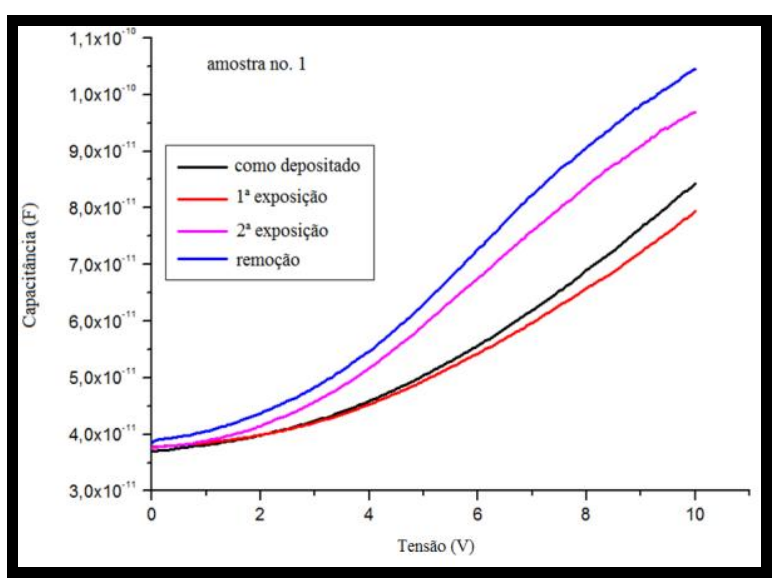

(A)

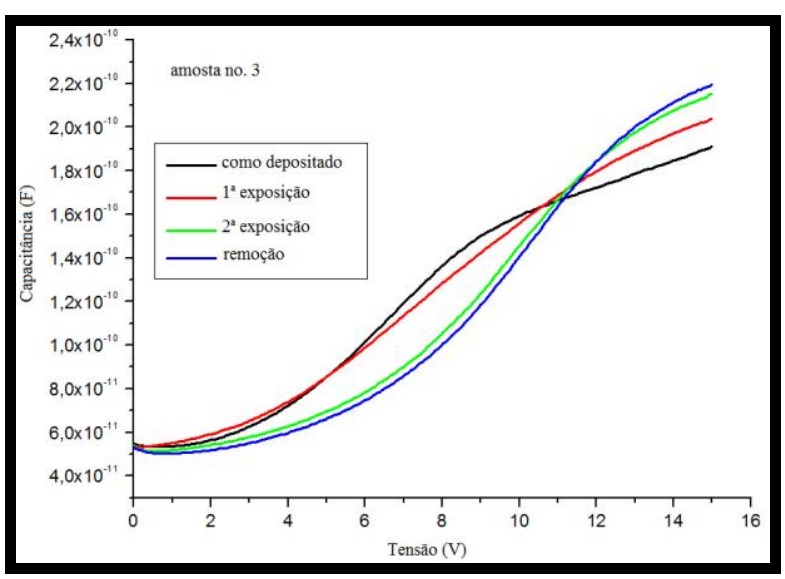

(C)

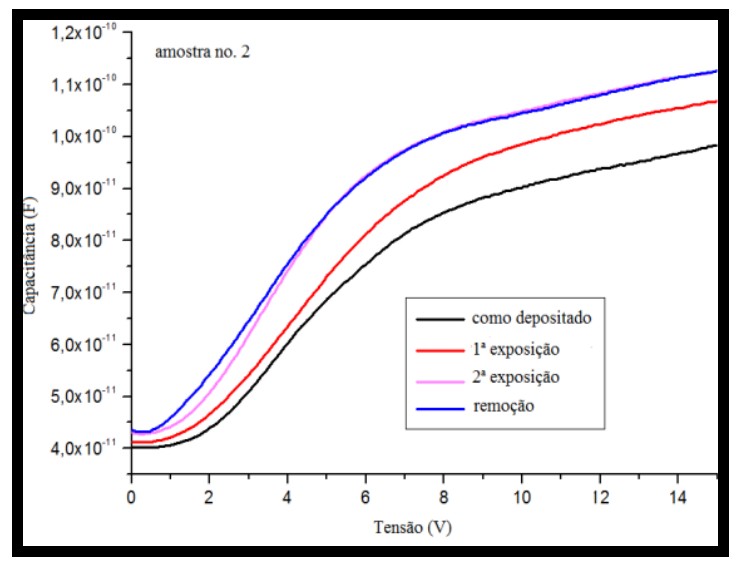

(B)

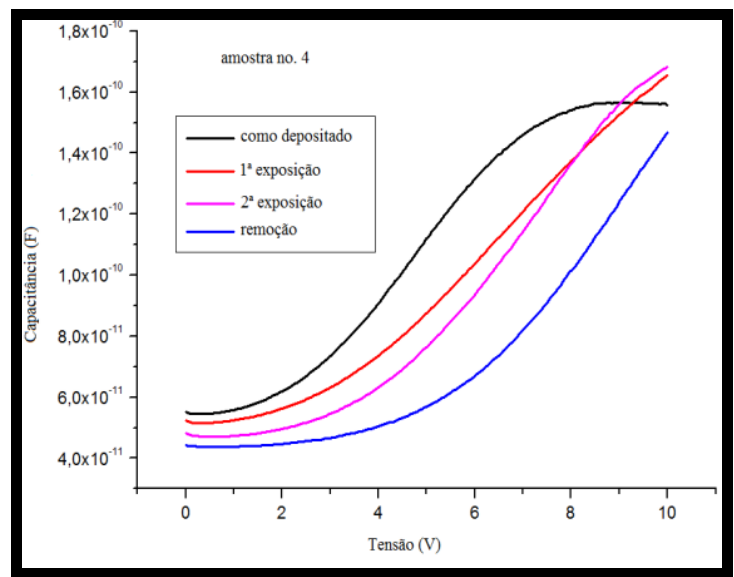

(D)

\section{Gráfico 4.1 - Curvas CV para amostras de 1 à 4 antes e depois da exposição ao vapor de n-hexano.}

\subsection{Caracterização: reagente polar}

Em filmes à base de HMDS (Gráfico 4.2A), o valor máximo muda significativamente devido à exposição ao isopropanol. A recuperação parcial do sinal é obtida facilmente passando apenas ar pela estrutura. Esta condição ocorre provavelmente devido à formação da camada de adsorção, mas diferentemente da exposição ao n-hexano, não há distorção em outras regiões do gráfico corresponde a uma situação reversível do sistema.

O filme fluorado (Gráfico 4.2B) é pouco sensível, apenas uma pequena alteração é obtida no valor máximo após exposição de 1 minuto. Além disso, somente a exposição por mais de 15 minutos gera uma variação similar à obtida com filme a base de HMDS, mas esta mudança é perdida rapidamente com a passagem de ar.

A dupla camada (Gráfico 4.2C) mostra uma mudança permanente na curva, provavelmente devido à retenção do reagente na interface; filme fluorado e filme a base de 
HMDS. Esta resposta é possível porque o isopropanol pode permear através do filme fluorado [121][128], mas isto também dificulta a remoção do reagente apenas pela exposição ao ar e o sinal não muda após a exposição de vários minutos ao ar puro.

O compósito (Gráfico 4.2D) apresenta comportamento similar às amostras de filme a base de HMDS, devido à quantidade elevada de HMDS na superfície. Todavia, a recuperação parcial do sinal indica que, provavelmente, o inchaço do filme é limitado pela presença de aglomerados fluorados na superfície.

O filme a base de HMDS foi exposto seqüencialmente ao isopropanol e depois ao nhexano e novamente medido. Este filme apresentou comportamento reversível nesses ciclos. Portanto, seu uso na superfície da estrutura pode ser útil, o compósito e a dupla camada, por outro lado, não apresentam resultados reprodutíveis ao longo dos ciclos e, por isso, não foram considerados promissores.

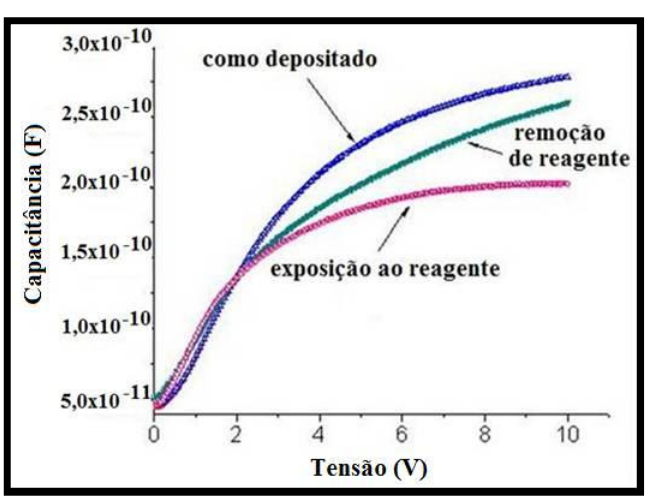

(A)

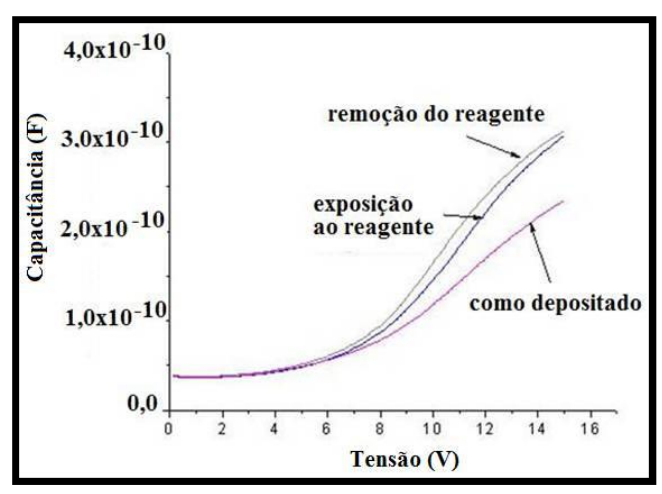

(C)

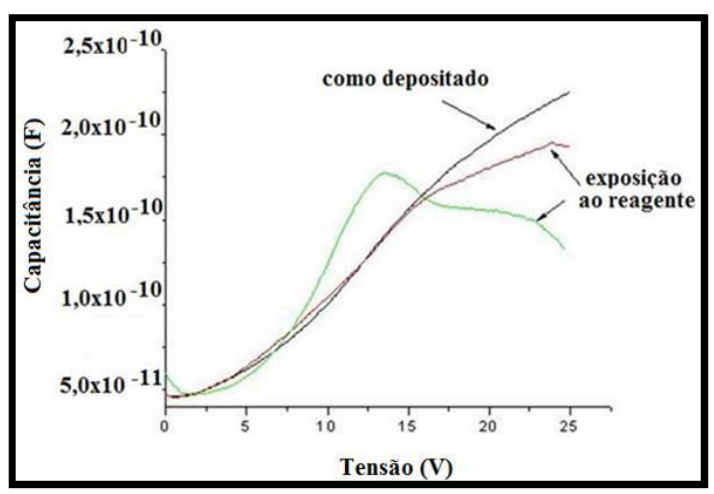

(B)

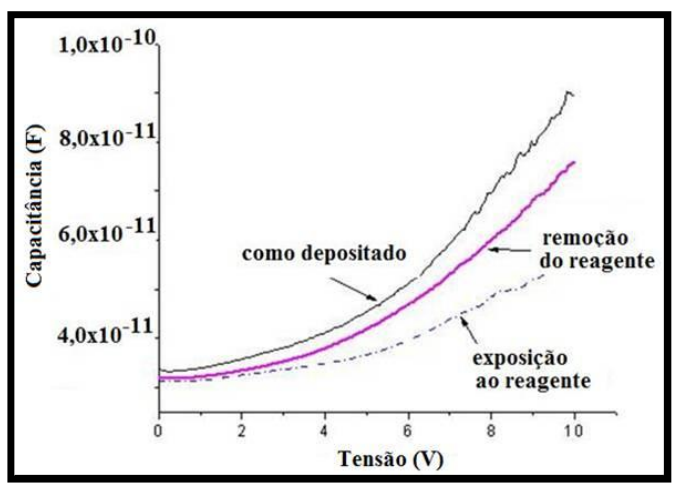

(D)

Gráfico 4.2 - Curvas CV para filmes expostos ao vapor de isopropanol: (A) HMDS, (B) fluorados; (C) camada dupla (fluorado na camada superior) e (D) compósito. 


\subsubsection{Compostos orgânicos fluorados}

Compostos à base de HFE apresentam boa resistência a ácidos e bases, são adsorventes para alguns compostos orgânicos polares, permitindo igualmente sua permeação pelo corpo do filme [129], o que pode dificultar o uso na estrutura.

Três tipos de amostras foram preparadas: a Tabela 4.4 resume as características de deposição do plasma. O primeiro tipo de amostra foi o filme advindo direto do HFE (tipo 1). Enquanto a amostra tipo 2, foi preparada pela polimerização por plasma de HFE sobre a superfície de filme previamente depositado por plasma de HMDS. Por fim, o filme de compósito, foi gerado pela co-deposição de plasma de HFE e HMDS (tipo 3).

A condição de deposição e a espessura de cada filme, são descritas na Tabela 4.4. Embora a deposição resulte de espécies neutras, reagentes fluorados necessitam de alta potência para produzir as espécies ativas responsáveis pela deposição; conseqüentemente, a alta pressão (concentração elevada de moléculas) e potência, (alta densidade de potência para obtenção dos precursores) são necessárias a fim de assegurar uma taxa de deposição razoável. Para comparação com os resultados obtidos com Vertrel®, depositou-se um filme por plasma a partir de um compósito obtido da mistura de HMDS e fluorado, e também fez-se dupla camada destes filmes.

Tabela 4.4 - Condições de deposição na câmara de plasma.

\begin{tabular}{|c|c|c|c|c|c|c|}
\hline \multirow{2}{*}{$\begin{array}{c}\text { Tipo } \\
\text { de } \\
\text { amostra }\end{array}$} & \multirow{2}{*}{ Composição do filme } & \multicolumn{2}{|c|}{$\begin{array}{c}\text { Sistema de injeção de } \\
\text { reagente }\end{array}$} & \multirow{2}{*}{$\begin{array}{l}\text { Faixa de } \\
\text { pressão de } \\
\text { deposição } \\
\text { (mTor) }\end{array}$} & \multirow{2}{*}{$\begin{array}{c}\text { Faixa de } \\
\text { voltagem } \\
\text { durante a } \\
\text { deposição } \\
\text { (V) }\end{array}$} & \multirow{2}{*}{$\begin{array}{c}\text { Taxa de } \\
\text { deposição } \\
(\AA / \text { min })\end{array}$} \\
\hline & & Principal & Auxiliar & & & \\
\hline 1 & Fluorado (HFE) & $\mathrm{HFE}$ & $\mathrm{HFE}$ & 100 & 550 & 200 \\
\hline 2 & $\begin{array}{c}\text { Dupla camada: filme } \\
\text { de HFE sobre filme de } \\
\text { HMDS } \\
\end{array}$ & HFE & HMDS & 100 & 400 & nd \\
\hline 3 & $\begin{array}{c}\text { Compósito: deposição } \\
\text { concomitante de HFE } \\
\text { e HMDS }\end{array}$ & HFE & HMDS & 100 & 430 & nd \\
\hline
\end{tabular}

nd - não determinado porque há mais de uma camada ou filme envolvido.

As principais características dos filmes são descritas na Tabela 4.5. Devido a alta concentração de carbono, os índices de refração são aproximadamente os mesmos para todos os filmes - os valores variam de 1,46 a 1,58 - e similares aos obtidos com os filmes finos orgânicos. 
Para filmes fluorados, índice de refração igual a 1,6 foi encontrado para carbono amorfo modificado com flúor, mas estes valores são menores para filmes obtidos pela polimerização por plasma e com estrutura similar ao Teflon®. Além disso, Doms [130] estudou a deposição por plasma usando materiais fluorados e obteve índices de refração que variavam de 1,2 a 1,9, dependendo dos parâmetros de processo de deposição.

As medidas de ângulo de contato revelam que a superfície hidrofóbica para os filmes tipo 1 e $2\left(80^{\circ}\right.$ e $75^{\circ}$, respectivamente, para gotas da água) devido à presença de flúor na superfície daquelas amostras. A alta hidrofobicidade dos filmes a base de HMDS [121], o filme tipo 3 teve o ângulo de contato mais elevado para a água $\left(90^{\circ}\right)$.

Tabela 4.5 - Medidas referentes ao índice de refração e ao ângulo de contato com a água para filmes da Tabela 4.4.

\begin{tabular}{||c||c|c||c||}
\hline $\begin{array}{c}\text { Tipo } \\
\text { de } \\
\text { amostra }\end{array}$ & Composição do filme & $\begin{array}{c}\text { Índice } \\
\text { de } \\
\text { refração** }\end{array}$ & $\begin{array}{c}\text { Angulo de } \\
\text { contato } \\
\text { com a água ( } \text { ( }) * * *^{*}\end{array}$ \\
\hline \hline 1 & Fluorado (HFE) & 1,58 & 80 \\
\hline \hline 2 & Filme a base de HFE sobre filme a base de HMDS (dupla \\
camada) & 1,50 & 75 \\
\hline \hline 3 & Compósito: deposição concomitante de HFE e HMDS & 1,50 & 90 \\
\hline
\end{tabular}

* - medido com elipsômetro em três comprimentos de onda; ** - medido em goniômetro.

A análise de FTIR indica a existência de espécies fluoradas e oxigenadas, como previamente descrito [129]. Os espectros apresentam bandas largas e intensas na faixa de $1000-1500 \mathrm{~cm}^{-1}$, com pico centrado na área de $1250 \mathrm{~s} \mathrm{~cm}^{-1}$, e outro aproximadamente em 1150 $\mathrm{cm}^{-1}$, devido ao estriramento do CF. Há outras bandas largas, embora menos evidentes, entre 750-650 $\mathrm{cm}^{-1}$, devido ao CF (bending), bastante comum entre polímeros com ligações cruzadas. Além disso, ocorre uma pequena banda em torno de $2880 \mathrm{~cm}^{-1}$, devido à presença de espécie $\mathrm{CH}_{\mathrm{n}}$. As espécies de $\mathrm{CO}$ são reconhecidas principalmente entre $1900 \mathrm{~cm}^{-1}-1600$ $\mathrm{cm}^{-1}$, em especial para os compostos fluorados (tipo 1), porém a existência de água no background dificulta a análise.

A topografia das amostras depositadas em silício, foi analisada por SEM; a Figura 4.1 apresenta os resultados típicos para filmes a base de HFE depositado em silício na face polida (Figura 4.1A) ou raspada (Figura 4.1B). Nos dois casos, as superfícies dos filmes são lisas com alguns clusters escassos, de $1 \mu \mathrm{m}$ ou menor. Este resultado está de acordo com mecanismo de deposição dependente de espécies neutras [122][131], com forte adsorção do reagente fluorado na superfície do silício. 
A superfície lisa dos filmes depositados no lado rugoso de lâmina de silício, indica boa cobertura de degrau, o que é importante para a deposição em estruturas usinadas em máquina convencionais, pois nestas a superfície apresenta-se rugosa.

Superfícies fluoradas expostas a soluções concentradas ácidas ou básicas (soluções aquosas de $1 \mathrm{M} \mathrm{HNO}_{3}$ ou de $1 \mathrm{M}$ de $\mathrm{NaOH}$ ), durante 5 minutos não mostraram nenhuma modificação, quando analisadas por microscopia óptica.

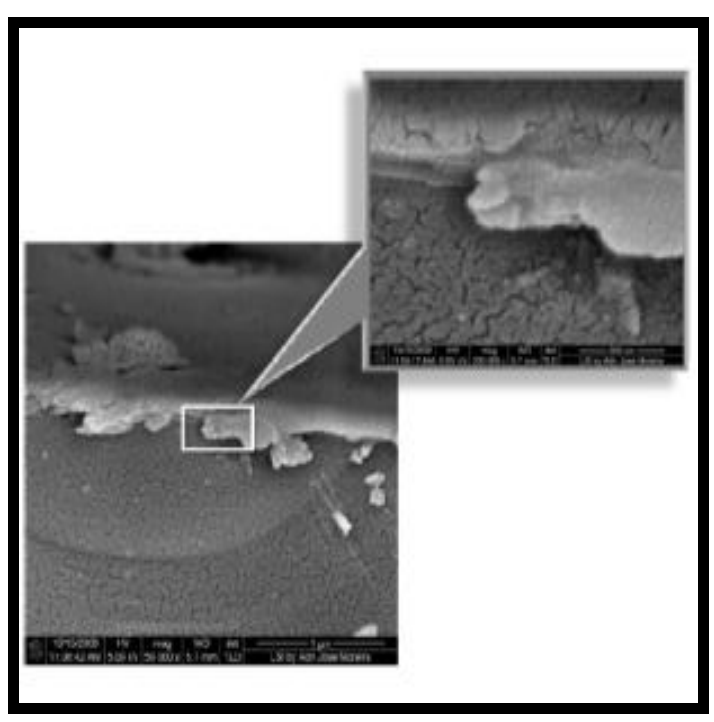

(A)

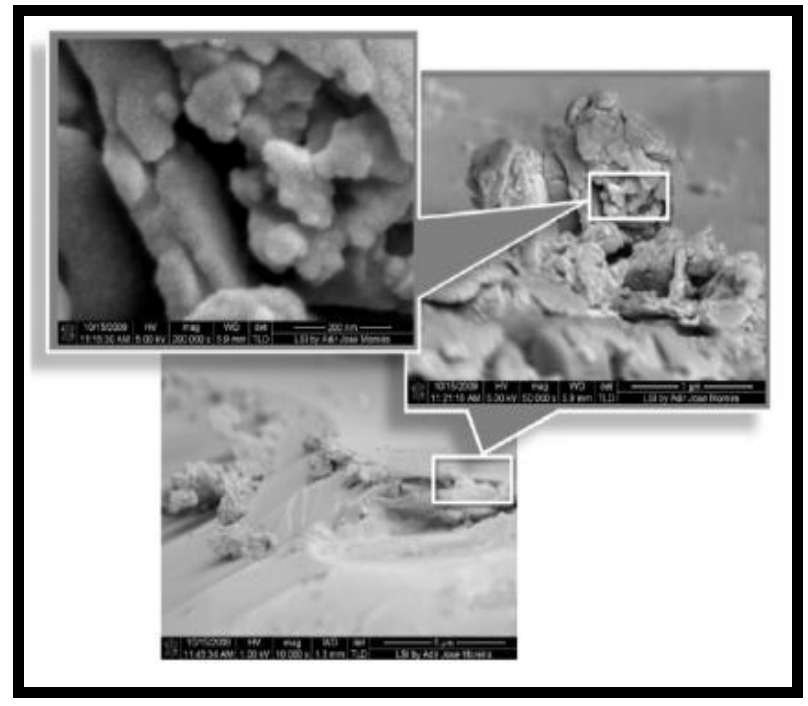

(B)

Figura 4.1 - Análise SEM: em silício, deposição de filme fluorado na superfície (A) polida ou (B) rugosa.

Quanto à caracterização elétrica, filmes fluorados mostraram pouca sensibilidade a compostos orgânicos, como é esperado, a presença do flúor favorece o comportamento oleofóbico, isto é, a adsorção não é favorecida. Conseqüentemente, com o intuito de avaliar o envelhecimento, a amostra foi exposta a diversos ciclos de n-hexano saturado, e posteriormente limpa com a passagem de ar durante longos períodos (Gráfico 4.3A).

Após uma exposição de 1 minuto, provavelmente ocorre à saturação e o mínimo da medida aumenta e esta mudança parece ser irreversível, pois o comportamento se repete com nova exposição. Este incremento provavelmente pode ser atribuído a variações na superfície em conseqüência da sobre exposição.

Para o filme tipo 2 (camada de filme a base de HFE sobre a camada já existente a base de HMDS) e o tipo 3 (deposição concomitante de filmes a base de HFE e de HMDS), exposições a n-hexano ou isopropanol são mostradas no Gráfico 4.3B e 4.3C, respectivamente. Nenhumas destas amostras apresentaram a histerese antes da exposição, o 
Gráfico 4.3 mostra apenas a parte significativa, isto é, onde observou-se variações. Todos os filmes mostram curvas similares antes da exposição aos compostos orgânicos, provavelmente, devido à espessura do filme e à estrutura química serem similares. Na dupla camada (tipo 2, Gráfico 4.3B) mesmo com uma única exposição, ocorre uma variação que parece indicar a saturação. Além disso, a tentativa de remoção do material adsorvido não é eficaz, correspondendo a uma condição irreversível. Embora o filme fluorado não seja sensível a compostos apolares, a permeação é possível e algum reagente pode ser retido, preferivelmente, perto da interface entre camadas. Além disso, os compostos apolares podem inchar o filme fino a base de HMDS, alterando a espessura. Inchar também poderia mudar a distância entre os dipólos permanentes, por exemplo, devido as ligações de Si-O, as ligações dos CF e dos CO.

Embora a amostra do compósito de HMDS (tipo 3, Gráfico 4.3C) mostre as mudanças similares às do filme em dupla camada, o comportamento geral devido à exposição ao nhexano é mais disperso quando comparado ao filme "como depositado" da amostra depositada. Uma possível explicação neste caso é que o filme fluorado não protege a superfície e o inchaço dos "grãos" do filme a base de HMDS esticará a camada inteira. Como o resultado final é a média de cada comportamento individual e o inchar é um processo irreversível, a curva depois de cada medida pode divergir bastante das precedentes. O filme fluorado exposto a vapores de isopropanol mostra mudanças significativas na curva somente após a segunda exposição consecutiva, como pode ser visto no Gráfico 4.3A. Esta figura também apresenta duas medidas em dois filmes finos diferentes, medidos "como depositados", o que indica a boa reprodutibilidade entre medidas.

Além disso, a remoção do reagente é conseguida facilmente usando ar limpo; portanto, pode-se dizer que os filmes fluorados são sensíveis apenas à alta concentração de compostos orgânicos voláteis e de maneira reversível. Na amostra tipo 2 (filme a base de HFE sobre filme a base de HMDS), devido à presença do filme a base de HMDS na parte inferior (Gráfico 4.3B), observa-se um comportamento diferenciado. Como indicado na figura, as duas medidas diferentes no filme "como depositado" não apresentam significativas mudanças no perfil da curva, o que indica reprodutibilidade nas medidas. Embora a primeira exposição não mostre nenhuma modificação significativa na curva, a segunda exposição muda o comportamento irreversivelmente e toda a tentativa de remoção do reagente é inútil. Esta situação está de acordo com a permeação do reagente e a adsorção que ocorre entre a interface e o filme, como se observa nas medidas com n-hexano. 


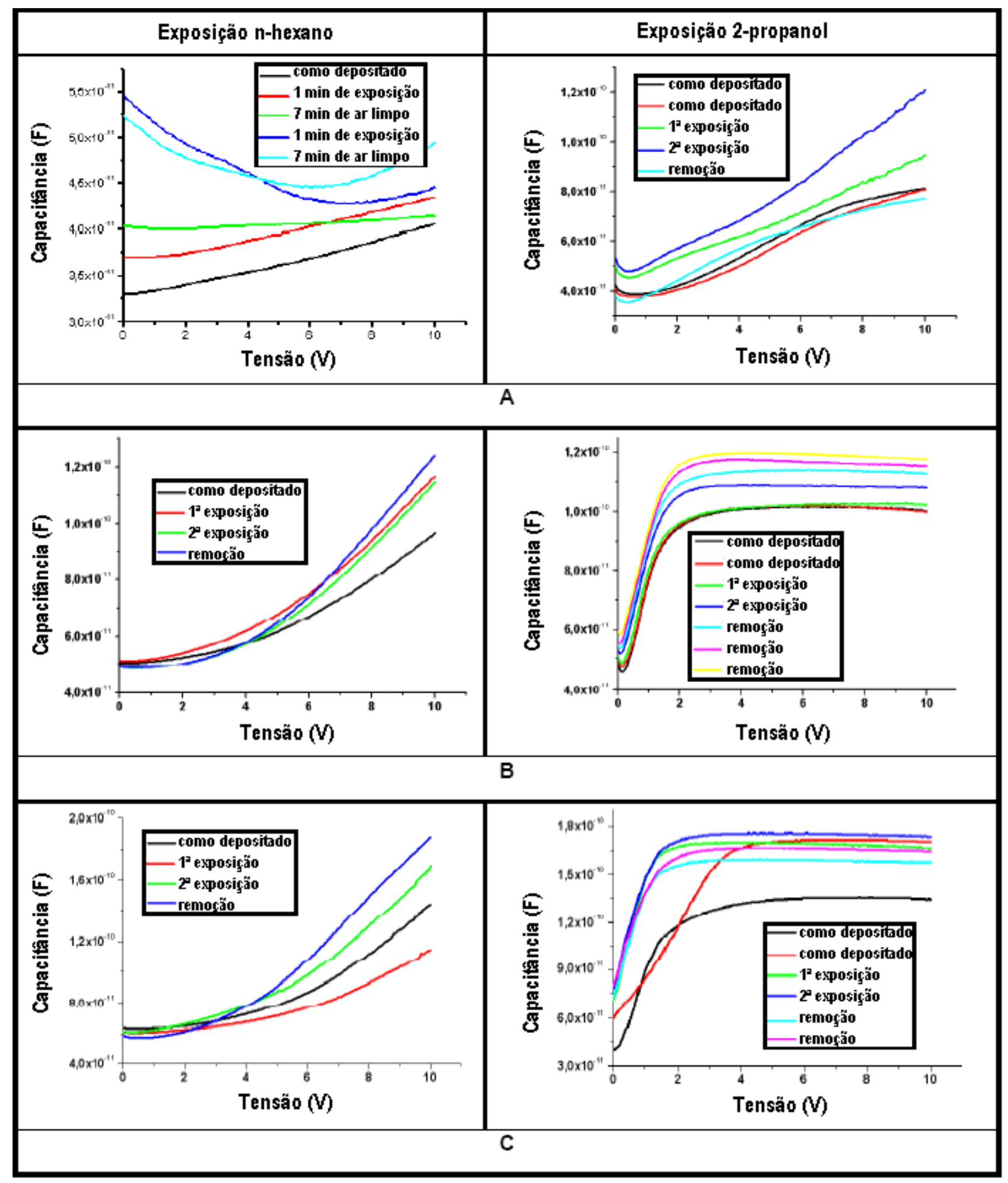

Gráfico 4.3 - Curva CV para (A) fluorados; (B) filmes com dupla camada e (C) compósito com o HMDS exposto ao n-hexano ou isopropanol e filme fluorado. 


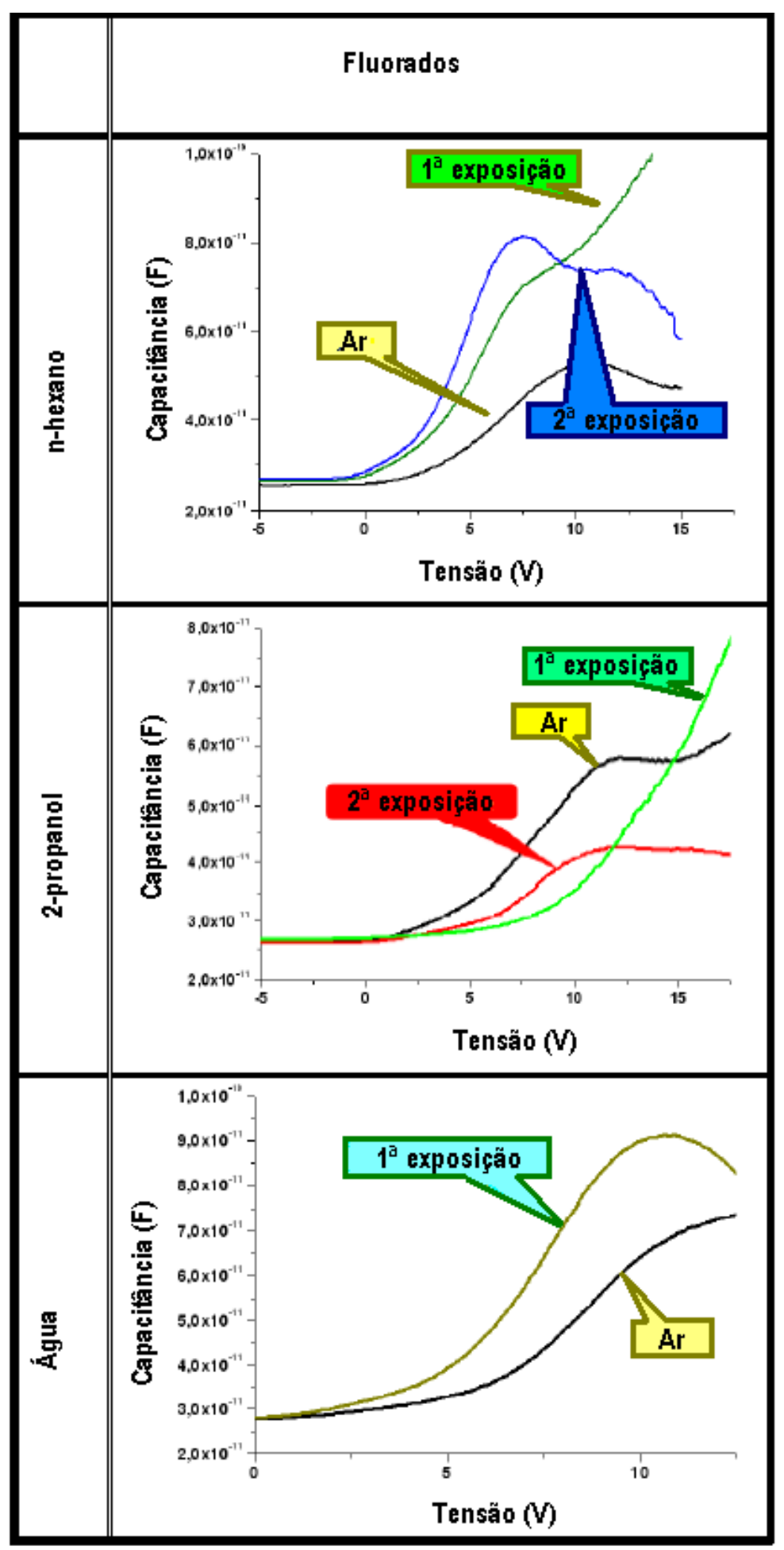

Gráfico 4.4 - Fluorados expostos por 5 minutos a ácido ou bases e testados para nhexano, isopropanol e à influência dos vapores de água.

O filme fluorado exposto a base ou ácido foi testado, o Gráfico 4.4 mostra resultados típicos; os filmes apresentam maior sensibilidade e ocorrem alterações devido à exposição ao 
reagente. Após a exposição, significativas mudanças ocorreram na superfície do filme, fato este que influencia as medidas, mas não a ponto de impedir a detecção do reagente.

\subsubsection{Conclusão parcial}

De modo geral, o filme que apresenta um comportamento mais adequado para ciclos de exposição a reagentes orgânicos, é o filme a base de HMDS e o uso de filmes fluorados para diminuir possíveis efeitos viscoelásticos (por exemplo, inchar) implica em outras dificuldades, tais como permeação e retenção na interface, o que pode gerar irreprodutibilidades.

\subsection{SPRAY}

Para a obtenção de estruturas miniaturizadas capazes de produzir um spray a partir de amostras líquidas, optou-se pelo uso de fluxo cruzado, porque entre outras vantagens, permite a construção de estruturas simples e de menor tamanho, quando comparado com outros desenhos descritos no capítulo 2 (aspectos teóricos). Os desenhos encontrados na literatura correspondem a estruturas planares e regime laminar.

Dois desenhos em fluxo cruzado e usando microcanais foram testados: canais planares e tridimensionais. Estas estruturas são apresentadas no capítulo 3 (materiais e métodos) e aqui repetidas, nas Figuras 4.2 e 4.3, apenas para facilitar a compreensão dos resultados.

Como descrito no capítulo 2, a estrutura em espiral planar apresenta um microcanal e a vantagem de ocorrer pré-concentração em meio gasoso, por outros meios que não adsorção [132]. Em meio líquido, aparentemente por processo semelhante ao cromatográfico, ocorre a adsorção [133]. Assim, a espiral planar apresenta uma dispersão lateral do escoamento, que foi demonstrada por simulação por Simões para a fase gasosa [134], mas que Nascimento [133] não avaliou em fase líquida, pois neste caso a pré-concentração foi analisada considerando-se as diferenças da adição ou não de filme adsorvente à superfície. Contudo, caso ocorra dispersão lateral também em líquido, a formação de spray pode ser beneficiada.

Quanto a canais tridimensionais, a estrutura proposta por Lima [103] mostrou-se útil como coluna cromatográfica [102], desde que a superfície fosse modificada pela deposição de filme adsorvente. Por outro lado, canais em espiral planar mostraram-se retentores, tanto em fase gasosa [134] como em fase líquida [54]. Contudo, a retenção dependeu da adição de 
partículas, para a formação de uma coluna empacotada. Além disso, Carvalho A.T. [100], por simulação, concluiu que essa estrutura, quando usado $\mathrm{N}_{2}$ como fluido, "corresponde à melhor otimização possível do escoamento para colunas cromatográficas e/ou microreatores, uma vez que o perfil de velocidade não mostrou prováveis vórtices e o tempo de residência mostrou-se longo (aproximadamente 1s) [...] e o menor passo de rosca permite a obtenção de uma estrutura de pequena dimensão". Por fim, se o passo da rosca é aumentado ou a estrutura é aquecida, a estrutura não mais se comporta como coluna, e sim como microreator.

O comportamento do fluido nestas duas estruturas foi avaliado experimentalmente e por simulação. As simulações foram efetuadas principalmente em fase líquida por já existir informações sobre a fase gasosa. Também fez-se análises experimentais, utilizando como recursos, em fase líquida filmagens (Figura 4.4) e em fase gasosa o cálculo do número de pratos teóricos. Para verificar como a química da superfície ou área superficial influencia a retenção dos compostos, filmes adsorventes foram depositados na superfície do canal. No presente caso, escolheu-se filme a base de HMDS [121], devido à sua boa adsorção de compostos orgânicos, como anteriormente exposto. A espiral tridimensional tem largura de canal de $100 \mu \mathrm{m}$, mas a espiral planar teve este canal variado de $100 \mu \mathrm{m}, 200 \mu \mathrm{m}$ e $500 \mu \mathrm{m}$, como será abordado posteriormente. As duas estruturas apresentam aproximadamente $70 \mathrm{~cm}$ de comprimento (Figura 4.2).

O desenho dos microcanais planares em forma espiral é similar ao previamente proposto [134], mas sem a constrição periódica e as estruturas com canal de $100 \mu \mathrm{m}$ apresentam a superfície e o volume de $1,4 \mathrm{~cm}^{2}$ e de $1,1.10^{-3} \mathrm{~cm}^{3}$, respectivamente, a relação da superfície/volume é igual a 1300.

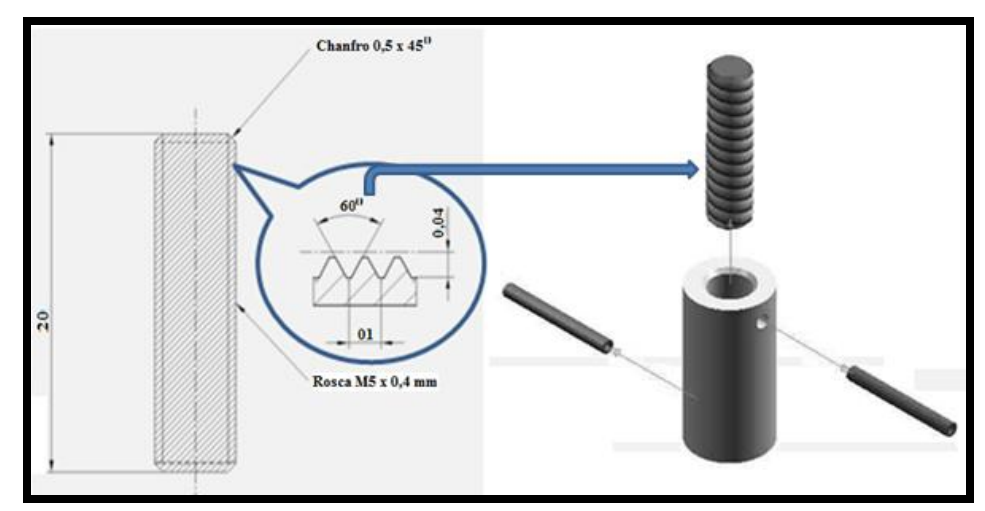

Figura 4.2 - Detalhe (mm) do microcanal com $100 \mu \mathrm{m}$ usinado na estrutura tridimensional. 


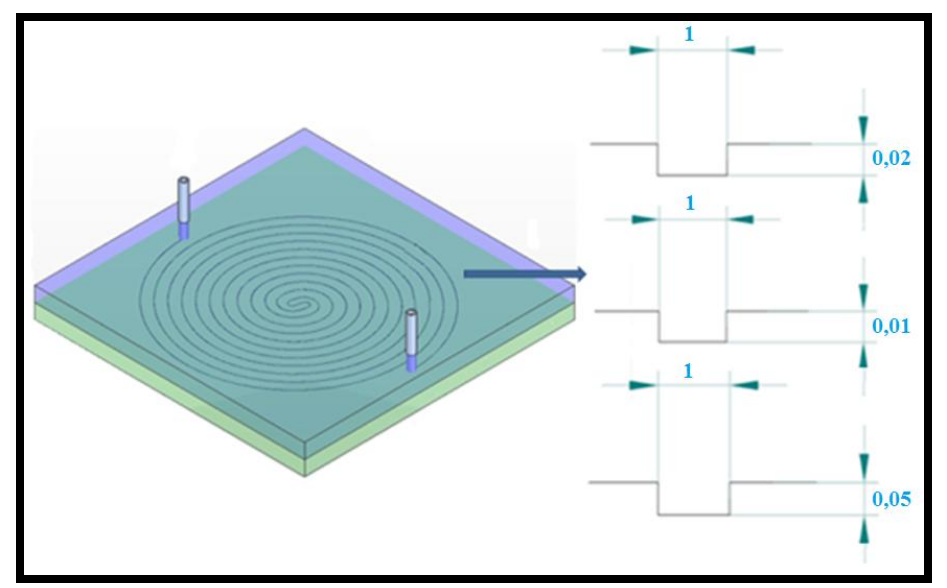

Figura 4.3 - Detalhe $(\mathrm{mm})$ do microcanal usinado na estrutura (microcanal pode variar em $100 \mu \mathrm{m}$, ou $200 \mu \mathrm{m}$ ou $500 \mu \mathrm{m})$ [55].

Assim, os testes para a construção do spray ocorreram em duas etapas: primeiro compreendeu-se o comportamento do fluído nos canais planares e tridimensionais e depois construiu-se os respectivos sistemas de spray.

\subsubsection{Simulações dos canais planares e tridimensionais}

Antes de fabricar a estrutura fez-se a simulação apenas como indicador para observar o comportamento do fluido dentro da estrutura.

\subsubsection{Canais planares}

Esta estrutura mostra um baixo Número de $\operatorname{Dean}^{b b}$ (igual a 2), o qual indica que o gradiente de pressão e a taxa de escoamento não são dependentes da curvatura, o perfil da velocidade axial é parabólico, sendo que se fosse um tubo reto, a velocidade seria inalterada [91].

Número de Dean (D): é um número admensional muito aplicado em mecânica dos fluidos para estudos de fluxos turbulentos em canais curvados. Definido pela equação a seguir (Equação 3).

\footnotetext{
${ }^{\mathrm{bb}}$ número admensional aplicado em mecânica dos fluidos para estudos de fluxos turbulentos em canais curvados.
} 


$$
D=\frac{\rho u a}{\mu}\left(\frac{a}{2 R}\right)^{1 / 2}
$$

\section{Equação 3}

Onde tem-se a densidade do fluido determinada pela letra " $\rho$ "; " $\mu$ " representa a viscosidade dinâmica do fluido; "u" é a velocidade axial; "a" representa a característica longitudinal associada à secção transversal do canal; e " $\mathrm{R}$ " é o raio curvatura do canal.

Portanto, o número de Dean é o produto do número de Reynolds, calculado pelo fluxo axial com velocidade "u" através de um canal com diâmetro "a", e a raíz quadrada do coeficiente de características longitudinais " $\mathrm{a} / \mathrm{R}$ ”.

Número de Reynolds (Re): o significado fundamental para o número de Reynolds é que este permite avaliar o tipo do escoamento, ou seja, pode indicar se o regime de escoamento é laminar ou turbulento. Valores onde Re é menor que 2.000 o regime de escoamento é considerado como laminar, para valores de Re maiores que 3.000 o escoamento tende a ser turbulento. Os valores intermediários apresentam um escoamento instável que está mudando de um regime para outro. A figura a seguir exemplifica como seria o regime de escoamento.

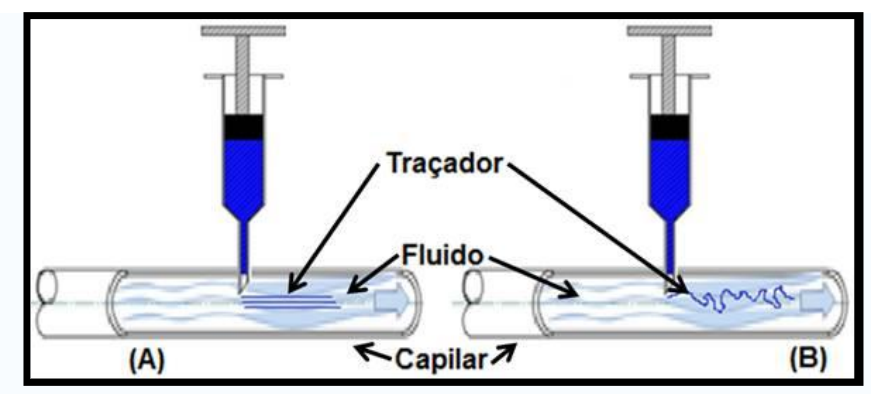

Figura 4.4 - Comportamento do fluido: esquema de como ocorre o escoamento dentro de um tubo (A) regime de escoamento laminar e (B) regime de escoamento turbulento.

O número de Reynolds (Re), admensional, é usado em mecânica dos fluidos para o cálculo do regime de escoamento de determinado fluido sobre uma superfície. O seu significado físico é um quociente de forças de inércia $(\rho u)$ entre forças de viscosidade $(\mu / a)$. É expressado pela Equação 4:

$$
R e=\frac{\rho u a}{\mu}
$$


As variáveis são definidas como as descritas para o número de Dean, "u" corresponde a velocidade média do fluido; "a" indica o raio do canal; " $\mu$ " representa a viscosidade dinâmica do fluido; e " $\rho$ " refere-se a massa específica do fluido.

As simulações dos canais planares consideraram o modelamento de Navier-Stokes, 2D, malha definida manualmente, pressão atmosférica, vazão de $10 \mathrm{~mL} / \mathrm{s}$ e $1 \mathrm{~mL} / \mathrm{s}$ fixada para cada fluidos gasoso e líquido, respectivamente. Simulações dinâmicas consideraram tempo total de 2 segundos com passo de 0,01 segundo.

Os perfis da velocidade resultante e de pressão absoluta em uma espiral planar com fluidos a base de ar atmosférico, glicerol e água foram simulados (Apêndice A) e a Tabela 4.6 mostra o valor mais alto da velocidade. A simulação do escoamento de água requer a suposição de regime de escoamento turbulento, provavelmente, devido às propriedades físicas da água serem bem diferentes das condições do gás ideal. As simulações permitiram observar que as condições de perda de carga aparentemente levam apenas a queda linear de pressão, os perfis da velocidade mostram uma variação cíclica, correlacionada aparentemente com a posição central da estrutura. Este comportamento é provavelmente devido à grande variação de vetores da velocidade na região central da estrutura.

Além disso, a oscilação na velocidade resultante é mais evidente na fase líquida, possivelmente, devido à velocidade axial elevada. Conseqüentemente, há diferenças entre os resultados obtidos pela simulação e os modelos analíticos usados na geometria curvada, não devido à espiral propriamente, mas ao projeto do centro que corresponde a duas conexões pequenas em $180^{\circ}$, ou seja, como a estrutura simulada é uma dupla espiral, pode-se criar turbulências ou variação no perfil do escoamento. Por simulação, não se encontrou um modo de diminuir essas variações de velocidade com a variação no formato da curva do centro. Este perfil de velocidade por ser distinto em fluidos com viscosidade diferente e poderia favorecer uma separação de dois fluidos em soluções e/ou emulsões (Apêndice A Figura A.2). Assim, simulou-se o perfil da concentração de n-hexano em solução de nitrogênio ( $1 \%$ em vol.) aquosa saturada. A solução encontrada apresenta uma variação de concentração ao longo do canal.

Em todos os líquidos, a velocidade axial elevada, exibida na Tabela 4.6, pôde explicar a dispersão observada em experiências com traçadores, como explicar-se-á mais à frente. Além disso, os valores da velocidade do glicerol e da água são conseguidos apenas se uma pequena quantidade de amostra do glicerol for adicionada ao microcanal; se o escoamento aumenta, a pressão de entrada aumentará rapidamente, alcançando 20 atm a 1 
$\mathrm{mL} / \mathrm{min}$, um valor elevado e raramente utilizado em dispositivos de MEMS ou sistemas miniaturizados. O resultado é facilmente compreendido considerando que há dificuldade de movimentação do fluido mais viscoso devido à presença do efeito de capilaridade. Simulações mostram tal fenômeno para sistemas ar atmosférico/glicerina [128].

\section{Tabela 4.6 - Velocidades máximas nos microcanais em espiral planar usando a água, o glicerol e ar atmosférico como fluidos. Simulação tridimensional com pressão de saída igual a 1 atm.}

\begin{tabular}{|c|c|c|c|c|c|}
\hline \multirow{2}{*}{$\begin{array}{l}\text { Fluido/ } \\
\text { Fluxo }\end{array}$} & \multirow{2}{*}{$\begin{array}{l}\text { Pressão } \\
\text { de } \\
\text { entrada } \\
\text { (atm) }\end{array}$} & \multicolumn{3}{|c|}{$\begin{array}{l}\text { Velocidade } \\
\qquad(\mathrm{m} / \mathrm{s})\end{array}$} & \multirow{2}{*}{$\begin{array}{c}\text { Simulações } \\
\text { condições /convergência }\end{array}$} \\
\hline & & Fluxo & Axial & Superior & \\
\hline $\begin{array}{l}\text { ar atmosférico } \\
10 \mathrm{sccm}\end{array}$ & 5 & 45 & 18 & 17 & $\begin{array}{l}\text { gás real com viscosidade e densidade obtidas usando } \\
\text { equações polinomiais, modelo de compressibilidade e } \\
\text { adiabático a } 300 \mathrm{~K} \text {, no slip nas paredes internas a } \\
\text { estrutura e escoamento contínuo. A simulação apresenta } \\
\text { regime laminar, convergência de } 10^{-3} \text { e a solução linear. }\end{array}$ \\
\hline $\begin{array}{l}\text { Vapor de água } \\
10 \mathrm{sccm}\end{array}$ & 4 & 78 & 58 & 15 & $\begin{array}{l}\text { gás real com viscosidade e densidade obtida usando } \\
\text { equações polinomiais, com variação da temperatura, } \\
\text { modelos compressível e térmico, no slip nas paredes } \\
\text { internas a estrutura e escoamento contínuo. A simulação } \\
\text { apresenta o regime turbulento, convergência de } 10^{-3} \text { e a } \\
\text { solução não-linear. }\end{array}$ \\
\hline $\begin{array}{l}\text { Água } \\
1 \mathrm{~mL} / \mathrm{min}\end{array}$ & 1 & $5,8.10^{-2}$ & $5,1.10^{-2}$ & $8.10^{-3}$ & $\begin{array}{l}\text { constante de viscosidade e de densidade sem variações de } \\
\text { temperatura }(300 \mathrm{~K}) \text {, modelo de incompressibilidade. A } \\
\text { simulação apresenta o regime laminar, convergência de } \\
10^{-4} \text { e a solução linear. }\end{array}$ \\
\hline $\begin{array}{c}\text { Glicerol } \\
0,01 \mathrm{~mL} / \mathrm{min}\end{array}$ & 1,2 & $5,7.10^{-4}$ & $5,1.10^{-4}$ & $4,3.10^{-2}$ & $\begin{array}{l}\text { constante de viscosidade e de densidade sem variações de } \\
\text { temperatura }(300 \mathrm{~K}) \text {, modelo de incompressibilidade. A } \\
\text { simulação apresenta o regime laminar e a convergência do } \\
10^{-2} \text { e solução não-linear. }\end{array}$ \\
\hline
\end{tabular}

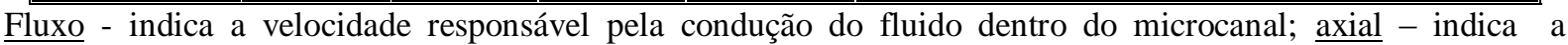
velocidade responsável pela dispersão do fluido dentro do microcanal; superior - refere-se a velocidade responsável pelo comportamento caótico dentro do microcanal, relacionado ao fator de fricção. Respectivamente, Vx, Vy e Vz (Apêndice A, Figura A.1).

\subsubsection{Canais tridimensionais}

Os perfis da velocidade resultante e da pressão absoluta em uma espiral tridimensional com ar atmosférico, glicerol e água podem ser observados no Apêndice A Figura A.3. A Tabela 4.7 mostra os valores máximos de velocidade. Para todas as condições, a queda da pressão é linear e a diferença da pressão é relativamente pequena se comparada à espiral planar. Além disso, a dispersão do fluido devido à velocidade axial é baixa mesmo com vapor de água, um gás não-ideal, as simulações não exigem mudanças de temperatura e o regime de escoamento é sempre laminar; conseqüentemente, esta estrutura assemelha-se a uma coluna cromatográfica, tanto em medidas gasosas como líquidas. Assim, o tempo de 
retenção e o número de pratos teóricos foram medidos, como explicado previamente, e são apresentados na Tabela 4.9 para o n-hexano e 2-propanol.

Tabela 4.7 - Picos de máximo das velocidades nos microcanais tridimensionais usando a água, glicerol e ar atmosférico como fluidos. Simulações tridimensionais com pressão de saída igual a 1 atm e $300 \mathrm{~K}$.

\begin{tabular}{|c|c|c|c|c|c|}
\hline $\begin{array}{l}\text { Fluido/ } \\
\text { Fluido }\end{array}$ & $\begin{array}{l}\text { Pressão } \\
\text { da } \\
\text { entrada } \\
\text { (atm) }\end{array}$ & \multicolumn{3}{|c|}{ Velocidade $(\mathrm{m} / \mathrm{s})$} & $\begin{array}{c}\text { Simulações } \\
\text { condições /convergência }\end{array}$ \\
\hline $\begin{array}{c}\text { Vapor de água } \\
10 \mathrm{sccm}\end{array}$ & 1,1 & 4,7 & 4,8 & 0,57 & $\begin{array}{l}\text { gás real com viscosidade e densidade obtidos usando } \\
\text { equações polinomiais, regime laminar, modelo de } \\
\text { compressibilidade e adiabático, no slip nas paredes e } \\
\text { escoamento contínuo. A simulação apresenta a } \\
\text { convergência de } 10^{-4} \text { e a solução linear. }\end{array}$ \\
\hline $\begin{array}{c}\text { Água } \\
1 \mathrm{~mL} / \mathrm{min}\end{array}$ & 1,1 & $6,7 \cdot 10^{-2}$ & $6,7 \cdot 10^{-2}$ & $9,1.10^{-3}$ & $\begin{array}{l}\text { constantes de viscosidade e de densidade sem } \\
\text { variações da temperatura, regime laminar e modelo } \\
\text { de incompressibilidade. A simulação apresenta a } \\
\text { convergência de } 10^{-4} \text { e a solução linear. }\end{array}$ \\
\hline
\end{tabular}

Fluxo e axial - indicam velocidade responsável pela circulação do fluido dentro do canal; superior - refere-se a velocidade responsável pelo comportamento caótico dentro do microcanal. Respectivamente, $\mathrm{Vx}, \mathrm{Vy}$ e $\mathrm{Vz}$ no Apêndice A, Figura A.2.

A importância do passo da rosca também foi avaliada, pois pode ser um fator determinante no projeto da estrutura usada para geração do spray, como abordado posteriormente. Para essa variação os canais tridimensionais e $\mathrm{N}_{2}$ como gás de arraste o passo da rosca de $0,8 \mathrm{~mm}$ corresponde ao maior passo que ainda permite o regime de escoamento laminar. Neste caso, a variação entre velocidade do fluido e de dispersão ainda é significativa, aproximadamente 2:1. Além disso, a variação é linear para a pressão e para a velocidade, ou seja, não se observam regiões com grandes variações de velocidade. Resultado similar é obtido utilizando água como fluido (Apêndice A, Figura A.4). 


\subsubsection{Testes experimentais usando traçadores em canais planares e tridimensionais}

\subsubsection{Canais planares}

Para testes em fase líquida usou-se como traçador solução, em água ou em glicerol de azul de metileno, (10\% em massa) e as Figura 4.5 e Figura 4.6 apresentam resultados típicos para a injeção de tais traçadores sob escoamento líquido (água). Para facilitar a visualização dos testes experimentais colocaram-se capilares, com diâmetro interno $1 \mathrm{~mm}$, sobre a flange usinada usando-a como guia para que os capilares reproduzissem o mesmo caminho dos microcanais. Para a interpretação das figuras, a ordem dos frames é indicada por um número na respectiva imagem. Devido à perda de resolução da figura não é possível observar os detalhes vistos durante os testes.

Nestas figuras, que são exemplos dos testes experimentais realizados com o auxílio de traçadores, quando se utiliza o traçador em solução aquosa observa-se que rapidamente o traçador é diluído na água, ou seja, ocorre a dispersão (Figura 4.5), mas esta parece ser uniforme (mais próxima da condição da Figura 4.4A). Nos testes realizados usando traçador em glicerol, contudo, observa-se comportamento bem diferenciado.

Quando este é inserido a dispersão não é uniforme e são observadas regiões onde o traçador não aparece no canal da estrutura (Figura 4.6, frame 22) ou é retido por longo tempo (Figura 4.6, frame 30). Há uma grande probabilidade de que este comportamento ocorra devido à formação de vórtices, resultando num escoamento de regime turbulento (mais próximo da condição da Figura 4.4B).

Para melhor compreender a dispersão na estrutura espiral planar, filmagens da entrada e da primeira volta da estrutura foram efetuadas em microscópio, observando-se que há dispersão do fluido já no início da primeira volta. Para partículas, muito embora estas pudessem deixar a estrutura sem dificuldade, foi observado comportamento similar. Além disso, a amostra pode ser parcialmente retida se a vazão for baixa, por exemplo, 0,35 $\mathrm{mL} / \mathrm{min}$. Essa retenção, contudo, não se mantém e é perdida em poucos segundos, devido à interação com o fluido aquoso. 


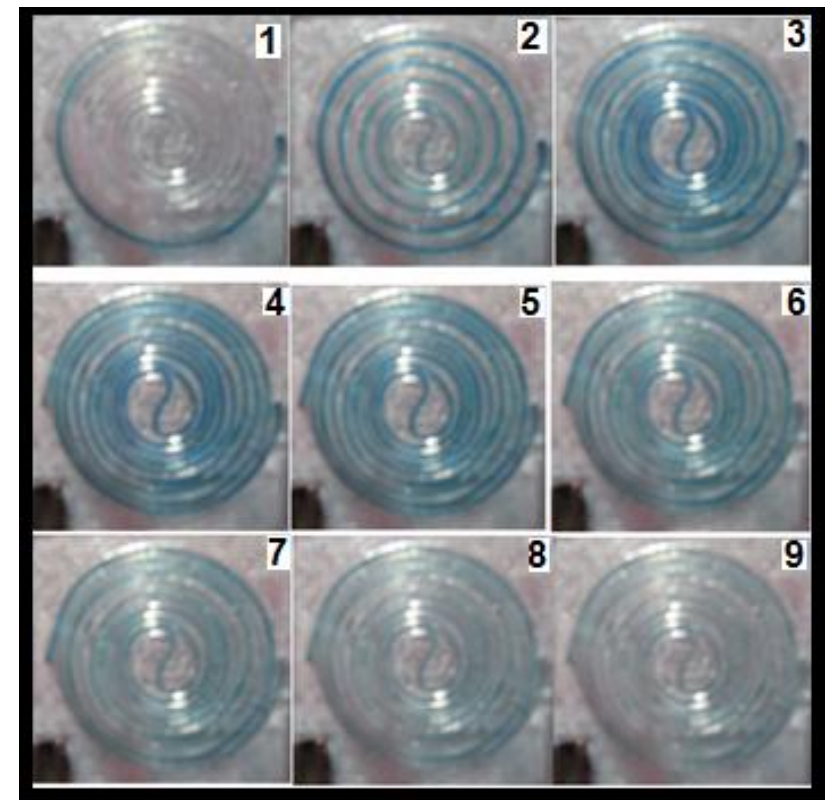

(A)

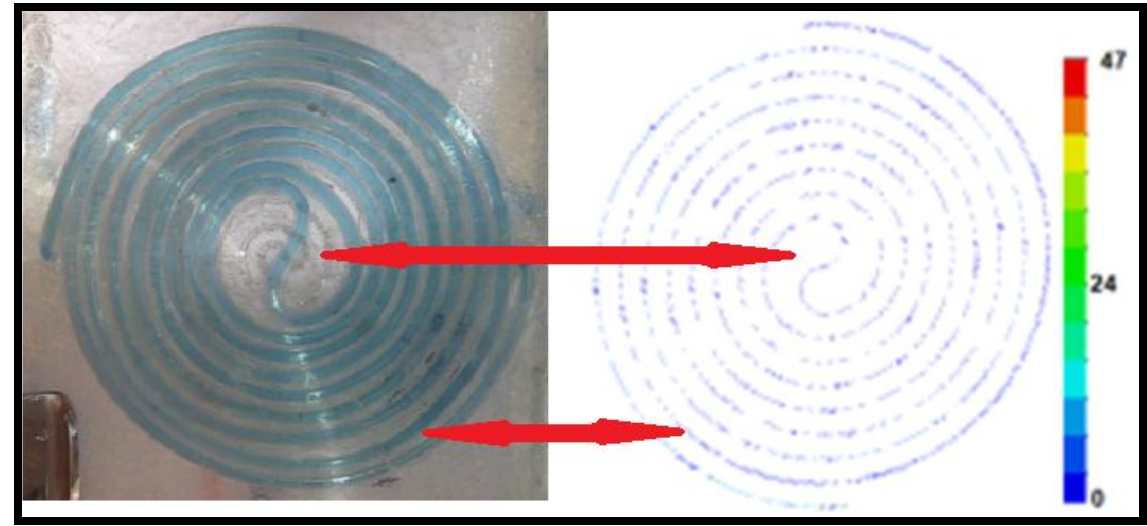

(B)

Figura 4.5 - Sequiência de fotografias para a injeção do traçador sob escoamento aquoso: azul de metileno $(\mathrm{A})$ água e $(\mathrm{B})$ comparação com a simulação referente à velocidade $(\mathrm{cm} / \mathrm{s})$ usando água. 

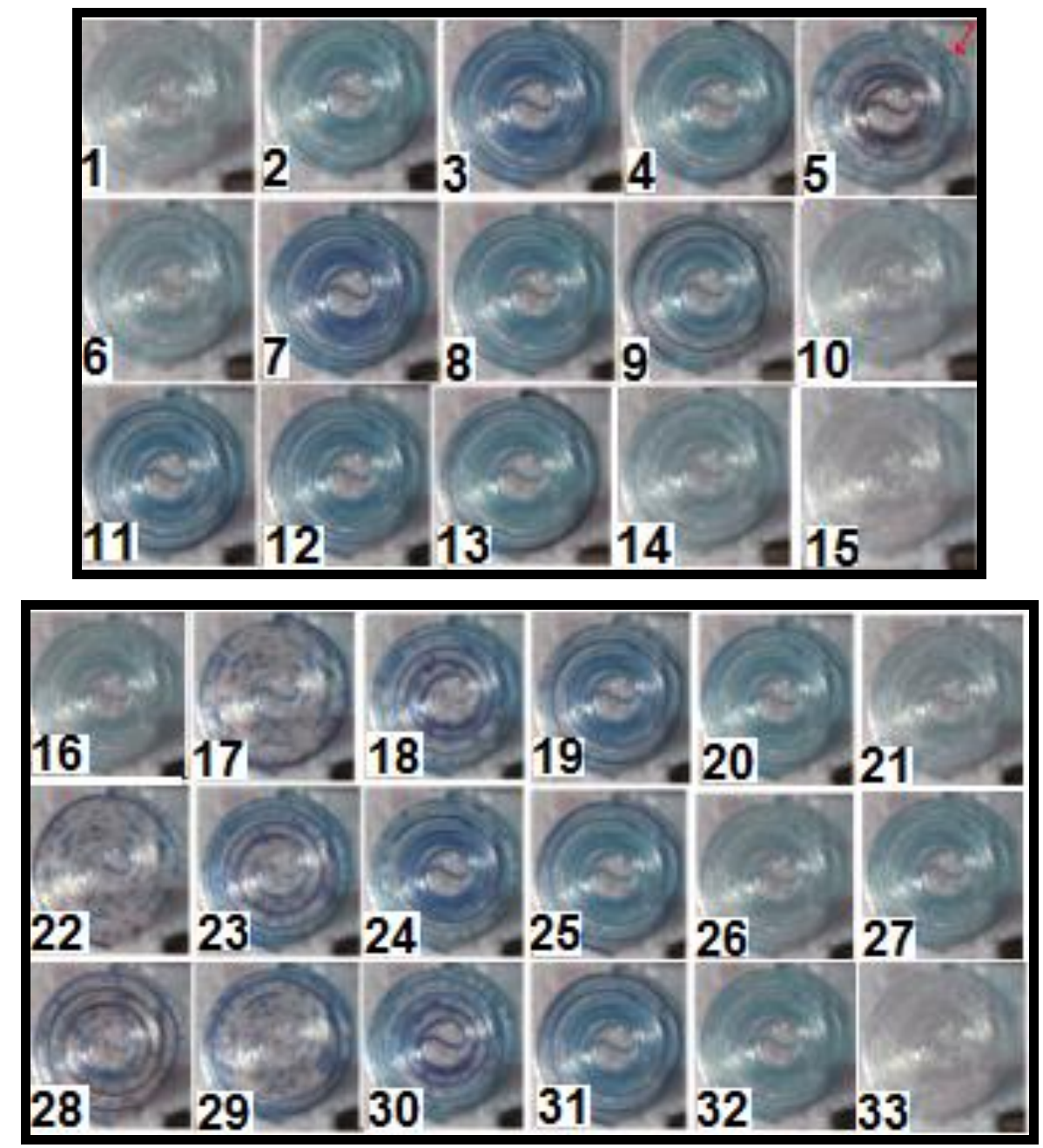

(A)

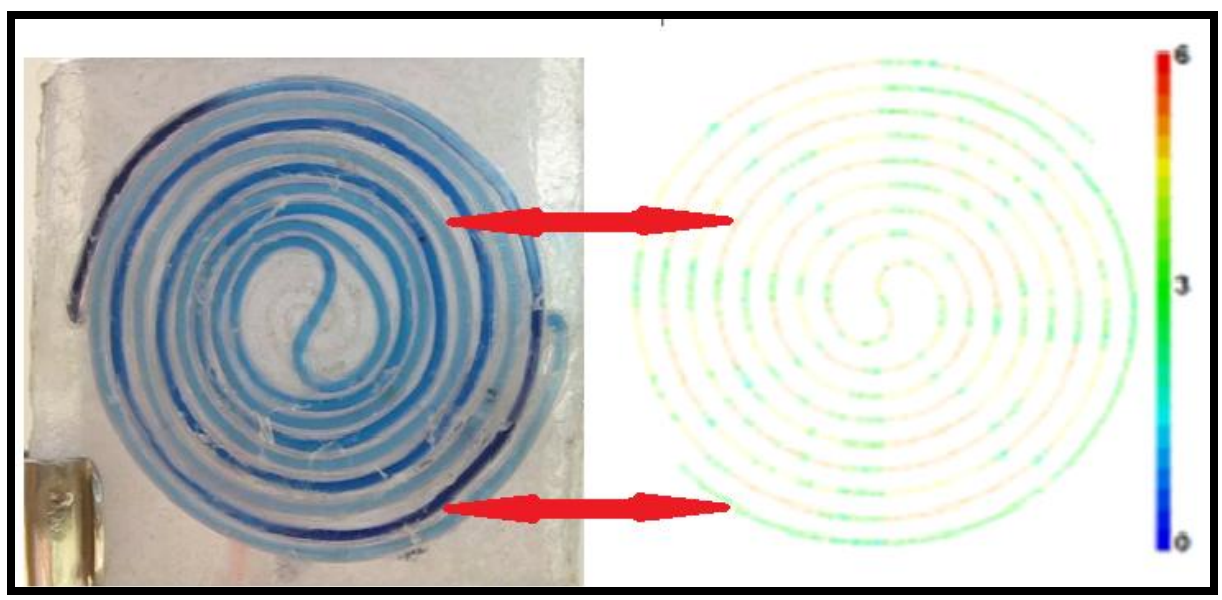

(B)

Figura 4.6 - Seqüência de fotografias para a injeção do traçador sob escoamento aquoso: azul de metileno (A) solução de glicerol e (B) comparação com a simulação referente à velocidade $(\mathrm{cm} / \mathrm{s})$ usando glicerol. 


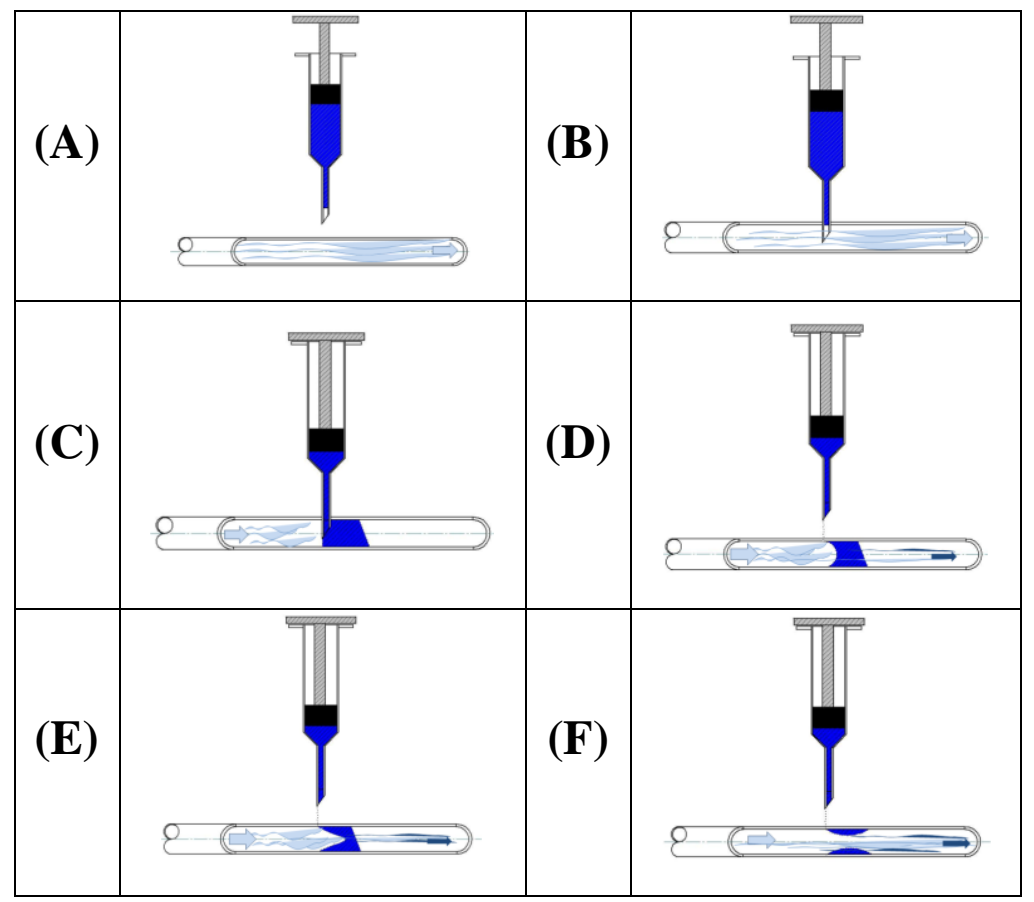

Figura 4.7 - Seqüência de injeção do traçador sob escoamento aquoso usando solução de glicerol.

Devido a baixa resolução das filmagens, não é possível observar (Figura 4.6) detalhes referentes ao comportamento do traçador com glicerol dentro do canal como mostrado na Figura 4.7. Nos itens A, B e C da Figura 4.7 é demonstrado o momento da inserção do traçador dentro do canal. Em meio ao fluido, o traçador (Figura 4.7D, E e F) começa a ser diluído apresentando regiões em que está ligado as paredes do canal sendo carregado lentamente pelo fluido até sua diluição total. Este comportamento justifica a maior quantidade de fotografias para as medidas com glicerol, a viscosidade altera a diluição do traçador.

Estes pontos em que o traçador fica ligado a parede da estrutura podem ser comparados com os obtidos no item 5 da seqüência de fotografias apresentadas na Figura 4.6 (indicação através da seta vermelha). Portanto, os resultados obtidos são concordantes com a simulação, a dispersão dificulta a remoção do traçador principalmente quando este se encontra dissolvido em glicerol, ou seja, as maiores diferenças entre o máximo e mínimo de velocidades provavelmente facilitam que "colisões" ocorram com as paredes e que o fluido seja mantido por longo tempo nessa região, o que permite que grande quantidade de traçador encontre-se no centro da estrutura muito tempo após a passagem deste pelo canal. 
As Figuras 4.5(B) e 4.6(B) possibilitam a comparação entre os dados simulados e os dados experimentais. Nestas, as setas vermelhas indicam regiões representadas por cores claras que indicam alta dispersão/alta velocidade lateral e cores escuras que indicam baixa dispersão/baixa velocidade lateral.

Embora seja difícil a visualização do reagente na fase gasosa, a injeção de um reagente no escoamento pode ser detectada e correlacionada com o comportamento do fluido. Os resultados de simulação indicam que a espiral planar favorece a retenção de compostos orgânicos voláteis (VOCs) em fase gasosa [134] ou mesmo líquida, se a superfície for mudada pela deposição de um filme fino adsorvente [135]. Essa retenção por dispersão tem efeito semelhante ao movimento aleatório do analito (eddy diffusion) que ocorre em uma coluna cromatográfica. Portanto, pode ser avaliada através da análise do formato do pico no cromatograma o que depende do tempo de retenção e do número de pratos teóricos [80].

O cálculo do número de pratos teóricos (Equação 1a) permite determinar a eficiência das estruturas como coluna cromatográfica e, indiretamente, a compreender possíveis dispersões do escoamento, já que estas diminuem o número de pratos teóricos e, principalmente em tempos de retenção longo, alargam a forma do pico. Assim, alguns canais foram recobertos pela deposição de filme fino a base de HMDS (100 nm de espessura) e avaliados como uma coluna cromatográfica. Os resultados típicos podem ser observados na Tabela 4.8, para 2-propanol e n-hexano como reagentes.

Devido à presença do filme, o número de pratos teóricos e/ou o tempo de retenção podem aumentar ligeiramente, mas, de modo geral, não é o que ocorre, o que indica uma interação menor com o filme e a superfície, isto é, a remoção do reagente é conduzida provavelmente por fenômenos dependentes do comportamento do fluido não da adsorção em superfície.

Tabela 4.8 - O número calculado de pratos teóricos e o tempo de retenção medido para a espiral planar (10 sccm de ar atmosférico).

\begin{tabular}{|c|c|c|c|c|}
\hline $\begin{array}{c}\text { Tempo de Retenção } \\
\text { (min) }\end{array}$ & $\begin{array}{c}\text { Número } \\
\text { de pratos } \\
\text { teóricos } \\
\end{array}$ & \begin{tabular}{|c}
$\begin{array}{c}\text { Altura equivalente } \\
\text { ao prato teórico } \\
\text { (cm) }\end{array}$ \\
\end{tabular} & $\begin{array}{l}\text { Presença de filme } \\
\text { fino de HMDS }\end{array}$ & Injeção de reagente \\
\hline 0,588 & 1,863 & 39 & Sim & \multirow{2}{*}{ n-hexano } \\
\hline 0,696 & 3,224 & 22 & Não & \\
\hline 1,070 & 6,093 & 12 & Sim & \multirow{2}{*}{ 2-propanol } \\
\hline 0,445 & 5,203 & 14 & Não & \\
\hline
\end{tabular}




\subsubsection{Canais tridimensionais}

Os testes com canais tridimensionais foram processados de modo similar aos descritos para canais planares. Assim como mencionado anteriormente, o uso de capilares é essencial para facilitar a visualização do traçador e utilizar diâmetro da ordem de décimos de milímetro. Foram também testados capilares seguindo a espiral, como um parafuso, e alterando o passo da rosca. Na Figura 4.8A observa-se uma seqüência, onde cada número indica a ordem dos frames na filmagem, da inserção do traçador em um capilar. Logo que é inserido o traçador, observa-se que este flui rápida e uniformemente, tanto em água como em glicerol. Em canais menores, de $40 \mu \mathrm{m}$ de diâmetro, a microscopia óptica (Figura 4.8B) também apresenta comportamento similar. A aparência é da formação de "linha" muito fina aparecendo apenas na região central do capilar. Este tipo de comportamento é observado nas simulações e, provavelmente, corresponde a um regime de escoamento laminar independente na viscosidade, ou seja, indica que existem regiões de pouca formação de vórtices e pouca ou nenhuma dispersão do fluido, o que pode resultar em mais regiões de equilíbrio termodinâmico, ou seja, maior número de pratos teóricos.

Estas condições são observadas também se partículas estão presentes em meio ao fluido. Conseqüentemente, a homogeneidade do escoamento ocorre devido à baixa velocidade axial e a estrutura assemelha-se a uma coluna cromatográfica. Estudo semelhante, mas em vários passos de rosca diferentes, não mostrou dispersão significativa em fase líquida.

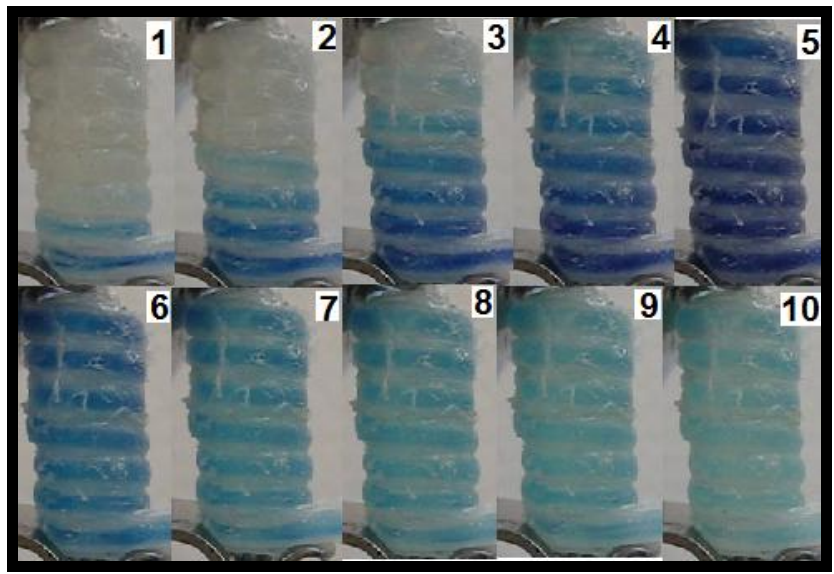

(A)
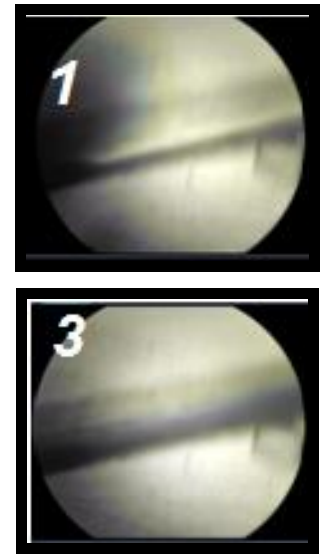

(B)
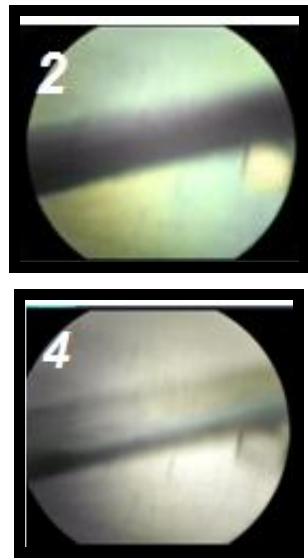

Figura 4.8 - (A) Seqüência de fotografias da solução de glicerol injetada nos microcanais tridimensionais e (B) detalhes dos microcanais fotografados usando um microscópio óptico (1- sem traçador; 2- traçador; 3- traçador parcialmente resolvido; 4- sem traçador). 
Para uma melhor compreensão do comportamento termodinâmico da estrutura faz-se necessário o cálculo do número de pratos teóricos.

Em fase gasosa, pela medida do tempo de retenção ou pelo cálculo do número de pratos teóricos (Equação 1a-d) (Tabela 4.9), é possível observar o comportamento diferenciado da estrutura quando esta estiver recoberta por um filme fino adsorvente ou apenas quando o reagente for diferente, o que indica que esta estrutura tem comportamento semelhante ao de uma coluna cromatográfica mesmo com quantidades elevadas de amostras, o que corrobora os resultados obtidos pelas simulações.

Tabela 4.9 - Cálculo do número de pratos teóricos e tempo de retenção medido para a espiral tridimensional (10 sccm de ar atmosférico).

\begin{tabular}{||c||c||c||c||c||}
\hline $\begin{array}{c}\text { Tempo de retenção } \\
\text { (min) }\end{array}$ & $\begin{array}{c}\text { Número } \\
\text { de pratos } \\
\text { teóricos }\end{array}$ & $\begin{array}{c}\text { Altura equivalente } \\
\text { aos pratos teóricos } \\
\text { (cm) }\end{array}$ & $\begin{array}{c}\text { Presença de filme } \\
\text { fino de HMDS }\end{array}$ & Injeção de reagente \\
\hline 0,053 & 5,587 & 13 & Sim & \multirow{2}{*}{ n-hexano } \\
\hline \hline 1,570 & 0,849 & 86 & Não & \multirow{2}{*}{ 2-propanol } \\
\hline \hline 0,089 & 62,693 & 0,048 & Sim & Não \\
\hline \hline 1,589 & 0,862 & 85 & \\
\hline
\end{tabular}

\subsubsection{Condições experimentais}

\subsection{Microcanais}

Como descrito anteriormente, os aspectos construtivos de colunas cromatográficas são uma variável importante na Equação de van Deemter (Equação 1a) e estes são considerados na constante A de tal equação.

Para minimizar tal influência nestas estruturas miniaturizadas, os seguintes fatores construtivos foram estudados/manipulados como segue:

*perfil e rugosidade: nestes microcanais, o perfil do microcanal é, aproximadamente triangular, como pode ser visto nas fotografias obtidas por Microscopia Eletrônica de Varredura (MEV) apresentada na Figura 4.9, onde se observa uma rugosidade muito inferior a $10 \mu \mathrm{m}$. Esta rugosidade não apresenta nenhuma regularidade de distribuição na estrutura que possa favorecer a pré-concentração pelo efeito de capilaridade [134]. Ademais, não foi observada nenhuma diferença significativa entre dois microcanais mesmo que a usinagem tenha sido feita em máquinas diferentes. Além disso, o filme fino à base de HMDS tem o papel de planarizar a superfície durante a deposição [121]. Todavia, para 
comparação, testes usando capilares de polipropileno foram realizados com a mesma metodologia para avaliar a relevância da superfície e das desuniformidades no perfil do cromatograma, como será explicado nos próximos itens.

*selagem: o processo da selagem não interfere na superfície interna dos microcanais; duas estruturas seladas foram desmontadas e avaliadas usando microscopia óptica e SEM e em torno da borda ou dentro dos microcanais não foram encontradas evidências de resíduos provenientes da selagem.

* sistema de entrada: foi usado exatamente o mesmo equipamento, apenas a coluna foi alterada.

*detector: ambos sistemas de entrada e de detecção, pertencem ao mesmo equipamento.

*injeção: embora a injeção fosse executada manualmente, apenas um operador realizou todas as experiências. A reprodutibilidade da injeção foi verifica pela inserção em capilares com diversos diâmetros internos $(0,1 \mathrm{~mm}$ a $1 \mathrm{~mm})$ e a análise do formato do pico.

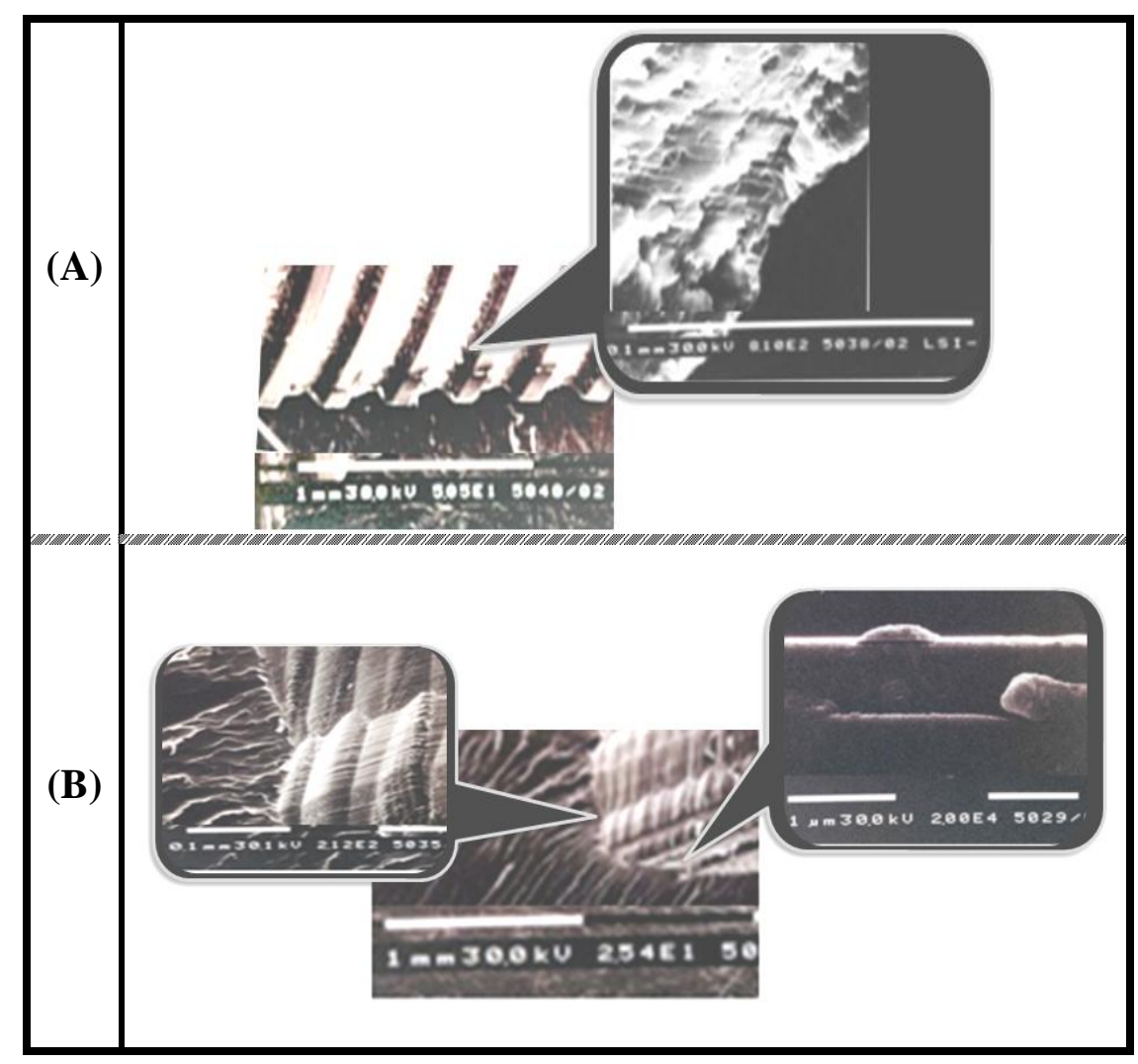

Figura 4.9 - Microscopia Eletrônica de Varredura (MEV) dos microcanais tridimensionais: (A) microcanal e rugosidade; (B) microcanal planar com rugosidade e efeito de planarização devido à deposição do filme a base de HMDS. 
Como nenhuma diferença significativa foi encontrada no formato do pico do cromatograma para qualquer diâmetro de capilar, pode-se assumir com boa segurança que não há diferença relevante na constante "A" para estas estruturas.

A constante "C" (resistência do processo a transferência de massa) foi minimizada considerando-se que o equilíbrio imediato e/ou a rápida transferência de massa - por dependerem de difusão - podem, aproximadamente, ser obtidos apenas aumentando-se a quantidade da amostra inserida. Esta aproximação implica que a altura equivalente $(H)$ na Equação 1a será anormalmente grande, isto é, as estruturas apresentarão um baixo desempenho cromatográfico, pois o pico será largo, embora o comportamento do fluído seja mais bem compreendido nesta condição.

Para preencher $1 \%$ do volume inteiro do microcanal, todas as experiências foram executadas usando a injeção de amostra igual a $0,01 \mu \mathrm{L}$. Este valor foi definido experimentalmente usando traçadores. Esta injeção ocorre em um regime laminar e usando F.I.A. (Sistema de Análise por Injeção), que assegura uma velocidade linear baixa e evita misturas por fenômenos secundários nas regiões localizadas antes da entrada do microcanal.

\subsection{Número de pratos teóricos: outras observações}

Como é importante verificar como o processo de difusão está influindo nos microcanais, para se ter uma correta descrição da $\mathrm{D}_{\text {eff }}$ (na Equação 2), o número de pratos teóricos foi avaliado de modo extensivo (várias condições de medida) e a Tabela 4.10 apresenta resultados obtidos para espiral tridimensional e planar. Os valores foram calculados para as estruturas planar e tridimensional, para meio aquoso e gasoso, usando n-hexano e 2propanol como reagente. Nesta tabela os valores são obtidos a partir diretamente do pico no cromatograma (tempo de retenção, largura do pico ou largura do pico a meia altura) e o número de pratos é então calculado a partir da Equação 1a. O fator de separação corresponde à capacidade da coluna em diferenciar dois compostos (Equação 1c), ou seja, à seletividade e o fator de capacidade ou de retenção à resolução da coluna (Equação 1d). Estes dois parâmetros são dependentes do tempo de retenção. Por fim, os picos podem ser tornar assimétricos devido a interações fortes entre analito e fase estacionária. Assim, o tempo de adsorção foi adicionado à tabela para permitir comparação com o tempo de retenção.

Observa-se que o número de pratos teóricos pode ser afetado por vários fatores, tais como, tamanho da amostra, comprimento e diâmetro interno do microcanal, tipo de filme depositado, tipo de reagente etc. De qualquer modo, a tendência à dispersão (menor número 
de pratos teóricos) é sempre maior com a espiral planar, o que está de acordo com o observado anteriormente por simulação, ou seja, a difusão lateral é fator de grande importância no sistema. 
Tabela 4.10 - Valores médios de 5 testes consecutivos usando estrutura espiral: tridimensional ou planar, modo de admissão pulsada.

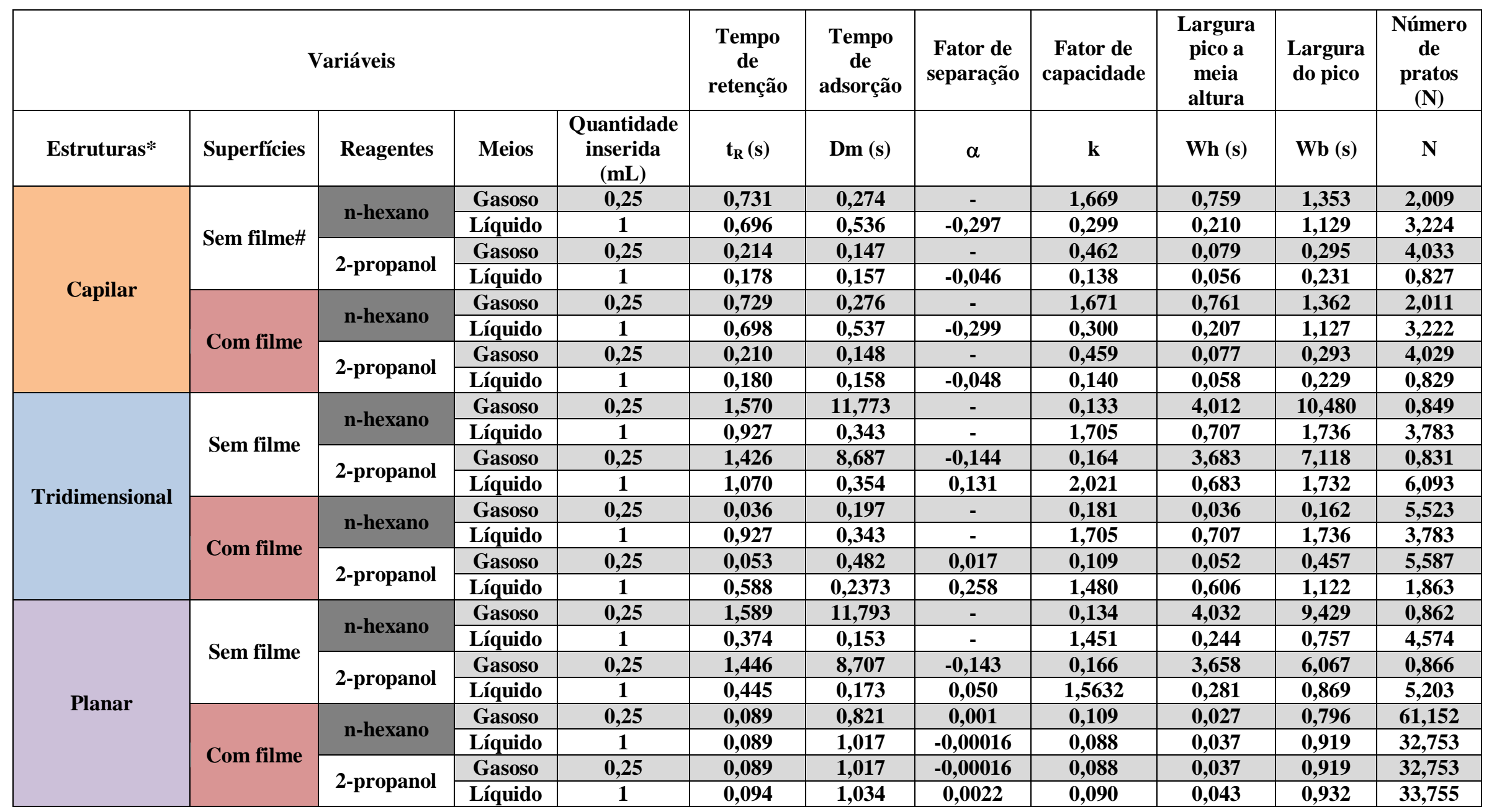

(-): valor igual a zero; (*): estruturas com $200 \mu \mathrm{m}$ de profundidade do microcanal, $40 \mu \mathrm{m}$ de diâmetro e 73 cm de comprimento de canal; (\#) Filme polimerizado a base de plasma de HMDS. 


\subsubsection{Modelo qualitativo}

O modelo qualitativo que emerge da simulação (alta velocidade lateral) das estruturas planares e que é suportado pelas medidas experimentais (Tabela 4.10) pode ser referendado por simulação de uma coluna cromatográfica usando o programa COMSOL (FEMLAB3.2®). A aproximação de difusão efetiva considera difusão isotrópica, que não é necessariamente verdadeira para geometria curvada, isto é, elevada difusão axial. Em tais casos um coeficiente de difusão artificial é admitido nas simulações, coeficientes baseados no modelo de Petrov-Galerkin e/ou alguma outra equação adicional à constante de difusão $\left(\mathrm{D}_{\text {eff }}\right)$. Este trabalho considerou ambas as alternativas.

No programa, os seguintes parâmetros podem ser alterados a fim de modelar a concentração do analito dentro dos microcanais usados para cromatografia, e os valores entre parênteses correspondem aos que foram usados nesse trabalho: (a) comprimento da coluna $(73 \mathrm{~cm})$; (b) área da coluna, supõe-se a planarização dos microcanais, ou seja, pouca rugosidade devido à deposição do filme; (c) porosidade da coluna, igual a 1, já que a coluna é capilar; (d) velocidade de escoamento da fase móvel, corresponde às velocidades utilizadas nos experimentos descritos nas Tabelas 4.5 e 4.6; (e) difusão efetiva, um parâmetro ser variado, como explicado na parte introdutória deste trabalho; (f) constante de adsorção, assumindo 0,04 m, um valor comum para adsorção moderada de VOCs; (g) concentração na fase estacionária, assumindo $10^{-6} \mathrm{~mol} / \mathrm{m}^{2}$, um valor aproximado para filme fino à base de HMDS; (h) concentração do analito, corresponde à quantidade de reagente injetada e o volume respectivo da entrada, neste caso o valor aproximado é de $1 \mathrm{~mol} / \mathrm{m}^{3}$ [98][136].

Os coeficientes de difusão ( $\mathrm{D}_{\text {eff }}$ ) são geralmente $10^{-8} \mathrm{~m}^{2} / \mathrm{s}$; entretanto, nos tubos cônicos a dispersão é alta e os coeficientes de dispersão de $10^{-4} \mathrm{~m}^{2} / \mathrm{s}$ são possíveis. Conseqüientemente, não só $10^{-8} \mathrm{~m}^{2} / \mathrm{s}$, mas também $10^{-4} \mathrm{~m}^{2} / \mathrm{s}$ foram igualmente testados como coeficientes de difusão efetiva.

Os Gráficos 4.5 e 4.6 apresentam resultados típicos, isto é, os valores mais dispersos para solução aquosa saturada de n-hexano com injeção de 0,1 $\mu \mathrm{L}$. Para tais condições, a estrutura planar leva a uma assimetria completa no pico (Gráfico 4.5A) enquanto a tridimensional apresenta somente um alargamento no pico (Gráfico 4.6A). 
Simulações usando FEMLAB 3.2B® foram realizadas a fim reproduzir picos assimétricos, que pudessem ser obtidos assumindo-se uma constante de difusão elevada $\left(10^{-4} \mathrm{~m}^{2} / \mathrm{s}\right)$ acrescentada de uma variação temporal, segue a Equação 5.

$$
\left[\mathrm{D}_{\text {eff }}=1.10^{-4}+\left(\operatorname{sen}\left(0.05^{t}\right) \cdot \operatorname{sen}\left(0.05^{t}\right)\right)\right] \quad \text { Equação } 5
$$

A equação foi montada considerando grande dispersão (termo $1.10^{-4}$ ) e que esta dispersão é dependente da velocidade axial; o termo senoidal foi inserido considerandose o número de máximos e mínimos encontrados nas simulações, ou seja, o valor da dispersão varia do mesmo modo que a velocidade axial; isto é, considera-se que a velocidade axial tem um papel importante no coeficiente de difusão e que seu comportamento cíclico pode aumentar o escoamento secundário e conduzir a um perfil assimétrico da concentração do analito dentro dos microcanais.

Os resultados das simulações são apresentados nos Gráficos 4.5 e 4.6. Os Gráficos 4.5(A) e 4.6(A) representam gráficos típicos obtidos em Microbalança de Quartzo (QCM) para estrutura planar e tridimensional, respectivamente. Essas medidas ocorreram em meio aquoso e a inserção de amostra ocorre após vários minutos da estabilização do sinal. Os Gráficos 4.5(B)(C) e 4.6(B)(C)(D) são gráficos típicos obtidos no simulador FEMLAB 3.2® e apenas indicam o formato provável do pico, não seu tempo de eluição. Assim, a forma do pico corresponde à forma esperada à saída do equipamento, ou seja, ao cromatograma. Estes gráficos são dispostos em conjunto para comparação entre os dados experimentais e os simulados e permitir observar as similaridades.

O comportamento cíclico de $\mathrm{D}_{\text {eff, }}$ na espiral planar (Gráfico 4.5B) leva a uma deformação perfil de concentração que, se também for associado a uma forte adsorção na fase estacionária (na equação, $10^{-3} \mathrm{em}$ lugar de $10^{-4}$ ), produz uma condição onde pico já não existe (Gráfico 4.5C), isto é, o sistema trabalha como um pré-concentrador.

Por outro lado, se a difusão é isotrópica (Gráfico 4.6B) ou há um incremento na difusão lateral de apenas 2 vezes (Gráfico 4.6C, modelo de Petrov-Galerkin) ou há mudanças exponenciais da difusão, com a constante de difusão igual a $10^{-4} \mathrm{~m}^{2} / \mathrm{s}$ (Gráfico 4.6D), a simetria é influenciada apenas ligeiramente. Portanto, esta estrutura é útil como uma coluna cromatográfica nestas várias condições. 


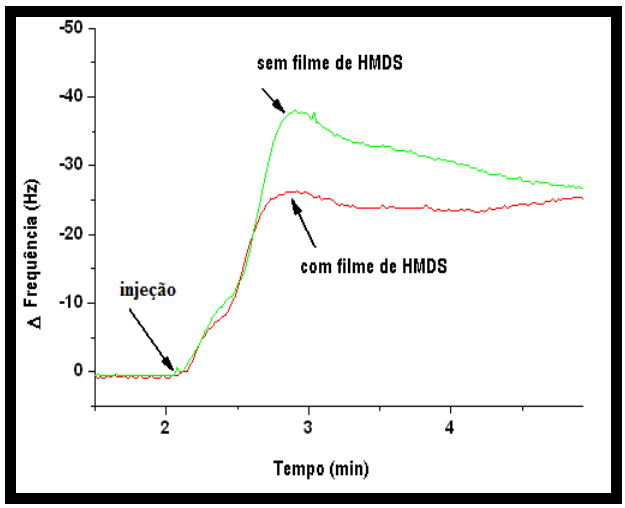

(A)

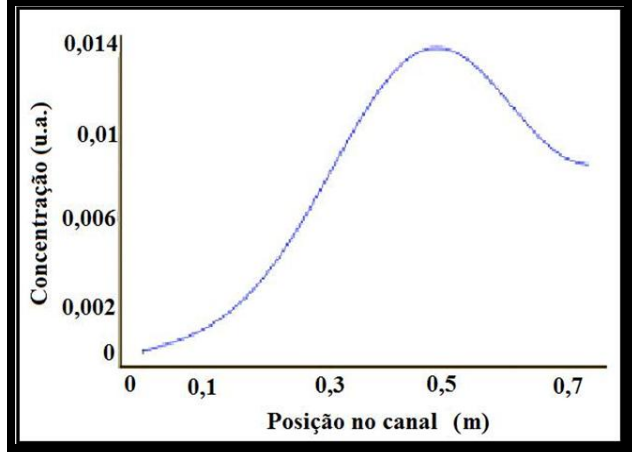

(B)

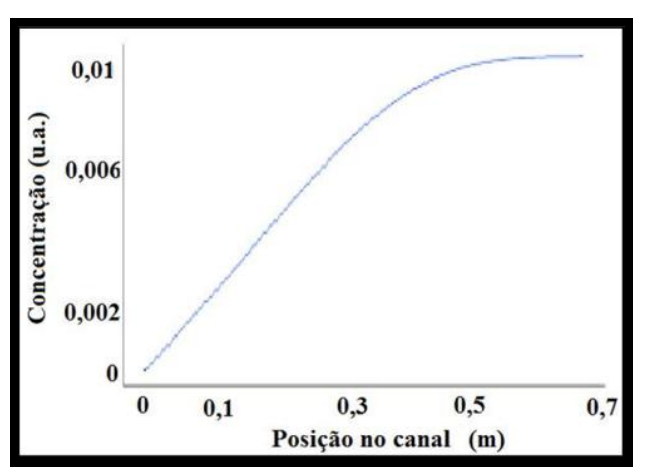

(C)

Gráfico 4.5 - Picos obtidos para as condições (solução aquosa de n-hexano, injeção de $0,1 \mu \mathrm{L}$ para volume total de água) (A) espiral planar; resultados de simulações, (B) e (C) concentração do analito em unidades arbitrárias em função da posição dentro dos microcanais. 

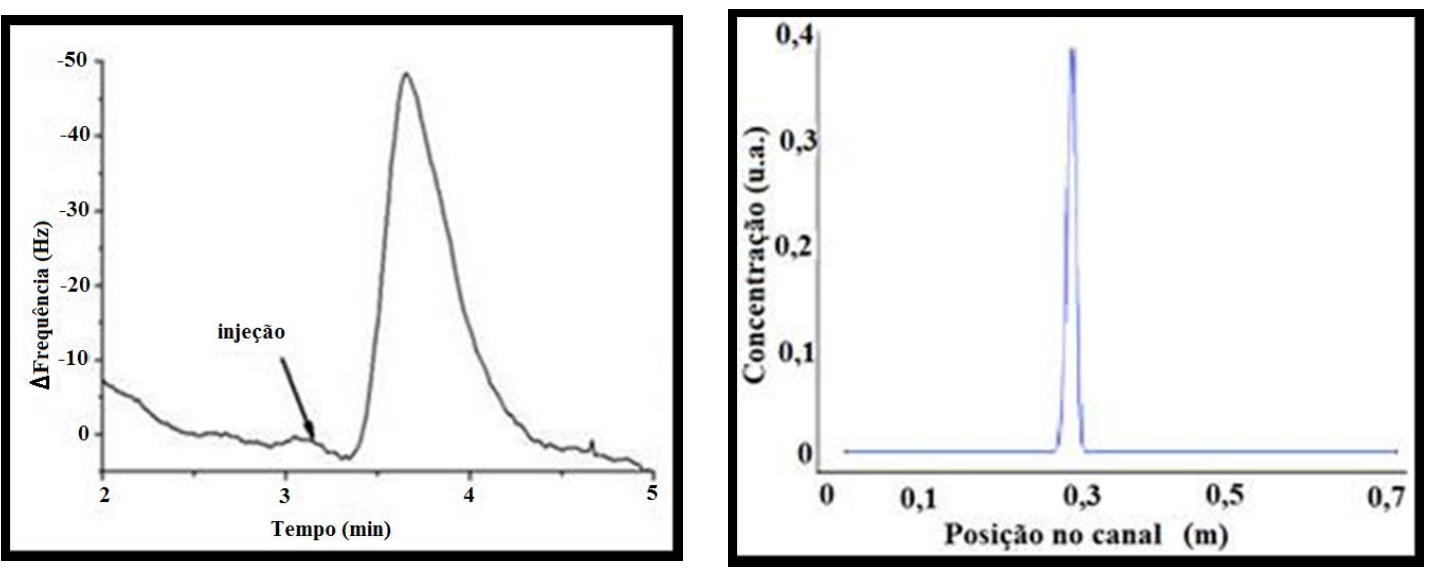

(A)

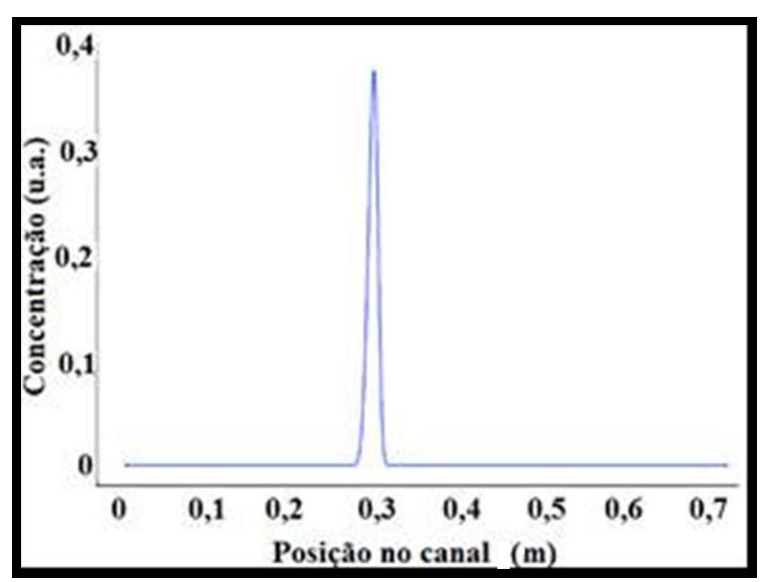

(C)
(B)

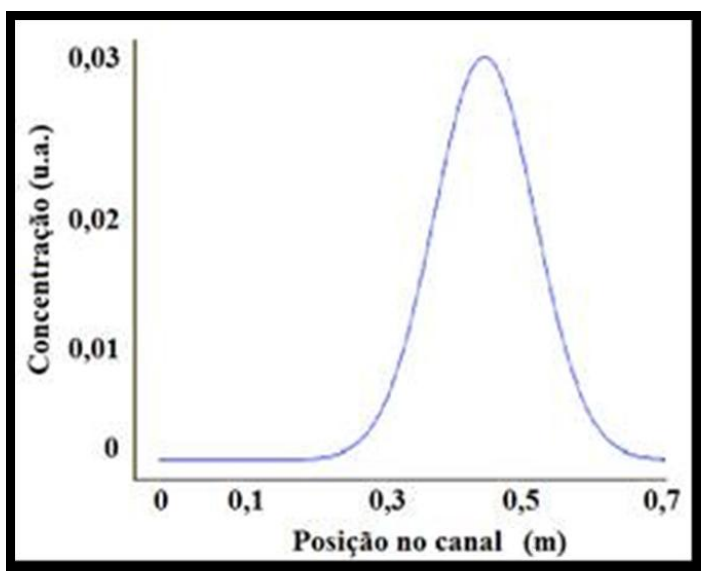

(D)

Gráfico 4.6 - Picos obtidos sob as "piores" condições (solução aquosa de n-hexano, injeção de $0,1 \mu \mathrm{L}$ para volume total de água) espiral (A) tridimensional; (B) helicoidal com difusão isotrópica $\left(10^{-8} \mathrm{~m}^{2} / \mathrm{s}\right) ;(C)$ aumento na difusão lateral (de 2 vezes) ou (D) aumento na taxa da difusão $\left(10^{-4} \mathrm{~m}^{2} / \mathrm{s}\right)$.

\subsubsection{Conclusão parcial}

A avaliação qualitativa do comportamento de microcanais tridimensionais em comparação com as estruturas planares usando traçadores para visualização em fase liquida, a injeção de reagentes e medidas cromatográficas em fase gasosa mostram boa coerência com os resultados das simulações e indicam outros usos aos microcanais, 
tanto planar quanto tridimensional, além da coluna cromatográfica. Muito embora ambas configurações já fossem usadas com sucesso como colunas cromatográficas, há vantagens significativas em usar microcanais tridimensionais como colunas cromatográficas e planares em unidades de pré-concentração.

Para a produção de spray, os resultados indicam vantagens no uso do canal planar devido à dispersão, mas o canal tridimensional apresenta uma dimensão final muito pequena além da facilidade de fabricação e manutenção.

\subsubsection{Configurações do spray}

Para a construção do spray, tanto canais planares como tridimensionais foram simulados e testados. As microestruturas capazes de gerar sistemas de spray são formadas por duas partes: a primeira possui o microcanal usinado enquanto a segunda tem como função apenas selar este canal. Estas estruturas foram desenvolvidas para permitir interações entre líquido e gás, e estão de acordo com o proposto por Pougatch [137].

A Figura 4.10 apresenta os esquemas detalhados das estruturas e dos microcanais usados/testados para geração do spray. Tanto as entradas para inserção de gás/líquido quanto os microcanais secundários foram feitos por usinagem mecânica. Os microcanais planares receberam um orifício na parte central da estrutura e, apenas para a comparação com a estrutura tridimensional, foram também divididos igualmente em duas partes. A estrutura tridimensional recebeu um risco perpendicular ao microcanal. Assim, a idéia geral é a admissão simultânea de gás e líquido em um único microcanal, mas com interações múltiplas do fluido. As estruturas têm volume interno de $1,1.10^{-3}$ $\mathrm{cm}^{3}$ e a área interna de $1,4 \mathrm{~cm}^{2}$, com a relação área/volume igual a 1300 . A integridade de ambas as estruturas foi avaliada e corresponde a uma sobre pressão de até $3 \mathrm{~atm}$, tanto sob escoamento líquido quanto gasoso. Os testes e as simulações usaram taxas de escoamento até $10 \mathrm{sccm}$ para fluidos gasosos e até $1 \mathrm{~mL} / \mathrm{min}$ para fluidos líquidos. Os fluidos usados em fase gasosa ou líquida foram de nitrogênio/ar atmosférico ou água, respectivamente. Devido às limitações da máquina, a simulação do canal tridimensional utilizou apenas um passo da rosca. 


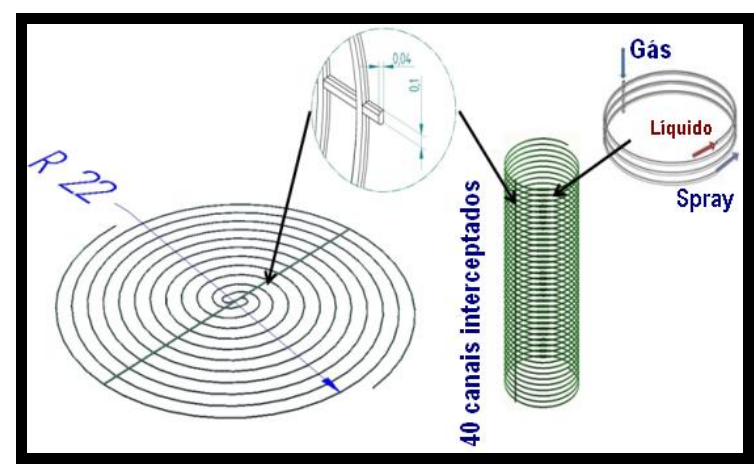

(A)

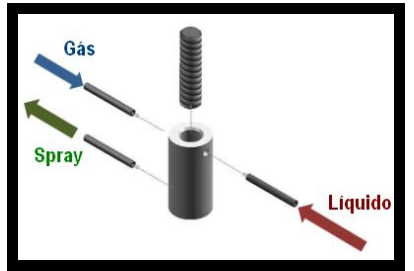

(B)

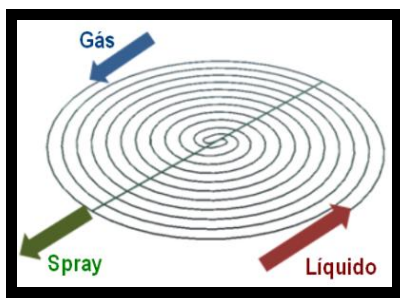

(C)

Figura 4.10 - Produção de spray com os microcanais: (A) planares e (B) tridimensionais e (C) detalhe de como é formado o spray nas estruturas planares.

O aparato (Figura 4.11) para produção do spray é formado por um compressor de ar atmosférico pequeno com duas saídas simultâneas e um capilar que trabalha como "porta" amostra; sendo assim, a quantidade máxima de líquido transformada em spray é controlada por seu volume. Uma folha de papel, utilizada como anteparo, é mantida a frente da estrutura, a $10 \mathrm{~cm}$, com o intuito de observar a formação de "bolhas/respingos", bem como, a forma e dimensão das gotas advindas do spray. Em tais testes somente as gotas maiores serão determinadas, ou seja, as formadas pelo mecanismo de Rayleigh [138].

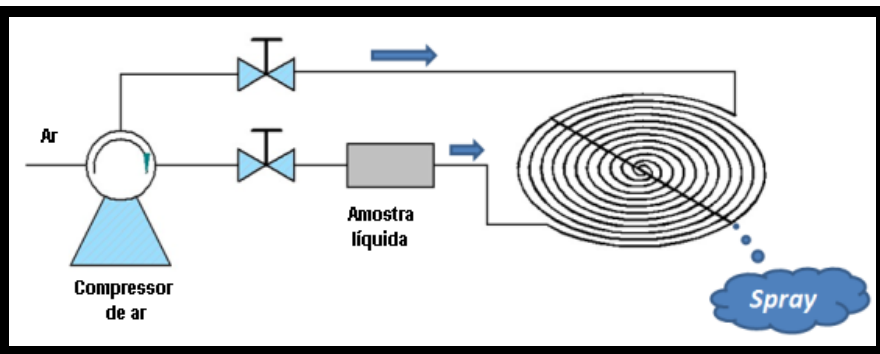

Figura 4.11 - Esquema do aparato montado para a formação do spray usando a estrutura planar.

É importante observar que no caso do canal planar, quando se utiliza apenas um ponto de admissão de gás, considera-se a possibilidade do aumento do número de gotas 
formadas, se comparadas a um canal curto, devido a existência da dispersão lateral do fluido. Por outro lado, para os canais tridimensionais é possível - através de um único sulco - adicionar vários pontos de admissão de gás o que aumenta a interação líquido/gás e resulta numa menor dispersão lateral.

\subsubsection{Testes do spray}

Esta etapa compreende não só avaliação do comportamento de spray por simulação como também os testes experimentais em microcanais planares e tridimensionais. Para testes nas duas estruturas utilizou-se a mesma configuração (Figura 4.11). Um compressor de ar com duas saídas foi utilizado para impulsionar a amostra (gás de arraste), que corresponde a um volume pré-determinado e é mantida em um capilar ("porta” amostra). É possível variar a vazão de cada uma das saídas do compressor com o uso de válvulas. O procedimento inicia-se com a adição de ar atmosférico, por uma das entradas da estrutura, seguido da adição da amostra; portanto, sempre ocorre interação entre líquido e gás. O spray formado é analisado por filmagens para verificação da homogeneidade da "nuvem" formada e o tamanho da gota é avaliado mantendo-se um anteparo a $10 \mathrm{~cm}$ de distância e, posterior mensuração do diâmetro das gotas que atingem tal anteparo. Quando a dispersão for utilizada, gotas serão formadas principalmente por um aglomerado de partículas, pois o líquido é adsorvido pelo anteparo. Como as partículas - devido ao tamanho - são difíceis de visualizar, usou-se o traçador para que fosse possível visualizar onde as gotículas são formadas.

\subsection{Spray: microcanais planares}

Os resultados da simulação obtidos são apresentados para admissão simultânea de água $(1 \mathrm{~mL} / \mathrm{min})$ e de gás, $\mathrm{N}_{2}(10 \mathrm{sccm})$.

Por simulação, observou-se que há variações periódicas na velocidade (cíclicas), na vorticidade e no Número de Reynolds, o que favorecer a formação do spray, mesmo que a admissão de gás e líquido ocorra em um único ponto (entrada) do canal (Figura A.5). Contudo, essa variação é bem menor que a observada se um orifício é inserido no centro da espiral. No centro da estrutura, a alta dispersão do escoamento e as grandes variações da velocidade e do Número de Reynolds que ocorrem, provavelmente 
favorecem a formação do spray. Três possibilidades diferentes foram simuladas e posteriormente testadas experimentalmente, como pode ser observado na Figura 4.12.

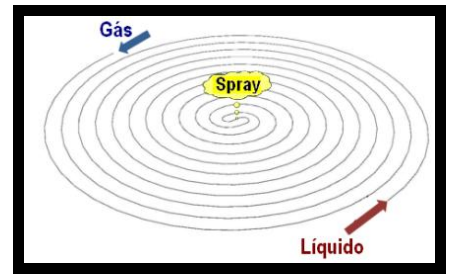

(A)

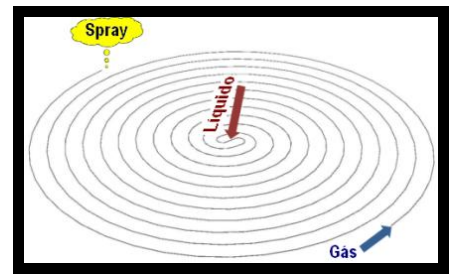

(B)

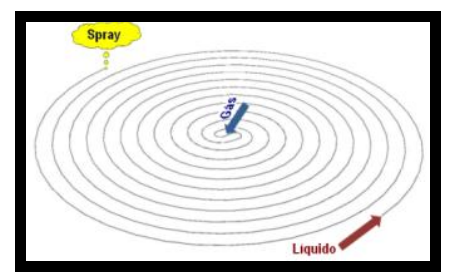

(C)

Figura 4.12 - Produção do spray usando os microcanais em espiral planar e um orifício no centro da estrutura: esquema de entradas e saída (A) saída do spray pelo orifício central, (B) entrada de líquido pelo orifício central e (C) entrada de gás pelo orifício central.

Para que seja produzido um spray com gotículas uniformes zonas de baixa velocidade, e provável regime laminar, seguidas por pequenas áreas com grandes turbulências são úteis. Tal situação pode ser observada nas simulações em regiões centrais da estrutura (Apêndice A, Figura A.6). Nessa condição aparentemente o spray pode ser obtido não importa que configuração seja utilizada (Figura 4.12). Contudo, as simulações apresentaram grandes diferenças na distribuição dessas zonas de baixa e alta velocidade e também no perfil de velocidade. Assim, se o spray é formado na região central da estrutura (Figura 4.12A) tem-se grande quantidade de regiões com alta velocidade (provável regime turbulento) seguidas de regiões com baixa velocidade (provável regime laminar).

Quando a inserção de líquido é feita na região central da estrutura (Figura 4.12B) o número dessas zonas diminui e o mesmo ocorre, com mais intensidade quando a inserção no centro corresponde a gás (Figura 4.12C). Uma provável consequiência é a variação no tamanho da gota e na distribuição desta, o que só pode ser verificado experimentalmente.

Também foram simuladas múltiplas interações entre o gás e o líquido para verificar se há formação de spray. Para tanto, fez-se um canal longo e perpendicular à entrada da estrutura (Figura 4.13A); esta configuração não gerou múltiplas interações. Por outro lado, diversos orifícios (um orifício em cada uma das interseções entre o microcanal da estrutura e o microcanal perpendicular) mostram uma interação melhor entre os líquidos nos microcanais perpendiculares, com vorticidade maior se comparada 
com apenas um único orifício; conseqüentemente, este formato parece ser útil para a obtenção de misturadores miniaturizados, simulações apresentadas na Figura 4.13(B)(C).

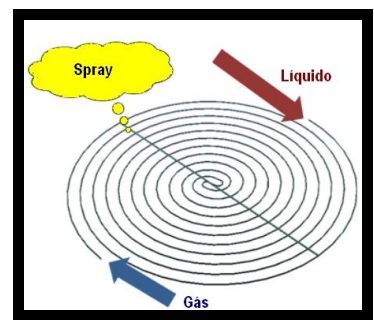

(A)

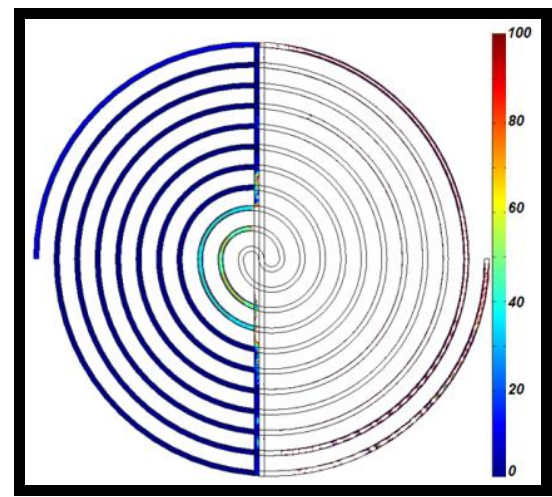

(B) (1 saída)

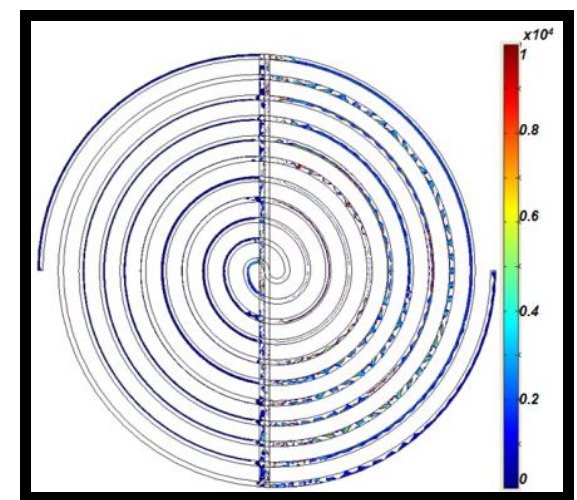

(C) (várias saídas)

Figura 4.13 - Múltiplas interações gás/líquido: (A) diagramas esquemáticos; e campo da velocidade $(\mathrm{cm} / \mathrm{s})$ em $(B)$ um ou $(C)$ diversos orifícios com a respectiva vorticidade $\left(\mathrm{s}^{-1}\right)$.

Os resultados experimentais mostram uma razoável concordância com as simulações. Todas as situações descritas na Figura 4.14 produziram gotas de spray; todavia, as gotas menores são obtidas a partir da coleta das gotas advindas do centro da estrutura (como apresentado na Figura 4.14A). Nesta condição, não são observadas gotas, isto é, o maior diâmetro da gota é menor que $20 \mu \mathrm{m}$, que corresponde à máxima resolução no sistema de filmagem. Por outro lado, nas outras duas condições, no início e no término da inserção da amostra advinda do capilar, gotas maiores, com diâmetro de até $0,1 \mathrm{~mm}$, são formadas. Assim, tem-se que pequenas áreas com alta e baixa velocidades intercaladas produzem spray com gotículas muito pequenas e grandes regiões de baixa velocidade spray com gotículas muito dispersas. Portanto, a melhor formação do spray ocorre quando a saída é feita pelo orifício central e a Figura 4.14 apresenta resultados típicos para os testes realizados nestas três condições. 

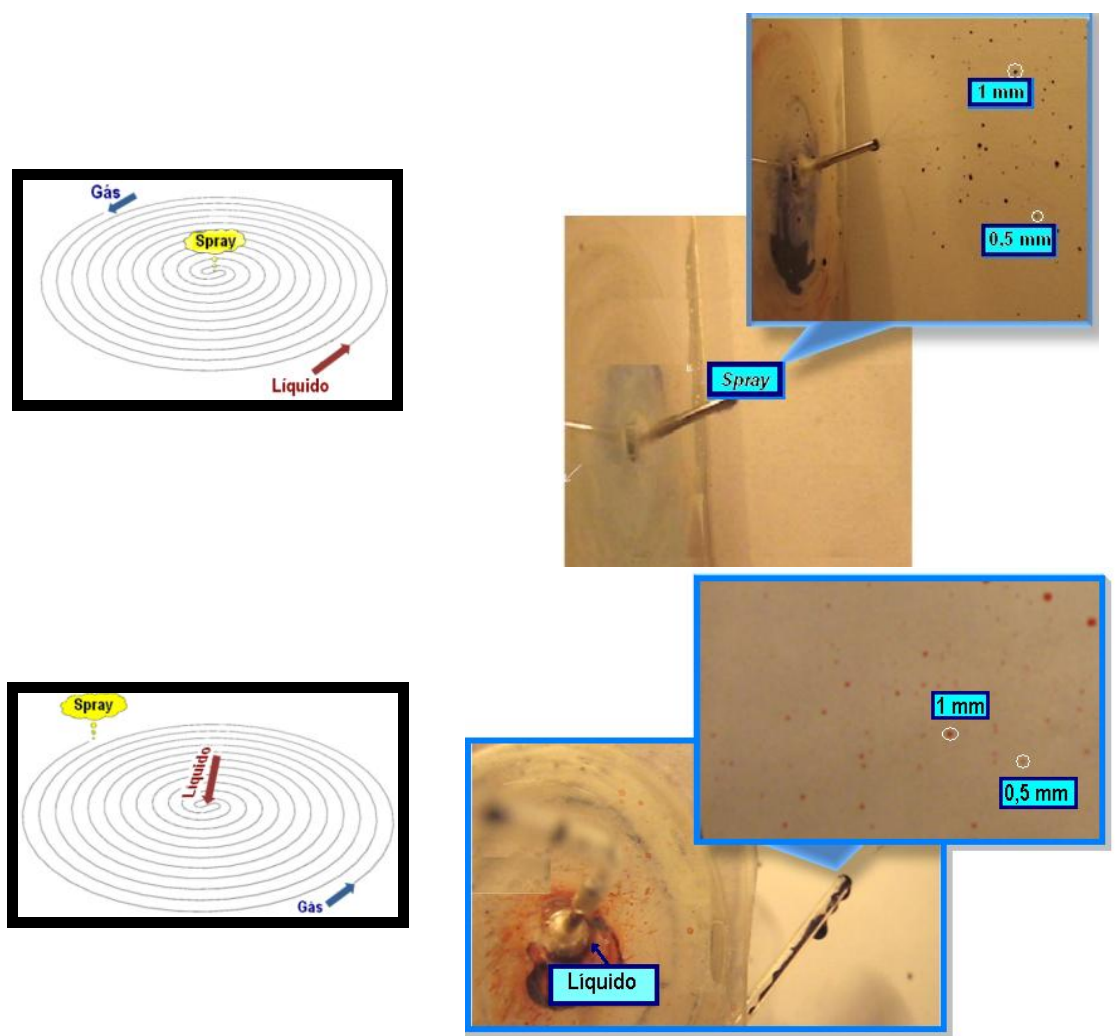

(A)
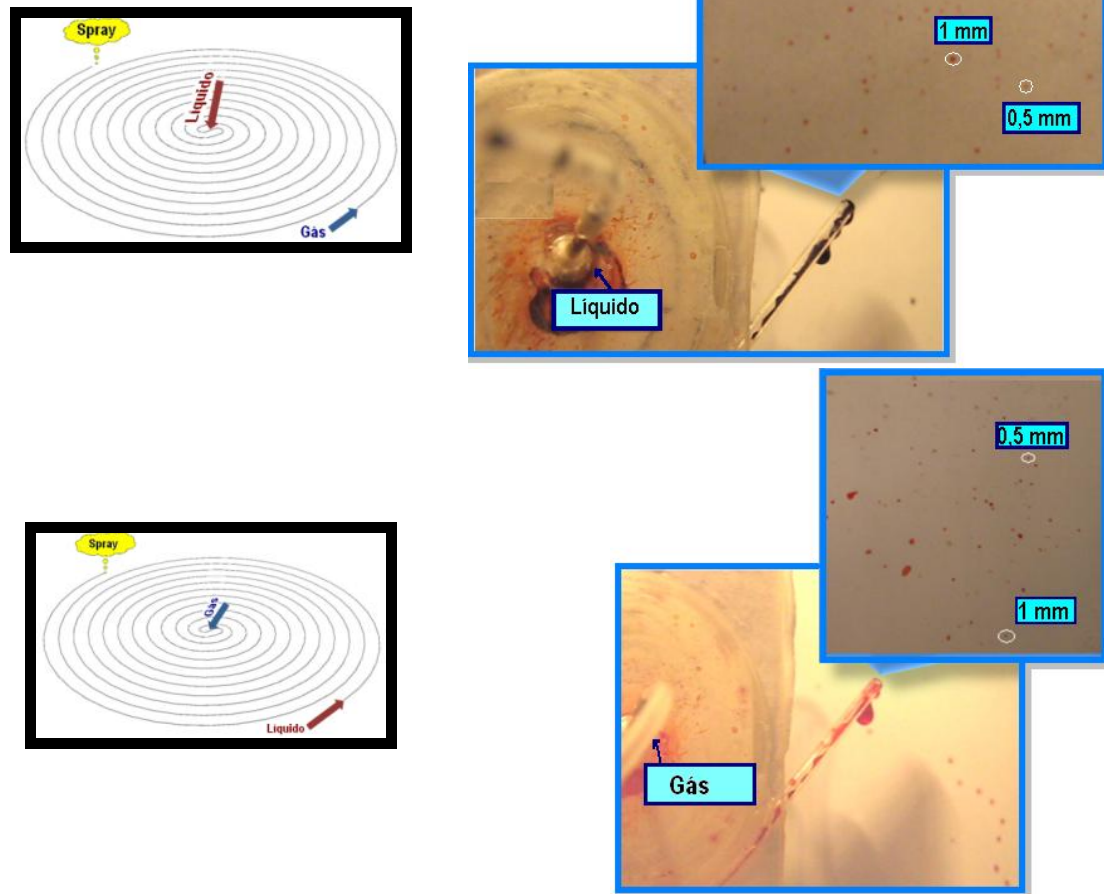

(B)

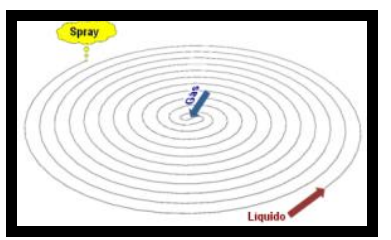

Figura 4.14 - (A) Esquema para geração do spray; (B) saída do spray pela região central da estrutura; (C) saída do spray pela lateral com inserção de líquido pela região central; e (D) saída do spray pela lateral com inserção de ar atmosférico pela região central da estrutura. Os detalhes representam a formação correspondente das gotas usando a solução aquosa e anilina inserida na estrutura planar. 
A Figura 4.15A apresenta os resultados experimentais para as condições que, segundo a simulação, não são tão favoráveis à formação do spray. Neste caso, ocorre a formação de uma primeira "gota", isto é, um jato de grande volume, o que é coerente com a menor variação do perfil de velocidade, como comentado anteriormente. A formação dessa gota não depende do tamanho do reservatório usado para inserção da amostra e nem da vazão das saídas de água e de ar atmosférico. Sendo assim, sua geração deve estar associada ao início da interação entre os fluidos, ou seja, há um "transiente" que não foi possível evitar mesmo fazendo alterações no procedimento. Após a formação da primeira gota o spray forma gotas menores, porém de grande volume se comparadas às obtidas nas outras configurações (Figura 4.15B).

Enquanto a primeira "gota" cria no anteparo uma mancha com dimensão aproximada de $10 \mathrm{~mm}$, independentemente do uso de água ou de dispersão e independente do tamanho da partícula na dispersão, as gotas subseqüentes no anteparo apresentam dimensão aproximada de $0,5 \mathrm{~mm}$ (Figura 4.16A). O uso de dispersão produz gotas no anteparo com dimensões que podem variar $0,5 \mathrm{~mm}$ até $1 \mathrm{~mm}$ para partículas com $13 \mu \mathrm{m}$ e de $1 \mathrm{~mm}$ até $3 \mathrm{~mm}$ para partículas com $50 \mu \mathrm{m}$, como apresentado nas Figura 4.16B e Figura 4.16C, respectivamente. Para facilitar a visualização do traçador dentro da estrutura usou-se poliflow® com diâmetro interno de $1 \mathrm{~mm}$ e mesmo com tamanho interno do canal diferente não se observou influência significativa no tamanho da gota formada. 


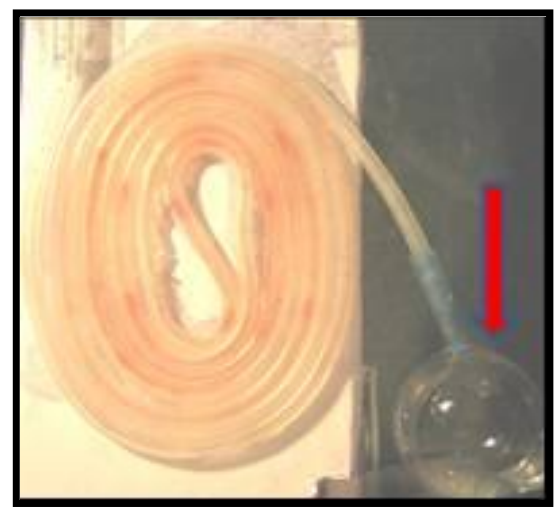

(A)

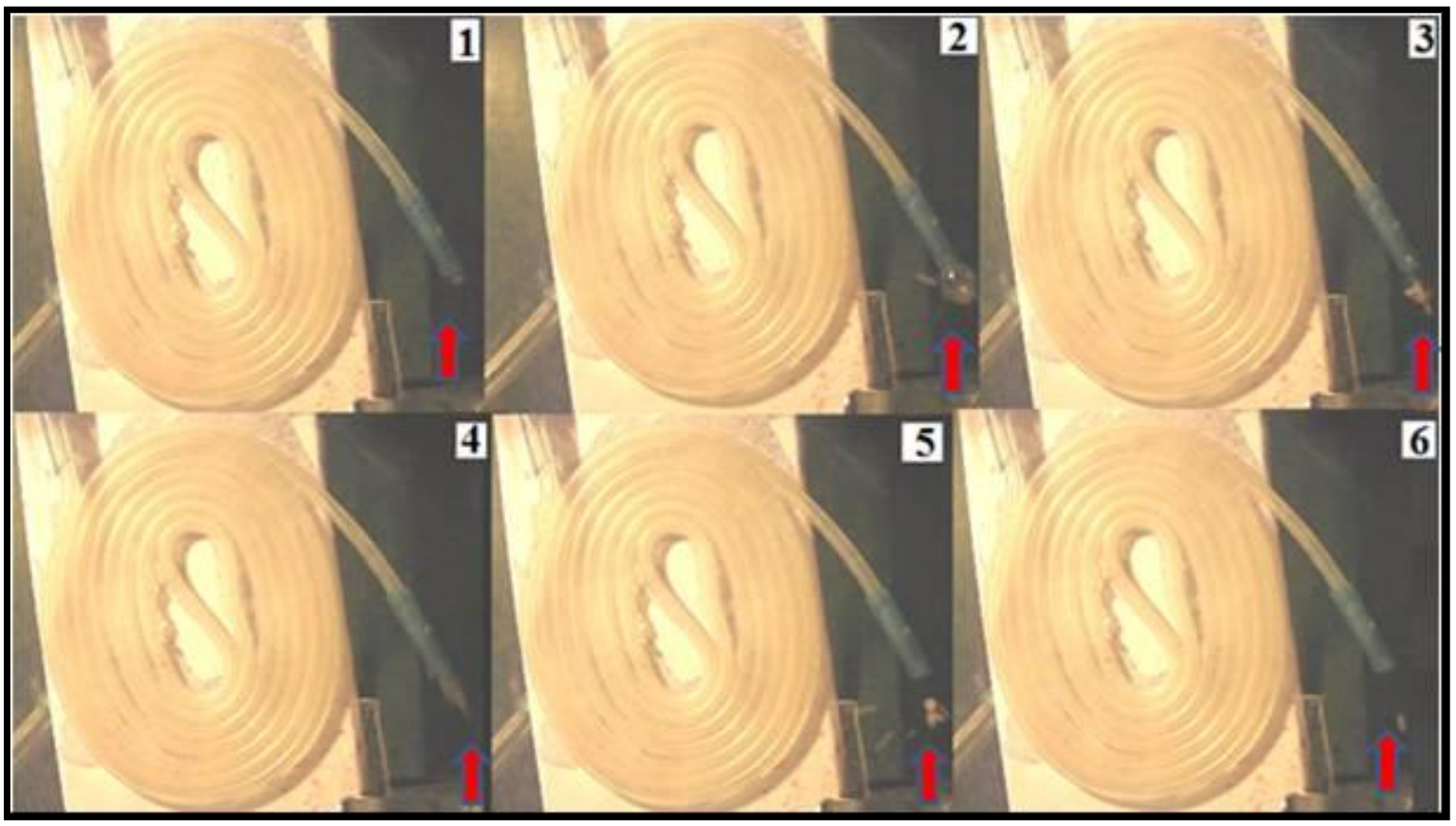

(B)

Figura 4.15 - Dispersão de partículas usando spray: (A) formação da "primeira gota em forma de bolha" e (B) seqüência de formação de gotas menores. 


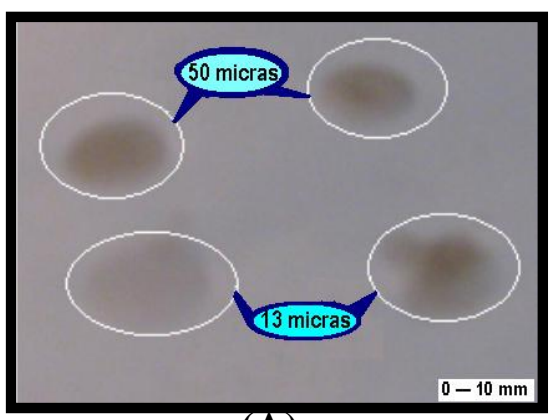

(A)

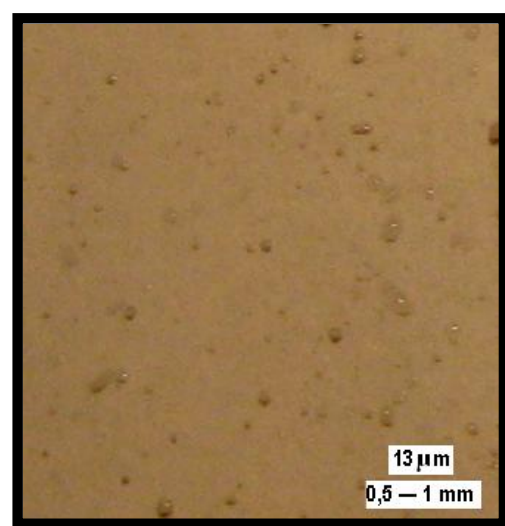

(B)

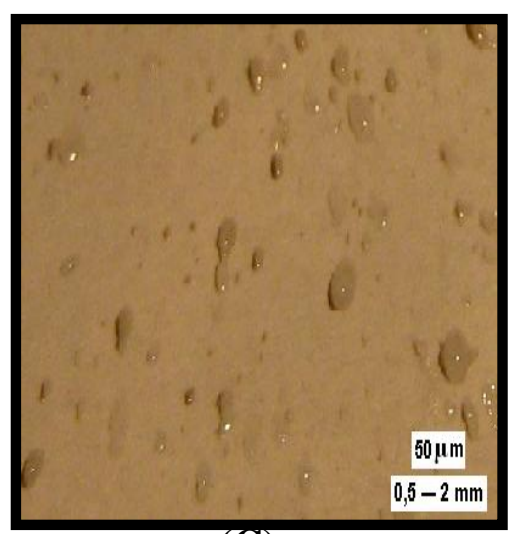

(C)

Figura 4.16 - Dispersão de partículas usando spray: (A) partículas de $13 \mu \mathrm{m}$ e $50 \mu \mathrm{m}$ obtidas na primeira gota, depositadas sobre o anteparo; (B) spray com partículas de $13 \mu \mathrm{m}$ e (C) $50 \mu \mathrm{m}$ sobre anteparo.

Outro possível uso para o spray na configuração planar é a mistura de fluidos e a Figura 4.17 mostra resultados típicos para a melhor configuração possível do aparato (spray formado no centro da estrutura) e a mistura de duas soluções distintas ou a formação do spray a partir suspensões. Nos dois casos as amostras foram coloridas para facilitar a visualização. Os testes de mistura utilizaram volume de amostra adequado para preencher completamente os microcanais, isto é, volume total mínimo de $1 \mu \mathrm{L}$ e duas amostras líquidas, com traçadores de cores diferentes - azul e vermelho, foram injetadas simultaneamente na estrutura. A observação da Figura 4.17 - que apresenta o aspecto do anteparo colocado a $10 \mathrm{~cm}$ de distância da saída do spray - indica que ocorreu mistura de líquidos, pois nesse anteparo observa-se uma área com grande concentração de gotículas com tonalidade roxa, devido à mistura dos dois traçadores. As gotas obtidas têm diâmetro mínimo $1 \mathrm{~mm}$, ou seja, são formadas por diversas gotas pequenas que atingiram o mesmo lugar. O sistema apresenta eficiência em torno de $90 \%$ porque, muito embora algumas diferenças da cor possam ser observadas, a tendência 
principal é a formação dos pontos escuros (mistura das cores vermelha e azul dos traçadores). Os testes com suspensões aquosas evidenciam que ocorre um aumento no diâmetro das gotas do spray e este aumento parece dependente do diâmetro da partícula, misturas apresentando as gotas maiores. Um mecanismo possível para explicar este comportamento é coalescência das partículas, que ocorre provavelmente durante a formação da gota dentro do microcanal e devido às variações de pressão, que indica esta configuração do spray às suspensões com $10 \%$ em peso, ou menos, de partículas.

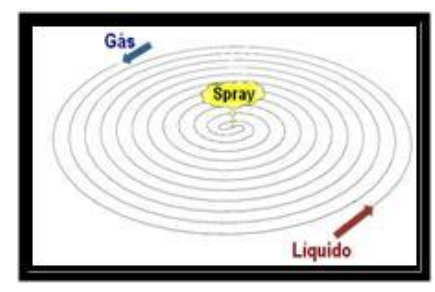

Melhor condição

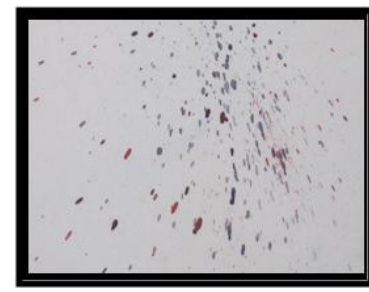

Mistura

Formação de gotas de spray com suspensão

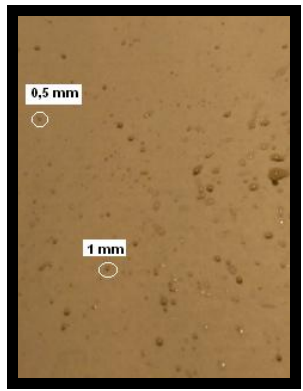

$(13 \mu \mathrm{m})$

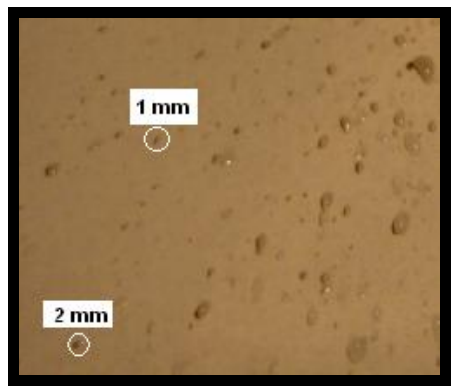

$(50 \mu \mathrm{m})$

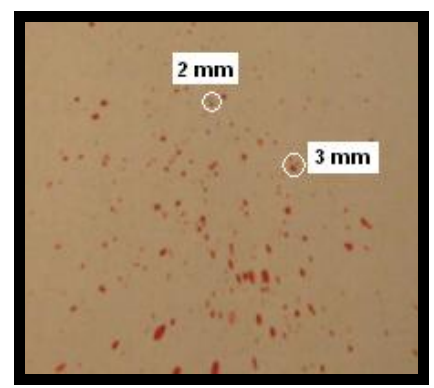

$(13 \mu \mathrm{m} \mathrm{e} 50 \mu \mathrm{m})$

Figura 4.17 - A melhor configuração para a formação do spray; mistura e gotas obtidas com suspensões de $13 \mu \mathrm{m}$ e/ou de $50 \mu \mathrm{m}$. 
Para melhor avaliar a eficiência do misturador, a estrutura espiral planar foi acoplada para admissão de reagentes em um microreator no formato cavidade selada [100]. A escolha desse reator deve-se à possibilidade de ocorrer caminhos preferenciais [139] nesse tipo de reator pode, o dificulta pode dificultar mistura. A Figura 4.18 apresenta uma foto da cavidade quando um ou dois fluidos são admitidos com o uso da espiral planar, onde não se observam caminhos preferenciais ou mesmo variação na coloração, o que evidencia que a mistura ocorreu de modo eficiente.

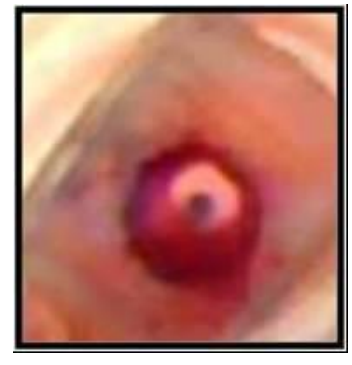

(A)

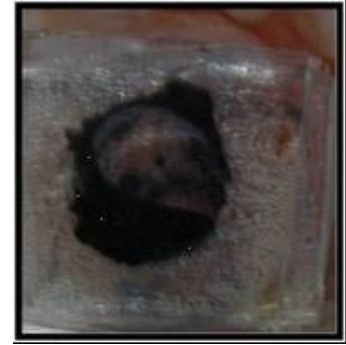

(B)

Figura 4.18 - Fotografia do microreator (formato cavidade selada) quando (A) um ou (B) dois fluidos são admitidos com o uso da estrutura espiral planar.

\subsection{Spray: microcanais tridimensionais}

Com o auxilio do simulador, foi possível observar que os microcanais tridimensionais não favorecem grande variação na vorticidade e/ou na velocidade (Apêndice A, Figura A.8), comportamento comum em colunas cromatográficas. Por outro lado, múltiplas interações entre gás/líquido podem ser obtidas facilmente.

Segundo Carvalho, o aumento do passo da rosca da estrutura tridimensional aumenta a velocidade do fluido [140]. Assim, para determinar a melhor condição de interação entre fluidos duas situações diferentes foram simuladas: interação entre dois microcanais com diferentes passos de rosca e uma linha perpendicular ao canal, ou seja, a maior variação possível na direção do fluido.

Para microcanais com pouca alteração do passo da rosca tem-se pouca perturbação no perfil de velocidade do fluido líquido mesmo que o fluido gasoso apresente uma variação significativa, isto dificulta a formação do spray, visto que para se ter um spray são necessárias variações bruscas de velocidade em pequenas regiões (Apêndice A, Figura A.8A). Entretanto, mantendo-se o passo da rosca como na 
estrutura original proposta por Lima [103] e interagindo-se gás e líquido em um ângulo de $90^{\circ}$, observa-se uma significativa mudança do perfil da velocidade, embora a velocidade máxima permaneça a mesma e, em consequiência destas interações, a vorticidade e o Número de Reynolds igualmente aumentam (Apêndice A, Figura A.8B).

As medidas experimentais demonstraram semelhanças com resultados obtidos por simulação. Na Figura 4.19(A) observa-se o esquema de como foram definidas as entradas e a saída da estrutura. O procedimento de teste consiste em manter escoamento contínuo de $1 \mathrm{~mL} / \mathrm{min}$ de ar nas conexões A e B. Na entrada "B" imediatamente antes da estrutura coloca-se a amostra (líquido, solução, suspensão etc.). Em “C” são expelidas as gotículas que serão capturadas no anteparo (em folha adsorvente) a $10 \mathrm{~cm}$ da saída. O jato do spray não pode ser perfeitamente distinguido na fotografia (Figura 4.19B), o que indica a formação de gotas minúsculas. As gotas advindas do spray e que atingiram um anteparo a $10 \mathrm{~cm}$ do bocal do jato são igualmente pequenas.

As gotas maiores não excedem $0,01 \mathrm{~mm}$ para as partículas de $13 \mu \mathrm{m}$ e $0,05 \mathrm{~mm}$ para as partículas de $50 \mu \mathrm{m}$, o tamanho da gota é determinado pelo diâmetro da partícula (Figura 4.19C e D). Um mecanismo simples para explicar tais resultados são as interações múltiplas do gás/líquido dentro dos microcanais. Devido à sequiência destas interações a coalescência é impedida, e mesmo uma dispersão fortemente contaminada (10\% em peso) pode produzir gotas pequenas. Um modo simples de evidenciar a importância das múltiplas interações é produzir uma estrutura em que ocorra apenas uma interação de fluidos. Neste caso, uma grande gota forma-se, inicialmente, não importando qual procedimento de produção de spray ou solução seja utilizado.

Uma característica importante observada nos microcanais tridimensionais é a queda relativamente pequena da pressão, isto é, nenhuma diferença na pressão foi encontrada durante os testes e já nas simulações tem-se a indicação de queda de pressão de apenas 1,1 atm na estrutura inteira. Por fim, o uso de estrutura tridimensional corresponde a diminuição do tamanho total do dispositivo, se comparado ao canal planar, o que é bastante atrativo para o desenvolvimento de dispositivos miniaturizados. 


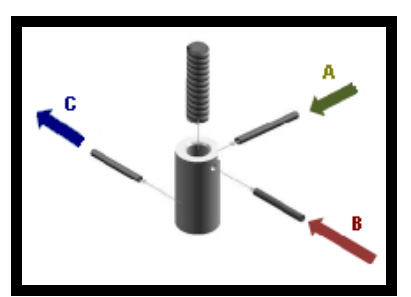

(A)

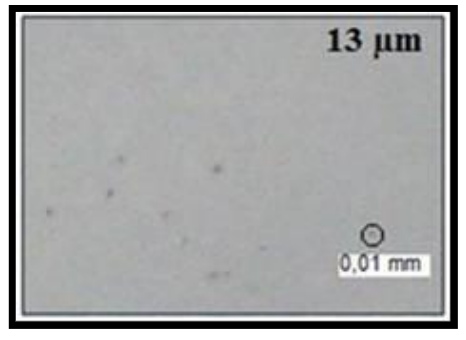

(C)

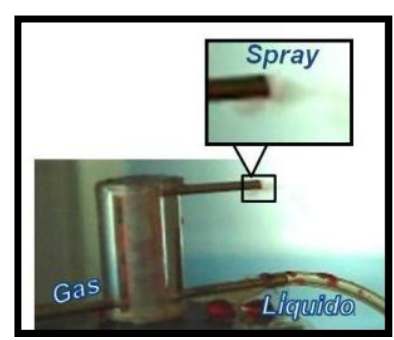

(B)

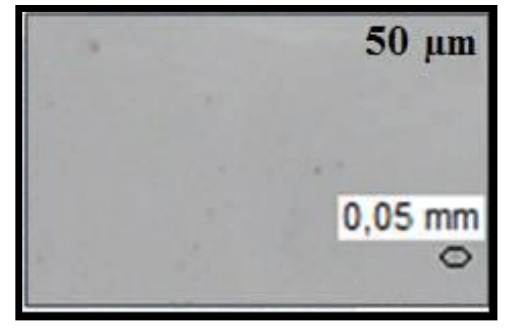

(D)

Figura 4.19 - (A) Esquema da estrutura usada para formação do spray; (B) detalhe da formação do spray, escoamento aquoso; jato do spray com suspensão de partículas de (C) $13 \mu \mathrm{m}$ e (D) $50 \mu \mathrm{m}$.

\subsubsection{Conclusão parcial}

Foi possível criar um sistema de spray tanto com estruturas planares quanto com tridimensionais. Contudo, a estrutura planar apresenta um spray não uniforme e pouco contínuo, o que dificulta a reprodutibilidade na inserção de amostras. Em contrapartida, esta estrutura apresenta comportamento interessante para mistura de reagentes.

A forma de spray mais promissora foi à obtida com a estrutura tridimensional. $\mathrm{O}$ spray mostrou-se mais eficaz porque as gotículas formadas são bem pequenas e dispersas uniformemente, ou seja, este comportamento não só garante a reprodutibilidade de inserção de amostra como facilita a captura das partículas nas placas coletoras da próxima etapa de tratamento de amostras, no impactador (estrutura capaz de reter partículas).

\subsection{Impactadores}

Os impactadores geralmente são usados para coletar partículas e/ou separá-las de acordo com suas dimensões. Diversos impactadores foram usados no último século de várias maneiras para avaliação ambiental, quer seja para grandes volumes, medidas 
voltadas para o meio ambiente (estudo de aerossóis) seja para pequenos volumes, usados em pré-tratamento de amostras. Atualmente são conhecidos inúmeros desenhos de impactadores e, entre eles, algumas miniaturizações [141][142].

Usando uma faixa de dimensão intermediária, sendo a miniaturização mais comum, um impactador bastante simples foi proposto e testado por Beraldo [99]. O impactador foi usado para coletar partículas advindas do ar mostrando alta capacidade de retenção; entretanto, este não se mostrou eficaz em amostras líquidas. Usou-se nestes impactadores filme adsorvente, contudo, este favoreceu a remoção de substâncias viscosas, como o silicone, presente na água.

Para compreender a baixa coleta de partículas em fase líquida, uma seqüência de fotografias sobre a inserção do traçador azul de metileno, foi obtida através de filmagens tanto em solução aquosa (Figura 4.20A) [53] quanto em silicone (Figura 4.20B) [16]. O comportamento do fluido assemelha-se ao obtido nas simulações por Silva [16]. A retenção pode ser compreendida observando-se as fotos, pois a solução aquosa deixa pouco, ou quase nenhum, resíduo (cor azul) entre as injeções simultâneas de traçador, já o mesmo não ocorre com a solução que contém silicone, como pode ser observado nas Figuras 4.20A e B.

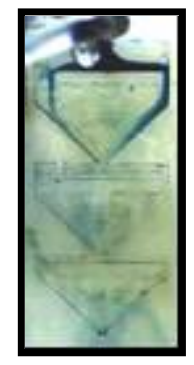

(A)

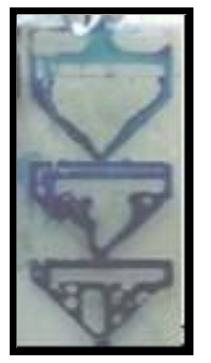

(B)

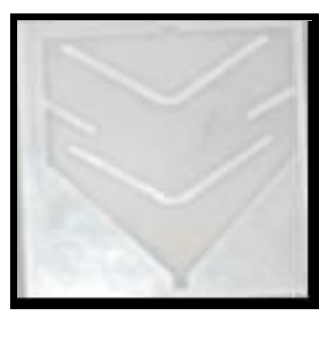

(C)

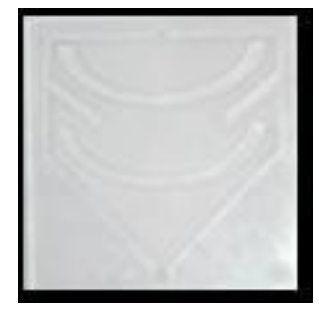

(D)

Figura 4.20 - Filmagens realizadas com a inserção de solução (A) aquosa; (B) silicone em azul de metileno na estrutura proposta por Beraldo [53][16][99]; novos desenhos utilizados para os impactadores (C) angular e (D) semi-circular.

Considerando as vantagens do uso dessas estruturas, o projeto de Beraldo [99] foi modificado e testado para remover as partículas de amostras líquidas. A questão principal na remoção da partícula em tais casos, é a interação forte entre o líquido e a placa coletora, que pode ser diminuída pelo uso de um spray. Observando o comportamento do fluido na placa coletora, nota-se grande interação. Portanto, para 
reter partículas/ reagentes, faz-se necessária a inserção não de anteparos com ângulos retos, mas com uma oblonga - aguda ou circular - para criar regiões de baixa velocidade. Assim, fizeram-se as novas estruturas denominadas: impactador angular (placa coletoras com ângulo agudo na região central da estrutura) e impactador semicircular (placas coletoras em forma semi-circular na região central da estrutura), Figura 4.20C e D.

Além disso, considerando que o spray é útil em Operações de Unitárias e/ou em pré-tratamento de amostra quando são utilizadas suspensões, os testes foram realizados usando um impactador miniaturizado e partículas suspensas tanto em amostras gasosas como líquidas.

\subsubsection{Simulações}

Para avaliar os mecanismos internos e a retenção de partículas, fez-se as simulações usando-se o simulador FEMLAB3.2B ${ }^{\circledR}$, simulação $2 \mathrm{D}$ e com base nas Equações de Navier-Stokes. Nas simulações, considerou-se como gás de arraste o Nitrogênio $10 \mathrm{sccm}$, para meio gasoso, ou água $1 \mathrm{~mL} / \mathrm{min}$, para meio aquoso. Também se simulou a inserção de partículas com diâmetro de $50 \mu \mathrm{m}$ e $13 \mu \mathrm{m}$ na estrutura.

\subsubsection{Impactador angular}

A estrutura com placas coletoras centrais angulares (ângulo agudo) apresenta velocidade praticamente nula nas regiões centrais das placas coletoras (coloração azul escuro, Apêndice A, Figura A.10). Esta também possui anteparos laterais capazes de induzir o escoamento para a região central da estrutura. As regiões de entrada e saída são as únicas que apresentam velocidade alta (coloração amarela e vermelha, Apêndice A, Figura A.10), isto é, apenas regiões distantes do centro da estrutura. O comportamento observado nas simulações sugere que estas regiões onde a velocidade apresenta-se praticamente nula serão as regiões onde as partículas ficarão aprisionadas. Como esperado, observou-se que o perfil de velocidade é coerente com o perfil de concentração relativa das partículas de $10 \mu \mathrm{m}$ (regiões representadas pela coloração avermelhada apresentadas no Apêndice A, Figura A.11A). 


\subsubsection{Impactador semi-circular}

No intuito de aumentar a área com baixa velocidade, os anteparos laterais foram removidos e o ângulo ao centro da placa coletora foi suavizado (água, vazão de 1 $\mathrm{mL} / \mathrm{min}$ ). Foi possível observar amplas regiões com baixa velocidade de escoamento (indicada pela coloração azul escuro no Apêndice A, Figura A.12), mas a remoção das placas laterais dificulta as partículas de atingirem o centro da segunda placa coletora, possivelmente por formação de caminho preferencial. Para verificar se há um caminho preferencial evidente, procedeu-se à simulação de partículas usando o mesmo regime de escoamento, anteriormente descrito. Nota-se que as partículas apresentam maior concentração na região central da placa coletora da estrutura, ou seja, provavelmente ocorreu retenção, mas com pouca eficiência (Apêndice A, Figura A.13).

Visto que os anteparos laterais realmente são necessários, esses foram adicionados à simulação da estrutura. Muito embora deva ocorrer "perda" de partículas (demonstradas por pontos amarelos localizados na saída da estrutura, Apêndice A, Figura A.14), uma grande porcentagem de partículas atinge o centro das duas placas coletoras, ocorrendo no centro da estrutura regiões com poucas partículas, portanto, há uma possibilidade de retenção, embora não seja possível determinar qual das duas estruturas (angular ou semi-circular) é mais eficiente.

\subsubsection{Testes experimentais}

O impactador foi avaliado de modo semelhante ao proposto por Beraldo [99], com partículas de $13 \mu \mathrm{m}$ e $50 \mu \mathrm{m}$. As partículas utilizadas também apresentam densidades e molhabilidades diferentes e, ao colocá-las em água, observa-se que as de $13 \mu \mathrm{m}$ flutuam e as de $50 \mu \mathrm{m}$ afundam. Na Figura 4.21 pode-se observar tal comportamento, pois adicionou-se simultaneamente partículas de $13 \mu \mathrm{m}$ e $50 \mu \mathrm{m}$ em 50 $\mathrm{mL}$ de água. Deste modo, a suspensão não pode ser guardada, ou seja, é fabricada e imediatamente utilizada nos testes. 


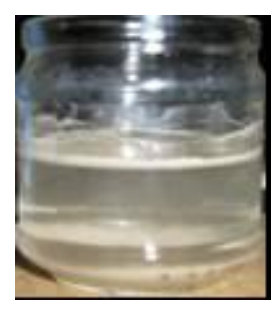

Figura 4.21 - Partículas de $13 \mu \mathrm{m}$ e $50 \mu \mathrm{m}$ em $50 \mathrm{~mL}$ de água.

\subsubsection{Fase gasosa}

Medidas usando partículas de $13 \mu \mathrm{m}$ e $50 \mu \mathrm{m}$ são difíceis de observar a olho nú na estrutura devido à sua coloração e, por este motivo, fez-se medidas em microscópio óptico. Para que seja possível observá-las é necessária uma grande quantidade de partículas o que provavelmente entupirá a entrada/saída da estrutura, que se romperá se a pressão interna ultrapassar 3 atmosferas. Para as condições onde a retenção de partículas é mais evidente, uma alternativa desenvolvida para facilitar a visualização foi a inserção de grãos de café torrados e moídos para observar onde as partículas ficariam alojadas. A Figura 4.22 apresenta fotografia do impactador angular e respectivas regiões onde se alojaram as partículas de café imediatamente após o rompimento da estrutura.

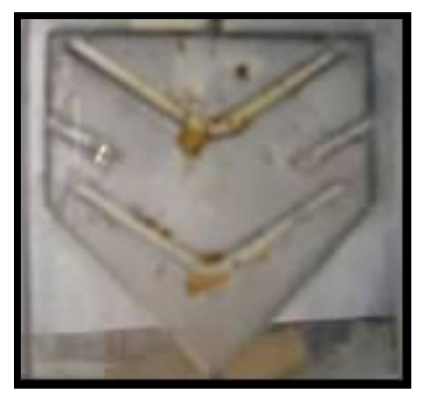

\section{Figura 4.22 - Estrutura impactadora angular com a inserção de grãos de café torrados e moídos sob escoamento aquoso.}

As partículas de $13 \mu \mathrm{m}$ apresentam facilidade para migrar com o fluido e a retenção destas ocorre não só na região onde há baixa velocidade, mas também onde existem contrições. A Figura 4.23 esquematiza os locais mais prováveis de ocorrer a retenção depois da inserção de partículas de $13 \mu \mathrm{m}$ (fotografia obtida usando o microscópio óptico). 


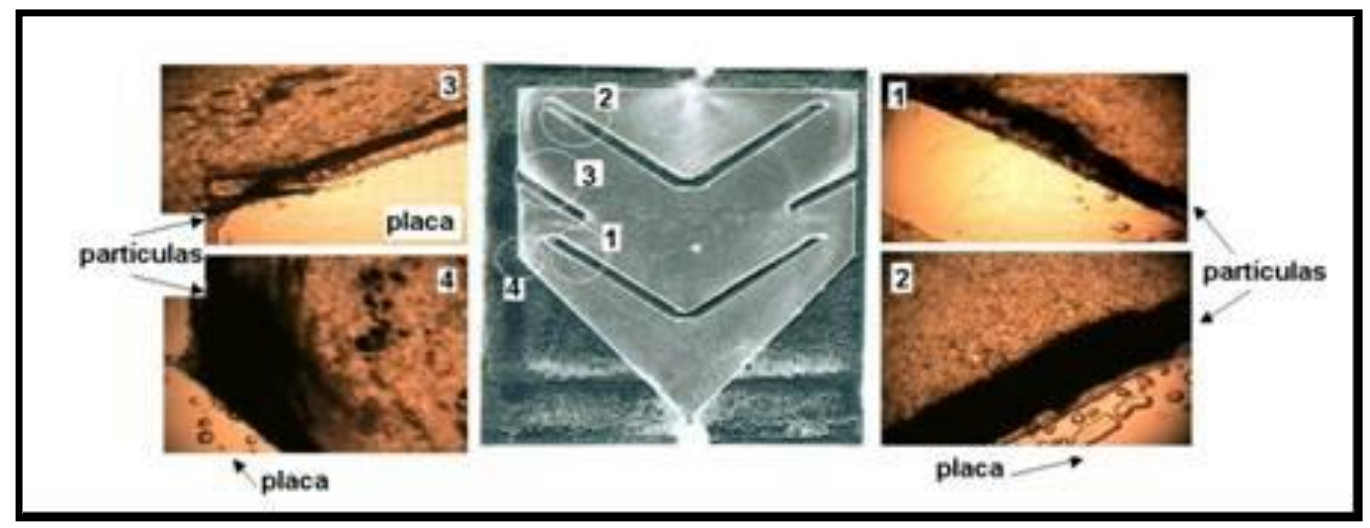

Figura 4.23 - Retenção de partículas de $13 \mu \mathrm{m}$, condição posterior a inserção.

Por outro lado, as partículas de $50 \mu \mathrm{m}$ apresentam maior tendência de se localizar no centro da placa coletora, como mostra a Figura 4.24, ou seja, o impactador é favorável à retenção. Nos dois casos, $13 \mu \mathrm{m}$ e $50 \mu \mathrm{m}$, a retenção foi de aproximadamente $100 \%$, pois não se observou partículas na saída da estrutura. $O$ tamanho total do impactador [que varia entre $0,5 \mathrm{~cm}$ e $5 \mathrm{~cm}$ ] não interfere no processo de retenção, apenas define a máxima quantidade retida; assim, partículas de $50 \mu \mathrm{m}$ serão melhor retidas em impactadores de $5 \mathrm{~cm}$ de comprimento, devido ao seu grande volume, enquanto impactadores de $2 \mathrm{~cm}$ de comprimento são mais adequados para 13 $\mu \mathrm{m}$.

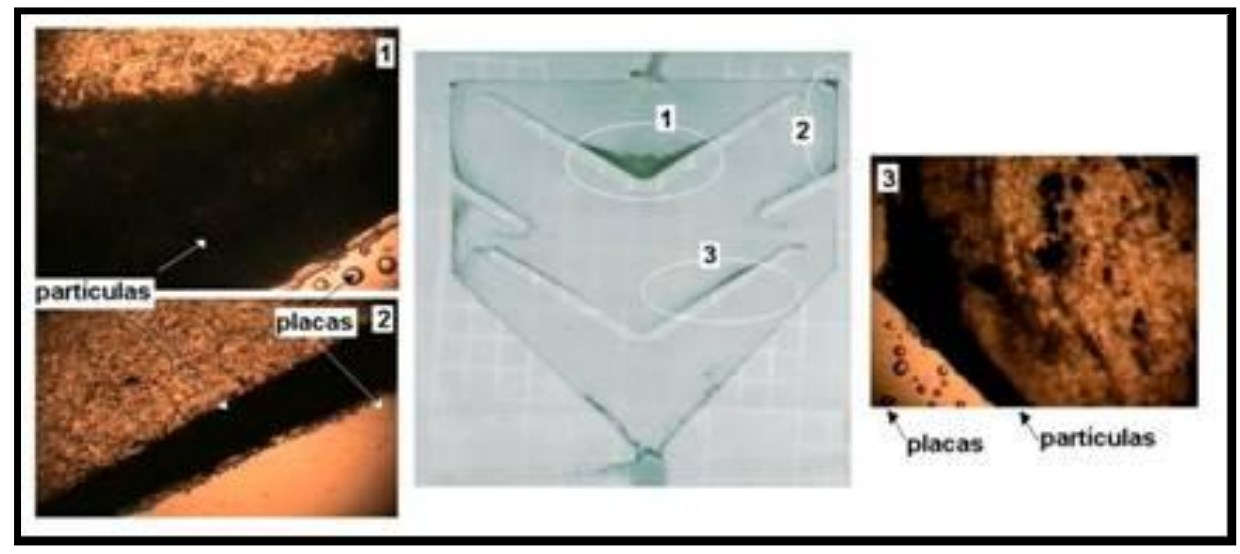

Figura 4.24 - Retenção de partículas de $50 \mu \mathrm{m}$, esquema dos locais mais prováveis de ocorrer à retenção após a inserção. 


\subsubsection{Fase líquida}

Durante os testes usando filmagens, inicialmente, observa-se que na região central, onde o ângulo é bastante acentuado, ocorre a formação de vórtices, porém, ao longo da estrutura observa-se a dispersão do escoamento pelas laterais da placa coletora central. Imediatamente abaixo, nas laterais da região de uniformização, nota-se alto escoamento, que é aproximadamente nulo na região central da estrutura. Além disso, percebe-se que as partículas mais "pesadas" $(50 \mu \mathrm{m})$ se concentram no primeiro coletor e as mais "leves" $(13 \mu \mathrm{m})$ no segundo. Para facilitar a visualização das partículas muito leves usou-se glicerol para observar como estas se comportariam (Figura 4.25).

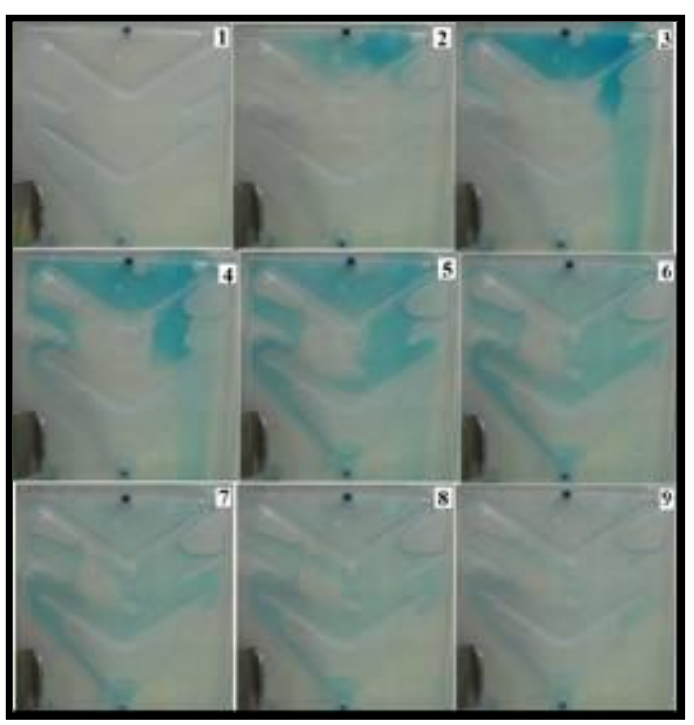

(A)

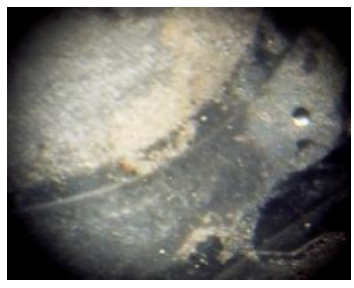

(C)

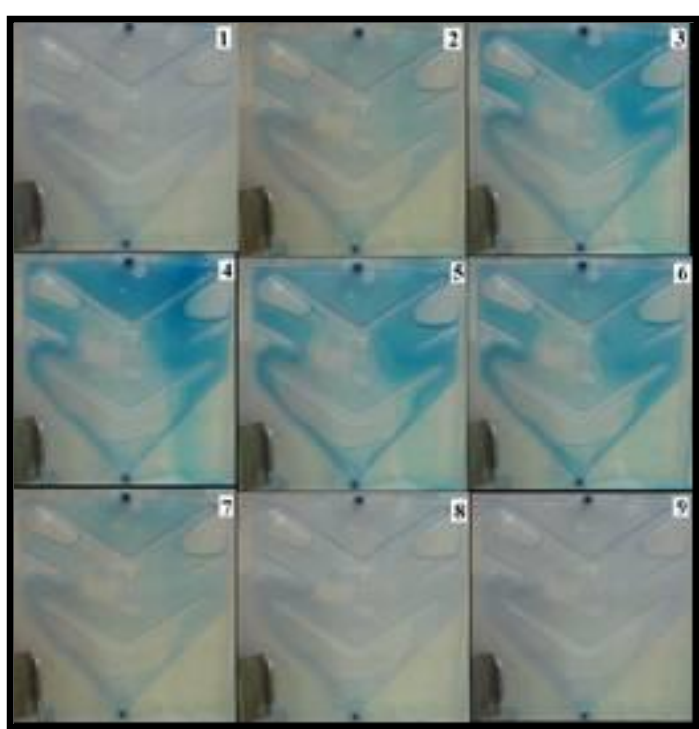

(B)

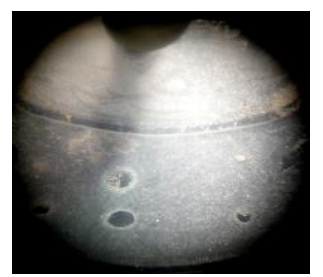

(D)

Figura 4.25 - Imagens do impactador angular com (A) solução 10\% azul de metileno em água destilada e (B) solução $10 \%$ azul de metileno em glicerol; (C)

Retenção na placa coletora do impactador semi-circular e (D) detalhe das partículas, usando pequena admissão, $5 \mu \mathrm{L}$, de amostra. 
Nas sequiências de fotografias observa-se regiões com pouco ou nenhum traçador - que onde há uma semelhança com a formação de bolhas de ar, porém, não se trata realmente de bolhas de ar, provavelmente nestas regiões não há escoamento devido a fenômenos como a formação de vórtices. Após os testes, pôde-se observar que a estrutura impactadora angular apresentou comportamento semelhante à estrutura desenvolvida por Beraldo [99] (testada para fase gasosa). Muito embora esse impactador apresente retenção para fase líquida, a eficiência é baixa, aproximadamente $20 \%$ e pouca quantidade de amostra (menor que $10 \mu \mathrm{L}$ ) é processada eficientemente.

Para verificar se é o mecanismo que causa a baixa eficiência, partículas foram adicionadas ao impactador e apenas água foi admitida, observando-se que ao longo do tempo o líquido removeu parte das partículas anteriormente assentadas na placa coletora, o que também explica porque apenas baixos volumes podem ser processados de cada vez. Assim, para se obter retenção próxima de 100\%, é necessária adição de uma pequena amostra de cada vez. Nesta condição a retenção ocorre nas regiões esperadas de acordo com a simulação, mesmo para o impactador semi-circular, como pode ser observado na Figura 4.25C.

\subsubsection{Sistema de spray}

Com o uso de spray, é possível retenção de partículas com alta eficiência independentemente do tamanho ou forma do impactador, a principal diferença corresponde à massa total retida. Após vários testes experimentais observou-se que o impactador miniaturizado (comprimento total de $7 \mathrm{~mm}$ e largura $5 \mathrm{~mm}$ e profundidade $500 \mu \mathrm{m})$ que se demonstrou mais eficiente, no presente caso foi, o impactador angular, quando acoplado ao sistema de spray.

A Figura 4.26 apresenta uma seqüência de fotografias de situações onde se observa o comportamento da dispersão aquosa fortemente contaminada com partículas (10\% em vol.). O líquido límpido, com redução de $90 \%$ das partículas, pode ser observado nas fotografias finais (Figura 4.26B, fotos 7 e 8). A sequiência indica que é possível remover tais partículas usando estas duas estruturas acopladas. Assim, a adição do sistema de spray permitiu que cada pequeno volume tratado, correspondendo às gotas formadas, não fosse atingido na sequiência por quantidade expressiva de solvente ou amostra, e a retenção tornou-se eficiente. 


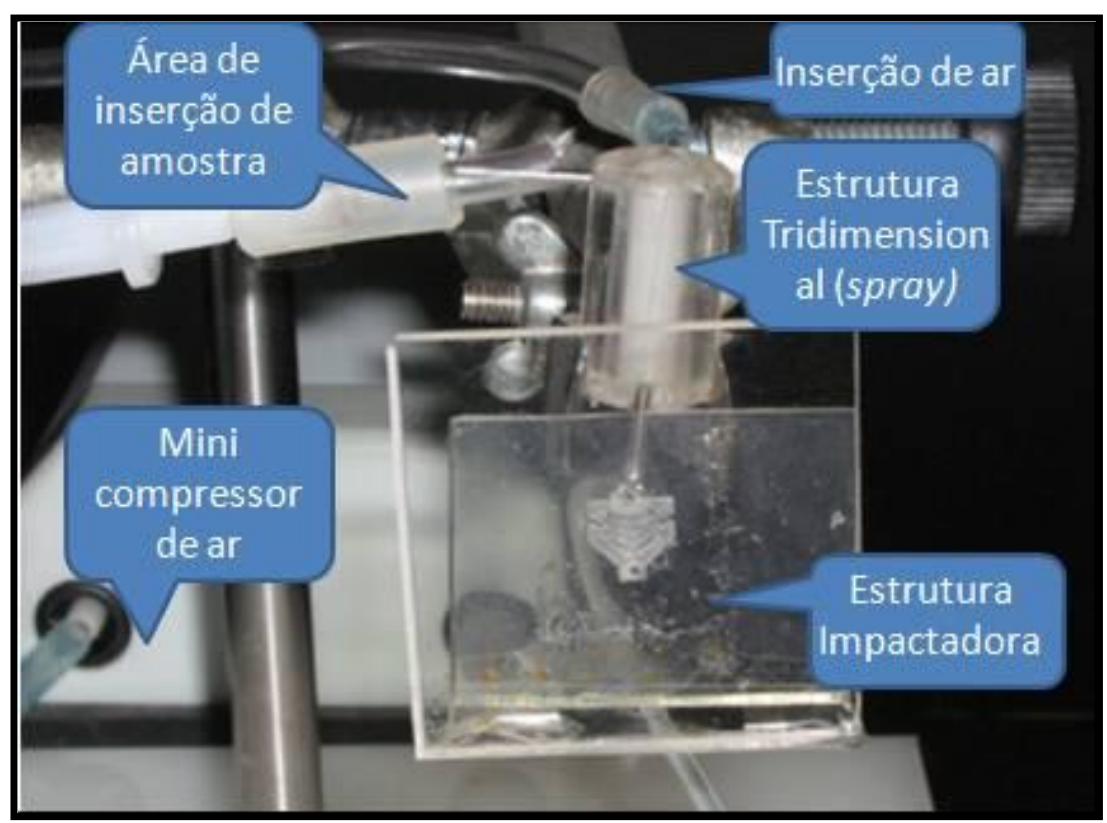

(A)

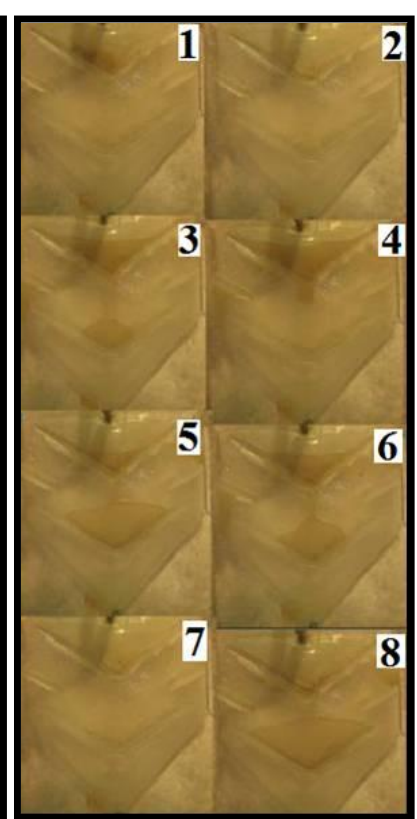

(B)

Figura 4.26 - (A) Aparato para injeção do spray no impactador e (B) seqüência de fotografias que indicam a remoção da partícula no impactador angular e uso de spray.

\subsubsection{Conclusão parcial}

Os impactadores testados são úteis para remoção de partículas em fase gasosa, e, pelo uso de sistema de spray, também em fase líquida. A grande vantagem do uso de tais estruturas é a pequena variação na pressão - que não pôde ser detectada em fase gasosa e é mínima (1,1 atm) em fase líquida.

\subsection{CANAIS TRIDIMENSIONAIS MODIFICADOS}

O uso dos microreatores é amplamente disseminado, não apenas em dispositivos $\mu$ TAS, mas também no desenvolvimento de Engenharia Química [143], uma vez que estes dispositivos não são caros e apresentam diversas vantagens, tais como, alta relação área/volume, que favorece a transferência térmica.

Entretanto, as abordagens entre as pesquisas realizadas em Engenharia Química ou em $\mu$ TAS são um pouco diferentes, pois a Engenharia Química é focada principalmente em sínteses de novos produtos e as pesquisas com $\mu$ TAS estão, atualmente, mais interessadas na capacidade de pré-tratamento de amostra para a análise 
química [132][144]. Assim, alguns autores já apontam a existência de uma barreira entre as nano-, micro- e macro-tecnologias [13] no campo da Engenharia Química. Além disso, o desenvolvimento de dispositivos miniaturizados para obter processos químicos adequados à Engenharia Verde é de importância notável, o que fez Igarashi [145] sugerir que há - principalmente para a catálise - uma barreira entre o processo que ocorre em nanoescala e os processos químicos que dependem das grandes plantas de produção.

Microreatores são dispositivos comuns que, embora possam apresentar diferentes formas, são geralmente formados por microcanais [146]. Todavia, os microcanais apresentam alguns inconvenientes devido à dificuldade em misturar corretamente os líquidos em pequenas dimensões e à obstrução durante o uso [147]. Algumas utilizações de microcanais, como abordado anteriormente, já foram testadas na EPUSP. Com dimensões muito pequenas, um microcanal tridimensional feito em torno convencional foi usado não apenas como microreator [148], mas como uma coluna cromatográfica [136] e como um pré-concentrador [98][149]. Este microcanal tridimensional foi usado para oxidar VOCs (compostos orgânicos voláteis) para o prétratamento da amostra, mas o tempo necessário para a reação é longo e a remoção do produto após esta reação é difícil.

Assim, o microcanal para remoção de VOCs proposto por Carvalho [100] sofreu uma pequena modificação que gerou um dispositivo compacto e com maior facilidade de remoção do produto após a reação. O dispositivo é essencialmente formado por um microcanal que foi seccionado de modo semelhante ao proposto neste trabalho para a obtenção de spray. Contudo, neste caso, utilizou-se quatro cortes dispostos simetricamente. Além disso, a microestrutura possui aquecimento interno que atinge $300^{\circ} \mathrm{C}$ em poucos segundos.

Portanto, a microestrutura é um microreator formado por uma matriz de 192 microcanais tridimensionais, com $40 \mu \mathrm{m}$ de largura e $8 \mathrm{~mm}$ de comprimento cada. A Figura 4.27 apresenta o esquema deste reator. Esse dispositivo tem como função remover, por catálise, hidrocarbonetos presentes no ar. Para tanto, a superfície dos microcanais foi modificada com a deposição de cobre, realizada por eletroless plating, com o intuito de promover a catálise. No presente caso, uma segunda entrada foi adicionada a essa estrutura, para permitir que funcionasse como misturador ou como separador, e será explicada posteriormente. 


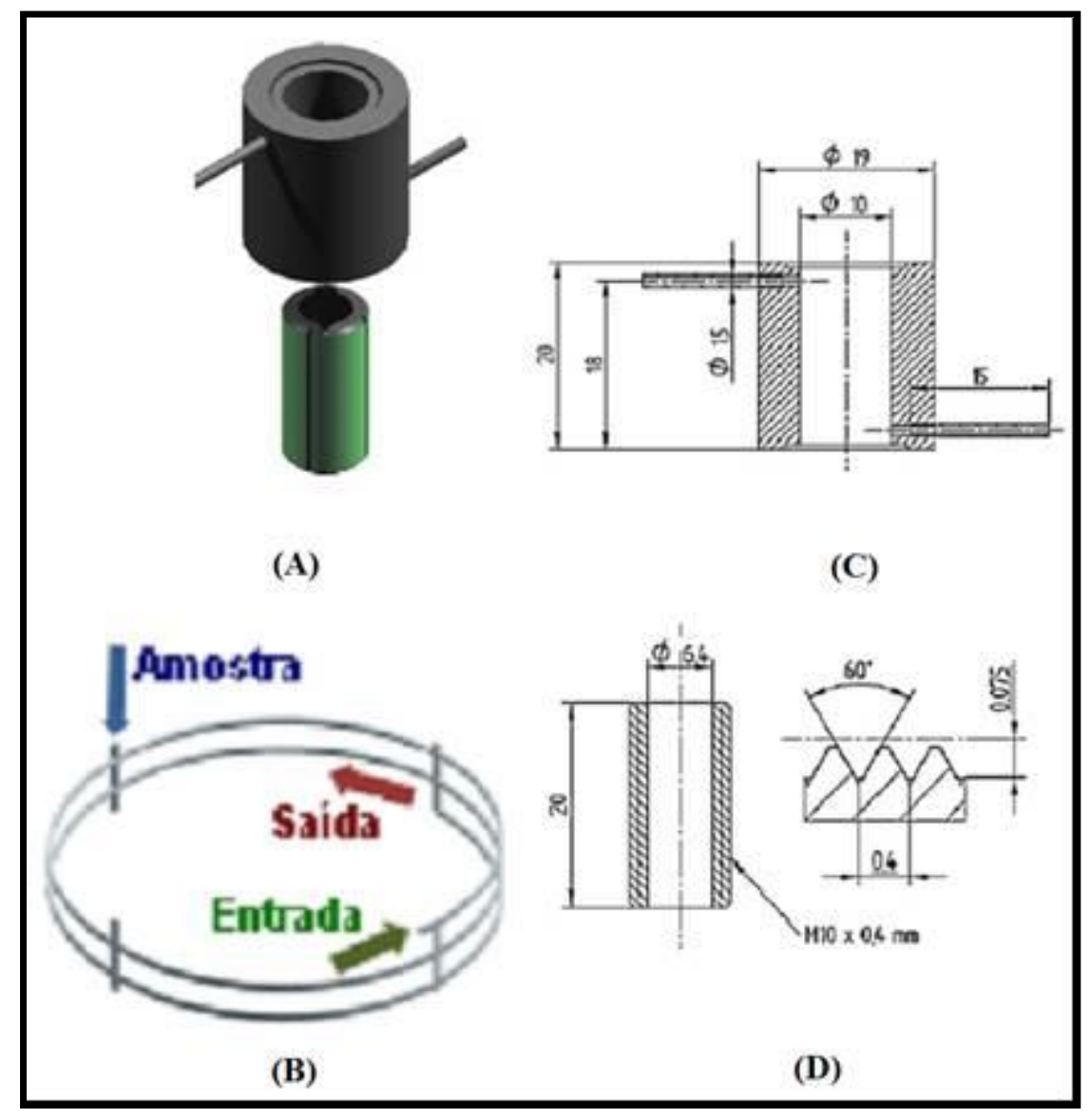

Figura 4.27 - (A) Esquema da microestrutura em perspectiva; (B) detalhe de como são os microcanais modificados com 4 cortes ortogonais e a adição de uma segunda entrada, denominada amostra, utilizada neste trabalho; $(C)$ detalhe do tubo externo e (D) tubo interno, com dimensões do microcanal [100].

Neste dispositivo - simples, compacto e de baixo custo - os microcanais são expostos a compostos orgânicos voláteis por cerca de 3 minutos, isto é, em processo de batelada, para promover a catálise. Contudo, estes canais não foram empacotados ou usados em escoamento contínuo porque as simulações indicaram que a microestrutura funciona como um misturador nessas condições. Por outro lado, Hernandez [89] demonstrou que o empacotamento dos canais ao invés de misturar os reagentes [89] pode levar à retenção devido à dispersão do fluido. Por fim, o maior tempo de retenção do fluido nos microcanais pode ser útil para permitir a transferência de calor entre dois compostos, em um sistema similar ao que ocorre em colunas de destilação.

Assim, dispositivos semelhantes ao proposto por Carvalho [100] foram construídos e testados, tanto como misturadores quanto separadores de compostos em mistura. Por outro lado, como a superfície pode provocar catálise, fez-se testes de aquecimento em estruturas com e sem filme de cobre para avaliar a possível 
interferência da catálise no comportamento da estrutura. Observe-se que a proposta de três usos distintos (reator para catálise, misturador e separador) para uma única estrutura está de acordo com que Charpentier [43][44][45] considera como essencial para o desenvolvimento da Engenharia Química e área correlatas.

\subsubsection{Construção dos canais}

A microestrutura foi fabricada seguindo as etapas descritas por Carvalho [100]. Assim, os dois cilindros que a compõem são de aço inoxidável AISI 316L e a usinagem é feita em torno mecânico convencional. Os microcanais foram usinados no lado externo de um tubo de 10 milímetros e 6 milímetros no diâmetro externo e interno, respectivamente. Os quatro canais longos, dispostos perpendicular e simetricamente ao microcanal, também têm largura de $40 \mu \mathrm{m}$. O segundo tubo tem 19 milímetros e 10 milímetros de diâmetro externo e interno, respectivamente, e encapsula os microcanais. Os microcanais apresentam $0,9 \mu \mathrm{L}$ como volume total e a relação área/volume é de 103. O sistema de entrada e saída foi feito com o auxílio de capilares em aço inoxidável e a selagem de toda a estrutura ocorre somente nas bordas usando TorrSeal® como adesivo.

Antes da selagem, algumas estruturas sofreram modificações: algumas delas tiveram sua superfície modificada, para permitir a avaliação de fenômenos, tais como a adsorção ou catálise, pela deposição de cobre através do processo de electroless plating e outras foram preenchidas com partículas. A deposição de cobre requer apenas a imersão da amostra (estrutura) em uma solução aquosa de $\mathrm{HF} / \mathrm{CuSO}_{4}$. A espessura da camada de cobre é de aproximadamente $20 \mathrm{~nm}$ (medida usando Microscópio Força Atômica) [100] e a uniformidade da deposição é controlada por microscopia óptica [143]. Como material de empacotamento usou-se nos microcanais esferas ocas de óxido de silício, com $30 \mu \mathrm{m}$ de diâmetro (Filite, EUA). Nas estruturas empacotadas testadas como misturadores uma segunda entrada foi adicionada ao arranjo utilizado por Carvalho [100], como explicado posteriormente.

A catálise foi estudada usando a análise de espectrometria de massa. Nesta etapa usou-se um espectrômetro de massa (Transpector 2, Inficon Gas Analysis Systems, USA) acoplado a um sistema de bomba de turbo molecular $(100 \mathrm{~L} / \mathrm{s})$ e a uma válvula agulha para injetar com precisão amostra, advinda da microestrutura e a pressão atmosférica, dentro da câmara do espectrômetro de massa. A pressão na câmara do 
espectrômetro é controlada para manter-se em $5.10^{-5}$ Torr, isto é, aproximadamente 10 vezes a pressão de base. Para os testes de catálise o sistema de aquecimento utilizado é formado por uma resistência elétrica e um controlador eletrônico (Contemp CTW 45, Brasil). A resistência é colocada internamente ao cilindro onde foi usinado o microcanal (ver a Figura 4.27A). Assim, a estrutura pode ser aquecida até $300^{\circ} \mathrm{C}$ em menos de 10 segundos. Nos testes de catálise, após a injeção, a estrutura é fechada usando válvulas on/off e é aquecida no mínimo por 3 minutos. Para testes de separação de componentes, a rampa de aquecimento e a temperatura máxima são determinadas experimentalmente.

Por fim, para comparação, uma estrutura formada apenas pelo canal longo foi também construída.

\subsubsection{Testes dos microcanais}

*Comportamento do fluido: estruturas com um único canal, empacotado ou não com partículas de sílica, semelhante à utilizada por Hernandez [89], foram testadas pela inserção seqüencial de pequenas massas de isopropanol $(0,3 \mathrm{mg})$ ou n-dodecano $(8$ $\mu \mathrm{g}$ ). O Gráfico 4.7 apresenta resultado típico, onde pode-se notar diferentes comportamentos se a microestrutura encontra-se ou não empacotada. Nesses gráficos, a variação de resistência é proporcional à variação de concentração. Enquanto o Gráfico 4.7A (coluna não empacotada) apresenta picos com perfil similar aos obtidos em um cromatógrafo de alta resolução, ocorre instabilidade na coluna empacotada (Gráfico 4.7B) - o que alarga o pico e modifica a linha de base - provavelmente devido à maior velocidade de dispersão. 

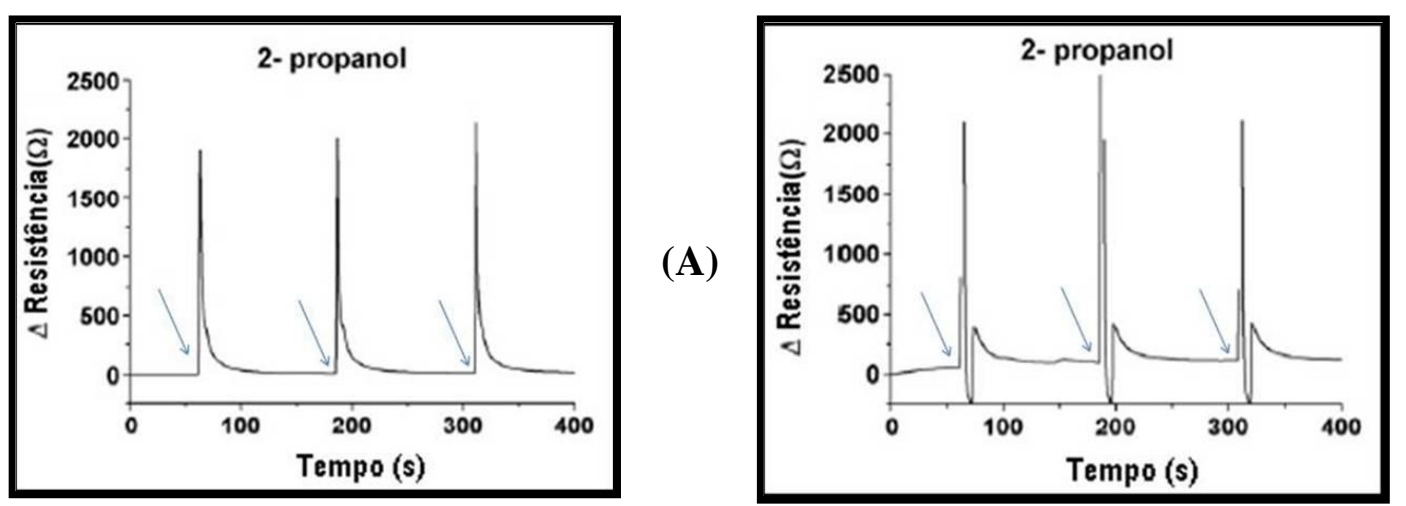

(B)

Gráfico 4.7 - Microcanal tridimensional, 10 sccm de $\mathbf{N}_{2}$, injeção seqüencial de 0,3 mg de isopropanol, usado como traçador, e detecção em função do tempo: na microestrutura (A) não empacotada e (B) na microestrutura empacotada. As flechas indicam o momento da injeção do reagente.

O aquecimento dessas estruturas leva a comportamentos bem distintos entre si e igualmente diferentes dos obtidos em cromatografia. Além da irreprodutibilidade no comportamento do sinal, os Gráficos 4.8A e 4.8B apresentam resultados típicos para a inserção seqüencial de isopropanol em estrutura aquecida a $100^{\circ} \mathrm{C}$. Embora todas as injeções tivessem a mesma quantidade $(50 \mu \mathrm{g})$, os picos apresentam valores distintos após a primeira injeção. Assim, para a coluna não empacotada (Gráfico 4.8A), para 3 seqüências de injeções de 2-propanol, a primeira inserção atinge uma intensidade muito maior que a subseqüentes, provavelmente devido à dessorção inicial favorecida pela alta temperatura na superfície. As estruturas empacotadas (como mostra Gráfico 4.8B) apresentam um pico mais largo e instabilidade em sua linha de base, provavelmente devido à dessorção aliada à dispersão do fluido, que dificulta o controle da vazão.

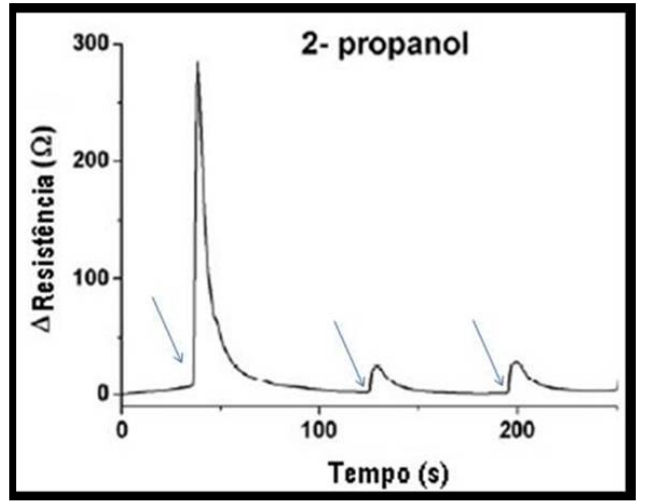

(A)

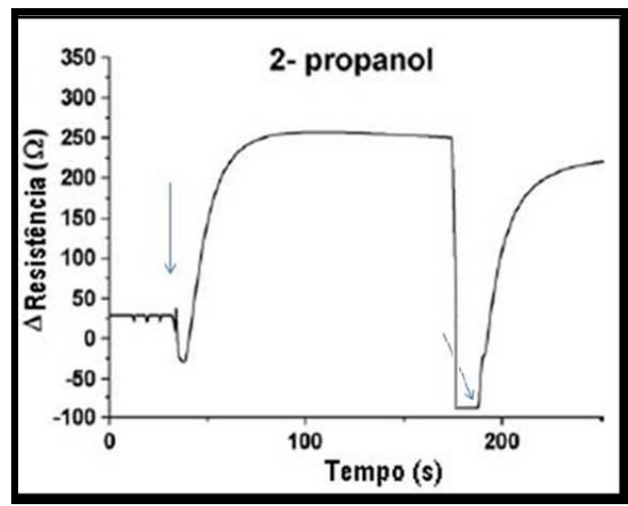

(B)

Gráfico 4.8 - Seqüência de injeções de isopropanol (50 $\mu \mathrm{g})$ nos microcanais (A) não empacotados e (B) microcanais empacotados. 
Por outro lado, a estrutura com microcanais perpendiculares apresenta comportamento bem distinto do obtido com o canal longo. Para facilitar a compreensão dos resultados experimentais, repete-se nas Figuras 4.28A e 4.28B as simulações de Carvalho [100] para estruturas empacotadas ou não. As dimensões na simulação correspondem a $40 \mu \mathrm{m}$ de largura e $500 \mu \mathrm{m}$ de profundidade. Devido às pequenas dimensões do canal e das distâncias entre eles, Carvalho os considerou como uma estrutura plana, o que implica em uma entrada, porém duas saídas, para haver simetria no dispositivo.

A Figura 4.28A apresenta a simulação da velocidade do escoamento em uma estrutura não empacotada formada por sete canais. O resultado aqui apresentado é obtido com nitrogênio, mas resultado semelhante é encontrado para os VOCs mais comuns (isopropanol, n-hexano e n-dodecano). A simulação indica uma predominância das velocidades mais altas nos canais mais longos e a diferença de pressão entre a entrada/saída é pequena (no máximo $2 \mathrm{~atm}$ ), o que significa que a configuração destes canais permite uma remoção fácil dos reagentes. A baixa velocidade nos microcanais secundários também deve favorecer a catálise.

Segundo Carvalho [100], o uso da estrutura empacotada em catálise não se mostra aconselhável devido ao perfil da velocidade nos canais, que rapidamente decai a partir da entrada, mesmo sobre aquecimento (Figura 4.28B). 


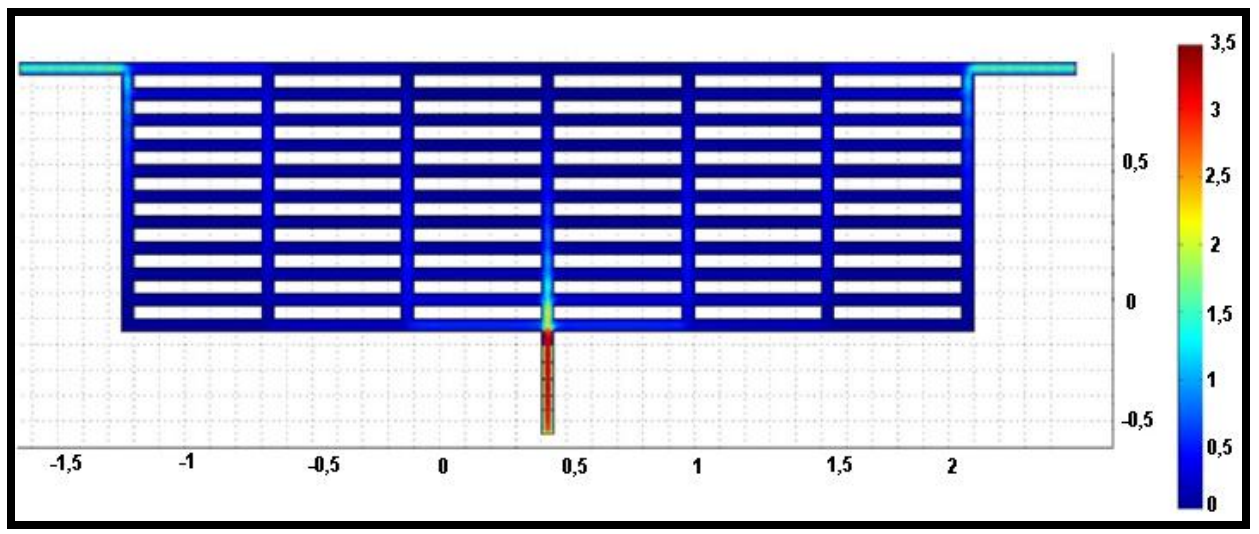

(A)

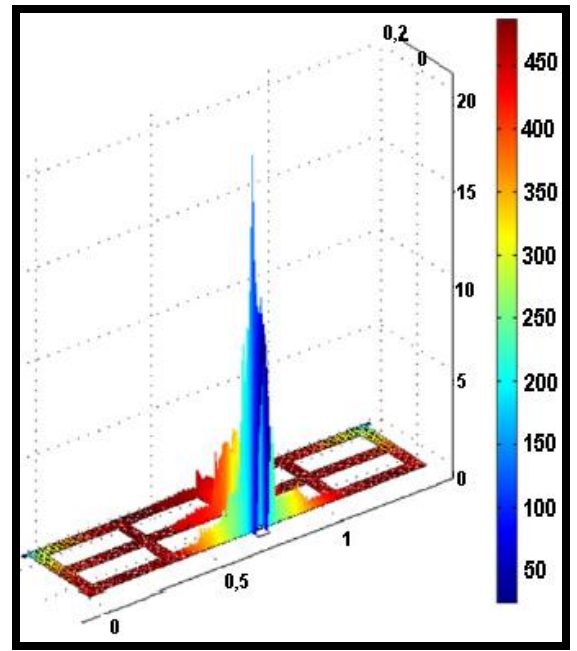

(B)

Figura 4.28 - Perfil da velocidade nos microcanais $\left(\mathrm{N}_{2}\right.$, velocidade linear na entrada de $2 \mathrm{~cm} / \mathrm{s}$, canais de $500 \mu \mathrm{m}$ ) (A) canais não empacotados e (B) canais empacotados, perfil de velocidade (eixo vertical, $\mathrm{mm} / \mathrm{s}$ ) e de temperatura (variação de cor, ${ }^{\circ} \mathrm{C}$ ) para admissão de amostra em estrutura aquecida a $300^{\circ} \mathrm{C}[100]$.

O Gráfico 4.9 mostra resultados típicos para quatro diferentes concentrações de isopropanol injetadas seqüencialmente na estrutura não empacotada $(30,20,10$ e $1 \mu \mathrm{g}$, respectivamente). A elevada quantidade de reagente que rapidamente sai da estrutura satura o detector por um ou dois segundos se a injeção de isopropanol exceder a $10 \mu \mathrm{g}$, mas o resultado é reprodutível e indica que a remoção do reagente é rápida, como encontrado por simulação, mesmo com o canal aquecido. Portanto, a existência dos canais laterais compensa a dispersão inserida pela existência das partículas. 


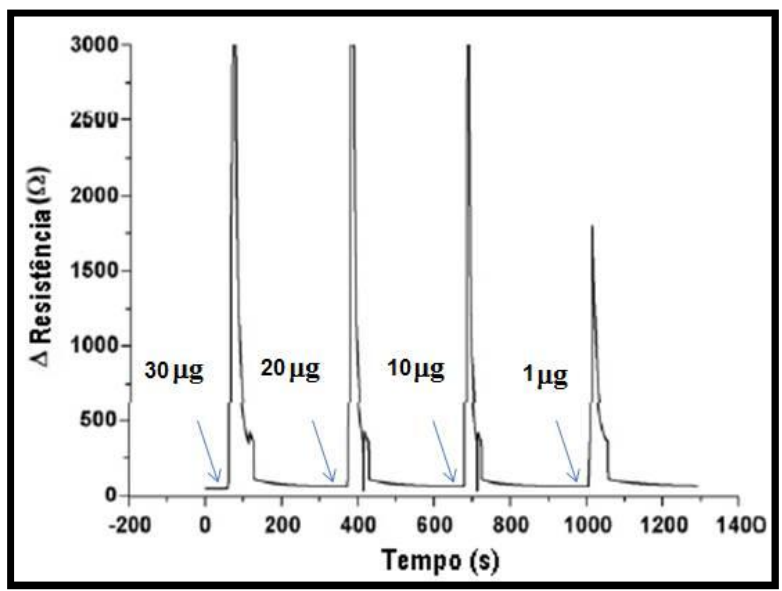

\section{Gráfico 4.9 - Injeção seqüencial na estrutura não empacotada de 30, 20, 10 e $1 \mu \mathrm{g}$ de isopropanol.}

$\mathrm{Na}$ Figura 4.28B a altura significa a velocidade do escoamento e as cores representam as variações de temperatura supondo que a amostra foi aquecida até $300^{\circ} \mathrm{C}$ antes da admissão dentro da estrutura. Neste caso, a velocidade decai rapidamente a partir da entrada da estrutura, o que dificulta a remoção de amostra. Além disso, há variações significativas na temperatura do fluído dentro dos canais, que pode resultar na formação de vórtices e retorno do fluido dentro dos canais (back stream). Por outro lado, esta é a condição ideal para uma boa separação de misturas em um sistema de destilação. Contudo Carvalho [100] não testou esta hipótese. Entretanto, ainda segundo Carvalho [100], os microcanais empacotados são adequados para misturas gasosas, como pode ser visto na Figura 4.29 que apresenta o gradiente de concentração para dois gases diferentes $\left(\mathrm{N}_{2}\right.$ e $\left.\mathrm{O}_{2}\right)$ aquecidos até $300^{\circ} \mathrm{C}$ e inseridos simultaneamente nos microcanais. 


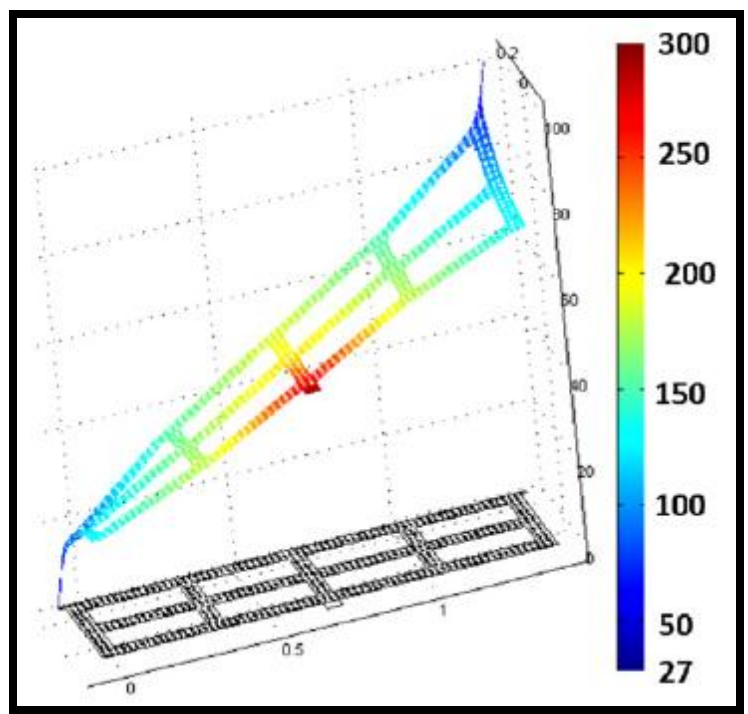

Figura 4.29 - Simulação com injeção de dois diferentes gases $\left(\mathrm{N}_{2}\right.$ e $\left.\mathrm{O}_{2}\right)$ no canal indicando o gradiente de concentração (eixo vertical, em porcentagem) e a temperatura (cores, ${ }^{\circ} \mathrm{C}$ ) [100].

$\mathrm{Na}$ Figura 4.29, a altura indica a concentração do fluído em porcentagem, enquanto as cores indicam as variações de temperatura. É possível observar que a tanto a concentração de um reagente como a temperatura do fluido varia de modo gradual em relação aos canais, obtendo-se $50 \%$ - boa mistura - e $300^{\circ} \mathrm{C}$ - boa troca de calor, ao final do processo; o que também corresponde a situação ideal em uma destilação.

Como a estrutura empacotada, é provavelmente útil para a separação de misturas. Uma adaptação foi feita em sua construção pela adição de outra entrada, de modo similar ao utilizado para a construção do spray. Neste novo arranjo, a estrutura foi testada quanto à mistura de dois ou mais compostos, para comparação, uma estrutura sem empacotamento foi também avaliada.

O teste utilizou a admissão de vapores de isopropanol e n-dodecano injetados nas duas entradas diametralmente opostas $\left(90^{\circ}\right)$, mas com atraso entre si de $1 \mathrm{~s}$, sendo ndodecano injetado por último. Os Gráficos 4.10A e 4.10B mostram os resultados típicos para os reagentes injetados em diversas concentrações nas estruturas não empacotadas e empacotadas, respectivamente.

Enquanto a estrutura não empacotada apresenta picos largos - o que diminui a máxima intensidade medida, a empacotada apresenta picos mais estreitos indicando que ocorreu uma mistura no segundo caso, mas não primeiro. Muito embora os valores de máximo no caso da estrutura empacotada possam decorrer por dessorção, os valores 
mais altos indicam que as duas amostras deixaram a estrutura em tempos muito próximos e/ou em completa mistura. Estes dados estão em boa concordância com o obtido por simulação por Carvalho [100].

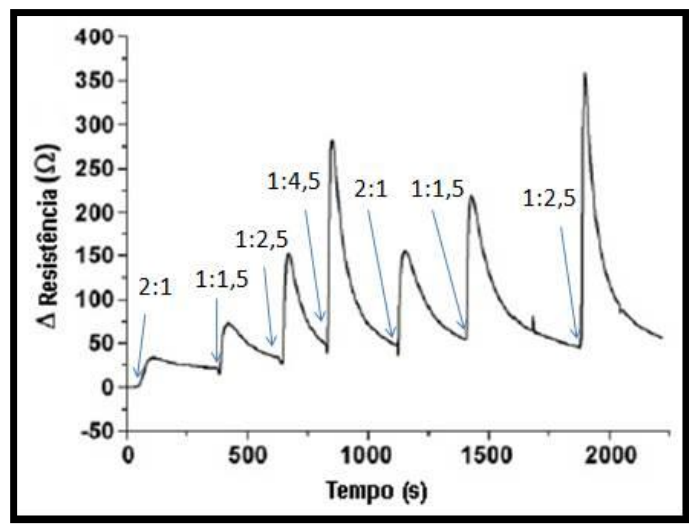

(A)

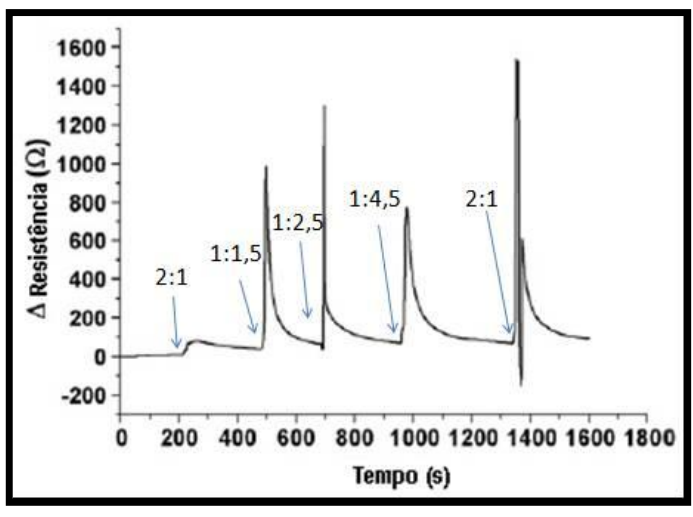

(B)

Gráfico 4.10 - Traçadores: injeções seqüenciais de n-dodecano e isopropanol em microestruturas (A) não empacotadas e (B) empacotadas (razão entre as amostras de $2: 1 ; 1: 1,5 ; 1: 2,5 ; 1: 4,5$ em volume).

*Catálise: uso destas estruturas em aço inoxidável pode ser dificultado por reações secundárias na superfície, por exemplo, a catálise. Por outro lado, não é possível usinar tais estruturas em vidro, já que são tridimensionais. Assim, testes foram processados para garantir que não ocorrem reações secundárias na superfície do aço inoxidável e, para comparação, testou-se também estruturas com superfície de cobre, onde a catálise é esperada.

A catálise do cobre já foi testada em canais longos e mostrou-se eficiente quando se usa n-hexano, mas não quando se usa isopropanol [100]. Desta forma, os mesmos reagentes e os mesmos procedimentos foram usados a fim de se comparar os resultados. A experiência foi realizada aquecendo a estrutura até $300^{\circ} \mathrm{C}$ e o reagente foi injetado (0,1 $\mathrm{mg}$ de isopropanol e 0,6 $\mathrm{mg}$ de $\mathrm{n}$-hexano), o suficiente para encher completamente os canais com o vapor saturado de reagente. Após a injeção, o sistema é fechado por 3 minutos e a amostra é injetada na câmara do espectrômetro de massa para análise após este tempo. O espectrômetro de massa foi programado para detectar moléculas de água (18 u.m.a.), nitrogênio (28 u.m.a.), oxigênio (32 u.m.a.), compostos orgânicos (41, 43 e 57 u.m.a.) e $\mathrm{CO}_{2}$ (44 u.m.a.), em varreduras contínuas que duram 5 segundos. 
No Gráfico 4.11, são apresentados resultados típicos para os testes de catálise. À temperatura ambiente, a adição de isopropanol ou n-hexano em uma estrutura com ou sem cobre na superfície mostra o mesmo comportamento. Quando a amostra é liberada e detectada no espectrômetro ocorre aumento, de maneira similar, nos valores de todas as intensidades no espectrômetro de massa, embora o $\mathrm{CO}_{2}$ seja detectado raramente conforme se observa no Gráfico 4.11A. Resultado semelhante é obtido para estrutura sem cobre, isto é com aço inoxidável na superfície, à temperatura de até $300^{\circ} \mathrm{C}$, e para a com cobre na superfície até $100^{\circ} \mathrm{C}$, temperatura em que a maioria dos VOCs já se encontra vaporizada.

Estes resultados estão de acordo com medidas obtidas em microbalança de quartzo [100], que sugere que a catálise em cobre inicia-se após $200^{\circ} \mathrm{C}$. A $300^{\circ} \mathrm{C}$, em uma estrutura com cobre na superfície, a adição de isopropanol não leva a variação significativa nas intensidades relativas, mas a linha de base é menos constante devido ao aquecimento (Gráfico 4.11B). 


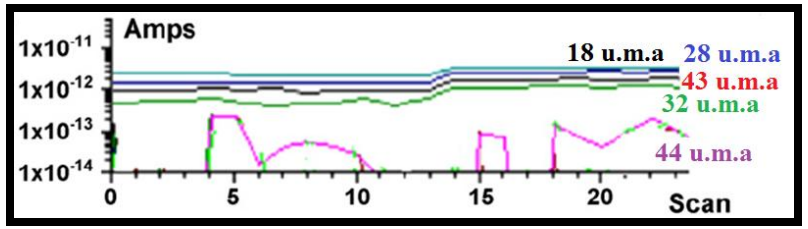

(A)

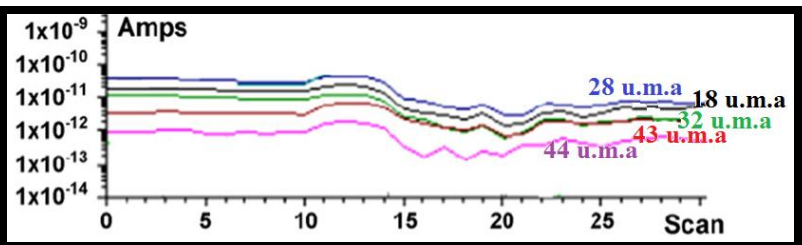

(B)
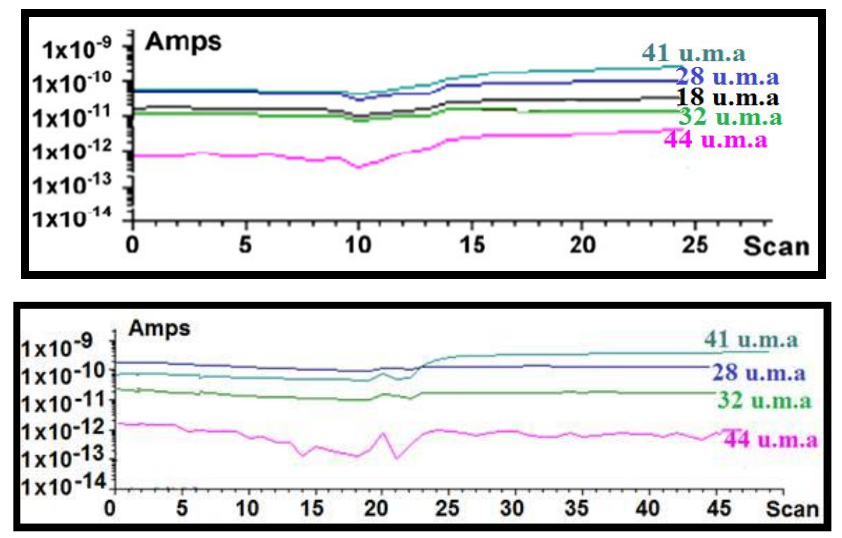

(C)

Gráfico 4.11 - Intensidade relativa (Amps definido como Ampères pelo equipamento) obtida no espectrômetro de massa em função da água (18 u.m.a.), nitrogênio (28 u.m.a.), oxigênio (32 u.m.a.), n-hexano (41, 43 u.m.a.) e $\mathrm{CO}_{2}$ (44 u.m.a.) para cada varredura (Scan no equipamento) de 5 segundos. (A) Adição de isopropanol na estrutura sem cobre na superfície, a temperatura ambiente; (B) Adição de isopropanol na estrutura com cobre na superfície, a $300^{\circ} \mathrm{C}$; (C) Adição de n-hexano na estrutura com cobre na superfície a $300^{\circ} \mathrm{C}$; e (D) Adição de nhexano: 2-propanol, 1:1 em vol., na estrutura com cobre na superfície a $300^{\circ} \mathrm{C}$.

Entretanto, adição de n-hexano em uma superfície de cobre aquecida permite uma elevação no sinal de $\mathrm{CO}_{2}$ - aumento relativo de um fator de 10 - muito embora a quantidade de oxigênio praticamente não mude (Gráfico 4.11C), pois o aumento relativo é de apenas 1,5 e o aumento relativo de nitrogênio seja de 2 .

Se uma mistura de n-hexano: isopropanol (1:1 em peso) é adicionada ao sistema, é encontrado um aumento na intensidade do $\mathrm{CO}_{2}$ igual a um fator de 5 , enquanto o aumento na quantidade de oxigênio permanece baixo, 1,6, indicando que o n-hexano pode reagir na presença de isopropanol (Gráfico 4.11D). Uma vez que o aumento na intensidade do $\mathrm{CO}_{2}$ é proporcional à oxidação do reagente, pelo menos $70 \%$ do nhexano foi consumido, mas este resultado pode ser melhorado se a amostra não estiver saturada. Os resultados são similares aos obtidos usando a técnica de microbalança de 
cristal de quartzo [100], que indicou variação de $80 \%$ na área do pico se um microcanal preenchido com o n-hexano for aquecido. Se apenas $10 \mu \mathrm{g}$ de $\mathrm{n}$-hexano for injetada, o pico correspondente não é detectado depois do aquecimento, o que indica que esta é a quantidade máxima removida num único teste.

Assim, essa estrutura pode ser aquecida até $300^{\circ} \mathrm{C}$ e utilizada com compostos orgânicos apenas quando sua superfície apresentar aço inoxidável. Por outro lado, $100^{\circ} \mathrm{C}$ pode ser uma temperatura adequada para a avaliação da maioria dos VOCs, o que permitiria utilizar uma única estrutura para funções diferentes.

\subsubsection{Testes da estrutura}

Os testes iniciais foram processados utilizando-se o aparato de teste apresentado na Figura 4.30. A estrutura fica sob passagem do fluido gasoso (ar atmosférico), de forma contínua e com vazão de $10 \mathrm{~mL} / \mathrm{min}$, em duas entradas distintas. A saída da estrutura está ligada ao sensor capaz de detectar variações de concentração de reagentes presentes na atmosfera próxima a ele na ordem de ppb. O computador provê a análise de dados.

Para garantir a estabilização da linha de base do equipamento é feita a inserção de reagente após 2 minutos. A inserção de reagente é feita através de um pulso com 0,10 $\mathrm{mL}$ de vapor de reagente. Para verificar se os fenômenos envolvidos nos testes dependem da estrutura ou de um artifício de detecção (por exemplo, ruído alto dificultando a detecção) o capilar foi testado usando ar como fluido saturado com vapor de água e inserção de isopropanol (0,01 mL). Usou-se um capilar de $1 \mathrm{~mm}$ de diâmetro, conectado ou não ao mini compressor de ar, em seguida é feita a admissão do reagente. 


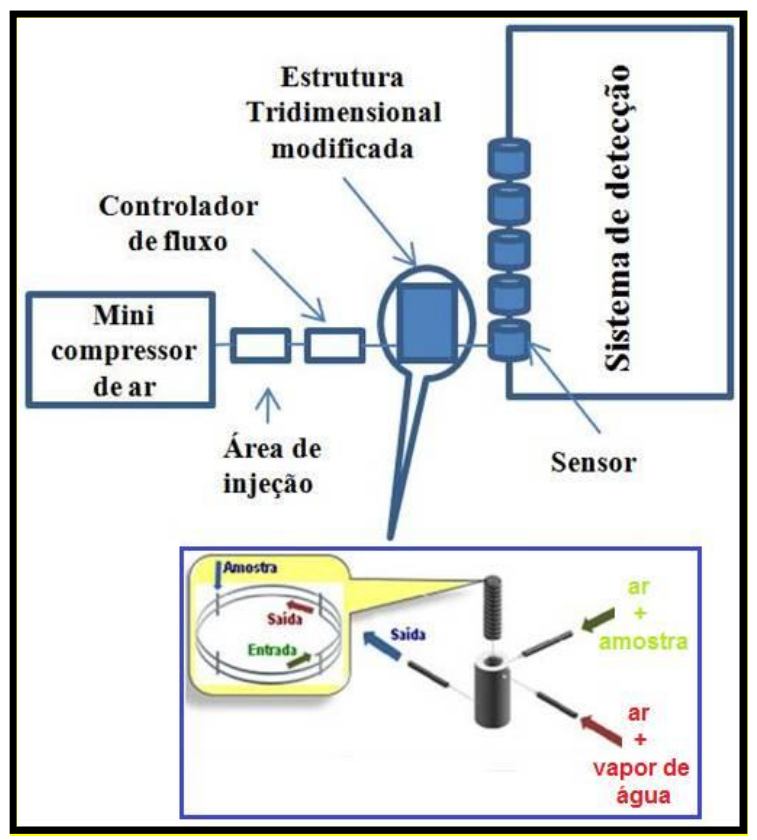

\section{Figura 4.30 - Esquema do aparato utilizado para testes usando a estrutura tridimensional modificada com 4 canais verticais ortogonais.}

A idéia dessa configuração é permitir que ocorra dentro dos canais interação entre dois fluxos distintos, de modo semelhante ao que ocorre em uma coluna de destilação. Assim, reagentes com maior volatilidade podem percorrer os canais em menor tempo e serem detectados mais rapidamente, ou seja, o objetivo é obter uma "impressão digital" da mistura. Alguns testes utilizaram ar saturado com vapor de água para favorecer a maior interação com alguns compostos, por exemplo, álcool, o que pode aumentar o número de informações durante a obtenção da "impressão digital".

A estrutura foi simulada para interação entre dois fluxos de ar e para fluxos de ar vapor de água. A Figura 4.31 apresenta linhas e perfis de velocidade para esta estrutura quando são admitidos como amostra gasolina ou isopropanol e o vapor de água encontra-se em contracorrente. As linhas de velocidade (linhas de coloração azul) são semelhantes dois casos e não é possível se observar grandes variações que possam sugerir interferência no escoamento, como a formação de vórtices, etc. Por outro lado, o perfil de velocidade com o uso da gasolina apresenta variação brusca o que sugere que o regime possa ser turbulento. Ademais, a estrutura apresentou para a velocidade uma resposta dependente do tempo, o que indica que a remoção da amostra não é constante e provavelmente é dependente de propriedades físico-químicas da amostra. Sem a adição de água em contracorrente, a principal diferença é a máxima velocidade apresentada 
pelas amostras, não o perfil de velocidade. Para estrutura empacotada, na simulação não se observa diferença de comportamento entre diferentes amostras.

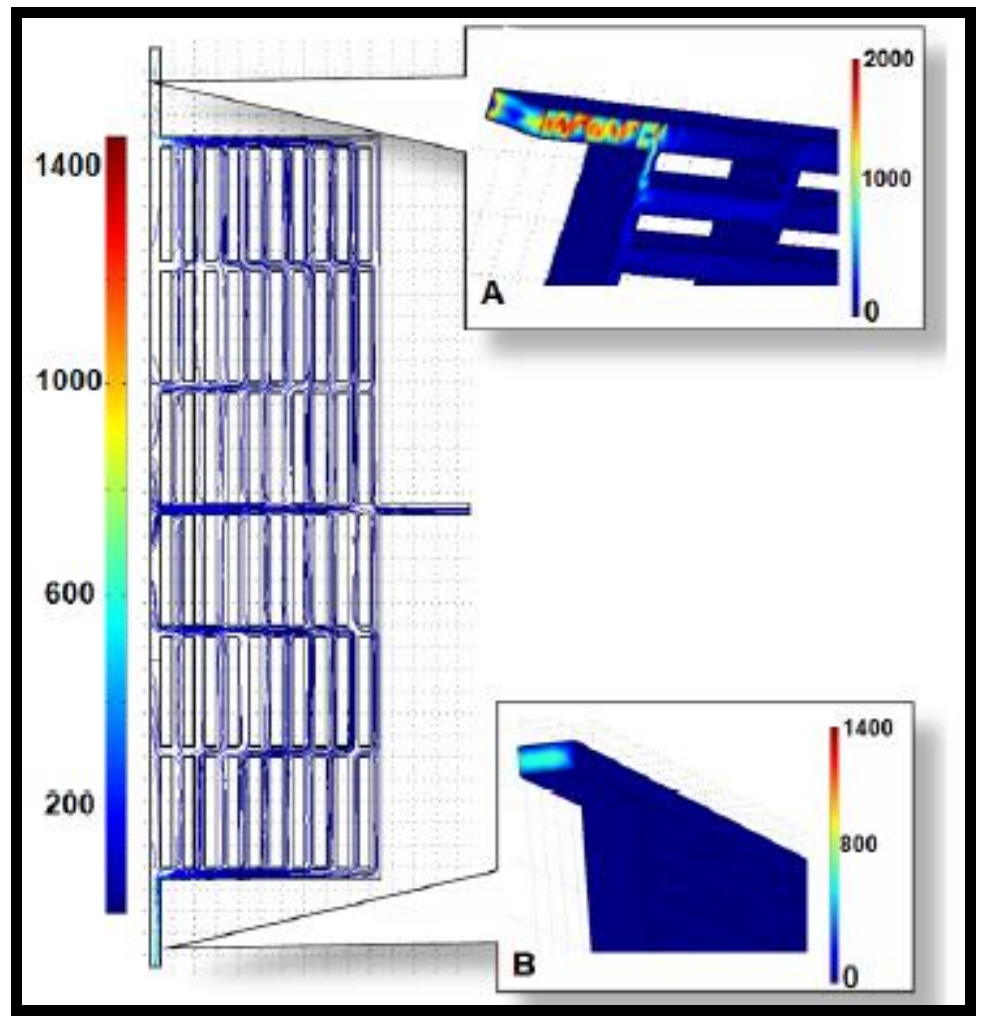

Figura 4.31 - Simulação das linhas de velocidade (linha azuis) e perfil de velocidade na saída (cor, $\mathrm{cm}_{.} \mathrm{s}^{-1}$ ) para estrutura tridimensional modificada como apresentado no detalhe da Figura 4.30 e supondo vapor de água admitida em uma das entradas: (A) gasolina e (B) isopropanol.

Os parâmetros testados são apresentados na Tabela 4.11. Para cada tipo de estrutura, a admissão pode ocorrer à temperatura ambiente ou em sistema aquecido. Neste último caso, como indicado por espectrometria de massas, a temperatura não deve exceder $100^{\circ} \mathrm{C}$, para evitar risco de destruição da amostra. Como gás de arraste para conduzir a amostra pela estrutura optou-se por ar, e não $\mathrm{N}_{2}$, já que se deseja um sistema de manutenção e manipulação simples. Por outro lado, pode-se admitir, ou não, outro reagente - no caso água - para interagir com a amostra. Como mencionado, a vantagem de se usar outro reagente é a possibilidade de estabelecer uma situação de equilíbrio químico, ou próximo, em cada um dos quase 200 canais, o que facilita a separação.

Devido ao pequeno comprimento dos microcanais da estrutura, o aquecimento desta facilita a remoção de compostos do interior dos canais, mas também dificulta a detecção de "picos" próximos. Por outro lado, a variação da temperatura desde 
temperatura ambiente até aproximadamente $90^{\circ} \mathrm{C}$ ou a manutenção desta a $90^{\circ} \mathrm{C}$, permite verificar se há variação significativa nos resultados obtidos devido ao gradiente ou à estabilidade da temperatura, ou se este intervalo corresponde a pequena variação.

As alterações de empacotamento das estruturas foram testadas para verificar se o aumento na dispersão do fluido pode favorecer a separação dos reagentes.

\section{Tabela 4.11 - Parâmetros testados na estrutura para a determinação da separação de compostos.}

\begin{tabular}{|c|c|c|c|}
\hline Condição & Tipo de estrutura & Temperatura & $\begin{array}{l}\text { Reagente para } \\
\text { admissão } \\
\text { de amostra }\end{array}$ \\
\hline$\overline{1}$ & \multirow{4}{*}{ Não empacotada } & \multirow[b]{2}{*}{ ambiente } & ar atmosférico \\
\hline 2 & & & $\begin{array}{c}\text { ar atmosférico+ } \\
\text { vapor de água }\end{array}$ \\
\hline 3 & & \multirow[b]{2}{*}{ aquecida } & ar atmosférico \\
\hline 4 & & & $\begin{array}{c}\text { ar atmosférico+ } \\
\text { vapor de água }\end{array}$ \\
\hline 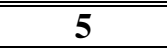 & \multirow{4}{*}{ Empacotada } & \multirow[b]{2}{*}{ ambiente } & ar atmosférico \\
\hline 6 & & & $\begin{array}{c}\text { ar atmosférico+ } \\
\text { vapor de Água }\end{array}$ \\
\hline 7 & & \multirow[b]{2}{*}{ aquecida } & ar atmosférico \\
\hline 8 & & & $\begin{array}{c}\text { ar atmosférico+ } \\
\text { vapor de água }\end{array}$ \\
\hline
\end{tabular}

\subsubsection{Testes com a estrutura não empacotada}

Para as colunas não empacotadas observaram-se resultados diferenciados para vários reagentes orgânicos e misturas. Usaram-se os reagentes seguindo a ordem: isopropanol, n-hexano, acetona, gasolina comum e mistura composta de etanol, isopropanol e água - 33\% em vol. Os dados com o uso da estrutura e/ou capilar - para comparação de comportamento - são apresentados em forma de gráficos da intensidade (unidades arbitrárias, u.a.) em função do tempo (ms) no Apêndice B (a partir da Figura B.1).

Como esperado, a resposta não se apresentou semelhante à de uma coluna cromatográfica em nenhuma dessas medidas. Para um capilar desconectado do mini compressor de ar, há um pico alto e largo logo no início, correspondendo à saída do reagente, e pequenos picos, de intensidade aproximada igual a 0,07 u.a. para o maior sinal, e não necessariamente oscilatórios; estes picos correspondem a ruídos. A resposta é coerente com um sistema com ampla superfície, que foi "contaminada" com um 
reagente volátil, mas que apresenta pouca área de contato com o ambiente, o que dificulta a remoção deste reagente. Assim, tem-se grande quantidade saindo imediatamente e, provavelmente, algum produto poderá ser detectado nos momentos seguintes.

Para o mini compressor ligado, observa-se que a intensidade máxima é de aproximadamente 0,15 u.a. para os $100 \mathrm{~ms}$ iniciais e passa a ser inferior a 0,05 u.a. até o final do teste. O pico obtido é mais estreito, mas não apresenta comportamento que possa ser considerado oscilatório. Isto indica que não há interferência significativa por parte do equipamento, o mini compressor ou do capilar, nos testes realizados nas estruturas.

Quando a estrutura é utilizada, o pico obtido assemelha-se aos encontrados anteriormente, por exemplo no Gráfico 4.8A, porém, um comportamento aparentemente oscilatório se sobrepõe ao formato do pico. Se o sinal é analisado por Transformada de Fourier obtém-se, para cada reagente, uma freqüência distinta, o que é coerente com a formação de equilíbrio químico nos canais da estrutura. Apenas para permitir comparação o Gráfico 4.12 apresenta o primeiro dos picos presentes no Gráfico 4.8A e o pico obtido com a estrutura utilizada com fluxo cruzado de ar atmosférico. 


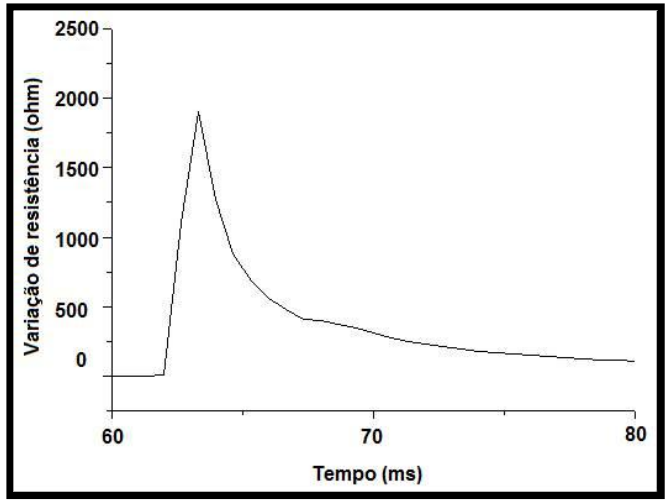

(A)

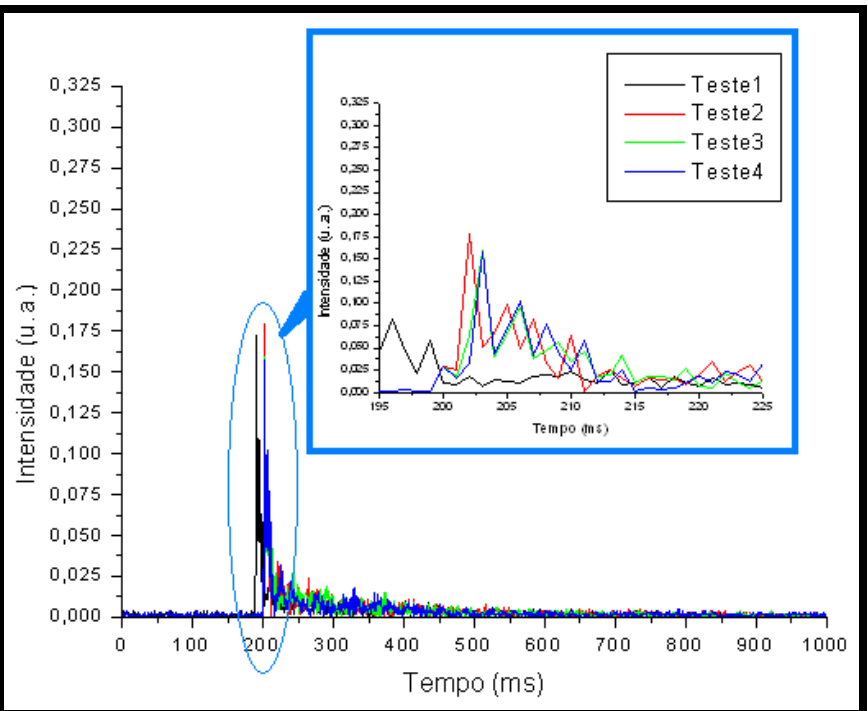

(B)

Gráfico 4.12 - Inserção de isopropanol na estrutura modificada: (A) primeiro pico presente no Gráfico $4.8 \mathrm{~A}$ e (B) pico obtido com a estrutura utilizada com fluxo cruzado de ar atmosférico. 

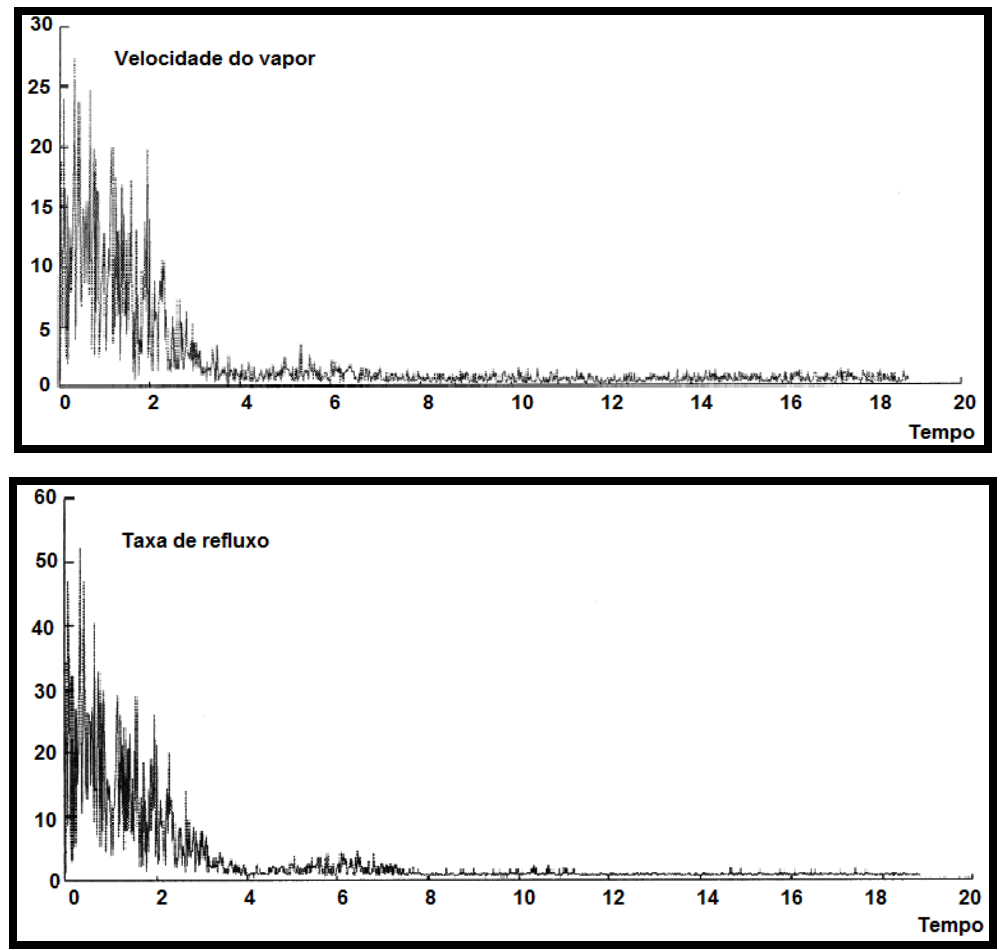

(A)
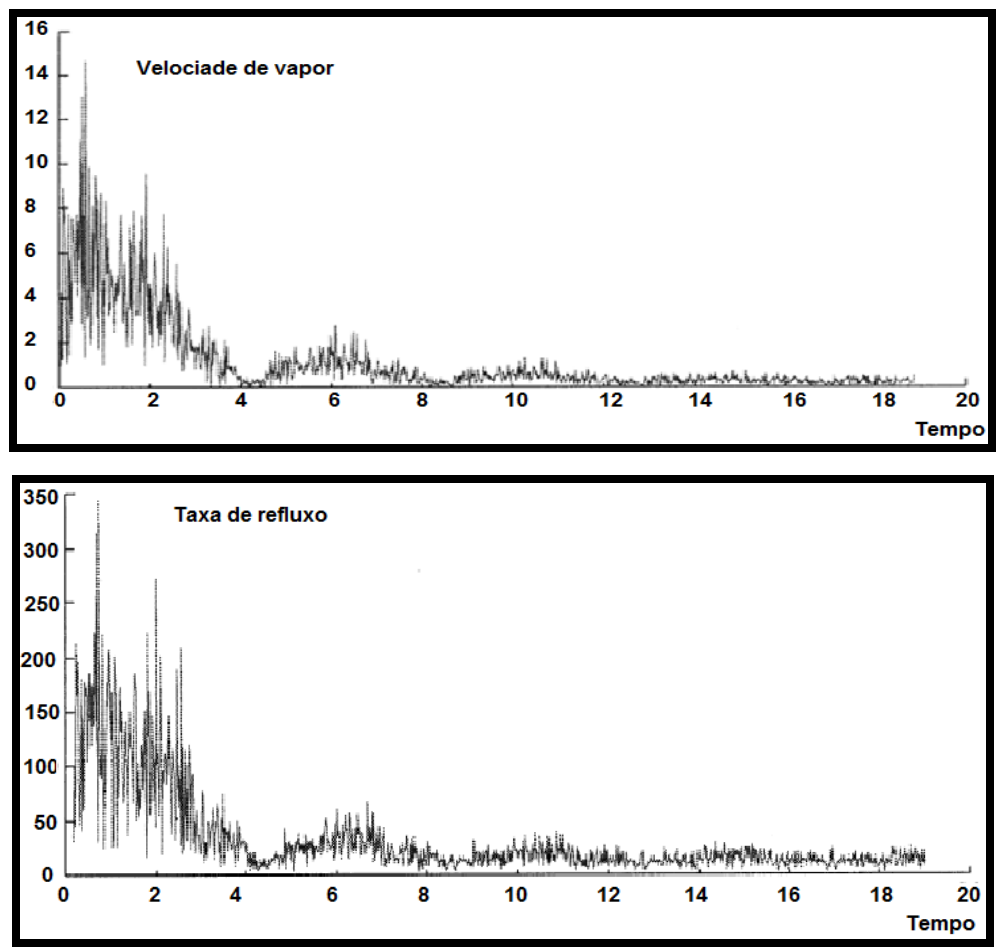

(B)

Gráfico 4.13 - Inserção de isopropanol: (A) resultados obtidos experimentalmente; e (B) respectiva simulação para velocidade do vapor $(\mathrm{mL} / \mathrm{min})$ e taxa de refluxo (\%) em coluna de destilação [150].

O comportamento oscilatório não é incomum em coluna de destilação e, apenas para exemplificar, alguns autores são aqui discutidos. Já em 1999, em uma coluna para 
planta piloto e separação de etanol e água em fluxo contínuo [150], a velocidade do vapor e a taxa de refluxo em função do tempo foram simuladas utilizando Transformada de Fourier (FFT). Vapor e refluxo correspondendo aos fluxos ascendentes e descendentes na coluna. Do mesmo modo, Natarajan [151] analisa os modelos para explicar destilação e ressalta o uso de FFT para analisar fenômenos dependentes de tempo nas colunas. Portanto, a estrutura parece apresentar um comportamento similar ao encontrado em colunas de destilação e os resultados obtidos forma tratados com o uso de FFT e os resultados mais relevantes encontram-se no apêndice B.

Quanto à mistura, foi possível obter frequiências semelhantes às obtidas para os reagentes, mas apenas em determinadas faixas, e em geral, na ordem de porcentagem para cada reagente. Este comportamento pode ser relativamente comparado com o de um destilador, indicando que está ocorrendo separação de reagentes.

Como a estrutura apresentou resultados diferentes dependendo do reagente utilizado, fizeram-se medidas usando gasolina de três postos diferentes para determinar se é possível encontrar diferenças significativas nos resultados. Com o uso da estrutura percebe-se que cada posto tem uma composição diferente para sua gasolina. A gasolina do posto 1 apresenta o comportamento de reagentes bastante voláteis, provavelmente, devido à menor concentração de álcool. A gasolina do posto 2 demora mais tempo para ser detectada, o que pode indicar maior quantidade de água ou álcool. Por fim, a gasolina do posto 3 ficou com tempo intermediário para a detecção. Com o intuito de avaliar se a estrutura permite determinação de contaminação nessas amostras, fez-se a mistura de gasolina com isopropanol. Novamente, as condições em que mistura e reagente são diferenciados, contudo, desde que o contaminante encontre-se na faixa de porcentagem.

Se o equilíbrio químico é favorecido nos canais da estrutura, a adição de água em "contra corrente" pode exacerbar a diferença de comportamentos entre os reagentes, de modo semelhante ao refluxo em uma coluna de destilação. Assim, o procedimento foi modificado, mantendo-se um escoamento contínuo de $1 \mathrm{~mL} / \mathrm{min}$ de ar atmosférico em uma entrada, sendo que nesta ocorre a inserção da amostra $(0,01 \mathrm{~mL}$ de vapor do reagente sob análise) em intervalos regulares $30 \mathrm{~s}$. Na conexão perpendicular a anterior admite-se ar saturado com vapor de água e a detecção ocorre na saída inferior (Figura 4.29). De modo semelhante às medidas anteriores, para definição da linha de base, a vazão de ar é mantida pelo menos por 10 s e a adição é repetida no mínimo 5 vezes, 
para verificar a reprodutibilidade das medidas. O uso de vapor de água não amostrou melhora nos resultados.

$\mathrm{O}$ aquecimento da estrutura, mesmo que apenas a $100^{\circ} \mathrm{C}$, facilita a remoção do reagente que deixa a estrutura ao mesmo tempo, ou seja, não há comportamento cíclico. Portanto, o aquecimento ao favorecer a rápida retirada do reagente, impede sua separação, tornando todos os resultados muito semelhantes, mesmo se os dados são analisados por Fourier.

\subsubsection{Testes com a estrutura empacotada}

Testes com a estrutura empacotada mostraram resultados semelhantes aos obtidos com a estrutura não empacotada e também foram dispostos em gráficos da intensidade (u.a.) em função do tempo (ms) para reagentes como: isopropanol, nhexano, acetona, gasolina comum, e mistura composta de etanol, isopropanol e água 33\% em vol. (Apêndice B, a partir do Gráfico B.8). Os testes foram feitos para verificar quais as principais diferenças nas oscilações dos sinais, verificando, assim, as principais freqüências que podiam compô-lo.

Para esta estrutura percebe-se que o tempo de resposta não é imediato após a inserção, isto indica que o tempo de residência é maior; portanto, a probabilidade de ocorrer interações e/ou separações dentro da estrutura empacotada é bem maior. Neste caso, o comportamento cíclico persiste, mas é menos evidente que na estrutura não empacotada, onde se observa a menor dependência do reagente com a respectiva frequiência obtida. Este resultado é coerente com o comportamento obtido por Carvalho [100] por simulação, e testado nesse trabalho no item anterior, para o uso da estrutura como misturador. O empacotamento dificulta o equilíbrio nos canais, mas facilita a interação para produção da mistura, isto pode estar vinculado à formação de caminhos preferenciais já que a simulação mostrou a tendência do fluido de percorrer os canais, preferencialmente, próximo à superfície e não no centro ou no entorno das partículas.

Novamente, o aquecimento da estrutura, mesmo que apenas a $100^{\circ} \mathrm{C}$, facilita a remoção do reagente e todas as amostras deixam a estrutura ao mesmo tempo.

Como as estruturas apresentaram possibilidade de comportamento diversificado com reagentes distintos, foram recolhidas amostras de gasolina de três postos diferentes e analisados na estrutura com ar como gás de arraste, mas o resultado não é tão evidente como o obtido em estrutura não empacotada. 


\subsubsection{Conclusão parcial}

Uma pequena modificação em uma estrutura anteriormente avaliada como microreator, permitiu-se obter uma informação grosseira a respeito da existência de mistura ou reagente puro nos canais. Uma possível utilização para essa estrutura é o controle de contaminação, por mistura, de um reagente em linha, já que a resposta é obtida rapidamente, pois não requer aquecimento.

Uma estrutura empacotada, que havia sido apenas simulada e corresponde a modificação interna do microreator, mostrou-se adequada como misturador.

Uma inegável vantagem do uso dessa estrutura é que o desenho sofre pouca modificação - tanto interna como externamente - entre os vários modos de utilização, o que atende ao proposto por Charpentier [43][44][45] quanto ao desenvolvimento na área de Engenharia Química.

\subsection{ESTRUTURA PARA SEPARAÇÃO PRELIMINAR DE COMPOSTOS}

Para melhorar a separação de uma mistura, comparada à estrutura anteriormente descrita, testou-se a miniaturização do desenho clássico do destilador [83], como apresentado na Figura 4.32. Observe-se que por se tratar de uma estrutura planar, de modo semelhante ao que ocorre com os impactadores, a miniaturização corresponde a uma pequena região (parte) da estrutura macroscópica, que é tridimensional.

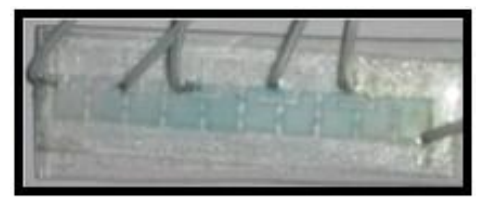

(A)

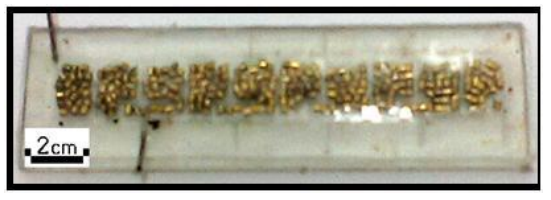

(B)

Figura 4.32 - (A) Fotografia da estrutura não empacotada e (B) estrutura com anéis de Raschig (empacotada).

A destilação baseia-se não só na diferença de volatilidade, mas também no equilíbrio químico entre duas fases (gás e líquido). A volatilidade é controlada com o controle do perfil de temperatura dentro da coluna. Para melhorar o contato entre essas 
duas fases, é comum o preenchimento da região por pequenas estruturas, isto é, o recheio, que não deve reagir com o material sendo separado na coluna. Um dos recheios mais comuns são os anéis de Raschig [83], que correspondem a anéis com diâmetro igual ao comprimento. A dimensão destes anéis é bem variada, assim como o tamanho das colunas a que eles se destinam, porém, são da ordem de $\mathrm{mm}$ a cm.

Nesta estrutura miniaturizada é possível o aquecimento, mas não haverá duas fases presentes e, devido às pequenas dimensões, a relação área/volume torna-se importante. No presente caso, tem-se relação área/volume igual a 50, devido à área ser de $1600 \mathrm{~cm}^{2}$ e o volume ser $32 \mathrm{~cm}^{3}$, e essa relação é dobrada se anéis de Raschig são utilizados. Portanto, a adsorção na superfície é um fator importante e foi avaliada com o auxilio da deposição por plasma de filmes finos. Vários filmes foram avaliados, como descrito anteriormente, optou-se pela utilização da deposição por plasma de filme a base de HMDS. Dos filmes testados a base de HMDS e de HFE, o filme a base de HMDS mostrou-se mais adequado à mudança de superfície da estrutura porque permite a adsorção tanto de compostos polares como apolares por longo tempo e de modo reversível.

Para a estrutura anterior, o pré-tratamento da amostra pressupõe a remoção de partículas, devido às dimensões do canal. Contudo, nesse novo desenho, apenas os orifícios poderiam sofrer algum tipo de entupimento; portanto, a estrutura foi testada quanto a inserção de partículas, tanto em gás quanto em líquido.

Por fim, as constrições que formam o orifício, em fase líquida, têm efeito semelhante às constrições em chicanas, já miniaturizadas por Santos [152]. Portanto, essa estrutura foi genericamente denominada, ao longo deste item, por chicana.

De modo geral, a Tabela 4.12 resume os parâmetros mais importantes para serem avaliados para compreender o comportamento da estrutura. 
Tabela 4.12 - Parâmetros mais importantes a serem avaliados na estrutura.

\begin{tabular}{||l|l||}
\hline \multicolumn{1}{|c|}{ Parâmetros } & \multicolumn{1}{c|}{ Observações } \\
\hline \hline Partículas & $\begin{array}{l}\text { A retenção de partículas presentes na amostra deve ser avaliada } \\
\text { para amostras em fase gasosa ou líquida. }\end{array}$ \\
\hline \hline Estado físico da amostra & $\begin{array}{l}\text { Amostras em fase gasosa ou líquida devem ser igualmente } \\
\text { avaliadas. }\end{array}$ \\
\hline \hline Perfil de temperatura & $\begin{array}{l}\text { Avaliada em cada cela da estrutura. Provavelmente corresponde } \\
\text { a uma região em equilíbrio, o que significa que este equilíbrio } \\
\text { pode facilmente ser modificado pela variação de temperatura. }\end{array}$ \\
\hline \hline Aquecimento da amostra & $\begin{array}{l}\text { Eventualmente, para avaliar a diferença de volatilidade da } \\
\text { amostra. }\end{array}$ \\
\hline \hline Modo de admissão da amostra & $\begin{array}{l}\text { A análise pode ocorrer com amostras em fluxo contínuo ou } \\
\text { inseridas em um único pulso. }\end{array}$ \\
\hline \hline Modo de recolhimento da amostra & $\begin{array}{l}\text { A detecção pode ser feita continuamente ou após a passagem de } \\
\text { toda a amostra pela estrutura ocorrendo a captura da amostra } \\
\text { nas respectivas saídas. }\end{array}$ \\
\hline \hline Outros & $\begin{array}{l}\text { Variações de pressão em cada cela podem ocorrer pela adição } \\
\text { de válvulas ou constrições. }\end{array}$ \\
\hline
\end{tabular}

\subsubsection{Simulação da estrutura}

As simulações tiveram por objetivo compreender o comportamento do fluido, usando gás ou líquido, na estrutura e em diversas condições de uso, tais como, a existência de partículas na amostra ou o uso de recheio ${ }^{c c}$ na estrutura entre outros. As simulações usaram vazão de $10 \mathrm{~mL} / \mathrm{min}$ (padrão) para gás e $1 \mathrm{~mL} / \mathrm{min}$ para líquido, em geral, $\mathrm{N}_{2}$ ou água, respectivamente.

O escoamento é melhor distribuído com presença dos anéis, mas nenhuma das estruturas apresentam regiões com grandes variações em função dos anteparos próximos às saídas (Apêndice A, Figura A.16). O mesmo ocorre com a variação na pressão interna, que tende a ser pequena (Apêndice A, Figuras A.16C e D), mesmo quando a estrutura encontra-se empacotada e a vazão é restringida pelo uso de válvulas. Resultados semelhantes são obtidos caso a estrutura seja aquecida (até $100^{\circ} \mathrm{C}$, Apêndice A, Figura A.16D) ou outros gases, ou mesmo vapores como o de querosene, sejam admitidos. Como em sistemas de destilação e/ou cromatografia, grandes variações na direção do fluxo são evitadas para minimizar perturbações no equilíbrio entre as fases, o resultado obtido é promissor.

\footnotetext{
${ }^{c c} \mathrm{O}$ uso do termo recheio é comum em Engenharia Química, mas restrito as colunas de destilação. Como os processos que ocorrem na estrutura aqui desenhada não são exatamente os mesmos que os de uma dessas colunas, sendo muito dependente de processos de adsorção, optou-se por denominar a estrutura por chicana empacotada, uma vez que coluna empacotada é um termo comum em cromatografia e descreve aquelas colunas que foram preenchidas com fase estacionária na forma de partícula. Além disso, os processos cromatográficos são muito dependentes de adsorção nesta fase.
} 
A velocidade, se todas as saídas têm a mesma dimensão, é maior nas saídas das duas primeiras celas das estruturas, empacotada ou não, para qualquer gás ou vapor, aquecido ou não (Apêndice A, Figura A.17).

O refluxo é comum em colunas de destilação e tem por objetivo obter melhor contato entre líquidos e vapores além de melhorar a separação. No presente caso foi avaliada, por simulação, a possível vantagem da interação de dois fluxos distintos admitidos na estrutura. Utilizaram-se vapores de água e querosene como reagentes, já que estes apresentam baixa miscibilidade. Adição de querosene na primeira cela e água em todas as celas restantes, a temperatura ambiente (Apêndice A, Figura A.18A, linhas de velocidade) provavelmente favorece a retenção de alguns compostos por mais tempo em cada cela. Por outro lado, se querosene é admitido na primeira cela e água na última, ocorre pouca interação e a água preferencialmente deixa a estrutura já na penúltima cela. Neste caso, portanto, o sistema não facilita o contato dos reagentes, principalmente porque os anteparos presentes em cada saída auxiliam na direção do escoamento. Resultados semelhantes são obtidos se o querosene é aquecido e/ou se a estrutura empacotada é utilizada (Apêndice A, Figura A.18B e C).

A simulação de partículas para fluido gasoso apresentou retenção e, tanto para $10 \mu \mathrm{m}$ como $50 \mu \mathrm{m}$, o perfil é semelhante. Neste caso, não se observa uma correlação clara entre velocidade e concentração, como era esperado, considerando-se a existência de paredes definindo as celas e a menor velocidade dos fluidos nas celas finais. Para 50 $\mu \mathrm{m}$, porém, a retenção parece ocorrer apenas nas primeiras celas.

O uso de filme adsorvente na estrutura diminui a velocidade, para próximo ou igual a zero, em quase todas as regiões após a primeira cela e aumenta a pressão, praticamente em toda a estrutura. Assim, filmes adsorventes podem ser úteis para reter (ou atrasar a saída) alguns compostos, mas podem também significar que a pressão está acima da máxima suportada pela estrutura.

Resultados semelhantes são obtidos supondo que os fluídos estejam na fase líquida para todas as condições anteriormente simuladas.

\subsubsection{Retenção de partículas e comportamento do fluido}

A adição de uma substância/partícula em um fluido pode funcionar tanto como traçador, para compreender os processos físico-químicos ocorrendo, ou como amostra, para testar a funcionalidade da estrutura (Apêndice A, Figura A.19). 
$\mathrm{Na}$ fase gasosa, a estrutura sem recheio foi avaliada quanto à retenção com partículas de $13 \mu \mathrm{m}$ e $50 \mu \mathrm{m}$. Na fase líquida foram avaliadas estruturas com ou sem recheio. A metodologia utilizada corresponde à injeção de pulsos de ar contaminado com partículas e filmagem. Avaliou-se também o comportamento do fluido em fase liquida, nesse caso utilizando-se traçadores.

\subsubsection{Retenção de partículas}

A Figura 4.33A, apresenta resultado típico para fase gasosa depois da inserção de partículas de $13 \mu \mathrm{m}$ e detalha alguns locais onde ocorre essa deposição. A deposição destas ocorre não só na região onde há alta velocidade (segundo a simulação), mas, também, nas regiões onde estão as celas mais distantes da entrada (penúltima e última) mesmo sendo regiões de menor fluxo. Por outro lado, as partículas de $50 \mu \mathrm{m}$ apresentam maior tendência de se localizar no centro da placa coletora (região onde fezse o jateamento), ou seja, nessas dimensões a estrutura assemelha-se ao impactador e é favorável à retenção (Figura 4.33B).

Estes resultados também podem ser observados nas simulações e a facilidade de "espalhamento" das partículas de menor dimensão $(13 \mu \mathrm{m})$, pode dever-se a vários fatores agindo simultaneamente, pois nessa faixa, em fase gasosa pode-se esperar retenção, por exemplo, por centrifugação, formação de ciclone, etc.

O comportamento do fluido também foi avaliado com a adição de gelo seco $\left(\mathrm{CO}_{2}\right)$ ao gás de arraste. Neste caso, regiões onde o fluido apresenta menor velocidade apresentam-se menos transparentes [101][121]. Foi possível verificar que o escoamento distribui-se de acordo com o observado na simulação e de modo semelhante ao encontrado com o uso de azul de metileno para a fase líquida. Porém, a filmagem não mostrou contraste suficiente.

Para fase líquida observa-se que tanto as partículas de $13 \mu \mathrm{m}$ como as de 50 $\mu \mathrm{m}$ espalham-se por toda a estrutura. 


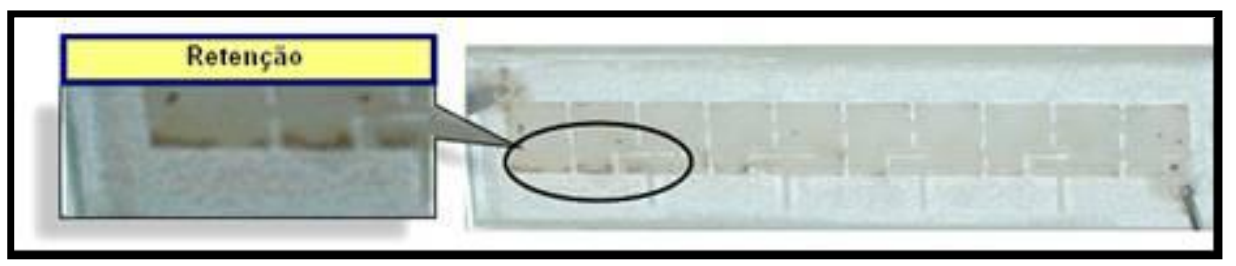

(A)

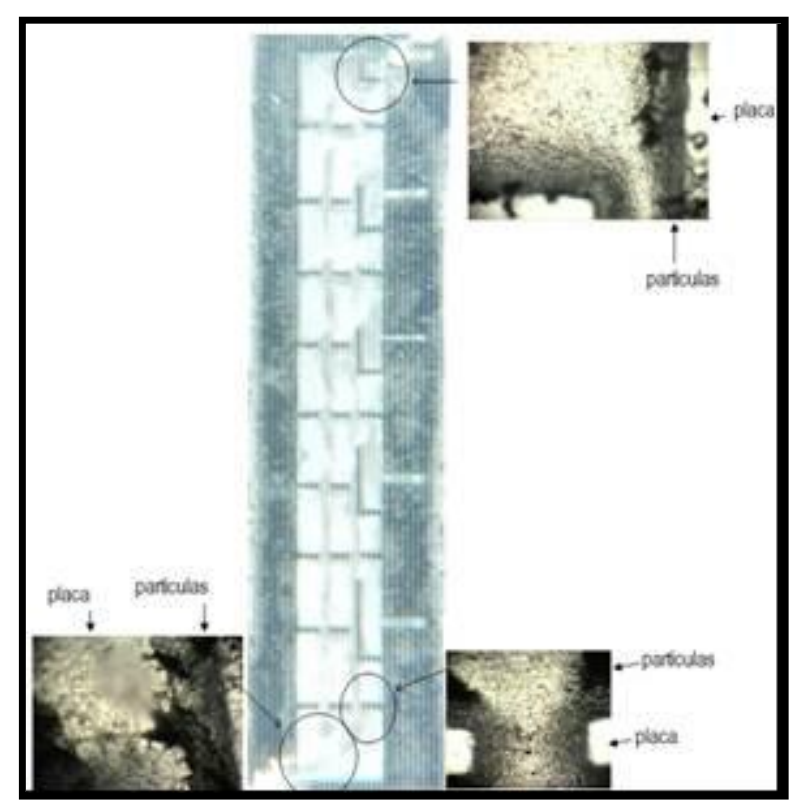

(B)

Figura 4.33 - Retenção de partículas de (A) $13 \mu \mathrm{m}$ e (B) $50 \mu \mathrm{m}$ : condição depois da inserção.

\subsubsection{Uso de traçadores}

Para a realização do procedimento de avaliação usando traçadores seguiram-se as etapas:

$>$ adicionou-se o fluido aquoso no interior da estrutura com apenas a última câmara aberta para o ambiente. Esperou-se até que não fosse visualizada a existência de áreas sem o fluido (preenchimento da estrutura);

$>$ liberou-se uma das câmaras para a atmosfera, e adicionou-se $0,01 \mathrm{~mL}$ do traçador. Recolheu-se o líquido em proveta e mediu-se o tempo necessário para o traçador começar a ser removido da estrutura;

$>$ repetiu-se o procedimento com outra câmara.

A vazão volumétrica é calculada simplesmente dividindo-se o volume pelo tempo e o comportamento do fluido é avaliado filmando-se a estrutura. Quanto à vazão, 
para a chicana empacotada, há uma variação aproximadamente linear devido à perda e a Figura 4.34A apresenta os gráficos da vazão medida em função da distância da entrada. Por outro lado, para a estrutura sem preenchimento, tem-se vazão constante e a velocidade do fluido é alta, permitindo a retirada do traçador em menos de $15 \mathrm{~s}$. A estrutura sem preenchimento apresenta caminhos preferenciais (locais mais escuros ao longo do escoamento) e é possível observar, em uma seqüência de fotos, por exemplo, que o traçador caminha sem grande dispersão para os lados, indicando que provavelmente o regime é laminar. Ademais, a coloração mais branda ao redor do fluido principal indica como ocorre a difusão do traçador nesse escoamento e que ocorrem espaços mortos (locais sem coloração do traçador) próximos às saídas. A Figura 4.34B apresenta uma sequiência destas fotos para as duas primeiras celas.

Utilizando solução aquosa com $10 \%$ de azul de metileno e anilina vermelha, fez-se a inserção das duas cores ao mesmo tempo para observar-se a ocorrência de mistura de fluidos e notou-se que há pouca probabilidade de mistura. A Figura 4.34C apresenta fotografia onde pode-se observar o fenômeno ocorrendo no meio da estrutura. 

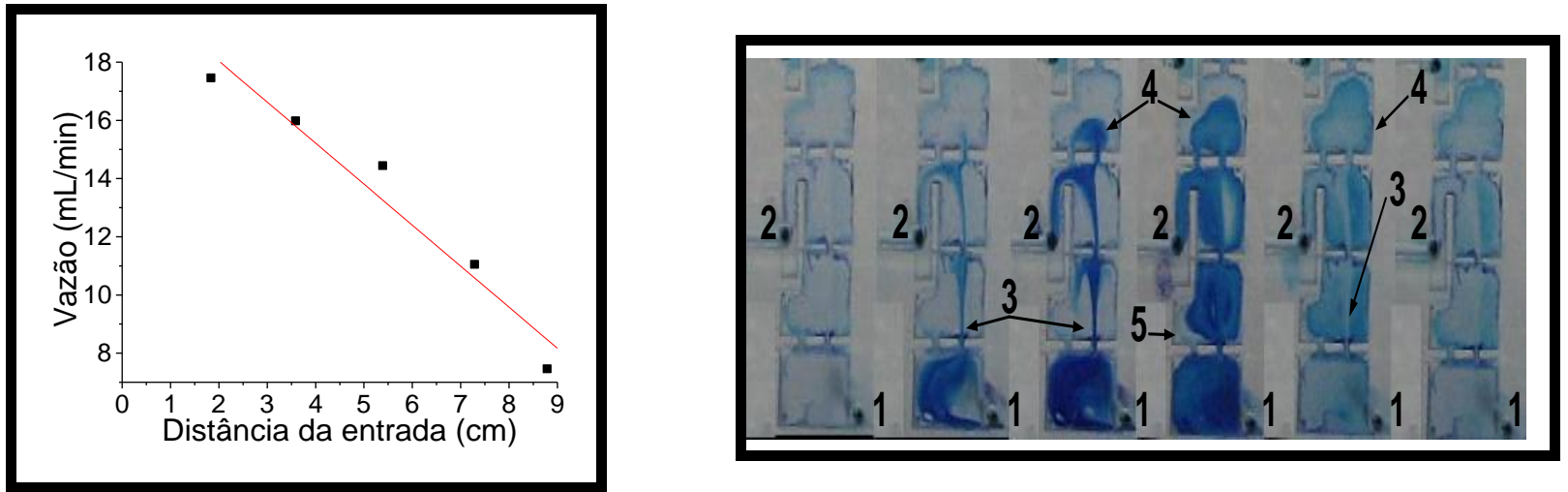

(A)

(B)

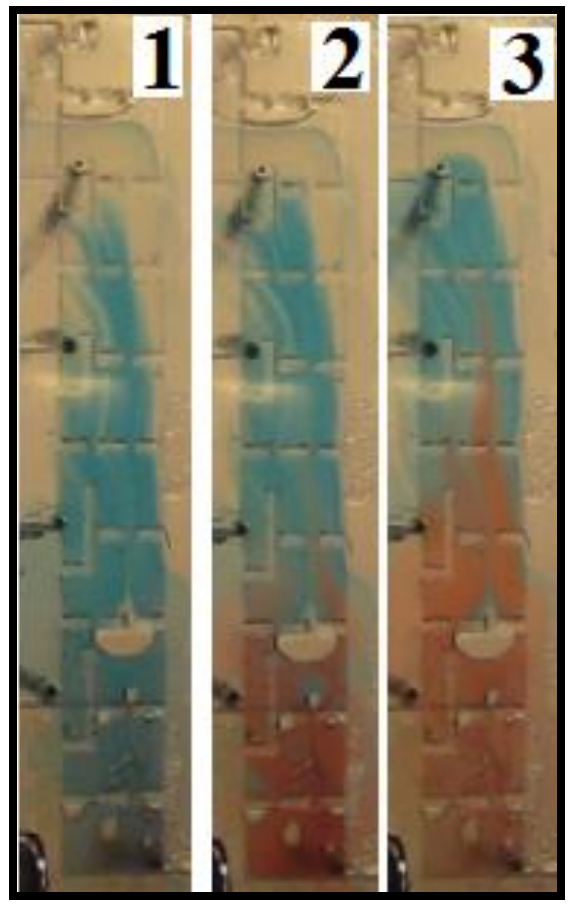

(C)

Figura 4.34 - Comportamento do fluido: (A) resultados típicos para a vazão em estruturas empacotadas em função da câmara avaliada. (B) sequiência de fotos na estrutura não preenchida após a adição do traçador: (1) entrada do fluido; (2)

saída do fluido; (3) caminho preferencial; (4) difusão; (5) espaço morto. (C) visualização da região da chicana onde observa-se a mistura de reagentes, no caso, corantes vermelho e azul.

Os caminhos preferenciais são mais evidentes com o uso de substância viscosa e, para comparação, a Figura 4.35 apresenta seqüência de fotos obtidas da filmagem pela inserção do traçador, azul de metileno, tanto em solução aquosa (A) como em glicerol (B). Assim, o uso de glicerol evidencia que o caminho preferencial existe em toda a estrutura e a saída lateral favorece o acúmulo de produto. 


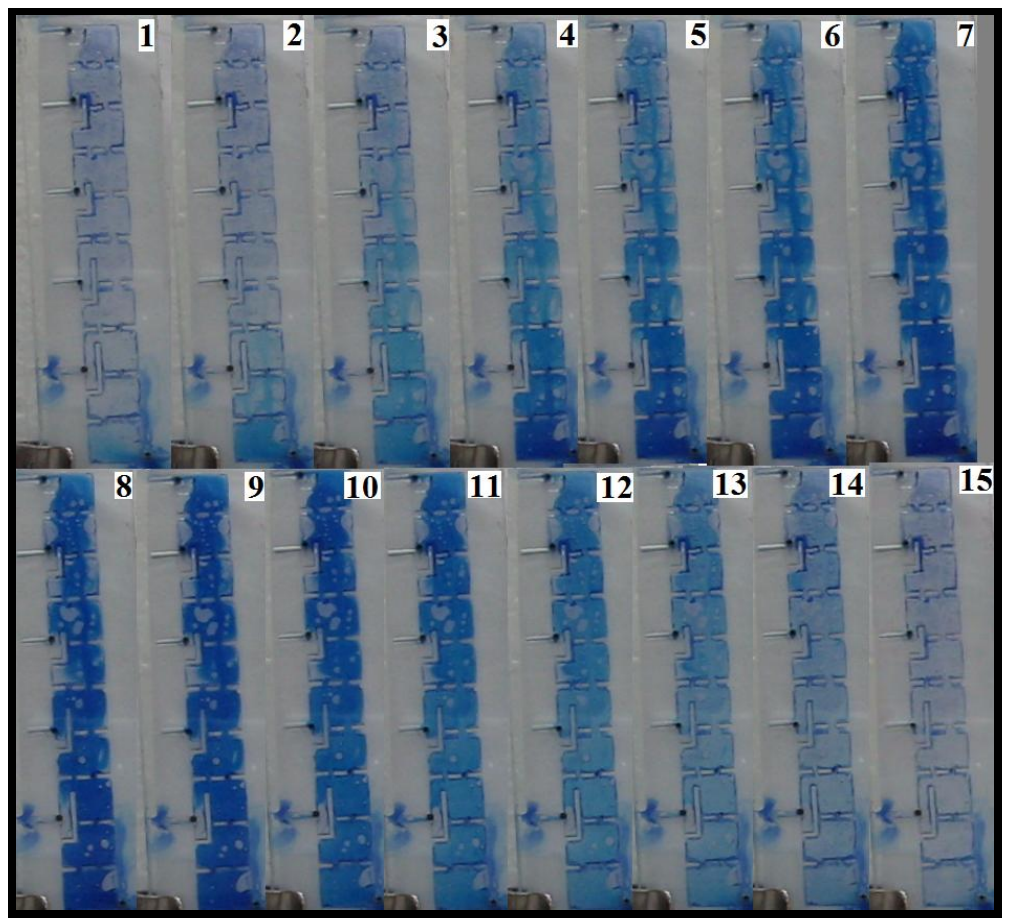

(A)

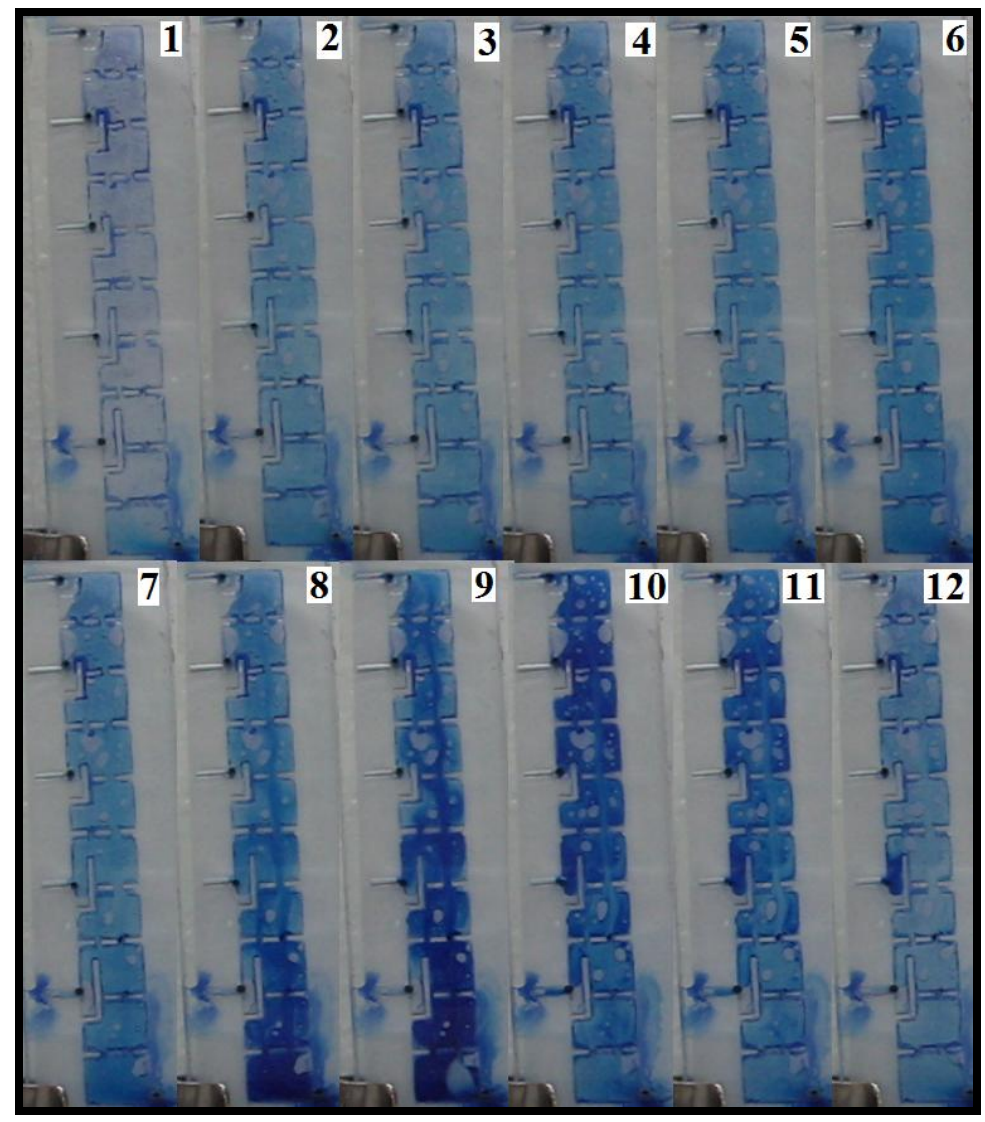

(B)

Figura 4.35 - Imagens da chicana com (A) solução $10 \%$ de azul de metileno em água destilada e (B) solução $10 \%$ de azul de metileno em glicerol. 
A observação da chicana empacotada com o uso de microscópio e de traçador permitiu encontrar várias formas de interação entre o fluido e os anéis. Na estrutura preenchida, é possível observar que a passagem do fluido pelo interior da estrutura é aparentemente aleatória, isto é, sem caminhos preferenciais, provavelmente devido às dimensões reduzidas do dispositivo, como comentado anteriormente. Verifica-se também que o fluido transita não só ao redor do anel como também no interior deste. A Figura 4.36 apresenta seqüência de fotos para exemplificar os fenômenos possíveis de se observar. As Figuras 4.36A e 4.36B apresentam situação onde os traçadores percorrem o fluido sem qualquer mistura, isto é, como esperado quando o regime deve ser laminar, e a Figura 4.36C apresenta a passagem do traçador internamente ao anel. 


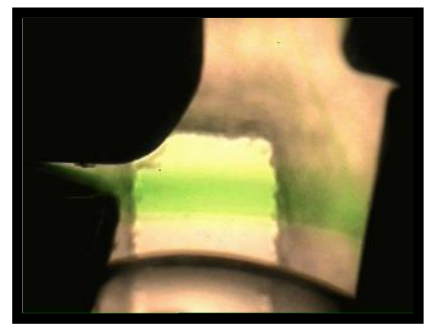

(A)
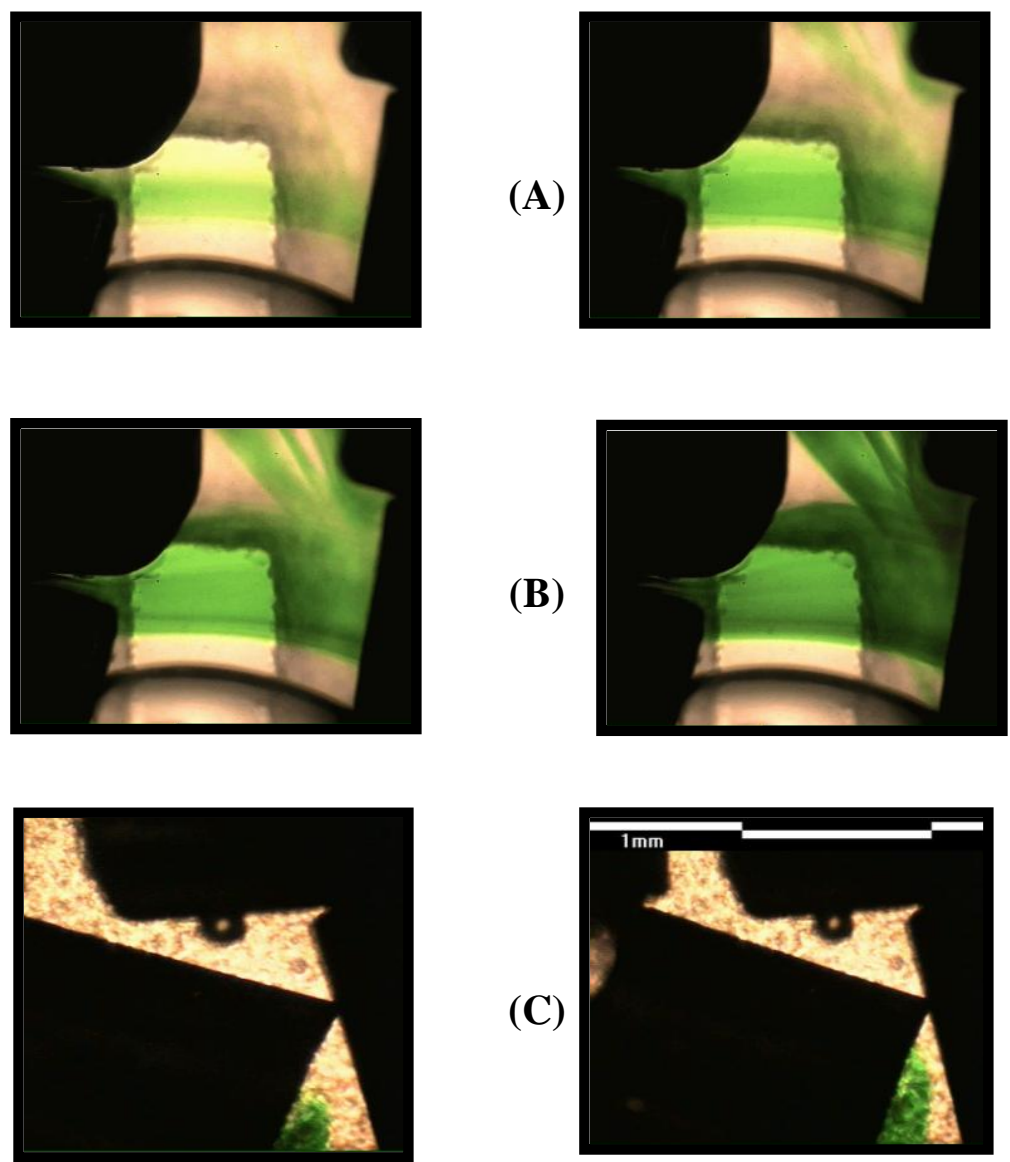

(B)

(C)

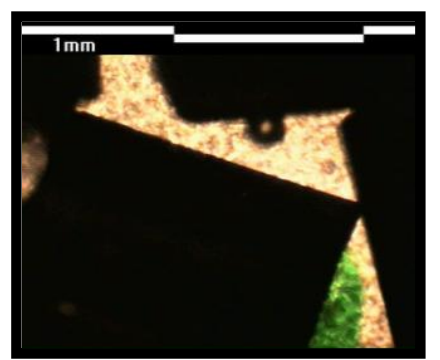

Figura 4.36 - Seqüência de fotografias exemplificando fenômenos possíveis de se observar na estrutura preenchida com anéis: (A) início do encontro de dois escoamentos de traçadores; (B) caminho de dois traçadores; (C) passagem do traçador internamente ao anel.

\subsubsection{Conclusão parcial}

A estrutura sob análise, devido ao pequeno número de Reynolds apresenta regime laminar, pouca interação entre fluidos, mesmo em fase líquida, e possibilidade de funcionamento mesmo com a inserção de amostra contaminada por partículas.

\subsubsection{Testes da estrutura}

Os testes necessários para comprovar que a estrutura em questão pode proceder a uma separação preliminar foram extensivos e os resultados são aqui apenas resumidos. Informação detalhada, contudo, pode ser encontrada no Apêndice C. 
O arranjo experimental (Figura 4.37) para testes em modo de admissão pulsado é composto de mini compressor de ar (Inalar Compact motor 1/40HP, potência 200 VA, freqüência $60 \mathrm{~Hz}$, Voltagem $127 \mathrm{~V}$, Sistema a Pistão, vazão de $10 \mathrm{~mL} / \mathrm{min}$ ) para impulsionar o ar, que corresponde ao gás carregador para admissão do reagente na estrutura; as conexões foram realizadas com o auxílio de tubulação de polipropileno de 1/4 polegada (poliflow ${ }^{\circledR)}$ ), detector de baixo custo (TGS 2614, Figaro, Japão). Há uma região específica para a inserção de reagentes (porta amostra) através de seringas de $1,00 \mathrm{~mL}$, localizada bem próxima entrada da estrutura.

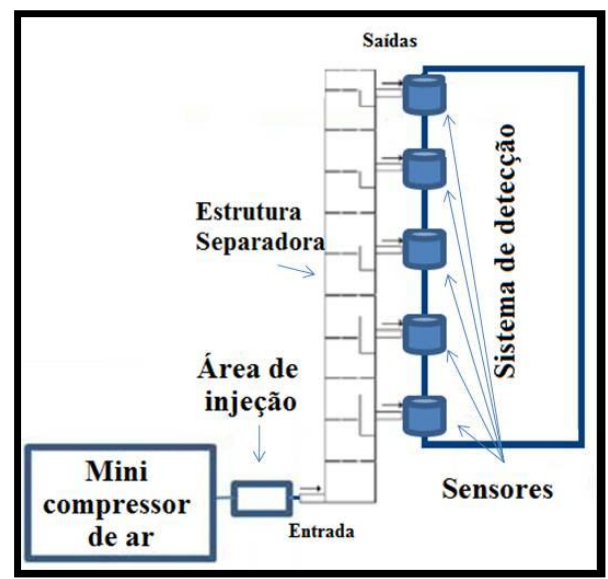

Figura 4.37 - Esquema do aparato utilizado durante os testes.

Para o controle de vazão usam-se válvulas on/off comuns e o tempo é determinado com o auxílio de um cronômetro (Taksun ${ }^{\circledR}$, Modelo TS*613 A, alimentação 1,0 V). Os testes de vazão são feitos tanto com as estruturas quanto sem as estruturas. A vantagem do uso deste sistema é a possibilidade de medição da vazão na saída da estrutura, considerando, portanto, sua perda de carga.

A detecção - que corresponde à variação da tensão no detector em função do tempo - pode ser armazenada na forma digital através de uma interface de coleta de $\operatorname{dados}^{\mathrm{dd}}$.

\footnotetext{
${ }^{\mathrm{dd}}$ Desenvolvimento em conjunto com Alisson Rodolfo Leite. O circuito eletrônico em questão permite a comunicação de dados on line para o computador de até oito sensores simultaneamente. A comunicação com o computador é serial. Neste caso, os dados da placa de comunicação são convertidos de nível TTL em RS232 e vice-versa, o que é feito com o circuito integrado MAX232. Para interpretador utiliza-se o microcontrolador AT89S8252 da Atmel. Além disso, tem-se uma fonte de tensão DC interna ( $\pm 5 \mathrm{~V})$ para alimentação do circuito e do sensor. A placa é alimentada por fonte externa DC, de 9V.
} 
No conjunto (estrutura/detector) proposto, fez-se os testes utilizando estruturas não empacotadas e empacotadas, sem e com filme a base de HMDS (Hexametildissilazana). Usaram-se diferentes reagentes para realização dos testes: isopropanol, gasolina comum, acetona, Varsol®, mistura $(1 \mathrm{~mL}$ de cada reagente: isopropanol+acetona+Varsol®), nesta ordem, respectivamente. Para determinar se o aquecimento poderia alterar as respostas, ou seja, facilitar a separação de componentes da mistura, fez-se o aquecimento utilizando água como fluido de trocador de calor e diferentes temperaturas $\left(92^{\circ}\right.$ à $87^{\circ} \mathrm{C} ; 70^{\circ}$ à $58^{\circ} \mathrm{C} ; 34^{\circ}$ à $20^{\circ} \mathrm{C} ; 20^{\circ} \mathrm{C} ; 20^{\circ} \mathrm{C}$, da primeira para a quinta cela, respectivamente) sob as estruturas. Repetiu-se 5 vezes cada teste nas mesmas condições para todas as estruturas e reagentes para verificação da reprodutibilidade.

Apenas descreve-se os resultados com o modo de admissão pulsada (apresentado em Materiais e Métodos), já que o escoamento contínuo não apresentou vantagens quando comparado a este.

\subsubsection{Estrutura não empacotada}

Os testes ocorreram com gás de arraste em modo contínuo, vazão de 0,10 $\mathrm{mL} / \mathrm{min}$ e injeções de $0,10 \mathrm{~mL}$ dos reagentes.

\subsection{Sem aquecimento}

Os resultados referentes aos tempos de injeção até a detecção e de duração da detecção, para isopropanol e gasolina, são apresentados no Gráfico 4.14. Enquanto o isopropanol (substância pura) tem tempo para sua detecção em torno de 45 segundos e apresenta um tempo de residência pequeno, a gasolina comum (mistura) tem o tempo de detecção após a injeção de 5 segundos, o que é coerente com sua baixa pressão de vapor, porém, permanece na cela por mais tempo, provavelmente pela diferença de volatilidade dos componentes da mistura, ou seja, há uma tendência à separação dos compostos de acordo com a variação de pressão de vapor. As celas com maior tempo de detecção são as primeiras, o que está de acordo com o obtido pela simulação. A vantagem das últimas celas, portanto, provavelmente é detecção de gases, não vapores. Eventualmente, uma medida pode apresentar um resultado díspar, como o teste número 3 para gasolina, porém, de modo geral os resultados são reprodutíveis. 

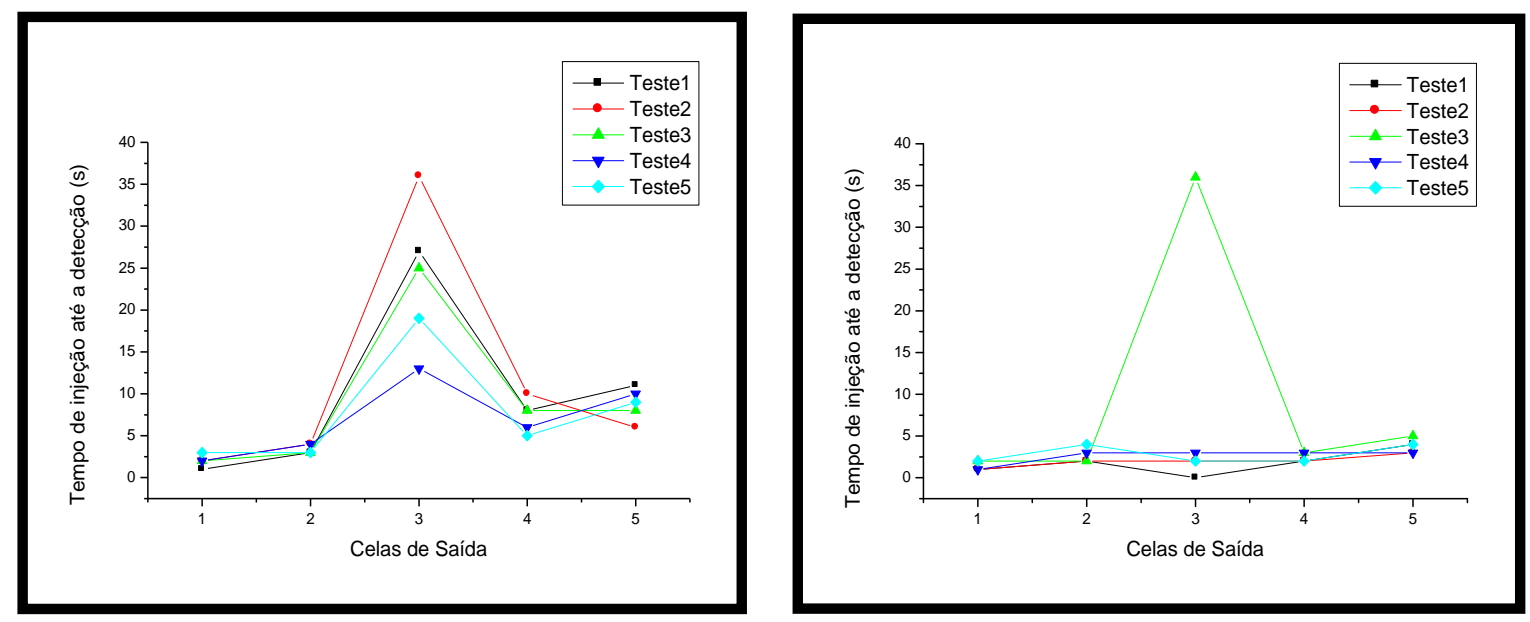

(A)
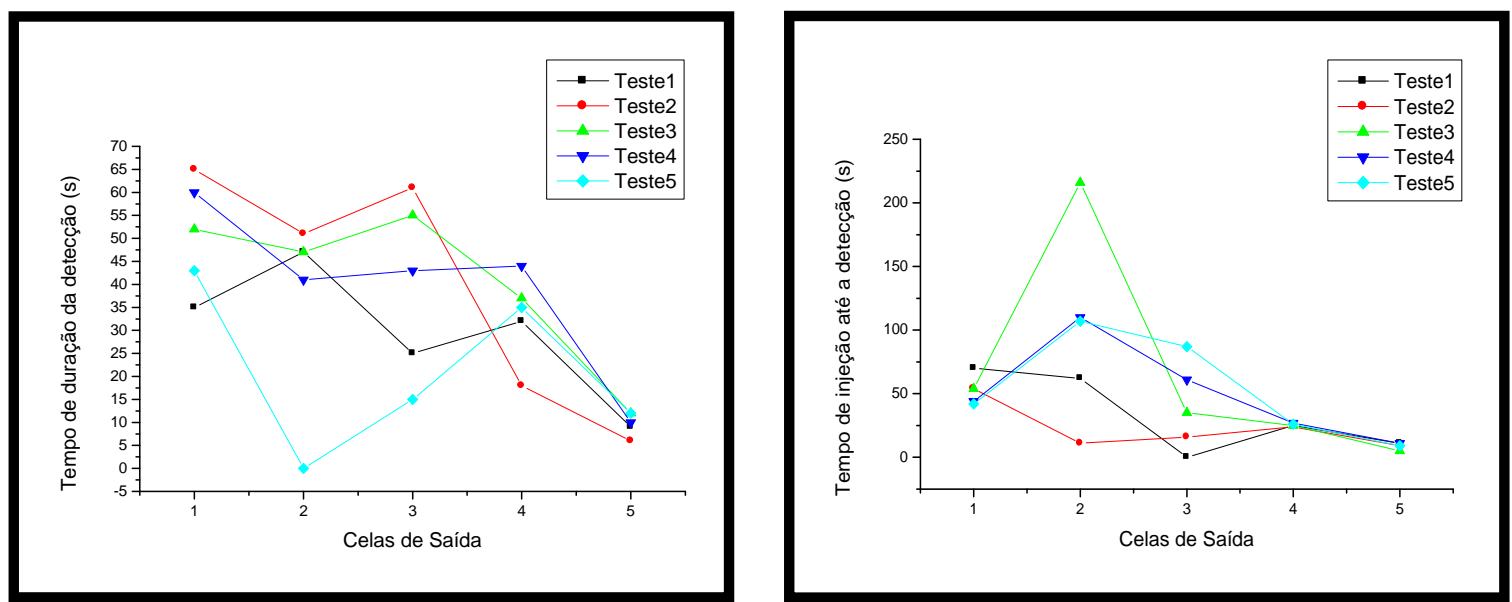

(B)

Gráfico 4.14 - Tempos de injeção até a deteç̧ão e de duração da detecção em função da cela da estrutura para (A) isopropanol e (B) gasolina comum.

\subsection{Com aquecimento}

Repetiu-se a metodologia anteriormente citada, porém, com aquecimento $\left(92^{\circ}\right.$ à $87^{\circ} \mathrm{C} ; 70^{\circ}$ à $58^{\circ} \mathrm{C} ; 34^{\circ}$ à $20^{\circ} \mathrm{C} ; 20^{\circ} \mathrm{C} ; 20^{\circ} \mathrm{C}$ ). As temperaturas foram controladas com um termômetro analógico que detecta de $0^{\circ}$ à $100^{\circ} \mathrm{C}$. Quando se comparam os dados obtidos (Gráfico 4.15) com os testes sem aquecimento, observa-se, como vantagem, a detecção também na terceira cela; ademais, o isopropanol "espalha-se" por toda a estrutura enquanto a gasolina preferencialmente deixa-a na terceira cela, provavelmente devido à menor pressão de vapor. $\mathrm{O}$ aquecimento mudou de modo evidente os tempos para isopropanol, mas não para gasolina, o que indica que o comportamento da estrutura, 
neste caso, pode ser dependente da temperatura de ebulição, mas, de modo geral, não há vantagem no uso de aquecimento.

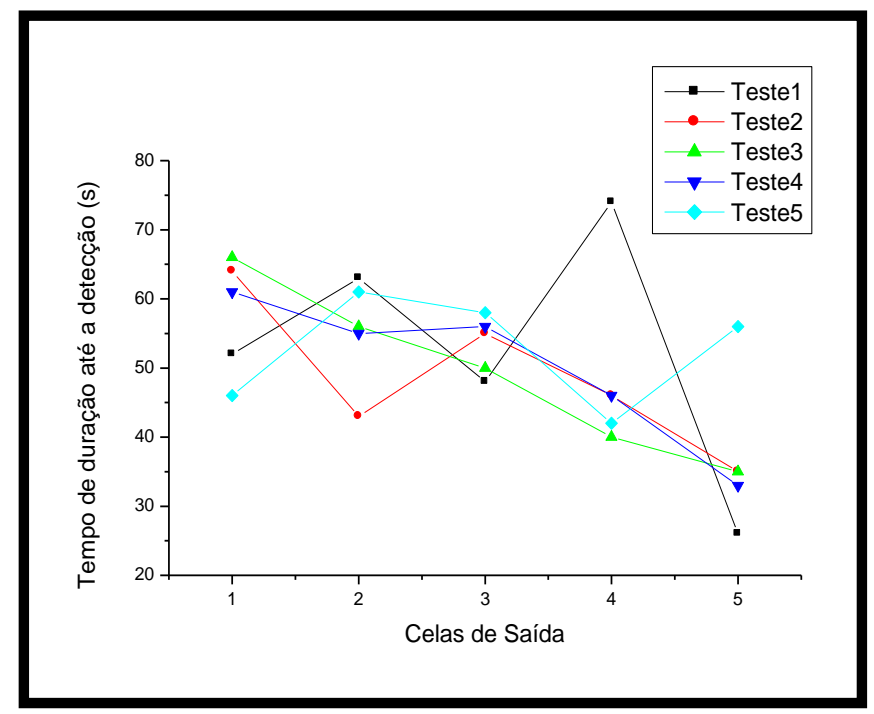

(A)

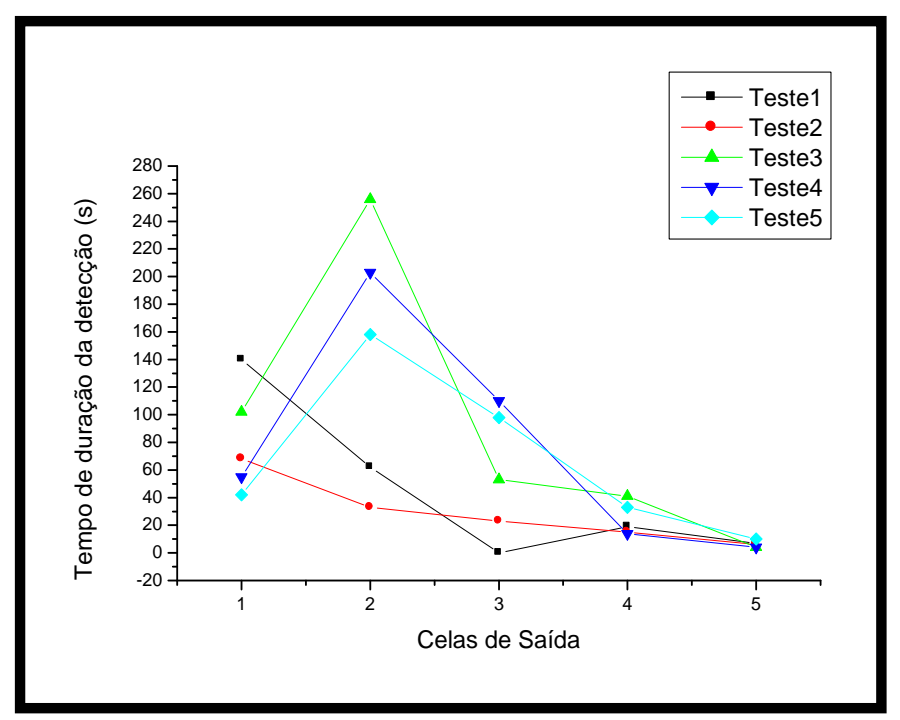

(B)

\section{Gráficos 4.15 - Tempos de duração da detecção em função da cela da estrutura usando aquecimento e (A) isopropanol ou (B) gasolina comum.}

\subsection{Recobrimento com filme adsorvente a base de HMDS}

Os testes realizados em estruturas com filme a base de HMDS depositado por plasma, tem o intuito de avaliar o comportamento funcional da estrutura ao inserir-se um filme adsorvente e se tais filmes, podem propiciar a remoção ou facilitar a separação de componentes de uma mistura inserida na estrutura. Com o intuito de reproduzir as mesmas condições dos testes realizados nas estruturas não empacotadas, testes idênticos foram processados nas estruturas com filme adsorvente.

\subsection{Sem aquecimento}

Não se observa alteração significativa para os tempos da injeção até a detecção, porém, têm-se situações com medidas intermitentes e/ou de baixa detecção o que indica que o filme está interagindo com o reagente.

Quanto ao tempo de duração dessa detecção, o Gráfico 4.16 apresenta resultados típicos para isopropanol e gasolina. Devido ao filme a base de HMDS 
adsorver tanto compostos polares como apolares, nota-se uma maior semelhança, se comparado ao Gráfico 4.16 ou 4.14, de comportamento entre isopropanol e gasolina.

É importante observar que, devido à existência do filme, a coloração da superfície da estrutura pode variar especialmente se houver adsorção. Assim, para gasolina comum observou-se uma variação indicativa de que pelo menos parcialmente o produto foi retido por aproximadamente 14 minutos na região imediatamente anterior ao primeiro anteparo; após isto, o produto aparentemente se concentra antes do segundo anteparo por alguns segundos e então essa variação desaparece rapidamente. Essa adsorção mais significativa de gasolina é esperada, pois o filme a base de HMDS apresenta radicais $\mathrm{CH}_{3}$ na superfície.

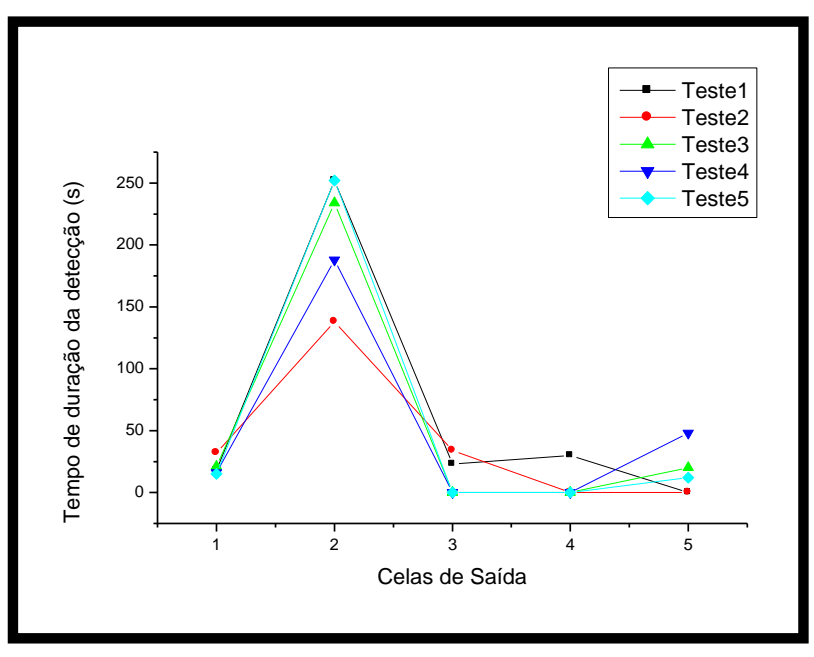

(A)

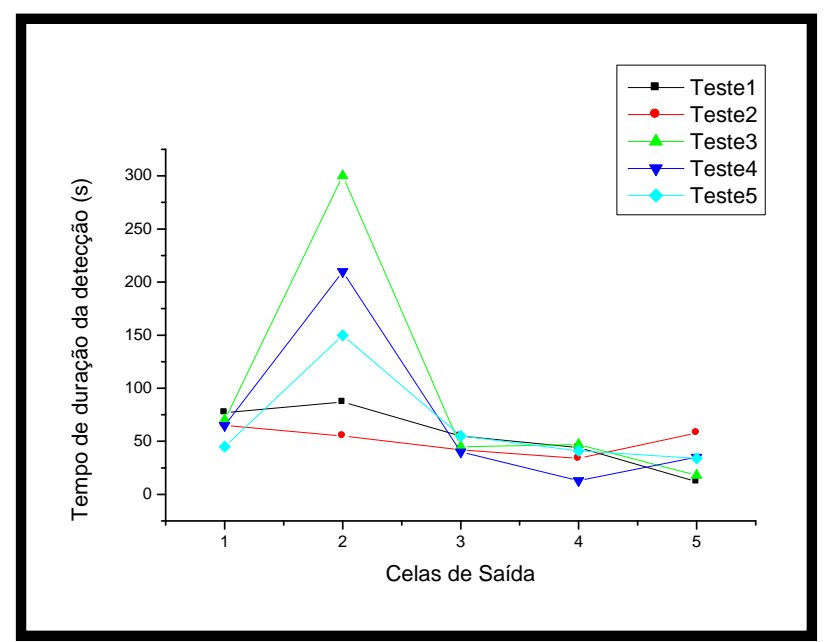

(B)

Gráfico 4.16 - Tempos de duração da detecção em função da cela da estrutura usando (A) isopropanol e (B) gasolina comum em estrutura com filme a base de HMDS e medidas sem aquecimento.

\subsection{Com aquecimento}

Nas mesmas condições dos testes anteriores fizeram-se testes idênticos para as estruturas com filme a base de HMDS, porém sobre aquecimento em temperaturas variadas $\left(92^{\circ}\right.$ à $87^{\circ} \mathrm{C} ; 70^{\circ}$ à $58^{\circ} \mathrm{C} ; 34^{\circ}$ à $\left.20^{\circ} \mathrm{C} ; 20^{\circ} \mathrm{C} ; 20^{\circ} \mathrm{C}\right)$ em ordem crescente para garantir que a remoção e o comportamento do reagente interno a estrutura seja alterado. Neste caso, se comparado às estruturas sem filme adsorvente, tem-se um tempo de injeção até a detecção maior para as últimas celas, porém com duração de detecção 
reduzida a partir de terceira cela de saída. Ocorreu, portanto, uma competição entre a adsorção e a remoção por aquecimento e a estrutura comportou-se de modo mais semelhante a uma coluna cromatográfica. Nos testes usando gasolina tem-se o tempo de injeção até a detecção na primeira cela reduz, aproximadamente, o dobro do obtido sem aquecimento indicando que o aquecimento pode alterar a remoção dos reagentes menos voláteis.

\subsubsection{Estrutura empacotada}

Todo o processo realizado com a estrutura não empacotada foi repetido com a estrutura empacotada e a Figura 4.38 apresenta a fotografia da estrutura usada. Nessa estrutura acrescentaram-se minitubos metálicos com dimensões similares às de anéis de Raschig.

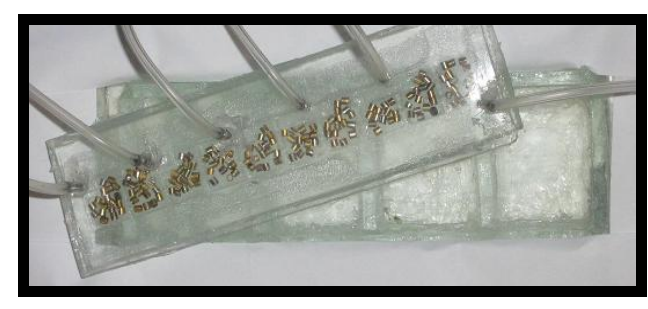

Figura 4.38 - Estrutura empacotada e sistema de aquecimento.

Quando as estruturas estão empacotadas tem-se o tempo de remoção ainda maior, podendo ultrapassar 10 minutos, utilizando os reagentes citados no item anterior. Uma grande variação de comportamento ocorre entre substâncias puras e misturas, isto mostra que, possivelmente, a estrutura está funcionando como separador.

\subsection{Recobrimento com filme adsorvente a base de HMDS}

Visto que o filme a base de HMDS apresenta grande adsorção, os minitubos foram também recobertos. 


\subsection{Sem aquecimento}

Nessas medidas, devido à perda de carga com a adição dos anéis, tem-se a redução de $50 \%$ da vazão nas celas de saída usando-se o mini compressor de ar com vazão igual a $10 \mathrm{~mL} / \mathrm{min}$. Para isopropanol ocorreu retenção e a detecção foi mínima durante todo o tempo de residência do reagente na estrutura; este tempo, contudo, é difícil estimar devido ao pequeno sinal obtido. Para a gasolina, apesar de ser possível detectá-la mais facilmente, ocorreram detecções intermitentes, provavelmente porque há maior área para adsorção, proporcionada pelos anéis. Estes anéis também dificultam a passagem do fluido e podem originar caminhos preferenciais, mas é menos provável, como verificado com traçadores anteriormente.

\subsection{Com aquecimento}

Para avaliar se realmente a pressão de vapor dos reagentes influiu nos testes anteriores, também realizaram-se testes com aquecimento. Adotou-se a mesma metodologia utilizada para as estruturas não empacotadas. Mesmo com aquecimento, o tempo da injeção até a detecção não sofre grandes alterações quando comparado com os tempos obtidos nos testes sem aquecimento, o que demonstra a importância da adsorção. Já no que diz respeito à duração do tempo de detecção, obtém-se tempos menos prolongados o que indica que o aquecimento está induzindo a dessorção do reagente. Por fim, o aquecimento permite que o reagente percorra toda a estrutura e possa ser detectado na quinta cela.

A maior alteração no tempo de injeção ocorre na terceira, quarta e quinta cela, e com aumento crescente. Estes fatos indicam que mesmo com aquecimento, os diferentes reagentes da gasolina estão sofrendo interferência tanto pelo filme a base de HMDS quanto pelos minitubos metálicos, ou seja, adsorção e caminhos preferenciais, respectivamente.

\subsubsection{Conclusão parcial}

As medidas obtidas neste item demonstram que a estrutura pode ser utilizada para uma separação preliminar de uma mistura. Essa separação exige que a estrutura seja calibrada inicialmente e, para compostos como gasolina, o uso da estrutura com 
filme a base de HMDS é suficiente para indicar a presença de isopropanol como contaminante. Tanto a injeção como a calibração da estrutura pode ser feita manualmente. O comportamento do fluido observado com traçadores está de acordo com o obtido por meios experimentais.

De modo geral, essa estrutura permite avaliar se duas misturas são similares e determinar se uma substância, ou mistura, encontra-se "contaminada", por exemplo, por uma única substância, já na ordem de décimos de porcentagem.

\subsection{PROPOSTA DE PROTÓTIPO}

As simulações e testes com as estruturas propostas neste trabalho permitem propor um protótipo para uso na área de análise química e/ou de Engenharia Química e algumas considerações são feitas a seguir.

\subsubsection{Engenharia Química e Análises}

Para propor um protótipo, definiram-se como condições de contorno os requisitos mínimos para montar um equipamento capaz de detectar amostras de compostos orgânicos, que fosse de baixo custo e portátil, além de ter fácil fabricação, manutenção e manipulação.

No desenvolvimento deste protótipo seguiram-se as 5 etapas: 1) definição de qual operação que se deseja (pré-concentração/ retenção/ separação); 2) definição da estrutura usada para operação (spray/ impactador/ destilação); 3) simulação de cada estrutura; 4) teste e desempenho individual de cada estrutura definindo sua respectiva função (análise experimental); 5) avaliação da proposta do equipamento.

São as principais características desse desenvolvimento:

*protótipo: condições de contorno atendidas: (1) a produção de sistemas de baixo custo; (2) utilização de componentes de fácil acesso, manutenção e adaptação; (3) aquisição de software de fácil manipulação. Essas condições de contorno são consideradas como pré-requisitos para programas de ensino onde um dos objetivos principais é o envolvimento de mulheres na ciência e na Engenharia e também são consideradas adequadas para atendimento de população de baixa renda [153].

*circuito eletrônico: utilizou-se um projeto de circuito eletrônico bastante simples e de baixo custo nos testes das estruturas. Para a proposta deste protótipo tem- 
se, igualmente, a possibilidade de uso de equipamento de aquisição de dados de baixo custo [154]. A Figura 4.39 apresenta o diagrama elétrico. Esse dispositivo mostrou-se bastante efetivo para medidas de VOCs em arranjo para ensino de controle de poluição.

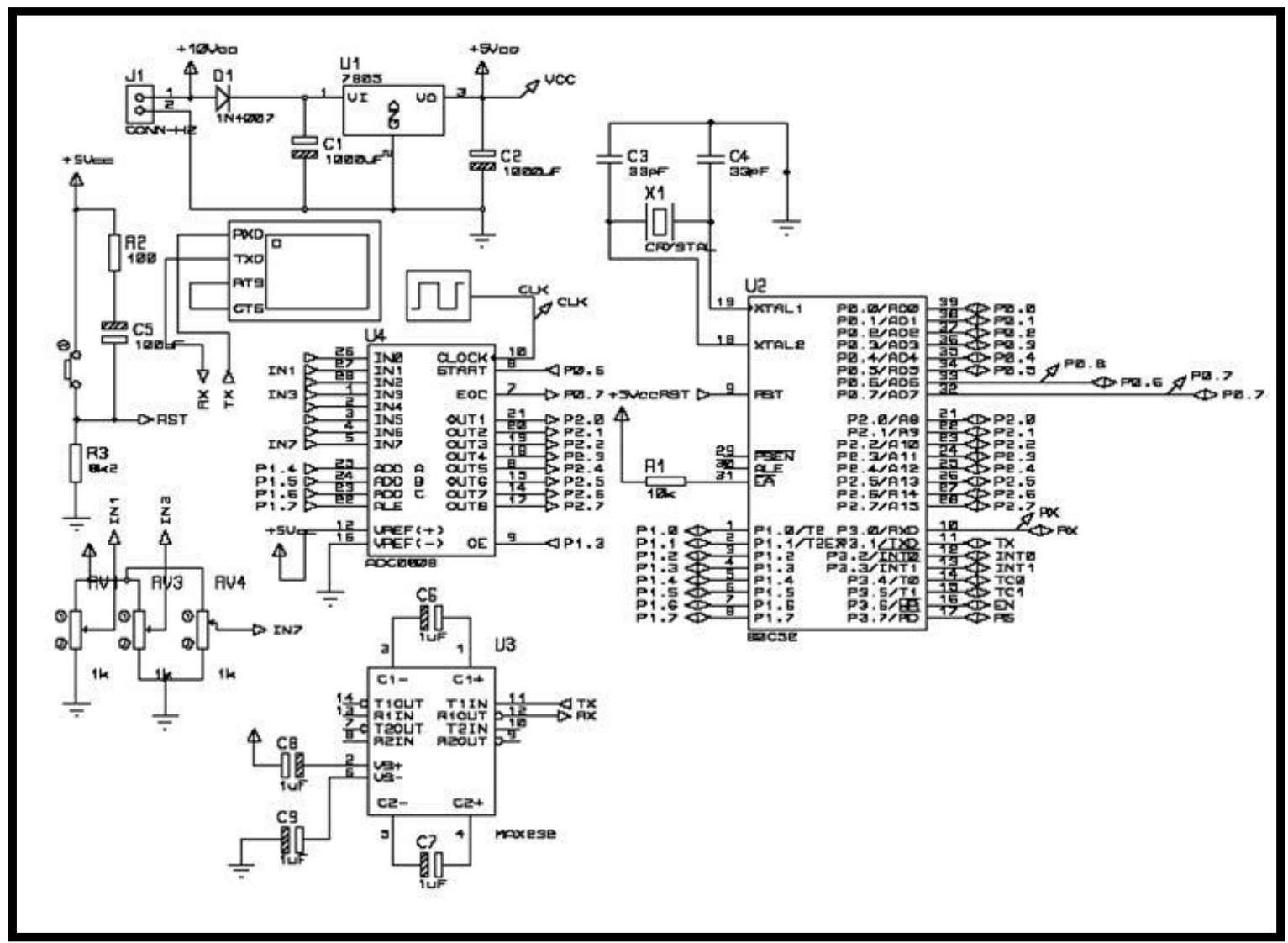

Figura 4.39 - Diagrama elétrico da placa de aquisição [154].

*estruturas: usinadas com o intuito de realizar análises de compostos orgânicos voláteis, bem como determinar quais reagentes estão presentes em misturas, por exemplo, gasolina. A utilização deve ser tanto para amostras gasosas quanto líquidas. Como descrito no capitulo 3 (materiais e métodos) estruturas foram fabricadas em aço inoxidável ou acrílico usando torno convencional, portanto de modo simples e de baixo custo. O baixo custo que advém do uso de equipamentos convencionais para produção das estruturas deve-se às dimensões destas, que são intermediárias as normalmente utilizadas em dispositivos miniaturizados da Engenharia Química e no desenvolvimento de dispositivos MEMS. Assim, tem-se a formação inicial de um spray, usando a estrutura tridimensional ou planar, seguido por estruturas separadoras/destiladoras. Estas são acopladas usando tubos de polipropileno ou capilar 
de aço inoxidável e válvulas on/off e a injeção de reagente é manual. Para obtenção do gás de arraste ou do fluido líquido, utiliza-se um mini compressor de ar com duas saídas. Para análise em meio aquoso e gasoso usaram-se vazões de $1 \mathrm{~mL} / \mathrm{min}$ e $10 \mathrm{sccm}$, respectivamente, tanto nas simulações quanto nos testes experimentais. Os testes experimentais envolvendo líquido usaram traçadores e filmagens para avaliação visual dos fenômenos envolvidos, além do auxílio de microscopia ótica quando necessário. O desempenho das estruturas é sumariado na Tabela 4.13.

É importante observar que a separação preliminar, apesar de requerer que a estrutura seja avaliada de muitos modos distintos com a composição provável da mistura, possui bom desempenho, pois o comportamento é bem diferente entre mistura e substância pura. Compostos puros e mistura saem rapidamente da estrutura, mas os compostos puros saem com apenas um pulso com tempo similar na saída de cada cela, as misturas requerem maior tempo para sair da estrutura completamente e o fazem com diferentes tempos para cada cela.

Tabela 4.13 - Estruturas miniaturizadas e respectiva função.

\begin{tabular}{||l||l||}
\hline \hline Estruturas & \multicolumn{1}{|c|}{ Função } \\
\hline \hline \multirow{2}{*}{ Spray } & $\begin{array}{l}\text { Permite que as amostras líquidas sejam transformadas em spray e inseridas em qualquer } \\
\text { outra estrutura. }\end{array}$ \\
\hline \hline \multirow{2}{\text{Impactador}}{} & $\begin{array}{l}\text { Remoção de partículas com 13 } \mu \mathrm{m} \text { e } 50 \mu \mathrm{m} \text { das amostras gasosas ou líquidas. Para } \\
\text { amostras líquidas a formação do spray faz-se necessária previamente. Duas disposições } \\
\text { possíveis e quatro dimensões diferentes podem otimizar o desempenho } \\
\text { (experimentalmente) da estrutura em relação ao volume da amostra. }\end{array}$ \\
\hline $\begin{array}{l}\text { Estrutura } \\
\text { tridimensional } \\
\text { modificada }\end{array}$ & $\begin{array}{l}\text { Permite o aquecimento da amostra (exigência para amostras líquidas com baixa pressão } \\
\text { de vapor). Util apenas para indicar se a amostra é uma mistura ou não. Não pode ser } \\
\text { usada com partículas, isto é, exige a remoção de particulados da amostra. }\end{array}$ \\
\hline \hline Chicana & $\begin{array}{l}\text { Permite que as partículas sejam removidas das amostras na própria estrutura. Pode ser } \\
\text { usada com amostra líquida, se aquecida. Fornece dados semi-quantitativos sobre a } \\
\text { mistura. }\end{array}$ \\
\hline
\end{tabular}

Quanto à estrutura para separação grosseira, um possível uso, além do protótipo proposto, é em conjunto com sistema desenvolvido anteriormente [100]. Carvalho propôs um microreator para catálise e para tanto utilizou esse arranjo de microcanais, mas também demonstrou que o microreator é mais eficiente para n-hexano que isopropanol. Por outro lado, a existência na faixa de porcentagem de álcool na gasolina foi identificada (item 4.4) por uma estrutura que corresponde uma modificação da usada por Carvalho [100]. Portanto a estrutura é facilmente acoplada ao conjunto 
sugerido por Carvalho [100] e poderia servir como um pré-teste para, caso a existência de mistura fosse constatada, o microreator ser usado para catálise.

*comportamento do conjunto: as estruturas foram, ao longo deste trabalho, testadas em conjunto de vários modos e a sua associação pode ser implementada facilmente por uma série de válvulas e a Figura 4.40 apresenta o conjunto de estruturas/detector/análise de dados (fotografia das estruturas, fotografia da placa de aquisição com detalhe da conexão do sensor, tela interativa do programa de aquisição de dados).

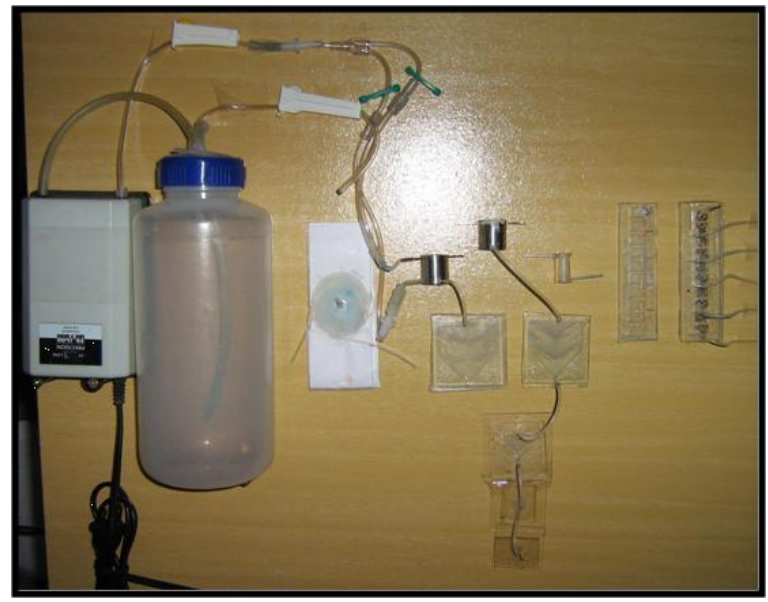

(A)
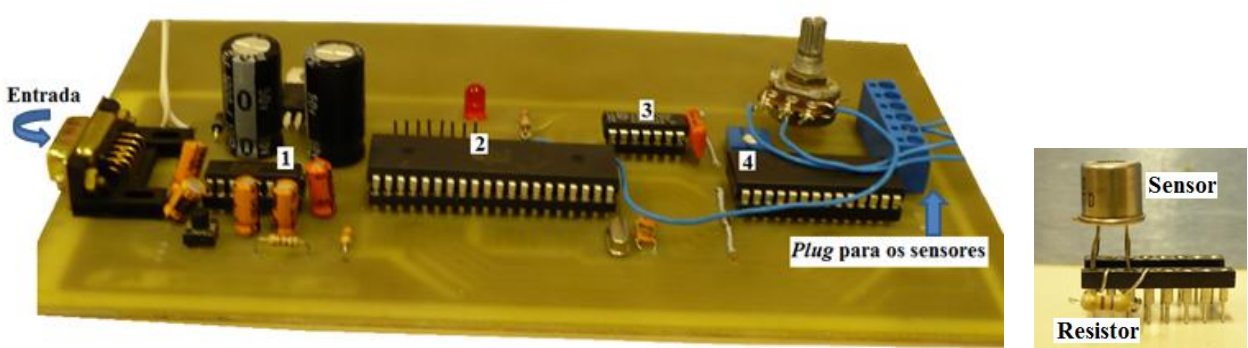

(B)

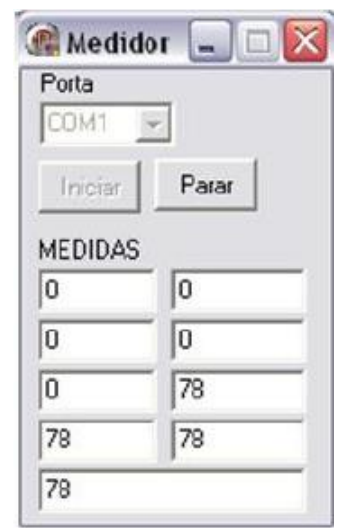

(C)

Figura 4.40 - Fotografia do (A) conjunto de estruturas; (B) placa de aquisição de dados, 1, 2, 3 e 4 indicam os microcontroladores e o detalhe da conexão com o sensor [154]; e (C) tela interativa do programa de análise de dados. 


\subsubsection{Aspecto educacional}

Inúmeros são os métodos e as formas de ensino, contudo, são inegáveis as vantagens da utilização de métodos/formas que privilegiem a informação visual [155][156], tanto pelo aspecto empírico como para favorecer a racionalização do conhecimento. Para a geração atual, bastante acostumada ao uso de instrumentos de informática, a linguagem linear (tipográfica) é menos eficiente que aquelas que favorecem a existência de imagens [157]. Portanto, com o uso de traçadores, imagens (filmagem, foto, etc.) e procedimentos em fase líquida, pode-se facilitar a compreensão de muitos fenômenos; especialmente porque essa metodologia pode ser utilizada para verificar a exatidão dos resultados obtidos nas simulações e também possibilita, em alguns casos, avaliar a cinética do fluido na estrutura.

\subsubsection{Conclusão parcial}

O uso de equipamentos de baixo custo deve ser amplamente incentivado. As reduções de estruturas podem ser muito úteis não só para redução de custos como também para manipulação e/ou análises de amostras gasosas in situ, por exemplo, para pré-concentração de compostos e pré-seleção de compostos de misturas de acordo com pressão de vapor e/ou volatilidade.

As estruturas aqui discutidas apresentam uma série de vantagens, desde a facilidade de uso até formas diferentes de análises para determinação de contaminação em reagentes, etc.

Estas estruturas podem também ser utilizadas no ensino, por exemplo, para verificação da mecânica dos fluidos, pois favorecem a abordagem sistêmica de processos químicos além de permitirem testes mais dinâmicos.

$\mathrm{O}$ fato de se utilizar pequena quantidade de solvente e gerar como resíduo pequenas quantidades de soluções que podem ser descartadas sem dificuldades, corresponde ao desenvolvimento de tecnologias mais limpas e favorece a sustentabilidade, o que deve ser uma preocupação constante em qualquer empreendimento, além de ser obrigatório no currículo das áreas de engenharia. 


\section{CAPÍTULO 5 - CONCLUSÕES}

Atualmente, a produção de equipamentos e produtos, com rapidez e eficiência, deve contar com o auxílio de novas metodologias como o design for $\mathrm{X}$. Este consiste numa metodologia onde $\mathrm{X}$ significa uma série que se estende desde características técnicas, como facilidade de montagem e desmontagem, até considerações mais gerais, como ser ou não ambientalmente correto [158].

Tanto a área de pesquisa quanto a área de ensino carecem de equipamentos de análise química e/ou ambiental, principalmente, que apresentem bom limite de detecção e baixo custo, além de serem mais ambientalmente corretos. A opção de diminuição de custo e de impacto ambiental, nesse caso, vai em direção à miniaturização e apresenta como solução desde a fabricação de simples sensores descartáveis até sistemas complexos, para análise de matrizes com maior número de interferentes, como os microTAS (micro total analysis system) [17].

Um dos itens mais importantes para análises ambientais é a determinação de compostos orgânicos voláteis (VOCs). Estes compostos são normalmente encontrados tanto no ciclo hidrológico como em emissões atmosféricas e correspondem a uma contaminação ambiental séria, já que são produtos emitidos em profusão pelo processo de produção moderno [159]. Sensores de baixo custo para VOCs, e com baixo limite de detecção, são comuns e um deles já foi utilizado para ensino em um arranjo de baixo custo [160]. Contudo, a opção pelo baixo custo, nesse caso, implica em pouca especificidade na medida, ou seja, não é possível determinar mesmo que preliminarmente se a amostra é uma mistura ou uma substância pura. Do mesmo modo, a Engenharia Química necessita de sistemas miniaturizados que possam avaliar em tempo curto a presença de VOCs.

Assim, foi objetivo deste trabalho a simulação, construção e testes de estruturas miniaturizadas bem como a proposta de um protótipo, de baixo custo e com sistema eletrônico simples, para análise de VOCs, tanto na Engenharia Química quanto na Química, neste último caso apenas pelo aspecto qualitativo. O protótipo aqui obtido e aqui descrito apresenta características que o torna útil para estas duas áreas. Ademais, o uso de dimensões que, apesar de pequenas são intermediárias às normalmente utilizadas na Engenharia Química e na produção de MEMS implica atuar em uma área onde fenômenos secundários, tais como capilaridade ainda não têm grande influência, o que 
também facilita a manipulação das amostras e a compreensão dos fenômenos envolvidos.

Os dispositivos aqui desenvolvidos têm uma série de vantagens. Foi possível desenvolver dispositivos nos formatos planar e 3D. Quanto às estruturas planares, foi possível sugerir um misturador de fácil construção e útil para manipulação de grandes volumes, se comparado com estruturas 3D. Enquanto esse misturador é mais adequado para fase líquida, estrutura 3D, útil para menor volume, é bastante adequada para fase gasosa, sendo capaz de misturar amostras que foram adicionadas ao dispositivo em intervalo de tempo da ordem de segundo. Ainda quanto a estruturas planares, os impactadores permitem manipular amostras líquidas e gasosas e remover partículas com dimensões da ordem de algumas micra. Pelo controle do tamanho da estrutura pode-se manipular amostras desde alguns microlitros até poucos mililitros. Por fim, a manipulação de amostra para determinação de impurificação pode ser efetuada, mesmo que exigindo calibração extensiva, por um outra estrutura.

As estruturas 3D são úteis não só como misturadores mas também para produção de spray e para avaliação grosseira da contaminação de uma amostra. Como as três estruturas não apresentam variação significativa em sua construção, sua interconexão é simples; portanto, é possível propor a construção de um array dessas estruturas, planejado de acordo com o problema a ser abordado. Essa concepção está de acordo com as tendências na área de Engenharia Químcia, que tenta criar sistemas que, com poucas adaptações, atendam mais de uma função.

Pelo aspecto educacional, este trabalho demonstrou o uso de dispositivos simples, pequeno e de baixo custo é viável, principalmente, para demonstrações/ análises em campo aberto, ou seja, no local onde se deseja fazer a análise. Também pode-se ter como foco do trabalho o estudo de correlação entre os fenômenos ocorridos no interior do sistema com o resultado final e com os dados obtidos nas simulações, por exemplo, o tempo de residência e sua variação, dificuldade de remoção de produtos da estruturas, a formação de caminhos preferenciais com a possível falta de reprodutibilidade da estrutura, etc. Assim, o estudo de vários fenômenos observados e sua comparação com o que ocorre em um equipamento de maior porte, por exemplo, em um sistema de destilação de laboratório permite ao aluno apreender sobre as novas tendências, tais como, miniaturização e suas implicações para a descrição dos fenômenos, já que fenômenos não relevantes em equipamentos macroscópicos são essenciais em sistemas miniaturizados. O pouco volume de recursos naturais gasto tanto 
na produção como no uso da estrutura e seus sistemas acoplados estão de acordo com os princípios da Engenharia Química Verde e torna o conjunto adequado para ensino de outros temas, por exemplo, a tecnologia limpa e/ou mais limpa e sustentabilidade.

Pelo exposto acima, nota-se que alguns trabalhos futuros podem ser propostos e serão de grande valia para as áreas de Engenharia e análises. É o caso de desenvolvimento de array das estruturas aqui avaliadas, incluindo, também, a possibilidade de reação das amostras, não só sua manipulação e/ou detecção. Deste modo, será possível criar novos sistemas de baixo custo e portáteis para várias outras funções.

As publicações geradas até o presente momento neste trabalho são apresentadas a seguir:

2006

- Silva, L. M.; Lima, R. R.; Carvalho, A. T.; Silva, M. L. P.; Madaleno, J. C.; Pereira L. Low cost microstructures for preconcentration of polar and non-polar organic compounds. Materials Science Forum. v. 514-516, p. 1250-1254, 2006. On line: http://www.scientific.net.

- Carvalho, A. T.; Nascimento Filho, A. P.; Silva, L. M.; Silva, M. L. P.; Madaleno, J. C.; Pereira, L. Use of electroless plating copper thin films for catalysis. Materials Science Forum. v. 514-516, p. 1328-1332, 2006. On line: http://www.scientific.net.

- Silva, L. M.; Lima, R. R.; Peres, H. M.; Silva, M. L. P. O uso da espectrometria de massa na caracterização da adsorção em microcanais. Boletim Técnico da Faculdade de Tecnologia de São Paulo, BT/20, ISSN 1518-9082. São Paulo, p. 63-68, 2006.

- $5^{\circ}$ ENCONTRO DA SOCIEDADE BRASILEIRA DE PESQUISA EM MATERIAIS. Carvalho, A. T.; Lima, R. R.; Silva, L.M.; Simões, E. W.; Silva, M. L. P. Design, simulation and manufacturing of microchannels for reaction of VOCs. SBPMat, Costão do Santinho, Florianópolis, 2006.

- XXVII CONGRESSO BRASILEIRO DE APLICAÇÕES DE VÁCUO NA INDUSTRIA E NA CIÊNCIA. Carvalho, A. T.; Silva, L. M.; Lima, R. R.; Silva, M. L. P. Avaliação da cavidade selada como dispositivos para catalise. XXVII CBRAVIC, Itatiba, São Paulo, 2006.

- XXXIV CONGRESSO BRASILEIRO DE ENSINO DE ENGENHARIA. Silva, L. M.; Tenório, E.; Fakri, M. A. Tecnologia de Ensino para Nível Superior de Conceitos "PBL" para Ecologia Industrial. Anais do XXXIV COBENGE 2006 Passo Fundo - RS. Tema 8, p. 1-7, 2006.

- XXXIV CONGRESSO BRASILEIRO DE ENSINO DE ENGENHARIA. Silva, L. M.; Tenório, E.; Fakri, M. A. Desenvolvimento de um protótipo para ensino em engenharia para detecção de gás e estudos de sensores. Anais do XXXIV COBENGE 2006 - Passo Fundo - RS. Tema 1, p. 907-915, 2006.

- Silva, L. M. e Silva, M. L. P. Retenção de Compostos Orgânicos m Microcanais Modificados por Filmes Adsorventes. Boletim Técnico da Escola Politécnica 
da USP, departamento de Engenharia de Sistemas Eletrônicos. BT/PSI/0602. ISSN 1517-3542. São Paulo, p. 1-13, 2006.

- XXXV CONGRESSOS BRASILEIRO DE EDUCAÇÃO EM ENGENHARIA, 2008, Curitiba- PR, Centro Universitário Positivo. Silva, L. M. et. al. Miniestruturas para remoção de partículas usadas no ensino em engenharia. In.: Anais do XXXV Congressos Brasileiro de Educação em Engenharia, 2007, v. XXXV, p. 17 1-17 10.

- $28^{\circ}$ CONGRESSO BRASILEIRO DE APLICAÇÕES DE VÁCUO NA INDÚSTRIA E NA CIÊNCIA, 2007, Natal. Silva, L. M. et. al. Miniestruturas para seleção de partículas. Revista Brasileira de aplicações de Vácuo, v. 28, 2007.

- $28^{\circ}$ CONGRESSO BRASILEIRO DE APLICAÇÕES DE VÁCUO NA INDÚSTRIA E NA CIÊNCIA, 2007, Natal. Silva, L. M. et. al. Remoção de partículas em estruturas miniaturizadas. Revista Brasileira de aplicações de Vácuo, v. 28, 2007.

2008

- XXXVI CONGRESSOS BRASILEIRO DE EDUCAÇÃO EM ENGENHARIA, 2008, São Paulo. Silva, L. M. et. al. Estruturas miniaturizadas e empacotadas usadas para ensino em engenharia. Anais do XXXVI Congressos Brasileiro de Educação em Engenharia, 2008, v. XXXVI, p. 1-15.

- Hernandez, L. F.; Silva, L. M.; Lima, R. R.; Simões, E. W.; Silva, M. L. P. A simple device initial separation of organic compounds. In.: 12 TH ICMS, 2008.

- $12^{\mathrm{TH}}$ ICMS, 2008. Carvalho, R. A. M.; Silva, L. M.; Lima, R. R.; Hernandez, L. F.; Silva, L. M. P Cellulose surface modifed for sample pretreatment.

- $12^{\mathrm{TH}}$ ICMS, 2008. Silva, L. M. et. al. Selection of particles from gaseous and liquid fluids in single miniaturized structure.

- $\quad 12^{\mathrm{TH}}$ ICMS, 2008. Lima, R. R.; Carvalho, R. A. M.; Silva, L. M.; Simões, E. W.; Silva, M. L. P. Single step process for particles surface modification or film composite production.

- XXIX CONGRESSO DE APLICAÇÃO DE VÁCUO NA INDUSTRIA E NA CIÊNCIA, 2008, Joinvile - SC. Silva, L. M. et. al. Avaliação do comportamento de fluidos em estruturas miniaturizadas para uso em cromatografia gasosa. Revista Brasileira de Aplicação de vácuo, 2008, v. XXIX.

- XXIX CONGRESSO DE APLICAÇÃO DE VÁCUO NA INDUSTRIA E NA CIÊNCIA, 2008, Joinvile - SC. Lima, R. R.; Carvalho, R. A. M.; Carvalho, A. T. Silva, L. M.; Silva, M. L. P. Comparação das propriedades adsorventes de filmes obtidos por plasma de HMDS e misturas com compósitos fluorados. Revista Brasileira de Aplicação de vácuo, 2008, v. XXIX.

- $7^{\circ}$ ENCONTRO DA SOCIEDADE BRASILEIRA EM MATERIAIS, 2008, Guarujá - SP. Lima, R. R.; Carvalho, R. A. M.; Silva, L. M.; Silva, M. L. P. Composite of plasma deposited thin film and particles obtained in single step.

- $10^{\circ}$ SIMPÓSIO DE INICIAÇÃO CIENTÍFICA E TECNOLÓGICA, 2008, São Paulo - SP. Matsuy, E. Y. Silva, L. M.; Silva, L. M. P. Estruturas para remoção de partículas de amostras em fase líquida. Boletim Técnico da Faculdade de Tecnologia de São Paulo. São Paulo: Ed. Faculdade de Tecnologia de São Paulo, 2008, v. BT-25, p. 74. 
- Silva, M. L. P.; Carvalho, A. T.; Simões, E. W. Lima, R. R.; Silva, L. M. Threedimensional microchannel as simple microreactor. Sensor and Act. B. Chemical, 2009.

- Carvalho, A. T.; Lima R. R.; Silva, L. M.; Silva, M. L. P. Nanostructure Cooper thin film used for catalysis. Sensor and Act. B. Chemical, v. 130, p. 141-149, 2008.

- Lima, R.R.; Carvalho, R.A.M.; Silva, L.M.; Simões, E.W.; Silva M.L.P. Single step process for particles surface modification or thin film composite production, Sensors and Act. B, v. 137, p. 170-179, 2009.

- Carvalho, A.T.; Lima, R.R.; Silva, L.M.; Simões, E.W.; Silva, M.L.P. Threedimensional microchannels as a simple microreactor, Sensors and Act. B, v. 137, p. 393-402, 2009.

- $11^{\mathrm{TH}}$ INTERNATIONAL CONFERENCE ON ADVANCED MATERIALS, ICAM 2009, Windsor Barra Hotel, Rio de Janeiro-RJ. Silva, L. M.; Matsuy, E. Y.; Lima, R. R.; Fachini E.; Silva, M. L. P. Composite as a Selective Membrane for Electronic Applications, CD ROM, pôster.

- XXX CONGRESSO BRASILEIRO DE APLICAÇÕES DE VÁCUO NA INDÚSTRIA E NA CIÊNCIA, XXX CBRAVIC 2009, Hotel Leão da Montanha - Campos do Jordão, SP. Ieiri, M. Y.; Matsuy, E. Y.; Lima, R. R.; Silva, L. M.; Simões, E. W.; Silva, M. L. P. Miniaturized spray injection system, CD ROM, pôster.

- XXX CONGRESSO BRASILEIRO DE APLICAÇÕES DE VÁCUO NA INDÚSTRIA E NA CIÊNCIA, XXX CBRAVIC 2009, Hotel Leão da Montanha - Campos do Jordão, SP. Matsuy, E. Y.; Lima, R. R.; Silva, L. M.; Simões, E. W.; Silva, M. L. P. Array of microchannels used to on line detection of VOCs in liquid flow, CD ROM, pôster.

- XXX CONGRESSO BRASILEIRO DE APLICAÇÕES DE VÁCUO NA INDÚSTRIA E NA CIÊNCIA, XXX CBRAVIC 2009, Hotel Leão da Montanha - Campos do Jordão, SP. Matsuy, E. Y.; Lima, R. R.; Silva, L. M.; Simões, E. W.; Silva, M. L. P. A simple way to enhance on line detection of VOCs in gas flow, CD ROM, pôster.

- XXX CONGRESSO BRASILEIRO DE APLICAÇÕES DE VÁCUO NA INDÚSTRIA E NA CIÊNCIA, XXX CBRAVIC 2009, Hotel Leão da Montanha - Campos do Jordão, SP. Ieiri, M. Y.; Matsui, E. Y.; Ferreira, E. S.; Silva, L. M.; Lima, R. R.; Silva, M. L. P. Electrical characterization of adsorbents films for VOCs detection, CD ROM, pôster.

- $1^{\text {ST }}$ CONFERENCE ON CHEMICAL ENGINEERING AND ADVANCED MATERIALS (CEAM) VIRTUAL FORUM, Naples 2009. Silva, L. M.; Lima, R. R.; Simões, E. W.; Silva, M. L. P. A Proposal of Portable Equipment for Pretreatment in Chemical Analysis. Section: H: Environmental, green and sustainable engineering, n. 76. CD ROM, pôster.

- Lima, R.R.; Fachini, E.; Silva, L.M.; Matsuy, E.Y.; Pecoraro, E.; Silva, M. L.P. Perfluorocompound and Hexamethyldisilazane Thin Film Composite Material used for Surface Modification. Materials Science Forum. v. 636-637, p. 10731078, 2010. On line: http://www.scientific.net. 
- Silva, L. M.; Lima, R. R.; Simões, E. W.; Silva, M. L. P. A Proposal of Portable Equipment for Pretreatment in Chemical Analysis, International Review on Chemical Engineering (I.RE.CHE.), v.2, n.1, p. 134-141, jan 2010.

- Ieiri, M. Y.; Matsui, E. Y.; Ferreira, E. S.; Silva, L. M.; Lima, R. R.; Silva, M. L. P. Electrical characterization of adsorbents films for VOCs detection, aceito na Revista Brasileira de Aplicações em Vácuo, 2010. 


\section{CAPÍTULO 6 - REFERÊNCIAS}

[1] GRAYSON, A. C. RICHARDS et. al. A BioMEMS Review: MEMS Technology for Physiologically Integrated Devices, Proceedings of the IEEE, v. 92, ed. 1, p. 6-21, 2004.

[2] VERPOORTE, E.; ROOIJ, N.F. Microfluidics Meets MEMS, Proceedings of the IEEE, v. 91, ed. 6, p. 930-953, 2003.

[3] REYES, D.; IOSSIFIDIS, D.; AUROUX, P.; MANZ, A. Micro total analysis systems. Part 1. Introduction, theory, and technology. Anal. Chem., v. 74, p. 26232636, 2002.

[4] AUROUX, P.; IOSSIFIDIS, D.; REYES, D.; MANZ, A. Micro total analysis systems. Part 2. Analytical standard operations and applications. Anal. Chem., v. 74, p. 2637-2652, 2002.

[5] TUDOS, A.; BESSELINK, G.; SCHASFOORT, R. Trends in miniaturized total analysis systems for point-of-care testing in clinical chemistry. Lab Chip, v. 1, p. 8395, 2001.

[6] VERPOORTE, E. Microfluidic chips for clinical and forensic analysis. Electrophoresis, v. 23, p. 677-712, 2002.

[7] BERG, A. VAN BEN; LAMMERINK, T. Micro total analysis systems: microfluidic aspects, integration concept and applications. Top. Curr. Chem., v. 194, p. 21-49, 1998.

[8] SHONNARD, D. R. et. al. Green Engineering Education Through A U.S. Epa/Academia Collaboration, Environ. Sci. Technol., v. 1.37, p. 5453-5462, 2003.

[9] STAPLES, E. J. The First Quantitatively Validated Electronic Nose for Environmental Testing of Air, Water and Soi, ACS National, 219: 236-ANYL Part 1, March 26-30, 2000, American Chemical Society (ACS2000).

[10] CIOSEK, P.; WRÓBLEWSKI, W. Sensor arrays for liquid sensing-electronic tongue systems. The Analyst, 2007. 
[11] LICHTENBERG, J.; ROOJI, N. F.; VERPOORTE, E. Sample pretreatment for chemical analysis. Talanta, v.56, p. 233-266, 2002.

[12] LiCHTENBERG, J.; ROOJI, N. F.; VERPOORTE, E. Sample pretreatment for chemical analysis. Talanta, v.56, p. 233-266, 2002.

[13] HASEBE, S. Design and operation of micro-chemical plants-bridging the gap between nano, micro and macro technologies. Computers \& Chemical Engineering, v. 29, i. 1, p. 65-64, 15 December 2004.

[14] GONZÁLEZ-LUNA, R.; RODRIGO, M.T.; JIMÉNEZ, C.; MARTÍNEZ-DUART, J.M., Deposition of Silicon Oxinitride Films from Hexamethyldisilizane (HMDS) by PECVD, Thin Solid Films, v. 317, i. 1-2, p. 347-350, 1998.

[15] MCCABE, W. L.; SMITH, J. C. AND HARRIOTT, P. Unit operations of chemical engineering. 4th ed. New York: McGraw-Hill, p. 960, 1985.

[16] SILVA, M. L. P.; FURLAN, R.; RAMOS, I. Development of Miniaturized Structures and Setups for Research and Teaching of New Concepts in Engineering. ICEE, Puerto Rico, p. 3059, 2006.

[17] CAVE, MARK R. et. al. Environmental analysis. Anal. at. Spectrom, v. 15, p. 181-235, 2000.

[18] LIGHTY, JOANN SLAMA; VERANTH, JOHN M.; SAROFIM, ADEL F. Combustion Aerosols: Factors Governing Their Size and Composition and Implications to Human Health. Journal of the Air \& Waste Management Association. v. 50, p. 1565-1618, 2000.

[19] GROSJEAN, DANIEL. In situ organic aerosol formation during a smog episode: Estimated production and chemical functionality, Atmospheric Environment, v. 26A, n. 6, p. 953-963, 1992.

[20] FOX, DONALD L. Air Pollution, Anal. Chem. v. 67, p. 183R-198R, 1995.

[21] TELGHEDER, URSULA; KHVOSTIKOV, VLADIMIR A. Collection and determination of metal contaminants in gases a review, Journal of Analytical Atomic Spectrometry, v. 12, p. 1-6, 1997. 
[22] VERANTH, JOHN M. AND ADEL, F. Combustion Aerosols: Factors Governing Their Size and Composition and Implications to Human Health. JoAnn Slama Lighty, Sarofim Lighty, Veranth and Sarofim, v. 50, p. 1565-1618, 2000.

[23] KANAKIDOU, M.; TSIGARIDIS, K.; DENTENER, F. J.; CRUTZEN, P. J. Human-activity-enhanced formation of organic aerosols by biogenic hydrocarbon oxidation, Journal of Geophysical Research, v. 105, ed. D7, p. 9243-9254, 2000.

[24] DAMLE, A. S.; ENSOR, D. S.; RANADE, M. B. Coal combustion aerosol formation mechanisms: a review: Aerosol Sci. Technol, v. 1, ed. 1, p. 119-133, 1982.

[25] LAWLER, D. F. Particle size distribution in treatment processes: theory and practice. Wat. Sci. Tech., v. 36, n. 4, p. 15-23, 1997.

[26] LEVINE, A. D.; TCHOBANOGLOUS, G.; ASANO, T. Characterization of the size distribution of contaminants in wastewater: treatment and reuse implications. $\mathbf{J}$. Wat. Pollut. Control Fed., v. 57, n. 07, p. 805-816, 1985.

[27] LEVINE, A. D.; TCHOBANOGLOUS, G.; ASANO, T. Size distribution of particulate contaminants in wastewater and their impact on treatability. Wat. Res. v. 25, n. 08, p. 911- 922, 1991.

[28] SANTOS, H. R. et. al. Applicability of particle size measurement techniques in water and wastewater treatment systems. Eng. Sanit. Ambient., v. 9, n. 4, p. 291-300. ISSN 1413-4152, 2004.

[29] SILVA, J. F. A. et. al. Simulations of silicon microstructure for preconcentration of metallic ions. Proceedings - Electrochemical Society (Proc., Electrochemical. Soc.), v. 9, p.420-427, 2003.

[30] $11^{\mathrm{TH}}$ INTERNATIONAL MEETING ON CHEMICAL SENSORS, Carvalho, A. T., Lima, R. R., Silva, M. L. P., Fachini, E. Nanostructured copper thin film used for catalysis, July 16-19, Brescia, Italy, A331, 2006.

[31] KORETSKY, M. D. et. al. Integration of Microelectronics-Based Unit Operations into the Che Curriculum, In: Proceedings Of The 2003 American Society For Engineering Education Annual Conference \& Exposition, 2003, ASEE, CD ROM, Session 1313, 2003. 
[32] DAHM, K. D.; HESKETH, R. P. E SAVELSKI, M. J. Che Curriculum, Is Process Simulation Used Effectively In Che Courses? Che Division Of American Society for Engineering Education, Winter, ASEE, p. 192-198, 2002.

[33] WILLIAMS, J. L. et. al. The Virtual Chemical Engineering Unit Operations Laboratory, Proceedings of the 2003 American Society for Engineering Education Annual Conference \& Exposition, ASEE, CD-ROM, session 2793, 2003.

[34] FREUND, HANNSJÖRG AND SUNDMACHER, KAI. Towards a methodology for the systematic analysis and design of efficient chemical processes: Part 1. From unit operations to elementary process functions. Chemical Engineering and Processing: Process Intensification, v. 47, ed. 12, p. 2051-2060, 2008.

[35] XAVIER, PATRÍCIA FARIA. Cálculo e avaliação do fator de separação, $\alpha_{I, J}$, para diversos sistemas de interesse industrial e para outros, para fins de estudo sistemático. Dissertação (Mestrado), Universidade Estadual de Campinas, Faculdade de Engenharia Química, Área de Concentração: Desenvolvimento de Processos Químicos, Campinas, SP, 2000.

[36] PERRY, ROBERT H. AND GREEN, DON W. Perry's Chemical Engineers' Handbook, ed. 6, McGraw-Hill, 1984.

[37] VOGEL, ARTHUR ISRAEL. Elementary practical organic chemistry, London: Longmans, 347 p., 1957.

[38] GONÇALVES, DANIEL. Química orgânica experimental. São Paulo: McGrawHill, 269 p., 1998.

[39] MANO, E. B.; DIAS, M. L.; OLIVEIRA, C. M. F. Química Experimental de Polímeros. 1a edição. São Paulo, Editora Edgard Blucher, 2004.

[40] KOLMET, KARL et. al. Design guidelines for using distillation simulation software in the field. Asia-Pac. J. Chem. Eng., v. 2, p. 308-314, 2007.

[41] COUPER, J. R.; PENNEY, W. R.; FAIR, J. R.; WALAS, S. M. Chemical Process Equipment: Selection and Design, edit. GPP, ed. 2, 776 p., 2005.

[42] HARMSEN, G. JAN. Reactive distillation: The front-runner of industrial process intensification: A full review of commercial applications, research, scale-up, design and operation Chemical Engineering and Processing, v. 46, i. 9, p. 774-780, 2007. 
[43] CHARPENTIER, JEAN-CLAUDE. In the frame of globalization and sustainability, process intensification, a path to the future of chemical and process engineering (molecules into money). Chemical Engineering Journal, v. 134, i. 1-3, p. 84-92, 2007.

[44] CHARPENTIER, JEAN-CLAUDE. Four main objectives for the future of chemical and process engineering mainly concerned by the science and technologies of new materials production. Chemical Engineering Journal, v. 107, i. 1-3, p. 3-17, 2005 .

[45] CHARPENTIER, J.C. \& MCKENNA, T.F. Managing complex systems: some trends for the future of chemical and process engineering. Chemical Engineering Science, v. 59, i. 8-9, p. 1617-1640, 2004.

[46] SU, AN-JHIH et. al. Control relevant issues in semiconductor manufacturing: Overview with some new results. Control Engineering Practice 15, p. 1268-1279, 2007.

[47] WOOTTON, ROBERT C. R. AND MELLO, ANDREW J. Continuous laminar evaporation: micron-scale distillation. Chem. Common, p. 266 - 267, 2004.

[48] HILL, S. J. et. al. Atomic spectrometry update. Environmental Analysis. J. Anal. At. Spectrom, v. 18, p. 170-202, 2003.

[49] MARPLE, V. A. History Of Impactors - The First 110 Years, Aerosol Science \& Technology, v. 38, p. 247-292, 2004.

[50] DOTTORI, M.; Fava, G. and Ruello, M. L. Bacteria Removal And Viability Attenuation By Means Of An Electrostatic Barrier, Indoor and Built Environ., v. 13, n. 4 p. 309-314, 2004.

[51] XIAOHONG, Z. et. al. Experimental Investigation Of Integrated Air Purifying Technology For Bioaerosol Removal And Inactivation In Central Air-Conditioning System, Chinese Science Bulletin, v. 49, n. 3, p. 3306-310, 2004.

[52] BERALDO, F.P. et. al. Design Of New Miniaturized Structures For Removal Of Particles From Gaseous Fluids, In: 11TH INTERNATIONAL MEETING ON CHEMICAL SENSORS, ICEE, Brescia, Italy, July 16-19, 2006. 
[53] DEMOKRITOU, P. et. al. Development of a high volume cascade impactor for toxicological and chemical characterization studies. Aerosol Science and Technology, 1521-7388, v. 36, n. 9, p. 925-933, 2002.

[54] NASCIMENTO FO, A. P. Fabricação de Sistemas para Retenção de Compostos Orgânicos em Fase Gasosa e Líquida. Tese de Doutorado. EPUSP, São Paulo, 2005.

[55] WASTE-water treatment technologies: a general review Economic And Social Commission For Western Asia, United Nations, New York, 2003.

[56] HAARHOFF, J. Design of around-the-end hydraulic flocculators. Journal of Water Supply: Research and Technology - Aqua, v. 47, n.3, p. 142-152. 1998.

[57] HAARHOFF, J. and Walt, J. Van Der. Towards optimal design parameters for around-the-end hydraulic flocculators. Journal of Water Supply: Research and Technology - Aqua, v. 50, n. 3, p. 149-159, 2001.

[58] MCCONNACHIE, G. L. and Liu, J. Design of baffled hydraulic channels for turbulence-induced flocculation. Water Research, v. 34, n. 6, p. 1886-1896. 2000.

[59] LIU, J.; Crappes, M. and McConnachie, G. L. An accurate approach to the design of channel hydraulic flocculators. Water Research, v. 38, n. 4, p. 875-886. 2004.

[60] MUTTAMARA, S. e Puetpaiboon, U. Nitrogen removals in baffled waste stabilization ponds. Wat. Sci. Tech., v. 33, n.7, p. 173-181, 1996.

[61] PEARSON, H.W.; Mara, D.D. e Arridge, H.A. The influence of pond geometry and configuration on facultative and maturation waste stabilization pond performance and eficiency. Wat. Sci. Tech., v. 31, n.12, p.129-139, 1995.

[62] PEARSON, H.W. et. al. The performance of an innovative tropical experimental waste stabilisation pond system operating at high organic loadings. Wat. Sci. Tech., v. 33, n. 7, p.63-73, 1996.

[63] RUBIO, J.; Souza, M. L. e Smith, R. W. Overview of flotation as a wastewater treatment technique. Minerals Engineering, v.15, n.3, p. 139-155, 2002. 
[64] SHIONO, K. and Teixeira, E. C. Turbulent characteristics in a baffled contact tank. Journal of Hydraulic Research, v. 38, n. 4, p. 271-278, 2000.

[65] NGUYEN, Nam-Trung et. al. Micromixers - a review, J. Micromech. Microeng, v. 15, p. R1-R16, 2005.

[66] KUILA, D. et. al. Characterization of Alumina and Silica Sol-Gel Encapsulated $\mathrm{Fe} / \mathrm{Co} / \mathrm{Ru}$ Nanocatalysts in Microchannel Reactors for F-T Synthesis of Higher Alkanes. Mat. Res. Soc. Symp. Proc., v. 820, p. O3.4.1 - O3.4.6, 2004.

[67] KANG, Tae Gon et. al. Colored particle tracking method for mixing analysis of chaotic micromixers. J. Micromech. and Microeng, v. 14, p. 891-899, 2004.

[68] XIA, H. M.; Wan, S. Y. M.; Shu, C. e Chew, Y. T. Chaotic micromixers using twolayer crossing channels to exhibit fast mixing at low Reynolds numbers. Lab Chip, v. 5, p. 748-755, 2005.

[69] MENGEAUD, Virginie; Josserand, Jacques and Girault, Hubert H.. Mixing Processes in a Zigzag Microchannel: Finite Element Simulations and Optical Study. Anal. Chem., v. 74, n. 16, p. 4279-4286, 2002.

[70] SANTOS, L.C. Desenvolvimento de Equipamento e Estrutura para Retenção de Microorganismos Presentes em Faze Líquida. Dissertação de Mestrado, EPUSP, São Paulo, 2006.

[71] BAYVEL, L. and Orzechowski, Z., Liquid Atomization, Taylor \& Francis, 1993.

[72] LEFEBVRE, A. H., Atomization and Sprays, Combustion: an International Series, Taylor \& Francis, USA 1989.

[73] LEFEBVRE, A. H., Gas Turbines Combustion, Taylor \& Francis, n. 2, USA, 1998.

[74] WU, WINSTON DUO et. al. Monodisperse Droplet Generators as Potential Atomizers for Spray Drying Technology. Drying Technology, v. 25, p. 1907-1916, 2007. 
[75] MANGINELL, R. P. et. al. Microfabricated planar preconcentrator, in Tech. Digest Solid-State Sensor and Actuator Workshop, Transducers Research Foundation, Hilton Head, SC, p. 179-182, 2000.

[76] BIOTERRORISM: HOMELAND DEFENSE SYMPOSIUM: The Next Steps, Conference Proceedings Section V: Tech Panel: Homeland Defense Beyond, VITKO, J. Chemical and Toxin Detection, Feb 8-10, Santa Monica, CA, USA, 2000.

[77] ZELLERS, E. T. et al. Determinations of Complex Vapor Mixtures in Ambient Air with a Wireless Microanalytical System: Vision, Progress, and Homeland Security Applications, Michigan, University of Michigan (Technical Report), p. 1-5, 2003.

[78] LU, C. J.; ZELLERS, E. T. Multi-adsorbent preconcentration/focusing module for portable-GC/microsensor-array analysis of complex vapor mixtures. The Analyst, v. 127, p. 1061-1068, 2002.

[79] YASHIIN, Y. A. Miniaturization of Gas-Chromatographic Instruments, Journal of Analytical Chemistry, v. 9, n. 56, p. 794-805, 2001.

[80] SANTOS; L.C. et. al. (Ed.) Desenvolvimento de Testes Semi-Automatizados de Miniestruturas. Revista Brasileira de Aplicações de Vácuo, v. 25, n. 2, p. 75-81, 2006.

[81] WONG, C e MOWRY, C. D. Separation Methods in Microanalytical Systems. Gas Chromatography on Microchips, Taylor and Francis, p. 580, 2006.

[82] JAMES, David et. al. Chemical Sensors for Electronic Nose Systems. Microchimica Acta, v. 149, n. 2, p. 1-17, 2005.

[83] WALAS, S. M. Chemical Process Equipment, Selection and Design, Copyright 1990 by Butterworth-Heinemann, a division of Reed Publishing (USA), p. 774. 1990.

[84] RUZICKA, J. e HANSEN, E. H. Flow Injection Analysis. John Willey \& Sons, i. 2, New York, 1988.

[85] RUZICKA, J.e HANSEN, E. H. Anal. Chim. Acta, v. 78, p. 145, 1975.

[86] WEIGL, Bernhard H.; Bardell, Ron L. e Cabrera, Catherine R. Lab-on-a-chip for drug development. Advanced Drug Delivery Reviews 55, p. 349-377, 2003. 
[87] CAPOTE, F. P. AND CASTRO, M. D. L. Analytical uses of ultrasound: II. Detectors and detection techniques TrAC. Trends in Analytical Chemistry, v. 23, n. 10-11, p. 829-838, 2004.

[88] SIMONeTTO, H. M. B. Pesquisa e Desenvolvimento de Protótipos de Células a Combustível com Membrana para Troca de Prótons a Hidrogênio. Dissertação de Mestrado. Pontifícia Universidade Católica do Rio Grande do Sul, Porto Alegre, 2006.

[89] HERNANDEZ, L. F. Uso de filme fino adsorvente para desenvolvimento de sistemas de retenção de compostos orgânicos. Dissertação de Mestrado, EPUSP, São Paulo, 2006.

[90] GESCHKE, O.; KLANK, H. ; TELLEMAN, P. Microsystem Engineering of Labon-a-Chip Devices 2004, Wiley-VCH, p. 213-247, (Chapter 10), 2004.

[91] NILSSON, S. \& Laurell, T. Miniaturization in analytical and bioanalytical chemistry, Analytical and Bioanalytical Chemistry, v. 378, p. 1676-1677, 2004.

[92] EIJKEL, J. C. T.; Naji, O. P.; Monaghan, P. and Manz, A. Can microTAS be Alternatives for Sensors?, Sensors, Proceedings of IEEE, v.1, p. 680-683, 2002.

[93] Disponível em:

http://www.metrohm.com.br/_upload/_pdf/rastreabilidade/vigor/PB-0017.pdf. Acessado em janeiro 2010.

[94] CZZAE, M.Z.; Wang, J. Pushing the detectability of voltammetry: how low can we go? Talanta, v.50, ed. 5, p. 921-928, 1999.

[95] HUBER, D. L. et. al. Programmed adsorptionn and release of proteins in a microfluidic device. Science, v. 5631, i. 301, p. 352-354, 2003.

[96] SILVA, J. A. F. et. al. Simulations of silicon microstructure for preconcentration of metallic ions. Proceedings - Electrochemical Society (Proc., Electrochem. Soc.), v. 9, p. 420-427, 2003.

[97] SILVA, M.L.P. e GAMEIRO, J.G. Pre-Concentrators: Trends And Future Needs. Revista Brasileira de Aplicações de Vácuo, v. 25, n. 3, p. 123-130, 2006. 
[98] SILVA, L. M. et. al. Low cost microestructures for preconcentration of polar and non-polar organic compounds. Materials Science Forum. v. 514-516, p. 1250-1254, 2006. On line: http://www.scientific.net.

[99] BERALDO, F. P. Desenvolvimento de Equipamento e Estrutura para Retenção de Microorganismos Presentes em Fase Gasosa. Dissertação de Mestrado, EPUSP, São Paulo, 2006.

[100] CARVALHO, A. T. Reatores miniaturizados para pré-tratamento de amostras para remoção de compostos orgânicos voláteis. Tese de Doutorado, EPUSP, São Paulo, 2009.

[101] LIMA, R. R. Construção de equipamento de plasma para obtenção de filmes finos e compósitos úteis na fabricação de sensores. Tese de Doutorado, EPUSP, São Paulo, 2009.

[102] SILVA, L. M. Retenção de compostos orgânicos voláteis em microcanais modificados por filmes adsorventes. Dissertação de Mestrado, EPUSP, São Paulo, 2005.

[103] LIMA. R. R. Polimerização por plasma de éter e ésteres orgânicos: caracterização e possíveis usos em microeletrônica. Dissertação de Mestrado, EPUSP, São Paulo, 2004.

[104] HERNANDEZ, L. F. et. al. Plasma Polymerized Acetaldehyde Thin Films For Retention Of Volatile Organic Compounds. Quim. Nova, v. 31, n. 6, p. 1410-1416, 2008.

[105] CARVALHO, A. T. et. al. Three-dimensional Microchannels as a Simple Microreator, Sens. Act. B, Chem., 2009.

[106] SMITH, C. G.; BUZANOWSKI, W. C.; GRAHAM, J. D.; ISKANDARANI, Z. CRC Handbook of chromatography: polymers, Boca Raton, Fla.: CRC Press, 1982.

[107] FOLLWEILER, J. M. AND SHERMA, J. CRC Handbook of chromatography: Pesticides and Related Organic Chemicals, Boca Raton, Fla.: CRC Press, 1984.

[108] MELLO, A. On-Chip Chromatography: The Last Twenty Years, Lab Chip, v. 2, p. 48n-54n, 2002. 
[109] KUROSAWA, S.; KAMO, N.; MATSUI, D.; KOBATAKE, Y. Gas Sorption to Plasma-Polymerized Copper Phthalocyanine Film Formed on a Piezoelectric Crystal, Anal. Chem. v. 62-65, p. 353-359, 1990.

[110] MAGGIONI, G. et. al. Deposition of Copper Phthalocyanine Films by GlowDischarge-induced Sublimation, Chem. Mater., v. 17, p. 1895-1904, 2005.

[111] D' AGOSTINO, R. Plasma deposition treatment and etching of polymers, Academic Press, New York, 528p, 1990.

[112] YASUDA, H. Plasma Polymerization, Academic Press Inc., London, 1985.

[113] JIAO, C. Q.; DEJOSEPH JR., C. A. AND GARSCADDEN, A. Ion chemistries in hexamethyldisiloxane, J. Vac. Sci. Technol. A, v.. 23, n. 5, p. 1295-1304, 2005.

[114] CALE, T. S. Cale,; Raupp, G. B. Raupp, and Gandy, T. H. Gandy, J. Vac Sci Technol. A, v. 10, n. 4, p. 1128, 1992.

[115] REN, X. Y. et. al. Gas-phase ion-molecule reactions of neutral C60 with the plasmas of trimethylsilyl ethers and ab initio study on the structures, J. Molecular Structure (Theochem), v. 664-665, p. 247-254, 2003.

[116] XAVIER, L. A.; Ambra, S. and Riveros, J. M. Gas-phase ion chemistry of silyl cations obtained from hexamethyldisilazane, Quím. Nova, v. 25, n. 5, p. 766-771, 2002.

[117] ZHUANG, R.-C. Synthesis of polymers and oligomers containing fluorinated side groups for the construction of hydrophobic surfaces. Thesis, Fakultãat Mathematik Und Naturwissenschaften Der Tachnischen Universitãat Dresden, 2005.

[118] PHANI, A. R. Structural, morphological, wettability and thermal resistance properties of hydrooleophobic thin film prepared by a wet process. Applied Surface Science, v. 253, n 4, p. 1873-1881, 2006.

[119] BEDMAR, P. A. Isotopos em Hidrologia. Editora Alhambra SA, Madrid (in Spanish), 1972.

[120] SILVA, M. L. P. et. al. (Ed.) Use of plasma polymerized higly hydrofobic hexamethyldissilazane (HMDS) films for sensor development, Sensors And Actuators B-Chemical, v. 91, p. 362-369, 2003. 
[121] LIMA, R. R. Et. al. (Ed.) Adsorbent new materials and composites produced in a single step, Sensors and Actuators B 137, p. 185-194, 2009.

[122] GENGENBACH, T.R.; GRIESSER, H.J. Compositional Changes in PlasmaDeposited Fluorocarbonfilms During Ageing. Surf. Interface Anal., v. 26, p. 498-511, 1998.

[123] TUTTOLOMONDO, M.E.; NAVARRO, A.; VARETTI, E.L.; ALTABEF, A.B., Infrared and Raman Spectra and Quantum Chemistry Calculations for 2,2,2Trifluoroethyl Trichloromethanesulfonate, $\mathrm{CCl}_{3} \mathrm{SO}_{2} \mathrm{OCH}_{2} \mathrm{CF}_{3}$. Spectrochim. Acta, Part A, v. 61, p. 1011-1019, 2005.

[124] MACKIE, N.M.; CASTNER, D.G.; FISHER, E.R., Characterization of PulsedPlasmapolymerized Aromatic Films. Langmuir, v. 14, p. 1227-1235, 1998.

[125] SCHARGE, T.; CEZARD, C.; ZIELKE, P.; SCHUTZ, A.; EMMELUTH, C.; SUHM, M.A., A Peptide Cosolvent Under Scrutiny: Self-Aggregation of 2,2,2Trifluoroethanol. Phys. Chem., v. 9, p. 4472-4490, 2007.

[126] SILVA, L.M.; LIMA, R.R.; FACHINI, E.R.; SIMÕES, E.W.; PECORARO, E.; SILVA, M.L.P. DA, Large Surface Area Of Hmds Plasma Polymerized Thin Film Used For Production Of Miniaturized Structures. Materials Science Forum, 2010. No prelo.

[127] HAUPT, M.; BARZ, J.; OEHR, C., Creation and Recombination of Free Radicals in Fluorocarbon Plasma Polymers: An Electron Spin Resonance Study. Plasma Processes and Polymers, v. 5, i. 1, p. 33-43, 2007.

[128] KANSAL, A. Sources and reactivity of NMHCs and VOCs in the atmosphere: a review. Journal of Hazardous Materials, v. 166, i. 1, p.17-26, 2009.

[129] LIMA, R.R. et. al. (Ed.) Corrosion resistant and adsorbent plasma polymerized thin film. Sensors and Actuators B, v. 141, p. 349-360, 2009.

[130] DOMS, M.; et. al. (Ed.) Hydrophobic coatings for MEMS: Applications. J. Micromech. Microeng, v. 18, i. 1-12, 2008.

[131] KUROSAWA, S. et. al. (Ed.) Detection of deposition rate of plasma-polymerized films by quartz crystal microbalance. Thin Solid Films, v. 374, i. 2, p. 262-267, 2000. 
[132] SIMÕES, E. W. et. al. (Ed.) Study of preconcentration of non-polar compounds in microchannels with constrictions. Sensors and Actuators B-Chemical, v. 115, p. 232239, 2006.

[133] NASCIMENTO FO, A. P.; CARVAlHO, A. T.; SIlVA, M. L. P.; DEMARQUETTE, N. R. Preconcentration in Gas or Liquid Phases Using Adsorbent Thin Films, Materials Research, v. 9, n. 1, p. 33-40, 2006.

[134] SIMÕES, E. W. et al. Microfluidic oscillator for gas flow control and measurement. Flow Measurement and Instrumentation, v. 16, ed.1, p. 7-12, 2005.

[135] NASCIMENTO Fo, A. P. et. al. Preconcentration in Gas or Liquid Phases Using Adsorbent Thin Films, Materials Research, v. 9, i. 1, p. 33-40, 2006.

[136] HESSEL, V.; KNOBLOCH, C.; LÖWE, H. Review on Patents in Microreactor and Micro Process Engineering. Recent Patents on Chemical Engineering, v. 1, p. 1$16,2008$.

[137] POUGATCH, K.; SALCUDEAN, M.; CHAN, E.; KNAPPER, B., A two-fluid model of gas-assisted atomization including flow through the nozzle, phase inversion, and spray dispersion, Journal of Multiphase Flow, v. 35, i. 7, p. 661-675, 2009.

[138] WANG, M.R.; YANG, K.H.; CHIU, C.H.; YANG, C.J. Mechanisms And Characteristics Of Spray Formation With Flow Focusing In A New Air-Assist MicroAtomizer. Modern Physics Letters B, v. 23, i. 3, p. 365-368, 2009.

[139] CARVALHO, A. T.; SIMÕES, E. W.; SILVA, M. L. P. Microreatores Para Avaliação De Adsorção: Simulação, Fabricação E Testes, Boletim Técnico da FATEC-SP, BT/24, p. 28-32, 2008.

[140] CARVALHO, A.T.; LIMA, R.R.; SILVA, L.M.; SIMÕES, E.W.; SILVA, M.L.P., Three-dimensional microchannels as a simple microreactor, Sensors and Actuators B, v. 137, i. 1, p. 393-402, 2009.

[141] LI, L.; CHEN, D. R.; QI, C.; KULKARNI, P. S. A miniature disk electrostatic aerosol classifier (mini-disk EAC) for personal nanoparticle sizers. Journal of Aerosol Science, v. 40, i. 11, p. 982-992, 2009. 
[142] SINGH, M.; MISRA, C.; SIOUTAS, C. Field evaluation of a personal cascade impactor sampler (PCIS). J. Atmospheric Environment, v. 37, i. 34, p. 4781-4793, 2003.

[143] MELLO, A. On-Chip Chromatography: The Last Twenty Years, Lab Chip, v. 2, p. 48n-54n, 2002.

[144] MELlO, A.; WOOTTON, R. But what is it good for? Applications of microreactor technology for the fine chemical industry. Review developments in microreactor technology. Lab Chip, v. 2, p. 7N-13N, 2002.

[145] ROBERGE, D.M.; DUCRY, L.; BIELER, N.; CRETTON, P.; ZIMMERMANN, B. Microreactor technology: a revolution for the fine chemical and pharmaceutical industries. Chemical Engineering \& Technology, v. 28, i. 3, p. 318-323, 2005.

[146] HASEBE, S. Design and operation of micro-chemical plants - bridging the gap between nano, micro and macro technologies. Computers \& Chemical Engineering, v. 29, i.1, p. 57-64, 2004.

[147] IGARASHI, A. Catalytic reaction engineering toward Green chemical processes. Journal of Chemical Engineering of Japan, v. 38, i. 10, p. 779-784, 2005.

[148] ZHANG, X.; WILES, C.; PAINTER, S.L.; HASWELL, S.J. Microreactors as tools for chemical research. Chemistry Today, v. 24, i. 2, p. 43-45, 2006.

[149] WALTER, St.; Malmberg, St.; Schmidt, B.; Liauw, M.A. Mass transfer limitations in microchannel reactors. Catalysis Today, v. 110, i. 1-2, p. 15-25, 2005.

[150] NOORAII, A.; ROMAGNOLI, J. A.; FIGUEROA, J. Process identification, uncertainty characterisation and robustness analysis of a pilot-scale distillation column. Journal of Process Control, v. 9, p. 247-264, 1999.

[151] NATARAJAN, K.; GILBERT, A. F.; PATEL, B.; SIDDHA R. Frequency response adaptation of PI controllers based on recursive least-squares process identification. ISA Transactions, v. 45, n. 4, p. 517-528, 2006.

[152] SANTOS, L.C., et. al. Miniaturization of macroscopic structures for removal of particles from liquid fluids. Sensors and Actuators B: Chemical, v. 130, i. 1, p. 310319, 2008. 
[153] FOX, M. F.; SONNERT, G.; NIKIFOROVA, I. Successful Programs for Undergraduate Women in Science and Engineering: Adapting versus Adopting the Institutional Environment, Research in Higher Education, v. 50, n. 4, p. 333-353, 2009.

[154] 4 TH WORKSHOP DA PÓS-GRADUAÇÃO, CEETEPS, 2009, São Paulo. LEITE, A. R. et. al. (Ed.) Proposta de uso de sensores de baixo custo no ensino: vantagens para a inserção de minorias, outubro 2009.

[155] MAIO, A. Z. F. Um modelo de núcleo virtual de aprendizagem sobre percepção visual aplicado às imagens de vídeo: análise e criação, Tese de Doutorado, Engenharia de Produção da Universidade Federal de Santa Catarina, 223p., Florianópolis, 2005.

[156] GONÇALVES, B. S. Cor aplicada ao design gráfico: um modelo de núcleo virtual para aprendizagem baseado na resolução de problemas. Tese de Doutorado, Engenharia de Produção, Centro Tecnológico, Universidade Federal de Santa Catarina, 146p., Santa Catarina, 2004.

[157] BABIN, P.; KOULOUMDJIAN, M. Os novos modos de compreender: A geração do audiovisual e do computador, Paulinas, São Paulo, 1989.

[158] INTERNATIONAL CONFERENCE ON ENGINEERING DESIGN, ICED`2007, Cite Des Sciences Et De L'industrie, Paris, France. Ontology building for design knowledge management systems based on patterns embedded in design-for-X methodologies, August 28 - 31, 2007.

[159] CHOW J. C. et. al. (Ed.) Megacities and Atmospheric Pollution. Journal of the Air \& Waste Management Association, v. 54, p. 1226-1235, 2004.

[160] KAMEOKA, É. et. al. (Ed.) Sistemas de baixo custo, para detecção de compostos orgânicos voláteis, úteis no ensino e na pesquisa, Boletim Técnico da FATEC-SP, BT/22, p. 23-27, julho/ 2007. 


\section{APÊNDICE A}

Neste descrever-se-á algumas simulações feitas nas estruturas para maior entendimento dos fenômenos internos a ela.

\section{A.1 Simulações dos canais planares e tridimensionais}

Fabricação das estruturas usando como ferramenta de apoio a simulação com o intuito de observar o comportamento do fluido dentro da estrutura.

\section{A.1.1 Canais planares}

A Figura A.1 mostra os perfis da velocidade resultante e da pressão absoluta em uma espiral planar com fluidos a base de ar atmosférico, glicerol e água. 


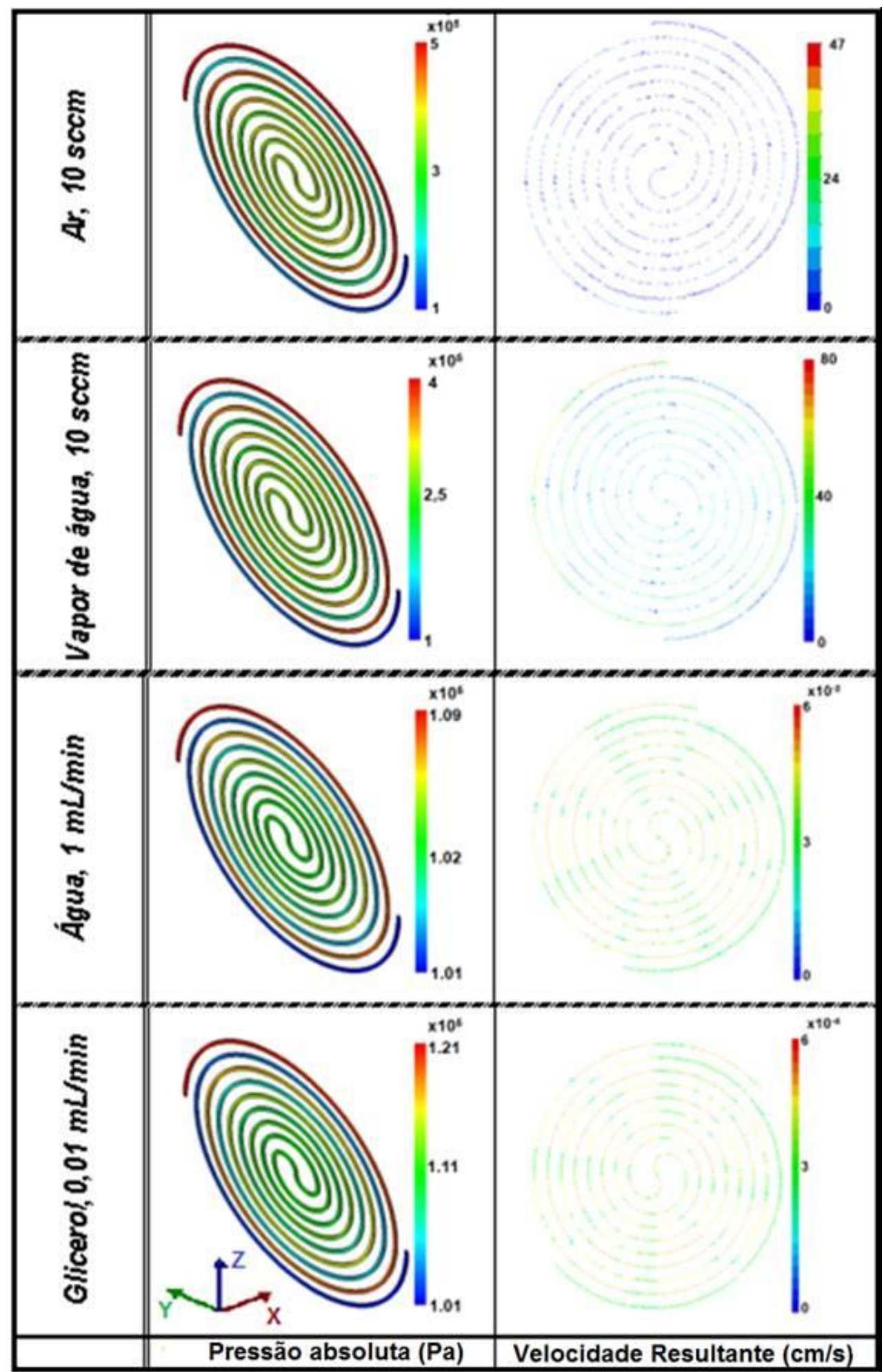

(A)

(B)

Figura A.1 - Perfis da (A) pressão absoluta (Pa) e da (B) velocidade resultante $(\mathrm{cm} / \mathrm{s})$ em estrutura espiral planar usando ar atmosférico, glicerol e água como fluidos, usando o programa de simulação das linhas de fluxo COSMOS Flow 5.0. 
A variação de velocidade é interpretada seguindo a coloração, quanto mais próxima do azul mais baixa será a velocidade ou a pressão. No item (A) observam-se as simulações referentes ao perfil de velocidade em (B) observa-se o perfil de pressão interno ao canal da estrutura. Os diferentes fluidos são usados para observar-se como varia o comportamento gasoso (ar atmosférico ou vapor de água) e líquido (água e um meio mais viscoso, glicerol). $\mathrm{O}$ ar atmosférico tende a obedecer às características de gás ideal enquanto que o vapor de água assume comportamento de gás real, devido às interações entre as moléculas. A viscosidade é alterada para verificar a transferência de energia (perda de carga).

Os gases, como o ar atmosférico e vapor de água, apresentam comportamento similar ao de um gás ideal formando gradiente de velocidade e pressão linear ao longo da estrutura, indicando possivelmente um escoamento de fluido sob regime laminar. Para a água e glicerol observa-se que a linearidade é alterada com a formação de regiões ora de alto ora de baixo perfil de velocidade e pressão indicando comportamento cíclico do fluido, provavelmente, devido a regiões em que o regime de escoamento apresenta-se turbulento.

Resultados típicos para soluções são mostrados na Figura A.2 para a estrutura espiral planar com canal de $100 \mu \mathrm{m}$. A Figura A.2A mostra grande variação de velocidade para nitrogênio; assim, a adição de n-hexano, em fase gasosa (Figura A.2B) ou em fase líquida (Figura A.2C) apresenta uma variação no perfil de concentração, com grande aumento da concentração relativa do reagente em regiões específicas da estrutura. Em ambas as figuras esse aumento de concentração prevalece em uma área pequena do comprimento do microcanal; muito embora, na água pareça ocorrer em uma área maior, provavelmente, devido ao fenômeno de transferência de massa. A alta concentração de reagente, por sua vez, favorece a retenção por outros meios que não adsorção, por exemplo, a capilaridade. 


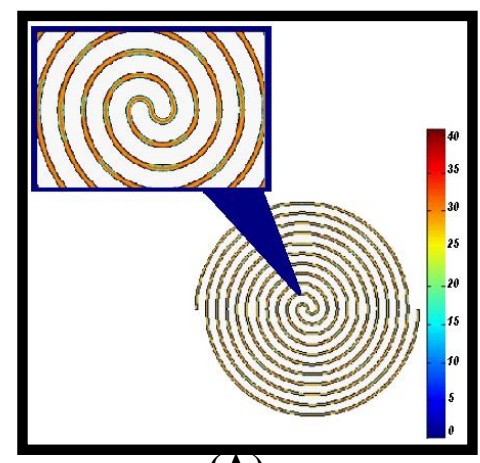

(A)

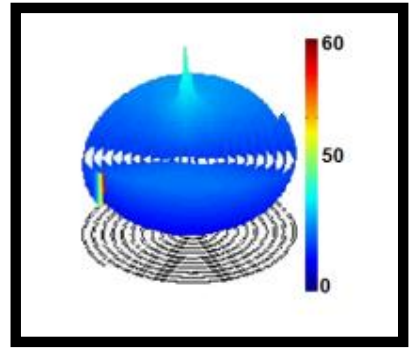

(B)

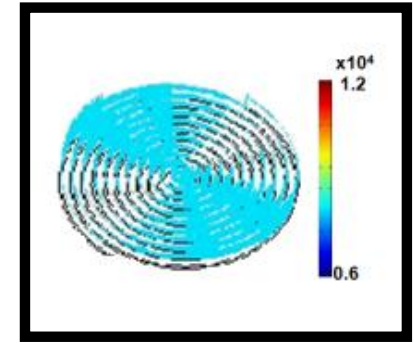

(C)

Figura A.2 - Imagens das simulações da estrutura espiral planar: (A) simulação com nitrogênio; (B) concentração de n-hexano (1\% em vol.) em Nitrogênio; (C) concentração de n-hexano obtido a partir de solução aquosa saturada usando o simulador FEMLAB3.2®. Cor- velocidade $\mathrm{cm} / \mathrm{s}$. Altura do sinal, concentração relativa do $\mathbf{n}$-hexano.

\section{A.1.2 Canais tridimensionais}

A Figura A.3 mostra que os perfis da velocidade resultante e da pressão absoluta em uma espiral tridimensional com ar atmosférico, glicerol e água. 


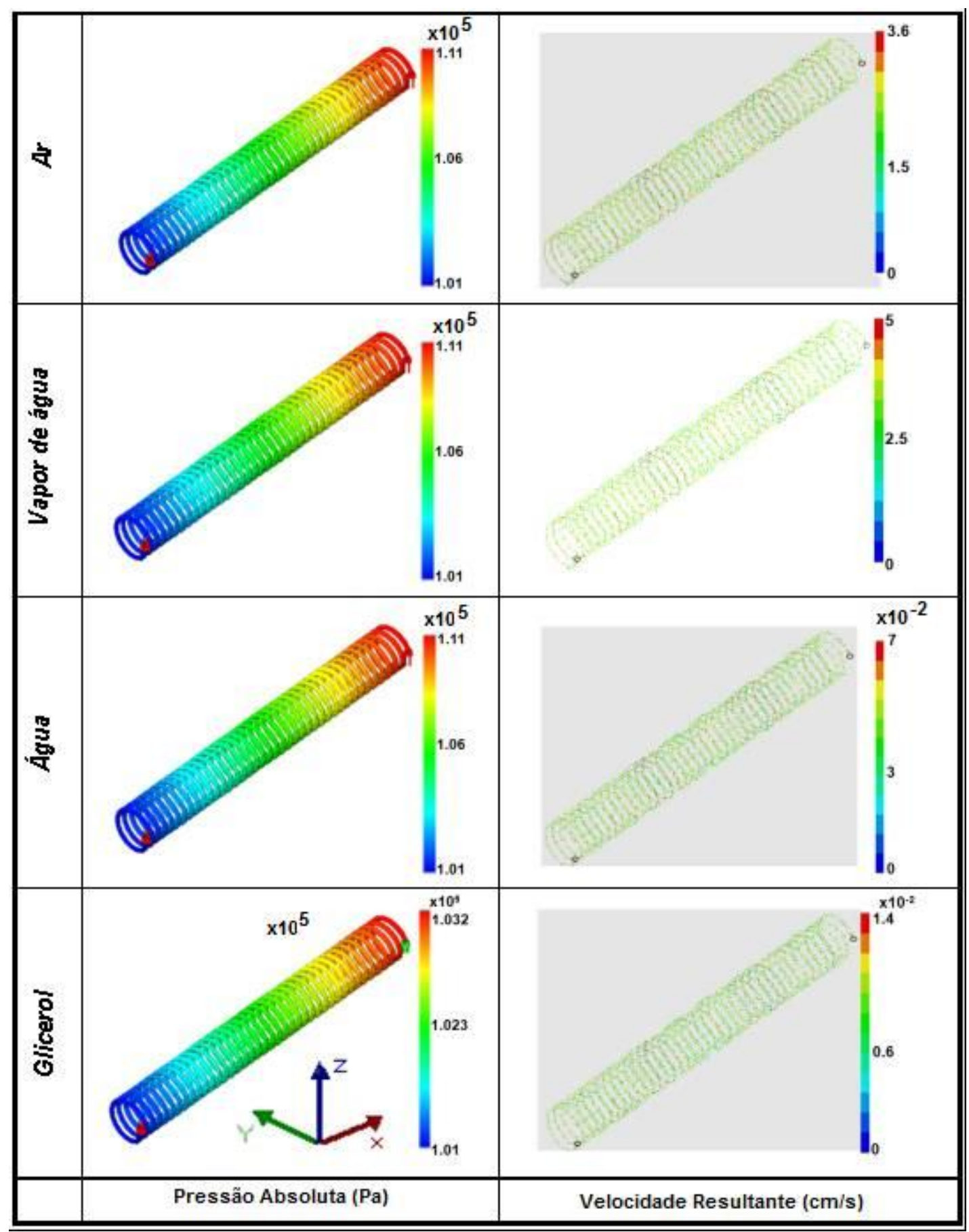

(A)

(B)

Figura A.3 - Perfil da (A) pressão absoluta (Pa) e da (B) velocidade resultante $(\mathrm{cm} / \mathrm{s})$ em uma espiral planar com ar atmosférico, glicerol e água como fluidos usando COSMOS Flow 5.0.

Para fabricação do spray a importância do passo da rosca também foi avaliada. Na Figura A.4 apresenta-se a variação de pressão e de velocidade, do fluxo $-\mathrm{v}_{\mathrm{y}} \mathrm{e}$ lateral $-\mathrm{v}_{\mathrm{z}}$, para os canais tridimensionais e $\mathrm{N}_{2}$ como gás de arraste, se o passo da 
rosca é de $0,8 \mathrm{~mm}$, correspondendo ao maior passo que ainda permite o regime de escoamento laminar.

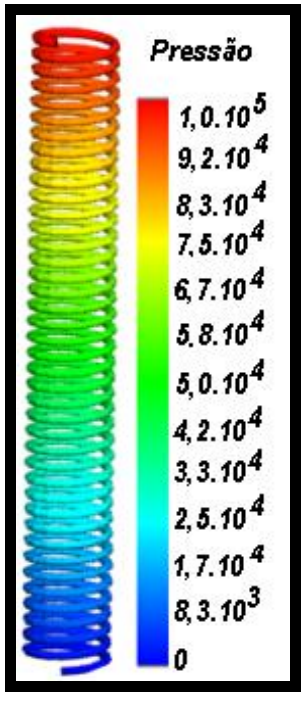

(A)

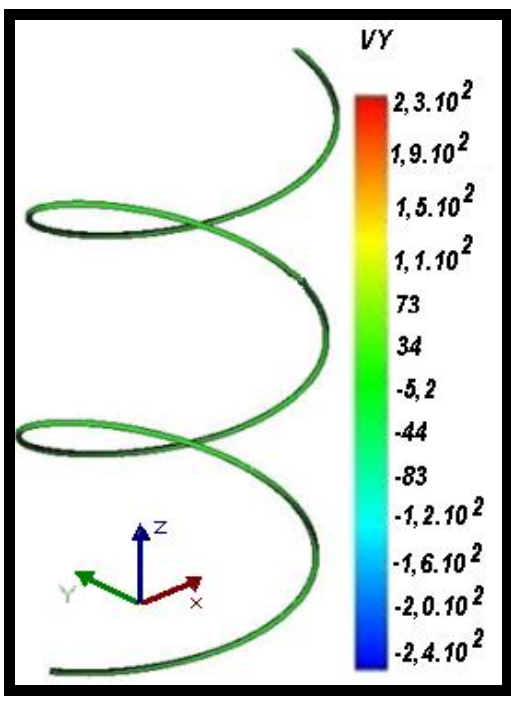

(B)

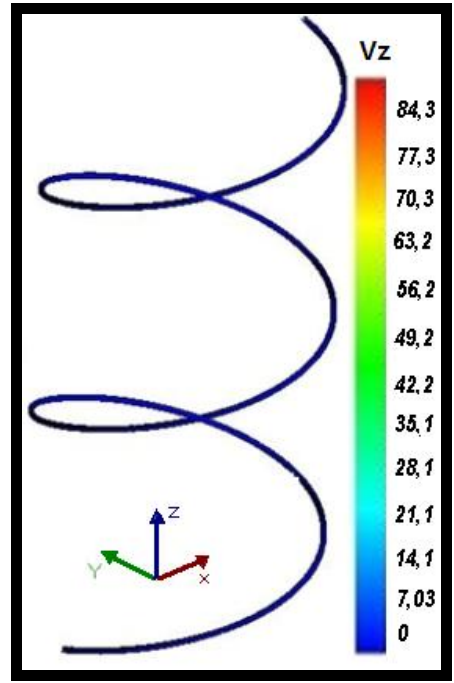

(C)

Figura A.4 - Variação de (A) pressão (Pa) e de (B) velocidade $(\mathrm{cm} / \mathrm{s})$ do fluido $v_{y} e(C)$ lateral - $v_{z}$ para canais tridimensionais, usando como gás de arraste $N_{2}$.

\section{A.1.3 Spray: microcanais planares}

Usando a configuração proposta por Nascimento [54] para a espiral planar fez-se a simulação da formação de spray inserindo gás e líquido na mesma entrada e observando o que ocorre na saída (Figura A.5). Os microcanais planares provavelmente favorecem a formação do spray devido às variações periódicas na velocidade de escoamento, vorticidade e Número de Reynolds.

Uma configuração onde é usado um orifício na região central da estrutura também favorece, provavelmente, a formação do spray devido a alta dispersão do escoamento e às grandes variações da velocidade e do Número de Reynolds. Simulou-se três possibilidades diferentes como pode ser observado na Figura A.6. 

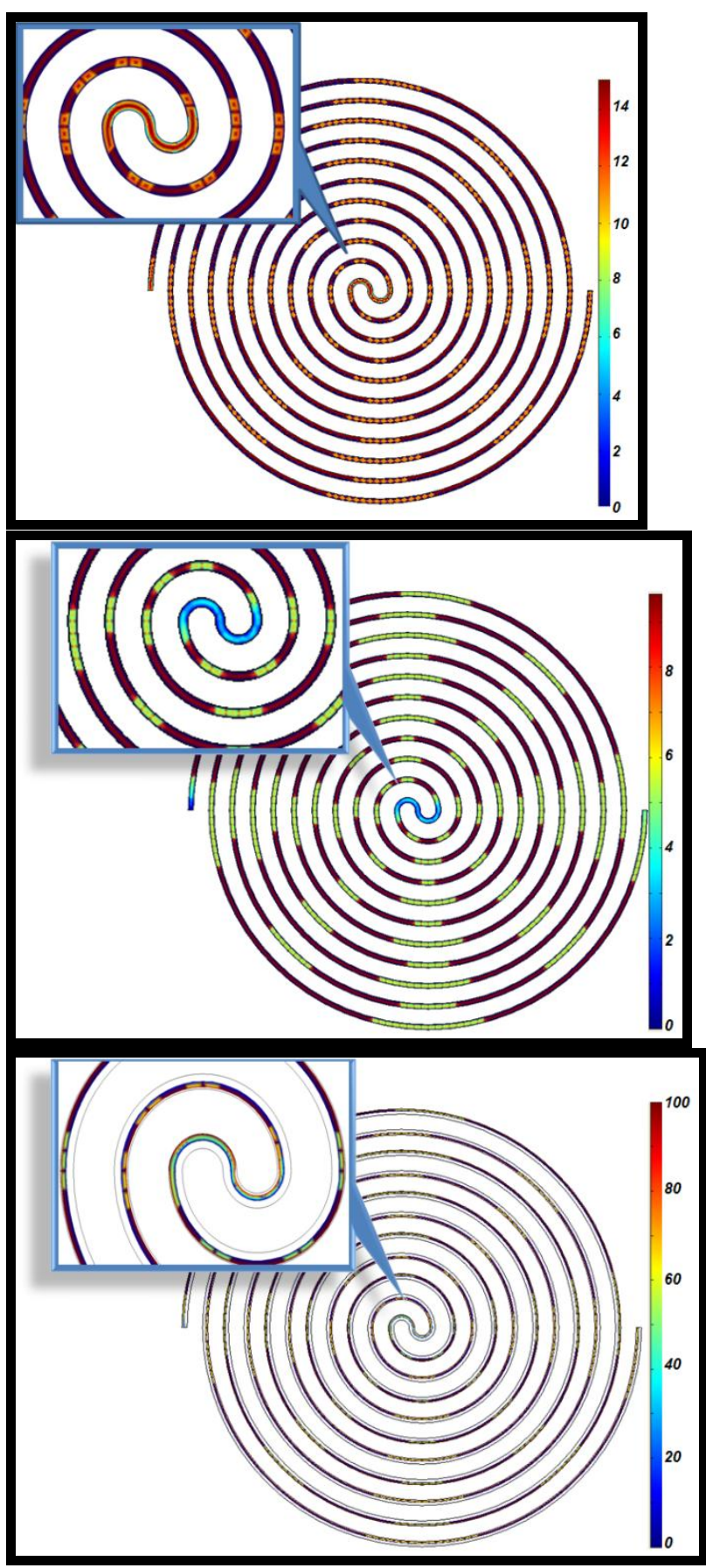

Líquido

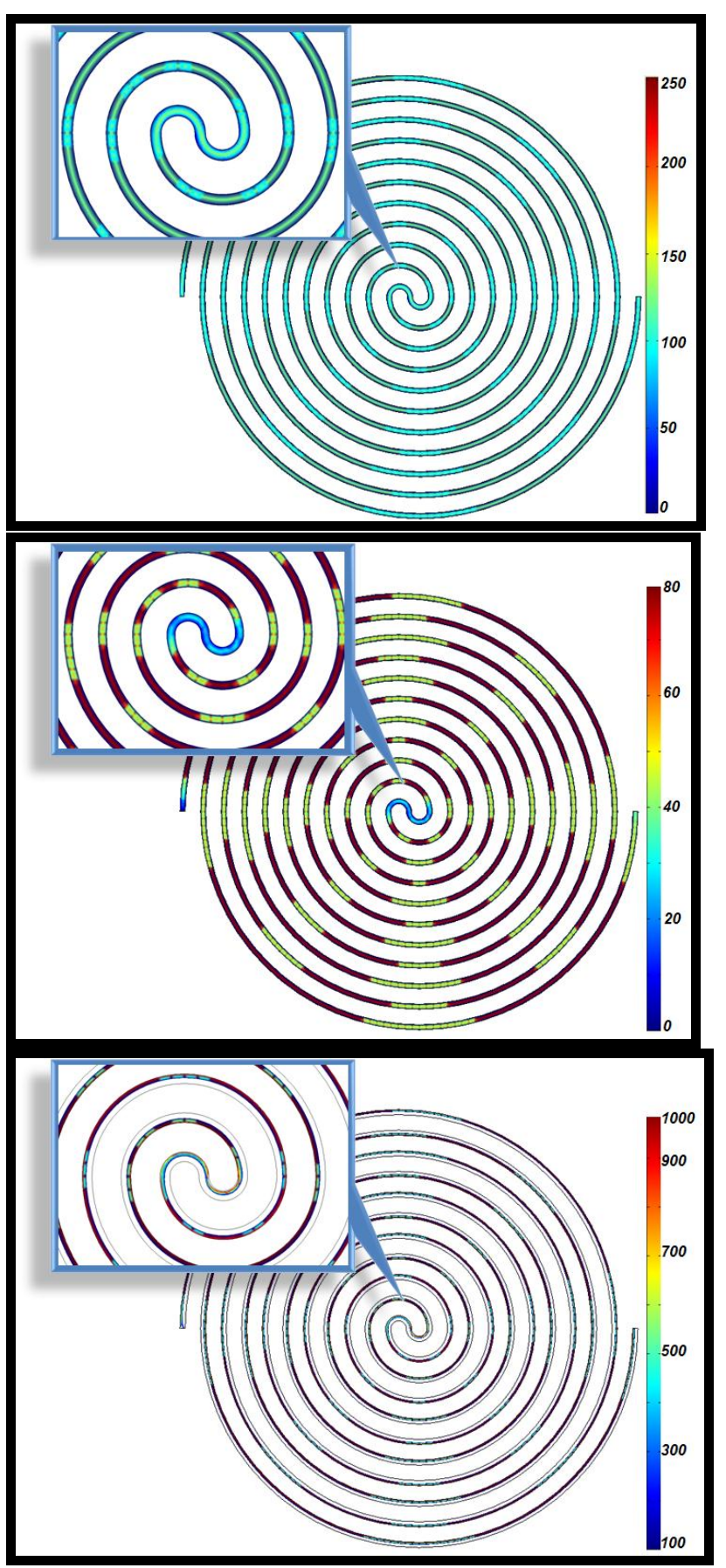

Gasoso

(A)

(B)

(C)

Figura A.5 - (A) Perfil da velocidade (cm/s); (B) número de Reynolds e (C) vorticidade $\left(\mathrm{s}^{-1}\right)$ do fluido gasoso ou líquido introduzidos em um canal planar. 

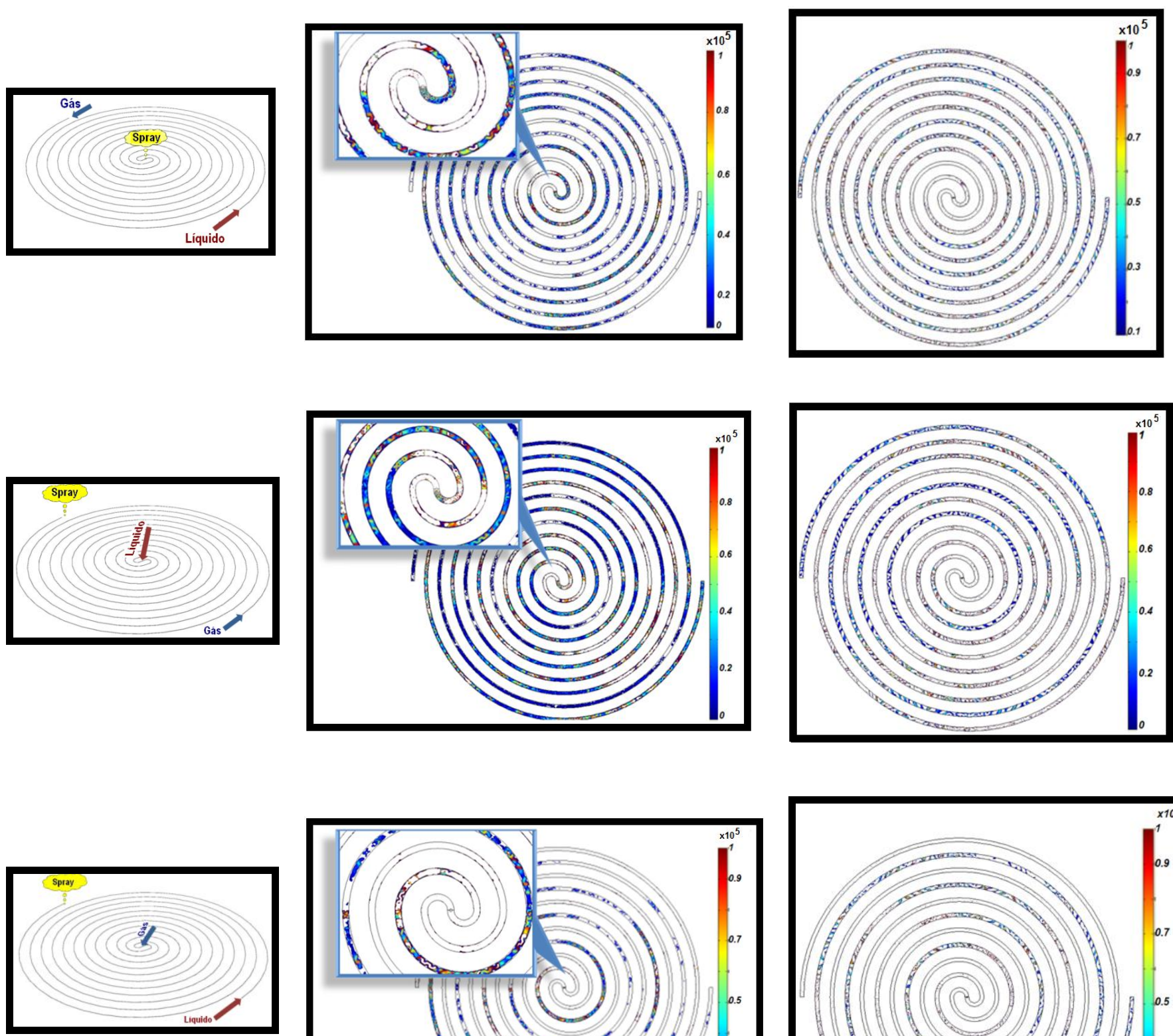

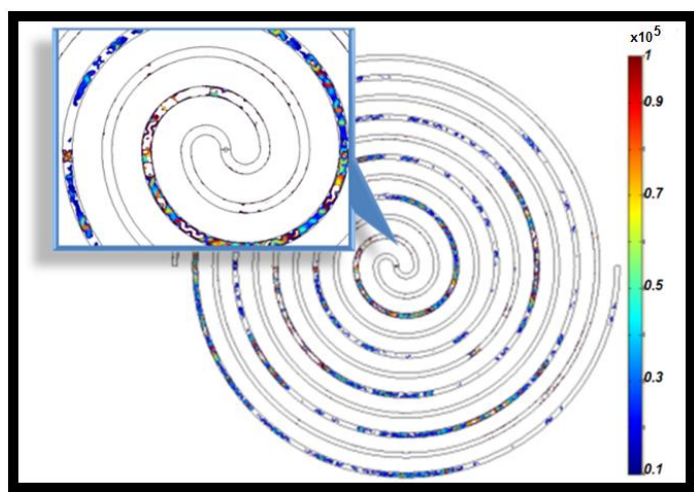

(B)

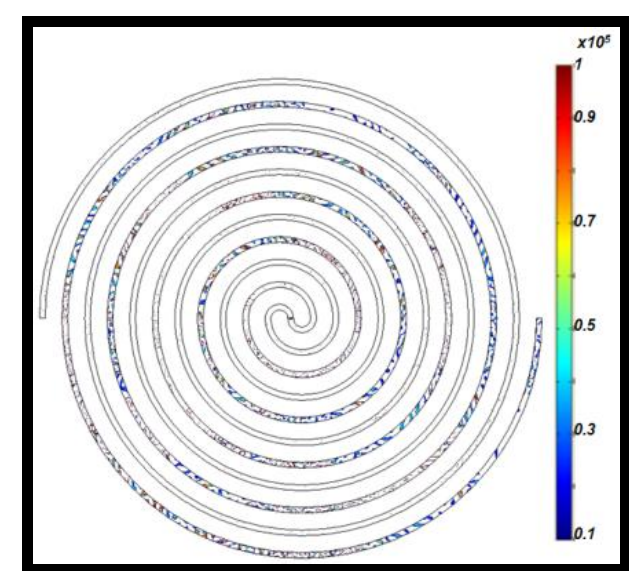

(C)

Figura A.6 - Produção do spray usando os microcanais em espiral planar e um orifício no centro da estrutura: (A) esquema de entradas e saída, (B) perfil da velocidade $(\mathrm{cm} / \mathrm{s})$ e $(\mathrm{C})$ vorticidade $\left(\mathrm{s}^{-1}\right)$.

Na Figura A.6, se a amostra é removida pelo centro da estrutura (opção A) zonas de advecção podem ser produzidas. Por outro lado, devido às diferenças de comprimento, cada curva da espiral apresenta um perfil diferente; assim, a adição de amostra líquida no centro pode perturbar o escoamento significativamente (opção B). A 
adição de gás no centro pode pressurizar a estrutura inteira, o que é igualmente útil para a produção do spray (opção C). Portanto, todas as possibilidades apresentaram o mesmo comportamento, com perfil de vorticidade e velocidade extremamente elevados, o que é característico em sistemas de spray.

Por outro lado, múltiplas interações entre o gás e o líquido são difíceis de obter nesse canal. Se um canal longo e perpendicular à entrada for criado nessa estrutura, como descrito esquematicamente na Figura A.7A, ocorre uma baixa interação entre as duas fases (Figura A.7B). Colocando diversos orifícios, (em cada uma das intersecções é feito um orifício entre o microcanal usinado na estrutura e o microcanal com usinagem perpendicular a entrada da estrutura) observam-se interações melhores entre os líquidos nos microcanais perpendiculares, com maior turbulência quando comparada com a situação em que há apenas um único orifício; sendo assim, este desenho pode ser usado para a fabricação de misturadores miniaturizados.

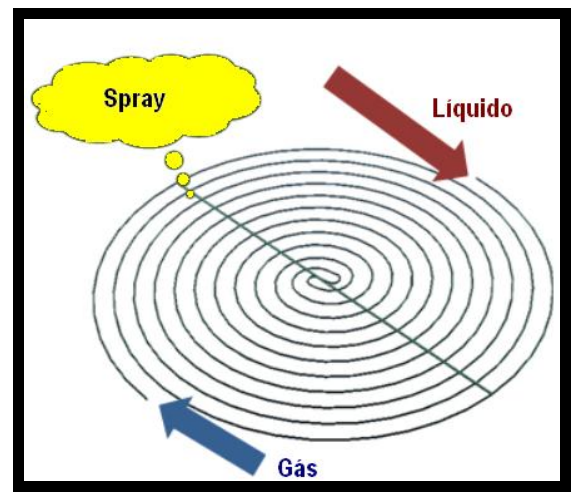

(A)

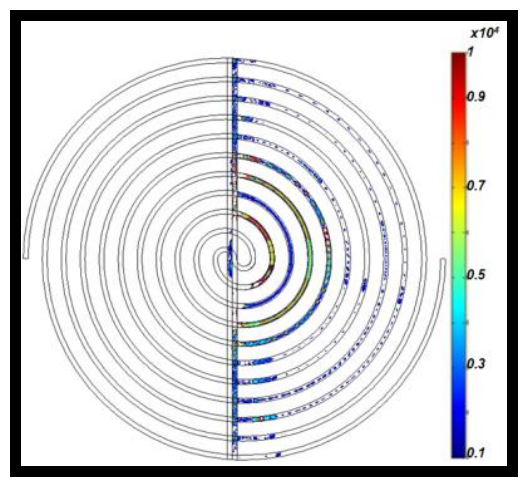

(B)

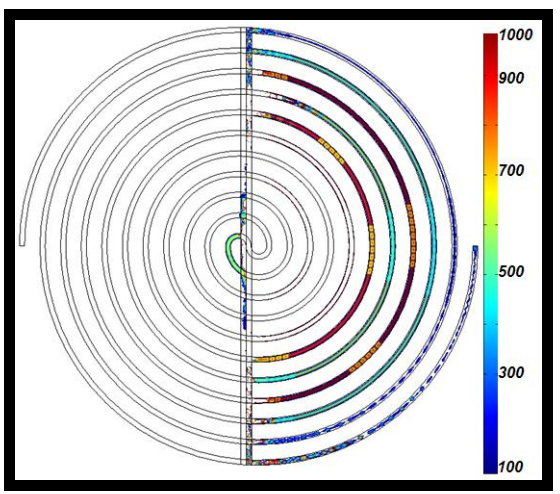

(C)

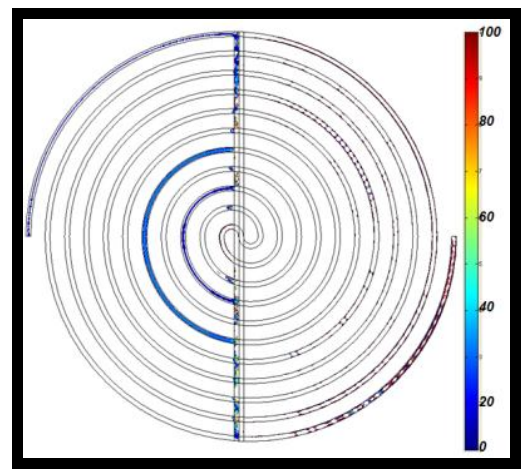

(D)

Figura A.7 - Múltiplas interações gás/líquido: (A) diagramas esquemáticos; e campo da velocidade $(\mathrm{cm} / \mathrm{s}) \mathrm{em}(\mathrm{B}) \mathrm{um},(\mathrm{C})$ diversos orifícios e (D) orifícios intercalados com a respectiva vorticidade $\left(\mathrm{s}^{-1}\right)$. 


\section{A.1.4 Spray: microcanais tridimensionais}

Mantendo o passo da rosca próximo de zero, o canal apresenta o comportamento esperado em uma coluna cromatográfica. Como pode-se observar na Figura A.8A, a velocidade é máxima (representada pela coloração vermelho-alaranjada) no centro do microcanal e aproximadamente nula nas regiões próximas à parede do microcanal (coloração azul escuro). Na Figura A.8B observa-se o número de Reynolds quase nulo (coloração azul escuro) nas proximidades das paredes e um pouco mais elevado nas regiões centrais dos microcanais (coloração azul claro) indicando, provavelmente, regime laminar. A vorticidade é praticamente nula nas paredes dos microcanais (coloração azul escuro) e muito pequena na região central do canal reforçando a possibilidade de regime laminar. 


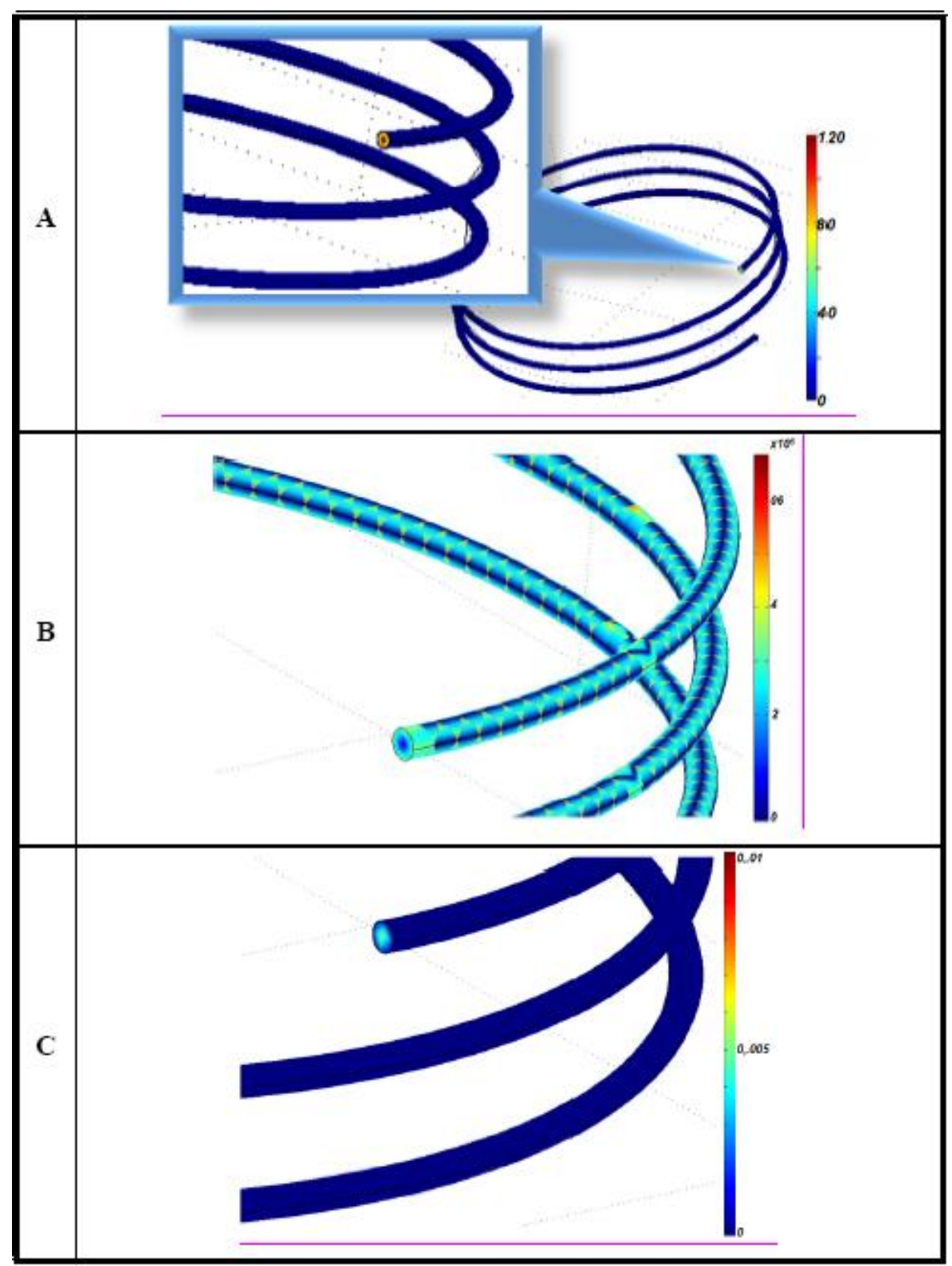

Figura A.8 - (A) Perfil da velocidade (cm/s); (B), número de Reynolds; (C) vorticidade $\left(\mathrm{s}^{-1}\right)$ do fluido gasoso ou líquido introduzidos em um microcanal tridimensional.

A Figura A.9 apresenta a interação na primeira volta dos dois microcanais se um deles tem um passo de rosca 4 vezes maior do que o outro (40 $\mu \mathrm{m}$ para o menor passo de rosca). Pode-se observar que com os microcanais colocados a $90^{\circ}$ o líquido e o gás interagindo perturbam o perfil de velocidade do gás, se comparado com a Figura A.8, em todo o comprimento do canal (coloração azulada com traços amarelo e vermelho no centro do microcanal), enquanto que o líquido apresenta uma região de interação grande, indicada pela coloração azul clara. Na Figura A.9B observa-se alto índice de vorticidade e velocidade na região central do microcanal indicados pela coloração amarela e vermelha e baixo vorticidade e velocidade nas regiões próximas a parede dos 
microcanais (coloração azul escuro), além de variação perceptível do número de Reynolds na área de interação. As regiões de alta turbulência são indicadas na simulação, principalmente, no encontro entre os microcanais (coloração avermelhada) indicadas na Figura A.9C.

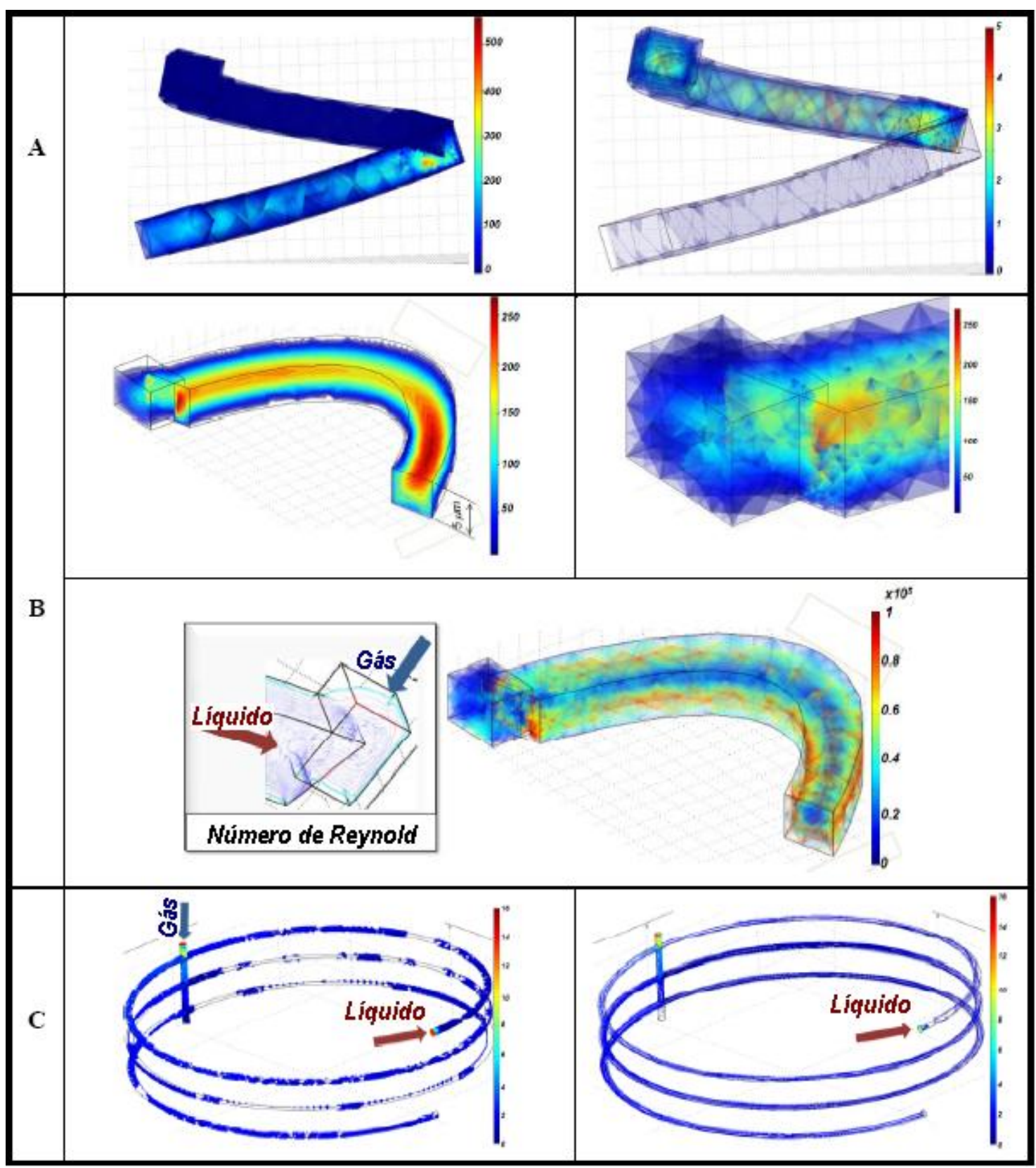

Figura A.9 - Interação na primeira volta de dois canais: perfil de velocidade para gás e líquido $(\mathrm{cm} / \mathrm{s})$ quando (A) um dos canais tem passo da rosca 4 vezes maior (40 $\mu \mathrm{m}$ para o menor passo de rosca); ou (B) está em ângulo de $90^{\circ}$, além de respectiva vorticidade $\left(\mathrm{cm}^{-1}\right)$ e número de Reynolds; e (C) interação entre três voltas consecutivas da estrutura com o canal secundário em ângulo de $90^{\circ} \mathrm{e}$ passo de rosca de $40 \mu \mathrm{m}$. 


\section{A.2 Simulações dos impactadores}

Para evitar desperdício de tempo e recursos, fez-se a simulação de estruturas impactadoras para fase líquida tendo com base as estruturas propostas por Beraldo [99] para fase gasosa. A principal modificação ocorreu na placa coletora central, pois esta, para apresentar menor interação, foi modificada formando um ângulo agudo ou uma reentrância, o que facilita uma menor velocidade na área de interação com a parede. Anteparos laterais foram colocados para que o fluxo atingisse a região central do anteparo. As duas formas foram avaliadas para verificar qual apresentava maior eficiência.

Assim, como descrito para testes de estruturas anteriormente mencionadas, fezse também o uso do simulador FEMLAB 3.2B ${ }^{\circledR}$ numa simulação $2 \mathrm{D}$ e a Equação de Navier-Stokes para avaliar os mecanismos internos e a retenção de partículas. O Nitrogênio, 10sccm, foi usado como gás de arraste, para meio gasoso, e a água $1 \mathrm{ml} / \mathrm{min}$, para meio aquoso. Também se simulou a inserção de partículas com diâmetro de $50 \mu \mathrm{m}$ e $13 \mu \mathrm{m}$ na estrutura.

\section{A.2.1 Impactador angular}

Na Figura A.10 segue o resultado obtido para o perfil de velocidade para simulação realizada com água e vazão de $1 \mathrm{~mL} / \mathrm{min}$.

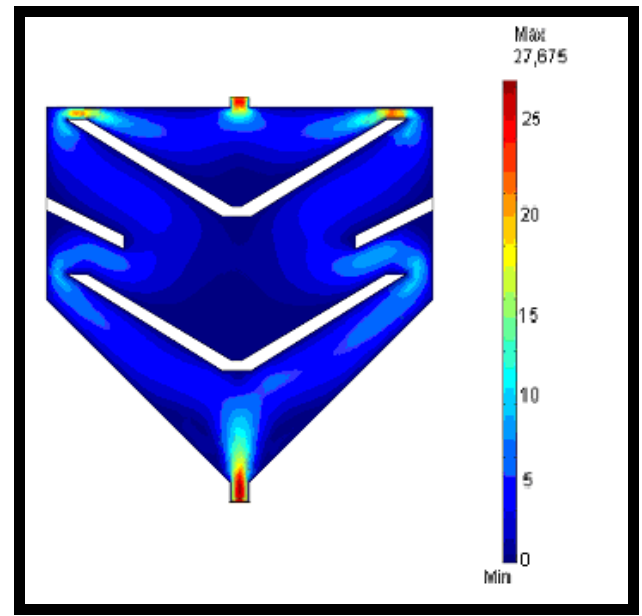

Figura A.10 - Simulações do desenho do impactador com velocidade da água $(\mathrm{cm} / \mathrm{s})$ no interior da estrutura e vazão de $0,1 \mathrm{~mL} / \mathrm{min}$. 
Na Figura A.10, observa-se que as regiões onde têm-se velocidade muito baixa (coloração azul escura) são aquelas próximas às placas coletoras centrais, como esperado. Porém, devido à presença de anteparos laterais e da região com constrição no início da estrutura, itens necessários para que a velocidade seja menor no centro da estrutura, têm-se regiões de alta velocidade, mas que distam consideravelmente deste centro. Este perfil de velocidade é coerente com o perfil de concentração relativa das partículas de $10 \mu \mathrm{m}$, apresentado na Figura A.11A, da simulação da estrutura na presença de partículas. Nota-se que as regiões onde há menor velocidade é a região que apresenta maior concentração de partículas. Para melhor visualização, o mesmo desenho anterior, porém, observado para as linhas de velocidade, encontra-se na Figura A.11B.

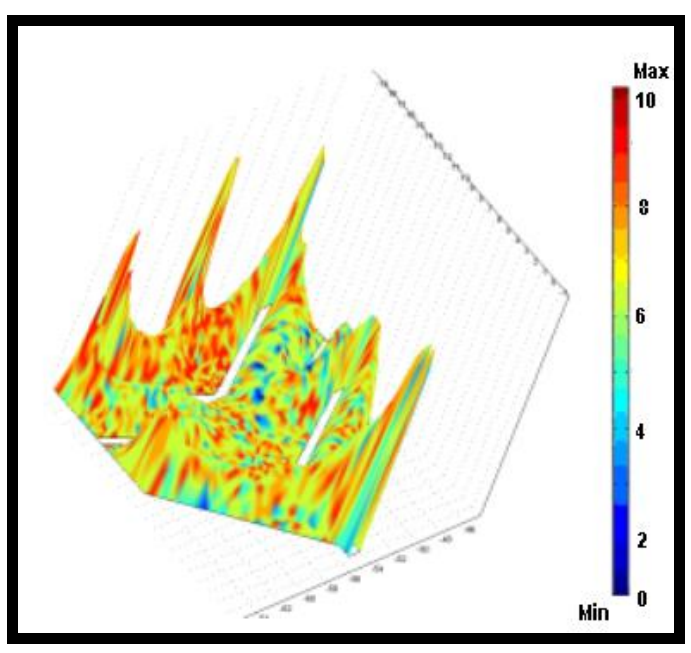

(A)

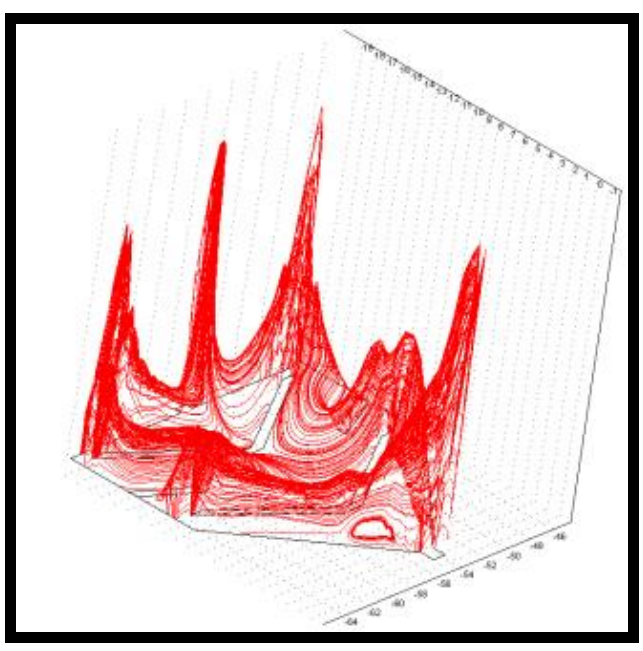

(B)

Figura A.11 - (A) Simulação da concentração relativa de partículas de $10 \mu \mathrm{m}$ (identificadas pela coloração) e respectiva velocidade $(\mathrm{cm} / \mathrm{s})$ do fluido (representada pela altura); (B) Simulação das linhas de velocidade na presença de partículas.

Nota-se que certas regiões apresentam variações bruscas nas linhas de velocidade, o que é indicativo da existência de vórtices e, devido à presença dos anteparos laterais, estes vórtices, provavelmente, ficam ainda mais intensos.

\section{A.2.2 Impactador semi-circular}

A Figura A.12 apresenta a simulação realizada para fluido aquoso com velocidade de $1 \mathrm{~mL} / \mathrm{min}$. 


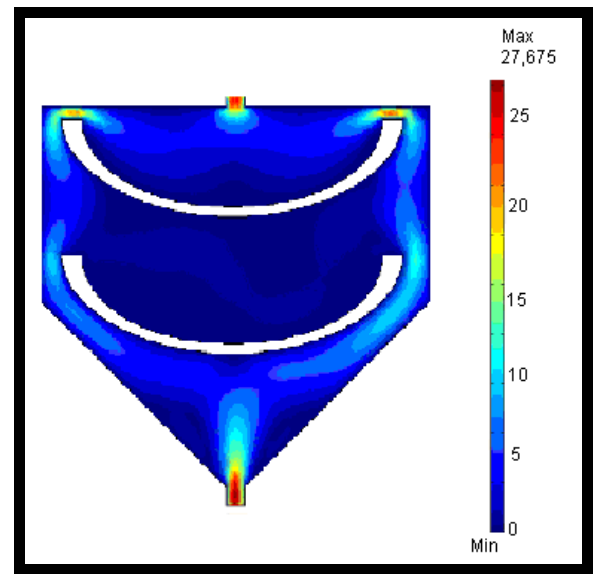

Figura A.12 - Simulação da velocidade $(\mathrm{cm} / \mathrm{s})$ para o fluxo da água.

Para verificar se há um caminho preferencial evidente, simulação de partículas usando a mesma vazão foi processada e é apresentada na Figura A.13. A maior concentração de partículas encontra-se na região central da estrutura representada pela coloração esverdeada, indicação de provável retenção.

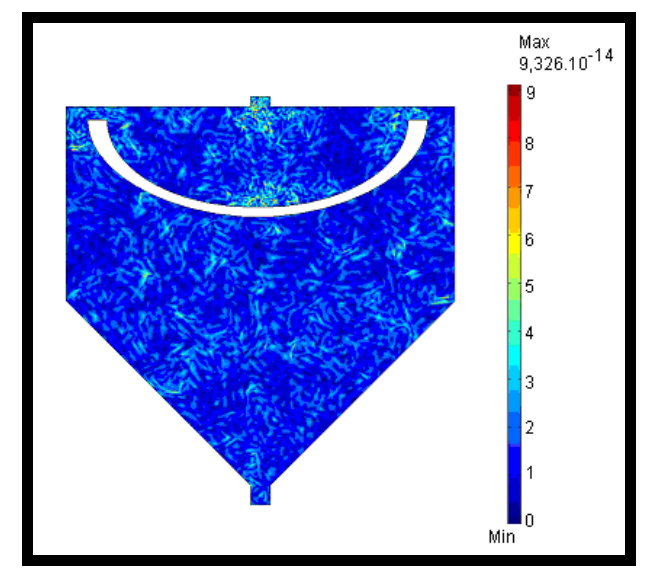

Figura A.13 - Simulação da concentração de partículas.

Para efeitos de comparação qualitativa entre as estruturas, a Figura A.14A e B apresentam a simulação da velocidade e concentração relativa de partículas. Em comparação com a Figura A.11A observa-se que há um perfil de velocidade semelhante, mas na placa coletora semi-circular a presença de partículas parece ser mais dispersa por toda a área da estrutura. 


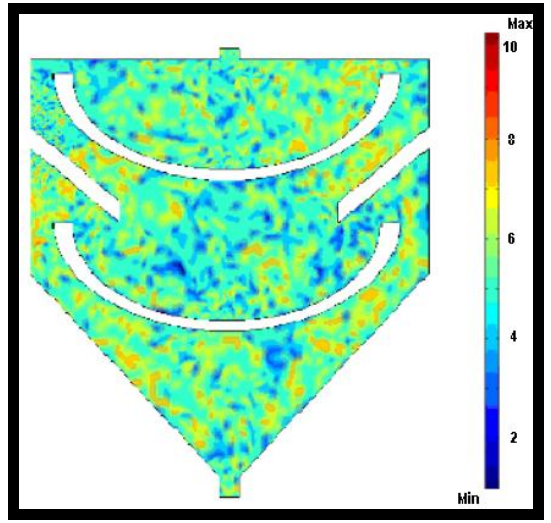

(A)

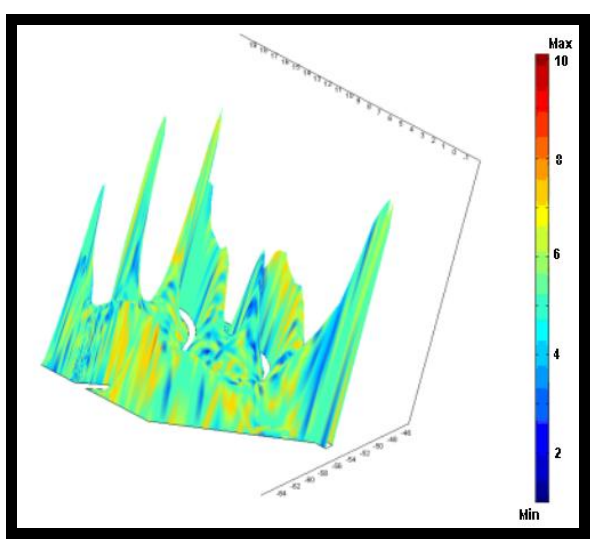

(B)

Figura A.14 - (A) Simulação da concentração relativa de partículas; (B) simulação da concentração relativa de partículas de $10 \mu \mathrm{m}$ (representada pelas cores) e respectiva velocidade de fluido $(\mathrm{cm} / \mathrm{s}$, representada pela altura).

Também para efeitos de comparação apresentam-se na Figura A.15 as linhas de velocidade, que são bastante semelhantes à do impactador angular (Figura A.11B), observando-se, inclusive, a provável presença de vórtices, neste caso em maior número, visto que há várias regiões com variação brusca de velocidade.

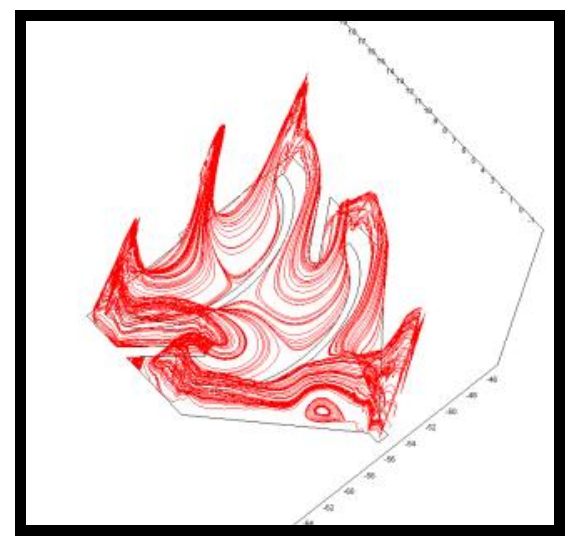

Figura A.15 - Simulação das linhas de velocidade na presença de partículas.

\section{A.3 Simulações do separador}

As simulações tiveram por objetivo compreender o comportamento do fluido usando gás ou líquido, na estrutura e em diversas condições de uso, tais como, a existência de partículas na amostra ou o uso de recheio. As simulações usaram vazão de 
$10 \mathrm{~mL} / \mathrm{min}$ (padrão) para gás e $1 \mathrm{sccm}$ para líquido, em geral, $\mathrm{N}_{2}$ ou água, respectivamente.

A Figura A.16 apresenta as linhas de velocidade de escoamento usando $\mathrm{N}_{2}$ e estrutura sem ou com recheio (Figuras A.16A e B, respectivamente). As Figuras A.16C e D apresentam variações na pressão interna, que tende a ser pequena, na estrutura empacotada mesmo se a vazão é restringida pelo uso de válvulas ou constrições. A $100^{\circ} \mathrm{C}$ (Figura A.16D) os resultados são semelhantes aos obtidos nos testes anteriores.

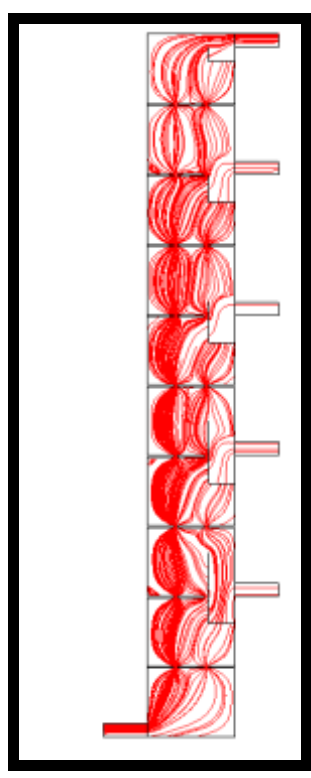

(A)

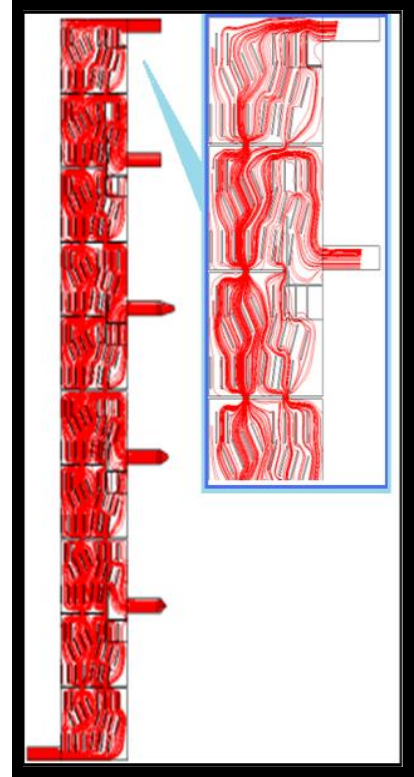

(B)

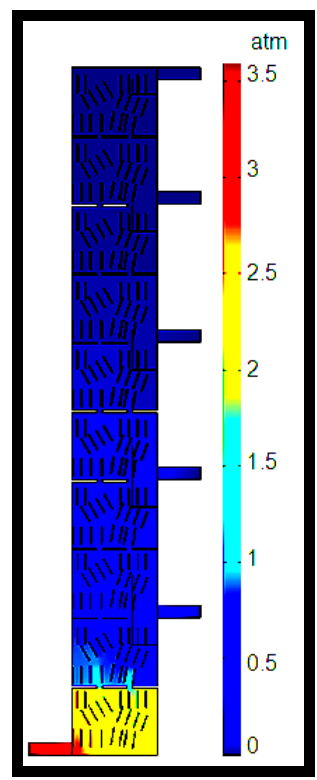

(C)

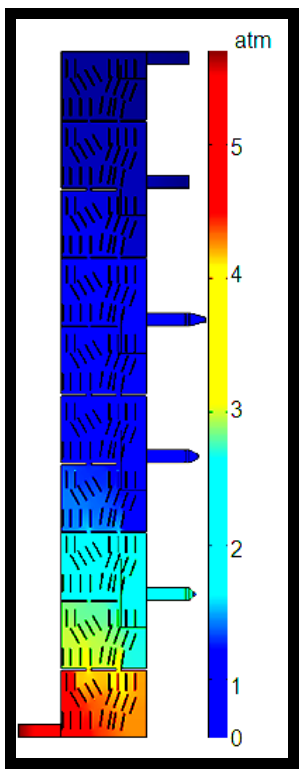

(D)

Figura A.16 - Simulação das estruturas usando como gás de arraste $\mathrm{N}_{2}$ (10 $\mathrm{mL} / \mathrm{min}$ padrão): linhas de velocidade (A) sem ou (B) com recheio e respectivas pressões (atm); para duas configurações de estrutura (C) sem constrições e (D) com constrições.

Como pode ser visualizado na Figura A.17, para a estrutura sem empacotamento, a principal diferença constitui-se na velocidade máxima, que é menor para vapores (por exemplo, querosene) quando usado como gás de arraste $\mathrm{N}_{2}$. 


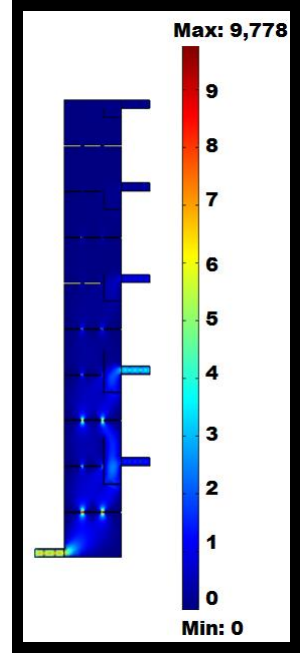

(A)

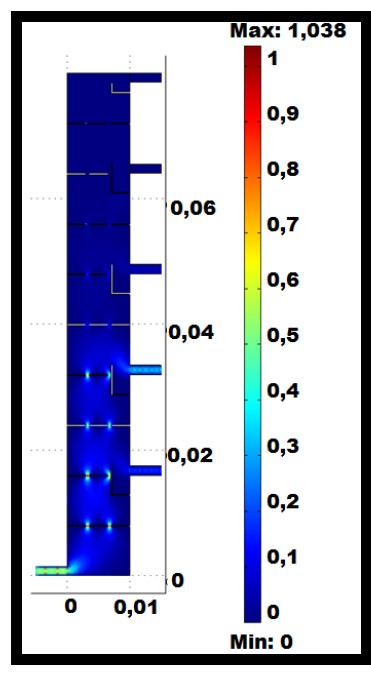

(B)

Figura A.17 - (A) Perfil de velocidade $(\mathrm{cm} / \mathrm{s})$ na chicana para vazão de $10 \mathrm{~mL} / \mathrm{min}$ (padrão) e usando como gás de arraste $\mathrm{N}_{2}$ ou (B) usando querosene.

O refluxo é comum em colunas de destilação e tem por objetivo obter melhor contato entre líquidos e vapores, além de melhorar a separação. No presente caso, foi avaliada, por simulação, a possível vantagem da interação de outros fluxos admitidos na estrutura. Utilizou-se água e querosene como reagentes, já que estes apresentam baixa miscibilidade; contudo, estes reagentes foram admitidos como vapores. A Figura A.18 apresenta os resultados para duas condições diferentes. No primeiro caso, avaliou-se adição de querosene na primeira cela e água em todas as celas restantes e a temperatura ambiente (Figura A.18A, linhas de velocidade). Provavelmente formam-se vórtices na estrutura, o que pode favorecer a retenção de alguns compostos por mais tempo em cada cela. Por outro lado, se querosene é admitido na primeira cela e água na última (Figura A.18B), o perfil de velocidade apresenta pouca variação se comparado ao obtido na Figura A.17, a principal diferença ocorre na penúltima cela, com a água preferencialmente deixando a estrutura. Neste caso, portanto, o sistema não facilita o contato dos reagentes, o que também é um bom indicativo que os anteparos presentes em cada saída auxiliam na direção do fluxo. Resultados semelhantes são obtidos se o querosene é aquecido e/ou se a estrutura empacotada é utilizada (Figura A.18C). 


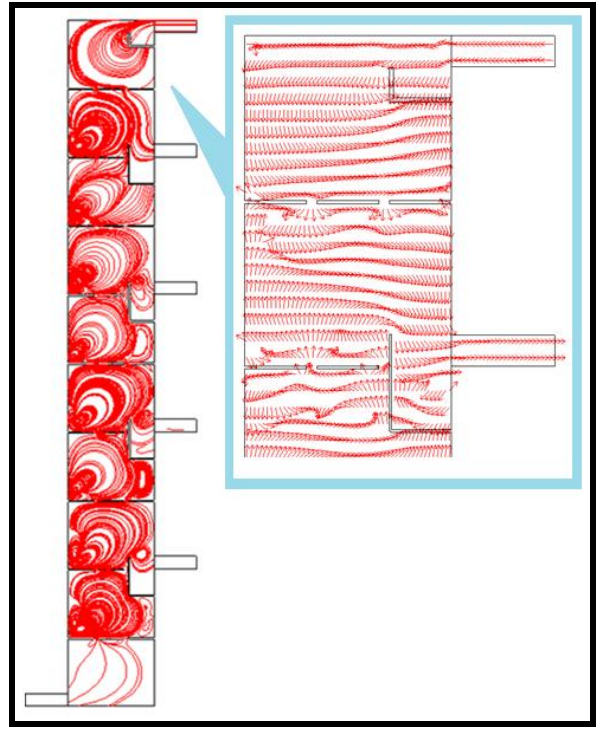

(A)

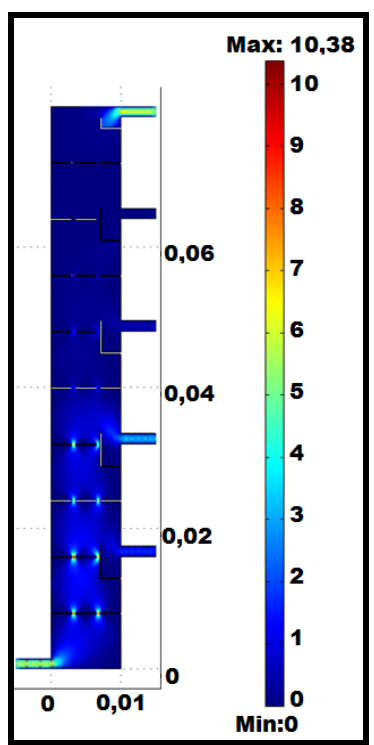

(B)

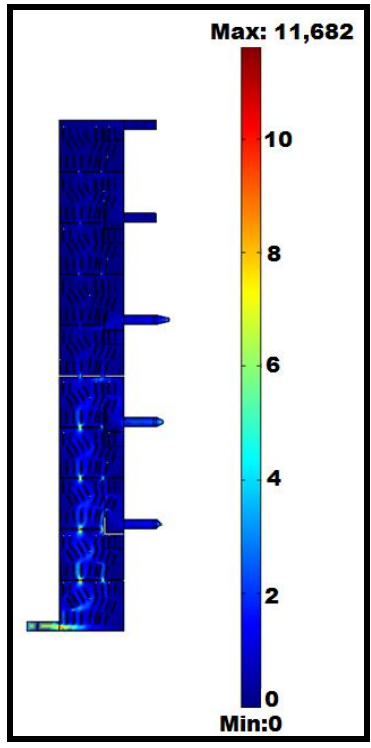

(C)

Figura A.18 - Simulação de dois fluxos (vapores de água e querosene), interagindo na estrutura a temperatura ambiente; (A) linhas de velocidade, e detalhe, obtidas com adição de querosene na primeira cela e água em todas as celas restantes; (B) perfil da velocidade $(\mathrm{cm} / \mathrm{s})$ pela adição de querosene na primeira cela e água na última; (C) perfil da velocidade $(\mathrm{cm} / \mathrm{s})$ na adição de querosene aquecido a $100^{\circ} \mathrm{C}$ na primeira cela e água na última em uma estrutura empacotada.

Simulação de partículas para fluido gasoso apresenta retenção tanto para $10 \mu \mathrm{m}$ como para $50 \mu \mathrm{m}$, com perfil semelhante. A Figura A.19 apresenta em cada cela da estrutura o perfil da velocidade (representada pela altura) e a concentração de partículas (representada pela cor) de $10 \mu \mathrm{m}$ ou $50 \mu \mathrm{m}$ (10\% em peso) carregadas por $\mathrm{N}_{2}$. 


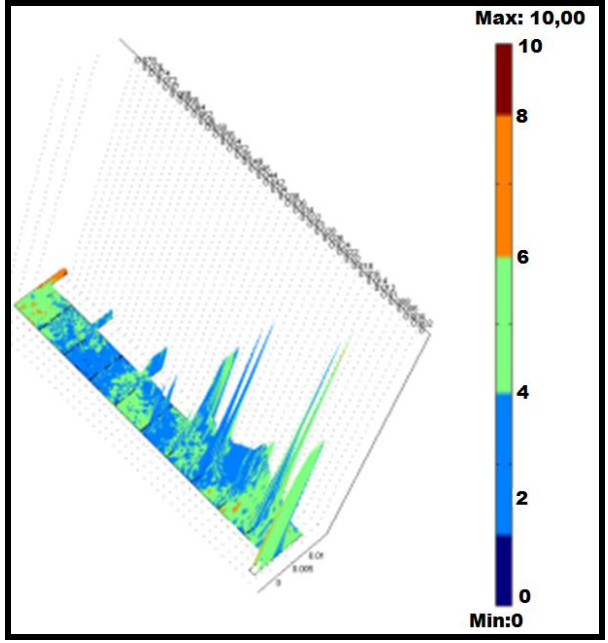

(A)

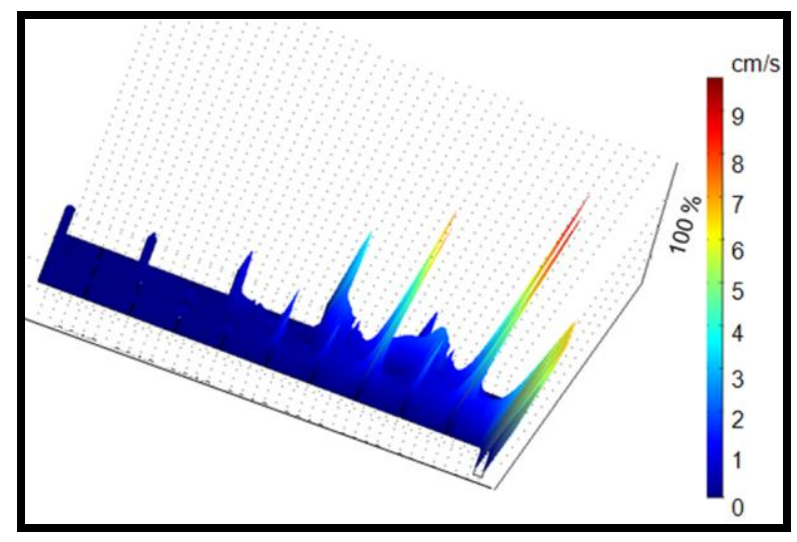

(B)

Figura A.19 - (A) Perfil da velocidade ( $\mathrm{cm} / \mathrm{s}$ - representada pela altura) e a concentração relativa de partículas de $10 \mu \mathrm{m}$ (representada pela cor) em cada cela da estrutura; (B) perfil de velocidade $(\mathrm{cm} / \mathrm{s}$ - representada pela cor) e a concentração relativa de partículas de $50 \mu \mathrm{m}$ (representada pela altura) em cada cela da estrutura.

Filme adsorvente pode ser simulado supondo que ocorram interações com as paredes $^{\text {ee }}$, a Figura A.20 apresenta resultados típicos.

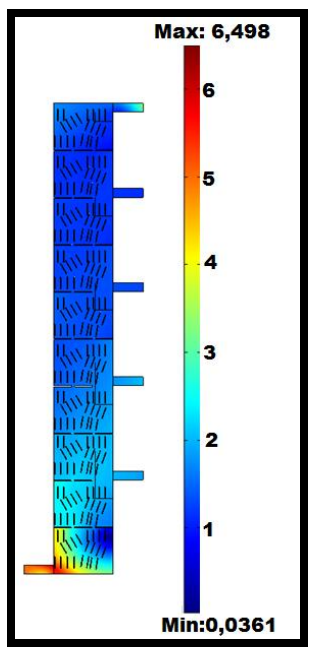

(A)

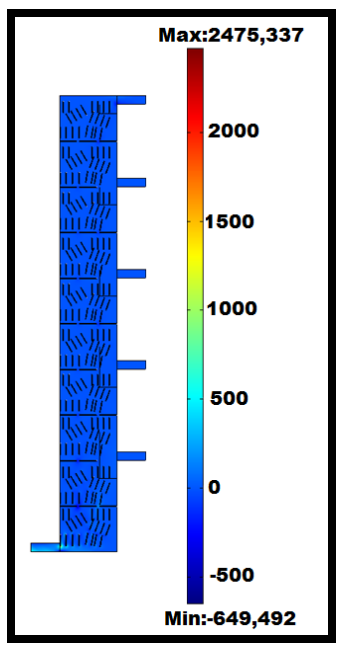

(B)

Figura A.20 - Simulação da chicana empacotada e admissão de $10 \mathrm{~mL} / \mathrm{min}$ padrão de querosene e temperatura ambiente, parede neutral: perfil da (A) velocidade $(\mathrm{cm} / \mathrm{s})$ e (B) da pressão (atm).

\footnotetext{
ee Denominado neutral, no software.
} 
Resultados semelhantes são obtidos supondo que os fluídos estejam na fase líquida para todas as condições anteriormente simuladas. 


\section{APÊNDICE B}

\section{B.1 Canais tridimensionais modificados}

\section{B.1.1 Testes experimentais}

Para cada estrutura fizeram-se testes usando a inserção de reagente no modo de admissão pulsada, ou seja, inserção mínima de reagente $(0,10 \mathrm{~mL})$, determinada experimentalmente como a quantidade mínima que o detector consegue captar. Repetiram-se os testes 5 vezes cada para verificar se os dados são reprodutíveis.

\section{B.1.1.1 Testes a temperatura ambiente}

\section{B.1.1.1.1 Estrutura não empacotada}

Para a coluna não empacotada, testaram-se vários reagentes orgânicos e misturas, além de uma mistura comercial, gasolina. Para verificar se existem alguns fenômenos, como ruído alto, dificultando a detecção, um capilar foi testado usando ar atmosférico como fluido e a inserção de isopropanol $(0,01 \mathrm{~mL})$ é feita de modo pulsado.

Para este arranjo, são apresentados resultados típicos para a estrutura a temperatura ambiente. No Gráfico B.1 são apresentados os dados referentes a uma única inserção de isopropanol usando apenas o capilar, ou seja, com o mini compressor de ar desconectado. O Gráfico B.2 repete o teste anterior, porém, com o mini compressor de ar ligado. 


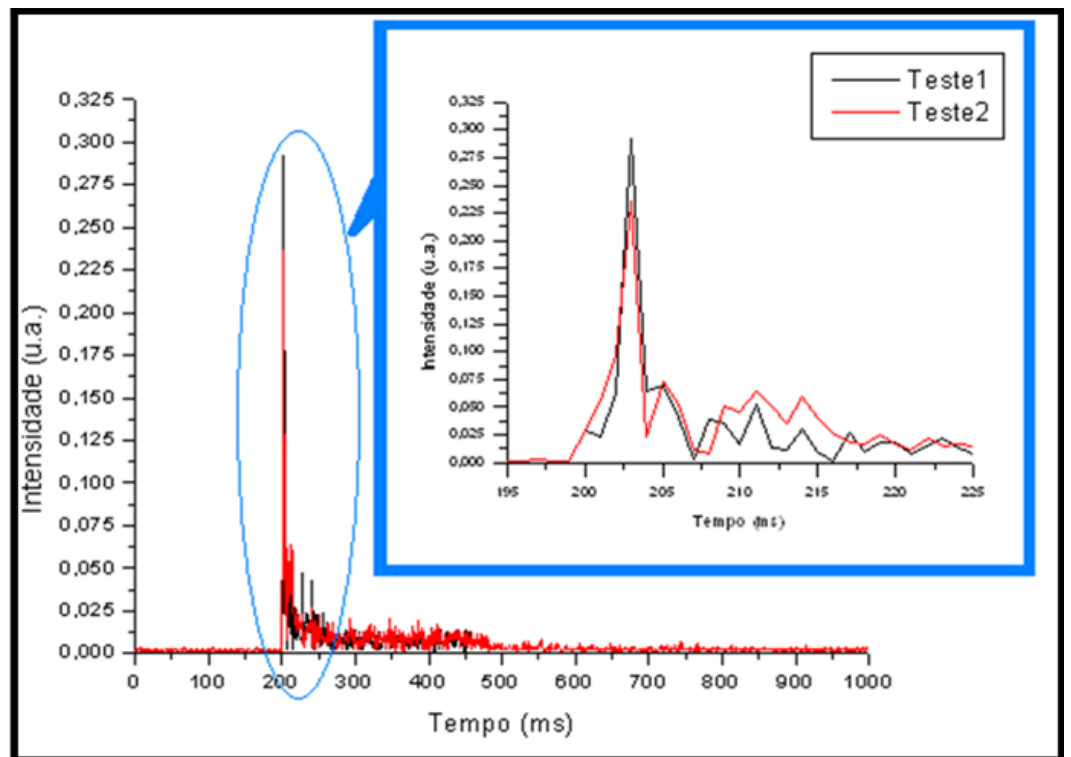

(A)

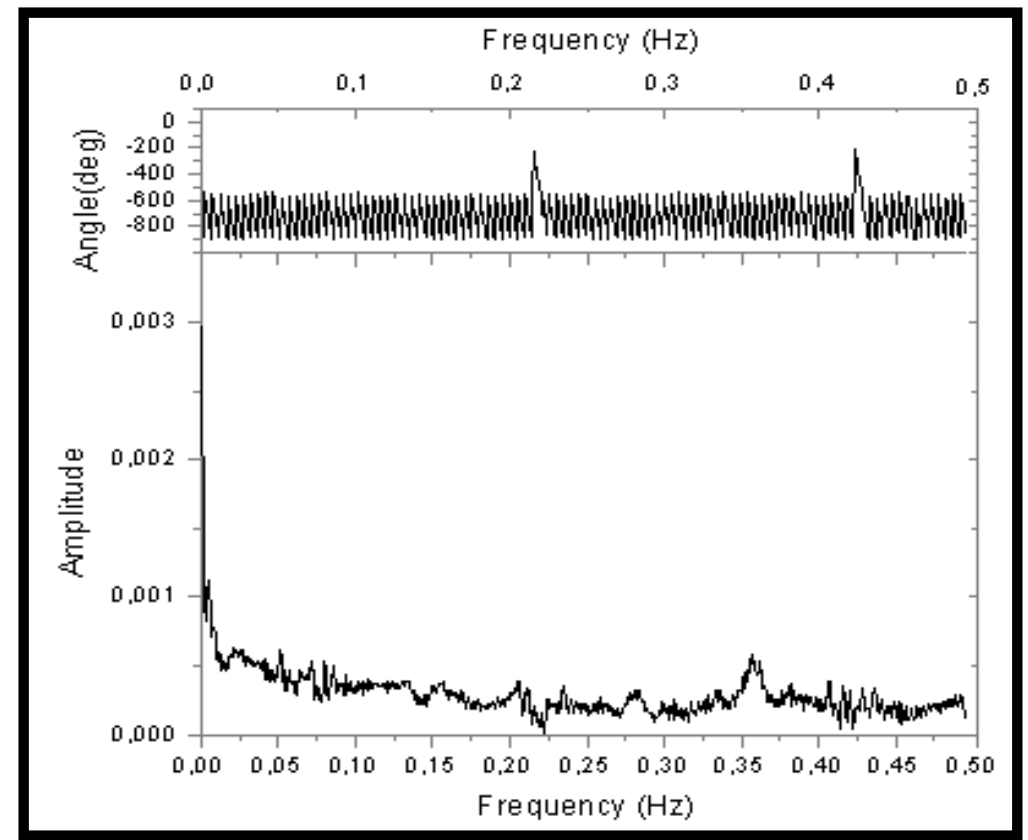

(B)

Gráfico B.1 - (A) Teste e (B) Transformada de Fourier usando apenas o capilar com o mini compressor de ar desconectado, usando como reagente isopropanol. 


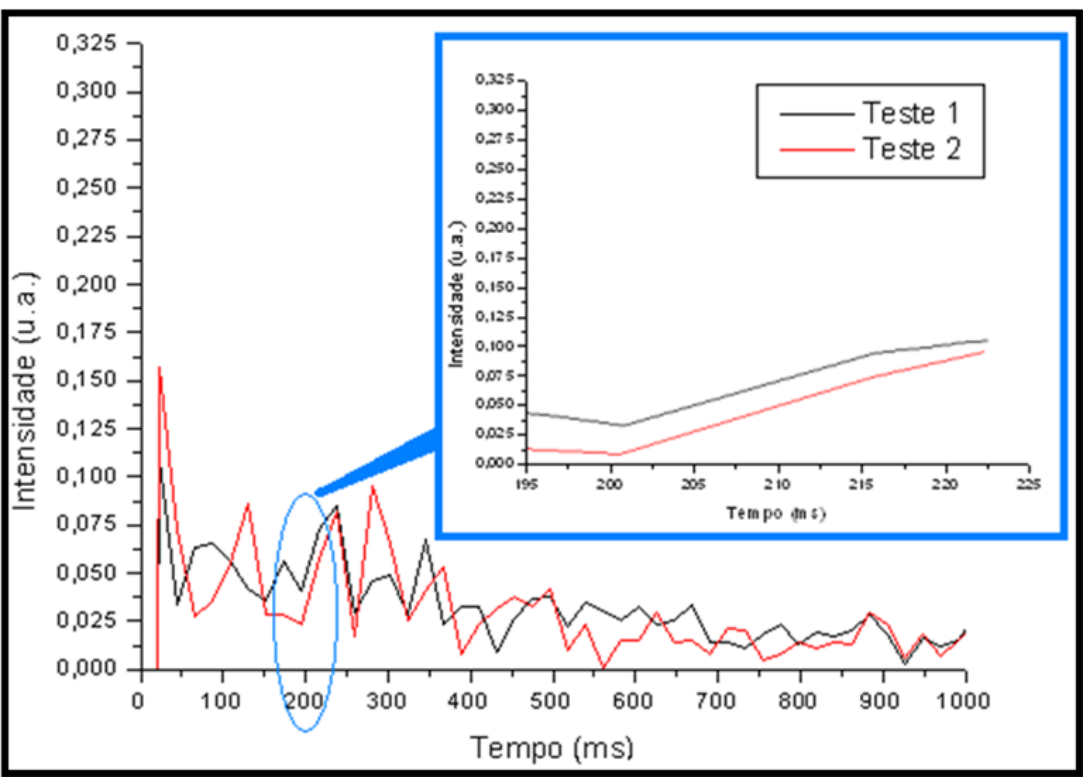

(A)

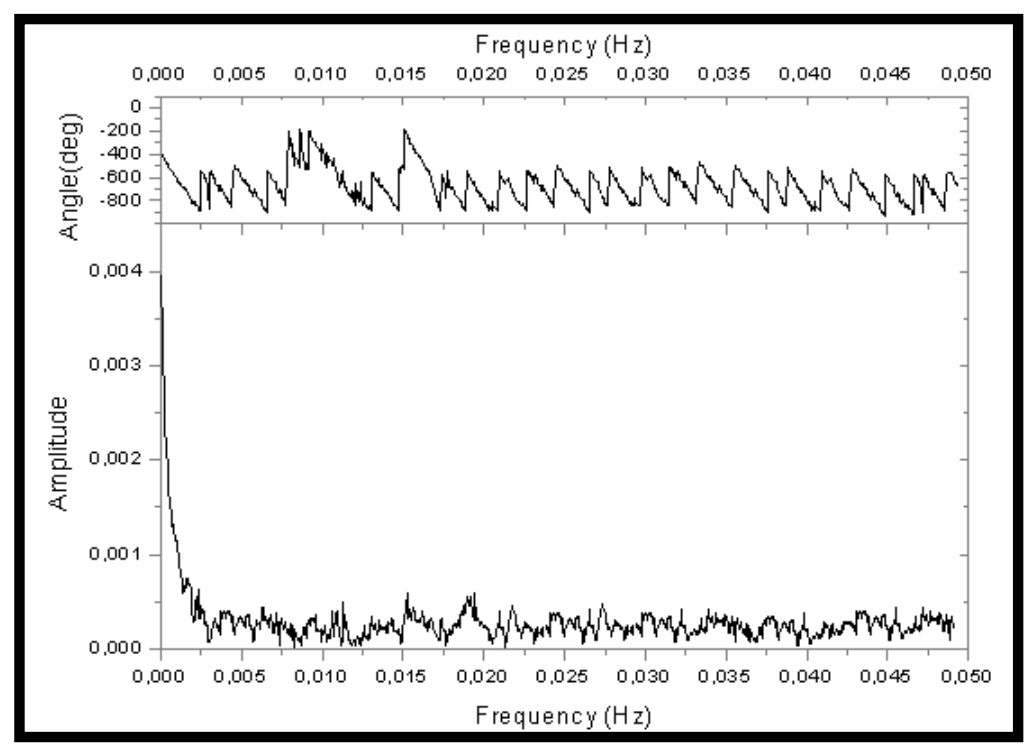

(B)

\section{Gráfico B.2 - (A) Teste e (B) Transformada de Fourier usando apenas o capilar com o mini compressor de ar ligado, usando como reagente isopropanol.}

Como esperado, a resposta não se apresentou semelhante à de uma coluna cromatográfica em nenhuma dessas medidas. O pico é largo se o compressor não está ligado porque não há modo eficiente de remoção do reagente, mas a aplicação da transformada de Fourier não indica a existência de uma frequiência típica.

Seguem os gráficos da intensidade (u.a.) em função do tempo (ms) para inserção de: isopropanol (Gráfico B.3A), n-hexano (Gráfico B.4A), acetona (Gráfico B.5A), gasolina comum (Gráfico B.6A), e mistura composta de etanol, isopropanol e água 33\% em vol. (Gráfico B.7A). E ao lado de cada gráfico da intensidade versus tempo são 
colocados os gráficos referentes à Transformada de Fourier (Gráfico B.3B isopropanol; Gráfico B.4B - n-hexano; Gráfico B.5B - acetona; Gráfico B.6B - gasolina comum; e Gráfico B.7B - mistura composta de etanol, isopropanol e água - 33\% em vol.) das médias dos testes para verificar se o sinal apresenta comportamento oscilatório e, em caso positivo, quais as principais diferenças nas oscilações dos sinais, verificando, assim, as principais freqüências que podem compô-lo.

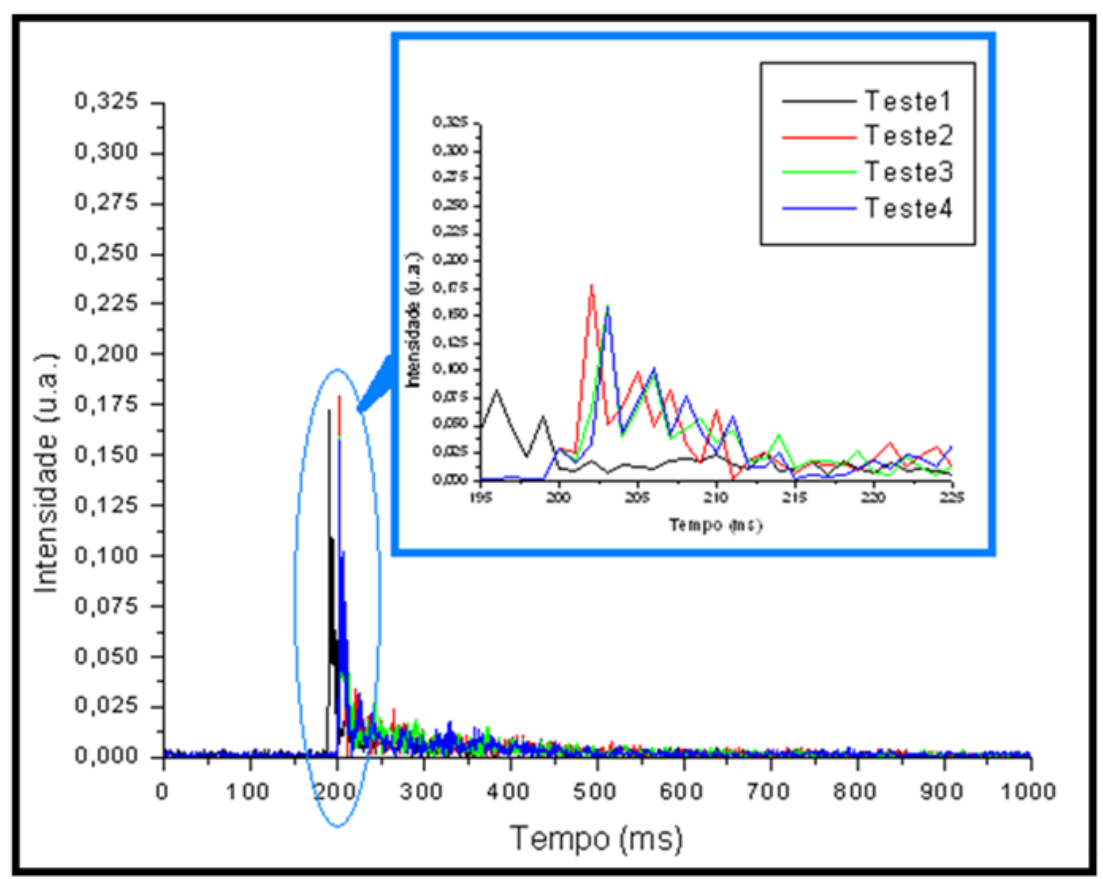

(A)

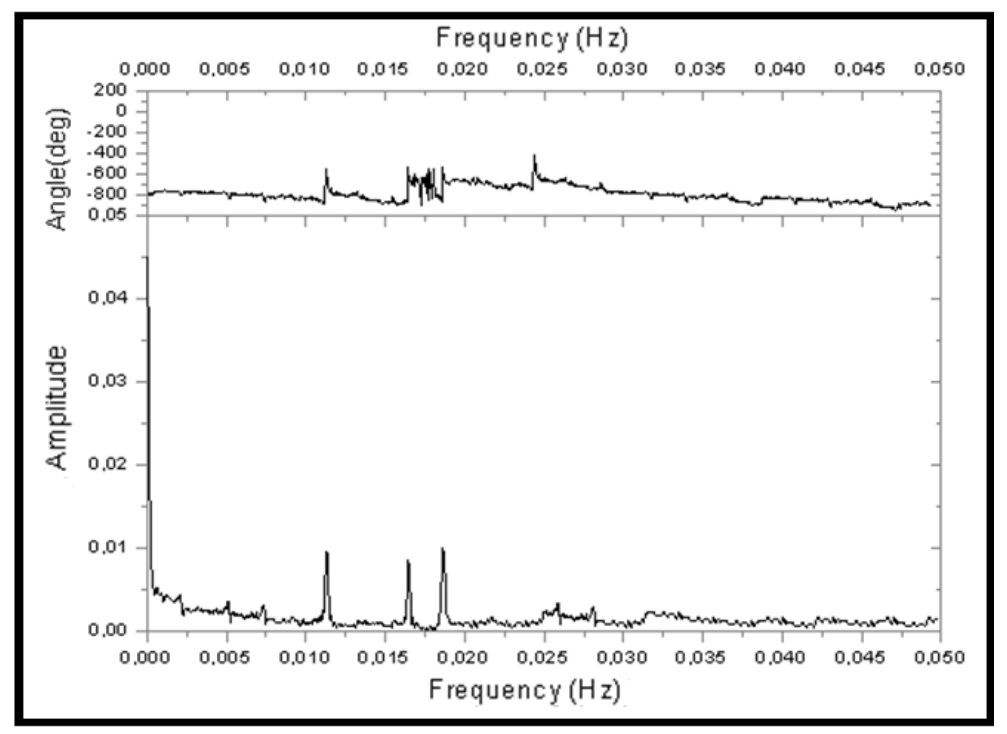

(B)

Gráfico B.3 - (A) Teste e (B) Transformada de Fourier usando a estrutura tridimensional modificada não empacotada, usando como reagente isopropanol. 


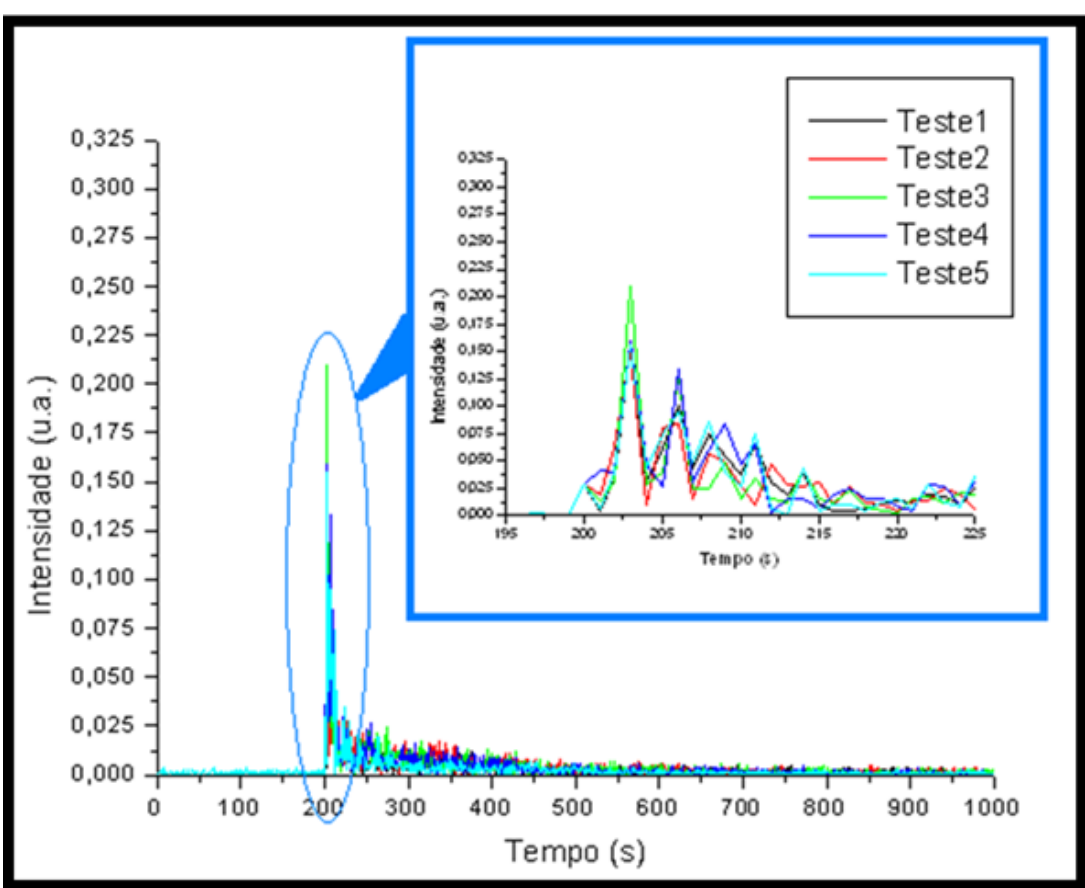

(A)

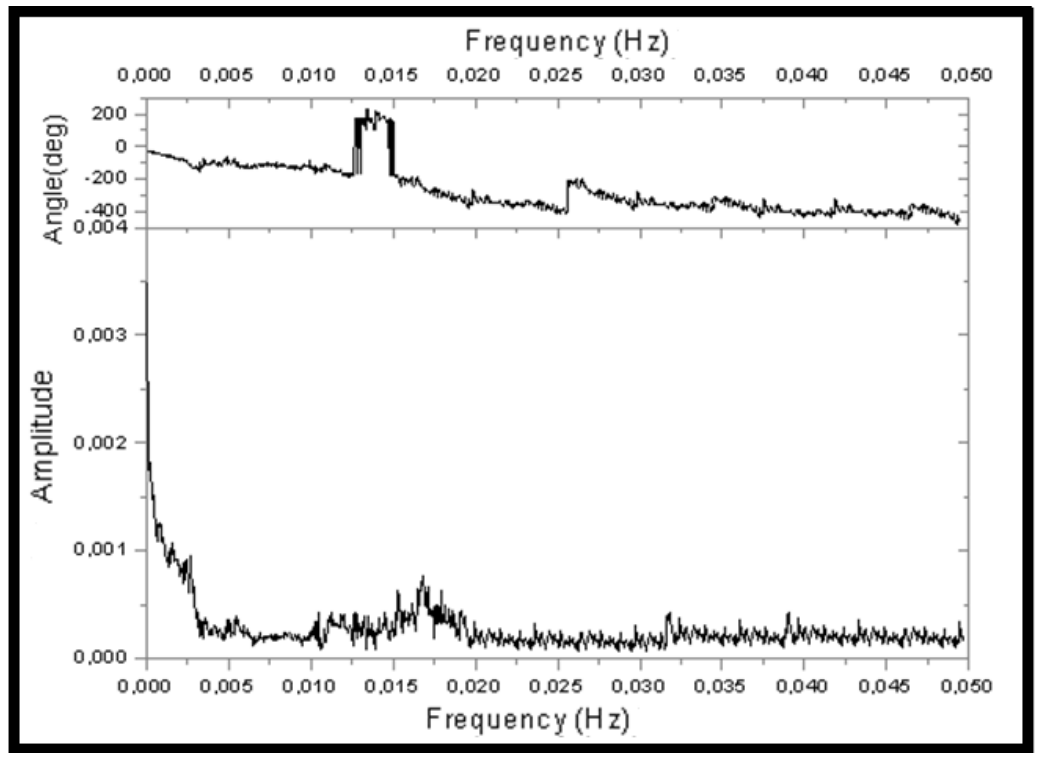

(B)

Gráfico B.4 - (A) Teste e (B) Transformada de Fourier usando a estrutura tridimensional modificada não empacotada, usando como reagente n-hexano. 


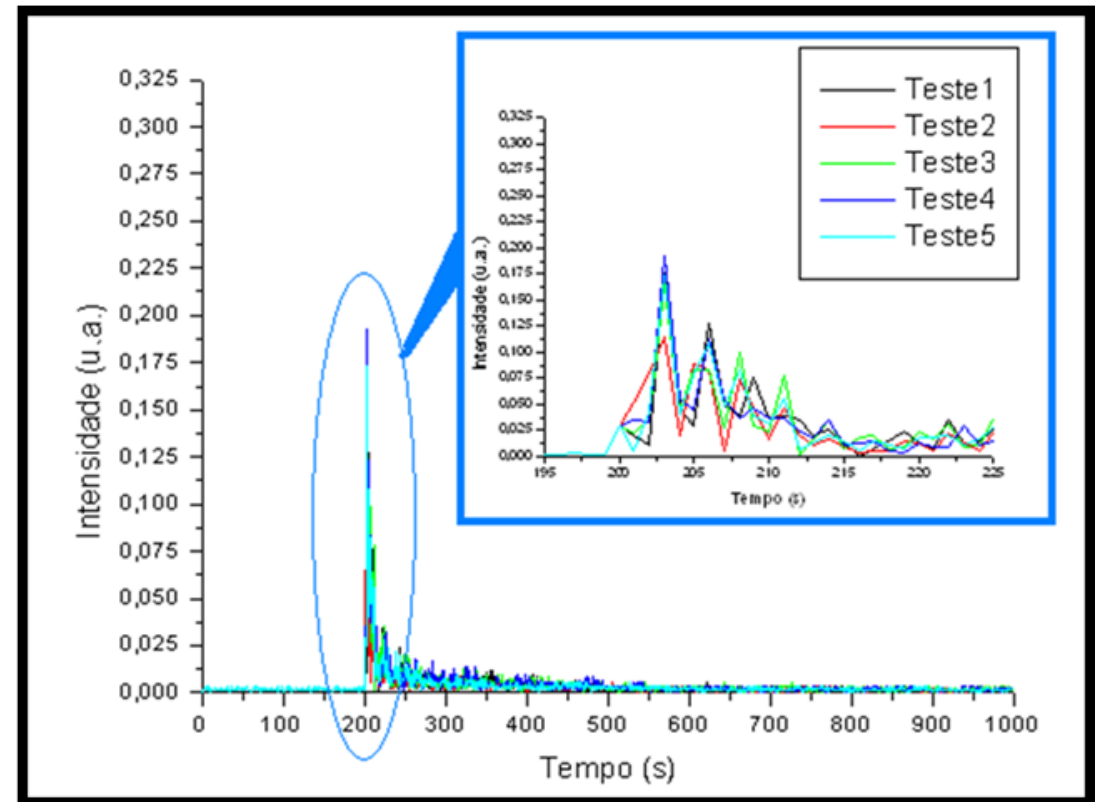

(A)

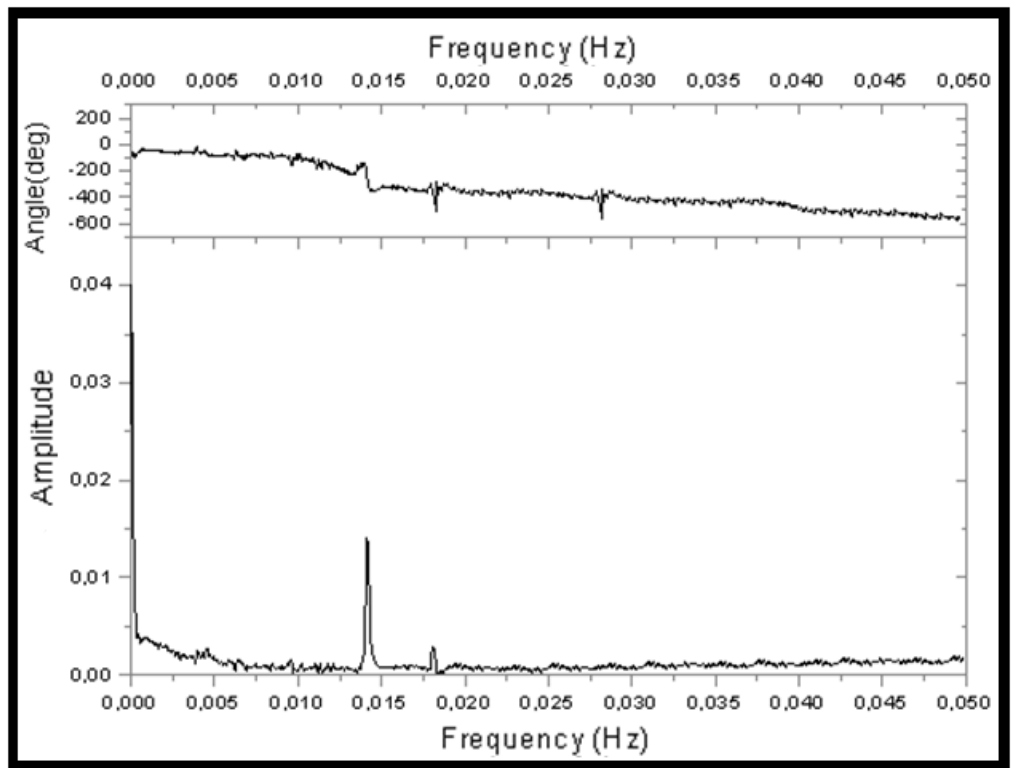

(B)

Gráfico B.5 - (A) Teste e (B) Transformada de Fourier usando a estrutura tridimensional modificada não empacotada, usando como reagente acetona. 


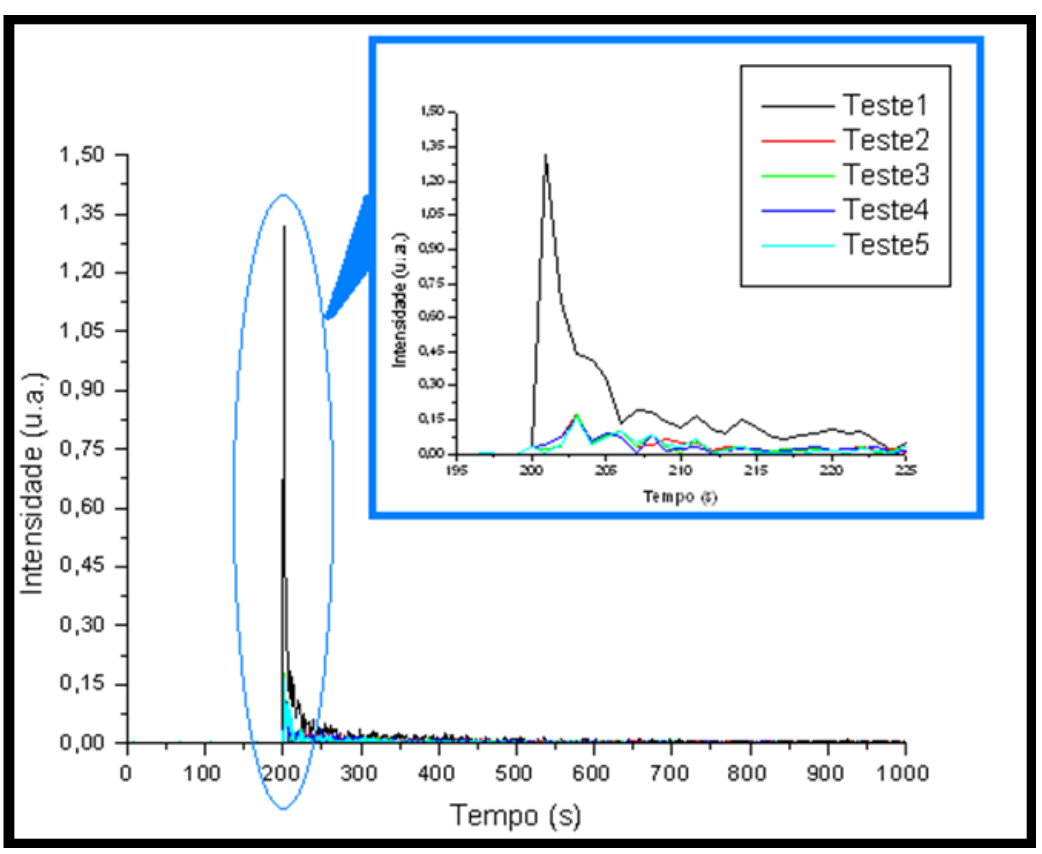

(A)

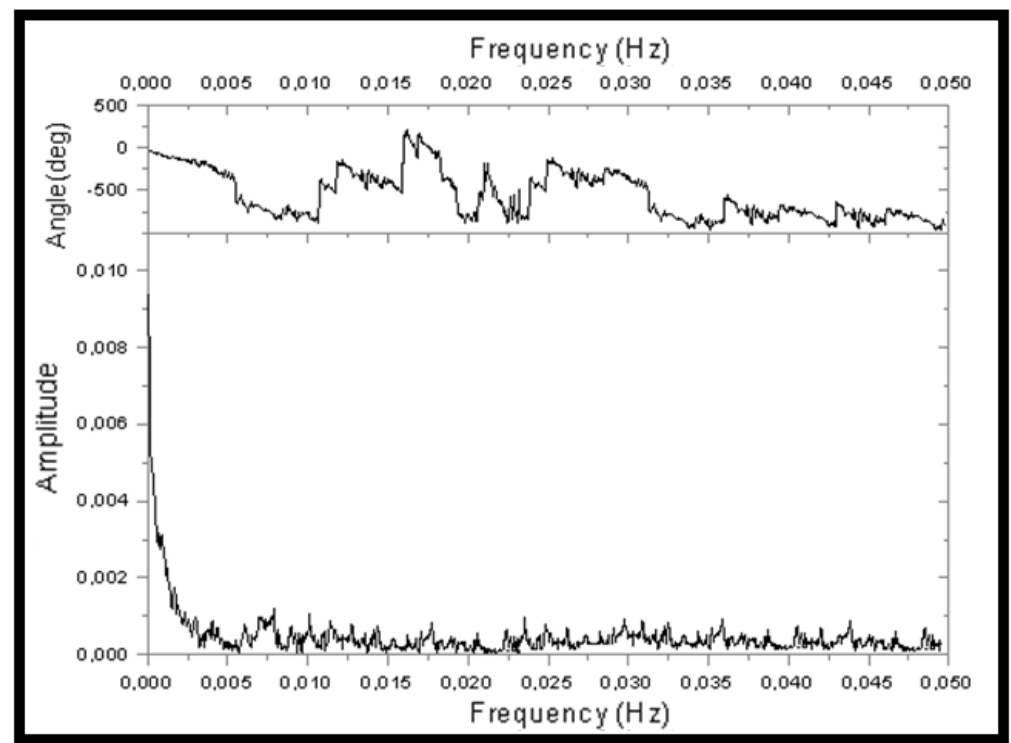

(B)

Gráfico B.6 - (A) Teste e (B) Transformada de Fourier usando a estrutura tridimensional modificada não empacotada, usando como reagente gasolina comum. 


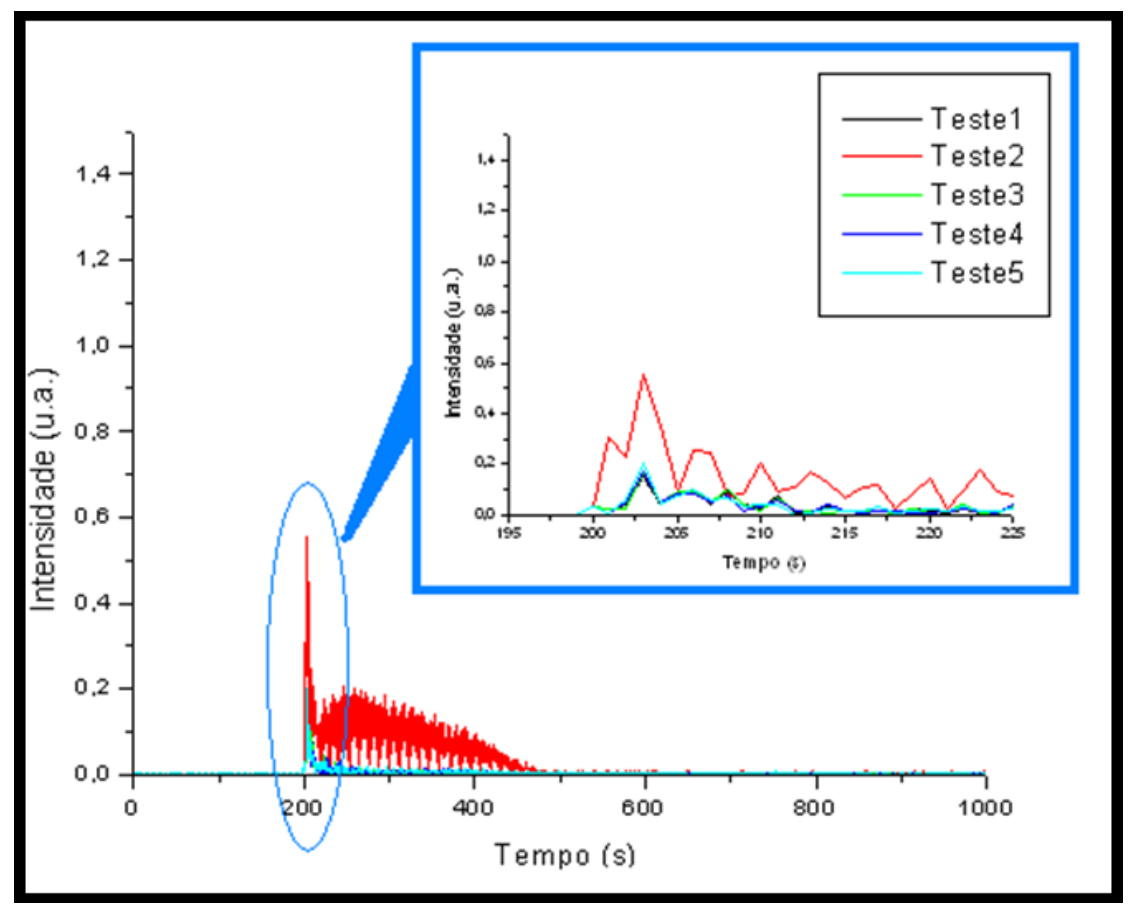

(A)

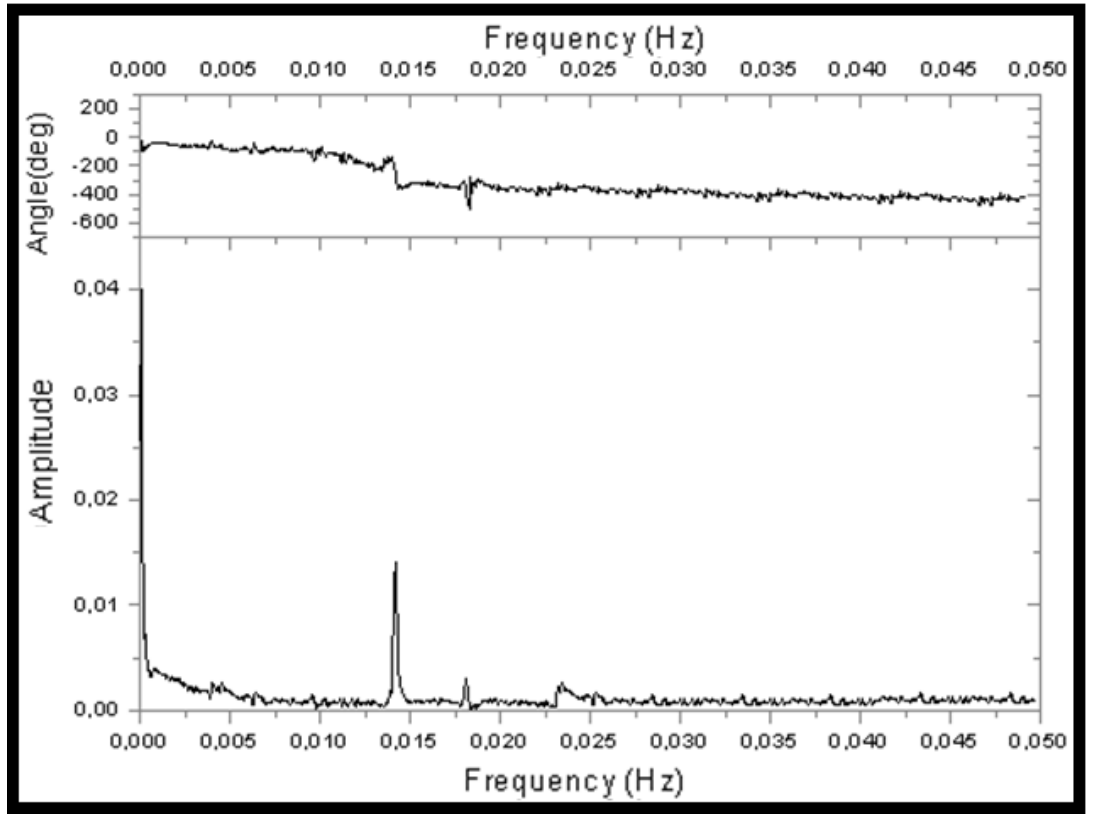

(B)

Gráfico B.7 - (A) Teste e (B) Transformada de Fourier usando a estrutura tridimensional modificada não empacotada, usando como reagente mistura (etanol+isopropanol+água, $33 \%$ em vol.).

Nos gráficos referentes às Transformadas de Fourier as funções denominadas "Frequency" correspondem às freqüências fundamentais obtidas e "angle" correlaciona os respectivos valores das freqüências; assim, a maior importância da informação é a freqüência. $\mathrm{O}$ sinal original foi avaliado por Fourier na sua integridade e também em 
intervalos, considerando ou não o maior pico. De modo geral, desde que o sinal seja considerado nos primeiros $500 \mathrm{~ms}$ (sendo o tempo zero o da injeção), o resultado que se obtém é o mesmo e não há necessidade de "filtros". Para os capilares, ligado ou não ao compressor, não se encontrou uma frequiência característica.

O que se pôde observar é que cada amostra apresenta freqüência(s) distinta(s), o que é coerente com a formação de equilíbrio químico nos canais da estrutura. Contudo, há uma tendência de substâncias puras apresentarem uma ou mais freqüência característica, o mesmo não ocorrendo com as misturas, que apresentam resposta mais dispersa, ou seja, uma região, não um frequiência característica. Para mistura notam-se algumas freqüências semelhantes às obtidas para os reagentes em seu estado considerado como puro, mas apenas em determinadas faixas, e em geral, na ordem de porcentagem para cada reagente.

No Gráfico B.7, por exemplo, há a predominância da freqüência encontrada para isopropanol, mesmo a mistura apresentando quantidades iguais (em vol.) ou próximas (em massa) de cada reagente. Isto pode estar ocorrendo devido à maior volatilidade de alguns dos reagentes, que facilita a saída dos canais, o que também explicaria a dificuldade de se obter picos bem definidos para acetona e gasolina.

\section{B.1.1.1.2 Estrutura empacotada}

Testes com a estrutura empacotada mostraram resultados semelhantes aos obtidos com a não empacotada e são apresentados nos gráficos da intensidade (u.a.) em função do tempo (ms) para reagentes como: isopropanol (Gráfico B.8A), n-hexano (Gráfico B.9A), acetona (Gráfico B.10A), gasolina comum (Gráfico B.11A), e mistura composta de etanol, isopropanol e água - 33\% em vol. (Gráfico B.12A). Ao lado de cada gráfico da intensidade versus tempo são colocados os gráficos referentes à Transformada de Fourier (Gráfico B.8B - isopropanol; Gráfico B.9B - n-hexano; Gráfico B.10B - acetona; Gráfico B.11B - gasolina comum; e Gráfico B.12B - mistura composta de etanol, isopropanol e água - 33\% em vol.) das médias dos testes para verificar quais as principais diferenças nas oscilações dos sinais, verificando, assim, as principais freqüências que podem compô-lo. 


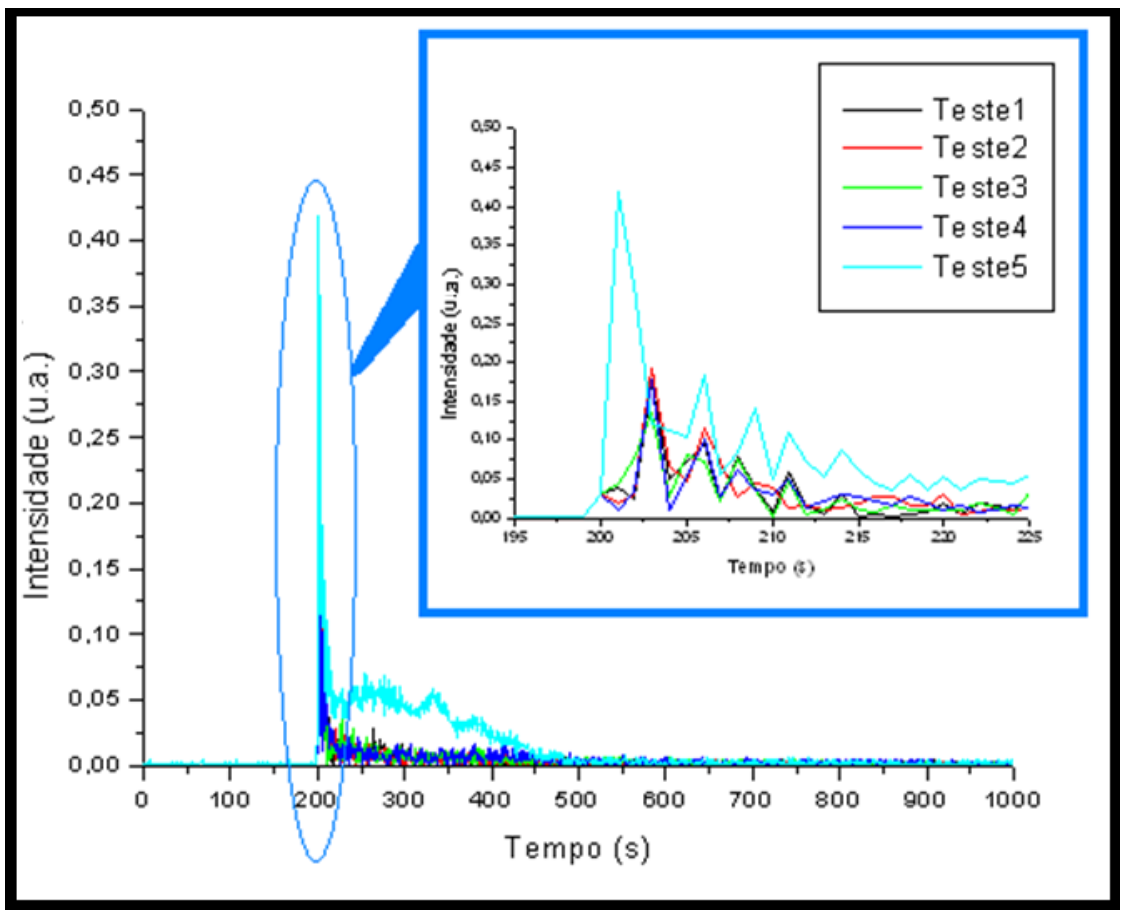

(A)

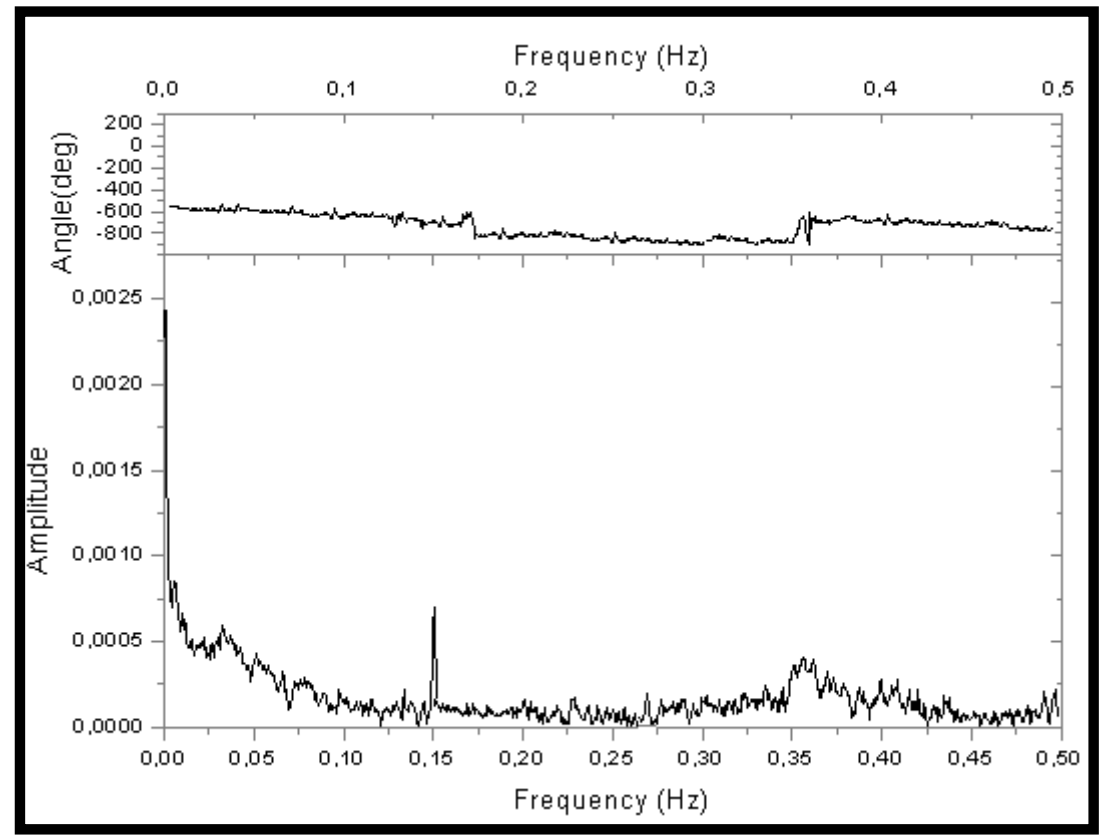

(B)

Gráfico B.8 - (A) Teste e (B) Transformada de Fourier usando a estrutura tridimensional modificada empacotada, usando como reagente isopropanol. 


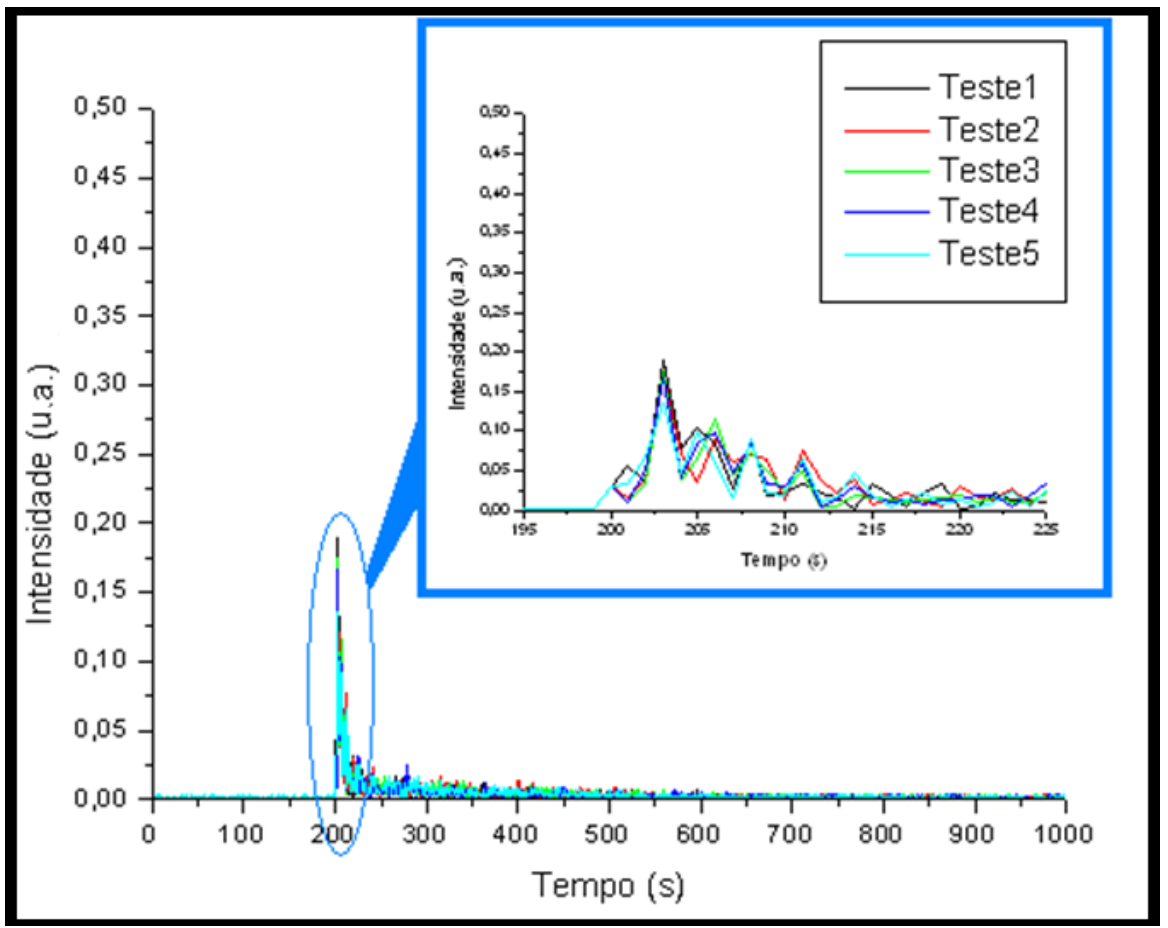

(A)

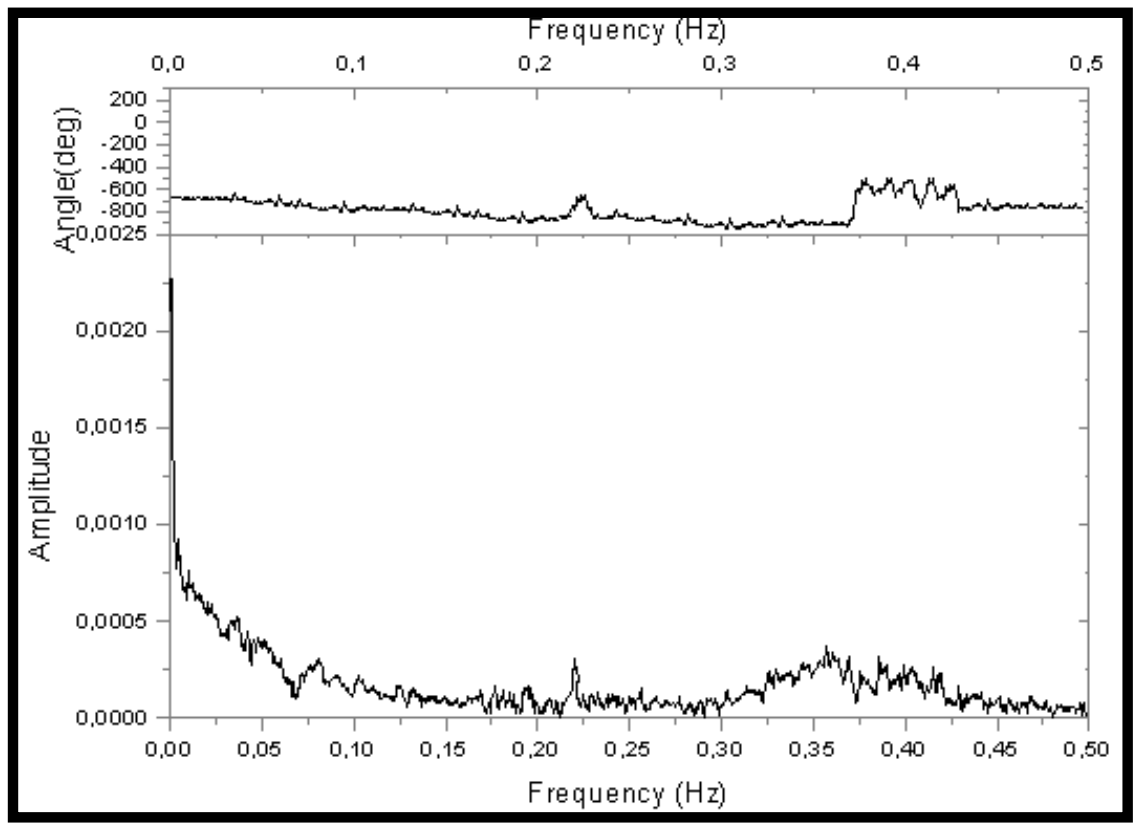

(B)

Gráfico B.9 - (A) Teste e (B) Transformada de Fourier usando a estrutura tridimensional modificada empacotada, usando como reagente n-hexano. 


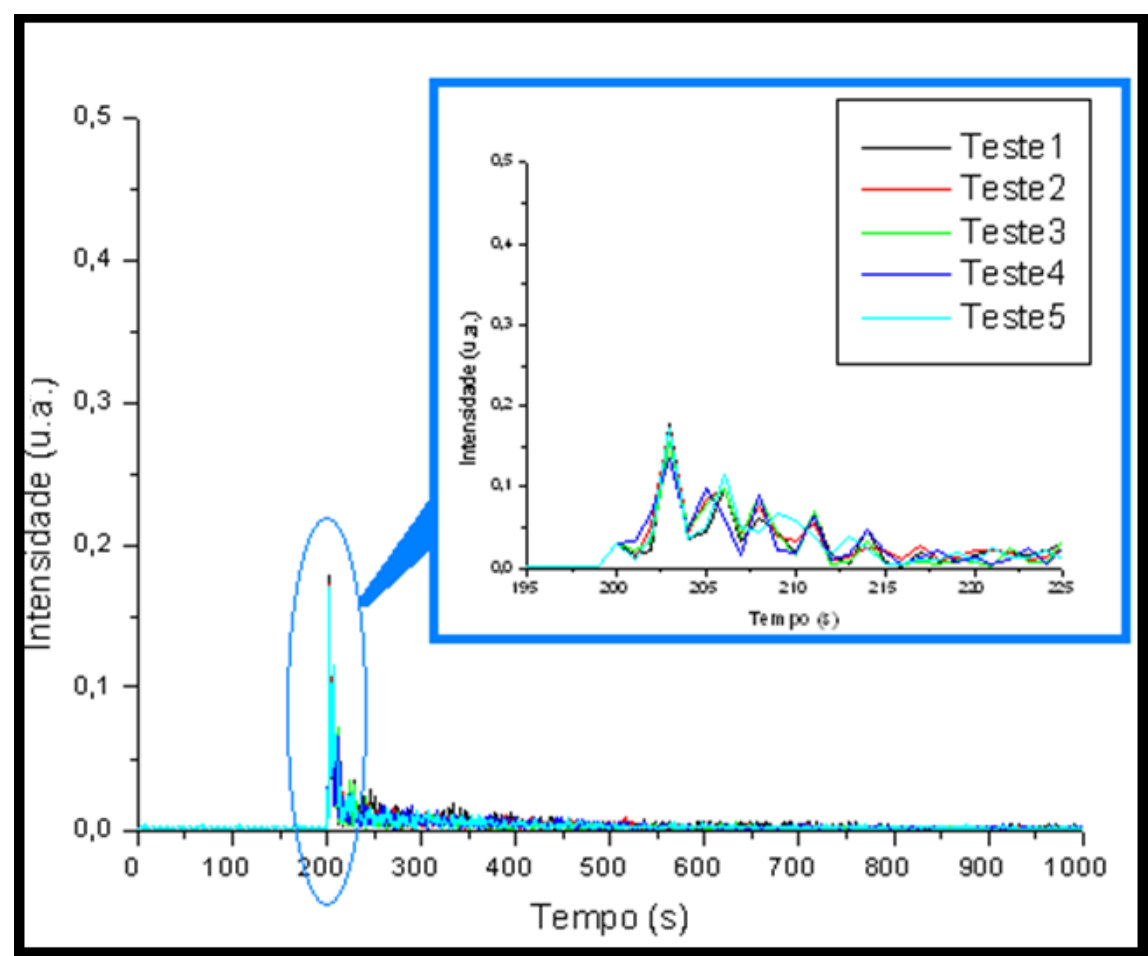

(A)

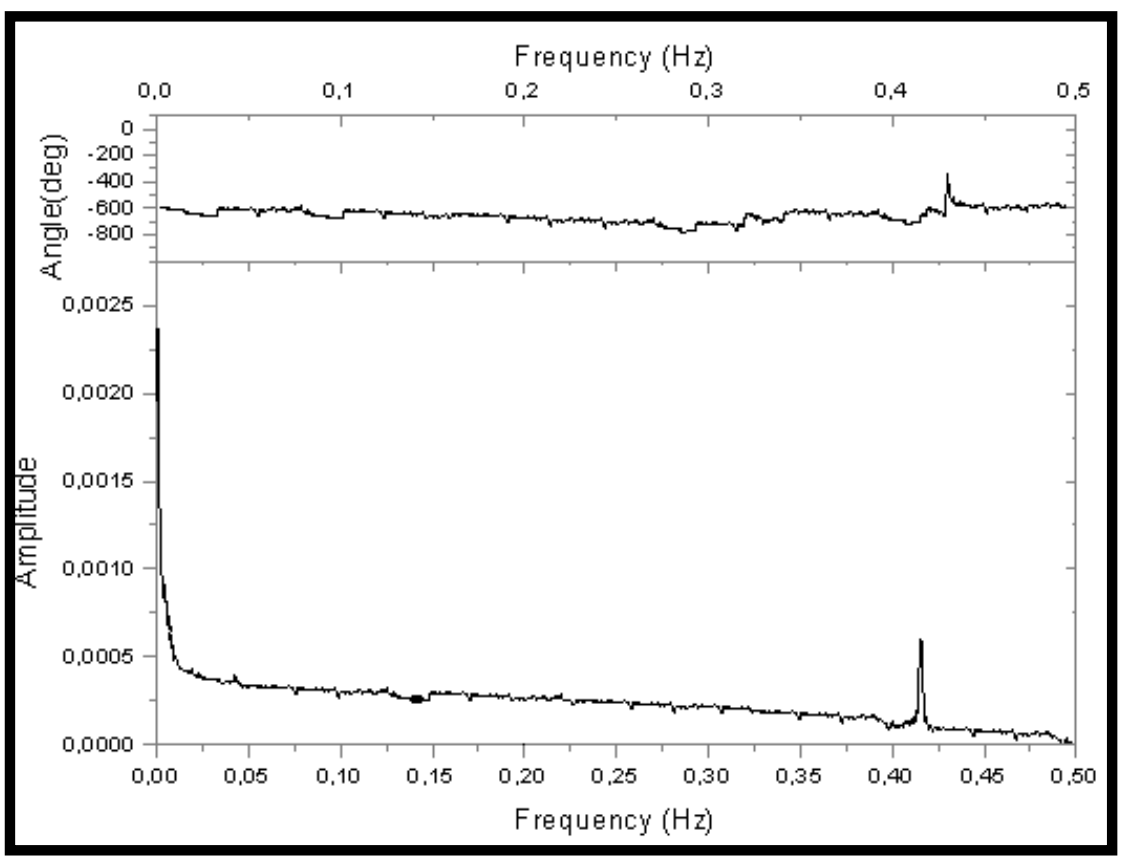

(B)

Gráfico B.10 - (A) Teste e (B) Transformada de Fourier usando a estrutura tridimensional modificada empacotada, usando como reagente acetona. 


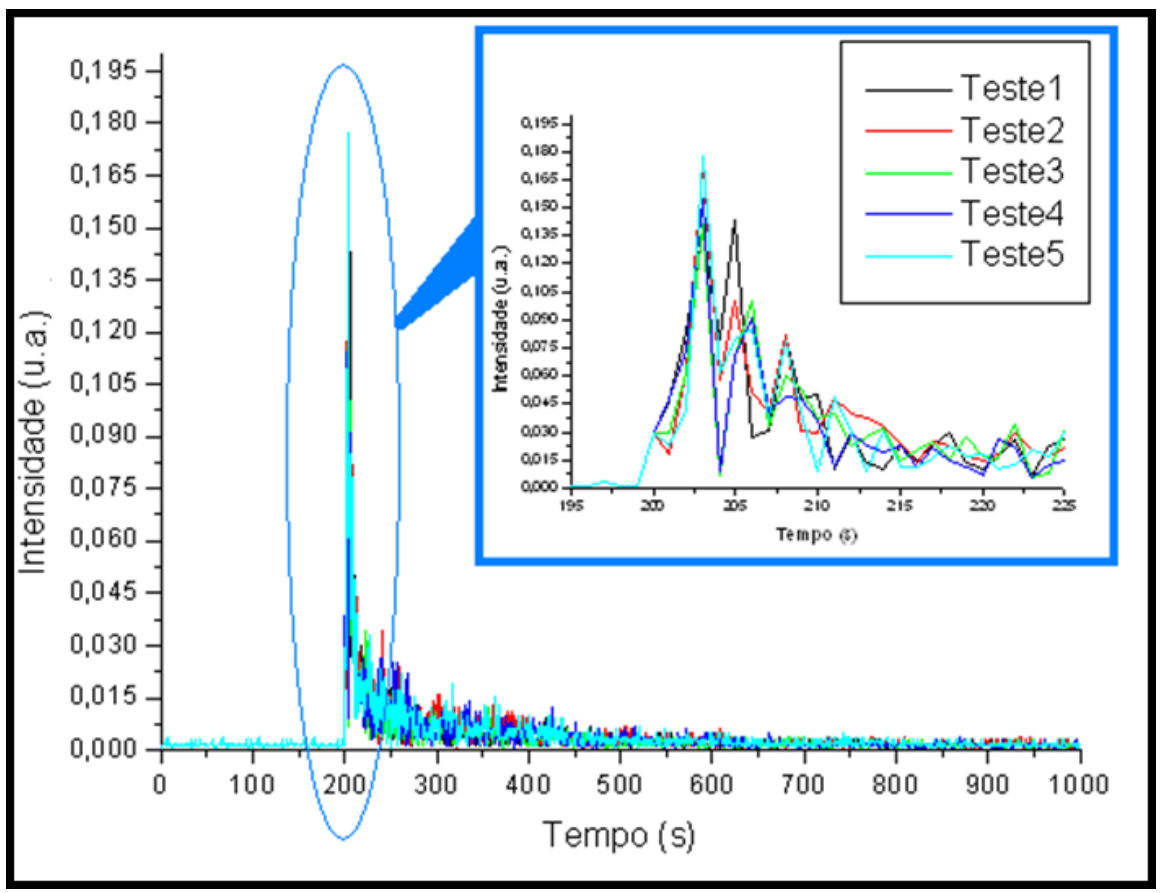

(A)

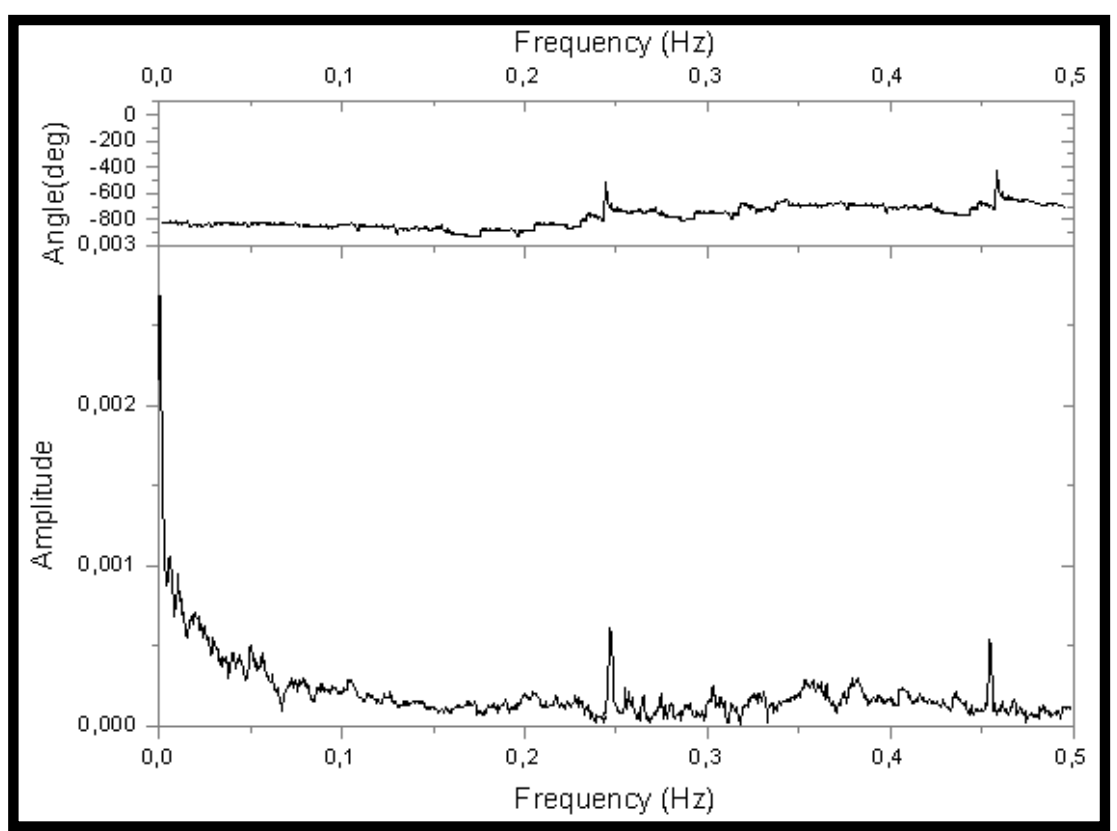

(B)

Gráfico B.11 - (A) Teste e (B) Transformada de Fourier usando a estrutura tridimensional modificada empacotada, usando como reagente gasolina comum. 


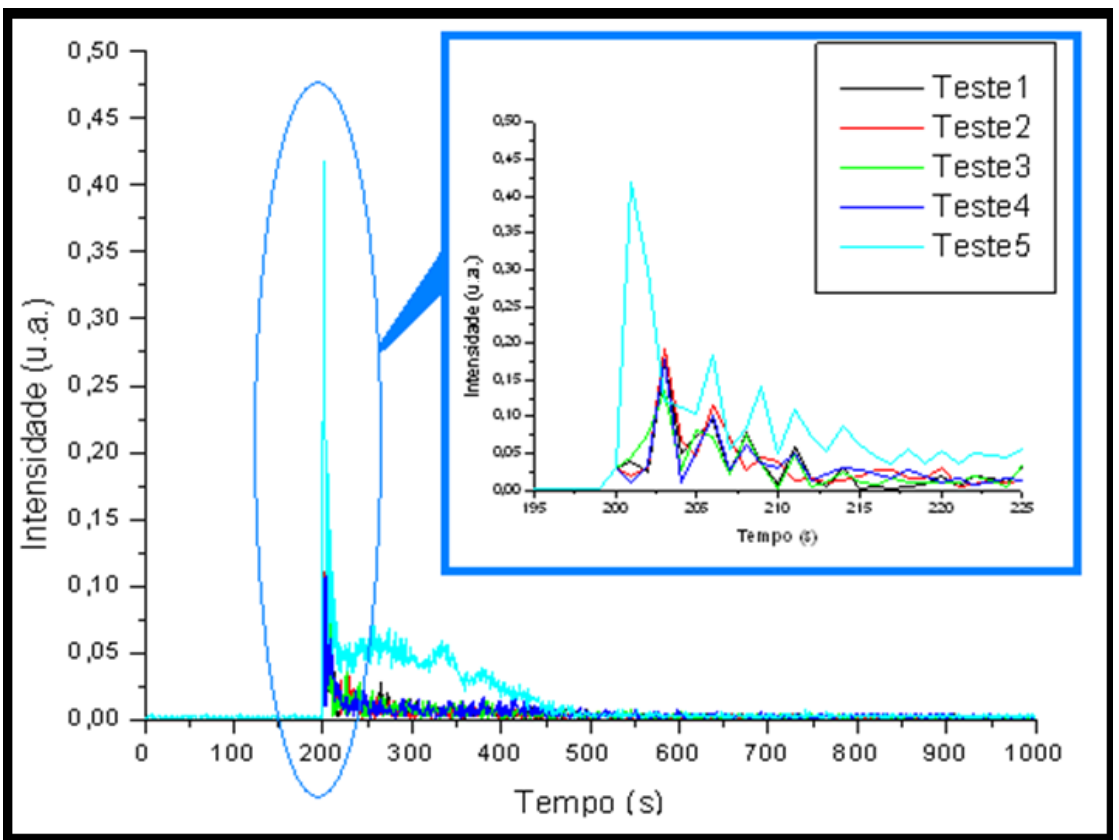

(A)

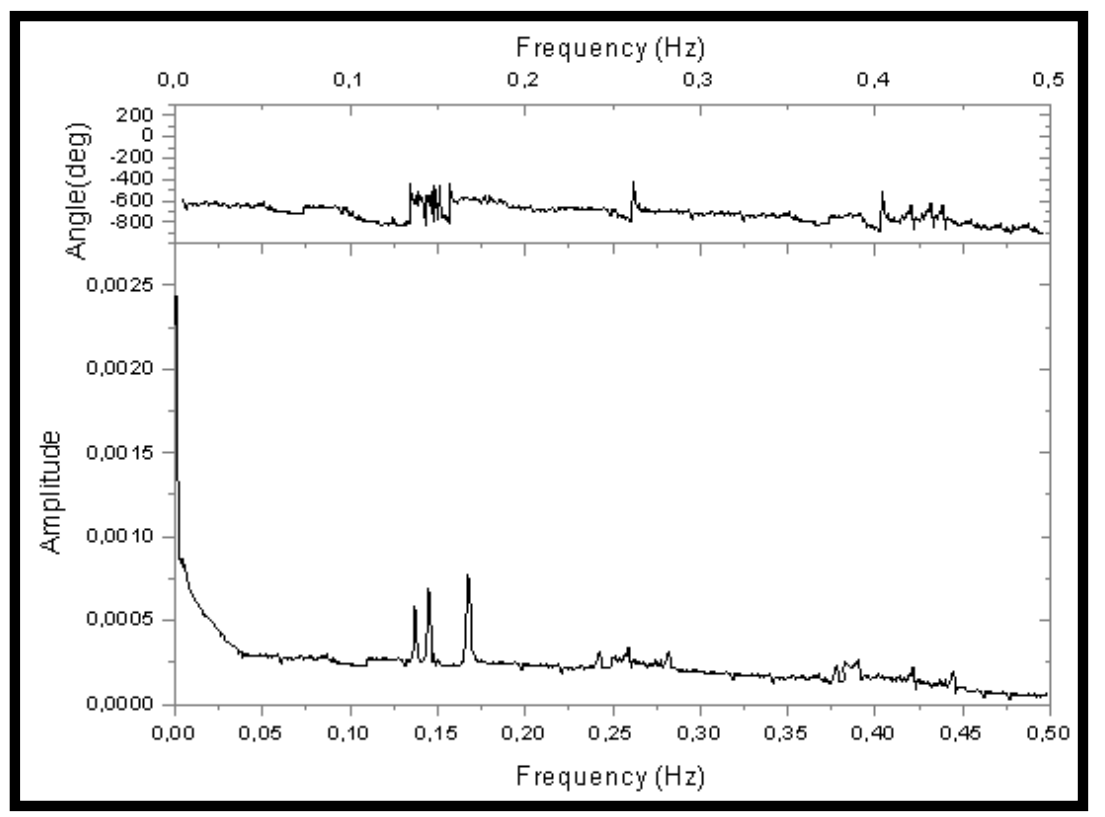

(B)

\section{Gráfico B.12 - (A) Teste e (B) Transformada de Fourier usando a estrutura tridimensional modificada empacotada, usando como reagente mistura (etanol+isopropanol+água, $33 \%$ em vol.).}

O comportamento cíclico persiste, mas é menos evidente que na estrutura não empacotada. Isto se reflete nos respectivos gráficos da Transformada de Fourier, onde se observa a menor dependência do reagente com a respectiva freqüência obtida. $O$ empacotamento dificulta o equilíbrio nos microcanais, em contra partida, pode facilitar a interação para a formação de misturas, isto pode estar vinculado à formação de caminhos preferenciais já que a simulação mostrou a tendência do fluido de percorrer os 
canais, preferencialmente, próximo à superfície e não no centro ou no entorno das partículas.

\section{B.1.1.2 Testes com aquecimento}

\section{B.1.1.2.1 Gasolinas de postos diferentes: não empacotada}

Resultados típicos são apresentados nos gráficos a seguir para a estrutura não empacotada e gasolina de três postos distintos (Gráficos B.13 a B.15) além de mistura com isopropanol (Gráfico B.16). Para esse caso, novamente as condições em que mistura e o reagente são diferenciados encontra-se na faixa de porcentagem. 


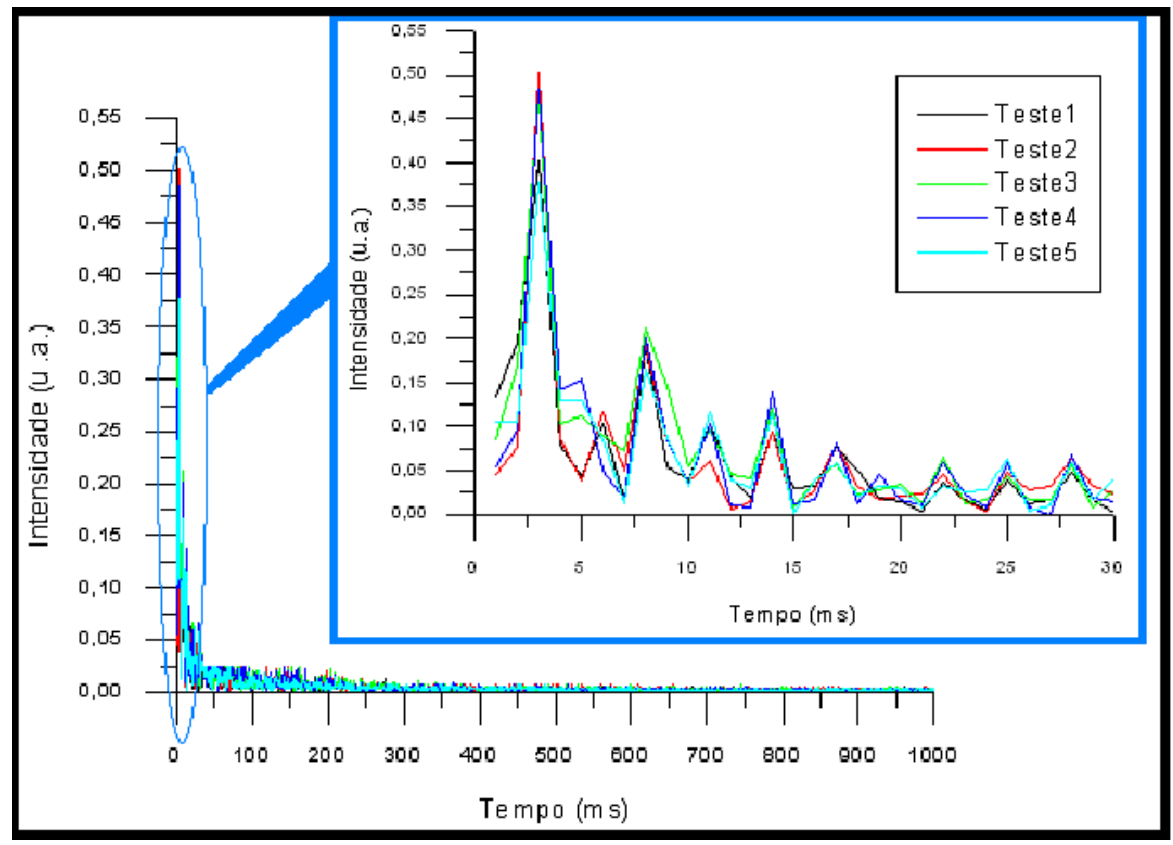

(A)

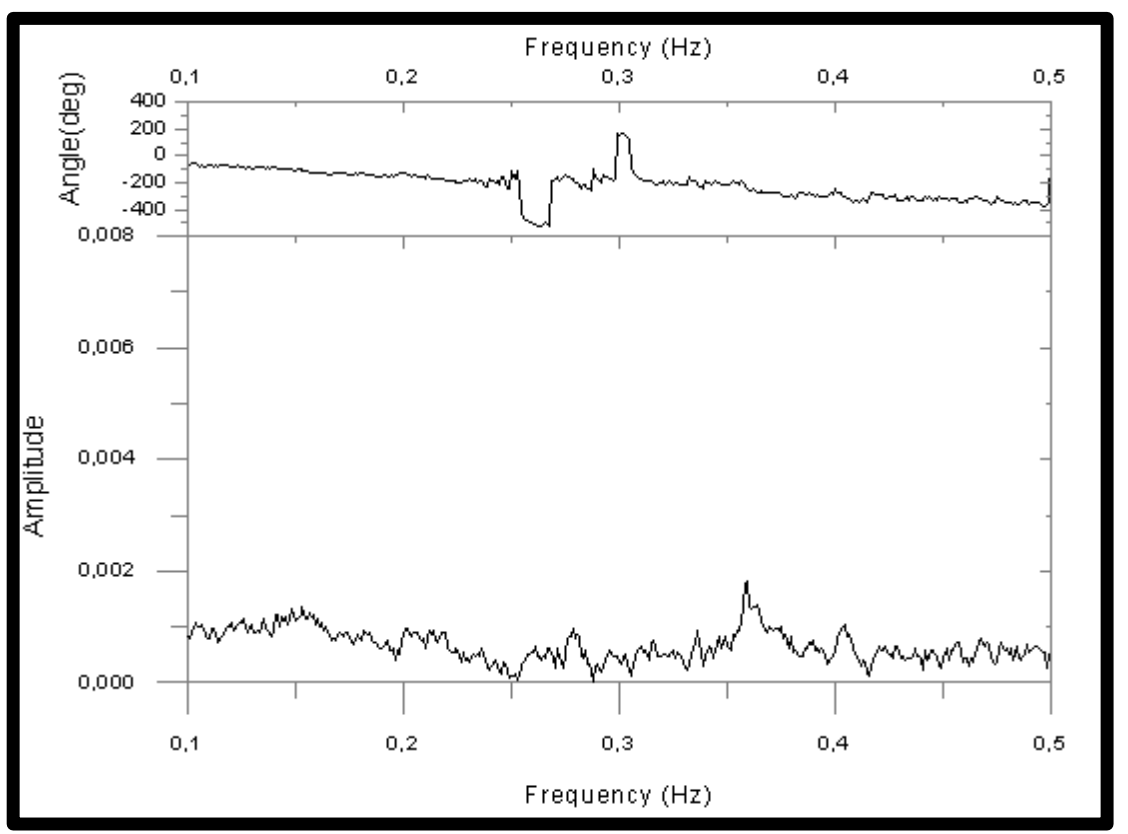

(B)

Gráfico B.13 - (A) Teste e (B) Transformada de Fourier usando a estrutura tridimensional modificada não empacotada, usando como reagente gasolina comum (posto 1). 


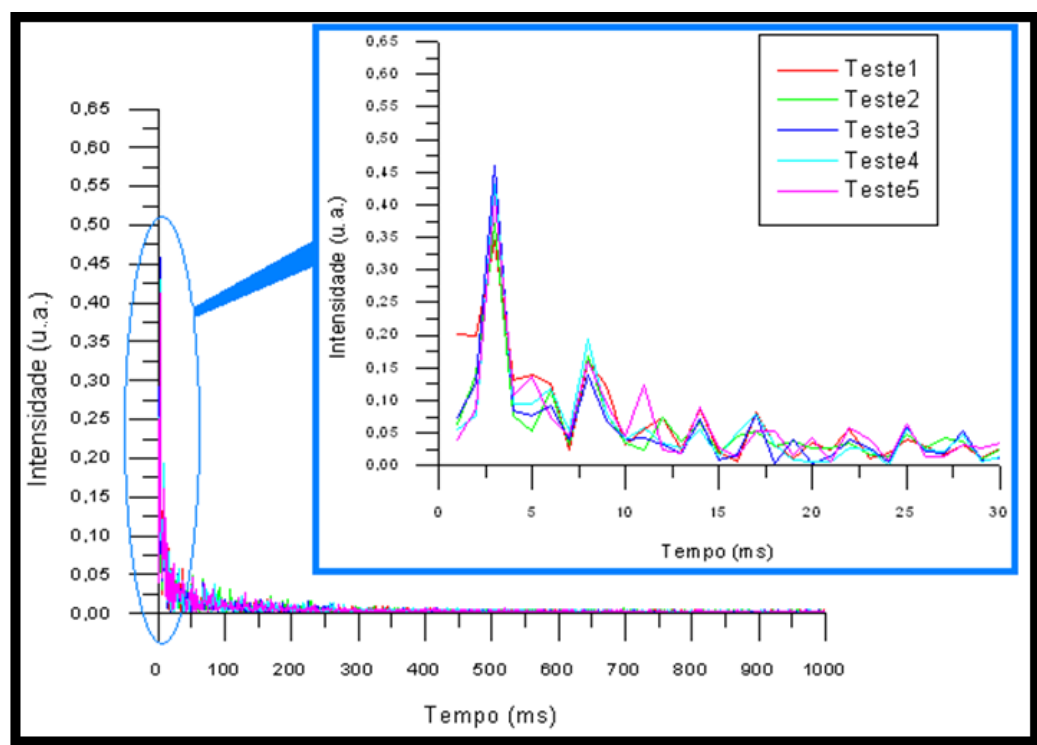

(A)

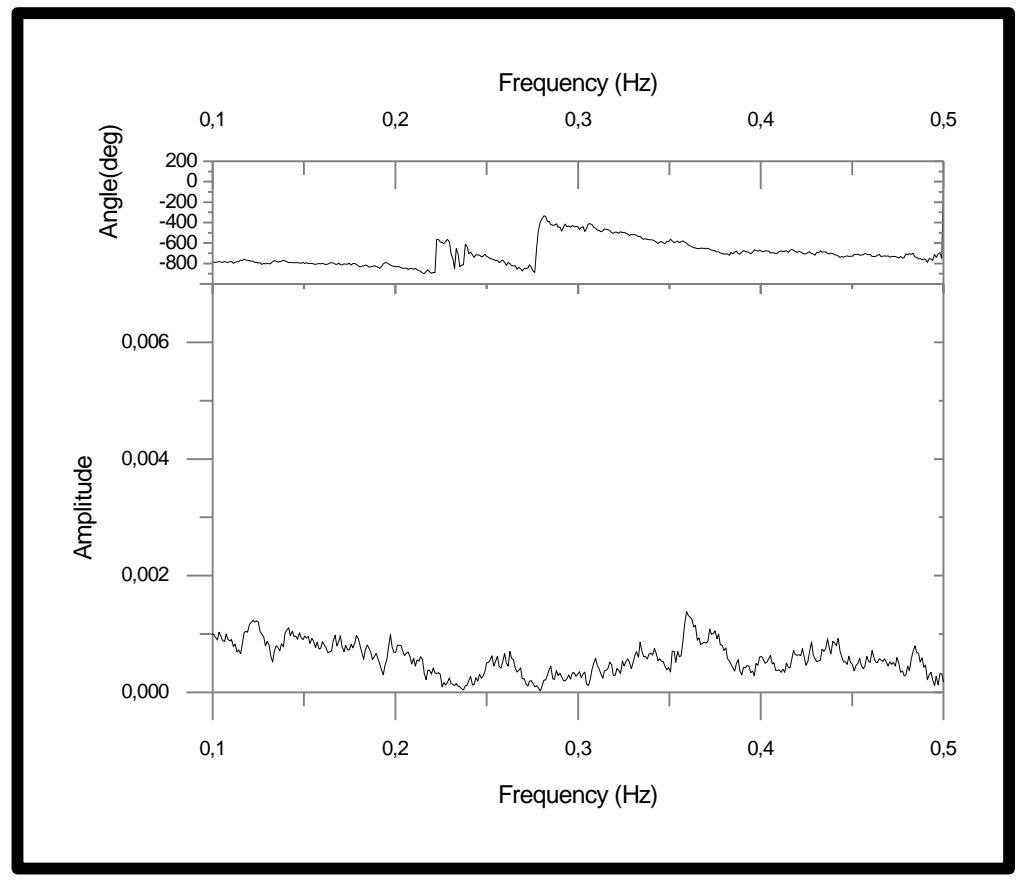

(B)

Gráfico B.14 - (A) Teste e (B) Transformada de Fourier usando a estrutura tridimensional modificada não empacotada, usando como reagente gasolina comum (posto 2). 


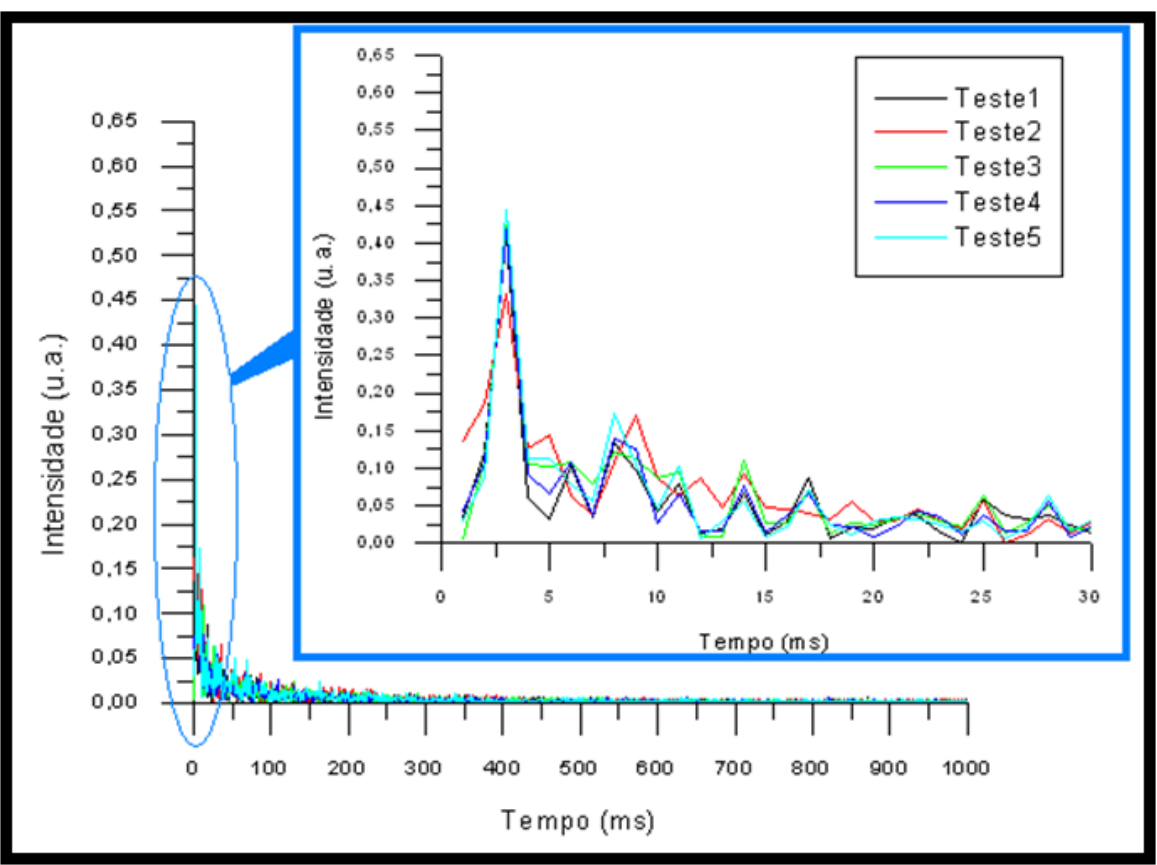

(A)

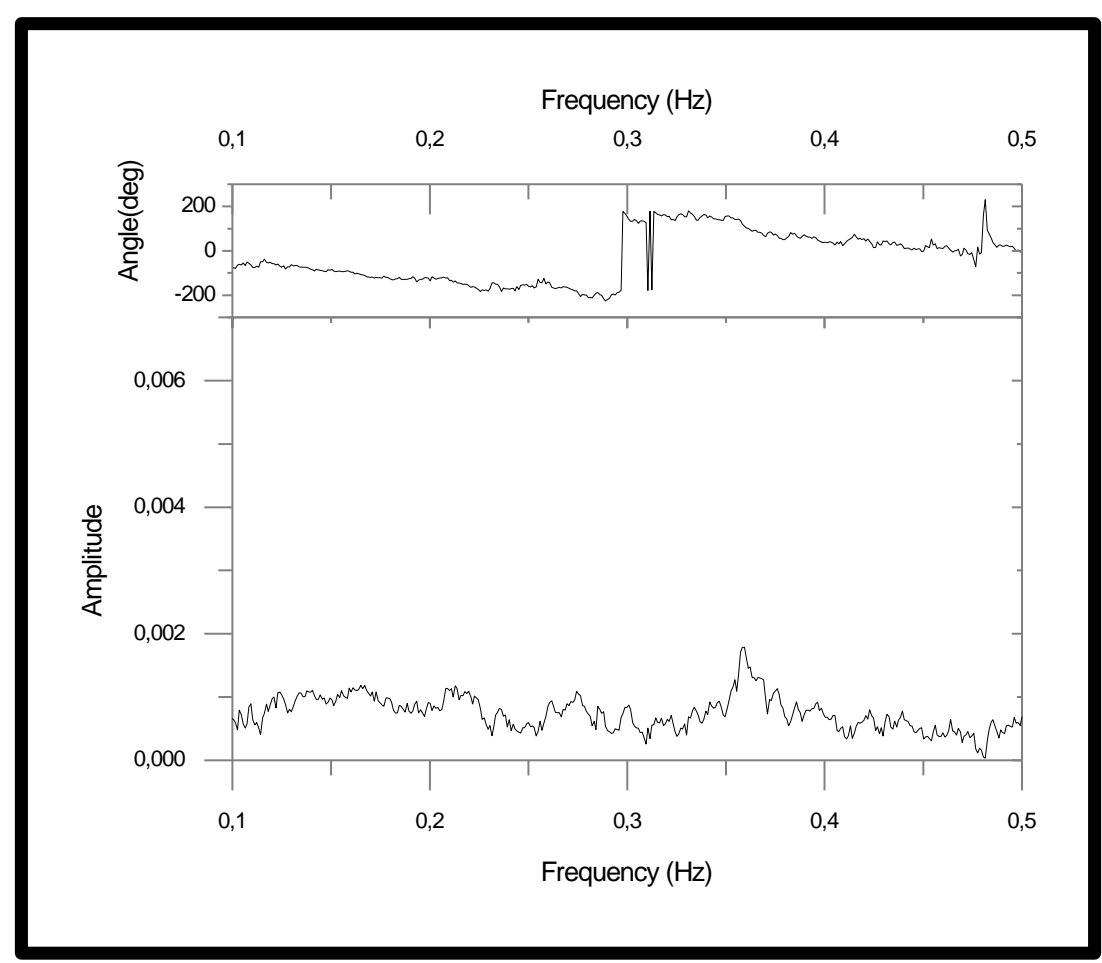

(B)

Gráfico B.15 - (A) Teste e (B) Transformada de Fourier usando a estrutura tridimensional modificada não empacotada, usando como reagente gasolina comum (posto 3). 
XL

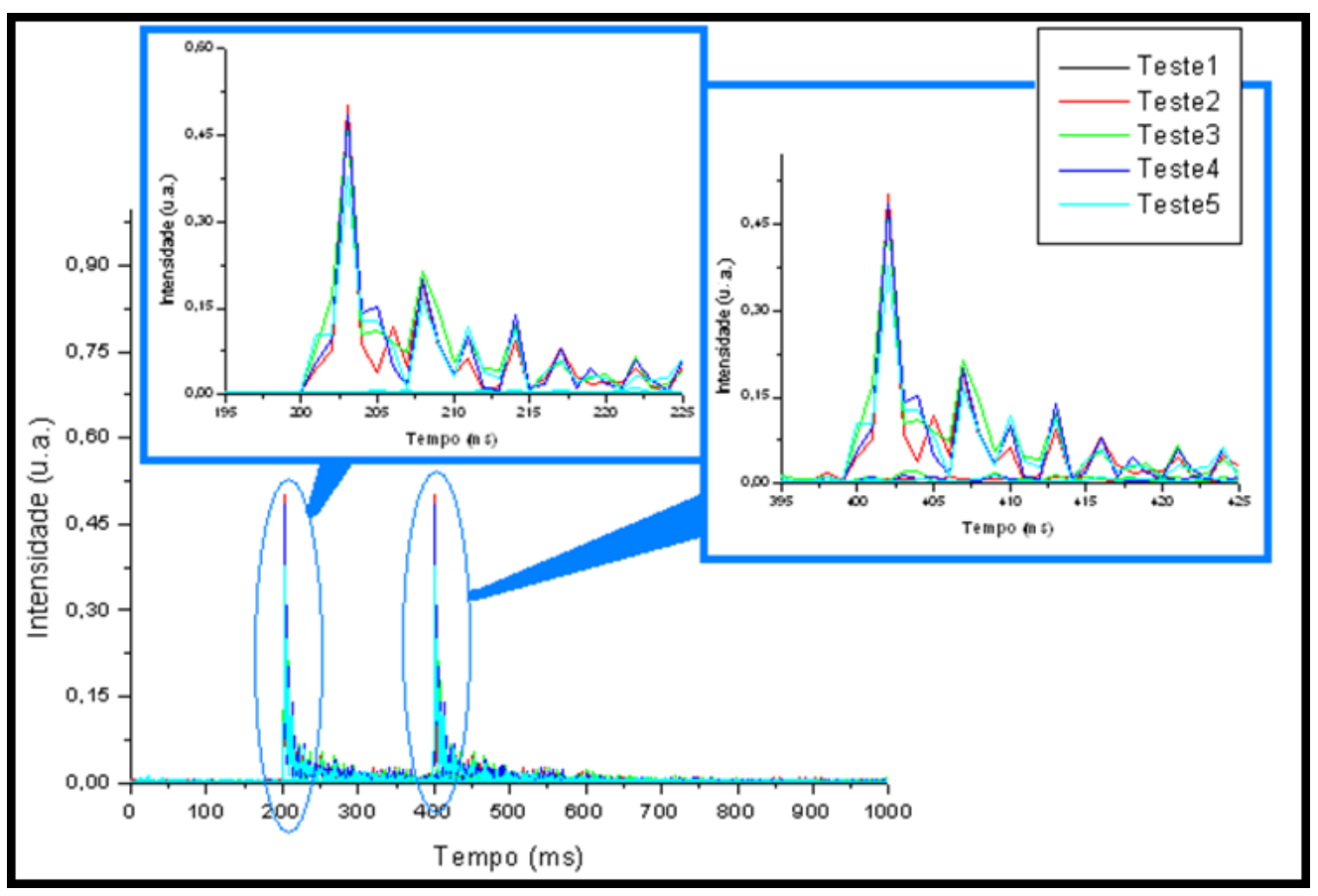

(A)

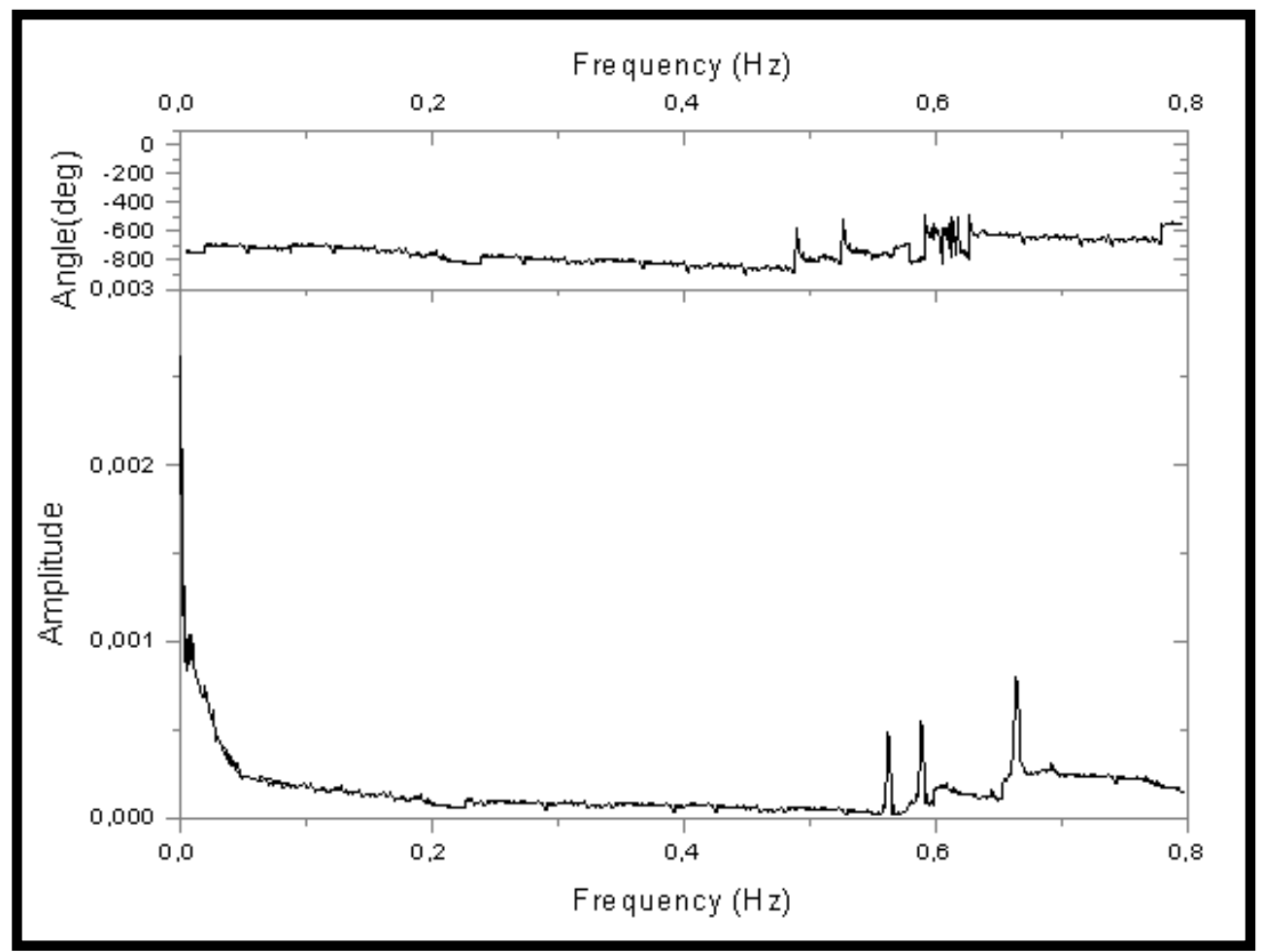

(B)

Gráfico B.16 - (A) Teste e (B) Transformada de Fourier usando a estrutura tridimensional modificada não empacotada, usando como reagente gasolina com isopropanol (posto 1). 


\section{B.1.1.2.2 Gasolinas de postos diferentes: empacotada}

Repetiram-se os testes na estrutura empacotada para avaliar a capacidade de retenção e/ou separação da estrutura. Seguem os gráficos referentes aos testes usando a estrutura empacotada a temperatura ambiente. Tanto para estrutura não empacotada quanto para empacotada percebe-se que há diferença entre os gráficos para as diferentes amostras; além disso, há semelhanças entre os gráficos obtidos com a gasolina misturada ou não a isopropanol. 


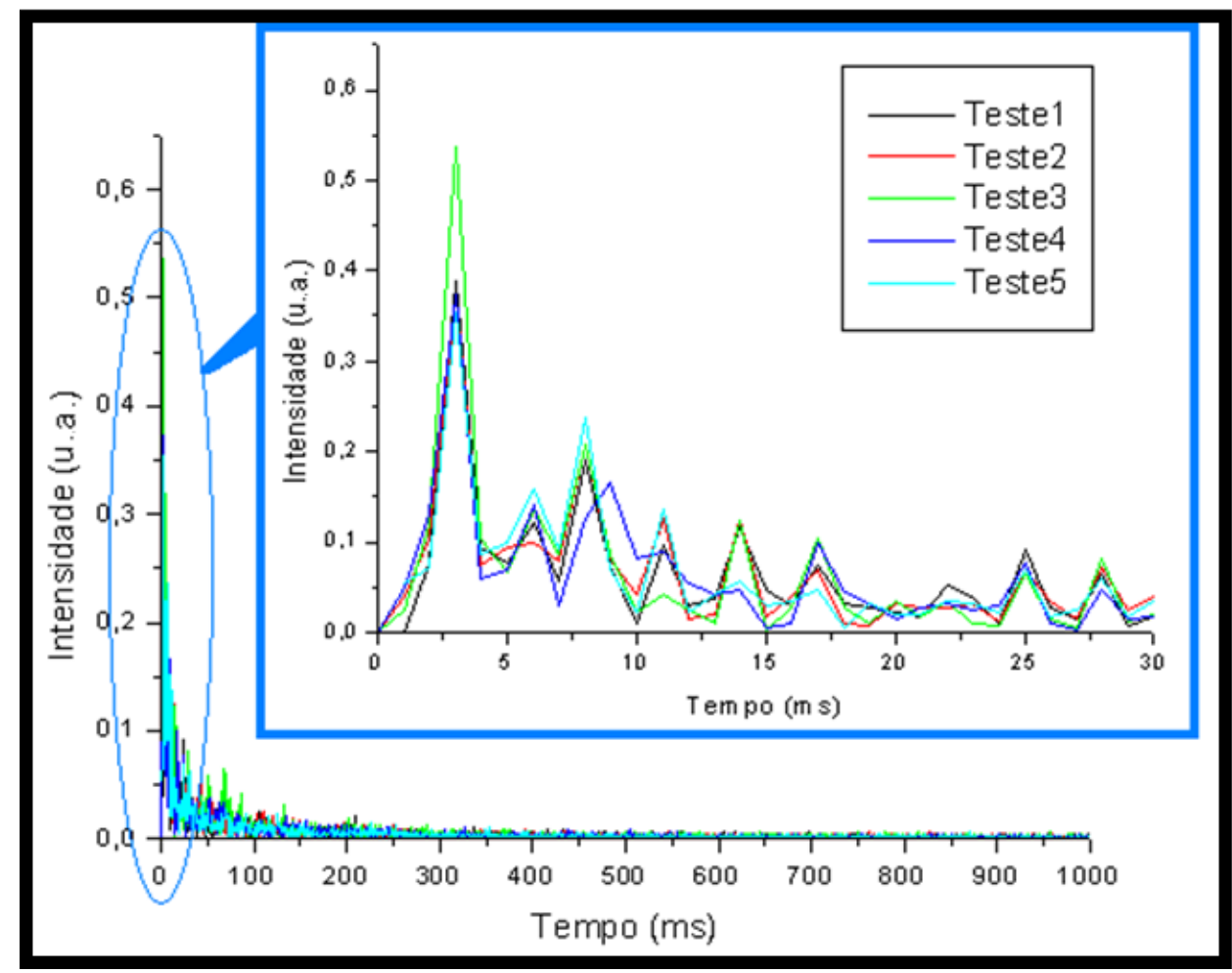

(A)

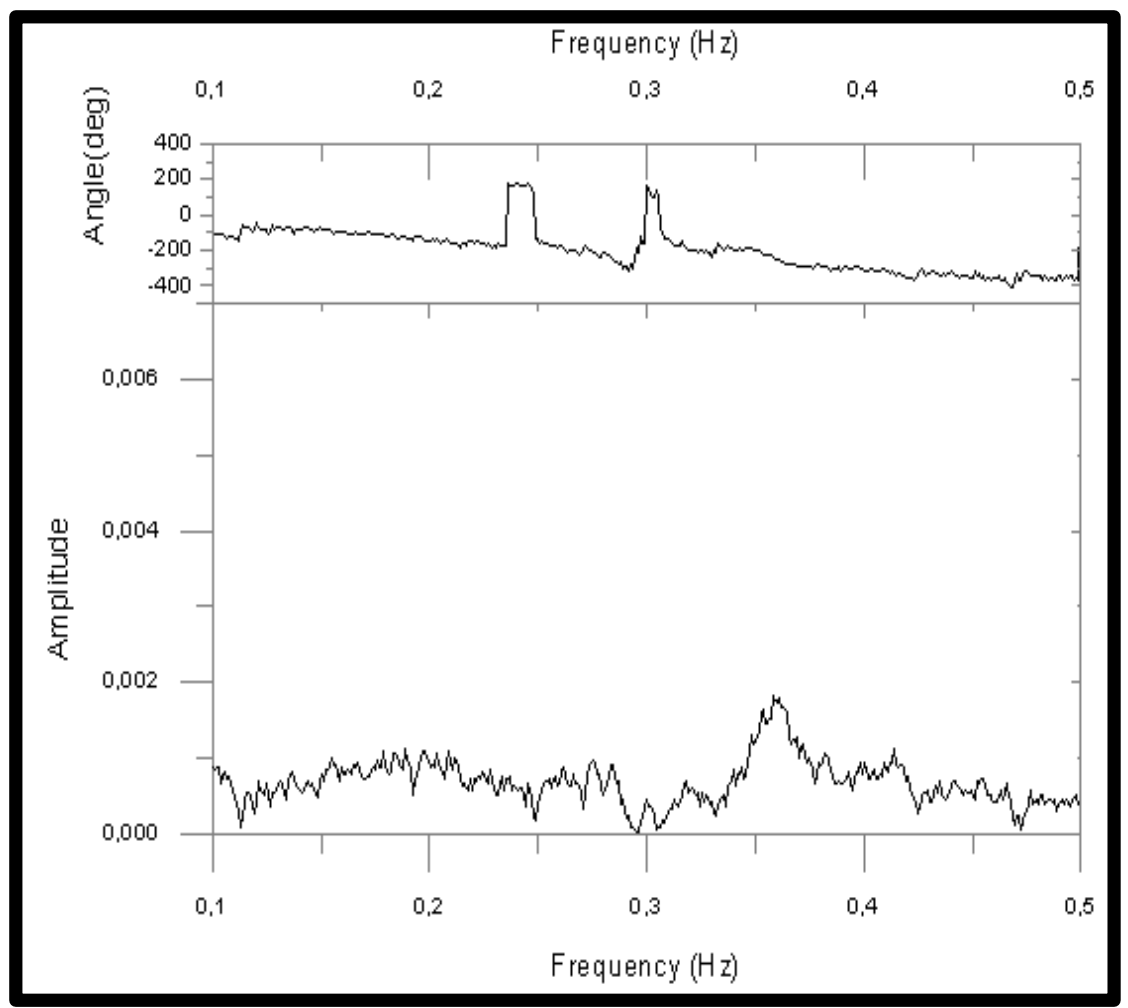

(B)

Gráfico B.17 - (A) Teste e (B) Transformada de Fourier usando a estrutura tridimensional modificada empacotada, usando como reagente gasolina comum (posto 1). 


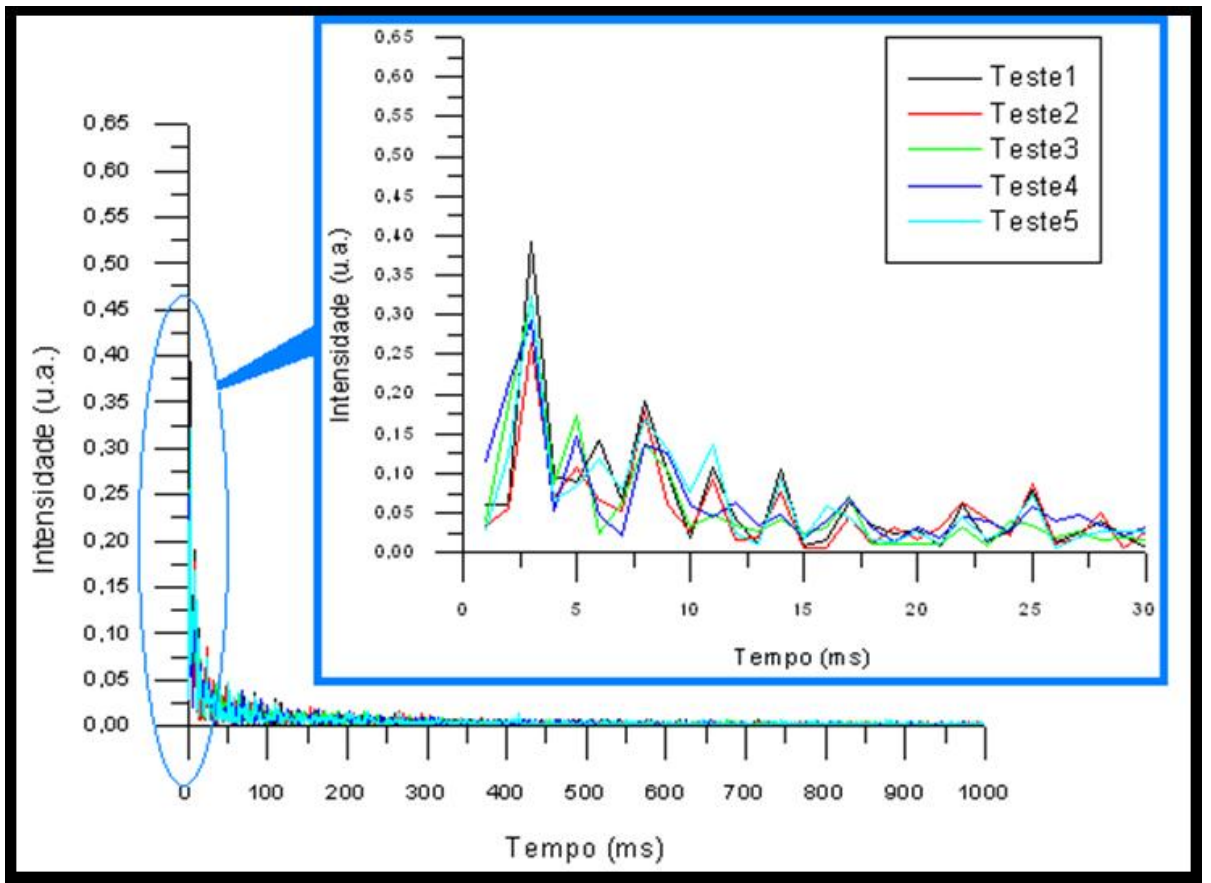

(A)

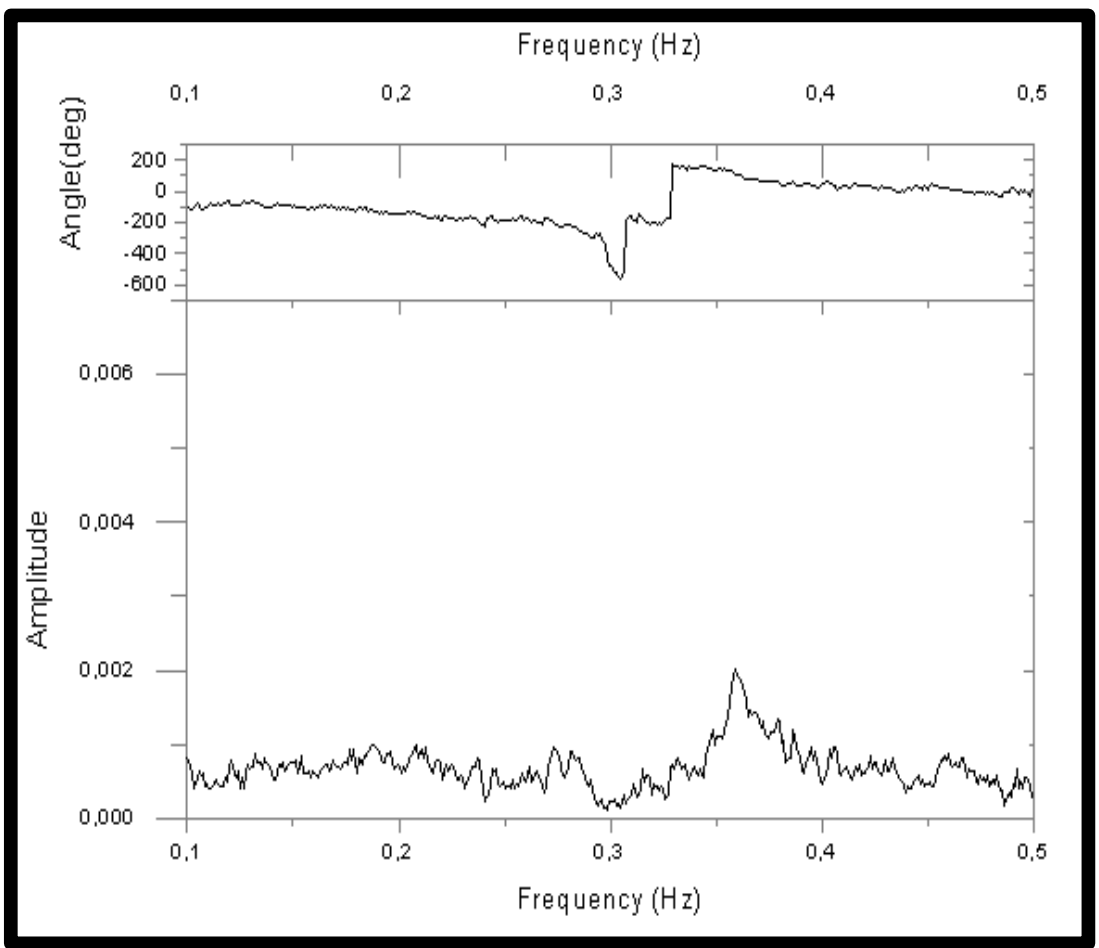

(B)

Gráfico B.18 - (A) Teste e (B) Transformada de Fourier usando a estrutura tridimensional modificada empacotada, usando como reagente gasolina comum (posto 2). 


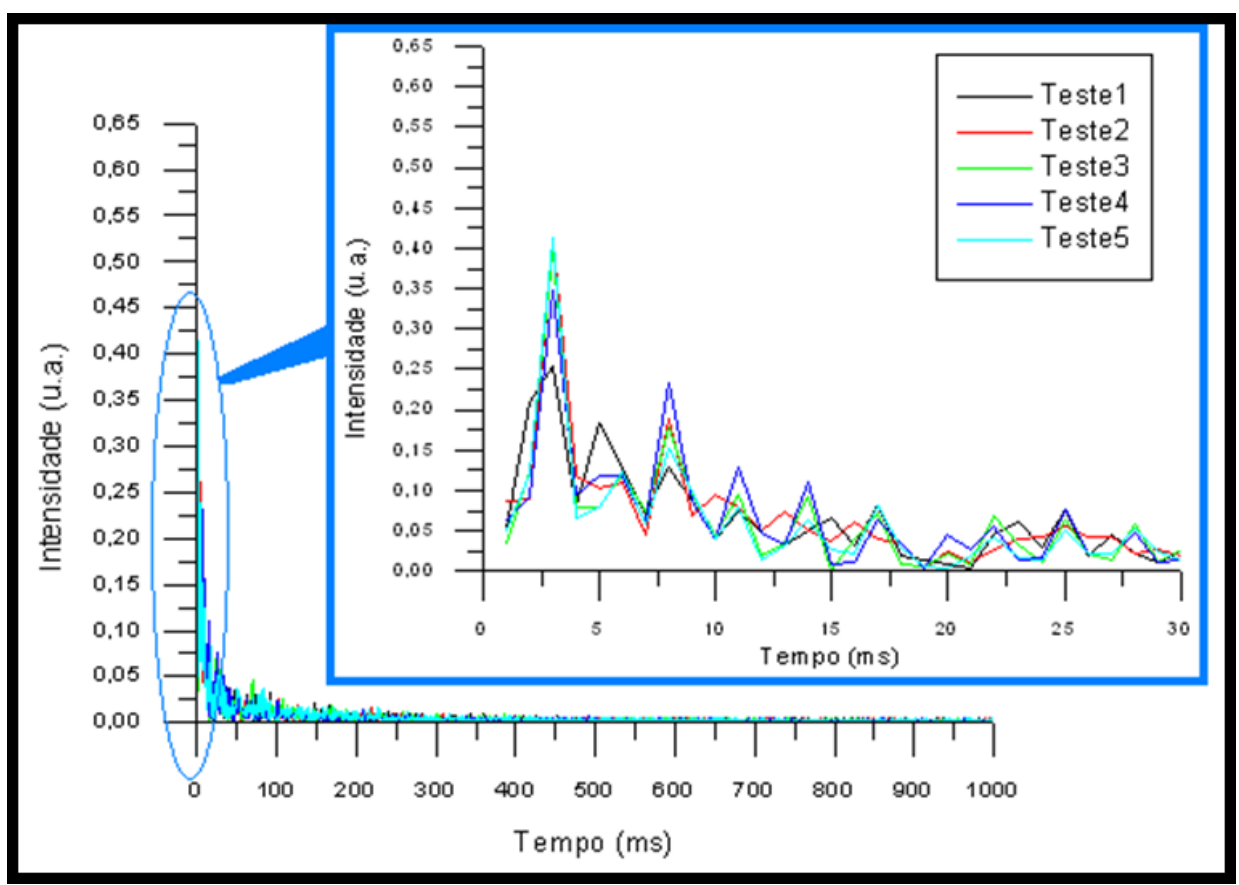

(A)

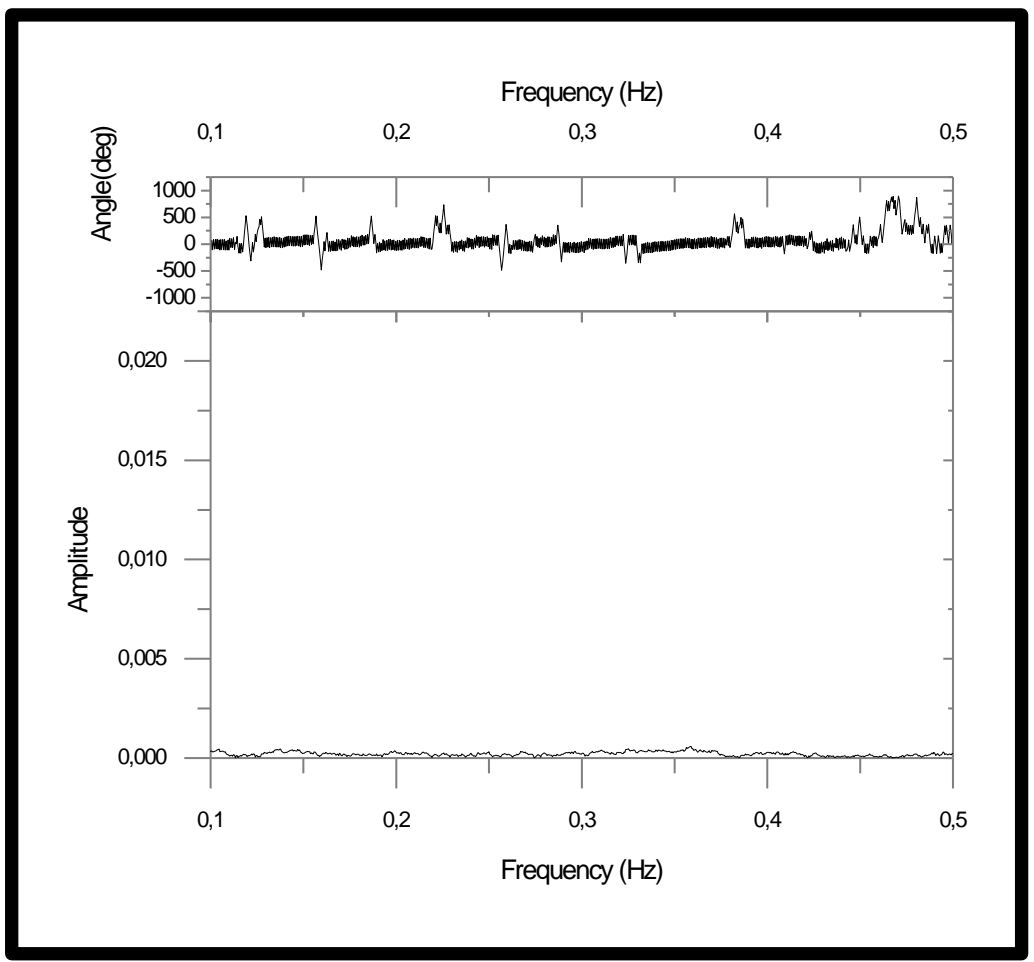

(B)

Gráfico B.19 - (A) Teste e (B) Transformada de Fourier usando a estrutura tridimensional modificada empacotada, usando como reagente gasolina comum (posto 3). 


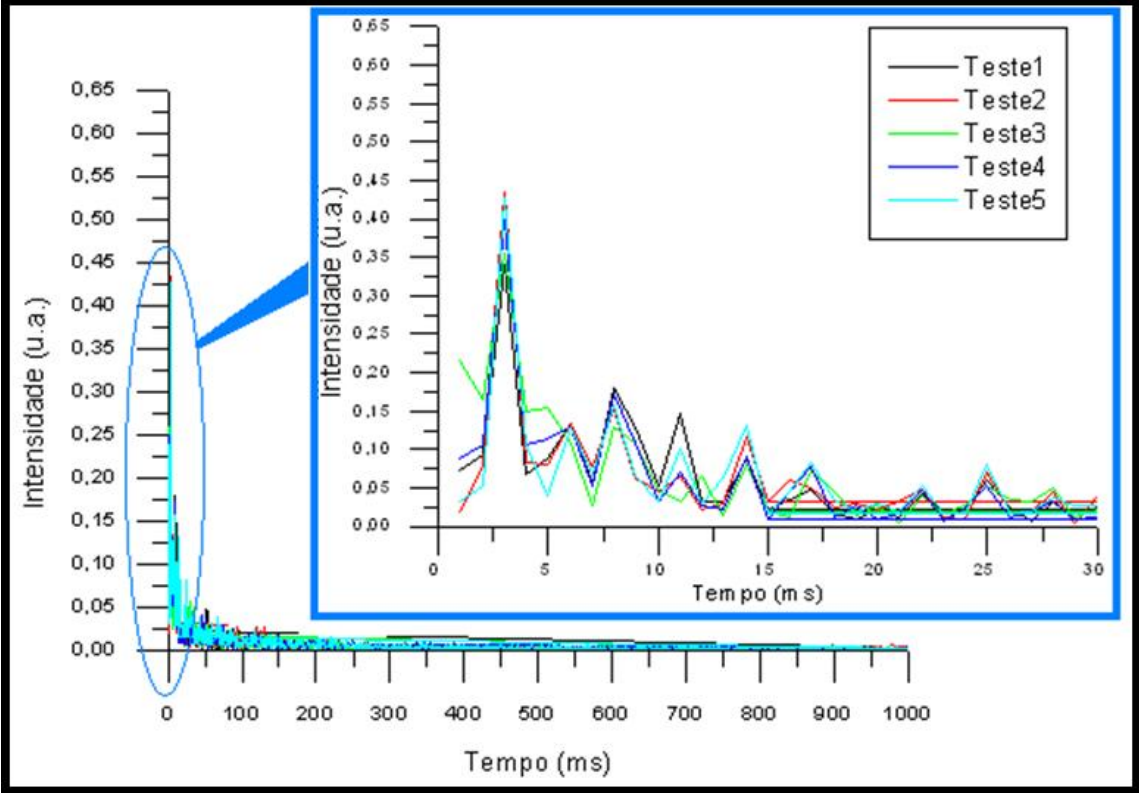

(A)

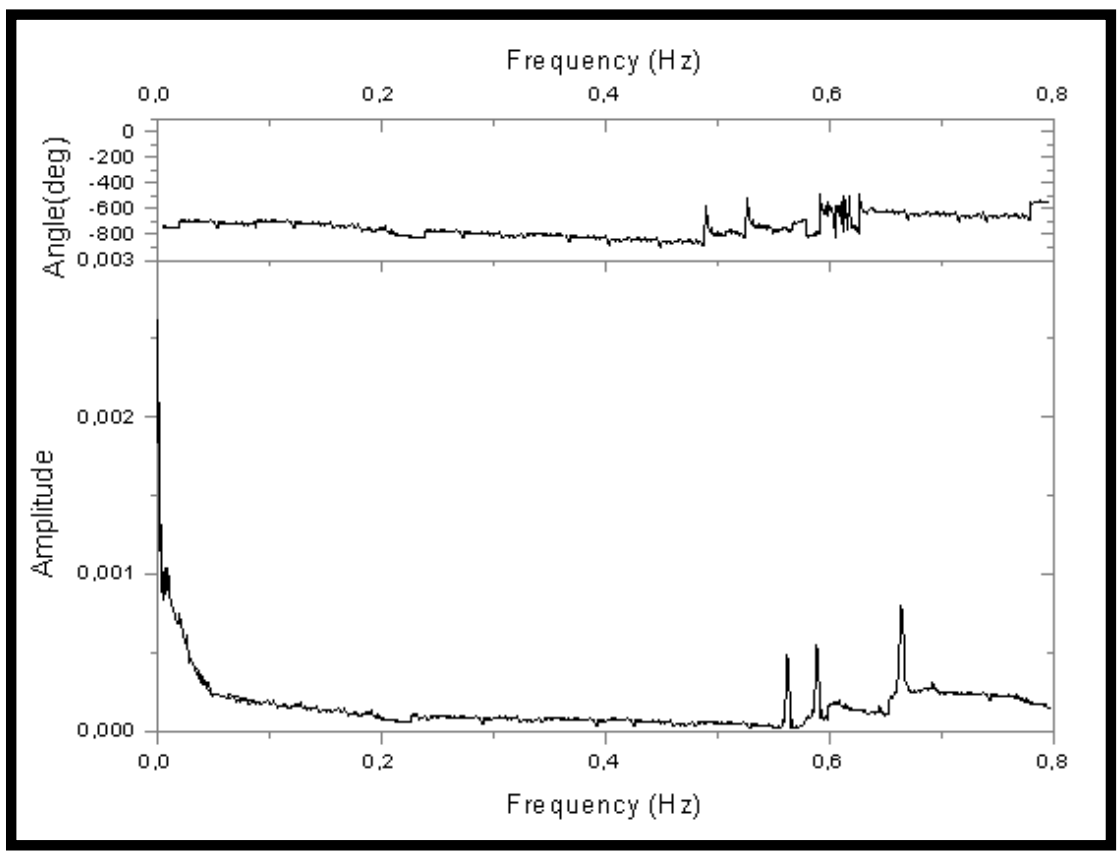

(B)

Gráfico B.20 - (A) Teste e (B) Transformada de Fourier usando a estrutura tridimensional modificada não empacotada, usando como reagente gasolina com isopropanol (posto 1). 


\section{APÊNDICE C}

\section{C.1 Estrutura chicana - variação dos parâmetros de teste}

\section{C.1.1 Modo de admissão pulsada}

\section{C.1.1.1 Condição 1}

Os testes na estrutura não empacotada, em escoamento contínuo (gás de arraste, vazão de $0,10 \mathrm{~mL} / \mathrm{min}$ ) e com injeções de $0,10 \mathrm{~mL}$ dos reagentes, modo pulsado (isopropanol, acetona, gasolina comum e $\operatorname{Varsol}{ }^{\circledR}$, nesta ordem respectivamente). Para realizar as medidas com a chicana e obter dados para todas as celas de saída foi necessário colocar constrições nas saídas, necessitando estrangular a primeira cela quase totalmente para que possa haver escoamento na última, em alguns casos. As medidas foram realizadas de forma crescente em se tratando das constrições. Assim, primeiro fez-se as medidas estrangulando todas as saídas e deixando aberta apenas a saída que se está medindo, como mostram as tabelas a seguir. Depois segue as medidas fechando as saídas em aproximadamente $90 \%$ da vazão para a primeira, $70 \%$ da vazão para a segunda, $50 \%$ da vazão para terceira, $20 \%$ para a quarta e $0 \%$ para a quinta saída.

Em geral, as respostas obtidas foram muito semelhantes às obtidas com o estrangulamento completo de cada saída, mas o procedimento é necessário para otimizar o fluxo dentro da estrutura. Por fim, seguem as medidas fechando em aproximadamente 50\% da vazão todas as saídas. Mesmo nestas condições, geralmente as três últimas celas de saída não emitem respostas. Apenas para comparação adicionam-se também os impactadores (angular e semi-circular) para verificar interferência na medida. 
Tabela C.1 - Dados obtidos para estrutura não empacotada, sem aquecimento e isopropanol.

\begin{tabular}{|c|c|c|c|c|c|c|c|c|c|c|c|c|}
\hline & \multirow[b]{2}{*}{ Entrada } & \multirow{3}{*}{ Saídas } & \multicolumn{10}{|c|}{ Tempo (s) } \\
\hline \multirow[t]{2}{*}{ Estrutura } & & & \multicolumn{5}{|c|}{ Injeção até detecção } & \multicolumn{5}{|c|}{ Duração da detecção } \\
\hline & & & 1 & 2 & 3 & 4 & 5 & 1 & 2 & 3 & 4 & 5 \\
\hline \multirow{5}{*}{ Chicana } & \multirow{5}{*}{1} & 1 & 1 & 2 & 2 & 2 & 3 & 35 & 65 & 52 & 60 & 43 \\
\hline & & 2 & 3 & 4 & 3 & 4 & 3 & 47 & 51 & 47 & 41 & \\
\hline & & 3 & 27 & 36 & 25 & 13 & 19 & 25 & 61 & 55 & 43 & 15 \\
\hline & & 4 & 8 & 10 & 8 & 6 & 5 & 32 & 18 & 37 & 44 & 35 \\
\hline & & 5 & 11 & 6 & 8 & 10 & 9 & 9 & 6 & 12 & 10 & 12 \\
\hline Impactador semi-circular & 1 & 1 & 10 & 15 & 18 & 9 & 10 & 3 & 22 & 33 & 21 & 56 \\
\hline Impactador angular & 1 & 1 & 3 & 2 & 2 & 1 & 2 & 24 & 51 & 24 & 26 & 30 \\
\hline
\end{tabular}

Tempo médio de injeção até detecção para impactador semi-circular é 14,2 s e angular $3 \mathrm{~s}$.

Tabela C.2 - Dados obtidos para estrutura não empacotada, sem aquecimento e gasolina.

\begin{tabular}{|c|c|c|c|c|c|c|c|c|c|c|c|c|}
\hline \multirow[b]{2}{*}{ Estrutura } & \multirow[b]{2}{*}{ Entrada } & \multirow[b]{2}{*}{ Saídas } & \multicolumn{10}{|c|}{ Tempo (s) } \\
\hline & & & \multicolumn{5}{|c|}{ Injeção até detecção } & \multicolumn{5}{|c|}{ Duração da detecção } \\
\hline & & & 1 & 2 & 3 & 4 & 5 & 1 & 2 & 3 & 4 & 5 \\
\hline \multirow{5}{*}{ Chicana } & \multirow{5}{*}{1} & 1 & 1 & 1 & 2 & 1 & 2 & 70 & 54 & 54 & 44 & 42 \\
\hline & & 2 & 2 & 2 & 2 & 3 & 4 & 62 & 11 & 216 & 110 & 107 \\
\hline & & 3 & - & 2 & 36 & 3 & 2 & 12 & 16 & 35 & 61 & 87 \\
\hline & & 4 & 2 & 2 & 3 & 3 & 2 & $\begin{array}{c}10 / 10 / \\
10 / 86 / 10\end{array}$ & $\begin{array}{c}11 / 12 / \\
11 / 75 / 13\end{array}$ & $\begin{array}{c}12 / 11 / \\
12 / 82 / 10\end{array}$ & $\begin{array}{c}11 / 12 / \\
13 / 89 / 10\end{array}$ & $\begin{array}{c}10 / 11 / \\
11 / 90 / 10\end{array}$ \\
\hline & & 5 & 4 & 3 & 5 & 3 & 4 & $\begin{array}{l}12 / 11 / \\
8 / 19 / 4\end{array}$ & $9 / 6 / 11$ & $5 / 2 / 8$ & $10 / 20 / 2$ & $5 / 12 / 10$ \\
\hline $\begin{array}{l}\text { Impactador } \\
\text { semi-circular }\end{array}$ & 1 & 1 & 23 & 2 & 3 & 2 & 41 & 5 & 100 & 95 & 10 & 4 \\
\hline Impactador angular & 1 & 1 & 2 & 4 & 1 & 4 & 4 & 18 & 17 & 23 & 16 & 16 \\
\hline
\end{tabular}

Tabela C.3 - Dados obtidos para estrutura não empacotada, sem aquecimento e acetona.

\begin{tabular}{|c|c|c|c|c|c|c|c|c|c|c|c|c|}
\hline \multirow[b]{2}{*}{ Estrutura } & \multirow[b]{2}{*}{ Entrada } & \multirow{3}{*}{ Saídas } & \multicolumn{10}{|c|}{ Tempo (s) } \\
\hline & & & \multicolumn{5}{|c|}{ Injeção até detecção } & \multicolumn{5}{|c|}{ Duração da detecção } \\
\hline & & & 1 & 2 & 3 & 4 & 5 & 1 & 2 & 3 & 4 & 5 \\
\hline \multirow{5}{*}{ Chicana } & \multirow{5}{*}{1} & 1 & 1 & 1 & 2 & 1 & 2 & 200 & 135 & 120 & 107 & 76 \\
\hline & & 2 & 2 & 1 & 3 & 2 & 14 & 177 & 153 & 133 & 40 & 46 \\
\hline & & 3 & 2 & 1 & 3 & 3 & 1 & 42 & 120 & 73 & 54 & 35 \\
\hline & & 4 & 3 & 4 & 12 & 3 & 2 & $\begin{array}{l}43 / 9 / \\
7 / 14 / 4\end{array}$ & $\begin{array}{c}50 / 8 / \\
14 / 5 / 10\end{array}$ & $\begin{array}{c}61 / 9 / \\
22 / 3 / 5\end{array}$ & $\begin{array}{l}78 / 10 / \\
18 / 2 / 5\end{array}$ & $\begin{array}{c}42 / 5 / \\
22 / 8 / 12\end{array}$ \\
\hline & & 5 & 3 & 4 & 3 & 4 & 6 & $91 / 27 / 12$ & 145 & $\begin{array}{c}18 / 33 / \\
4 / 20\end{array}$ & $\begin{array}{c}25 / 10 / \\
36 / 6\end{array}$ & $\begin{array}{c}7 / 3 / \\
9 / 7 / 3\end{array}$ \\
\hline $\begin{array}{l}\text { Impactador } \\
\text { semi-circular }\end{array}$ & 1 & 1 & 6 & 5 & 32 & 13 & 11 & 17 & 16 & 38 & 13 & 65 \\
\hline Impactador angular & 1 & 1 & 6 & 7 & 9 & 8 & 5 & 16 & 11 & 8 & 7 & 21 \\
\hline
\end{tabular}


Tempo médio de injeção até detecção para impactador semi-circular 13,4 s e angular $7 \mathrm{~s}$.

Tabela C.4 - Dados obtidos para estrutura não empacotada, sem aquecimento e Varsol@.

\begin{tabular}{|c|c|c|c|c|c|c|c|c|c|c|c|c|}
\hline & \multirow{3}{*}{ Entrada } & \multirow{3}{*}{ Saídas } & \multicolumn{10}{|c|}{ Tempo (s) } \\
\hline \multirow[t]{2}{*}{ Estrutura } & & & \multicolumn{5}{|c|}{ Injeção até detecção } & \multicolumn{5}{|c|}{ Duração da detecção } \\
\hline & & & 1 & 2 & 3 & 4 & 5 & 1 & 2 & 3 & 4 & 5 \\
\hline \multirow{5}{*}{ Chicana } & \multirow{5}{*}{1} & 1 & 2 & 1 & 2 & 3 & 2 & 12 & 19 & 17 & 14 & 12 \\
\hline & & 2 & 12 & 95 & - & - & 3 & 2 & 1 & - & - & 3 \\
\hline & & 3 & 25 & 3 & 44 & - & - & 2 & 26 & 4 & - & - \\
\hline & & 4 & - & - & - & - & - & - & - & - & - & - \\
\hline & & 5 & - & - & - & - & - & - & - & - & - & - \\
\hline Impactador semi-circular & 1 & 1 & 12 & 11 & 46 & 15 & 7 & 24 & 26 & 34 & 41 & 33 \\
\hline Impactador angular & 1 & 1 & 2 & 2 & 1 & 5 & 14 & 17 & 77 & 107 & 156 & 59 \\
\hline
\end{tabular}

- $\rightarrow$ não detectada

$* \rightarrow$ Tempo médio de injeção até detecção para impactador semi-circular 18,5 s e angular 4,8 s.

Tabela C.5 - Dados obtidos para estrutura não empacotada, sem aquecimento e mistura.

\begin{tabular}{|c|c|c|c|c|c|c|c|c|c|c|c|c|}
\hline & & & \multicolumn{10}{|c|}{ Tempo (s) } \\
\hline \multirow[t]{2}{*}{ Estrutura } & \multirow[t]{2}{*}{ Entrada } & \multirow[t]{2}{*}{ Saídas } & \multicolumn{5}{|c|}{ Injeção até detecção } & \multicolumn{5}{|c|}{ Duração da detecção } \\
\hline & & & 1 & 2 & 3 & 4 & 5 & 1 & 2 & 3 & 4 & 5 \\
\hline \multirow{5}{*}{ Chicana } & \multirow{5}{*}{1} & 1 & 2 & 1 & 1 & 2 & 2 & 157 & 502 & 80 & 194 & $65 / 97 / 20$ \\
\hline & & 2 & 11 & 3 & 3 & 4 & 2 & 98 & 193 & $154 / 2$ & $37 / 54 / 3$ & $158 / 5 / 11$ \\
\hline & & 3 & 4 & 3 & 2 & 4 & 4 & 42 & 21 & 38 & 52 & 95 \\
\hline & & 4 & 3 & 3 & 4 & 3 & 2 & $\begin{array}{c}21 / 10 / \\
40 / 51 / 2\end{array}$ & $\begin{array}{c}10 / 22 / \\
11 / 84 / 23\end{array}$ & $\begin{array}{c}9 / 19 / \\
12 / 20 / 40\end{array}$ & $\begin{array}{c}18 / 2 / \\
19 / 98 / 5\end{array}$ & $\begin{array}{c}10 / 2 / 18 \\
10 / 90\end{array}$ \\
\hline & & 5 & 6 & 8 & 5 & 2 & 9 & $\begin{array}{c}22 / 8 / \\
18 / 30 / 2\end{array}$ & $8 / 56 / 11$ & $9 / 52 / 2 / 8$ & $10 / 20 / 30 / 2$ & $15 / 52 / 10 / 2$ \\
\hline
\end{tabular}

MISTURA - $1 \mathrm{~mL}$ de acetona + isopropanol + álcool etílico

O tempo de resposta, desde o momento da injeção até a detecção, se deu quase que instantaneamente, aproximadamente 2 segundos, para quase todos reagentes exceto para o $\operatorname{Varsol}{ }^{\circledR}$ onde existiram situações em que o reagente não foi detectado. O tempo de detecção do instante em que o equipamento começa a medir até o momento em que para de emitir o sinal, é diferente para cada reagente. Quando se trata do isopropanol fica em torno de 45 segundos de medição de uma única vez para todas as saídas. Para a gasolina têm-se tempos de aproximadamente 135 segundos para as primeiras saídas e a partir da $4^{\mathrm{a}}$ saída já ocorre a partição de detecção, ou seja, o equipamento passa a emitir sinal por etapas, tempo de emissão de um sinal à outro de aproximadamente 50 segundos. Para a acetona têm-se situações semelhantes as da gasolina, porém, o tempo de detecção a partir da $4^{\mathrm{a}}$ saída é dividido em aproximadamente 30 segundos entre uma detecção e outra. Quando se utiliza Varsol® tem-se situação semelhante à do 
isopropanol com detecções únicas e rápidas, porém, na maioria das medidas não foi possível detectar sinal algum.

\section{C.1.1.2 Condição 2}

A metodologia é a mesma que a anterior, porém, com aquecimento contínuo de $88^{\circ} \mathrm{C}$ para os impactadores e diferenciado em cada cela da chicana, $\left(92^{\circ}\right.$ à $87^{\circ} \mathrm{C} ; 70^{\circ}$ à $68^{\circ} \mathrm{C} ; 54^{\circ}$ à $40^{\circ} \mathrm{C} ; 38^{\circ}$ à $30^{\circ} \mathrm{C} ; 20^{\circ} \mathrm{C}$ ) - a ordem inversa não provoca resultados significativos aos obtidos sem aquecimento. Para controlar a temperatura usou-se um termômetro analógico de $0^{\circ} \mathrm{C}-120^{\circ} \mathrm{C}$. $\mathrm{O}$ aquecimento aumenta a detecção na terceira cela, mas não melhora as condições de detecção da mistura. As constrições nas saídas das celas obtém respostas semelhantes. Através das medições, observou-se que há reprodutibilidade nos resultados, com o comportamento de separação para a chicana.

Tabela C.6 - Dados obtidos para estrutura não empacotada, com aquecimento e isopropanol.

\begin{tabular}{|c|c|c|c|c|c|c|c|c|c|c|c|c|}
\hline & \multirow[b]{2}{*}{ Entrada } & \multirow[b]{2}{*}{ Saídas } & \multicolumn{10}{|c|}{ Tempo (s) } \\
\hline Estrutura & & & \multicolumn{5}{|c|}{ Injeção até detecção } & \multicolumn{5}{|c|}{ Duração da detecção } \\
\hline & & & 1 & 2 & 3 & 4 & 5 & 1 & 2 & 3 & 4 & 5 \\
\hline \multirow{5}{*}{ Chicana } & \multirow{5}{*}{1} & 1 & 4 & 3 & 2 & 7 & 6 & 52 & 64 & 66 & 61 & 46 \\
\hline & & 2 & 6 & 8 & 5 & 8 & 3 & 63 & 43 & 56 & 55 & 61 \\
\hline & & 3 & 9 & 5 & 6 & 6 & 4 & 48 & 55 & 50 & 56 & 58 \\
\hline & & 4 & 8 & 6 & 6 & 9 & 5 & 74 & 46 & 40 & 46 & 42 \\
\hline & & 5 & 4 & 2 & 9 & 3 & 5 & 26 & 35 & 35 & 33 & 56 \\
\hline $\begin{array}{c}\text { Impactador } \\
\text { semi-circular }\end{array}$ & 1 & 1 & 12 & 22 & 29 & 16 & 3 & 32 & 38 & 29 & 35 & 52 \\
\hline Impactador angular & 1 & 1 & 18 & 16 & 12 & 8 & 2 & 30 & 42 & 33 & 26 & 33 \\
\hline
\end{tabular}

Tabela C.7 - Dados obtidos para estrutura não empacotada, com aquecimento e gasolina comum.

\begin{tabular}{|c|c|c|c|c|c|c|c|c|c|c|c|c|}
\hline \multirow[b]{2}{*}{ Estrutura } & \multirow[b]{2}{*}{ Entrada } & \multirow{3}{*}{ Saídas } & \multicolumn{10}{|c|}{ Tempo (s) } \\
\hline & & & \multicolumn{5}{|c|}{ Injeção até detecção } & \multicolumn{5}{|c|}{ Duração da detecção } \\
\hline & & & 1 & 2 & 3 & 4 & 5 & 1 & 2 & 3 & 4 & 5 \\
\hline \multirow{5}{*}{ Chicana } & \multirow{5}{*}{1} & 1 & 2 & 2 & 3 & 1 & 2 & 140 & 68 & 102 & 55 & 42 \\
\hline & & 2 & 3 & 3 & 1 & 3 & 4 & 62 & 33 & 256 & 203 & 158 \\
\hline & & 3 & 4 & 3 & 2 & 3 & 2 & 0 & 23 & 53 & 110 & 98 \\
\hline & & 4 & 1 & 2 & 1 & 3 & 2 & $\begin{array}{c}14 / 16 / \\
28\end{array}$ & $\begin{array}{c}22 / 12 / \\
11 /\end{array}$ & $\begin{array}{c}23 / 19 \\
/ 82\end{array}$ & $\begin{array}{c}10 / 22 / \\
10\end{array}$ & $\begin{array}{c}8 / 11 / \\
80\end{array}$ \\
\hline & & 5 & 2 & 0 & 3 & 0 & 4 & $6 / 8$ & $5 / 6$ & $7 / 2$ & $6 / 2$ & $8 / 12 / 10$ \\
\hline $\begin{array}{l}\text { Impactador } \\
\text { semi-circular }\end{array}$ & 1 & 1 & 2 & 2 & 1 & 0 & 2 & 15 & 78 & 105 & 45 & 26 \\
\hline Impactador angular & 1 & 1 & 3 & 1 & 1 & 1 & 0 & 25 & 47 & 88 & 98 & 45 \\
\hline
\end{tabular}


Tabela C.8 - Dados obtidos para estrutura não empacotada, com aquecimento e acetona.

\begin{tabular}{|c|c|c|c|c|c|c|c|c|c|c|c|c|}
\hline \multirow[b]{2}{*}{ Estrutura } & \multirow[b]{2}{*}{ Entrada } & \multirow[b]{2}{*}{ Saídas } & \multicolumn{10}{|c|}{ Tempo (s) } \\
\hline & & & \multicolumn{5}{|c|}{ Injeção até detecção } & \multicolumn{5}{|c|}{ Duração da detecção } \\
\hline & & & 1 & 2 & 3 & 4 & 5 & 1 & 2 & 3 & 4 & 5 \\
\hline \multirow{5}{*}{ Chicana } & \multirow{5}{*}{1} & 1 & 2 & 2 & 3 & 1 & 2 & 100 & 135 & 120 & 107 & 76 \\
\hline & & 2 & 1 & 1 & 2 & 2 & 3 & 200 & 153 & 133 & 40 & 46 \\
\hline & & 3 & 1 & 1 & 2 & 3 & 1 & 89 & 120 & 73 & 54 & 35 \\
\hline & & 4 & 2 & 5 & 1 & 3 & 2 & $53 / 4$ & $68 / 45$ & $78 / 20$ & $88 / 47 / 3$ & $42 / 8 / 3$ \\
\hline & & 5 & 2 & 3 & 3 & 4 & 4 & $78 / 9 / 3$ & $78 / 98$ & $78 / 45$ & $45 / 86$ & $7 / 8 / 9$ \\
\hline $\begin{array}{l}\text { Impactador } \\
\text { semi-circular }\end{array}$ & 1 & 1 & 2 & 1 & 1 & 2 & 1 & 22 & 14 & 30 & 10 & 11 \\
\hline Impactador angular & 1 & 1 & 2 & 3 & 1 & 0 & 0 & 11 & 8 & 9 & 10 & 4 \\
\hline
\end{tabular}

0 - tempo inferior a 1 segundo.

Tabela C.9 - Dados obtidos para estrutura não empacotada, com aquecimento e

\section{Varsol@.}

\begin{tabular}{|c|c|c|c|c|c|c|c|c|c|c|c|c|}
\hline \multirow[b]{2}{*}{ Estrutura } & \multirow[b]{2}{*}{ Entrada } & \multirow{3}{*}{ Saídas } & \multicolumn{10}{|c|}{ Tempo (s) } \\
\hline & & & \multicolumn{5}{|c|}{ Injeção até detecção } & \multicolumn{5}{|c|}{ Duração da detecção } \\
\hline & & & 1 & 2 & 3 & 4 & 5 & 1 & 2 & 3 & 4 & 5 \\
\hline \multirow{5}{*}{ Chicana } & \multirow{5}{*}{1} & 1 & 1 & 0 & 1 & 2 & 2 & 10 & 22 & 32 & 14 & 16 \\
\hline & & 2 & 0 & 0 & 1 & 1 & 2 & 8 & 4 & 0 & 0 & 0 \\
\hline & & 3 & 0 & 1 & 1 & 0 & 2 & 2 & 16 & 22 & 0 & 0 \\
\hline & & 4 & 1 & 0 & $*$ & * & 0 & $*$ & $*$ & $*$ & $*$ & $*$ \\
\hline & & 5 & 0 & $*$ & 0 & 0 & $*$ & $*$ & * & $*$ & $*$ & $*$ \\
\hline $\begin{array}{l}\text { Impactador } \\
\text { semi-circular }\end{array}$ & 1 & 1 & 0 & 0 & 1 & 1 & 2 & 78 & 55 & 30 & 61 & 45 \\
\hline Impactador angular & 1 & 1 & 0 & 2 & 1 & 2 & 1 & 22 & 88 & 95 & 188 & 65 \\
\hline
\end{tabular}

0 - tempo inferior a 1 segundo; * - medida não detectada.

Tabela C.10 - Dados obtidos para estrutura não empacotada, com aquecimento e mistura (1 mL de mistura 1:1:1 de acetona + isopropanol + álcool etílico).

\begin{tabular}{|c|c|c|c|c|c|c|c|c|c|c|c|c|}
\hline \multirow[b]{2}{*}{ Estrutura } & \multirow[b]{2}{*}{ Entrada } & \multirow{3}{*}{ Saídas } & \multicolumn{10}{|c|}{ Tempo (s) } \\
\hline & & & \multicolumn{5}{|c|}{ Injeção até detecção } & \multicolumn{5}{|c|}{ Duração da detecção } \\
\hline & & & 1 & 2 & 3 & 4 & 5 & 1 & 2 & 3 & 4 & 5 \\
\hline \multirow{5}{*}{ Chicana } & \multirow{5}{*}{1} & 1 & 1 & 0 & 1 & 1 & 1 & 125 & 230 & 100 & 194 & $65 / 97 / 20$ \\
\hline & & 2 & 1 & * & 2 & 1 & 2 & 100 & 300 & 253 & $37 / 54 / 3$ & $158 / 5 / 11$ \\
\hline & & 3 & 2 & 1 & 1 & 1 & 0 & 56 & 210 & 97 & 52 & 95 \\
\hline & & 4 & 1 & 1 & 1 & 0 & 1 & 14 & 20 & 18 & 12 & 9 \\
\hline & & 5 & 0 & * & $*$ & 0 & 1 & $8 / 5 / 3$ & $5 / 3 / 2$ & $4 / 8 / 9$ & $4 / 5 / 5$ & $4 / 5 / 9$ \\
\hline
\end{tabular}

$* \rightarrow$ medida não detectada; 0 - tempo inferior a 1 segundo.

\section{C.1.1.3 Condição 3}

Semelhante à condição 1, porém com filme a base de HMDS depositado na superfície. Não se observa alteração significativa. 
Tabela C.11 - Dados obtidos para estrutura não empacotada, sem aquecimento e isopropanol.

\begin{tabular}{|c|c|c|c|c|c|c|c|c|c|c|c|c|}
\hline & \multirow[b]{2}{*}{ Entrada } & \multirow{3}{*}{ Saídas } & \multicolumn{10}{|c|}{ Tempo (s) } \\
\hline \multirow[t]{2}{*}{ Estrutura } & & & \multicolumn{5}{|c|}{ Injeção até detecção } & \multicolumn{5}{|c|}{ Duração da detecção } \\
\hline & & & 1 & 2 & 3 & 4 & 5 & 1 & 2 & 3 & 4 & 5 \\
\hline \multirow{3}{*}{ Chicana } & \multirow{3}{*}{1} & 2 & 2 & 2 & 5 & 3 & 4 & 252 & 138 & 234 & 188 & 252 \\
\hline & & 3 & 32 & 21 & 3 & 4 & 3 & 23 & 34 & $30 / 4$ & $24 / 2$ & $12 / 5$ \\
\hline & & 5 & - & - & 8 & 14 & 29 & - & - & 20 & 48 & 12 \\
\hline $\begin{array}{l}\text { Impactador semi- } \\
\text { circular }\end{array}$ & 1 & 1 & 12 & 2 & 4 & 3 & 7 & 32 & 38 & 29 & $35 / 4 / 2$ & $52 / 3 / 14$ \\
\hline Impactador angular & 1 & 1 & 10 & 2 & 5 & 6 & 8 & 40 & $25 / 5 / 41$ & $2 / 9 / 12$ & 18 & 22 \\
\hline
\end{tabular}

$-\rightarrow$ detecção quase imperceptível

Tabela C.12 - Dados obtidos para estrutura não empacotada, sem aquecimento e gasolina comum.

\begin{tabular}{|c|c|c|c|c|c|c|c|c|c|c|c|c|}
\hline \multirow[b]{2}{*}{ Estrutura } & \multirow[b]{2}{*}{ Entrada } & \multirow{3}{*}{ Saídas } & \multicolumn{10}{|c|}{ Tempo (s) } \\
\hline & & & \multicolumn{5}{|c|}{ Injeção até detecção } & \multicolumn{5}{|c|}{ Duração da detecção } \\
\hline & & & 1 & 2 & 3 & 4 & 5 & 1 & 2 & 3 & 4 & 5 \\
\hline \multirow{5}{*}{ Chicana } & \multirow{5}{*}{1} & 1 & 1 & 3 & 1 & 1 & 2 & 70 & 54 & 54 & 44 & 42 \\
\hline & & 2 & 1 & 3 & 3 & 3 & 1 & 62 & 11 & 216 & 110 & 107 \\
\hline & & 3 & 1 & 2 & 1 & 2 & 2 & - & 16 & 35 & 61 & 87 \\
\hline & & 4 & 1 & 2 & 1 & 1 & 2 & $\begin{array}{c}10 / 10 / \\
10 / 86 / 10\end{array}$ & $\begin{array}{c}11 / 12 / \\
11 / 75 / 13\end{array}$ & $\begin{array}{c}12 / 11 / \\
12 / 82 / 10\end{array}$ & $\begin{array}{c}11 / 12 / \\
13 / 89 / 10\end{array}$ & $\begin{array}{c}10 / 11 / \\
11 / 90 / 10\end{array}$ \\
\hline & & 5 & 6 & 5 & 5 & 7 & 7 & $\begin{array}{l}12 / 11 / \\
8 / 19 / 4\end{array}$ & $9 / 6 / 11$ & $5 / 2 / 8$ & $10 / 20 / 2$ & $5 / 12 / 10$ \\
\hline $\begin{array}{l}\text { Impactador semi- } \\
\text { circular }\end{array}$ & 1 & 1 & 4 & 2 & 4 & 1 & 1 & 20 & 52 & 80 & 13 & 10 \\
\hline $\begin{array}{l}\text { Impactador } \\
\text { angular }\end{array}$ & 1 & 1 & 3 & 2 & 1 & 2 & 2 & 20 & 45 & 40 & 12 & 6 \\
\hline
\end{tabular}

Tabela C.13 - Dados obtidos para estrutura não empacotada, sem aquecimento e acetona.

\begin{tabular}{|c|c|c|c|c|c|c|c|c|c|c|c|c|}
\hline \multirow[b]{2}{*}{ Estrutura } & \multirow[b]{2}{*}{ Entrada } & \multirow{3}{*}{ Saídas } & \multicolumn{10}{|c|}{ Tempo (s) } \\
\hline & & & \multicolumn{5}{|c|}{ Injeção até detecção } & \multicolumn{5}{|c|}{ Duração da detecção } \\
\hline & & & 1 & 2 & 3 & 4 & 5 & 1 & 2 & 3 & 4 & 5 \\
\hline \multirow{5}{*}{ Chicana } & \multirow{5}{*}{1} & 1 & 1 & 1 & 2 & 1 & 2 & 352 & 201 & 180 & 154 & 100 \\
\hline & & 2 & 1 & 1 & 2 & 2 & 1 & 235 & 254 & 266 & 125 & 85 \\
\hline & & 3 & 1 & 2 & 2 & 2 & 1 & 80 & 180 & 124 & 100 & 25 \\
\hline & & 4 & 1 & 2 & 1 & 3 & 2 & $54 / 9 / 2$ & $60 / 2 / 8$ & $70 / 5 / 6$ & $80 / 9 / 7$ & $41 / 25 / 5$ \\
\hline & & 5 & 2 & 4 & 1 & 4 & 2 & $21 / 14 / 6$ & $24 / 15 / 2$ & $\begin{array}{c}45 / 25 / \\
13\end{array}$ & $20 / 12 / 4$ & $31 / 2 / 14$ \\
\hline $\begin{array}{l}\text { Impactador } \\
\text { semi-circular }\end{array}$ & 1 & 1 & 2 & 1 & 2 & 3 & 1 & 20 & 30 & 22 & 28 & 25 \\
\hline Impactador angular & 1 & 1 & 1 & 1 & 2 & 2 & 4 & 33 & 30 & 21 & 19 & 21 \\
\hline
\end{tabular}


Tabela C.14 - Dados obtidos para estrutura não empacotada, sem aquecimento e Varsol@.

\begin{tabular}{|c|c|c|c|c|c|c|c|c|c|c|c|c|}
\hline \multirow[b]{2}{*}{ Estrutura } & \multirow[b]{2}{*}{ Entrada } & \multirow[b]{2}{*}{ Saídas } & \multicolumn{10}{|c|}{ Tempo (s) } \\
\hline & & & \multicolumn{5}{|c|}{ Injeção até detecção } & \multicolumn{5}{|c|}{ Duração da detecção } \\
\hline & & & 1 & 2 & 3 & 4 & 5 & 1 & 2 & 3 & 4 & 5 \\
\hline \multirow{5}{*}{ Chicana } & \multirow{5}{*}{1} & 1 & 0 & 1 & 0 & 1 & 2 & 12 & 19 & 17 & 14 & 12 \\
\hline & & 2 & 2 & 3 & 2 & 2 & 3 & 2 & 1 & - & - & 3 \\
\hline & & 3 & 16 & 28 & 12 & 14 & 11 & 2 & 26 & 4 & - & - \\
\hline & & 4 & 52 & 62 & 75 & - & - & - & 359 & - & - & 548 \\
\hline & & 5 & - & - & 89 & - & 123 & - & - & - & 458 & - \\
\hline Impactador semi-circular & 1 & 1 & 2 & 3 & 1 & 1 & 1 & 32 & 44 & 45 & 56 & 74 \\
\hline Impactador angular & 1 & 1 & 2 & 2 & 1 & 3 & 3 & 20 & 45 & 89 & 89 & 91 \\
\hline
\end{tabular}

- $\rightarrow$ detecção quase imperceptível

Tabela C.15 - Dados obtidos para estrutura não empacotada, sem aquecimento e mistura (1 mL de mistura 1:1:1 de acetona + isopropanol + álcool etílico).

\begin{tabular}{|c|c|c|c|c|c|c|c|c|c|c|c|c|}
\hline \multirow{3}{*}{ Estrutura } & \multirow[b]{2}{*}{ Entrada } & \multirow{3}{*}{ Saídas } & \multicolumn{10}{|c|}{ Tempo (s) } \\
\hline & & & \multicolumn{5}{|c|}{ Injeção até detecção } & \multicolumn{5}{|c|}{ Duração da detecção } \\
\hline & & & 1 & 2 & 3 & 4 & 5 & 1 & 2 & 3 & 4 & 5 \\
\hline \multirow{5}{*}{ Chicana } & \multirow{5}{*}{1} & 1 & 1 & 1 & 1 & 2 & 1 & 201 & 425 & 160 & 254 & $74 / 82 / 12$ \\
\hline & & 2 & 2 & 3 & 2 & 1 & 2 & 103 & 254 & $123 / 52$ & $45 / 5 / 2$ & $56 / 45 / 3$ \\
\hline & & 3 & 1 & 1 & 2 & 2 & 1 & 52 & 43 & 25 & 52 & 89 \\
\hline & & 4 & 7 & 9 & 12 & 23 & 14 & $21 / 12 / 4$ & $21 / 20 / 23$ & $21 / 20 / 14$ & $32 / 22 / 4$ & $32 / 21 / 25$ \\
\hline & & 5 & 10 & 12 & 10 & 9 & 9 & $12 / 9 / 4$ & $10 / 5 / 9$ & $9 / 5 / 2$ & $10 / 2$ & $8 / 2$ \\
\hline
\end{tabular}

\section{C.1.1.4 Condição 4}

Semelhante à condição 2, porém com filme a base de HMDS depositado na superfície. Quando realizaram-se as medidas, usando gasolina comum observa-se o produto evaporando rapidamente devido ao aquecimento provocado pela água bastante aquecida do primeiro anteparo. Após isto, o produto fica imperceptível na estrutura. As medidas realizadas com a chicana empacotada com os anéis de Raschig não apresentaram resposta mínima suficiente para detecção.

Tabela C.16 - Dados obtidos para estrutura não empacotada, com aquecimento e isopropanol.

\begin{tabular}{|c|c|c|c|c|c|c|c|c|c|c|c|c|}
\hline \multirow{3}{*}{ Estrutura } & \multirow[b]{2}{*}{ Entrada } & \multirow{3}{*}{ Saídas } & \multicolumn{10}{|c|}{ Tempo (s) } \\
\hline & & & \multicolumn{5}{|c|}{ Injeção até detecção } & \multicolumn{5}{|c|}{ Duração da detecção } \\
\hline & & & 1 & 2 & 3 & 4 & 5 & 1 & 2 & 3 & 4 & 5 \\
\hline \multirow{5}{*}{ Chicana } & \multirow{5}{*}{1} & 1 & 1 & 1 & 1 & 0 & 0 & 25 & 36 & 28 & 32 & 33 \\
\hline & & 2 & 1 & 0 & 0 & 1 & 1 & 50 & 51 & 54 & 41 & - \\
\hline & & 3 & 4 & 3 & 3 & 5 & 4 & 23 & 21 & 33 & - & - \\
\hline & & 4 & 12 & 10 & 9 & 12 & 11 & 32 & 18 & 23 & 21 & 20 \\
\hline & & 5 & 15 & 18 & 14 & 18 & 12 & 9 & 6 & 5 & 3 & - \\
\hline $\begin{array}{l}\text { Impactador } \\
\text { semi-circular }\end{array}$ & 1 & 1 & 1 & 1 & 2 & 1 & 1 & 12 & 14 & 25 & 21 & 26 \\
\hline Impactador angular & 1 & 1 & 1 & 1 & 1 & 2 & 2 & 11 & 32 & 32 & 26 & 28 \\
\hline
\end{tabular}


Tabela C.17 - Dados obtidos para estrutura não empacotada, com aquecimento e gasolina comum.

\begin{tabular}{|c|c|c|c|c|c|c|c|c|c|c|c|c|}
\hline \multirow[b]{2}{*}{ Estrutura } & \multirow[b]{2}{*}{ Entrada } & \multirow{3}{*}{ Saídas } & \multicolumn{10}{|c|}{ Tempo (s) } \\
\hline & & & \multicolumn{5}{|c|}{ Injeção até detecção } & \multicolumn{5}{|c|}{ Duração da detecção } \\
\hline & & & 1 & 2 & 3 & 4 & 5 & 1 & 2 & 3 & 4 & 5 \\
\hline \multirow{5}{*}{ Chicana } & \multirow{5}{*}{1} & 1 & 1 & 1 & 1 & 1 & 0 & 65 & 65 & 65 & 54 & 42 \\
\hline & & 2 & 1 & 1 & 1 & 2 & 2 & 75 & 22 & 89 & 90 & 102 \\
\hline & & 3 & 2 & 3 & 3 & 3 & 3 & 45 & 32 & 35 & 56 & 65 \\
\hline & & 4 & 4 & 5 & 5 & 5 & 1 & $12 / 25 / 3$ & $9 / 12 / 10$ & $8 / 17 / 17$ & $20 / 22 / 12$ & $13 / 12 / 14$ \\
\hline & & 5 & 7 & 9 & 9 & 4 & 2 & $14 / 15 / 14$ & $5 / 6 / 6$ & $4 / 5 / 9$ & $9 / 8 / 8$ & $5 / 12 / 10$ \\
\hline $\begin{array}{l}\text { Impactador } \\
\text { semi-circular }\end{array}$ & 1 & 1 & 1 & 1 & 1 & 2 & 3 & 23 & 52 & 100 & 5 & 6 \\
\hline Impactador angular & 1 & 1 & 2 & 2 & 1 & 1 & 1 & 32 & 33 & 23 & 32 & 20 \\
\hline
\end{tabular}

$\rightarrow$ detecção quase imperceptível.

Tabela C.18 - Dados obtidos para estrutura não empacotada, com aquecimento e acetona.

\begin{tabular}{|c|c|c|c|c|c|c|c|c|c|c|c|c|}
\hline \multirow[b]{2}{*}{ Estrutura } & \multirow[b]{2}{*}{ Entrada } & \multirow[b]{2}{*}{ Saídas } & \multicolumn{10}{|c|}{ Tempo (s) } \\
\hline & & & \multicolumn{5}{|c|}{ Injeção até detecção } & \multicolumn{5}{|c|}{ Duração da detecção } \\
\hline & & & 1 & 2 & 3 & 4 & 5 & 1 & 2 & 3 & 4 & 5 \\
\hline \multirow{5}{*}{ Chicana } & \multirow{5}{*}{1} & 1 & 1 & 1 & 2 & 1 & 2 & 200 & 135 & 120 & 107 & 76 \\
\hline & & 2 & 3 & 1 & 2 & 2 & 3 & 177 & 153 & 133 & 40 & 46 \\
\hline & & 3 & 1 & 1 & 3 & 3 & 1 & 42 & 120 & 73 & 54 & 35 \\
\hline & & 4 & 1 & 2 & 5 & 5 & 2 & $\begin{array}{c}43 / 9 / \\
7 / 14 / 4\end{array}$ & $\begin{array}{c}50 / 8 / \\
14 / 5 / 10\end{array}$ & $\begin{array}{c}61 / 9 / \\
22 / 3 / 5\end{array}$ & $\begin{array}{l}78 / 10 / \\
18 / 2 / 5\end{array}$ & $\begin{array}{c}42 / 5 / \\
22 / 8 / 12\end{array}$ \\
\hline & & 5 & 2 & 7 & 3 & 7 & 6 & $91 / 27 / 12$ & 145 & $\begin{array}{c}118 / 33 / \\
4 / 20\end{array}$ & $\begin{array}{c}25 / 10 / \\
36 / 6\end{array}$ & $\begin{array}{c}7 / 3 / \\
9 / 7 / 3\end{array}$ \\
\hline $\begin{array}{l}\text { Impactador semi- } \\
\text { circular }\end{array}$ & 1 & 1 & 2 & 3 & 3 & 2 & 1 & 23 & 32 & 38 & 23 & 45 \\
\hline Impactador angular & 1 & 1 & 3 & 1 & 1 & 1 & 2 & 12 & 22 & 22 & 23 & 21 \\
\hline
\end{tabular}

Tabela C.19 - Dados obtidos para estrutura não empacotada, com aquecimento e Varsol@.

\begin{tabular}{|c|c|c|c|c|c|c|c|c|c|c|c|c|}
\hline \multirow[b]{2}{*}{ Estrutura } & \multirow[b]{2}{*}{ Entrada } & \multirow{3}{*}{ Saídas } & \multicolumn{10}{|c|}{ Tempo (s) } \\
\hline & & & \multicolumn{5}{|c|}{ Injeção até detecção } & \multicolumn{5}{|c|}{ Duração da detecção } \\
\hline & & & 1 & 2 & 3 & 4 & 5 & 1 & 2 & 3 & 4 & 5 \\
\hline \multirow{5}{*}{ Chicana } & \multirow{5}{*}{1} & 1 & 1 & 1 & 2 & 1 & 2 & 22 & 25 & 32 & 14 & 12 \\
\hline & & 2 & 2 & 3 & 2 & 1 & 1 & 4 & 5 & 5 & 3 & 3 \\
\hline & & 3 & 55 & 43 & 44 & 41 & - & 2 & 26 & 4 & - & - \\
\hline & & 4 & - & 115 & - & - & - & - & - & - & 446 & 556 \\
\hline & & 5 & - & - & - & 148 & - & - & 356 & - & - & - \\
\hline $\begin{array}{l}\text { Impactador } \\
\text { semi-circular }\end{array}$ & 1 & 1 & 1 & 2 & 2 & 4 & 7 & 22 & 16 & 21 & 30 & 33 \\
\hline Impactador angular & 1 & 1 & 1 & 2 & 1 & 3 & 10 & 14 & 23 & 55 & 65 & 57 \\
\hline
\end{tabular}


Tabela C.20 - Dados obtidos para estrutura não empacotada, com aquecimento e mistura (1 mL de mistura 1:1:1 de acetona + isopropanol + álcool etílico).

\begin{tabular}{|c|c|c|c|c|c|c|c|c|c|c|c|c|}
\hline & & & \multicolumn{10}{|c|}{ Tempo (s) } \\
\hline \multirow[t]{2}{*}{ Estrutura } & \multirow[t]{2}{*}{ Entrada } & \multirow[t]{2}{*}{ Saídas } & \multicolumn{5}{|c|}{ Injeção até detecção } & \multicolumn{5}{|c|}{ Duração da detecção } \\
\hline & & & 1 & 2 & 3 & 4 & 5 & 1 & 2 & 3 & 4 & 5 \\
\hline \multirow{5}{*}{ Chicana } & \multirow{5}{*}{1} & 1 & 1 & 1 & 1 & 2 & 2 & 123 & 223 & 100 & 203 & 102 \\
\hline & & 2 & 1 & 3 & 2 & 2 & 2 & 103 & 201 & $98 / 23$ & $25 / 20$ & $35 / 25$ \\
\hline & & 3 & 2 & 3 & 2 & 2 & 2 & 55 & 103 & 58 & 52 & 35 \\
\hline & & 4 & 8 & 8 & 12 & 14 & 11 & $23 / 12 / 5$ & $23 / 12 / 5$ & $12 / 15 / 3$ & $12 / 13 / 2$ & $10 / 12 / 14$ \\
\hline & & 5 & 13 & 12 & 12 & 9 & 9 & $12 / 9 / 8$ & $10 / 8 / 9$ & $5 / 6 / 6$ & $8 / 2$ & $7 / 8 / 8$ \\
\hline
\end{tabular}

\section{C.1.1.5 Condição 5}

Testes semelhantes à condição 3, mas para a estrutura empacotada.

Tabela C.21 - Dados obtidos para estrutura empacotada, sem aquecimento e isopropanol.

\begin{tabular}{|c|c|c|c|c|c|c|c|c|c|c|c|c|}
\hline \multirow[b]{2}{*}{ Estrutura } & \multirow[b]{2}{*}{ Entrada } & \multirow[b]{2}{*}{ Saídas } & \multicolumn{10}{|c|}{ Tempo (s) } \\
\hline & & & \multicolumn{5}{|c|}{ Injeção até detecção } & \multicolumn{5}{|c|}{ Duração da deteçãa } \\
\hline & & & 1 & 2 & 3 & 4 & 5 & 1 & 2 & 3 & 4 & 5 \\
\hline \multirow{5}{*}{ Chicana } & \multirow{5}{*}{1} & 1 & 1 & 3 & 1 & 2 & 3 & 7 & 4 & 13 & 3 & 2 \\
\hline & & 2 & - & - & 1 & 1 & 2 & - & - & 3 & 8 & 6 \\
\hline & & 3 & 4 & 5 & - & - & - & 2 & 1 & - & - & - \\
\hline & & 4 & - & 2 & - & - & - & - & 17 & - & - & - \\
\hline & & 5 & 3 & 1 & 2 & 3 & 2 & 6 & 16 & 15 & 6 & 8 \\
\hline
\end{tabular}

- $\rightarrow$ detecção quase imperceptível

Tabela C.22 - Dados obtidos para empacotada, sem aquecimento e gasolina comum.

\begin{tabular}{|c|c|c|c|c|c|c|c|c|c|c|c|c|}
\hline \multirow[b]{2}{*}{ Estrutura } & \multirow[b]{2}{*}{ Entrada } & \multirow[b]{2}{*}{ Saídas } & \multicolumn{10}{|c|}{ Tempo (s) } \\
\hline & & & \multicolumn{5}{|c|}{ Injeção até deteção } & \multicolumn{5}{|c|}{ Duração da deteção } \\
\hline & & & 1 & 2 & 3 & 4 & 5 & 1 & 2 & 3 & 4 & 5 \\
\hline \multirow{5}{*}{ Chicana } & \multirow{5}{*}{1} & 1 & 1 & 1 & 2 & 3 & 1 & 12 & 10 & 15 & 10 & 9 \\
\hline & & 2 & 1 & 1 & 2 & 2 & 3 & 14 & 18 & 16 & $16 / 2$ & 15 \\
\hline & & 3 & 2 & 2 & 1 & 1 & 1 & $22 / 4 / 2$ & $20 / 12 / 4$ & $19 / 13$ & $22 / 15 / 2$ & $23 / 18 / 5$ \\
\hline & & 4 & 1 & 3 & 3 & 2 & 2 & $26 / 12 / 2$ & $25 / 20 / 11 / 2$ & $24 / 11 / 12$ & $25 / 20 / 11$ & $28 / 19 / 10 / 2$ \\
\hline & & 5 & 3 & 3 & 3 & 2 & 2 & $29 / 11 / 3$ & $28 / 10$ & $26 / 3 / 5$ & $25 / 10 / 16$ & $29 / 20 / 11 / 3$ \\
\hline
\end{tabular}

Tabela C.23 - Dados obtidos para estrutura empacotada, sem aquecimento e acetona.

\begin{tabular}{|c|c|c|c|c|c|c|c|c|c|c|c|c|}
\hline \multirow[b]{2}{*}{ Estrutura } & \multirow[b]{2}{*}{ Entrada } & \multirow[b]{2}{*}{ Saídas } & \multicolumn{10}{|c|}{ Tempo (s) } \\
\hline & & & \multicolumn{5}{|c|}{ Injeção até deteç̧ão } & \multicolumn{5}{|c|}{ Duração da detecção } \\
\hline & & & 1 & 2 & 3 & 4 & 5 & 1 & 2 & 3 & 4 & 5 \\
\hline \multirow{5}{*}{ Chicana } & \multirow{5}{*}{1} & 1 & 1 & 2 & 2 & 1 & 2 & 16 & 7 & 16 & 9 & 10 \\
\hline & & 2 & 1 & 1 & 2 & 1 & 1 & 9 & 15 & 9 & 14 & 9 \\
\hline & & 3 & 1 & 1 & 1 & 2 & 2 & 4 & 19 & 14 & 15 & 13 \\
\hline & & 4 & 3 & 2 & 4 & 2 & 2 & 6 & 8 & 5 & 7 & 6 \\
\hline & & 5 & 1 & 1 & 2 & 1 & 1 & 4 & 5 & 14 & 10 & 9 \\
\hline
\end{tabular}


Tabela C.24 - Dados obtidos para estrutura empacotada, sem aquecimento e Varsol@.

\begin{tabular}{|c|c|c|c|c|c|c|c|c|c|c|c|c|}
\hline & & & \multicolumn{10}{|c|}{ Tempo (s) } \\
\hline \multirow[t]{2}{*}{ Estrutura } & \multirow[t]{2}{*}{ Entrada } & \multirow[t]{2}{*}{ Saídas } & \multicolumn{5}{|c|}{ Injeção até detecção } & \multicolumn{5}{|c|}{ Duração da detecção } \\
\hline & & & 1 & 2 & 3 & 4 & 5 & 1 & 2 & 3 & 4 & 5 \\
\hline \multirow{5}{*}{ Chicana } & \multirow{5}{*}{1} & 1 & 1 & 1 & 2 & 2 & 3 & 4 & 2 & 5 & 3 & 4 \\
\hline & & 2 & 1 & 2 & 1 & 1 & 1 & 6 & 6 & 8 & 7 & 9 \\
\hline & & 3 & 3 & 5 & 4 & 6 & 5 & 8 & 4 & 7 & 5 & 5 \\
\hline & & 4 & 2 & 2 & 1 & 1 & 1 & 2 & 3 & 3 & 2 & 2 \\
\hline & & 5 & 1 & 2 & 3 & 3 & 3 & 6 & 5 & 6 & 4 & 7 \\
\hline
\end{tabular}

Tabela C.25 - Dados obtidos para estrutura empacotada, sem aquecimento e mistura (1 mL de mistura 1:1:1 de acetona + isopropanol + álcool etílico).

\begin{tabular}{|c|c|c|c|c|c|c|c|c|c|c|c|c|}
\hline \multirow[b]{2}{*}{ Estrutura } & \multirow[b]{2}{*}{ Entrada } & \multirow[b]{2}{*}{ Saídas } & \multicolumn{10}{|c|}{ Tempo (s) } \\
\hline & & & \multicolumn{5}{|c|}{ Injeção até detecção } & \multicolumn{5}{|c|}{ Duração da detecção } \\
\hline & & & 1 & 2 & 3 & 4 & 5 & 1 & 2 & 3 & 4 & 5 \\
\hline \multirow{5}{*}{ Chicana } & \multirow{5}{*}{1} & 1 & 1 & 1 & 2 & 2 & 2 & 12 & 15 & 20 & 19 & 21 \\
\hline & & 2 & 1 & 1 & 1 & 2 & 2 & 20 & 22 & 19 & 20 & 21 \\
\hline & & 3 & 3 & 4 & 4 & 5 & 5 & $28 / 6 / 2$ & $23 / 10 / 8$ & $16 / 11 / 12$ & $20 / 11 / 3$ & $15 / 10 / 5$ \\
\hline & & 4 & 4 & 4 & 3 & 2 & 1 & $22 / 10$ & $28 / 12 / 10$ & $23 / 9 / 8$ & $29 / 22 / 12 / 3$ & $32 / 20 / 11$ \\
\hline & & 5 & 4 & 3 & 3 & 3 & 2 & $33 / 10 / 2$ & $30 / 18 / 5$ & $22 / 10 / 5 / 2$ & $24 / 12 / 11$ & $25 / 16 / 8 / 2$ \\
\hline
\end{tabular}

\section{C.1.1.6 Condição 6}

Semelhante à condição 5, mas com aquecimento. Mesmo com aquecimento, o tempo da injeção até a detecção não sofre grandes alterações quando comparado com os tempos obtidos nas medidas sem aquecimento.

Tabela C.26 - Dados obtidos para estrutura empacotada, com aquecimento e isopropanol.

\begin{tabular}{|c|c|c|c|c|c|c|c|c|c|c|c|c|}
\hline & & & \multicolumn{10}{|c|}{ Tempo (s) } \\
\hline \multirow[t]{2}{*}{ Estrutura } & \multirow[t]{2}{*}{ Entrada } & \multirow[t]{2}{*}{ Saídas } & \multicolumn{5}{|c|}{ Injeção até detecção } & \multicolumn{5}{|c|}{ Duração da detecção } \\
\hline & & & 1 & 2 & 3 & 4 & 5 & 1 & 2 & 3 & 4 & 5 \\
\hline \multirow{5}{*}{ Chicana } & \multirow{5}{*}{1} & 1 & 1 & 2 & 3 & 1 & 1 & 10 & 8 & 16 & 7 & 6 \\
\hline & & 2 & 1 & 1 & 2 & 2 & 1 & 3 & 4 & 8 & 10 & 12 \\
\hline & & 3 & 1 & 2 & 3 & 2 & 1 & 5 & 4 & 5 & 6 & 5 \\
\hline & & 4 & 1 & 2 & 1 & 1 & 1 & 3 & 5 & 7 & 6 & 5 \\
\hline & & 5 & 1 & 2 & 2 & 2 & 1 & 13 & 20 & 18 & 10 & 12 \\
\hline
\end{tabular}

$-\rightarrow$ detecção quase imperceptível 
Tabela C.27 - Dados obtidos para estrutura empacotada, com aquecimento e gasolina comum.

\begin{tabular}{|c|c|c|c|c|c|c|c|c|c|c|c|c|}
\hline \multirow[b]{2}{*}{ Estrutura } & \multirow[b]{2}{*}{ Entrada } & \multirow{3}{*}{ Saídas } & \multicolumn{10}{|c|}{ Tempo (s) } \\
\hline & & & \multicolumn{5}{|c|}{ Injeção até detecção } & \multicolumn{5}{|c|}{ Duração da detecção } \\
\hline & & & 1 & 2 & 3 & 4 & 5 & 1 & 2 & 3 & 4 & 5 \\
\hline \multirow{5}{*}{ Chicana } & \multirow{5}{*}{1} & 1 & 1 & 1 & 1 & 3 & 2 & 16 & 11 & 17 & 12 & 12 \\
\hline & & 2 & 3 & 2 & 1 & 1 & 1 & 16 & 19 & 16 & 16 & 18 \\
\hline & & 3 & 1 & 1 & 1 & 1 & 1 & 25 & 22 & 23 & 25 & 28 \\
\hline & & 4 & 2 & 1 & 2 & 3 & 1 & 28 & 29 & 26 & 28 & 32 \\
\hline & & 5 & 1 & 1 & 2 & 2 & 2 & 31 & 30 & 33 & 30 & 31 \\
\hline
\end{tabular}

Tabela C.28 - Dados obtidos para estrutura empacotada, com aquecimento e acetona.

\begin{tabular}{|c|c|c|c|c|c|c|c|c|c|c|c|c|}
\hline & \multirow[b]{2}{*}{ Entrada } & \multirow{3}{*}{ Saídas } & \multicolumn{10}{|c|}{ Tempo (s) } \\
\hline Estrutura & & & \multicolumn{5}{|c|}{ Injeção até detecção } & \multicolumn{5}{|c|}{ Duração da detecção } \\
\hline & & & 1 & 2 & 3 & 4 & 5 & 1 & 2 & 3 & 4 & 5 \\
\hline \multirow{5}{*}{ Chicana } & \multirow{5}{*}{1} & 1 & 1 & 1 & 2 & 2 & 2 & 22 & 15 & 20 & 24 & 30 \\
\hline & & 2 & 1 & 1 & 2 & 2 & 1 & 18 & 20 & 25 & 28 & 20 \\
\hline & & 3 & 1 & 2 & 2 & 2 & 2 & 6 & 23 & 28 & 26 & 25 \\
\hline & & 4 & 1 & 2 & 2 & 2 & 2 & 13 & 14 & 16 & 16 & 14 \\
\hline & & 5 & 2 & 2 & 1 & 1 & 1 & 9 & 10 & 18 & 13 & 15 \\
\hline
\end{tabular}

Tabela C.29 - Dados obtidos para estrutura empacotada, com aquecimento e Varsol@.

\begin{tabular}{|c|c|c|c|c|c|c|c|c|c|c|c|c|}
\hline & & & \multicolumn{10}{|c|}{ Tempo (s) } \\
\hline Estrutura & Entrada & \multirow[t]{2}{*}{ Saídas } & \multicolumn{5}{|c|}{ Injeção até detecção } & \multicolumn{5}{|c|}{ Duração da deteccão } \\
\hline & & & 1 & 2 & 3 & 4 & 5 & 1 & 2 & 3 & 4 & 5 \\
\hline \multirow{5}{*}{ Chicana } & \multirow{5}{*}{1} & 1 & 1 & 1 & 1 & 2 & 1 & 6 & 5 & 10 & 13 & 8 \\
\hline & & 2 & 1 & 1 & 1 & 1 & 1 & 10 & 12 & 15 & 17 & 12 \\
\hline & & 3 & 1 & 2 & 1 & 1 & 3 & 10 & 12 & 9 & 10 & 15 \\
\hline & & 4 & 2 & 1 & 1 & 1 & 1 & 8 & 9 & 6 & 6 & 4 \\
\hline & & 5 & 1 & 1 & 2 & 2 & 3 & 8 & 7 & 7 & 8 & 8 \\
\hline
\end{tabular}

Tabela C.30 - Dados obtidos para estrutura empacotada, com aquecimento e mistura (1 mL de mistura 1:1:1 de acetona + isopropanol + álcool etílico).

\begin{tabular}{|c|c|c|c|c|c|c|c|c|c|c|c|c|}
\hline & \multirow[b]{2}{*}{ Entrada } & \multirow{3}{*}{ Saídas } & \multicolumn{10}{|c|}{ Tempo (s) } \\
\hline Estrutura & & & \multicolumn{5}{|c|}{ Injeção até detecção } & \multicolumn{5}{|c|}{ Duração da detecção } \\
\hline & & & 1 & 2 & 3 & 4 & 5 & 1 & 2 & 3 & 4 & 5 \\
\hline \multirow{5}{*}{ Chicana } & \multirow{5}{*}{1} & 1 & 1 & 1 & 1 & 1 & 2 & 18 & 20 & 20 & 21 & 25 \\
\hline & & 2 & 1 & 2 & 1 & 1 & 1 & 33 & 28 & 26 & 24 & 20 \\
\hline & & 3 & 2 & 2 & 1 & 1 & 1 & $30 / 12 / 4$ & $26 / 20$ & $20 / 15 / 4$ & $19 / 10 / 3$ & $16 / 12 / 8$ \\
\hline & & 4 & 1 & 2 & 2 & 2 & 1 & $28 / 9 / 3$ & $30 / 8$ & $29 / 12 / 2$ & $33 / 10 / 5$ & $40 / 8 / 2$ \\
\hline & & 5 & 1 & 2 & 2 & 3 & 1 & $38 / 8$ & $39 / 12 / 6$ & $29 / 12 / 9$ & $26 / 20 / 18 / 4$ & $28 / 20 / 4$ \\
\hline
\end{tabular}

\section{C.1.1.7 Condição 7}

O teste foi efetuado para verificar a reprodutibilidade do sistema e utilizou outro detector, de baixo custo, qualitativo e sem conexão com computador. Portanto, o 
resultado pode ser muito afetado pelo operador, o que requer cuidado na explicação do procedimento e na análise dos dados. De modo geral, o equipamento permite avaliar a saída da substância ou mistura baseando-se apenas no sinal sonoro. É necessária apenas uma calibração prévia, como descrita no manual do fabricante. É proveitoso estabelecer o início e o fim, isto é, o começo e o término da saída do produto sob análise de uma cela como também o ponto de máximo sonoro, que corresponde a uma maior concentração do produto em questão. As Tabelas C.31 à C.34 apresentam os resultados obtidos para os produtos testados em estrutura sem preenchimento. Para permitir averiguar a reprodutibilidade do procedimento, procedeu-se a cinco medidas para cada produto sob análise. O tempo de resposta desde o momento da injeção até a detecção, se deu quase que instantaneamente, aproximadamente 2 segundos, para quase todos reagentes, exceto para o $\operatorname{Varsol}{ }^{\circledR}$ onde houve situações em que o reagente não foi detectado. O tempo de detecção do momento em que o equipamento começa a medir até o momento em que para de emitir o sinal, é diferente para cada reagente. Assim, mesmo com a mudança do detector, a estrutura foi adequada para identificar a existência de mistura ou substância pura.

Tabela C.31 - Tempo para detecção de isopropanol na chicana sem preenchimento (5 medidas consecutivas) e tempo para total retirada do reagente.

\begin{tabular}{|c|c|c|c|c|c|c|c|c|c|c|}
\hline \multirow{3}{*}{ Celas de saídas } & \multicolumn{10}{|c|}{ Tempo } \\
\cline { 2 - 13 } & \multicolumn{3}{|c|}{$\begin{array}{c}\text { Tempo decorrido entre a Injeção } \\
\text { e o início da detecção (s) }\end{array}$} & \multicolumn{7}{|c|}{ Tempo de deteç̧̃o(s) } \\
\cline { 2 - 13 } & 1 & 2 & 3 & 4 & 5 & 1 & 2 & 3 & 4 & 5 \\
\hline $\mathbf{1}$ & 1 & 2 & 2 & 2 & 3 & 35 & 65 & 52 & 60 & 43 \\
\hline $\mathbf{2}$ & 3 & 4 & 3 & 4 & 3 & 47 & 51 & 47 & 41 & 42 \\
\hline $\mathbf{3}$ & 27 & 36 & 25 & 13 & 19 & 25 & 61 & 55 & 43 & 15 \\
\hline $\mathbf{4}$ & 8 & 10 & 8 & 6 & 5 & 32 & 18 & 37 & 44 & 35 \\
\hline $\mathbf{5}$ & 11 & 6 & 8 & 10 & 9 & 9 & 6 & 12 & 10 & 12 \\
\hline
\end{tabular}

Tabela C.32 - Tempo para detecção de acetona na estrutura sem preenchimento (5 medidas consecutivas) e tempo para total retirada do reagente.

\begin{tabular}{|c|c|c|c|c|c|c|c|c|c|c|}
\hline \multirow{3}{*}{ Celas de saída } & \multicolumn{10}{|c|}{ Tempo } \\
\hline & \multicolumn{5}{|c|}{$\begin{array}{c}\text { Tempo decorrido entre a } \\
\text { Injeção e o início da detecção } \\
\text { (s) }\end{array}$} & \multicolumn{5}{|c|}{ Tempo de detecção(s) } \\
\hline & 1 & 2 & 3 & 4 & 5 & 1 & 2 & 3 & 4 & 5 \\
\hline 1 & 1 & 1 & 2 & 1 & 2 & 200 & 135 & 120 & 107 & 76 \\
\hline 2 & 2 & 1 & 3 & 2 & 14 & 177 & 153 & 133 & 40 & 46 \\
\hline 3 & 2 & 1 & 3 & 3 & 1 & 42 & 120 & 73 & 54 & 35 \\
\hline 4 & 3 & 4 & 12 & 3 & 2 & $\begin{array}{c}43 / 9 / \\
7 / 14 / 4\end{array}$ & $\begin{array}{c}50 / 8 / \\
14 / 5 / 10\end{array}$ & $\begin{array}{c}61 / 9 / \\
22 / 3 / 5\end{array}$ & $\begin{array}{l}78 / 10 / \\
18 / 2 / 5\end{array}$ & $\begin{array}{c}42 / 5 / \\
22 / 8 / 12\end{array}$ \\
\hline 5 & 3 & 4 & 3 & 4 & 6 & $91 / 27 / 12$ & 145 & $\begin{array}{c}118 / 33 / \\
4 / 20\end{array}$ & $\begin{array}{c}25 / 10 / \\
36 / 6\end{array}$ & $\begin{array}{c}7 / 3 / \\
9 / 7 / 3\end{array}$ \\
\hline
\end{tabular}


Tabela C.33 - Tempo para detecção de gasolina na estrutura sem preenchimento ( 5 medidas consecutivas) e tempo para total retirada do reagente.

\begin{tabular}{|c|c|c|c|c|c|c|c|c|c|c|}
\hline \multirow{3}{*}{ Celas de saída } & \multicolumn{10}{|c|}{ Tempo } \\
\hline & \multicolumn{5}{|c|}{$\begin{array}{c}\text { Tempo decorrido entre a } \\
\text { Injeção e o início da detecção } \\
\text { (s) }\end{array}$} & \multicolumn{5}{|c|}{ Tempo de detecção (s) } \\
\hline & 1 & 2 & 3 & 4 & 5 & 1 & 2 & 3 & 4 & 5 \\
\hline 1 & 1 & 1 & 2 & 1 & 2 & 70 & 54 & 54 & 44 & 42 \\
\hline 2 & 2 & 2 & 2 & 3 & 4 & 62 & 11 & 216 & 110 & 107 \\
\hline 3 & - & 2 & 36 & 3 & 2 & - & 16 & 35 & 61 & 87 \\
\hline 4 & 2 & 2 & 3 & 3 & 2 & $\begin{array}{c}10 / 10 / \\
10 / 86 / 10\end{array}$ & $\begin{array}{c}11 / 12 / \\
11 / 75 / 13\end{array}$ & $\begin{array}{c}12 / 11 / \\
12 / 82 / 10\end{array}$ & $\begin{array}{c}11 / 12 / \\
13 / 89 / 10\end{array}$ & $\begin{array}{c}10 / 11 / \\
11 / 90 / 10\end{array}$ \\
\hline 5 & 4 & 3 & 5 & 3 & 4 & $\begin{array}{l}12 / 11 / \\
8 / 19 / 4\end{array}$ & $9 / 6 / 11$ & $5 / 2 / 8$ & $10 / 20 / 2$ & $5 / 12 / 10$ \\
\hline
\end{tabular}

Tabela C.34 - Tempo para detecção de Varsol ${ }^{\circledR}$ na estrutura sem preenchimento (5 medidas consecutivas) e tempo para total retirada do reagente.

\begin{tabular}{|c|c|c|c|c|c|c|c|c|c|c|c|}
\hline \multirow{3}{*}{ Celas de saída } & \multicolumn{9}{|c|}{ Tempo } \\
\cline { 2 - 12 } & \multicolumn{3}{|c|}{$\begin{array}{c}\text { Tempo decorrido entre a Injeção } \\
\text { e o início da detecção (s) }\end{array}$} & \multicolumn{7}{c|}{ Tempo de detecção (s) } \\
\cline { 2 - 12 } & 1 & 2 & 3 & 4 & 5 & 1 & 2 & 3 & 4 & 5 \\
\hline $\mathbf{1}$ & 2 & 1 & 2 & 3 & 2 & 12 & 19 & 17 & 14 & 12 \\
\hline $\mathbf{2}$ & 12 & 95 & - & - & 3 & 2 & 1 & - & - & 3 \\
\hline $\mathbf{3}$ & 25 & 3 & 44 & - & - & 2 & 26 & 4 & - & - \\
\hline $\mathbf{4}$ & - & - & - & - & - & - & - & - & - & - \\
\hline $\mathbf{5}$ & - & - & - & - & - & - & - & - & - & - \\
\hline
\end{tabular}

\section{C.1.1.8 Condição 8}

Semelhante às medidas da condição 7, testaram-se duas situações diferentes: modo estático, onde o reagente é aprisionado em eppendorfs e posteriormente medido pelo detector; modo dinâmico, o reagente é medido diretamente na saída de cada cela da estrutura. Estes testes correspondem a condições onde o refluxo poderia aumentar dentro da estrutura em uma situação semelhante à encontrada em colunas de destilação e à extração de solventes, em alguns casos. Também assemelham-se à criação de transiente, usado em testes físico-químicos para entender a cinética de reação, no presente caso, adsorção apenas.

Nos testes, fez-se a inserção pulsada de $0,01 \mathrm{~mL}$ de dois reagentes diferentes, no caso, um reagente puro, isopropanol, e uma mistura, solução $50 \%$ álcool etílico e água destilada. Com a mesma estrutura fizeram-se testes com variações de superfície: com ou sem deposição de filme a base de HMDS, de empacotamento (com ou sem anéis de Raschig). Efetuaram-se testes em temperatura ambiente e com aquecimento em 
torno de $70{ }^{\circ} \mathrm{C}$ na primeira cela e decrescendo a temperatura ao longo da estrutura até a temperatura ambiente $20^{\circ} \mathrm{C}$.

Modo dinâmico: a seqüência pode ser descrita assim: compressor de ar ligado por capilar à estrutura e mantendo um escoamento contínuo de ar como gás de arraste; neste capilar há uma região imediatamente anterior à entrada da estrutura onde é inserido o reagente; em cada saída da estrutura são colocados capilares com eppendorfs em suas extremidades onde será feita a captura do reagente para a medição; após a inserção do reagente, é colocado o prendedor nos capilares posteriores às estruturas, fechando as saídas todas ao mesmo tempo; o detector de gás está conectado ao computador; após coleta, abre-se cada eppendorf e mede-se a intensidade máxima obtida. Entre um teste e outro, a estrutura fica sob o efeito do gás de arraste por 10 minutos com o intuito de remover possíveis resíduos do reagente inserido anteriormente.

\section{C.1.1.8.1 Estrutura não empacotada}

Tabela C.35 - Reagente: isopropanol com aquecimento.

\begin{tabular}{|c|c|c|c|c|}
\hline Saídas & Testes & Pico de intensidade de freqüência $(\mathrm{Hz})$ & Tempo de pico $(s) * *$ & Tempo de detecção máxima * \\
\hline \multirow{3}{*}{1} & 1 & 139,4 & 20 & 30 \\
\hline & 2 & 269,4 & 12 & 68 \\
\hline & 3 & 112,3 & 9 & 120 \\
\hline \multirow{3}{*}{2} & 1 & 44,7 & 12 & 68 \\
\hline & 2 & 29,4 & 45 & 74 \\
\hline & 3 & 35,6 & 30 & 67 \\
\hline \multirow{3}{*}{3} & 1 & 210,7 & 28 & 72 \\
\hline & 2 & - & - & 120 \\
\hline & 3 & - & - & 120 \\
\hline \multirow{3}{*}{4} & 1 & 29,4 & 33 & 122 \\
\hline & 2 & - & - & 120 \\
\hline & 3 & - & - & 120 \\
\hline \multirow{3}{*}{5} & 1 & 4,9 & 29 & 120 \\
\hline & 2 & 4,9 & 22 & 89 \\
\hline & 3 & - & - & 120 \\
\hline
\end{tabular}


Tabela C.36 - Reagente isopropanol sem aquecimento.

\begin{tabular}{|c|c|c|c|c|}
\hline Saídas & Testes & Pico de intensidade de freqüência $(\mathrm{Hz})$ & Tempo de pico $(\mathrm{s}) * *$ & Tempo de detecção máxima * \\
\hline \multirow{3}{*}{1} & 1 & 93,6 & 42 & 78 \\
\hline & 2 & 49,2 & 21 & 112 \\
\hline & 3 & 89,2 & 22 & 132 \\
\hline \multirow{3}{*}{2} & 1 & 58,3 & 22 & 67 \\
\hline & 2 & - & - & 120 \\
\hline & 3 & - & - & 120 \\
\hline \multirow{3}{*}{3} & 1 & - & - & 120 \\
\hline & 2 & 9,8 & 34 & 65 \\
\hline & 3 & - & - & 120 \\
\hline \multirow{3}{*}{4} & 1 & - & - & 120 \\
\hline & 2 & 4,9 & 32 & 62 \\
\hline & 3 & - & - & 120 \\
\hline \multirow{3}{*}{5} & 1 & - & - & 120 \\
\hline & 2 & 44,1 & 56 & 65 \\
\hline & 3 & - & - & 120 \\
\hline
\end{tabular}

* - Tempo máximo de detecção de reagente saindo da estrutura para cada saída.

** - Tempo em que se obteve o pico de intensidade de freqüência.

Tabela C.37 - Reagente: solução 50\% álcool etílico e água destilada sem aquecimento.

\begin{tabular}{|c|c|c|c|c|}
\hline Saídas & Testes & Pico de intensidade de frequiência $(\mathrm{Hz})$ & Tempo de pico $(s) * *$ & Tempo de detecção máxima * \\
\hline \multirow{3}{*}{1} & 1 & 34,3 & 22 & 68 \\
\hline & 2 & 38,6 & 24 & 95 \\
\hline & 3 & 31,2 & 20 & 85 \\
\hline \multirow{3}{*}{2} & 1 & - & - & 120 \\
\hline & 2 & - & - & 120 \\
\hline & 3 & - & - & 120 \\
\hline \multirow{3}{*}{3} & 1 & - & - & 120 \\
\hline & 2 & - & - & 120 \\
\hline & 3 & - & - & 120 \\
\hline \multirow{3}{*}{4} & 1 & - & - & 120 \\
\hline & 2 & - & - & 120 \\
\hline & 3 & - & - & 120 \\
\hline \multirow{3}{*}{5} & 1 & - & - & 120 \\
\hline & 2 & - & - & 120 \\
\hline & 3 & - & - & 120 \\
\hline
\end{tabular}

* - Tempo máximo de detecção de reagente saindo da estrutura para cada saída.

** - Tempo em que se obteve o pico de intensidade de frequiência. 
Tabela C.38 - Reagente: solução $50 \%$ álcool etílico e água destilada com aquecimento.

\begin{tabular}{|c|c|c|c|c|}
\hline Saídas & Testes & Pico de intensidade de frequiência $(\mathrm{Hz})$ & Tempo de pico $(s) * *$ & Tempo de detecção máxima * \\
\hline \multirow{3}{*}{1} & 1 & 151,2 & 7 & 22 \\
\hline & 2 & 162,3 & 12 & 35 \\
\hline & 3 & 133,4 & 10 & 45 \\
\hline \multirow{3}{*}{2} & 1 & - & - & 120 \\
\hline & 2 & - & - & 120 \\
\hline & 3 & - & - & 120 \\
\hline \multirow{3}{*}{3} & 1 & - & - & 120 \\
\hline & 2 & - & - & 120 \\
\hline & 3 & - & - & 120 \\
\hline \multirow{3}{*}{4} & 1 & - & - & 120 \\
\hline & 2 & - & - & 120 \\
\hline & 3 & - & - & 120 \\
\hline \multirow{3}{*}{5} & 1 & - & - & 120 \\
\hline & 2 & - & - & 120 \\
\hline & 3 & - & - & 120 \\
\hline
\end{tabular}

* - Tempo máximo de detecção de reagente saindo da estrutura para cada saída.

** - Tempo em que se obteve o pico de intensidade de freqüência.

\section{C.1.1.8.2 Estrutura não empacotada e com filme a base de HMDS}

Tabela C.39 - Reagente: isopropanol sem aquecimento.

\begin{tabular}{|c|c|c|c|c|}
\hline Saídas & Testes & Pico de intensidade de freqüência $(\mathrm{Hz})$ & Tempo de pico $(\mathrm{s})$ *** & Tempo de detecção máxima * \\
\hline \multirow{3}{*}{1} & 1 & 102,3 & 40 & 87 \\
\hline & 2 & 65,4 & 18 & 98 \\
\hline & 3 & 98,3 & 21 & 102 \\
\hline & & & & \\
\hline \multirow{3}{*}{2} & 1 & 52,1 & 11 & 60 \\
\hline & 2 & 45,2 & 10 & 72 \\
\hline & 3 & 50,1 & 15 & 90 \\
\hline & & & & \\
\hline \multirow{3}{*}{3} & 1 & 4,9 & 30 & 48 \\
\hline & 2 & 9,8 & 45 & 50 \\
\hline & 3 & 4,9 & 21 & 33 \\
\hline & & & & \\
\hline \multirow{3}{*}{4} & 1 & 4,9 & 30 & 42 \\
\hline & 2 & 4,9 & 28 & 35 \\
\hline & 3 & 9,8 & 25 & 32 \\
\hline & & & & \\
\hline \multirow{3}{*}{5} & 1 & 35,6 & 55 & 78 \\
\hline & 2 & 40,1 & 45 & 65 \\
\hline & 3 & 38,9 & 52 & 72 \\
\hline
\end{tabular}

* - Tempo máximo de detecção de reagente saindo da estrutura para cada saída.

** - Tempo em que se obteve o pico de intensidade de frequiência. 
Tabela C.40 - Reagente: isopropanol com aquecimento.

\begin{tabular}{|c|c|c|c|c|}
\hline Saídas & Testes & Pico de intensidade de freqüência $(\mathrm{Hz})$ & Tempo de pico (s) ** & Tempo de detecção máxima * \\
\hline \multirow{3}{*}{1} & 1 & 110,3 & 23 & 45 \\
\hline & 2 & 278,3 & 20 & 72 \\
\hline & 3 & 265,4 & 18 & 98 \\
\hline \multirow{3}{*}{2} & 1 & 65,3 & 20 & 123 \\
\hline & 2 & 66,2 & 21 & 124 \\
\hline & 3 & 75,3 & 25 & 135 \\
\hline \multirow{3}{*}{3} & 1 & 223,3 & 25 & 78 \\
\hline & 2 & 254,3 & 28 & 79 \\
\hline & 3 & 241,2 & 29 & 98 \\
\hline \multirow{3}{*}{4} & 1 & 30,1 & 33 & 78 \\
\hline & 2 & 34,5 & 35 & 86 \\
\hline & 3 & 36,3 & 36 & 88 \\
\hline \multirow{3}{*}{5} & 1 & 4,9 & 33 & 126 \\
\hline & 2 & 9,8 & 35 & 98 \\
\hline & 3 & 4,9 & 32 & 112 \\
\hline
\end{tabular}

* - Tempo máximo de detecção de reagente saindo da estrutura para cada saída.

** - Tempo em que se obteve o pico de intensidade de freqüência.

Tabela C.41 - Reagente: solução aquosa 50\% em vol. de álcool etílico sem aquecimento.

\begin{tabular}{|c|c|c|c|c|}
\hline Saídas & Testes & Pico de intensidade de freqüência $(\mathrm{Hz})$ & Tempo de pico $(\mathrm{s}) * *$ & Tempo de detecção máxima * \\
\hline \multirow{3}{*}{1} & 1 & 42,3 & 20 & 72 \\
\hline & 2 & 45,6 & 25 & 88 \\
\hline & 3 & 52,1 & 28 & 75 \\
\hline \multirow{3}{*}{2} & 1 & - & - & 120 \\
\hline & 2 & - & - & 120 \\
\hline & 3 & - & - & 120 \\
\hline \multirow{3}{*}{3} & 1 & - & - & 120 \\
\hline & 2 & - & - & 120 \\
\hline & 3 & - & - & 120 \\
\hline \multirow{3}{*}{4} & 1 & - & - & 120 \\
\hline & 2 & - & - & 120 \\
\hline & 3 & - & - & 120 \\
\hline \multirow{3}{*}{5} & 1 & - & - & 120 \\
\hline & 2 & - & - & 120 \\
\hline & 3 & - & - & 120 \\
\hline
\end{tabular}

* - Tempo máximo de detecção de reagente saindo da estrutura para cada saída.

** - Tempo em que se obteve o pico de intensidade de freqüência. 
Tabela C.42 - Reagente: solução aquosa $50 \%$ em vol. de álcool etílico com aquecimento.

\begin{tabular}{|c|c|c|c|c|}
\hline Saídas & Testes & Pico de intensidade de freqüência $(\mathrm{Hz})$ & Tempo de pico (s) ** & Tempo de detecção máxima * \\
\hline \multirow{3}{*}{1} & 1 & 178,2 & 8 & 22 \\
\hline & 2 & 182,1 & 5 & 32 \\
\hline & 3 & 165,3 & 12 & 33 \\
\hline \multirow{3}{*}{2} & 1 & - & - & 120 \\
\hline & 2 & - & - & 120 \\
\hline & 3 & - & - & 120 \\
\hline \multirow{3}{*}{3} & 1 & - & - & 120 \\
\hline & 2 & - & - & 120 \\
\hline & 3 & - & - & 120 \\
\hline \multirow{3}{*}{4} & 1 & - & - & 120 \\
\hline & 2 & - & - & 120 \\
\hline & 3 & - & - & 120 \\
\hline \multirow{3}{*}{5} & 1 & - & - & 120 \\
\hline & 2 & - & - & 120 \\
\hline & 3 & - & - & 120 \\
\hline
\end{tabular}

* - Tempo máximo de detecção de reagente saindo da estrutura para cada saída.

** - Tempo em que se obteve o pico de intensidade de freqüência.

\section{C.1.1.8.3 Chicana empacotada}

Tabela C.43 - Reagente: isopropanol sem aquecimento.

\begin{tabular}{|c|c|c|c|c|}
\hline Saídas & Testes & Pico de intensidade de frequiência $(\mathrm{Hz})$ & Tempo de pico $(s) * *$ & Tempo de detecção máxima * \\
\hline \multirow{3}{*}{1} & 1 & 102,3 & 55 & 60 \\
\hline & 2 & 56,2 & 68 & 72 \\
\hline & 3 & 45,5 & 78 & 88 \\
\hline \multirow{3}{*}{2} & 1 & 4,9 & 45 & 50 \\
\hline & 2 & 4,9 & 98 & 102 \\
\hline & 3 & 9,8 & 87 & 99 \\
\hline \multirow{3}{*}{3} & 1 & 4,9 & 3 & 10 \\
\hline & 2 & 4,9 & 6 & 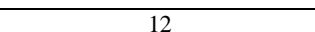 \\
\hline & 3 & 4,9 & 7 & 9 \\
\hline & & & & \\
\hline \multirow{3}{*}{4} & 1 & 4,9 & 2 & 8 \\
\hline & 2 & 4,9 & 5 & 8 \\
\hline & 3 & 4,9 & 2 & 5 \\
\hline \multirow{3}{*}{5} & 1 & 4,9 & 7 & 12 \\
\hline & 2 & 4,9 & 12 & 15 \\
\hline & 3 & 4,9 & 6 & 9 \\
\hline
\end{tabular}

* - Tempo máximo de detecção de reagente saindo da estrutura para cada saída.

** - Tempo em que se obteve o pico de intensidade de freqüência. 
Tabela C.44 - Reagente: isopropanol com aquecimento.

\begin{tabular}{|c|c|c|c|c|}
\hline Saídas & Testes & Pico de intensidade de freqüência $(\mathrm{Hz})$ & Tempo de pico (s) $* *$ & Tempo de detecção máxima * \\
\hline \multirow{3}{*}{1} & 1 & 106,3 & 45 & 78 \\
\hline & 2 & 102,3 & 35 & 85 \\
\hline & 3 & 98,8 & 26 & 97 \\
\hline \multirow{3}{*}{2} & 1 & 14,7 & 32 & 62 \\
\hline & 2 & 21,3 & 20 & 78 \\
\hline & 3 & 22,3 & 22 & 102 \\
\hline \multirow{3}{*}{3} & 1 & 14,2 & 2 & 16 \\
\hline & 2 & 9,8 & 9 & 18 \\
\hline & 3 & 16,3 & 12 & 12 \\
\hline \multirow{3}{*}{4} & 1 & 4,9 & 3 & 12 \\
\hline & 2 & 4,9 & 7 & 10 \\
\hline & 3 & 4,9 & 7 & 9 \\
\hline \multirow{3}{*}{5} & 1 & 4,9 & 12 & 18 \\
\hline & 2 & 4,9 & 14 & 22 \\
\hline & 3 & 4,9 & 14 & 20 \\
\hline
\end{tabular}

* - Tempo máximo de detecção de reagente saindo da estrutura para cada saída.

** - Tempo em que se obteve o pico de intensidade de frequiência.

Tabela C.45 - Reagente: solução aquosa $50 \%$ em vol. de álcool etílico sem aquecimento.

\begin{tabular}{|c|c|c|c|c|}
\hline Saídas & Testes & Pico de intensidade de freqüência $(\mathrm{Hz})$ & Tempo de pico $(\mathrm{s}) * *$ & Tempo de detecção máxima * \\
\hline \multirow{3}{*}{1} & 1 & 24,5 & 155 & 300 \\
\hline & 2 & 25,6 & 235 & 320 \\
\hline & 3 & 33,5 & 335 & 350 \\
\hline \multirow{3}{*}{2} & 1 & - & - & 120 \\
\hline & 2 & - & - & 120 \\
\hline & 3 & - & - & 120 \\
\hline \multirow{3}{*}{3} & 1 & - & - & 120 \\
\hline & 2 & - & - & 120 \\
\hline & 3 & - & - & 120 \\
\hline \multirow{3}{*}{4} & 1 & - & - & 120 \\
\hline & 2 & - & - & 120 \\
\hline & 3 & - & - & 120 \\
\hline \multirow{3}{*}{5} & 1 & - & - & 120 \\
\hline & 2 & - & - & 120 \\
\hline & 3 & - & - & 120 \\
\hline
\end{tabular}

* - Tempo máximo de detecção de reagente saindo da estrutura para cada saída.

** - Tempo em que se obteve o pico de intensidade de freqüência. 
Tabela C.46 - Reagente: solução aquosa $50 \%$ em vol. de álcool etílico com aquecimento.

\begin{tabular}{|c|c|c|c|c|}
\hline Saídas & Testes & Pico de intensidade de freqüência $(\mathrm{Hz})$ & Tempo de pico $(s) * *$ & Tempo de detecção máxima * \\
\hline \multirow{3}{*}{1} & 1 & 35,2 & 102 & 320 \\
\hline & 2 & 44,2 & 198 & 410 \\
\hline & 3 & 38,9 & 189 & 320 \\
\hline \multirow{3}{*}{2} & 1 & 25,3 & 15 & 20 \\
\hline & 2 & 14,7 & 22 & 35 \\
\hline & 3 & 19,2 & 19 & 45 \\
\hline \multirow{3}{*}{3} & 1 & - & - & 120 \\
\hline & 2 & - & - & 120 \\
\hline & 3 & - & - & 120 \\
\hline \multirow{3}{*}{4} & 1 & - & - & 120 \\
\hline & 2 & - & - & 120 \\
\hline & 3 & - & - & 120 \\
\hline \multirow{3}{*}{5} & 1 & - & - & 120 \\
\hline & 2 & - & - & 120 \\
\hline & 3 & - & - & 120 \\
\hline
\end{tabular}

\section{C.1.1.8.4 Chicana empacotada e com filme a base de HMDS depositado}

Tabela C.47 - Reagente: isopropanol sem aquecimento.

\begin{tabular}{|c|c|c|c|c|}
\hline Saídas & Testes & Pico de intensidade de freqüência $(\mathrm{Hz})$ & Tempo de pico (s) ** & Tempo de detecção máxima * \\
\hline \multirow{3}{*}{1} & 1 & 303,2 & 2 & 62 \\
\hline & 2 & 290,2 & 5 & 78 \\
\hline & 3 & 304,1 & 8 & 98 \\
\hline \multirow{3}{*}{2} & 1 & 9,8 & 30 & 68 \\
\hline & 2 & 12,7 & 35 & 74 \\
\hline & 3 & 14,7 & 30 & 88 \\
\hline \multirow{3}{*}{3} & 1 & 9,8 & 20 & 32 \\
\hline & 2 & 14,7 & 63 & 79 \\
\hline & 3 & 19,6 & 100 & 120 \\
\hline \multirow{3}{*}{4} & 1 & 4,9 & 3 & 32 \\
\hline & 2 & - & - & 120 \\
\hline & 3 & - & - & 120 \\
\hline \multirow{3}{*}{5} & 1 & 4,9 & 10 & 20 \\
\hline & 2 & - & - & 120 \\
\hline & 3 & - & - & 120 \\
\hline
\end{tabular}


Tabela C.48 - Reagente: isopropanol com aquecimento.

\begin{tabular}{|c|c|c|c|c|}
\hline Saídas & Testes & Pico de intensidade de freqüência $(\mathrm{Hz})$ & Tempo de pico $(s) * *$ & Tempo de detecção máxima * \\
\hline \multirow{3}{*}{1} & 1 & 14,7 & 11 & 20 \\
\hline & 2 & 24,5 & 44 & 87 \\
\hline & 3 & 26,3 & 42 & 98 \\
\hline \multirow{3}{*}{2} & 1 & - & - & 120 \\
\hline & 2 & - & - & 120 \\
\hline & 3 & - & - & 120 \\
\hline \multirow{3}{*}{3} & 1 & - & - & 120 \\
\hline & 2 & - & - & 120 \\
\hline & 3 & - & - & 120 \\
\hline \multirow{3}{*}{4} & 1 & - & - & 120 \\
\hline & 2 & - & - & 120 \\
\hline & 3 & - & - & 120 \\
\hline \multirow{3}{*}{5} & 1 & - & - & 120 \\
\hline & 2 & - & - & 120 \\
\hline & 3 & - & - & 120 \\
\hline
\end{tabular}

* - Tempo máximo de detecção de reagente saindo da estrutura para cada saída.

** - Tempo em que se obteve o pico de intensidade de freqüência.

Tabela C.49 - Reagente: solução aquosa $50 \%$ em vol. de álcool etílico sem aquecimento.

\begin{tabular}{|c|c|c|c|c|}
\hline Saídas & Testes & Pico de intensidade de freqüência $(\mathrm{Hz})$ & Tempo de pico $(s) * *$ & Tempo de detecção máxima * \\
\hline \multirow{3}{*}{1} & 1 & 274,3 & 5 & 21 \\
\hline & 2 & 281,2 & 12 & 30 \\
\hline & 3 & 263,1 & 16 & 20 \\
\hline \multirow{3}{*}{2} & 1 & - & - & 120 \\
\hline & 2 & - & - & 120 \\
\hline & 3 & - & - & 120 \\
\hline \multirow{3}{*}{3} & 1 & - & - & 120 \\
\hline & 2 & - & - & 120 \\
\hline & 3 & - & - & 120 \\
\hline \multirow{3}{*}{4} & 1 & - & - & 120 \\
\hline & 2 & - & - & 120 \\
\hline & 3 & - & - & 120 \\
\hline \multirow{3}{*}{5} & 1 & - & - & 120 \\
\hline & 2 & - & - & 120 \\
\hline & 3 & - & - & 120 \\
\hline
\end{tabular}

* - Tempo máximo de detecção de reagente saindo da estrutura para cada saída.

** - Tempo em que se obteve o pico de intensidade de freqüência. 
Tabela C.50 - Reagente: solução aquosa $50 \%$ em vol. de álcool etílico com aquecimento.

\begin{tabular}{|c|c|c|c|c|}
\hline Saídas & Testes & Pico de intensidade de freqüência $(\mathrm{Hz})$ & Tempo de pico $(s) * *$ & Tempo de detecção máxima * \\
\hline \multirow{3}{*}{1} & 1 & 280,2 & 13 & 20 \\
\hline & 2 & 279,3 & 15 & 23 \\
\hline & 3 & 288,1 & 22 & 30 \\
\hline \multirow{3}{*}{2} & 1 & 53,9 & 10 & 20 \\
\hline & 2 & 3,07 & 3 & 8 \\
\hline & 3 & - & - & 120 \\
\hline \multirow{3}{*}{3} & 1 & 4,9 & 7 & 10 \\
\hline & 2 & - & - & 120 \\
\hline & 3 & - & - & 120 \\
\hline \multirow{3}{*}{4} & 1 & 4,9 & 8 & 10 \\
\hline & 2 & - & - & 120 \\
\hline & 3 & - & - & 120 \\
\hline \multirow{3}{*}{5} & 1 & 4,9 & 5 & 8 \\
\hline & 2 & - & - & 120 \\
\hline & 3 & - & - & 120 \\
\hline
\end{tabular}

Modo estático: similar ao modo dinâmico até a inserção do reagente, neste caso ocorre o aprisionamento do reagente dentro da estrutura. Antes de realizar a inserção do reagente fecham-se todas as saídas. É feita inserção e mantém-se ligado o compressor de ar por 1 minuto. Abrem-se as celas rapidamente e fecham-se também rapidamente e mede-se a intensidade de freqüência em cada eppendorf ligado a cada saída utilizando o detector de gás que está conectado ao computador. Entre um teste e outro, a estrutura fica sob o efeito do gás de arraste por 10 minutos com o intuito de remover possíveis resíduos provenientes do reagente inserido anteriormente. 


\section{C.1.1.8.5 Chicana não empacotada}

Tabela C.51 - Reagente: isopropanol sem aquecimento.

\begin{tabular}{|c|c|c|c|c|}
\hline Saídas & Testes & Pico de intensidade de freqüência $(\mathrm{Hz})$ & Tempo de pico $(s) * *$ & Tempo de detecção máxima * \\
\hline \multirow{3}{*}{1} & 1 & 235,2 & 15 & 108 \\
\hline & 2 & 249,9 & 25 & 92 \\
\hline & 3 & 222,4 & 19 & 118 \\
\hline \multirow{3}{*}{2} & 1 & 102,9 & 28 & 84 \\
\hline & 2 & 106,3 & 25 & 93 \\
\hline & 3 & 98,7 & 18 & 76 \\
\hline \multirow{3}{*}{3} & 1 & 44,1 & 15 & 82 \\
\hline & 2 & 38,6 & 12 & 93 \\
\hline & 3 & 40,2 & 20 & 88 \\
\hline \multirow{3}{*}{4} & 1 & 19,6 & 22 & 58 \\
\hline & 2 & 22,3 & 25 & 56 \\
\hline & 3 & 19,2 & 28 & 72 \\
\hline \multirow{3}{*}{5} & 1 & 4,9 & 12 & 30 \\
\hline & 2 & 4,9 & 18 & 25 \\
\hline & 3 & 9,8 & 15 & 22 \\
\hline
\end{tabular}

* - Tempo máximo de detecção de reagente saindo da estrutura para cada saída.

** - Tempo em que se obteve o pico de intensidade de freqüência.

Tabela C.52 - Reagente: isopropanol com aquecimento.

\begin{tabular}{|c|c|c|c|c|}
\hline Saídas & Testes & Pico de intensidade de freqüência $(\mathrm{Hz})$ & Tempo de pico $(\mathrm{s}) * *$ & Tempo de detecção máxima * \\
\hline \multirow{3}{*}{1} & 1 & 255,3 & 12 & 70 \\
\hline & 2 & 262,3 & 10 & 85 \\
\hline & 3 & 254,3 & 15 & 65 \\
\hline \multirow{3}{*}{2} & 1 & 122,3 & 24 & 78 \\
\hline & 2 & 115,3 & 30 & 98 \\
\hline & 3 & 132,2 & 33 & 68 \\
\hline \multirow{3}{*}{3} & 1 & 52,3 & 21 & 45 \\
\hline & 2 & 59,5 & 28 & 58 \\
\hline & 3 & 68,3 & 30 & 42 \\
\hline \multirow{3}{*}{4} & 1 & 22,3 & 20 & 40 \\
\hline & 2 & 31,4 & 22 & 45 \\
\hline & 3 & 32,1 & 25 & 55 \\
\hline \multirow{3}{*}{5} & 1 & 19,4 & 8 & 20 \\
\hline & 2 & 16,7 & 12 & 16 \\
\hline & 3 & 14,5 & 17 & 20 \\
\hline
\end{tabular}

* - Tempo máximo de detecção de reagente saindo da estrutura para cada saída.

** - Tempo em que se obteve o pico de intensidade de freqüência. 
Tabela C.53 - Reagente: solução aquosa 50\% em vol. de álcool etílico sem aquecimento.

\begin{tabular}{|c|c|c|c|c|}
\hline Saídas & Testes & Pico de intensidade de frequiência $(\mathrm{Hz})$ & Tempo de pico $(s) * *$ & Tempo de detecção máxima * \\
\hline \multirow{3}{*}{1} & 1 & 44,3 & 18 & 78 \\
\hline & 2 & 42,5 & 25 & 102 \\
\hline & 3 & 57,3 & 21 & 98 \\
\hline \multirow{3}{*}{2} & 1 & 33,3 & 10 & 120 \\
\hline & 2 & 25,3 & 10 & 120 \\
\hline & 3 & - & - & 120 \\
\hline \multirow{3}{*}{3} & 1 & - & - & 120 \\
\hline & 2 & - & - & 120 \\
\hline & 3 & - & - & 120 \\
\hline \multirow{3}{*}{4} & 1 & - & - & 120 \\
\hline & 2 & - & - & 120 \\
\hline & 3 & - & - & 120 \\
\hline \multirow{3}{*}{5} & 1 & - & - & 120 \\
\hline & 2 & - & - & 120 \\
\hline & 3 & - & - & 120 \\
\hline
\end{tabular}

* - Tempo máximo de detecção de reagente saindo da estrutura para cada saída.

** - Tempo em que se obteve o pico de intensidade de freqüência.

Tabela C.54 - Reagente: solução aquosa $50 \%$ em vol. de álcool etílico com aquecimento.

\begin{tabular}{|c|c|c|c|c|}
\hline Saídas & Testes & Pico de intensidade de freqüência $(\mathrm{Hz})$ & Tempo de pico $(\mathrm{s}) * *$ & Tempo de deteç̧ão máxima * \\
\hline \multirow{3}{*}{1} & 1 & 135,6 & 14 & 79 \\
\hline & 2 & 142,3 & 24 & 98 \\
\hline & 3 & 156,8 & 20 & 95 \\
\hline \multirow{3}{*}{2} & 1 & - & - & 120 \\
\hline & 2 & - & - & 120 \\
\hline & 3 & - & - & 120 \\
\hline \multirow{3}{*}{3} & 1 & - & - & 120 \\
\hline & 2 & - & - & 120 \\
\hline & 3 & - & - & 120 \\
\hline \multirow{3}{*}{4} & 1 & - & - & 120 \\
\hline & 2 & - & - & 120 \\
\hline & 3 & - & - & 120 \\
\hline \multirow{3}{*}{5} & 1 & - & - & 120 \\
\hline & 2 & - & - & 120 \\
\hline & 3 & - & - & 120 \\
\hline
\end{tabular}

* - Tempo máximo de detecção de reagente saindo da estrutura para cada saída.

** - Tempo em que se obteve o pico de intensidade de freqüência. 
C.1.1.8.6 Chicana não empacotada e com filme a base de HMDS

Tabela C.55 - Reagente: isopropanol sem aquecimento.

\begin{tabular}{|c|c|c|c|c|}
\hline Saídas & Testes & Pico de intensidade de freqüência $(\mathrm{Hz})$ & Tempo de pico $(s) * *$ & Tempo de detecção máxima * \\
\hline \multirow{3}{*}{1} & 1 & 114,3 & 20 & 102 \\
\hline & 2 & 98,4 & 13 & 99 \\
\hline & 3 & 102,3 & 15 & 97 \\
\hline \multirow{3}{*}{2} & 1 & 68,2 & 8 & 75 \\
\hline & 2 & 74,2 & 12 & 85 \\
\hline & 3 & 55,9 & 18 & 87 \\
\hline \multirow{3}{*}{3} & 1 & 4,9 & 22 & 32 \\
\hline & 2 & 4,9 & 30 & 45 \\
\hline & 3 & 4,9 & 28 & 30 \\
\hline \multirow{3}{*}{4} & 1 & 4,9 & 33 & 46 \\
\hline & 2 & 4,9 & 35 & 40 \\
\hline & 3 & 4,9 & 41 & 48 \\
\hline \multirow{3}{*}{5} & 1 & 44,1 & 62 & 88 \\
\hline & 2 & 42,3 & 52 & 60 \\
\hline & 3 & 35,6 & 55 & 68 \\
\hline
\end{tabular}

* - Tempo máximo de detecção de reagente saindo da estrutura para cada saída.

** - Tempo em que se obteve o pico de intensidade de freqüência.

Tabela C.56 - Reagente: isopropanol com aquecimento.

\begin{tabular}{|c|c|c|c|c|}
\hline Saídas & Testes & Pico de intensidade de freqüuência $(\mathrm{Hz})$ & Tempo de pico (s) ** & Tempo de detecção máxima * \\
\hline \multirow{3}{*}{1} & 1 & 120,3 & 12 & 99 \\
\hline & 2 & 112,3 & 10 & 102 \\
\hline & 3 & 110,1 & 12 & 78 \\
\hline \multirow{3}{*}{2} & 1 & 72,1 & 9 & 65 \\
\hline & 2 & 76,2 & 11 & 78 \\
\hline & 3 & 98,2 & 10 & 88 \\
\hline \multirow{3}{*}{3} & 1 & 4,9 & 15 & 20 \\
\hline & 2 & 4,9 & 18 & 22 \\
\hline & 3 & 4,9 & 10 & 20 \\
\hline \multirow{3}{*}{4} & 1 & 4,9 & 12 & 20 \\
\hline & 2 & 4,9 & 20 & 23 \\
\hline & 3 & 4,9 & 15 & 33 \\
\hline \multirow{3}{*}{5} & 1 & 50,1 & 32 & 52 \\
\hline & 2 & 43,2 & 45 & 50 \\
\hline & 3 & 44,5 & 40 & 45 \\
\hline
\end{tabular}

* - Tempo máximo de detecção de reagente saindo da estrutura para cada saída.

** - Tempo em que se obteve o pico de intensidade de freqüência. 
Tabela C.57 - Reagente: solução aquosa $50 \%$ em vol. de álcool etílico sem aquecimento.

\begin{tabular}{|c|c|c|c|c|}
\hline Saídas & Testes & Pico de intensidade de freqüência $(\mathrm{Hz})$ & Tempo de pico $(s) * *$ & Tempo de detecção máxima * \\
\hline \multirow{3}{*}{1} & 1 & 50,3 & 22 & 45 \\
\hline & 2 & 46,3 & 32 & 80 \\
\hline & 3 & 48,5 & 33 & 88 \\
\hline \multirow{3}{*}{2} & 1 & - & - & 120 \\
\hline & 2 & - & - & 120 \\
\hline & 3 & - & - & 120 \\
\hline \multirow{3}{*}{3} & 1 & - & - & 120 \\
\hline & 2 & - & - & 120 \\
\hline & 3 & - & - & 120 \\
\hline \multirow{3}{*}{4} & 1 & - & - & 120 \\
\hline & 2 & - & - & 120 \\
\hline & 3 & - & - & 120 \\
\hline \multirow{3}{*}{5} & 1 & - & - & 120 \\
\hline & 2 & - & - & 120 \\
\hline & 3 & - & - & 120 \\
\hline
\end{tabular}

* - Tempo máximo de detecção de reagente saindo da estrutura para cada saída.

** - Tempo em que se obteve o pico de intensidade de freqüência.

Tabela C.58 - Reagente: solução aquosa $50 \%$ em vol. de álcool etílico com aquecimento.

\begin{tabular}{|c|c|c|c|c|}
\hline Saídas & Testes & Pico de intensidade de frequiência $(\mathrm{Hz})$ & Tempo de pico (s) ** & Tempo de detecção máxima * \\
\hline \multirow{3}{*}{1} & 1 & 182,3 & 12 & 25 \\
\hline & 2 & 185,2 & 15 & 55 \\
\hline & 3 & 174,3 & 10 & 33 \\
\hline & & & & \\
\hline \multirow{3}{*}{2} & 1 & - & - & 120 \\
\hline & 2 & - & - & 120 \\
\hline & 3 & - & - & 120 \\
\hline & & & & \\
\hline \multirow{3}{*}{3} & 1 & - & - & 120 \\
\hline & 2 & - & - & 120 \\
\hline & 3 & - & - & 120 \\
\hline & & & & \\
\hline \multirow{3}{*}{4} & 1 & - & - & 120 \\
\hline & 2 & - & - & 120 \\
\hline & 3 & - & - & 120 \\
\hline & & & & \\
\hline \multirow{3}{*}{5} & 1 & - & - & 120 \\
\hline & 2 & - & - & 120 \\
\hline & 3 & - & - & 120 \\
\hline
\end{tabular}

* - Tempo máximo de detecção de reagente saindo da estrutura para cada saída.

** - Tempo em que se obteve o pico de intensidade de freqüência. 
C.1.1.8.7 Chicana empacotada

Tabela C.59 - Reagente: isopropanol sem aquecimento.

\begin{tabular}{|c|c|c|c|c|}
\hline Saídas & Testes & Pico de intensidade de frequiência $(\mathrm{Hz})$ & Tempo de pico (s) *** & Tempo de detecção máxima * \\
\hline \multirow{3}{*}{1} & 1 & 45,6 & 45 & 50 \\
\hline & 2 & 55,3 & 40 & 62 \\
\hline & 3 & 58,6 & 33 & 60 \\
\hline \multirow{4}{*}{2} & & & & \\
\hline & 1 & 9,8 & 80 & 90 \\
\hline & 2 & 4,9 & 78 & 100 \\
\hline & 3 & - & - & - \\
\hline & & & & \\
\hline \multirow{3}{*}{3} & 1 & 4,9 & 50 & 98 \\
\hline & 2 & - & - & - \\
\hline & 3 & 9,8 & 65 & 100 \\
\hline & & & & \\
\hline \multirow{3}{*}{4} & 1 & - & - & 120 \\
\hline & 2 & - & - & 120 \\
\hline & 3 & - & - & 120 \\
\hline & & & & \\
\hline \multirow{3}{*}{5} & 1 & - & - & 120 \\
\hline & 2 & - & - & 120 \\
\hline & 3 & - & - & 120 \\
\hline
\end{tabular}

* - Tempo máximo de detecção de reagente saindo da estrutura para cada saída.

** - Tempo em que se obteve o pico de intensidade de freqüência.

Tabela C.60 - Reagente: isopropanol com aquecimento.

\begin{tabular}{|c|c|c|c|c|}
\hline Saídas & Testes & Pico de intensidade de freqüência $(\mathrm{Hz})$ & Tempo de pico (s) $* *$ & Tempo de detecção máxima * \\
\hline \multirow{3}{*}{1} & 1 & 55,6 & 35 & 45 \\
\hline & 2 & 65,2 & 32 & 50 \\
\hline & 3 & 60,3 & 28 & 52 \\
\hline \multirow{3}{*}{2} & 1 & 12,3 & 22 & 30 \\
\hline & 2 & 17,5 & 28 & 45 \\
\hline & 3 & 20,1 & 21 & 41 \\
\hline \multirow{3}{*}{3} & 1 & 11,2 & 4 & 10 \\
\hline & 2 & 10,4 & 5 & 13 \\
\hline & 3 & 11,8 & 7 & 15 \\
\hline \multirow{3}{*}{4} & 1 & - & - & 120 \\
\hline & 2 & - & - & 120 \\
\hline & 3 & - & - & 120 \\
\hline \multirow{3}{*}{5} & 1 & - & - & 120 \\
\hline & 2 & - & - & 120 \\
\hline & 3 & - & - & 120 \\
\hline
\end{tabular}

* - Tempo máximo de detecção de reagente saindo da estrutura para cada saída.

** - Tempo em que se obteve o pico de intensidade de freqüência. 
Tabela C.61 - Reagente: solução aquosa $50 \%$ em vol. de álcool etílico sem aquecimento.

\begin{tabular}{|c|c|c|c|c|}
\hline Saídas & Testes & Pico de intensidade de frequiência $(\mathrm{Hz})$ & Tempo de pico (s) $* *$ & Tempo de detecção máxima * \\
\hline \multirow{3}{*}{1} & 1 & 22,3 & 200 & 250 \\
\hline & 2 & 20,1 & 198 & 300 \\
\hline & 3 & 17,4 & 245 & 287 \\
\hline \multirow{3}{*}{2} & 1 & - & - & 120 \\
\hline & 2 & - & - & 120 \\
\hline & 3 & - & - & 120 \\
\hline \multirow{3}{*}{3} & 1 & - & - & 120 \\
\hline & 2 & - & - & 120 \\
\hline & 3 & - & - & 120 \\
\hline \multirow{3}{*}{4} & 1 & - & - & 120 \\
\hline & 2 & - & - & 120 \\
\hline & 3 & - & - & 120 \\
\hline \multirow{3}{*}{5} & 1 & - & - & 120 \\
\hline & 2 & - & - & 120 \\
\hline & 3 & - & - & 120 \\
\hline
\end{tabular}

* - Tempo máximo de detecção de reagente saindo da estrutura para cada saída.

** - Tempo em que se obteve o pico de intensidade de freqüência.

Tabela C.62 - Reagente: solução aquosa $50 \%$ em vol. de álcool etílico com aquecimento.

\begin{tabular}{|c|c|c|c|c|}
\hline Saídas & Testes & Pico de intensidade de freqüência $(\mathrm{Hz})$ & Tempo de pico $(\mathrm{s}) * *$ & Tempo de detecção máxima * \\
\hline \multirow{3}{*}{1} & 1 & 30,3 & 185 & 200 \\
\hline & 2 & 25,6 & 145 & 250 \\
\hline & 3 & 21,0 & 187 & 230 \\
\hline \multirow{3}{*}{2} & 1 & 14,7 & 12 & 18 \\
\hline & 2 & 16,7 & 15 & 22 \\
\hline & 3 & 18,9 & 18 & 23 \\
\hline \multirow{3}{*}{3} & 1 & - & - & 120 \\
\hline & 2 & - & - & 120 \\
\hline & 3 & - & - & 120 \\
\hline \multirow{3}{*}{4} & 1 & - & - & 120 \\
\hline & 2 & - & - & 120 \\
\hline & 3 & - & - & 120 \\
\hline \multirow{3}{*}{5} & 1 & - & - & 120 \\
\hline & 2 & - & - & 120 \\
\hline & 3 & - & - & 120 \\
\hline
\end{tabular}

* - Tempo máximo de detecção de reagente saindo da estrutura para cada saída.

** - Tempo em que se obteve o pico de intensidade de freqüência. 
C.1.1.8.8 Chicana empacotada e com filme a base de HMDS depositado

Tabela C.63 - Reagente: isopropanol sem aquecimento.

\begin{tabular}{|c|c|c|c|c|}
\hline Saídas & Testes & Pico de intensidade de freqüência $(\mathrm{Hz})$ & Tempo de pico (s) ** & Tempo de detecção máxima * \\
\hline \multirow{3}{*}{1} & 1 & 303,2 & 2 & 62 \\
\hline & 2 & 290,2 & 5 & 78 \\
\hline & 3 & 304,1 & 8 & 98 \\
\hline \multirow{3}{*}{2} & 1 & 9,8 & 30 & 68 \\
\hline & 2 & 12,7 & 35 & 74 \\
\hline & 3 & 14,7 & 30 & 88 \\
\hline \multirow{3}{*}{3} & 1 & 9,8 & 20 & 32 \\
\hline & 2 & 14,7 & 63 & 79 \\
\hline & 3 & 19,6 & 100 & 120 \\
\hline \multirow{3}{*}{4} & 1 & 4,9 & 3 & 32 \\
\hline & 2 & - & - & 120 \\
\hline & 3 & - & - & 120 \\
\hline \multirow{3}{*}{5} & 1 & 4,9 & 10 & 20 \\
\hline & 2 & - & - & 120 \\
\hline & 3 & - & - & 120 \\
\hline
\end{tabular}

* - Tempo máximo de detecção de reagente saindo da estrutura para cada saída.

** - Tempo em que se obteve o pico de intensidade de freqüência.

Tabela C.64 - Reagente: isopropanol com aquecimento.

\begin{tabular}{|c|c|c|c|c|}
\hline Saídas & Testes & Pico de intensidade de freqüência $(\mathrm{Hz})$ & Tempo de pico (s) ** & Tempo de detecção máxima * \\
\hline \multirow{3}{*}{1} & 1 & 14,7 & 11 & 20 \\
\hline & 2 & 24,5 & 44 & 87 \\
\hline & 3 & 26,3 & 42 & 98 \\
\hline \multirow{3}{*}{2} & 1 & - & - & 120 \\
\hline & 2 & - & - & 120 \\
\hline & 3 & - & - & 120 \\
\hline \multirow{3}{*}{3} & 1 & - & - & 120 \\
\hline & 2 & - & - & 120 \\
\hline & 3 & - & - & 120 \\
\hline \multirow{3}{*}{4} & 1 & - & - & 120 \\
\hline & 2 & - & - & 120 \\
\hline & 3 & - & - & 120 \\
\hline \multirow{3}{*}{5} & 1 & - & - & 120 \\
\hline & 2 & - & - & 120 \\
\hline & 3 & - & - & 120 \\
\hline
\end{tabular}


Tabela C.65 - Reagente: solução aquosa 50\% em vol. de álcool etílico sem aquecimento.

\begin{tabular}{|c|c|c|c|c|}
\hline Saídas & Testes & Pico de intensidade de frequiência $(\mathrm{Hz})$ & Tempo de pico $(s) * *$ & Tempo de detecção máxima * \\
\hline \multirow{3}{*}{1} & 1 & 274,3 & 5 & 21 \\
\hline & 2 & 281,2 & 12 & 30 \\
\hline & 3 & 263,1 & 16 & 20 \\
\hline \multirow{3}{*}{2} & 1 & - & - & 120 \\
\hline & 2 & - & - & 120 \\
\hline & 3 & - & - & 120 \\
\hline \multirow{3}{*}{3} & 1 & - & - & 120 \\
\hline & 2 & - & - & 120 \\
\hline & 3 & - & - & 120 \\
\hline \multirow{3}{*}{4} & 1 & - & - & 120 \\
\hline & 2 & - & - & 120 \\
\hline & 3 & - & - & 120 \\
\hline \multirow{3}{*}{5} & 1 & - & - & 120 \\
\hline & 2 & - & - & 120 \\
\hline & 3 & - & - & 120 \\
\hline
\end{tabular}

* - Tempo máximo de detecção de reagente saindo da estrutura para cada saída.

** - Tempo em que se obteve o pico de intensidade de frequiência.

Tabela C.66 - Reagente: solução aquosa 50\% em vol. de álcool etílico com aquecimento.

\begin{tabular}{|c|c|c|c|c|}
\hline Saídas & Testes & Pico de intensidade de freqüência $(\mathrm{Hz})$ & Tempo de pico (s) ** & Tempo de detecção máxima * \\
\hline \multirow{3}{*}{1} & 1 & 280,2 & 13 & 20 \\
\hline & 2 & 279,3 & 15 & 23 \\
\hline & 3 & 288,1 & 22 & 30 \\
\hline \multirow{3}{*}{2} & 1 & 53,9 & 10 & 20 \\
\hline & 2 & 3,07 & 3 & 8 \\
\hline & 3 & - & - & 120 \\
\hline \multirow{3}{*}{3} & 1 & 4,9 & 7 & 10 \\
\hline & 2 & - & - & 120 \\
\hline & 3 & - & - & 120 \\
\hline \multirow{3}{*}{4} & 1 & 4,9 & 8 & 10 \\
\hline & 2 & - & - & 120 \\
\hline & 3 & - & - & 120 \\
\hline \multirow{3}{*}{5} & 1 & 4,9 & 5 & 8 \\
\hline & 2 & - & - & 120 \\
\hline & 3 & - & - & 120 \\
\hline
\end{tabular}

* - Tempo máximo de detecção de reagente saindo da estrutura para cada saída.

** - Tempo em que se obteve o pico de intensidade de freqüência.

Nenhuma das condições anteriores apresentaram vantagens em relação à injeção em modo pulsado e detecção, condições de 1 à 7 . A escolha da melhor condição entre as 7 possíveis, contudo, depende de teste do reagente a ser analisado. Para o caso 
de gasolina e Varsol@, o uso de filme a base de HMDS é útil, o mesmo não ocorrendo para isopropanol. É preciso observar que nos testes iniciais realizados com os impactadores acoplados à estrutura, foi possível notar que estes apresentam comportamento de estrutura para retenção, caso sua superfície receba um filme adsorvente.

\section{C.1.2 Modo de admissão contínua}

Esta metodologia foi aplicada com o intuído de avaliar se as estruturas saturam rapidamente ou são capazes de se manter em funcionamento por longo tempo. Se a estrutura mantém seu comportamento por longo tempo, a injeção de amostras com grande volume é possível. Testou-se a estrutura com melhor desempenho: a chicana empacotada e com filme a base de HMDS depositado sobre sua superfície e sobre a superfície dos anéis de Raschig.

Para o desenvolvimento destas medidas, utilizaram-se como reagentes isopropanol e Varsol ${ }^{\circledR}$ e o detector de gás mencionado nas medidas realizadas nos itens anteriores. Para avaliar a capacidade de remoção sob alteração de temperatura também realizaram-se medidas com aquecimento da estrutura $\left(92^{\circ}\right.$ à $87^{\circ} \mathrm{C} ; 70^{\circ}$ à $68^{\circ} \mathrm{C} ; 54^{\circ}$ à $40^{\circ}$ $\mathrm{C} ; 38^{\circ}$ à $30^{\circ} \mathrm{C} ; 20^{\circ} \mathrm{C}$ da primeira a última cela). Repetiram-se 5 vezes cada teste nas mesmas condições para todas as estruturas e reagentes para verificação da reprodutibilidade.

\section{C.1.2.1 Medidas sem aquecimento}

Os testes realizados na estrutura, ocorreram com fluxo contínuo tanto de gás de arraste quanto de reagente. Para garantir que a superfície ficasse saturada de reagente fez-se a inserção de reagente por até 10 minutos. Liga-se a bomba de ar por 1 minuto, faz-se a inserção de reagente durante vários minutos (duas válvulas anteriores à estrutura estão abertas), fecham-se as válvulas e deixa-se passar o gás de arraste por 30 minutos. Mantém-se a detecção do reagente por todo o tempo. A ordem dos reagentes é álcool e $\operatorname{Varsol}{ }^{\circledR}$, respectivamente. Após as medidas utilizando álcool, é dada uma injeção de $0,10 \mathrm{~mL}$ de $\operatorname{Varsol}{ }^{\circledR}$ em temperatura ambiente para verificar se há ou não 
eluição do álcool. Faz-se, então, as medidas utilizando Varsol ${ }^{\circledR}$ e ao término injeta-se 0,10 mL de álcool , também em temperatura ambiente, para verificação de eluição.

Testou-se saturar a estrutura com inserção de reagente por 2,5 e 8 minutos e 10 minutos, mas são necessárias 10 minutos para ser possível detectar os primeiros sinais de reagentes na estrutura. Logo no início da segunda inserção, porém, já se obtém resposta do detector, devido à dessorção.

Após cada medida foi feita a pesagem do frasco com reagente e observou-se que ocorre consumo de 4,06 mg por medida realizada com álcool.

Tabela C.67 - Dados obtidos em medidas usando modo de admissão contínua de álcool na chicana empacotada sem o uso de aquecimento.

\begin{tabular}{|c|c|c|c|c|c|c|c|c|c|c|c|}
\hline \multirow[b]{2}{*}{ Testes } & \multirow[b]{2}{*}{ Saídas } & \multicolumn{10}{|c|}{ Tempo (s) } \\
\hline & & \multicolumn{5}{|c|}{ Detecção durante inserção de 10 min } & \multicolumn{5}{|c|}{ Duração da detecção } \\
\hline \multirow{5}{*}{1} & 1 & 226 & 245 & 263 & 271 & 356 & 3 & 3 & 8 & 20 & $*$ \\
\hline & 2 & 70 & $*$ & $*$ & $*$ & $*$ & $*$ & $*$ & $*$ & $*$ & * \\
\hline & 3 & 168 & 202 & 207 & 209 & 211 & 3 & 5 & 120 & 120 & $*$ \\
\hline & 4 & 81 & 123 & 152 & 220 & 314 & 37 & 26 & 62 & 86 & $*$ \\
\hline & 5 & 85 & 113 & 170 & 222 & 244 & 3 & 17 & 24 & 17 & * \\
\hline \multirow{5}{*}{2} & 1 & 223 & 235 & 256 & 260 & 352 & 2 & 3 & 7 & 22 & * \\
\hline & 2 & 80 & 77 & 66 & 65 & 69 & 3 & 5 & 12 & 33 & * \\
\hline & 3 & 159 & 198 & 206 & 210 & 212 & 3 & 7 & 90 & 89 & * \\
\hline & 4 & 98 & 110 & 150 & 222 & 300 & 36 & 32 & 56 & 88 & $*$ \\
\hline & 5 & 89 & 110 & 150 & 223 & 234 & 5 & 25 & 26 & 28 & * \\
\hline \multirow{5}{*}{3} & 1 & 223 & 246 & 268 & 287 & 365 & 5 & 5 & 12 & 33 & * \\
\hline & 2 & 100 & 98 & 200 & 78 & 99 & 12 & 9 & 22 & 44 & * \\
\hline & 3 & 165 & 199 & 200 & 201 & 220 & 3 & 7 & 98 & 100 & * \\
\hline & 4 & 90 & 100 & 112 & 201 & 305 & 42 & 32 & 35 & 90 & * \\
\hline & 5 & 95 & 114 & 187 & 230 & 255 & 5 & 22 & 24 & 32 & $*$ \\
\hline
\end{tabular}


Tabela C.68 - Dados obtidos em medidas usando modo de admissão contínua de Varsol ${ }^{\circledR}$ na chicana empacotada sem o uso de aquecimento.

\begin{tabular}{|c|c|c|c|c|c|c|c|c|c|c|c|}
\hline \multirow[b]{2}{*}{ Testes } & \multirow[b]{2}{*}{ Saídas } & \multicolumn{10}{|c|}{ Tempo (s) } \\
\hline & & \multicolumn{5}{|c|}{ Detecção durante inserção de 10 min } & \multicolumn{5}{|c|}{ Duração da detecção } \\
\hline \multirow{5}{*}{1} & 1 & 195 & 220 & 254 & 260 & 321 & 4 & 6 & 10 & 30 & * \\
\hline & 2 & 55 & 65 & 23 & 31 & 40 & 5 & 3 & 25 & 45 & * \\
\hline & 3 & 154 & 188 & 198 & 187 & 196 & 5 & 6 & 15 & 25 & * \\
\hline & 4 & 75 & 112 & 145 & 220 & 320 & 45 & 23 & 56 & 86 & * \\
\hline & 5 & 98 & 110 & 190 & 223 & 255 & 2 & 12 & 32 & 17 & * \\
\hline \multirow{5}{*}{2} & 1 & 202 & 218 & 235 & 255 & 319 & 5 & 7 & 11 & 33 & * \\
\hline & 2 & 60 & 64 & 20 & 32 & 44 & 5 & 7 & 26 & 45 & * \\
\hline & 3 & 156 & 192 & 199 & 198 & 196 & 5 & 6 & 17 & 29 & * \\
\hline & 4 & 78 & 115 & 152 & 221 & 321 & 48 & 27 & 56 & 86 & * \\
\hline & 5 & 98 & 112 & 191 & 222 & 254 & 2 & 19 & 32 & 17 & * \\
\hline \multirow{5}{*}{3} & 1 & 203 & 220 & 234 & 258 & 317 & 5 & 7 & 13 & 36 & * \\
\hline & 2 & 62 & 67 & 21 & 31 & 40 & 5 & 8 & 25 & 55 & * \\
\hline & 3 & 125 & 178 & 188 & 195 & 196 & 5 & 6 & 15 & 45 & * \\
\hline & 4 & 88 & 117 & 155 & 225 & 333 & 52 & 32 & 57 & 89 & * \\
\hline & 5 & 102 & 114 & 201 & 224 & 258 & 2 & 19 & 55 & 45 & * \\
\hline
\end{tabular}

Após cada medida foi feita a pesagem do frasco com reagente e observou-se que ocorre consumo de 5,08 mg por medida realizada com Varsol® .

\section{C.1.2.2 Medidas com aquecimento}

O tempo para saturação da estrutura também foi de 10 minutos. O aquecimento no modo inverso (primeira cela em menor temperatura) também foi testado, porém, não gera alterações significativas nos dados. 
Tabela C.69 - Dados obtidos em medidas usando modo de admissão contínua de álcool na chicana empacotada com o uso de aquecimento.

\begin{tabular}{|c|c|c|c|c|c|c|c|c|c|c|c|}
\hline \multirow[b]{2}{*}{ Testes } & \multirow[b]{2}{*}{ Saídas } & \multicolumn{10}{|c|}{ Tempo (s) } \\
\hline & & \multicolumn{5}{|c|}{ Detecção durante inserção de 10 min } & \multicolumn{5}{|c|}{ Duração da detecção } \\
\hline \multirow{5}{*}{1} & 1 & 150 & 170 & 195 & 212 & 250 & 5 & 12 & 52 & * & $*$ \\
\hline & 2 & 85 & 95 & 65 & 55 & 20 & 23 & 32 & 21 & $*$ & $*$ \\
\hline & 3 & 55 & 45 & 56 & 85 & 78 & 5 & 8 & 25 & 25 & $*$ \\
\hline & 4 & 78 & 98 & 99 & 120 & 156 & 23 & 32 & 28 & 30 & * \\
\hline & 5 & 65 & 87 & 88 & 100 & 125 & 2 & 12 & 25 & 19 & $*$ \\
\hline \multirow{5}{*}{2} & 1 & 148 & 198 & 201 & 200 & 202 & 6 & 10 & 98 & 87 & * \\
\hline & 2 & 98 & 102 & 98 & 90 & 98 & 6 & 12 & 58 & 63 & * \\
\hline & 3 & 65 & 64 & 68 & 67 & 87 & 3 & 12 & 65 & 32 & * \\
\hline & 4 & 102 & 100 & 123 & 143 & 165 & 23 & 25 & 33 & 55 & * \\
\hline & 5 & 75 & 78 & 74 & 81 & 98 & 5 & 22 & 20 & 30 & * \\
\hline \multirow{5}{*}{3} & 1 & 200 & 198 & 198 & 230 & 280 & 5 & 20 & 62 & 56 & * \\
\hline & 2 & 100 & 102 & 98 & 65 & 25 & 32 & 42 & 32 & 45 & $*$ \\
\hline & 3 & 65 & 52 & 55 & 100 & 98 & 8 & 10 & 32 & 33 & * \\
\hline & 4 & 98 & 120 & 123 & 100 & 180 & 32 & 54 & 45 & 42 & * \\
\hline & 5 & 102 & 98 & 78 & 102 & 202 & 9 & 21 & 32 & 22 & * \\
\hline
\end{tabular}

* - após a inserção de reagente o detector emite sinal contínuo por 1200 segundos ou mais.

Após cada medida foi feita a pesagem do frasco com reagente e observou-se que ocorre consumo de 4,98 mg por medida realizada com álcool. 
Tabela C.70 - Dados obtidos em medidas usando modo de admissão contínua de Varsol $@$ na chicana empacotada com o uso de aquecimento.

\begin{tabular}{|c|c|c|c|c|c|c|c|c|c|c|c|}
\hline \multirow[b]{2}{*}{ Testes } & & \multicolumn{10}{|c|}{ Tempo (s) } \\
\hline & \multirow{2}{*}{$\begin{array}{c}\text { Saídas } \\
\\
1\end{array}$} & \multicolumn{5}{|c|}{ Detecção durante inserção de 10 min } & \multicolumn{5}{|c|}{ Duração da detecção } \\
\hline \multirow{5}{*}{1} & & 98 & 110 & 132 & 190 & 198 & 6 & 11 & 65 & $*$ & $*$ \\
\hline & 2 & 78 & 90 & 70 & 55 & 35 & 5 & 15 & 22 & $*$ & $*$ \\
\hline & 3 & 60 & 50 & 52 & 75 & 78 & 5 & 5 & 12 & $*$ & $*$ \\
\hline & 4 & 65 & 89 & 95 & 100 & 132 & 12 & 16 & 20 & 22 & $*$ \\
\hline & 5 & 55 & 45 & 70 & 97 & 102 & 8 & 14 & 25 & 19 & $*$ \\
\hline \multirow{5}{*}{2} & 1 & 102 & 120 & 150 & 202 & 203 & 8 & 10 & 75 & 85 & $*$ \\
\hline & 2 & 102 & 103 & 101 & 102 & 55 & 12 & 22 & 25 & 33 & $*$ \\
\hline & 3 & 87 & 87 & 65 & 72 & 78 & 12 & 12 & 12 & 23 & * \\
\hline & 4 & 75 & 95 & 102 & 100 & 154 & 23 & 20 & 33 & 22 & $*$ \\
\hline & 5 & 65 & 55 & 63 & 100 & 105 & 12 & 12 & 32 & 22 & $*$ \\
\hline \multirow{5}{*}{3} & 1 & 102 & 123 & 145 & 202 & 210 & 8 & 22 & 63 & 75 & $*$ \\
\hline & 2 & 98 & 102 & 90 & 75 & 45 & 10 & 23 & 22 & 33 & $*$ \\
\hline & 3 & 80 & 65 & 85 & 80 & 84 & 9 & 9 & 21 & 52 & $*$ \\
\hline & 4 & 75 & 92 & 95 & 142 & 98 & 21 & 32 & 21 & 21 & $*$ \\
\hline & 5 & 65 & 65 & 81 & 102 & 105 & 10 & 25 & 32 & 22 & $*$ \\
\hline
\end{tabular}

Após cada medida foi feita a pesagem do frasco com reagente e observou-se que ocorre consumo de 5,87 mg por medida realizada com Varsol® .

De modo geral, é possível trabalhar com grandes amostras de reagentes sem perda de reprodutibiliddae, porém, a solução de passagem de ar por vários minutos entre as admissões de amostras é mais adequada por evitar possíveis eluições de amostras retidas anteriormente.

\section{C.1.2.3 Aquecimento do reagente}

Uma outra forma de uso da estrutura é o aquecimento do reagente previamente à admissão na estrutura, e o teste efetuado elevou a temperatura dos reagentes a aproximadamente $90^{\circ} \mathrm{C}$. Porém, nestes testes não se observou detecção alguma de reagente, isto pode ter ocorrido porque o reagente atravessou a estrutura muito rapidamente. 


\section{C.1.2.4 Adição de água}

A extração por solvente foi tentada com o uso de água em todas as condições que se mostraram adequadas para separação.

Tabela C.71 - Dados obtidos para teste de escoamento inverso em função do tempo (segundos) na estrutura chicana não empacotada para diferentes reagentes (isopropanol, n-hexano, gasolina) e para diferentes temperaturas (sem e com aquecimento gradativo $-85^{\circ}, 6^{\circ}, 45^{\circ}, 20^{\circ} \mathrm{C}$ ).

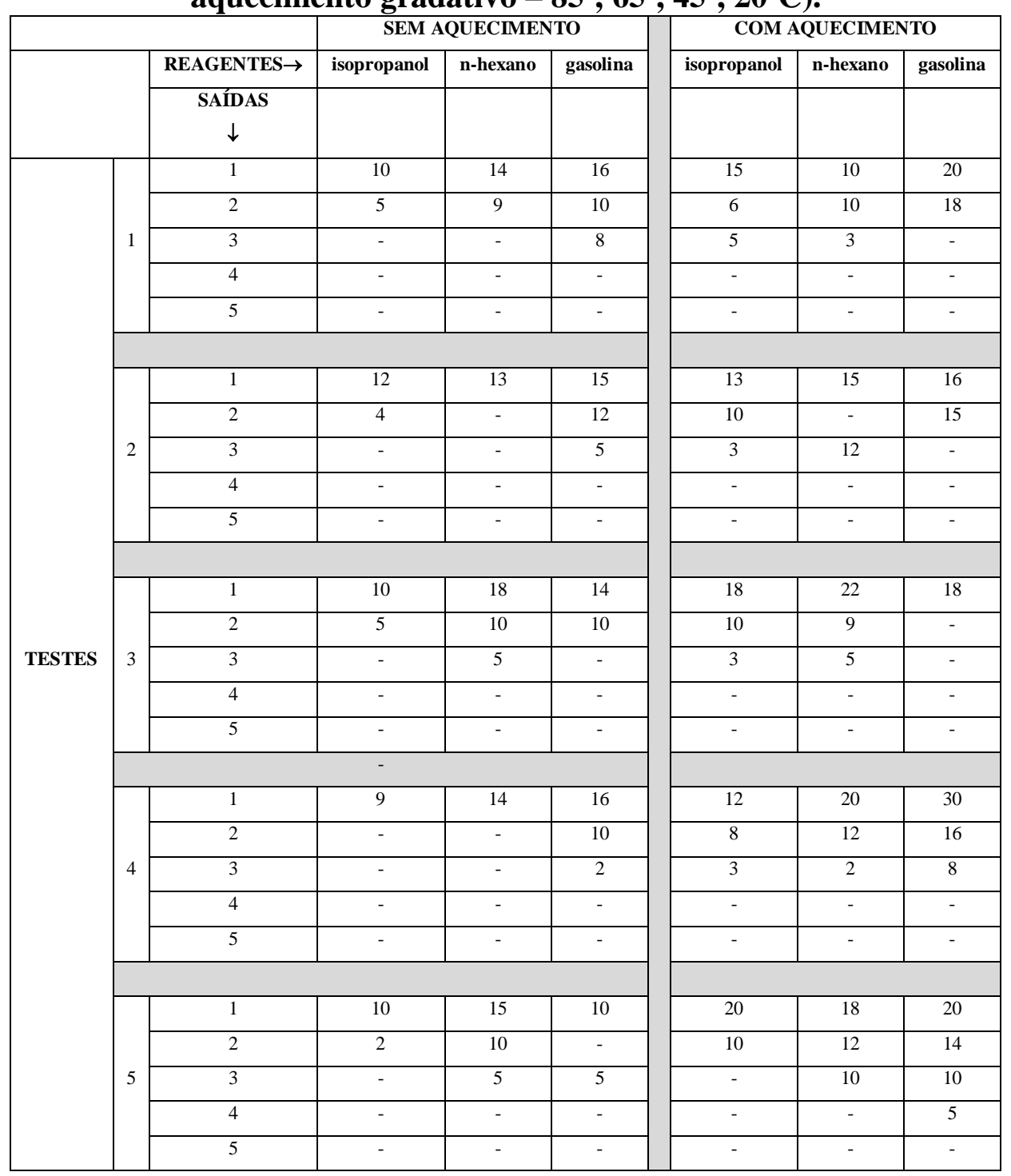


Tabela C.72 - Dados obtidos para teste de escoamento inverso em função do tempo (segundos) na estrutura chicana empacotada para diferentes reagentes (isopropanol, n-hexano, gasolina) e para diferentes temperaturas (sem e com aquecimento gradativo $\left.-8^{\circ}, 6^{\circ}, 45^{\circ}, 20^{\circ} \mathrm{C}\right)$.

\begin{tabular}{|c|c|c|c|c|c|c|c|c|}
\hline & & & SEM & QUECIME & & COM & QUECIMP & \\
\hline & & REAGENTES $\rightarrow$ & isopropanol & n-hexano & gasolina & isopropanol & n-hexano & gasolina \\
\hline & & SAÍDAS & & & & & & \\
\hline \multirow{26}{*}{ TESTES } & \multirow{5}{*}{1} & 1 & 8 & 12 & 12 & 20 & 23 & 35 \\
\hline & & 2 & - & 10 & 11 & 12 & 15 & 23 \\
\hline & & 3 & - & - & - & 4 & 2 & - \\
\hline & & 4 & - & - & - & - & - & - \\
\hline & & 5 & - & - & - & - & - & - \\
\hline & \multirow{5}{*}{2} & 1 & 10 & 15 & 18 & 22 & 25 & 29 \\
\hline & & 2 & - & - & 11 & 15 & 5 & 20 \\
\hline & & 3 & - & - & - & - & - & 5 \\
\hline & & 4 & - & - & - & - & - & - \\
\hline & & 5 & - & - & - & - & - & - \\
\hline & \multirow{5}{*}{3} & 1 & 12 & 16 & 17 & 15 & 25 & 30 \\
\hline & & 2 & 8 & 8 & 12 & 13 & 12 & 10 \\
\hline & & 3 & - & - & 5 & - & 4 & 4 \\
\hline & & 4 & - & - & - & - & - & - \\
\hline & & 5 & - & - & - & - & - & - \\
\hline & \multicolumn{5}{|c|}{ - } & & & \\
\hline & \multirow{5}{*}{4} & 1 & 7 & 15 & 18 & 15 & 22 & 28 \\
\hline & & 2 & 3 & 8 & 12 & 10 & 15 & 18 \\
\hline & & 3 & - & - & - & - & 8 & 5 \\
\hline & & 4 & - & - & - & - & 3 & 3 \\
\hline & & 5 & - & - & - & - & - & - \\
\hline & \multirow{5}{*}{5} & 1 & 8 & 16 & 22 & 16 & 23 & 29 \\
\hline & & 2 & 8 & 8 & 10 & 12 & 14 & 18 \\
\hline & & 3 & 2 & 3 & - & 3 & 8 & 3 \\
\hline & & 4 & - & - & - & - & 3 & 5 \\
\hline & & 5 & - & - & - & - & - & - \\
\hline
\end{tabular}

De modo geral, o teste em fluxo contínuo demonstrou que o uso da estrutura em sua concepção mais simples é adequado para uma separação preliminar de misturas. 